\title{
CHOREOGRAPHING ARCHITECTURE
}

by

Ashley Brooke Biren

Bachelor of Architectural Science, Ryerson University, 2011

A thesis

presented to Ryerson University

in partial fulfillment of the

requirements for the degree of

Master of Architecture

in the Program of

Architecture

Toronto, Ontario, Canada, 2015

(C) Ashley Brooke Biren, 2015 



\section{Author's Declaration}

I hereby declare that I am the sole author of this thesis. This is a true copy of the thesis, including any required final revisions, as accepted by my examiners.

I authorize Ryerson University to lend this thesis to other institutions or individuals for the purpose of scholarly research.

I further authorize Ryerson University to reproduce this thesis by photocopying or by other means, in total or in part, at the request of other institutions or individuals for the purpose of scholarly research.

I understand that my thesis may be made electronically available to the public. 
Architecture is emotive space that moves us. It's not the backdrop to our lives, but the one that participates in our very existence. Architecture is a space that isolates you within a moment in time. The world of experience opens up in that space of the present moment.

Great architecture connects us from within the core of our being to its concrete presence.

Great architecture is analogous to a great performance. You're mesmerized, engaged and not thinking of anything else but feeling and seeing the performance around you. 
Choreographing Architecture

Ashley Brooke Biren

Master of Architecture 2015

Architecture Program, Ryerson University

\section{Abstract}

Our bodies are in constant dialogue with our built environment: we move to experience architecture, and in turn, are moved by its presence. Movement is intrinsically linked to the way we experience our buildings, yet the body in motion has not been acknowledged for understanding and conceiving architectural form. In this thesis, the phenomenon of kinesthetic empathy will be unleashed within the exploration of a choreographic architecture, where body, form and movement share an entangled relationship in the creation of an architectural composition. This approach investigates an architecture that embraces gestural and physiological behaviour for the development of a corporeal environment capable of stimulating and reawakening the mind and body. With the current technologies available for analyzing human movement, this investigation probes human kinesis as an external force for the formation of space, and thus, cultivates a new theory towards making architecture move - choreographing an architecture of kinesthetic empathy. 



\section{Acknowledgements}

I would like to thank my thesis supervisor, John Cirka, for exposing me to the wonderful world of design research. His support, guidance and enthusiasm fostered the discovery of new boundaries and realms in my work, challenging all my preconceived notions of movement in architecture. I am indebted to John for providing me a solid foundation in the development of my investigations. Everything I learned under his mentorship will undoubtingly cultivate the growth of my future career as an architect and researcher.

I would also like to express my gratitude towards my committee members, Vincent Hui and Miljana Horvat. Both have played an instrumental role in developing my initial thesis ideas, stemming from their M.Arch Studio in Collaborative Practice. Even prior to graduate studies, Vincent has been supportive of my interest in the intersection between neuroscience and architecture, serving as a supervisor for my undergraduate independent study and mentor for my first conference presentation.

From 3D printing to more 3D printing, I am very grateful for Frank Bowen, Blaine Evans, Jordan So and Peter Bradley's dedication in helping me fabricate all my physical prototypes for this thesis exploration.

I would like to also thank my dearest friend, Fraydie Bonan, for her patience in proofreading this exhaustive thesis. Her excellent editing advice and precise sense of language played a critical role in the final document.

Last but not least, I would like to thank my family: my mother, brothers and Perry for your whole-hearted support. My family has instilled confidence in myself, making me believe our uniqueness can make a difference in how we conceive and create our world. 


\section{Table of Contents}

Author's Declaration iii

Author's Reflection iv

Abstract $\quad v$

Acknowledgments vii

Table of Contents viii

List of Figures $\quad x$

List of Appendices xxiii

01 Introduction 1

02 Movement \& The Body 14

2.1 The Forgotten Sense 15

2.2 The Fascination for Movement 17

2.3 Kinesthetic Empathy \& Bodily Perceptions 20

03 Movement \& The Arts $\quad 24$

3.1 Motion in the Visual Arts 25

$\begin{array}{ll}3.2 & \text { Motion in Film \& Photography } \\ \end{array}$

$04 \quad$ Movement \& Space 34

$\begin{array}{lll}4.1 & \text { Dynamic Forms } & 35\end{array}$

4.2 Dynamic Inhabitation $\quad 36$

4.3 Dynamic Structures 39

4.4 Dynamic Processes $\quad 42$

05 Body \& Space 50

5.1 The Ideal Body 51

5.2 The Moving Body 53

$\begin{array}{lll}5.3 & \text { The Virtual Body } & 57\end{array}$

$06 \quad$ Choreographing Architecture 61

6.1 Empathetic Elements: 63

Translation from Motion to Form

6.2 Choreographing Components 65

6.3 Choreographing Architecture as a Body + 67 Choreographing The Body in Space

i. The Dynamic Stairway 68

ii. Choreographing Negative Space $\quad 74$

6.4 The Dynamic House 83 
$\begin{array}{lll}07 & \text { A Visionary Proposition } & 93\end{array}$

7.1 Stage \#1: Choreographing Focal Points 95

7.2 Stage \#2: Choreographing the Spatial Framework 97

$\begin{array}{lll}7.3 & \text { Stage\# 3: Choreographing Kinesthetic Components } & 111\end{array}$

$\begin{array}{lll}7.4 & \text { Project Reflections } & 153\end{array}$

08 Move Architecture | Move Us 156

$\begin{array}{lll}8.1 & \text { Materiality } & 161\end{array}$

$\begin{array}{lll}8.2 & \text { Spatial Narrative } & 163\end{array}$

8.2.1 Transition from Air to Water 166

$\begin{array}{lll}\text { 8.2.2 Water } & 167\end{array}$

8.2.3 Transition from Water to Air 171

$\begin{array}{ll}\text { 8.2.4 Water-Air } & 175\end{array}$

8.2.5 Transition to the Summit 179

8.2.6 Air 183

$\begin{array}{lll}\text { 8.3 Project Conclusion } & 188\end{array}$

09 Choreographing Architecture: A Future for Architecture 191

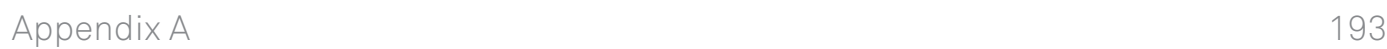

$\begin{array}{lr}\text { Appendix B } & 215\end{array}$

$\begin{array}{ll}\text { Appendix C } & 227\end{array}$

$\begin{array}{ll}\text { Appendix D } & 271\end{array}$

$\begin{array}{ll}\text { Appendix E } & 291\end{array}$

$\begin{array}{ll}\text { Works Cited } & 327\end{array}$

Works Considered 335 


\section{List of Figures}

Figure 1: Defining parameters of the moving body through Grasshopper software and motion sensing device - Kinect.

Source: Ashley Brooke Biren

Figure 2: Kinesthetic Components

Source: Ashley Brooke Biren

Figure 3: Stages of transformation from points to virtual planes and finally kinesthetic components in the Visionary Proposition.

Source: Ashley Brooke Biren

Figure 4: Zoomed in perspectives of the Visionary Proposition

Source: Ashley Brooke Biren

Figure 4b: Zoomed in perspectives of the Visionary Proposition

Source: Ashley Brooke Biren

Figure 5: Under the Electron Microscope

Source: http://www.flickriver.com/photos/bionerd/sets/

Figure 6: Blurred Body

Source: http://secular-elegance.tumblr.com/post/41536313443/hitodama-esther-vanderhart

Figure 7: Somatic Senses Pathways

Source: http://slideplayer.com/slide/3478625/

Figure 8: Velocity of Cars and Light (Balla)

Source: http://www.museothyssen.org/en/thyssen/contenidos_articulo/9

Figure 9: Triptych Paintings: States of Mind (Boccioni)

Source: http://www.moma.org/collection/artists/624?locale=en

Figure 10: Unique Forms of Continuity in Space (Boccioni)

Source: http://www.moma.org/collection/works/81179

Figure 11: Dynamism of a Dog on a Leash (Balla)

Source: http://www.britannica.com/topic/Dynamism-of-a-Dog-on-a-Leash 
Figure 12: Nude Descending a Staircase, No. 2 (Duchamp)

Source: http://www.philamuseum.org/collections/permanent/51449.html

Figure 13: Étienne-Jules Marey's Photographic Gun

Source:http://www.dailymail.co.uk/sciencetech/article-2317218/Photos-portable-moviecamera-designed-look-work-like-rifle.html

Figure 14: Evolution of Chronophotography

Source: http://langanfilms.com/choros.html

Figure 14b: Langan and Maher's film titled Choros

Source: https://vimeo.com/35770492(Screen Capture from Video)

Figure 15: Collage of Movement \& Space

a. Baroque Architecture

Source: http://www2.washjeff.edu/german/culturalhistory/gothab/9.jpg

b. Carpenter Center for the Visual Arts - Harvard University - Le Corbusier

Source: https://www.flickr.com/photos/scottnorsworthy/3391026174

c. Carpenter Center for the Visual Arts - Harvard University - Le Corbusier

Source: https://www.flickr.com/photos/shipark/2656070891/sizes/l

d. Bernard Tschumi's Parc de la Villette

Source: http://lifesansbldgs.tumblr.com/post/76484845056/bernard-tschumi-parc-de-la-

villette-1987

e. Aegis Hyposurface

Source: www.hyposurface.org

f. Blob Wall (Greg Lynn)

Source: http://glform.com/environments/blobwall/

g. Adaptive Facade (Marilena Skavara)

Source:http://www.dailytonic.com/\%E2\%80\%98adaptive-facade\%E2\%80\%99-by-marilenaskavara/ 
Figure 16: Architectural Promenade (Corbusier's Villa Savoye)

Source: Edited by Ashley Brooke Biren (Originial image retrieved from: http://www.quondam. com/31/3171.htm)

Figure 17: Neue Staatsgalerie Stuttgart, presentation model, James Stirling, Michael Wilford and Associates

Source:http://www.metalocus.es/content/en/blog/\%E2\%80\%9Cjames-frazer-stirling-notesarchive-crisis-modernism\%E2\%80\%9D\#

Figure 18: Aegis Hyposurface (dECOi)

Source: https://www.pinterest.com/pin/383157880770226162/

Figure 19: Blur (Diller \& Scofidio)

Source: https://classconnection.s3.amazonaws.com/279/flashcards/2821279/png/final_9413E72A98BBB7DB78680.png

Figure 20: Freshwater Pavilion (NOX)

Source:http://topology.rz-a.com/

Figure 21: Parc de la Villette: Exploded Axonometric, Points Lines Surfaces (Bernard Tschumi) Source: http://www.uncubemagazine.com/blog/15708387

Figure 22: Alteka Office Building (Peter Eisenman)

Source: G. Lynn (ed), Architectural Design, no:102, (London: Academy Group Ltd, 1993), pp: 2829 (http://archive.bridgesmathart.org/2007/bridges2007-415.pdf)

Figure 23: Embryological House (Greg Lynn)

Source: http://www.classics.ucla.edu/people/faculty/bergren/website/easierBeautylmages. html

Figure 24: Collage of Body \& Space

a. Le Modulor - 1

Source: https://www.flickr.com/photos/24619336@N00/5767196734

b. Le Modulor - 2

Source: https://www.flickr.com/photos/duncan1013/3475932536/

c. Le Modulor - 3

Source: https://www.flickr.com/photos/vbratone/4916815267/sizes/l/ 
d. Triadic Ballet - 'Musical Clown' (Oskar Schlemmer)

Source: http://bauhaus-online.de/en/magazin/artikel/oskar-schlemmer-jean-tinguely-erichhauser

e. Triadic Ballet - 2 (Oskar Schlemmer)

Source: http://41.media.tumblr.com/tumblr_lz6capF7xc1r4hjz9o3_r1_500.jpg

f. Triadic Ballet - 3 (Oskar Schlemmer)

Source: https://www.pinterest.com/pin/399694535649237440/

g. Triadic Ballet - 'Daisy Spies as the Spiral' (Oskar Schlemmer)

Source: http://www.moma.org/interactives/objectphoto/objects/83995.html

h. Icosahedron (Rudolf Von Laban)

Source: https://www.pinterest.com/pin/518617713311108641/

i. Slat Dance (Oskar Schlemmer)

Source: http://library.calvin.edu/hda/node/1444

j. Cerebral Hut (Guvenc Ozel)

Source: https://vimeo.com/71503761

k. The Living Breathing Wall (Behnaz Farahi)

Source: http://www.suckerpunchdaily.com/2014/05/28/the-living-breathing-wall/

Figure 25: Diversity of Female Bodies (Photograph in Howard Schatz Book titled "Athletes")

Source: http://www.huffingtonpost.com/2013/11/19/howard-schatz-photos-women-

professional-athletes_n_4297902.html

Figure 26: Le Modulor (Le Corbusier)

Source: http://patiochico.blogspot.ca/2007/05/modulor.html

Figure 27: Kinesphere

Source: Ashley Brooke Biren

Figure 28: Choreutics, an "analysis of forms in movement."(Rudolf Von Laban)

Source: http://onartandspace.blogspot.ca/2014/06/measuring-space.html

Figure 29: Drawings of the figures in Schlemmer's Triadic Ballet

Source: http://principieprincipi.blogspot.ca/2012/06/oskar-schlemmer-il-balletto-triadico. html 
Figure 30: Lawrence Halprin's score for the Overhoff-Halprin 1962 World's Fair

Source: Halprin, L. (1970). The RSVP cycles: creative processes in the human environment: G.

Braziller.

Figure 31: Cerebral Hut (Guvenc Ozel)

Source: http://www.designboom.com/readers/cerebral-hut-by-guvenc-ozel/

Figure 32: Ambient Alternity (F. Myles Sciotto)

Source: http://alternity.info/works/alternity/

Figure 33: Movement + Space

Source: (See Fig. 15)

Figure 34: Body + Space

Source: (See Fig. 24)

Figure 35: Movement + Body + Space

Source: Ashley Brooke Biren

Figure 36: Choreographing Architecture - Formal typologies of choreographing negative space. Source: Ashley Brooke Biren

Figure 37: Empathetic Elements - Geometric outcome of tracking human movement.

Source: Ashley Brooke Biren

Figure 38: Empathetic Elements - Elevation

Source: Ashley Brooke Biren

Figure 39: Empathetic Elements - Perspective

Source: Ashley Brooke Biren

Figure 40: Choreographing Components - Perspective

Source: Ashley Brooke Biren

Figure 41: Choreographing Components - Translation from human poses to geometric form. Source: Ashley Brooke Biren

Figure 42: Choreographing Components - Elevations (Top); Floor Plan (Bottom)

Source: Ashley Brooke Biren 
Figure 43: Choreographing Components - Axonometric

Source: Ashley Brooke Biren

Figure 44: Choreograph the body in space

Source: Ashley Brooke Biren

Figure 45: Choreograph architecture as a body

Source: Ashley Brooke Biren

Figure 46: Tracing movements from Eadweard Muybridge's "Man ascending stairs" (1884-1885)

Source: Edited by Ashley Brooke Biren (Original image retrieved from: https://commons. wikimedia.org/wiki/File:Muybridge_ascending_stairs.jpg)

Figure 47: The Dynamic Stairway- Plan Perspective

Source: Ashley Brooke Biren

Figure 48: The Dynamic Stairway- Perspective

Source: Ashley Brooke Biren

Figure 48b: The Dynamic Stairway- Elevations

Source: Ashley Brooke Biren

Figure 49: Choreographing Negative Space

Source: Ashley Brooke Biren

Figure 50: Choreographing Negative Space - Isometric projection showcasing the process of choreographing the body of architecture.

Source: Ashley Brooke Biren

Figure 51: Plan of Design Iteration

Source: Ashley Brooke Biren

Figure 52: Elevations of Design Iteration

Source: Ashley Brooke Biren

Figure 53: Choreographing Negative Space - Perspective

Source: Ashley Brooke Biren 
Figure 54: Choreographing Negative Space - Perspectives

Source: Ashley Brooke Biren

Figure 55: Choreographing Negative Space - Perspectives

Source: Ashley Brooke Biren

Figure 56: Choreographing Negative Space - Perspective

Source: Ashley Brooke Biren

Figure 57: Initial sketches of the Dynamic House

Source: Ashley Brooke Biren

Figure 58: Initial sketches of the Dynamic House

Source: Ashley Brooke Biren

Figure 59: Image of "Victory Housing" in Toronto neighbourhoods

Source: http://www.torontoneighbourhoods.net/neighbourhoods/north-york/amesbury/ homes

Figure 60: Visualization of mid-century residential bungalow

Source: http://modernrealtor.blogspot.ca/2011/03/campeau-in-alta-vista.html

Figure 61: Dynamic House - Exploded Axonometric

Source: Ashley Brooke Biren

Figure 62: Dynamic House - Perspective Elevation

Source: Ashley Brooke Biren

Figure 63: Dynamic House - Conceptual Renderings of Initial House Transformations

Source: Ashley Brooke Biren

Figure 64: Dynamic House - Interior Perspective

Source: Ashley Brooke Biren

Figure 65: Dynamic House - Interior Perspective

Source: Ashley Brooke Biren

Figure 66: Dynamic House - Back yard Perspective

Source: Ashley Brooke Biren 
Figure 67: Dynamic House - Front Yard Perspective

Source: Ashley Brooke Biren

Figure 68: Dynamic House Choreographic Notations - Tracking movement for form generation Source: Ashley Brooke Biren

Figure 69: Three stages of transformation for the Visionary Proposition: points, planes and kinesthetic components.

Source: Ashley Brooke Biren

Figure 70: Stage\#1 - Choreographing Focal Points

Source: Ashley Brooke Biren

Figure 71: Process of choreographing the spatial framework

Source: Ashley Brooke Biren

Figure 72: Stage\#2 - Choreographing Spatial Framework

Source: Ashley Brooke Biren

Figure 73: Spatial Framework diagram showcasing the formal relationship between hand and foot

Source: Ashley Brooke Biren

Figure 74: Spatial Framework Parameters

Source: Ashley Brooke Biren

Figure 75: Stage\#2 - Choreographing the Spatial Framework (Lower Level)

Source: Ashley Brooke Biren

Figure 76: Stage\#2 - Choreographing Spatial Framework (Lower Level)

Source: Ashley Brooke Biren

Figure 77: Stage\#2 - Choreographing the Spatial Framework (Main Level)

Source: Ashley Brooke Biren

Figure 78: Stage\#2 - Choreographing the Spatial Framework (Second Level)

Source: Ashley Brooke Biren 
Figure 79: Stage\#2 - Choreographing the Spatial Framework (Third Level)

Source: Ashley Brooke Biren

Figure 80: Stage\#3 - Choreographing Kinesthetic Components

Source: Ashley Brooke Biren

Figure 81: Kinesthetic Components Parameters

Source: Ashley Brooke Biren

Figure 82: Visionary Proposition - Interior Perspective

Source: Ashley Brooke Biren

Figure 83: Visionary Proposition - Axonometric of Each Level

Source: Ashley Brooke Biren

Figure 84: Visionary Proposition - Floor Plans

Source: Ashley Brooke Biren

Figure 85: Visionary Proposition - Longitudinal Elevation

Source: Ashley Brooke Biren

Figure 86: Visionary Proposition - Rear Elevation

Source: Ashley Brooke Biren

Figure 87: Visionary Proposition - Front Elevation

Source: Ashley Brooke Biren

Figure 88: Visionary Proposition - Third Level

Source: Ashley Brooke Biren

Figure 89: Visionary Proposition - Third Level (Zoomed in Perspectives of Image 1)

Source: Ashley Brooke Biren

Figure 90: Visionary Proposition - Third Level (Zoomed in Perspectives of Image 2)

Source: Ashley Brooke Biren

Figure 91: Visionary Proposition - Second Level

Source: Ashley Brooke Biren 
Figure 92: Visionary Proposition - Second Level (Zoomed in Perspectives of Image 4) Source: Ashley Brooke Biren

Figure 93: Visionary Proposition - Second Level (Zoomed in Perspectives of Image 3) Source: Ashley Brooke Biren

Figure 94: Visionary Proposition - Main Level

Source: Ashley Brooke Biren

Figure 95: Visionary Proposition - Main Level

Source: Ashley Brooke Biren

Figure 96: Visionary Proposition - Main Level (Zoomed in Perspectives of Image 3) Source: Ashley Brooke Biren

Figure 97: Visionary Proposition - Main Level (Zoomed in Perspectives of Image 4) Source: Ashley Brooke Biren

Figure 98: Visionary Proposition - Lower Level

Source: Ashley Brooke Biren

Figure 98: Visionary Proposition - Lower Level

Source: Ashley Brooke Biren

Figure 99: Visionary Proposition - Lower Level (Zoomed in Perspectives of Image 1) Source: Ashley Brooke Biren

Figure 100: Visionary Proposition - Lower Level (Zoomed in Perspectives of Image 2) Source: Ashley Brooke Biren

Figure 101: Visionary Proposition - Lower Level (Zoomed in Perspectives of Image 3) Source: Ashley Brooke Biren

Figure 102: Visionary Proposition - Overall Perspective Source: Ashley Brooke Biren

Figure 103: Visionary Proposition - Transverse Section Source: Ashley Brooke Biren 
Figure 104: Visionary Proposition - Overall Perspective

Source: Ashley Brooke Biren

Figure 105: Transitions Through Space

Source: Ashley Brooke Biren

Figure 106: Design Elevations

Source: Ashley Brooke Biren

Figure 107: Movement Derived Components

Source: Ashley Brooke Biren

Figure 108: Axonometric

Source: Ashley Brooke Biren

Figure 109: Floor Plans

Source: Ashley Brooke Biren

Figure 110: Spatial Narrative-Transition from Air to Water

Source: Ashley Brooke Biren

Figure 111: Submerging into the Water

Source: Ashley Brooke Biren

Figure 112: Spatial Experience Underwater

Source: Ashley Brooke Biren

Figure 112b: Spatial Experience Underwater

Source: Ashley Brooke Biren

Figure 113: Spatial Narrative - Transition from Water to Air

Source: Ashley Brooke Biren

Figure 114: Transition from Water to Air

Source: Ashley Brooke Biren

Figure 115: Spatial Experience on the Water's Surface

Source: Ashley Brooke Biren 
Figure 115b: Spatial Experience on the Water's Surface

Source: Ashley Brooke Biren

Figure 116: Spatial Narrative - Transition to the Summit

Source: Ashley Brooke Biren

Figure 117: Transition to the Summit

Source: Ashley Brooke Biren

Figure 118: Spatial Experience in the Air

Source: Ashley Brooke Biren

Figure 118b: Spatial Experience in the Air

Source: Ashley Brooke Biren

Figure 119: Composition of three zones: Underwater, Water's Surface and Air Source: Ashley Brooke Biren 



\section{List of Appendices}

\section{Appendix A}

Early Design \& Research Investigations

\section{Appendix B}

Additional Drawings for Choreographing Architecture Methods

Appendix C

Additional Design Explorations with the Kinect

Appendix D

Design Experiments Following the Visionary Proposition

Appendix E

Physical Models 


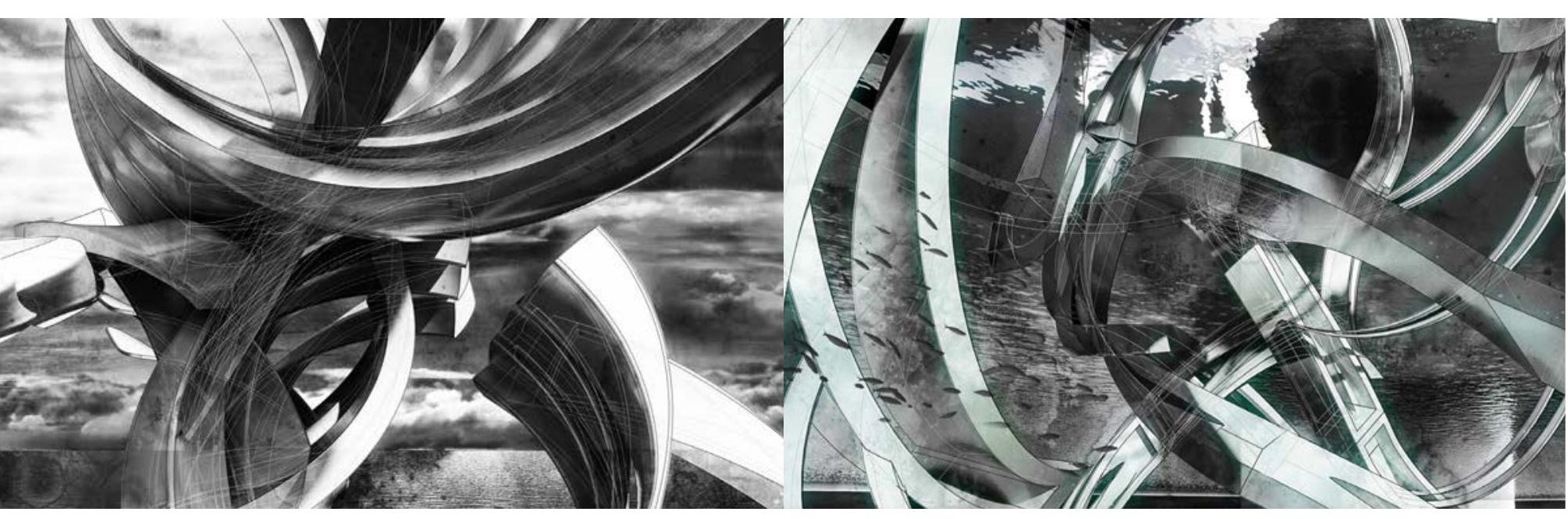




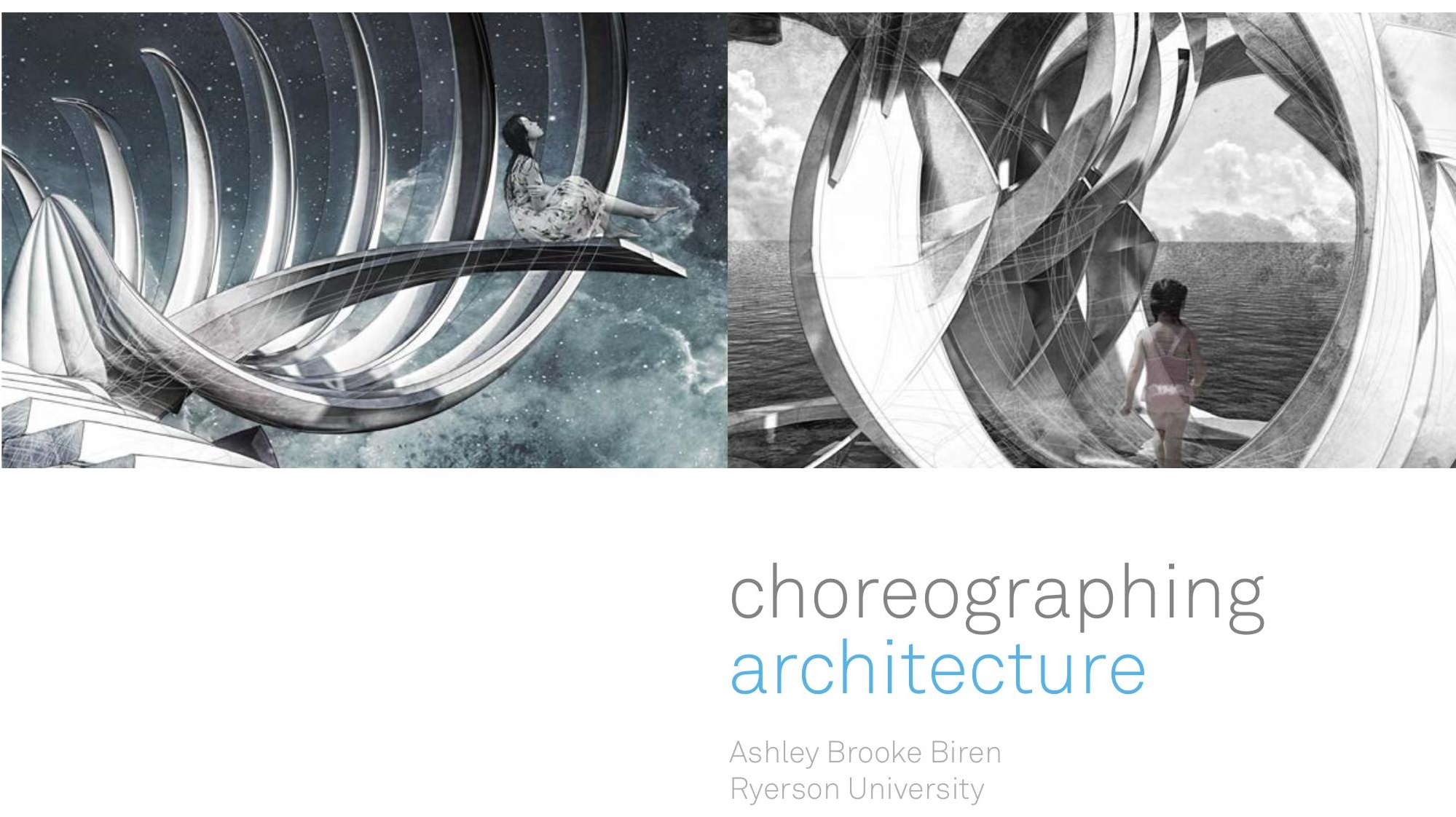




\section{Introduction}

This thesis revives the discussion of kinesthetic empathy and movement in architecture that was initiated in German aesthetic theories in the late nineteenth century. The study of aesthetics during this time investigated the perception and understanding of architecture's ability to express an emotion or mood, and in turn, spur a corporeal resonance in the viewer. Art historian Heinrich Wölfflin established contemporary concepts of movement and the perception of form in an influential depiction of Baroque architecture, and consequently a general description for the arts in all periods. Wölfflin's student Sigfried Giedion made movement essential in his conviction that modern architecture was critical for historical development, making space the appropriate medium of architecture and allowing us to experience it empathetically through movement (Macarthur, 2007). Since the era of modern architecture, the concept of movement has been addressed in architectural discourse including the architectural promenade (Le Corbusier), architecture as events (Bernard Tschumi), architecture as animate form (Greg Lynn) and more recently in the age of pervasive computing through kinetic and responsive architecture. Yet the discourse has yet to revive the notion of kinesthetic empathy in architecture as part of the consideration for understanding and conceiving architectural form. In this investigation, the phenomenon of kinesthetic empathy is explored by analyzing the body in motion for the creation of space. A choreographic method has been adopted to construct a kinesthetic experience in architecture in which body, form and movement share an entangled relationship in the creation of an architectural composition. This approach investigates an architecture that embraces gestural and physiological behaviour for the development of an environment that stimulates and reawakens the mind and body. In short, this thesis contributes to the discourse by investigating a new theory towards making architecture move, choreographing an architecture of kinesthetic empathy. 
Fundamentally, for architecture to move, it must incorporate modes of motion into its thinking and conception. Architecture is traditionally conceived as the study of the static through its dedication to paradigms of permanence and timelessness. Even more essential to its role of giving shelter, architecture is considered to impart culture through stasis. The notion of the static is critical to architecture as both a concept of literal structure and as a dominant expectation. Yet an architecture that moves challenges this embedded assumption about its structure, heavily reliant on the paradigm of the static that feeds the desire for timelessness, linked to formal purity and autonomy. This proposition for an architecture to move does not imply a literal motion but a dynamic model for organization and formation. Actual motion typically engages a mechanical approach of multiple distinct positions, whereas virtual movement advocates that form occupies a multiplicity of potential positions continuously within a spatial framework (Lynn, 1999). The idea of motion based form can be traced in Greg Lynn's early writings that explore the theoretical underpinning of a dynamically conceived architecture.

Greg Lynn in Animate Form (1999) examines the shift from a "passive space of inert coordinates to an active space of interactions" implying a move from the "autonomous purity to contextual specificity" in today's discourse ( $p$. 11). In other words, while physical form can be defined and organized using static coordinates, the virtual force of the environment could contribute to its formation and organization. In his book, Animate Form, he provides two cases that illustrate the relationship between force, motion and form. The first case discusses the surface of a boat hull as a stable result of the force and motion it is designed to perform under. As opposed to being conceived in a space absent of force and motion, the hull's surface retains the various possibilities of its environment in its shape. Thus, the animate form or surface, he describes, is a type of geometry that stores a "supple set of relationships between forces" (Garcia, 2010, p. 96). The second example explores the potential of contained information within the vectors that create forms, using the analogy of a dog chasing a Frisbee ${ }^{\mathrm{TM}}$. When a Frisbee ${ }^{\mathrm{TM}}$ is thrown, it possesses both direction and speed. A dog chasing this object also has a speed and direction, so does the environment if the wind is blowing in this case. If the dog were to meet the Frisbee ${ }^{\mathrm{TM}}$, it must continuously recalculate the results of multiple vector fields and successfully anticipate the point at which he meets the object. If one were to record the path of the dog, then at any position along the path would represent the magnitude of all the forces 
at a given moment in time. Although the dog does not actually calculate a differential equation, he perceives and anticipates the unfolding of multiple vector fields performing in space and time. Similarly, it is not necessary for architects to calculate the equations that create topological forms, but instead acknowledge the patterns that develop through varying performance (Lynn, 1999).

Similar to Lynn's exploration of form as a result of external forces, a choreographic architecture embraces human kinesis as the force of its creation. This method investigates the virtual forces of the body in movement, along with the relationship between the parts of the body for organizing and conceiving geometry. The paradigm of an architecture instilled by human kinesis challenges the traditional role the human body has served for the creation of architecture. Since the age of Vitruvius, the entire concept of architecture was dependent on the unified body, from architectural proportional systems to treatises and theories. The characteristics of the ideal body have been described in terms of architecture, rendering any particular body unfavourable with a preference for all bodies in general. Architects have conceived many variations of the ideal figure as a model in architecture, based on a universal archetype of symmetry and proportion. Due to the desire to define a totalizing model of the body, one that is in essence static, "only bodies that can be ideally reduced through a process of division to whole numbers are acknowledge[d] in architecture" (Lynn, 1998, p. 135). A temple derived from the proportions of a well-shaped body is based on a single organization determining all components which lead to a well-proportioned whole, where classical architecture's module is used as a standardized unit. This method of creating an architecture through a closed system, in which all components are determined by the proportion, is formulated from a topdown approach. What is missing in this architectural notion is the richness of intricate local behaviours of the body, the individual idiosyncrasies of the body's form and the vast amount of relationships we can define through its virtual parameters. This concept of choreographing architecture could then contribute to the composition of the whole, redefining the role of the body in architecture (from the static ideal human form to human kinesis) that engenders a more open and dynamic conceptualization of how to design architectural form. 
Choreographing architecture proposes a new kind of understanding of form and organization; one that replaces the static body that guides a system of proportions for classical construction, with a system of parameters and forces defined by human kinesis as a guide for geometry and structure. A choreographic architecture cannot be reduced to one single, general, universal or ideal organization, as it results from complex interactions of disparate systems rooted in the parameters defined by the moving body. With this method, architects should acknowledge the variation of topological forms that unfold dynamically through an analysis of movement, as opposed to understanding the geometric outcome solely as shapes. These forms are the result of decisions made by parameters that define the relationship between the moving body and geometry. In one application of this dynamic principle, the numerical data retrieved from the human body in motion, using motion capture, describes the characteristics of this external force and ultimately has an impact on the forms which result. From a dynamic modelling system, these numerical parameters are linked through expressions or a series of relationships that alter the shape of an object. Beyond its shape, these parameters control gradient characteristics of fields such as warps and directional forces defined by human kinesis. The associations between the characteristics of time, movement, form and parameters combine to establish the virtual possibilities for design using the dynamic body rather than its static conception.

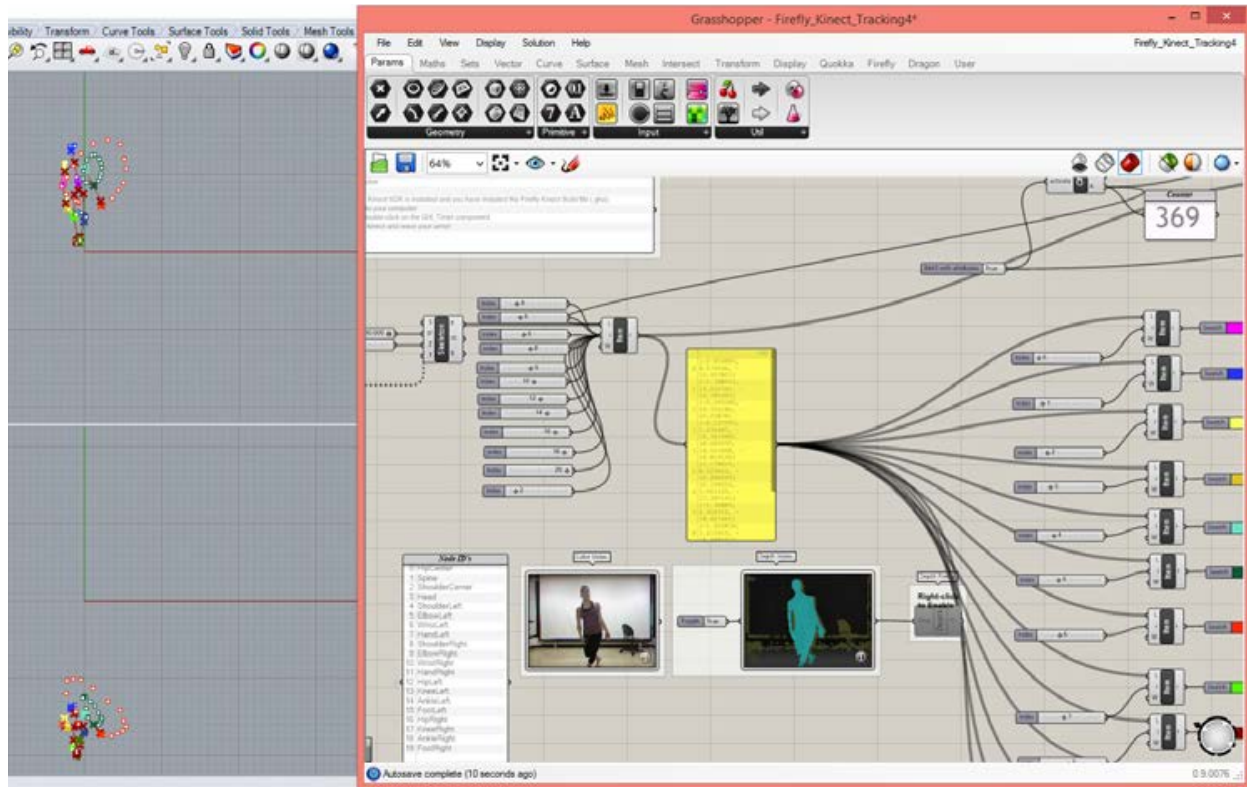

Fig.1: Defining parameters of the moving body through Grasshopper software and motion sensing device - Kinect. 
Q $\phi \uparrow \uparrow \uparrow \uparrow \uparrow$

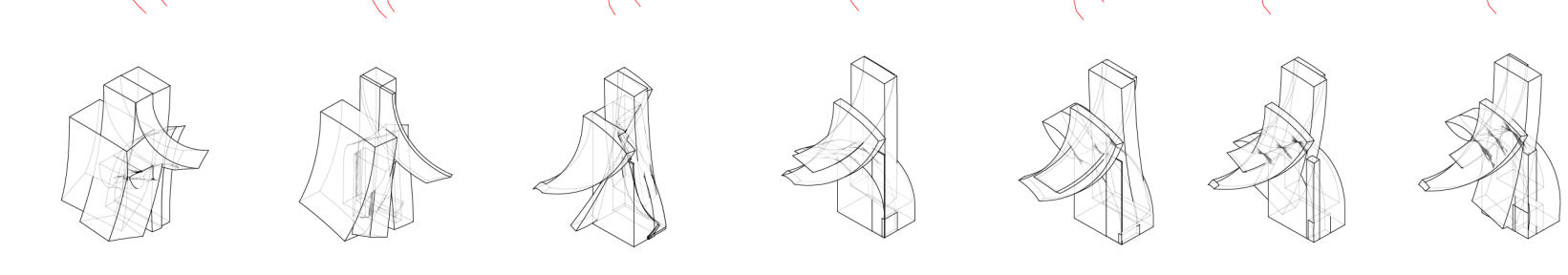

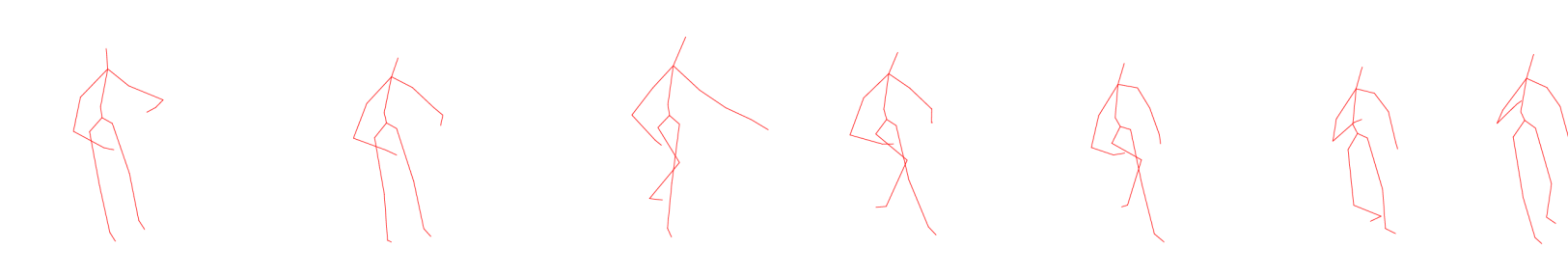

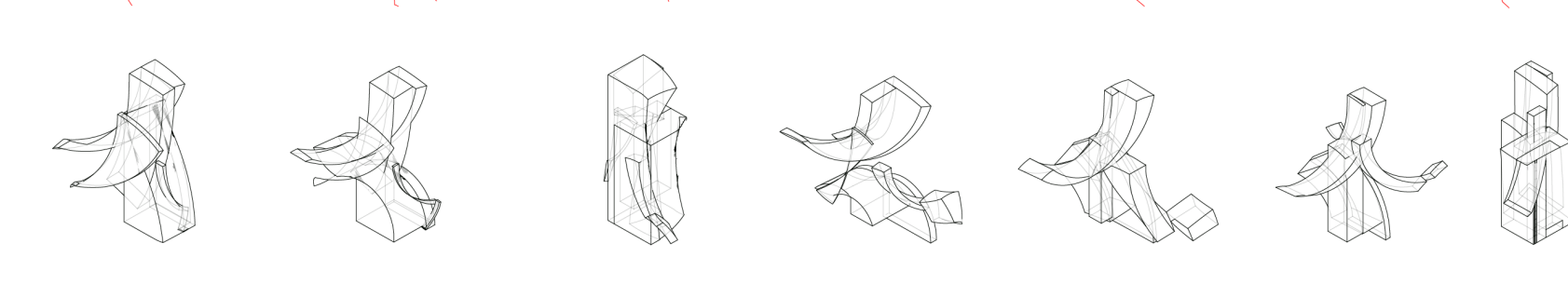

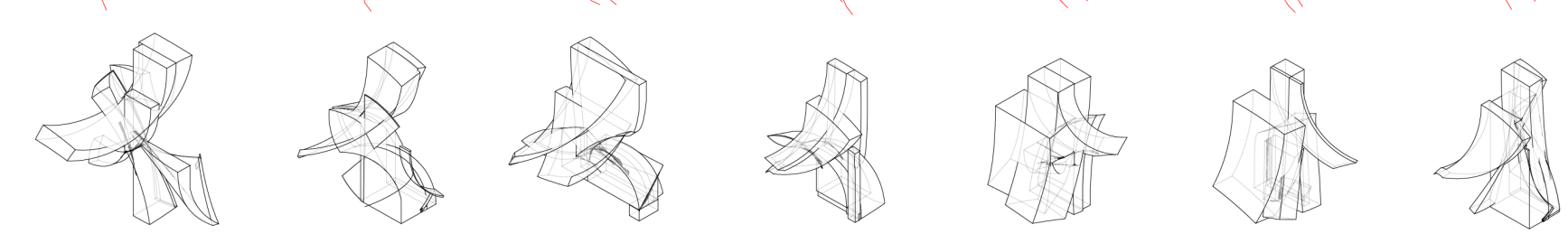



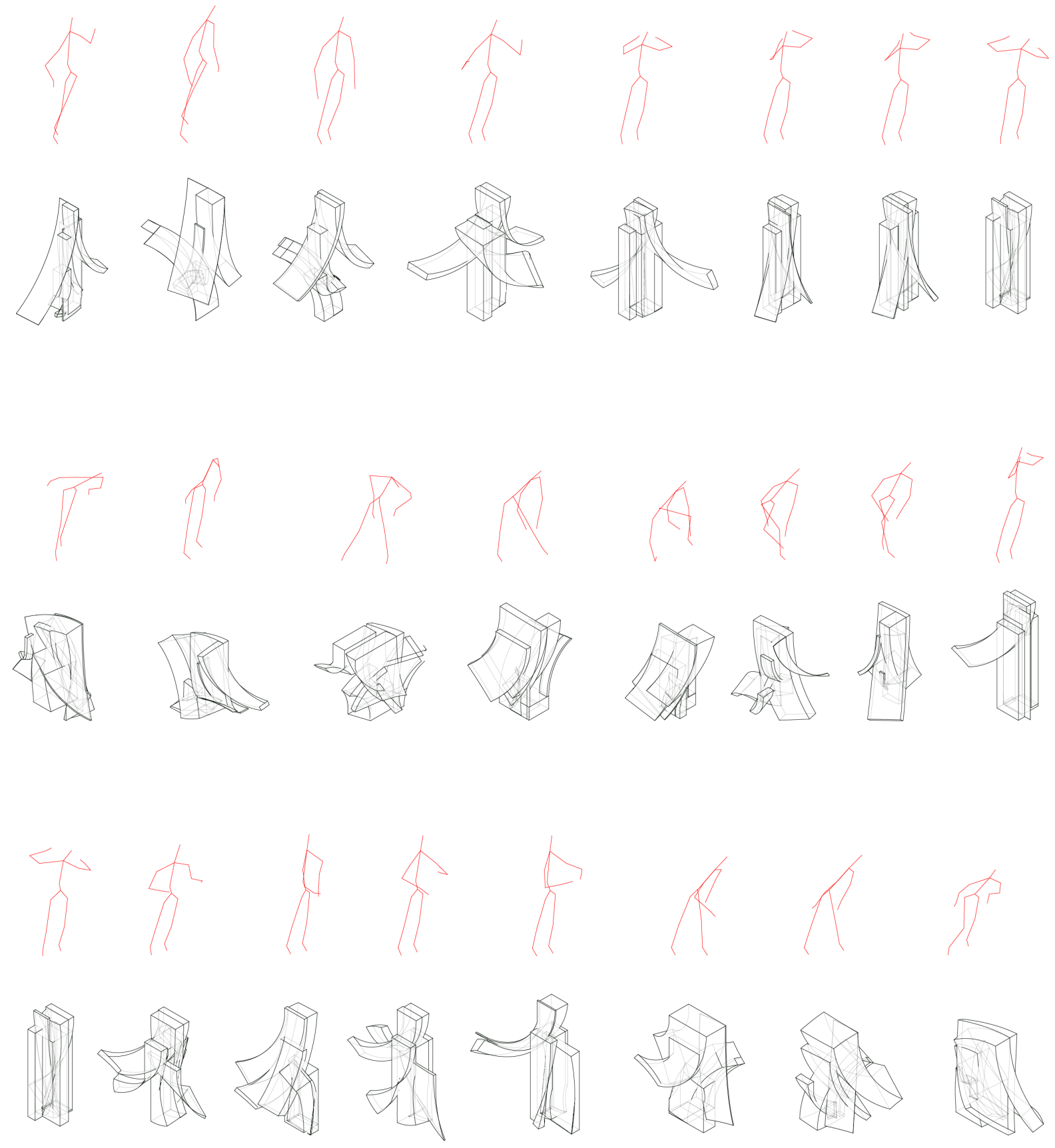

Fig.2: Kinesthetic Components

Kinesthetic Components are produced from movements of habitation. The experiment above demonstrates the motion and forces in form through the act of showering. The diagrams on the left demonstrate the motion and forces in the activities that take place at the dining room table. Each volume is created from a relationship between two points of the body. A virtual force, an arc defined by the body, deforms the volume. Seven components are produced simultaneously as the body engages in movement every 20 milliseconds. (The parameters defined for these motions are later discussed in Section 7.3) 
The formal outcomes of these parameters are geometries that are not static but rather stable, as they embody forces and relationships originating from a moving body. The difference between static and stable is critical for understanding these kinesthetic forms. In a simple response to gravity, stasis is the regulating factor through the fixed constant force of the ground point. In a more complex response to gravity, "stability is the ordering of motion into rhythmic phases." In the static example of gravity, motion is removed from the equation at the start of the design process. In the complex, stable example of gravity, movement is an ordering basis in which form is being influenced by several forces at once. Similarly, "discreteness, timelessness, and fixity are characteristic of stasis; multiplicity, change, and development are characteristic of stability" (Lynn, 1998, p. 15). Even though these forms are stable, they may take up frenetic outcomes, depending upon the movements and parameters defined. As such, it captures the movement and forces of human kinesis. The gradient forces of motion that embrace deformation, inflection and curvature are an expression of motion, force and time through form. As to thinking of deformation as a separation of the pure, the term deformation can be acknowledged as a system of regulation and order that progresses through a combination and resolution of multiple forces or parameters. These kinesthetic forms are then defined as composite entities that take the shape of a multiplicity; they are composed from a continuous stream of relative values, defined by the relationship between parts of the human body in motion.

The assemblages of kinesthetic forms in space are continuous and follow a temporary internal order. In the design experiment titled, A Visionary Proposition (Fig. 3), a virtual framework is established for these entities to be attracted toward and eventually dissolve the provisional framework in the final composition. When choreographed together, they develop a heterogeneous composition rather than the consistency of homogeneous modules, and exhibit varying degrees of unity and diversity based on the influence of human kinesis. Similar to a baroque space, it is geometrically highly continuous and differentiated, formulated around multiple radii in space. Yet, unlike baroque geometries, these radii are subject to change and thus influencing the formation and geometry of the kinesthetic forms. For example, a focal 
point is established in space that is defined to attract a particular species of kinesthetic forms. This species, for instance, are movements that occur while sleeping. The variation of kinesthetic forms produced from tossing, turning and stretching while resting would thus populate the area defined by the focal point. To further this notion, if the point transforms into a virtual plane and if the plane changes its orientation, so will the composition of kinesthetic forms. They may shift, rotate, merge and reformulate its position in space according to its reference, the virtual plane.
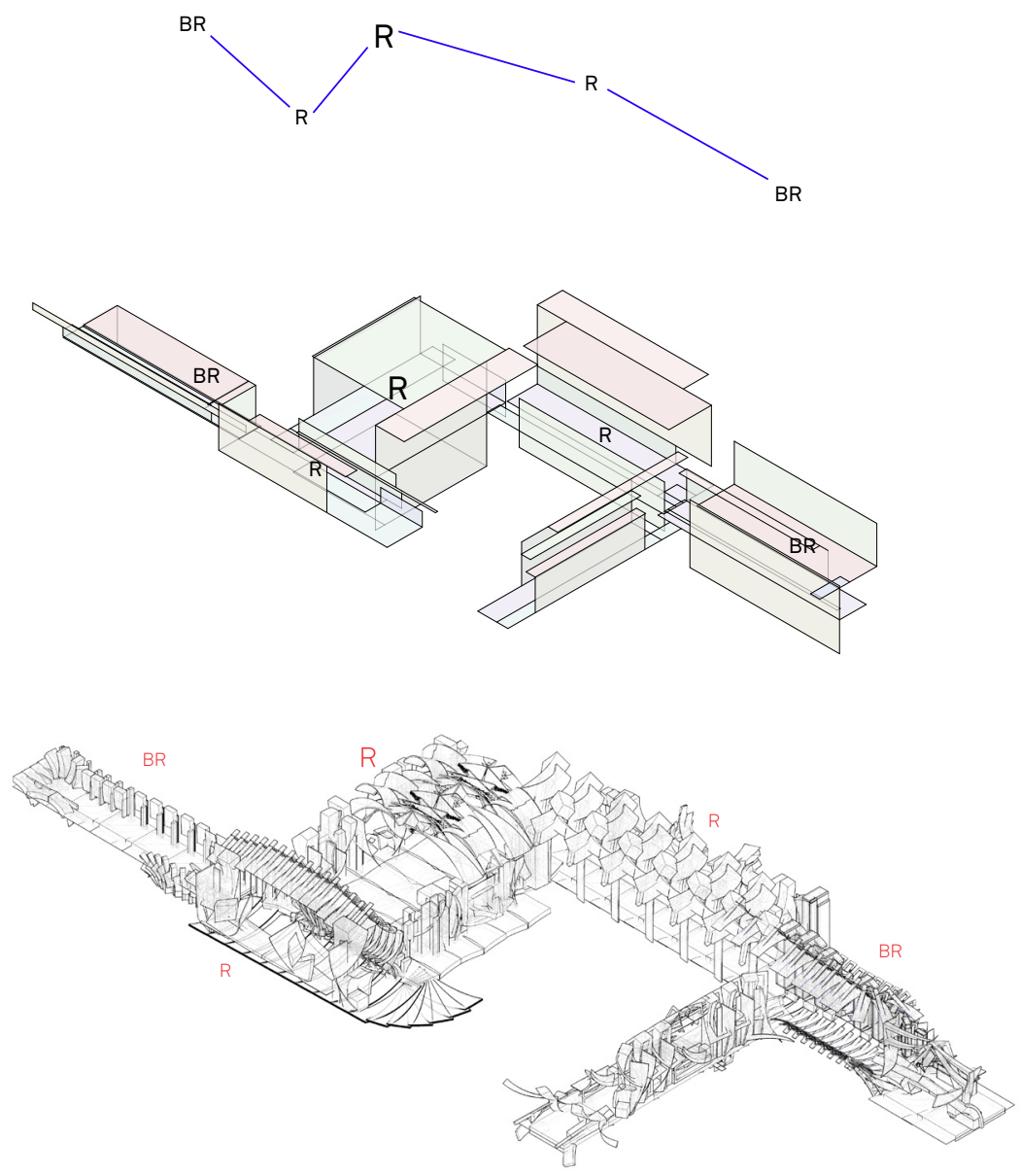

Fig. 3: Stages of transformation from points to virtual planes and finally kinesthetic components in the Visionary Proposition. (Refer to Section 7) 
The technique demonstrated in A Visionary Proposition challenges the traditional mode of discussing movement in architecture, which has typically been one of a cinematic model, "where the multiplication and sequencing of static snap-shots simulates movement" (Lynn, 1998, p. 11). As Lynn discusses in Animate Form, the underlying issue using a cinematic analogy is that architecture then takes the role of the static frame through which movement proceeds. As a result, force and motion are only introduced after the design is in place, through concepts and methods of visual processions. In contrast, a choreographic architecture proposes form, forces, movement and parameters to be ingrained within the design process. It can be identified as a mobile participant in dynamic flows, where there is no privileged or fixed type but instead a series of relationships between a range of potentials. By characterizing space as a medium inhabited by differential forces of attraction and motion, one starts to acknowledge the shaping and directional forces that can be constructed into an architecture, directing both its form and organization, like an ocean current. In other words, choreographing architecture uses emergent behaviours defined by the relationship between form, movement, human kinesis and its parameters, thus providing a new means of formalizing geometry and the organization of space.

Beyond the method of composition, a choreographic architecture instills the phenomenon of kinesthetic empathy within the geometry it creates. The kinesthetic gestures described above innately express motion and force through form in which the observer can sense its mass and perceived gravity, directly affecting our perceptions of the architectural object. Kinesthetic empathy explores this link between space and object with the kinesthetic sense, in which an internal physical sensation of motion and engagement is infused through our bodies while perceiving (Hunter, 2009). Vernon Lee, speaks of this sensation in The Beautiful, and observes:

You always, in contemplating objects, especially systems of lines and shapes, experience bodily tensions and impulses relative to the forms you apprehend, the rising and sinking, rushing, colliding, reciprocal checking ... of shapes (Lee, 1913, p. 61).

This feeling of motion can be associated with the physical aspects of scale and shape, eliciting the body in the appreciation of a form's size and character. Many theorists and architects examine the relationship between architecture, 

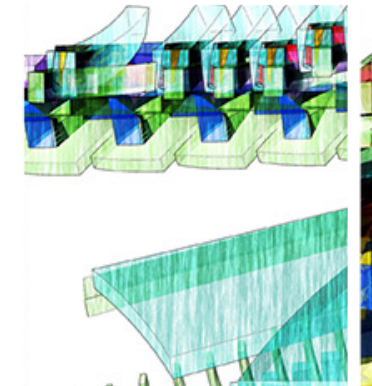

sathlly.
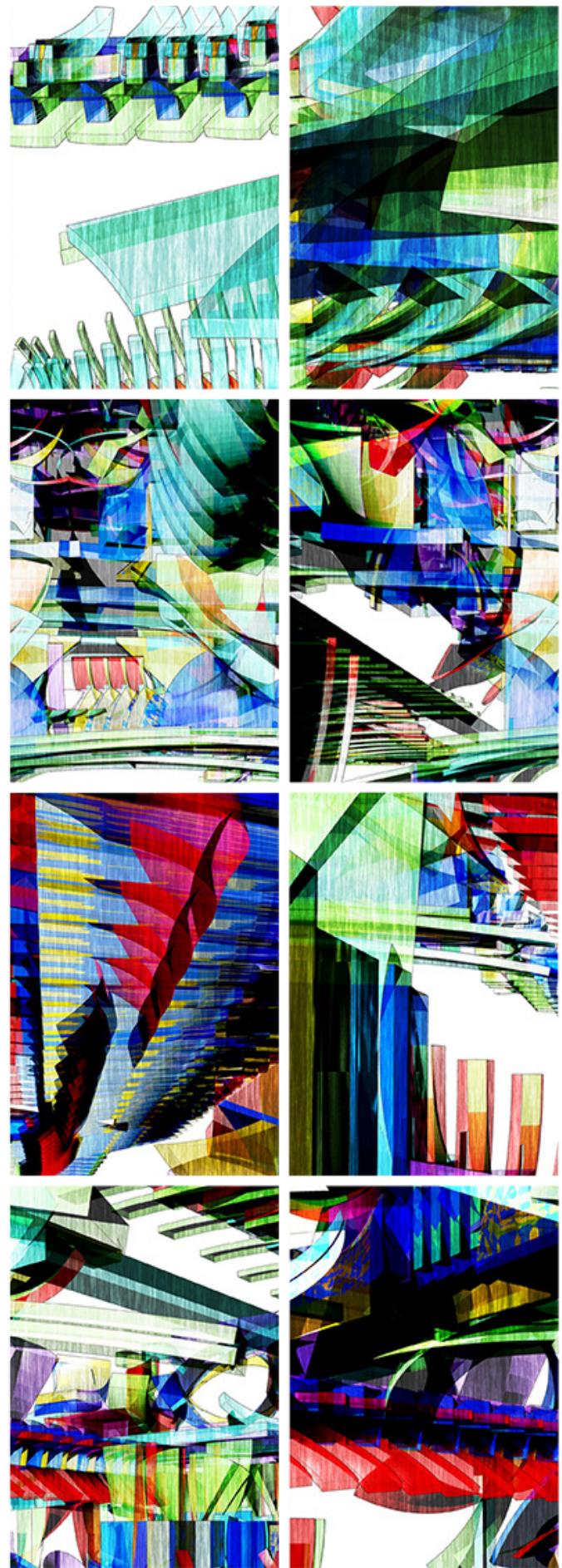
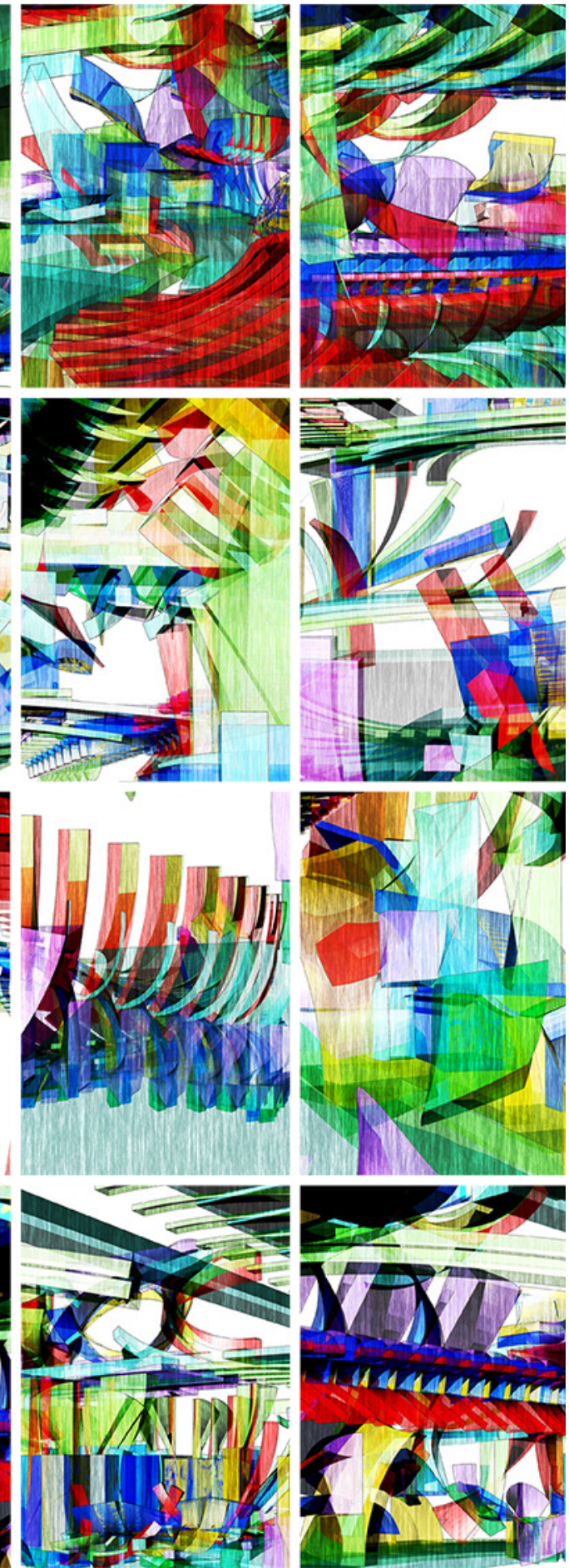

Fig. 4: Zoomed in perspectives of the Visionary Proposition. (Refer to Section 7) 
perception and kinesthesia along with its significance. Heinrich Wölfflin discusses architecture as an energetic animation of masses where conflict arises "between matter and force and form." His perspective of architecture is nothing less than an exhibition of expressive moods that are drawn from a state of embodiment (Mallgrave, 2011, p. 80). Finnish architect and theorist, Juhani Pallasmaa, discusses the body's ability to read the physical world and engage in "an unconscious bodily mimesis" with visual perceptions. He describes "our gaze strokes distant surfaces, contours and edges, and the unconscious tactile sensation determines the agreeableness or unpleasantness of the experience"; therefore, good architecture should offer "shapes and surfaces molded for the pleasurable touch of the eye" (Pallasmaa, 1994, p. 34).

In a choreographic architecture, the outcome of topological gestures expresses the forces, motions and tensions of the human body in movement. Similar to how watching human movement stimulates the motor sensation, forms generated from human kinesis would have a corresponding effect on the observer. Being exposed to geometry that embraces bodily tensions unveils the richness of variation underlining human kinesis, thus stimulating our kinesthetic senses when merely observing and perceiving these objects. In contrast, not all architecture is capable of sharing an intimate connection with the observer. In Pallasmaa's essay titled, The Geometry of Feeling, he opens with the question: "Why do so few modern buildings appeal to our emotions?" Theorists and architects believe part of this answer may reside in the rising rationalism of the last few centuries, along with the unwarranted formalism of the last few decades (Mallgrave, 2011). Perhaps, the answer lies in the quality of the architecture prohibiting our imagination to wander away from the world of everyday realities. For instance, a circle does not imply a sense of depth, yet a group of forms that deform, collide and intersect one another, similar to the kinesthetic gestures, allow the eye more space to explore and follow various organic paths (Fig. 4). Pallasmaa furthers this discussion by explicitly stating "an authentic work of art always pushes our consciousness off of its commonplace track and focuses it onto reality's deeper structure" (Pallasmaa \& Mackeith, 2005, p. 89). A choreographic architecture does not hinder the mind from wandering, as would a typical banal building, but instead allows our minds to rethink, engage and interpret the complexity of motions we sense through our bodies. These forms feed our desire to seek its inner language and provide meaning to the sensations we internalize. 


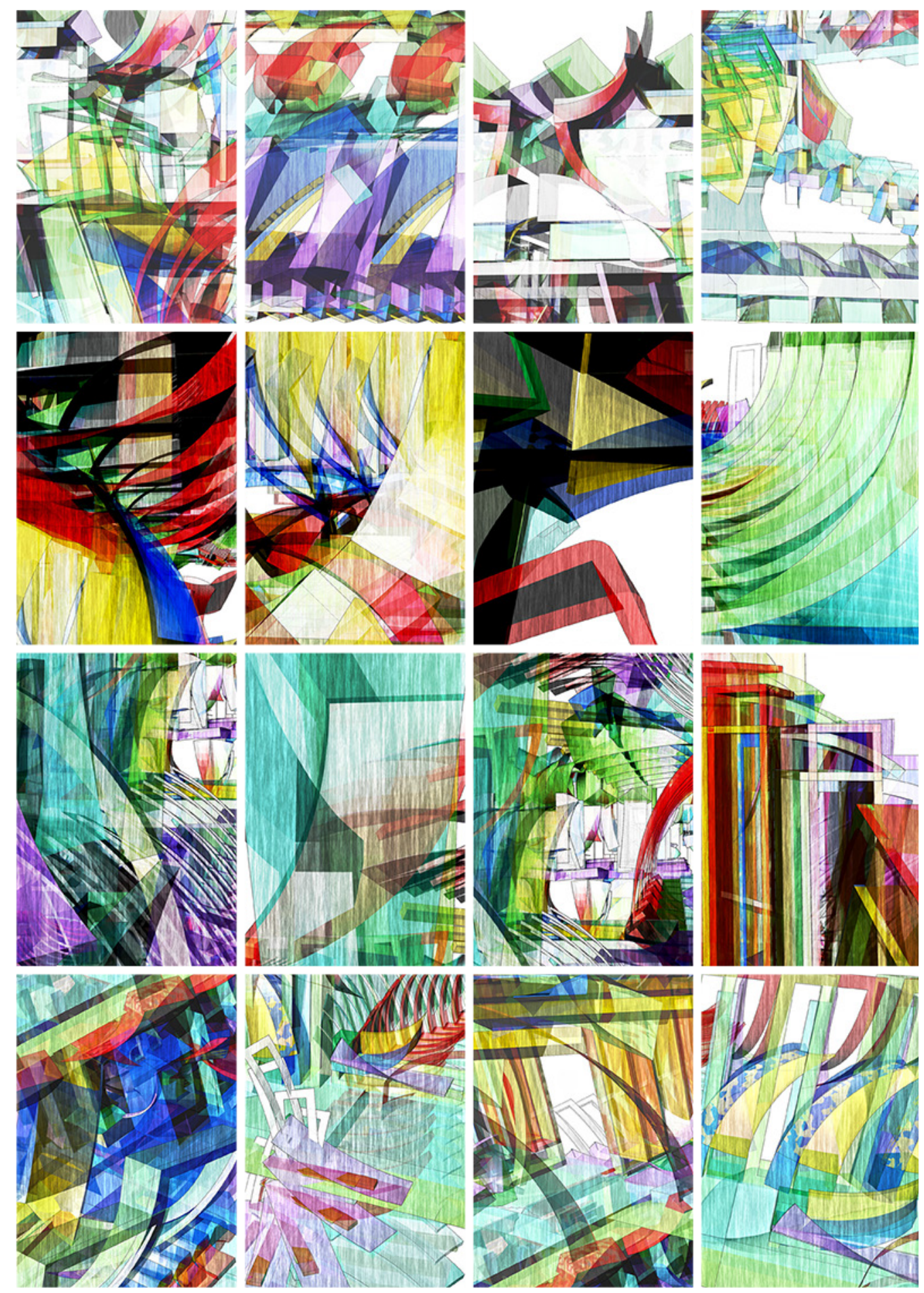

Fig. 4b: Zoomed in perspectives of the Visionary Proposition. (Refer to Section 7) 


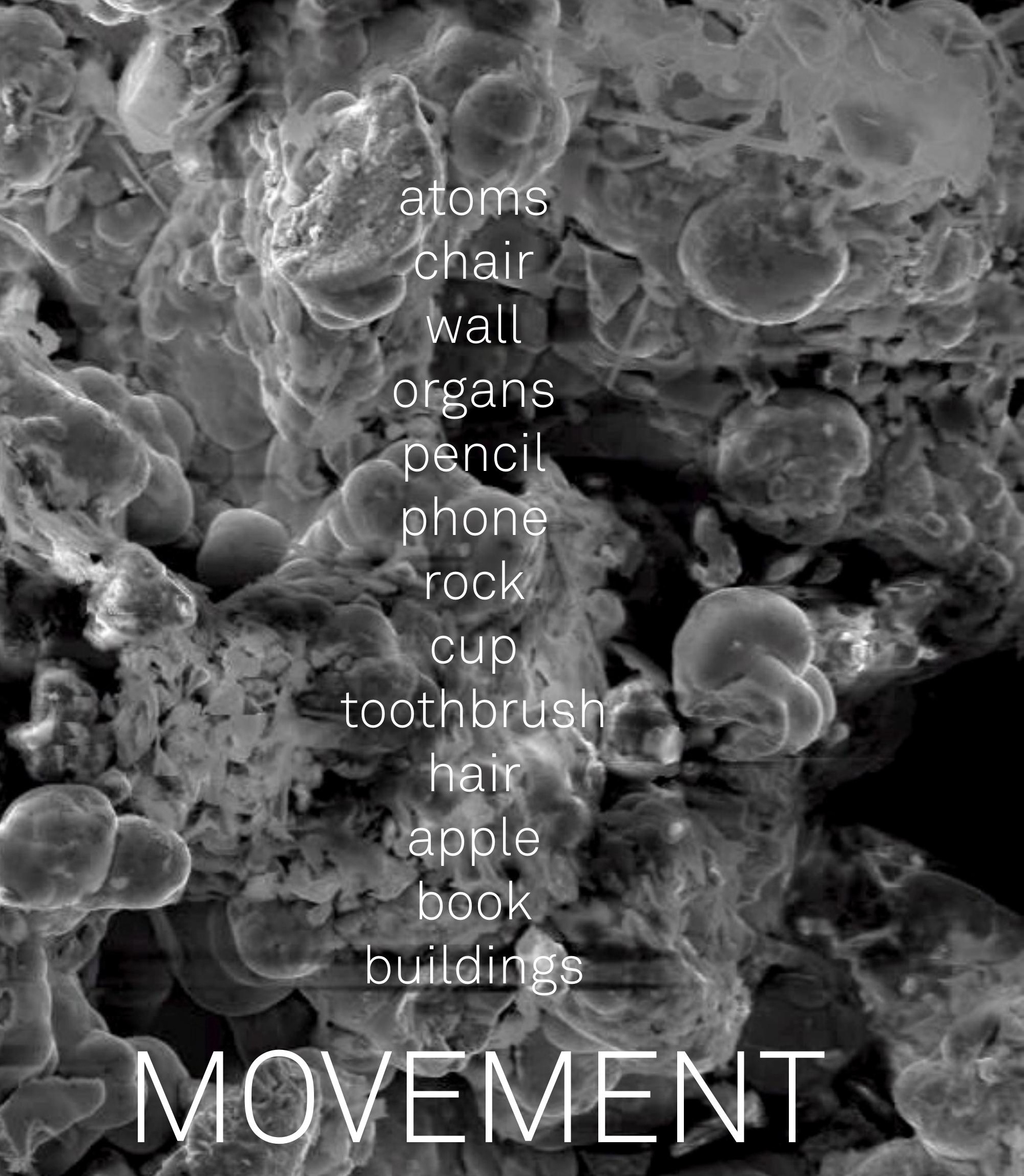


All life vibrates. Everything is in motion. Nothing sits at idle. The very form which we see, touch and experience and take for reality is nothing but a "fortuitous concourse of atoms" - indivisible particles of matter, varied in size and figure, all in constant motion (Raleigh, 1993, p.4). All forms are merely a result of the harmonious vibration of atoms of which it is composed and invisible to the naked eye. The material we are currently reading from, whether it be a tangible book or screen, appears to us as solid. As we gaze upon this surface we believe: here is reality; truly here is substance. This paper or screen which we view as being so real is in fact millions of atoms, comparatively as far apart as the earth is from the sun, which are revolving around one another, vibrating about each other; held together by a binding power which unifies all rhythms, tones and vibrations (Raleigh, 1993). The only reason why it seems to be solid, concrete and real is because of the strong nuclear force which allows stable molecules to form. If these binding forces failed to exist, immediately the paper or screen would dissolve into its constituent atoms, they would all go off on a tangent, the force which maintains the equilibrium between the molecules would cease, and these words would simply vanish.

Similar to the objects that surround us, "there is never a body without movement" (Leibniz, 1996, p. 54). Our lungs expand as we breathe in air, muscles tense and release as we move through space, and our minds churn as we sense the world around us. Therefore, it can be said that motion is intrinsically linked to the relationship between our bodies and the built environment. To be in a place where you currently sit or stand, you had to walk to get there. The way you carry out your daily routine in the house and at work is all through locomotion. Buildings even instill internal motion within our bodies. Think about the sensation you feel being underneath the summit of a tower; or the feeling of standing beneath a larger atrium, looking up through a central void towards a large skylight; it's uplifting. Such a space makes you feel weightless as you unconsciously compare the scale of the structure with your own human form. Our bodies are in constant dialogue with our buildings as we move and perceive our surroundings. We move to experience architecture, and in turn, are moved by its presence.

Finnish architect Juhani Pallasmaa speaks of this interaction between body, movement and space in The Eyes of the Skin: Architecture of the Senses (1996):

I confront the city with my body; my legs measure the length of the arcade and the width of the square; my gaze unconsciously projects my body onto the facade of the cathedral, where it roams over the mouldings and contours, sensing the size of recesses and projections; my body weight meets the mass of the cathedral door, and my hand grasps the door pull as I enter the dark void behind. I experience myself in the city, and the city exists through my embodied experience. The city and my body supplement and define each other. I dwell in the city and the city dwells in me (Pallasmaa, 1996, p. 40). 


\section{$02.1 \quad$ The Forgotten Sense}

The Absence of Human Kinesis in Architecture

When discussing the senses of our bodies in relation to how we perceive our built environment, the kinesthetic sense is often disregarded. Pallasmaa argues that our visual sense has taken priority over the tactile senses of our bodies. In his book, The Eyes of the Skin, he declares that architecture is presented in such a way as to create a visual spectacle, rather than being conceived through the body. He asserts the kinesthetic senses of the body form the primary sense, as opposed to the "hegemonic eye" (Pallasmaa, 1996, p. 22). Pallasmaa's philosophy of the relationship between body and space is rooted in Merleau-Ponty's belief that the human body is the heart of our experiential world. Kearney, writing on the philosopher, furthers this argument by stating that our bodies are living centers that belong to this world at the basis of intentionality, in which "we choose the world and it chooses us" (Kearney, 1986, p. 74). As Merleau-Ponty (1945) proclaimed in his own words: "our own body is in the world as the heart is in the organism: it keeps the visible spectacle constantly alive, it breathes life into it and sustains it inwardly, and with it forms a system" (as cited in Merleau-Ponty \& Smith, 2002, p. 235). This system he discussed is the sensory experience, often unstable in our natural perception that integrates within our bodies and unleashes a realm of interacting sensations.

In the field of psychology and neuroscience, the notion of the body schema or body image entails this center of integration that occurs as we perceive our environments. The body image is defined as an organization of (sometimes conscious) attitudes, perceptions and beliefs affecting one's own body. The body schema, however, is a non-conscious operation of processes that continuously regulate both movement and posture (Gallagher, 2005, p. 234). In both cases, these phenomena uncover the constant interaction our bodies and movement share as we inhabit our world; the environment and the self communicate and redefine one another endlessly. As we move through space, the perceived mental image of the body and impression of the world unite to form a single continuous experience; there is no body detached from its home in space, and likewise, there is no space unconnected to the unconscious image of the perceiving body (Pallasmaa, 1996). 
Kent C Bloomer and Charles W Moore (1977), in their book Body, Memory and Architecture, discuss the formation of the body image and its significance in the realm of architecture. Through studies of the body and the senses in spatial experience, they initiate their argument by stating "the body image $\ldots$ is informed fundamentally from haptic and orienting experiences early in life. Our visual images are developed later on, and depend for their meaning on primal experiences that we acquired haptically" (p. 44). They further their argument by outlining "the potential transactions between body, imagination, and environment" are absent from architecture today: "To at least some extent every place can be remembered, partly because it is unique, but partly because it has affected our bodies and generate enough associations to hold it in our personal worlds" (p. 44).

Architects have disregarded a realm of human spatial experience with a "historic overemphasis on seeing as the primary sensual activity in architecture" (Bloomer, 1977, p.49). Even with a generation of environment and behaviour studies in architecture, architects are still fixated on one form of perceptual experience. Within the architectural field today, there are ample reasons for taking into account a variety of perceptual sensibilities in design, including movement of the body in space. Movement mediated through architecture unveils a new realm of spatial experience, an environment that shares a richer, more aesthetic and haptic sensorial quality for the occupant to inhabit. Studies have outlined the conditions of sensory variance in our architecture, movement being one of the critical components capable of igniting the senses and satisfying environmental preference. Perhaps undergoing the investigation of human sensorial, gestural and physiological behaviour is necessary for developing a corporeal architecture that enhances well-being. This thesis investigates the human body, our most fundamental three-dimensional possession, and movement as a consideration in the understanding of architectural form. With the technologies available for analyzing human kinesis, we can understand its relationships as an external force that could then inform a new theory of making architecture move. 
02.2 The Fascination With Movement

"I'm not interested in how people move, but in what moves them."

- Pina Bausch (2009)

Humans are captivated by movement. Consider the thrill you feel when watching your favourite action movie, sports game or dance performance. At times, you cringe when someone has fallen or feel a rush when you have observed a flawless performance. We take pleasure in watching movement that displays artistry, in particular involving balance, coordination and refined technique. Scientists in neuroscience and psychology have investigated motion and our desire to seek and feel pleasure when watching movement. This section will discuss the anatomical effects of observing both actual motion, including the performing arts, and implied motion through photography.

Some of the most interesting research has been conducted on the neuroscience of dance, including the observation of a performance by both novices and experts. Research has already proven that dance has a biological impact on the human heart and brain. For instance, complex structures and variations in choreography can generate a healthy variable pattern of the heartbeat and stimulate the motor planning areas of the brain for viewers. The appreciation of dance and other forms of movement activities is related to the interchange of expectations and their fulfillments. This phenomenon is known as the perceptual anticipation of movement, in which our brains foresee the next set of movements prior to the actual occurrence. When our brain predicts the next sequence correctly, we are pleased; however, when our expectations are wrong, we are taken by surprise and become pleasantly awakened. Brain scans reveal humans are hard-wired to receive pleasure from unexpected events; the nucleus accumbens, the main area of the ventral striatum responsible for reward and pleasure, is activated in response to an unexpected incidence (Sommerfeld Health) (Hagendoorn, 2003).

At times, we also experience the physical sensation referred to as "chills" or "shivers down the spine," a feeling that occurs when our minds are emotionally stimulated by the perceived movement. In 2001, neuroscientists Anne Blood and Robert Zatorre examined the neural mechanisms of this effect in a neuroimaging study at the Montreal Neurological Institute of McGill University. 
They discovered that the intensity of the "chills" correlates with increased activity in brain regions associated with emotion and arousal (Hagendoorn, 2003). Further studies conclude viewing a performance deemed aesthetically pleasing by the viewer has the ability to increase blood flow in the brain's limbic system by as much as 10\% - the equivalent increase we experience when gazing at a person we love (Ishizu \& Zeki, 2011).

Beyond actual movement, it has been demonstrated that observing a photograph of an object or human in movement stimulates motor areas in the brain. In 1983, an article written by cognitive psychologist Jennifer Freyd demonstrated that photos of a moving object, for example a falling glass, unveils information about its dynamism, an effect described as "implied motion." By observing these "action stills," our brain's regions linked to perceiving movement is stimulated, documented by professors Nancy Kanwisher and Zoe Kourtzi (2000) of the Massachusetts Institute of Technology. Here, cognitive science tells us how the camera freezes motion in such a way, that it appears to continue, generating a feeling of motion in the observer. Motion and emotion are therefore inherently linked: "one is moved by movement (perception; impression; affection) and moved to move (action; expression; emotion)" (Fuchs et al., 2014). Based on these and other findings, psychologists and neuroscientists have argued that watching movement "submerges the brain in motor imagery, the motor correlate of visual imagery" (Fogtmann, 2007). Motor imagery is defined as the kinesthetic sensation of movement without actually moving. Our ability to simulate and embody the action of a perceived motion is made possible through the phenomenon of kinesthetic empathy.

The term kinesthetic empathy can be understood first by isolating the meanings of the two terms: kinesthesia and empathy. In her book titled, Choreographing Empathy, anthropologist Susan Foster explains empathy as sensation felt in the body stimulated by encountering another, whether the "other" is a human, an environment or static object, and kinesthesia as the perception of bodily movement and position in space. Kinesthetic empathy therefore entails a perception of how our bodies sense and react in explicit and subtle ways to the world in which we live. Vernon Lee reveals that to have an empathetic experience, it must originate "in one's own awareness of the kinesthetic responsiveness to the object"; in other words, we must sense our 
our environment with our bodies prior to empathizing with it (Foster, 2010, p. 155). Therefore, kinesthetic empathy can be defined as an exchange between our bodies and our surroundings, as we perceive and register the multiplicities that make up our world around us.

Our ability to sense and feel movement is made possible from our somesthetic and haptic perceptions including exteroception, proprioception and interoception. Exteroception concerns the senses situated on the surface of the body and exposed to the exterior world. Proprioception relates to our sense of balance and proper positioning in space, and to muscular tensions. Lastly, interoception refers to all the sensations of the visceral organs situated in the body's interior (Leder, 1990, p.39). Kinesthesia is informed by these three senses which include vision and hearing as well as internal sensations of muscle tension and body position (Reynolds, 2007, p.185). It is also rooted in a system of sensory modalities including hearing and touch, which have also been associated with the mirror neuron system (Keysers et al., 2004; Gazzola et al., 2006). In addition to mirror neuron research, this links with studies on the topic of perception and its interrelation with the various senses. Studies in this research are interdisciplinary, including information drawn from aesthetic theories, Gestalt psychology, Maurice Merleau-Ponty's phenomenology of perception (1945) and neuroscience. The next section will trace the evolving understanding of kinesthetic empathy and bodily perceptions in art and architecture from these perspectives.

Fig. 7: Somatic Senses Pathways

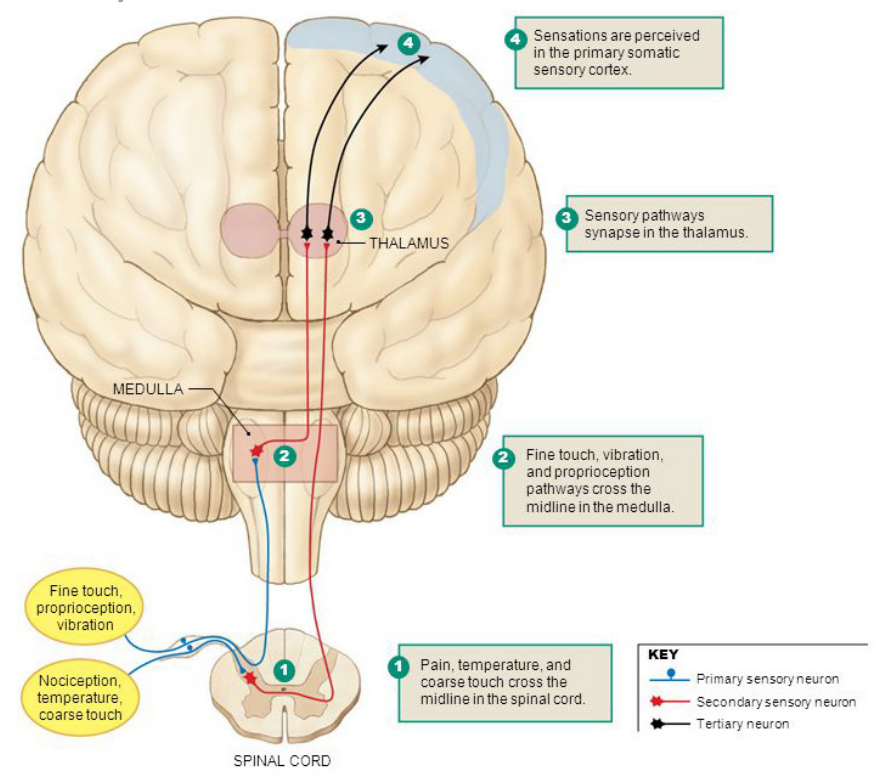




\title{
02.3 Kinesthetic Empathy \& Bodily Perceptions
}

\author{
Theories of Aesthetics to Mirror Neurons
}

"Perception is a primordial structure of encounter and engagement of the lived-body with and in the world. It is the mode of access, the opening upon the world, that allows consciousness its objects through the agency of body."

- Vivian Carol Sobchack (1992)

on Maurice Merleau-Ponty's Phenomenology of Perception

Maurice Merleau-Ponty's phenomenological thinking explores the relation between perception and space through the body. His theory on perceptual experience reveals the inseparable interaction between body and space; the body as the medium that forms the environment around it respectively, or changes with it through perceptual experience. The body encounters space, exploring both hidden and boundless affective qualities of our environment. This importance of the lived body urges architecture to be explored not as a visual composition, but as a kinesthetic exploration felt through our body (Chronopoulou, 2014).

Merleau-Ponty's concepts are also studied in relation to the theory of Empathy (Robert Vischer's Einfühlung, 1870-1910) and Gestalt psychology (around 1920). Robert Vischer's theory of Einfühlung ("in-feeling" or "feelinginto") constitutes the unconscious projection of our "own bodily form - and with this also the soul - into the form of the object" (Vischer, Mallgrave \& Ikonomou, 1994, p. 92). Empathy in architecture begins to reveal the affective potential of form, not merely through the experience of vision, but through our entire physical body. As we move through space, we are simultaneously being moved by the forms our body perceives. Our projection of the environment's disposition is an outcome of the body's attempt to alter its spatiality in relation to the perceived object. We unconsciously create imaginary scenarios of how our body would feel in the inanimate form's position. As Vischer claimed, "we move in and with the forms... and caress their spatial discontinuities" (Vischer et al., 1994, p.101). The concept of Einfühlung became a prevalent subject in Germanic theory in the late-nineteenth century explored by a number of psychologists and artists, including Theodor Lipps, Wilhelm Worringer and Heinrich Wölfflin. In particular, Wölfflin theorized the ability for architectural forms to express a feeling or mood in his dissertation entitled Prolegomena to a Psychology of Architecture. Wölfflin examined Charles Darwin's theory 
of facial expressions to illustrate the affecting characteristics of movement embodied in Baroque architecture and art (Holden, 2007). He primarily focused on understanding form merely as an expression, placing less emphasis on imagination in Vischer's concept. Wölfflin begins with the anthropomorphic principal that "physical forms possess a character only because we ourselves possess a body;" in other words, our bodily composition is the medium through which we take in everything physical (Vischer et al., 1994, p. 151). For instance, if a building possessed an unbalanced formal expression, the inhabitant would react with a physical sensation of uneasiness as it upsets his or her bodily balance. The sense of apprehension is not the outcome of the active imagination but of an explicit feeling of an unbalanced state on our muscles. Even so, the vestibular system will attempt to understand the surrounding environment through our body's organization. Architecture, as Wölfflin perceived, is an "energetic animation of masses" where conflict arises "between matter and force of form." Thus, Wölfflin's perspective of architecture is nothing less than the exhibition of expressive moods that are drawn from a state of embodiment (Mallgrave, 2011, p. 80).

A decade later following the conception of Einfühlung, the emergence of Gestalt psychology took prevalence in the field of psychology and philosophy, later applied to visual perception in art and architecture. Gestalt theorists, including Rudolf Arnheim, emphasized that human experience cannot be reduced to a sum of parts of which each corresponds to a stimulus-response pattern. Rather, human experience is a complex intersection of body, environment and consciousness, most appropriately addressed by Gestalt principles of perceptual organization. Whether we are observing movement, perceiving objects, or grasping an idea, these principles explain our ability to see our world in "unified wholes," as opposed to isolated elements (King, Viney \& Woody, 2009, p.374).

Originally developed through studies of aesthetics, the discourse of kinesthetic empathy reignited interest in the field of neuroscience through mirror neuron research. In the 1980s and 1990s, neuroscientists investigated how mirror neuron activity allows us to sense others' thoughts and sensations through simulation. First detected in macaque monkeys, the mirror neurons were seen activated while carrying out actions and also when observing actions performed by another (di Pellegrino et al. 1992; Gallese et al. 1996). Mirror neurons are defined as cells in the monkey brain that have the same 
behavioural pattern when executing a particular activity (i.e. reaching a banana), and when observing another animal engaging in the same action. Additional studies have also show a parallel mirror neuron system in humans for gestural recognition. A series of experiments reveal the mirror mechanism in the human brain "unifies action production and action observation, allowing the understanding of the actions of others from the inside" (Rizzolatti \& Sinigaglia, 2010). As such, it has been hypothesized that the mirror neuron system is linked to the human's ability to share feelings with others by "activating the observer's own neural substrates for the corresponding state" or by offering "shared affective neuronal networks" (Preston et al. 2007; de Vignemont \& Singer, 2006). Neuroscientist Vittorio Gallese, one of the key members who discovered the mirror neuron, explains embodied simulation as the "functional mechanism underpinning Einfühlung" and reasons that it furthers our understanding of how humans share emotional states. Here, the spectator's embodied simulation (also referred to as kinesthetic empathy) produces a "body state shared by observer and observed" (Gallese, 2008, p. 771).

Kinesthetic empathy allows us to describe a range of pleasures, emotional and imaginative responses we have towards artistic and embodied practices. Throughout history, artists have embraced movement through various mediums of expression, enabling the spectator to experience sensorial and imaginative sensations of kinesthetic pleasures. In order to understand empathy in the arts, we first must investigate the role of movement in artistic practices including visual arts, photography and architecture. 


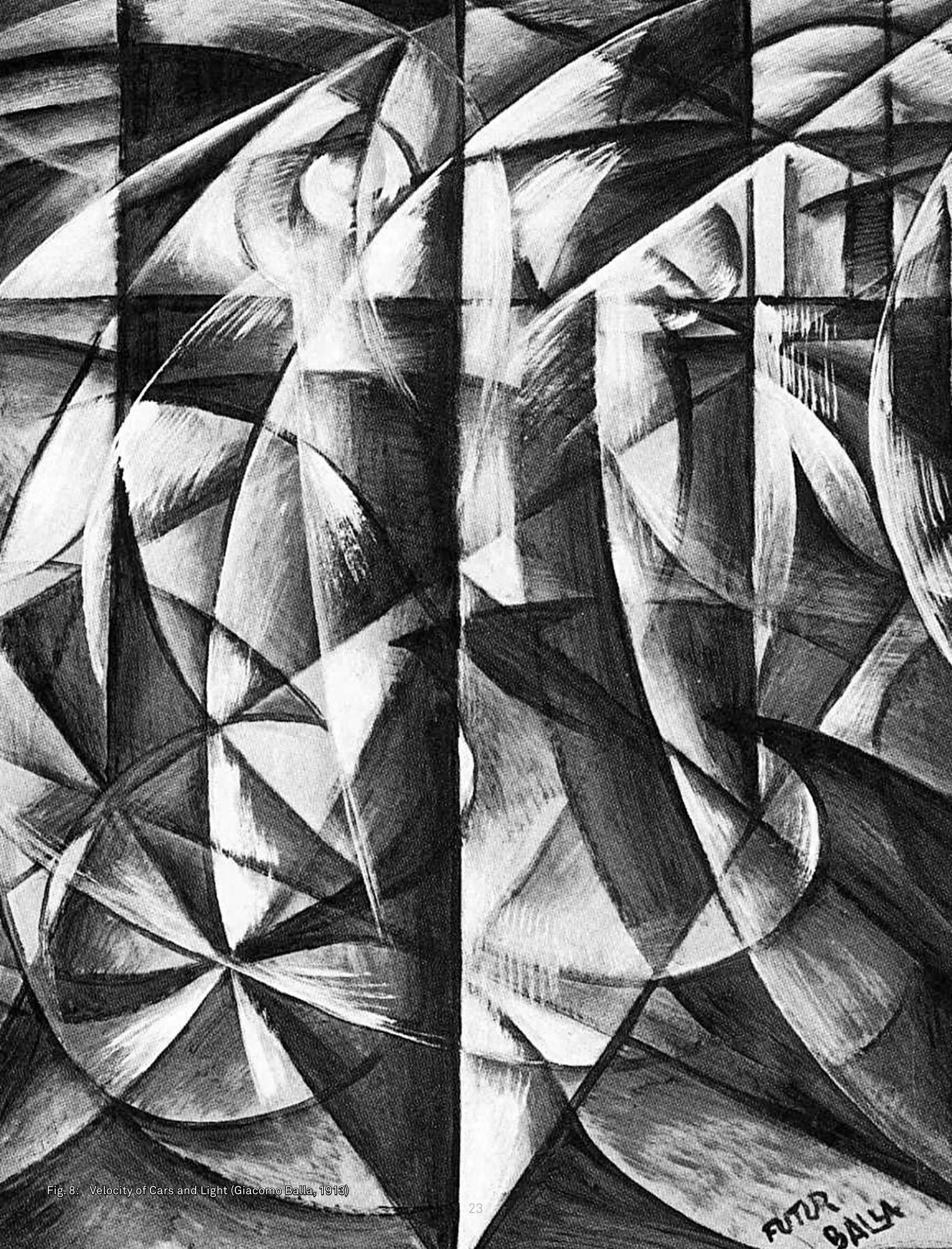




\section{Movement \& The Arts}

"What we want to do is to show the living object in its dynamic growth"

Umberto Boccioni (1913) on The Avant-Garde Art Movement Futurism

At the turn of the twentieth century, artists depicted the sensation of movement inspired by advanced photographic methods and other forms of technology and transportation. Photographers, painters and sculptors were enamoured with physical dynamics such as trains, cars and airplanes that fueled the industrial world. Movement was all the rage in the new era of Futurism, a celebration of modernity, change, speed and motion through the medium of art. 


\subsection{Motion in the Visual Arts}

The streets bustled with automobiles, trains carved through cities, airplanes roared through the skies trailing smoke along their paths. The world began to change its pace at the beginning of the twentieth century. Life, work and leisure time all obtained new rhythms; the uproar of movement consumed everything with its power of dynamism and energy. At the epicenter of modernity in the early 1900s, the Italian avant-garde art movement Futurism - promoted a vision of a mass culture of the modern industrial world. The movement praised innovative technologies and urban modernity, revealing the magnificent spectacle of machines, speed and change. French philosopher, Henri Bergson, and his view of the world as dynamic as opposed to static, exerted a considerable influence on the advancement of Futurism. Bergson claimed our understanding of the world was in constant flux; therefore, one frame of mind, one observation of action is continuously changing. He believed our immediate experience is infused by the recalling of emotions and thus every following experience will be influenced in turn:

Bergson emphasized that our consciousness is always fluid, always becoming, always dependent on emotional states so there is no one perceptual reality...The truth of one's own experience in what Bergson called 'duration' is therefore too fluid and complex to be grasped by reason. Only sudden intuition can give us access to memories of past experience stored in the unconscious. Only in those moments when we are connected with the fundamental self can we act freely. So if artists aim to capture these feelings, they must choose subjects with which they are long familiar. So they can channel the sudden subjective response (Bonnard et al., 1989, p. 86).

Bergson's philosophy gave expression to the way the modern world was experienced by many artists of the period (Berghaus, 1996). Marinetti, the founder of the Futurist movement, was well aware of Bergson's philosophies of time, memory and space, and thus were the rest of the Futurists. Marinetti's manifesto encouraged a group of young artists in Milan to employ these concepts to the visual arts. Together, the Futurists intended to express through art the dynamism and atmosphere of a modern age in motion. They proposed a vision that captured a sensory perception of what is observed, and the recollection that one possesses of that object or environment. As a result, 

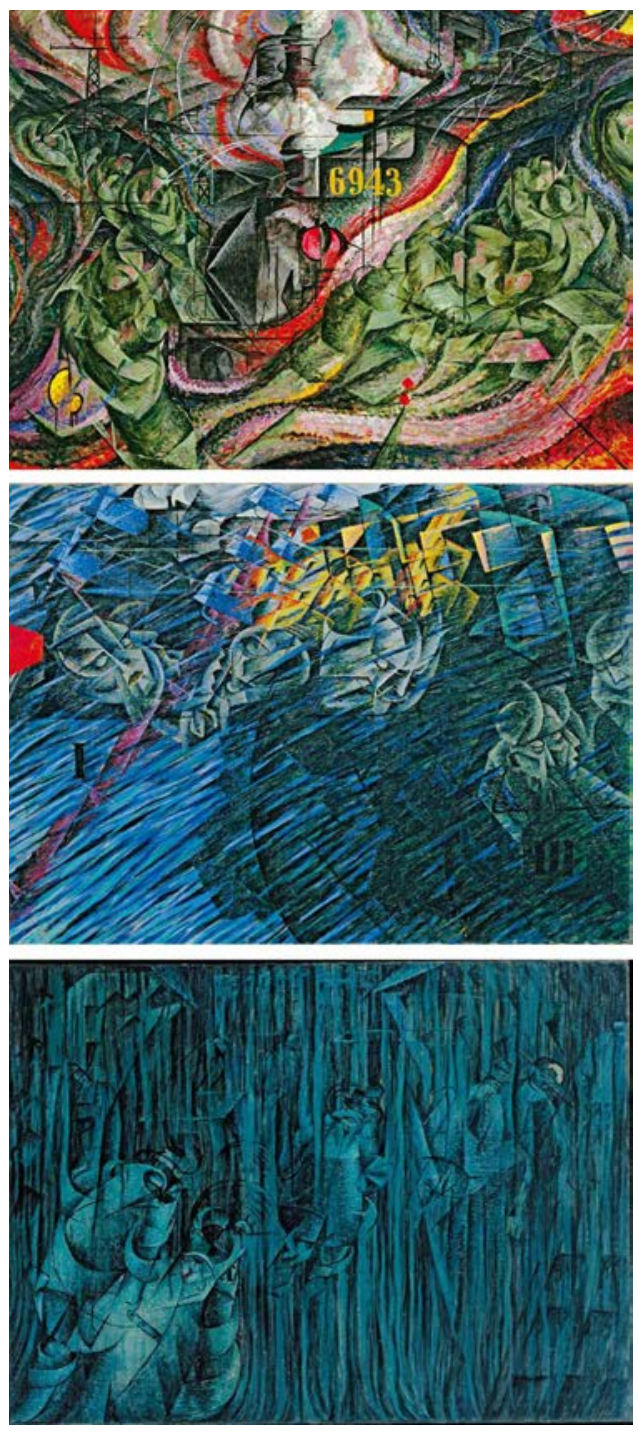

Fig. 9: Triptych Paintings: States of Mind (Boccioni)

their paintings portrayed physical, sensory and emotional elements, reflecting both dynamic speed and noise of a world in movement.

Marinetti was the poet and publicist of the Futurist movement, expressing concepts through print and speech, while the visual artists such as Boccioni, Balla, Russolo and Severini communicated their ideas through sculptures and paintings. Umberto Boccioni is often regarded as the most influential of the artists serving as the "artistic voice of Futurism" (Brown, 2013, p.4). It was not until he encountered the style of Cubism that he sought to create a new post-Impressionist approach, embodying the dynamism and plasticity of the modern age. His work, along with other Futurists artists, demonstrated a "dynamic cubism" where objects influenced by the modern aspects of speed, acceleration and light were illustrated. While Cubism rendered objects from various perspectives in a static mode, Futurism embraced the notion of simultaneity, conveying not merely numerous viewpoints, but also multiple sensory sensations in time. Boccioni's triptych painting, States of Mind (1911), captured these theoretical ideas influenced by Bergson, Cubism and the experience of modern life's transitory nature (Fig. 9). Set in a train station, the artworks express the sensation of motion by applying new modes of expression including the following: "lines of force," illustrating the directional motion of objects through space; "simultaneity," by merging memories, impressions of the present, and events anticipated in the future; and "emotional ambience," where the artist attempts to link the sympathies between art and the spectator's 
emotions (Humphreys, 1999). Using these techniques, Boccioni represents the dynamism of modernity in the three paintings titled The Farewells, Those Who Go, \& Those Who Stay. In the Farewells, Boccioni portrays an uproar of movement by blending figures in a stream encased by the train's smoke. Those Who Go reveals a sense of departure with the use of oblique lines, expressing confusion, isolation and anguish. In Those Who Stay, the artist predominately uses vertical lines to express the melancholic feeling for those staying behind (MoMA, 2006).

Here, Boccioni not only fuses time, motion and travel in his work, but also evokes a multitude of emotional perspectives of those who stay and those who are left behind. His intentions in art were strongly influenced by Bergson's notion of intuition, where the spectator experiences sympathy by projecting oneself into the inner being of an object. Futurist artists strived to facilitate this relationship between the viewer, artwork and its content, in which one is able to grasp the inner being of the depicted art (Brown, 2013).

Boccioni collapsed the gap even further between space, viewer and artwork by turning to sculpture as a means to convey his Futurists ideas:

This systematization of the vibration of light and of the interpenetrations of planes will produce Futurist sculpture: it will be architectonic in character, not only from the point of view of the construction of the masses, but also because the sculptural block will contain the architectonic elements of the sculptural milieu in which the subject lives (Boccioni, 1912).

In his sculpture, Unique Forms of Continuity in Space (1913), he infused the dynamism and energy of the environment upon the body represented (Fig. 10). The form of the moving subject appears to be shaped by the power of speed and wind in a striding position, unveiling the relationship between environment and object. Boccioni sculpts the figure and environment as one entity, where flame-like shapes begin at the legs and demonstrate the air sweeping away from the body in movement.

At the same time, other Futurist artists explored a different approach altogether towards space and time, with a focus on the moving image. The early work of Giacomo Balla, such as Dynamism of a Dog on a Leash (1912), 


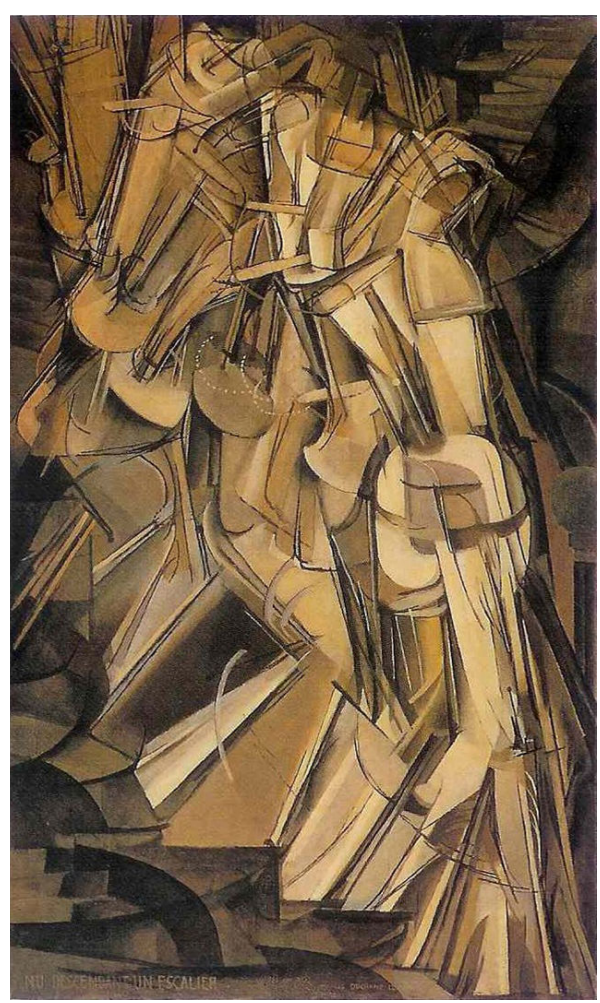

Fig. 12: Nude Descending a Staircase, No. 2 (Duchamp) exemplified multiple-exposure painting techniques where a single shape is repeated and shifted, created an illusion of movement (Fig. 11). Balla takes a typical subject from an Impressionist painting, a street scene with bourgeois promenaders, and picks out one lady walking a dog, a chosen clip that now becomes the focus of the picture. He multiplies the number of tails, ears, legs and shoes creating an impression of an owner and her dachshund out for a quick walk.

Marcel Duchamp's 1912 painting Nude Descending a Staircase, No.2, also demonstrates this layered-time technique representing a subject itself in motion (Fig. 12). The figure is manipulated to appear in a stop frame animation, combining Cubism's method of fracturing form, while showcasing one view through many stages in time. In the painting, a single figure is repeated six times in movement with shins distorted, curved lines denoting the swinging of legs, together with dotted lines illustrating how the shapes shift through time.
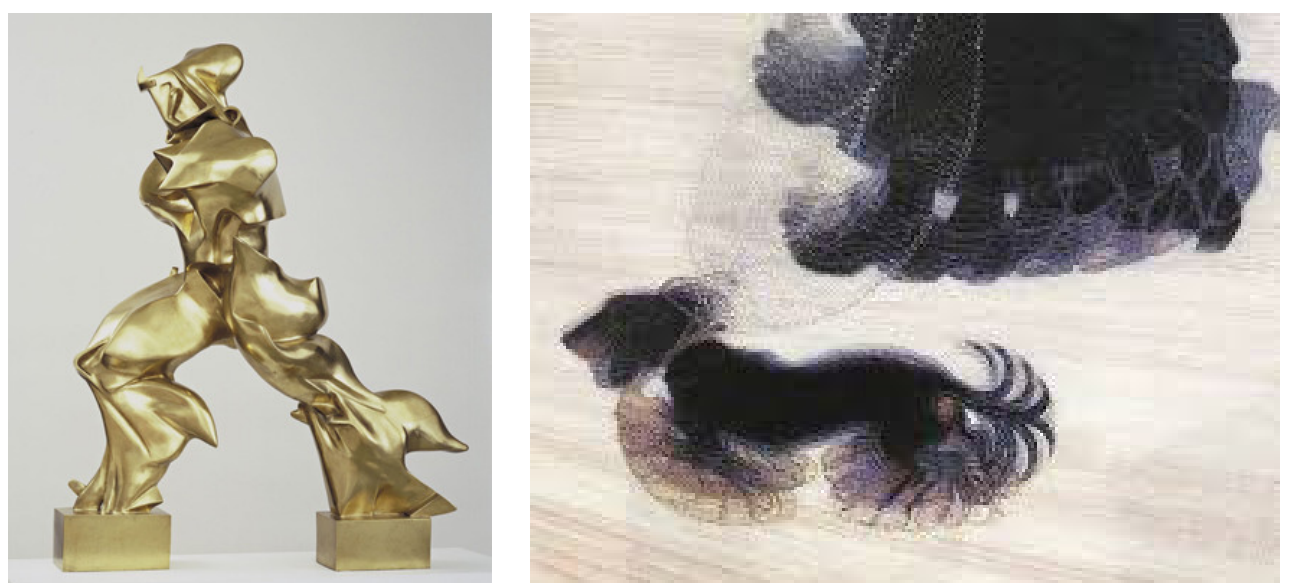

(Left) Fig. 10: Unique Forms of Continuity in Space (Boccioni)

(Right) Fig. 11: Dynamism of a Dog on a Leash (Balla) 


\subsection{Motion in Photography}

Both Balla and Duchamp were inspired by the experimental photography works of Eadweard Muybridge, Étienne-Jules Marey and Thomas Eakins. These pioneers of photography offered a model to such artists, who examined movement by analyzing it through a series of moments in time. Muybridge's pioneering work in photographic investigations of motion was influential to artists, especially for his analysis on the galloping horse. In 1872, Muybridge was requested to settle a bet concerning the positioning of a horse's legs when galloping and trotting. He discovered the movement of a horse has been misrepresented for centuries, after documenting its motion using his newly invented mechanically tripped shutters. His advancements in film were able to showcase a horse trotting at top speed, with all hooves off the ground at the same time, and in a different configuration from that of a galloping horse (Pipes, 2003).

Thomas Eakins also took interest in the new advancements of motion photography. He assisted with Muybridge's work at the University of Pennsylvania, later carrying out his own trials in documenting phases of motion superimposed on one negative, a method used in Marey's work known as chronophotography. French physiologist Étienne-Jules Marey adopted this approach of recording movement, transforming our way of seeing time and motion. He experimented with the idea of creating multiple exposures on one photographic surface, using both film strips and glass plates. Marey became fascinated with the flight of birds but had no success in photographing birds in flight, similar to the galloping horse in Muybridge's experiments. As a result, Marey invented a "photographic gun" to register the stages of a bird's flight using a "clock-mechanism that made 12 exposures at 1/72nd of a second" (Pipes, 2003, p.121) (Fig. 13). In addition, he conducted many studies of humans in motion wearing black attire with white bands along the length of the limbs. The individuals moved in front of black panels, documenting their motions using only one camera and recorded on a single glass plate. His photographs and diagrams inspired artists throughout the age of Futurism and continued to reverberate throughout the first decades of twentieth-century visual arts. 


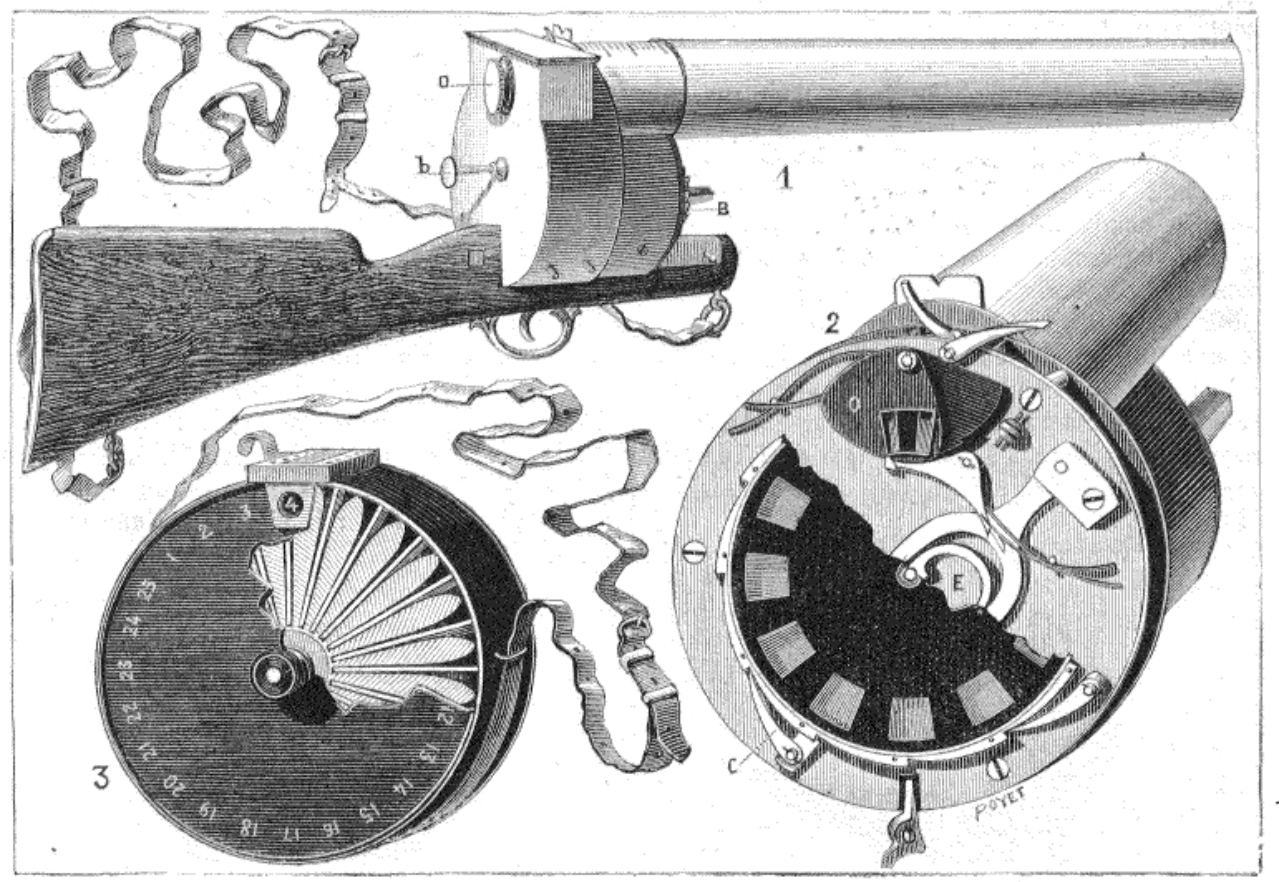

Fi h. 2. Mécanisme du fusil photograpl.ique.

1 Vue d'ensemble de l'appareil. - 2. Yue de l'obturatour et du disque à fenctre, - z. Bote contenant vingt-cinq plaques sensibles.

Fig. 13: Étienne-Jules Marey's Photographic Gun - Drawings of the photographic gun camera's internal mechanisms. A gelatin plate is situated in the magazine of the gun, and when the trigger is pulled, a photograph is captured on the plate.

Marey's pioneering work in the field of chronophotography also inspired film artist Norman McLaren in his short film Pas de Deux. In 1968, the film adopted the layering technique to motion pictures, where McLaren used an optical printer to produce and overlay numerous images of dancers' movements. Similar to Marey, the film adopts the chronophotographic method "to focus not on the movement's poses but on the activity of the interval through which movement's preacceleration can be felt" (Manning, 2009, p. 116). In recent years, films have revisited this technique through cutting-edge advancements in digital compositing. Michael Langan and Terah Maher's film titled Choros (2011), takes chronophotography to the next level using digital innovations to layer thirty-two sequential instances of a single movement, drawn out over time. Following the works of Marey and McLaren, Langan and Maher explore dance, music and image layering through film, enhancing our perception of motion (Langan, 2011). 

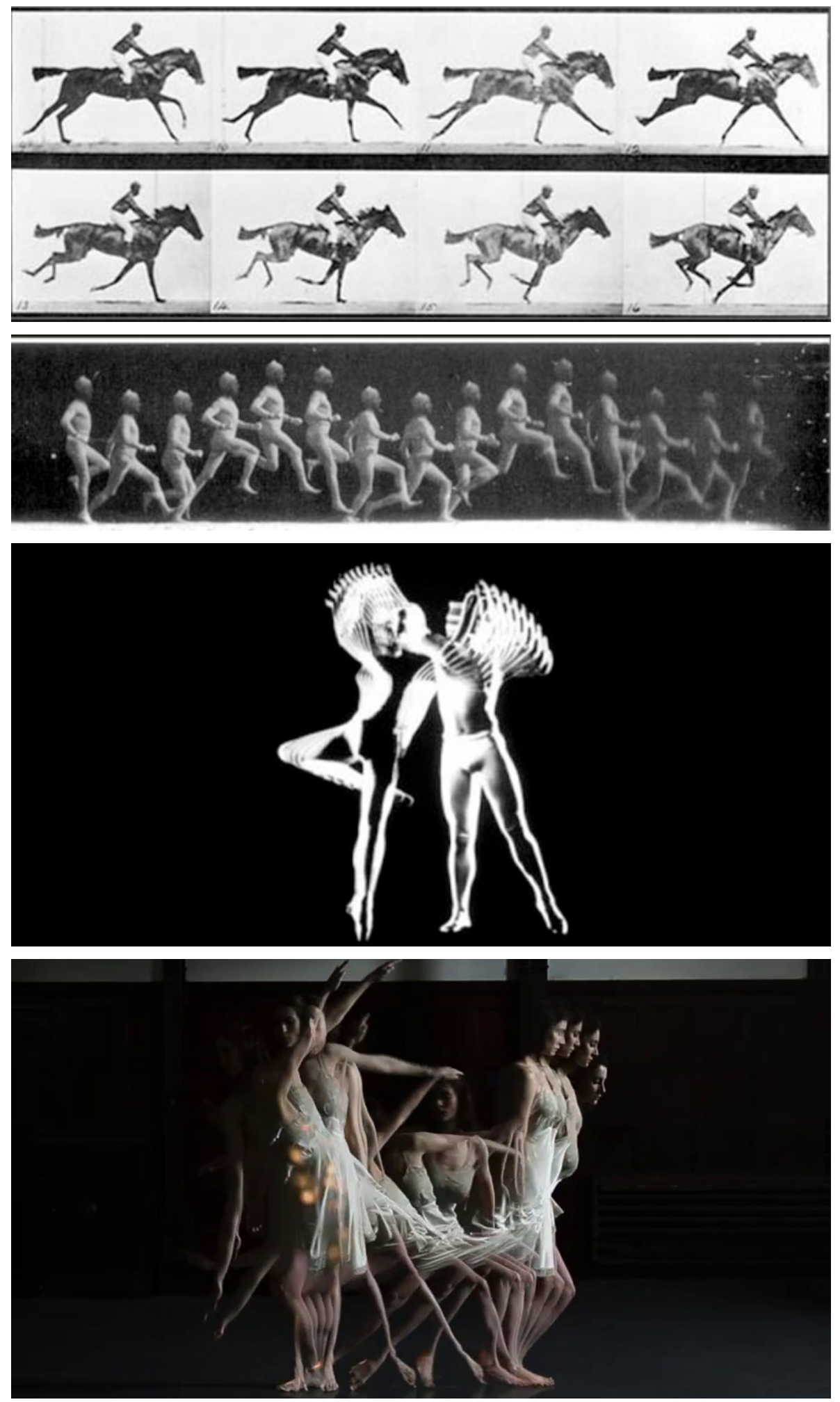

Fig. 14: Evolution of Chronophotography (Top to Bottom): Muybridge, Marey, McLaren, Langan \& Maher Right Fig. 14b: Langan and Maher's film titled Choros 


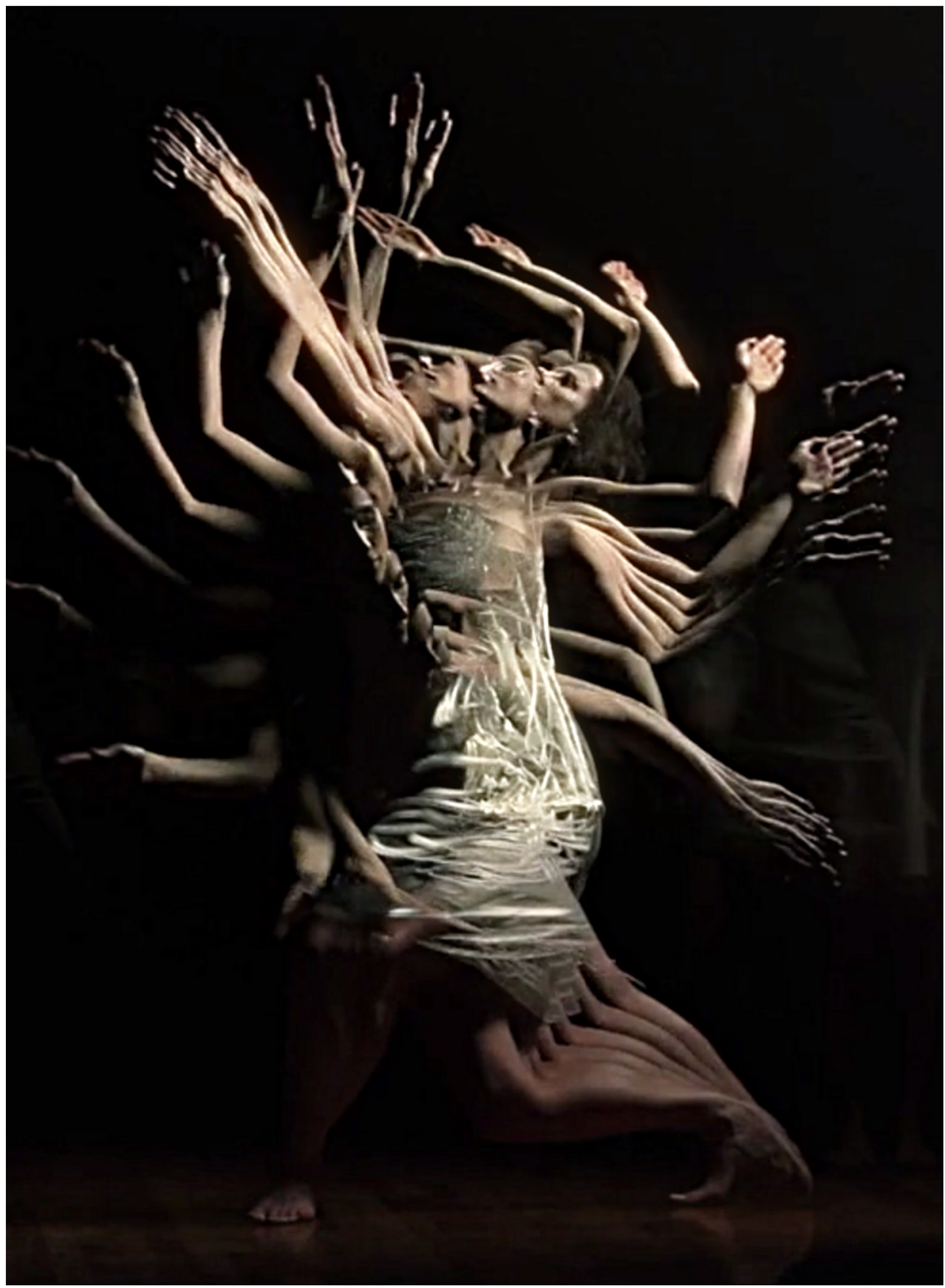



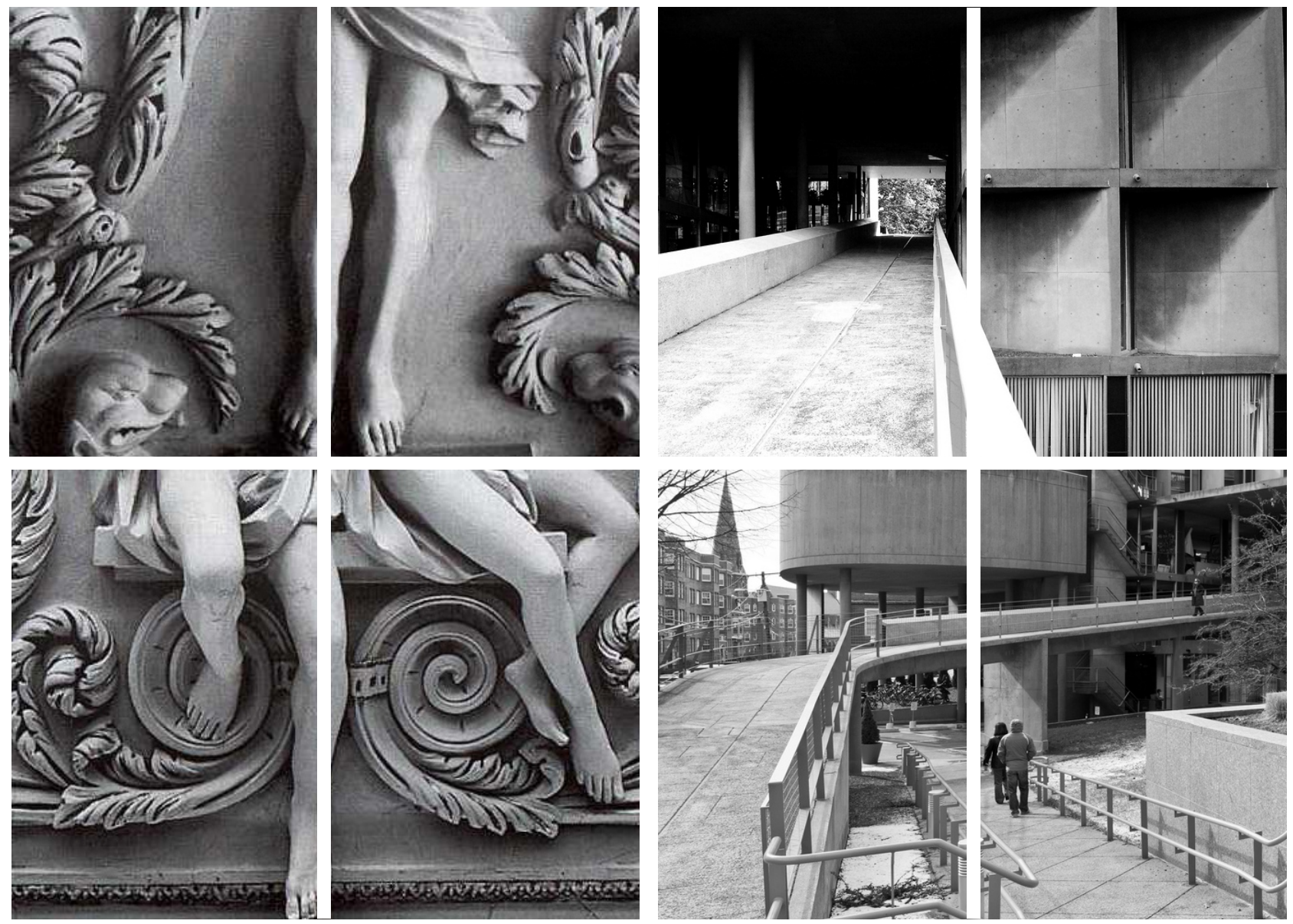

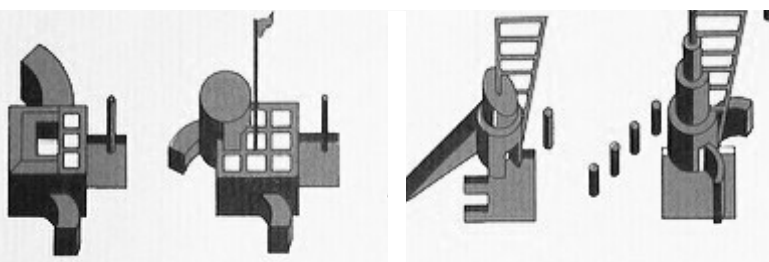
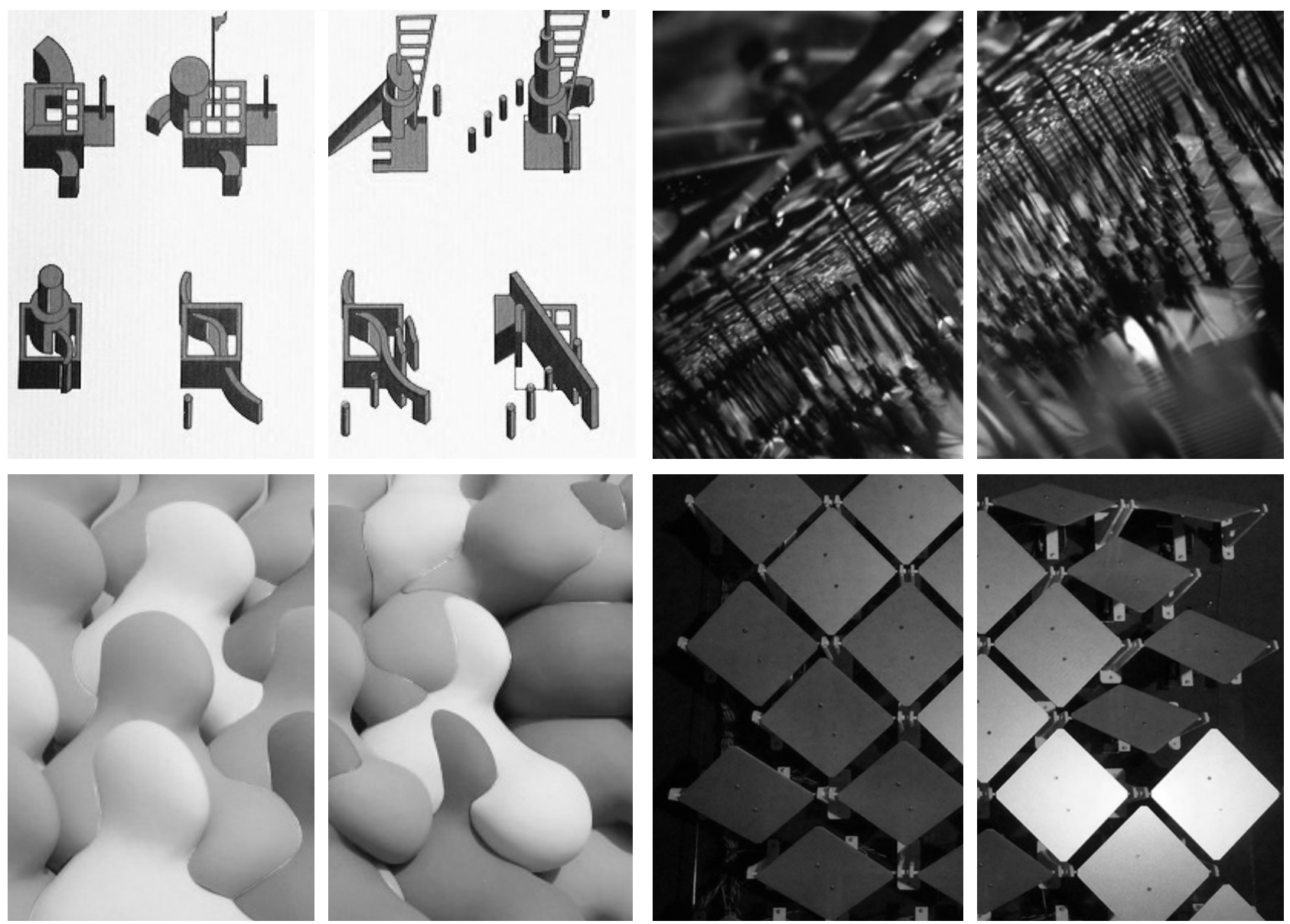


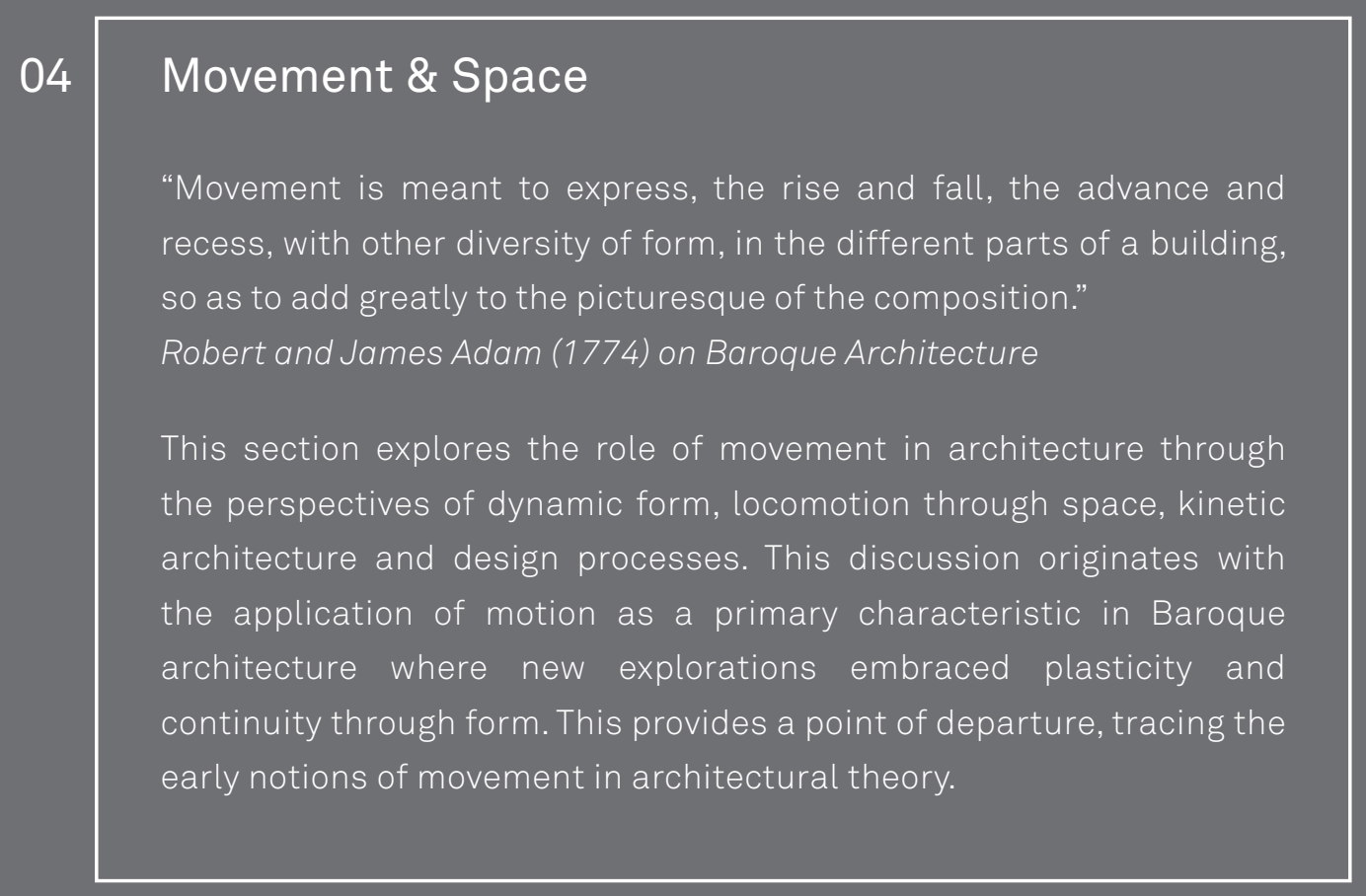




\section{$04.1 \quad$ Dynamic Forms}

Baroque Architecture \& The Picturesque-Effect

"Wölfflin noted that the Baroque is marked by a certain number of material traits: horizontal widening of the lower floor, flattening of the pediment, low and curved stairs that push into space; matter handled in masses or aggregates, with the rounding of angles and avoidance of perpendiculars, the circular acanthus replacing the jagged acanthus, use of limestone to produce spongy, cavernous shapes, or to constitute a vertical form always put in motion by renewed turbulence, which tends to spill over in space, to be reconciled with fluidity at the same time fluids themselves are divided into masses." (Deleuze, 1993).

The prime example of an art known for moving the spirit is also an art that infuses motion within its medium. In his seminal study, Renaissance and Baroque, Heinrich Wölfflin suggested movement to be the fundamental characteristic of the Baroque architectural style. He identified Baroque architecture as "movement imported into mass" that allows the observer to imagine columns moving forward and back [and] the walls thrusting outward" (Macarthur, 2007). Roman baroque churches were conceived not to be finished designs but rather to be a frozen stage in a process in which constraints have been established. Therefore, the movement infused into the forms brought life to the building and connected the observer to the architecture.

Wölfflin used the German word for picturesque, malerisch, to describe the sensation of movement as an effect of the "painterly" quality of work. In architecture, he claimed the role of what he calls the "picturesque movement-effect" explains why picturesque built environments are not "static fixed artworks" but instead are moving entities. For him, movement in architecture was a matter of empathetic relations with the building, which are not associated with the body's locomotion and spatial extension but rather matters of posture, pose and gesture. While the importance of the foregoing accounts for the empathy theory to revive the study of anthropomorphism in architecture, it also returns movement to a focus of imitation: "Architecture imitates us in our capacity for movement, but not our actual passage through space, rather, the gestures through which we give movement a communicative and affective form" (MacArthur, 2007, p. 234). 


\section{$04.2 \quad$ Dynamic Inhabitation}

Sigfried Giedion - Modernism \& Movement

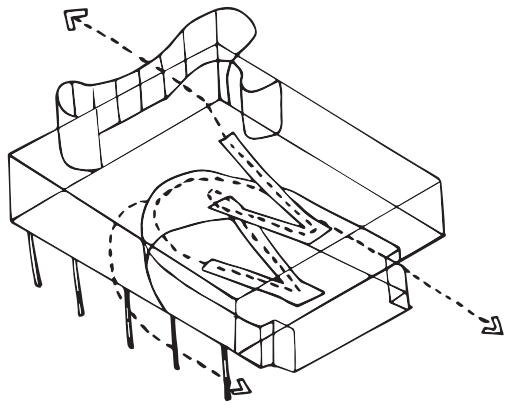

Fig. 16: Architectural Promenade

(Corbusier's Villa Savoye)
The notion of movement as an event of spatial unfolding became critical in modern architecture, spearheaded by Wölfflin's student Sigfried Giedion. Giedion acknowledged the importance of movement in his argument that modern architecture was an essential historical development, making space the medium to experience architecture empathetically through locomotion. Giedion applied Wölfflin's analytic

notions of art history to the promotion of modernism, making connections between Baroque movement and Le Corbusier's architectural promenade in his influential book Space, Time and Architecture of 1941, and to mechanized culture overall, in Mechanization Takes Command of 1948. In his writings, he declares the attempt to follow Wölfflin's method, by "emphasizing the Baroque and its qualities of movement being prescient of modernism" (Macarthur, 2007, p. 234). The "Space-Time" concept of Giedion's book title, he states, is a progression from the spatial investigation of Cubism, the movement studies of Futurism and a rather bewildering reference to Einstein's physics; however, one of his fundamental examples he discusses is Le Corbusier's Villa Savoye and its renowned architectural promenade, here he returns to the Baroque:

It is impossible to comprehend the Savoie house by a view from a single point; quite literally, it is a construction in space-time. The body of the house has been hollowed out in every direction: from above and below, within and without. A cross section at any point shows inner and outer space penetrating each other inextricably. Borromini had been on the verge of achieving the interpenetration of inner and outer space in some of his late baroque churches (Giedion, 1967, p. 529).

Architectural Promenade, a spectator's route through built space, became a fundamental element of Le Corbusier's architecture and city planning. The promenade unveils a series of composed vistas for the observer to experience 
when advancing towards and through the built environment. Le Corbusier sets a narrative of hierarchal architectural events that must be experienced through the circulation system in order for his work to be read. Architecture becomes "processes of movement" that seamlessly blend indoor and outdoor spaces, as the visitor transcends through the sequence of architectural moments. In Villa Savoye, Le Corbusier choreographed movement in and around architecture, allowing the visitor to truly see and participate in a "sequence of memorable experiences" (Baker, 1984, p.261). In the house, the circulation adds to the cinematic effect, where a spiral stair turns in on itself together with a diagonal ramp, giving all the surrounding effects mobility. These two forms of circulation not only contribute toward the literal motion of the inhabitant through space, but also the series of events that unfolds through time. When moving from room to room, one can feel the "surfaces follow[ing] [the body], approaching and receding," while the dweller connects and disconnects from "one effects-series of perceptual and built fragments to the next" (Frichot \& Loo, 2013, p. 155). Here, Le Corbusier's adopts an architectural theory of effects that reject any formal structure, in favour of mobilizing dynamic events through space for the inhabitant to experience.

Architects have continued to celebrate the promenade as a critical aspect of movement in architecture, even following the era of modernism. British Architect James Stirling applied Corbusier's design vehicle in is work, Neue Staatsgalerie of the Stuttgart Museum, often described as the masterpiece of movement. Completed in 1984, the building resembles Stirling's previous competition entries for museums in both Dusseldorf and Cologne exploring circulation in architecture. These projects demonstrate the promenade as a central theme, where approaching the site and moving throughout the buildings only became coherent when viewed in a sequence of Stirling's "preferred route" (Shane, 1976). The language of an extended circulation path intersecting between, above and below through distinguishable forms, symbolized the function of city scale for one to experience through locomotion.

In Neue Staatsgalerie, the building has solid street facades, implanting the museum on all three sides into the urban context. On the fourth side where the main entrance resides, the facade dissipates into a collection of divided forms, disrupting the monolithic characteristic of the building. The ground level is informally composed around a circular sculpture rotunda, along with a gallery with a series of large rooms with pseudo-classical framed windows. 
This collagist juxtaposition of neo-classical and contemporary architectural elements becomes clear when moving through the narrative of space. For Stirling, architecture concerned itself with the composition of space and movement, allowing for place and activity to exist. He encouraged varied spaces and forms that display the usage and way of life for the occupants (Kaminer, 2011).

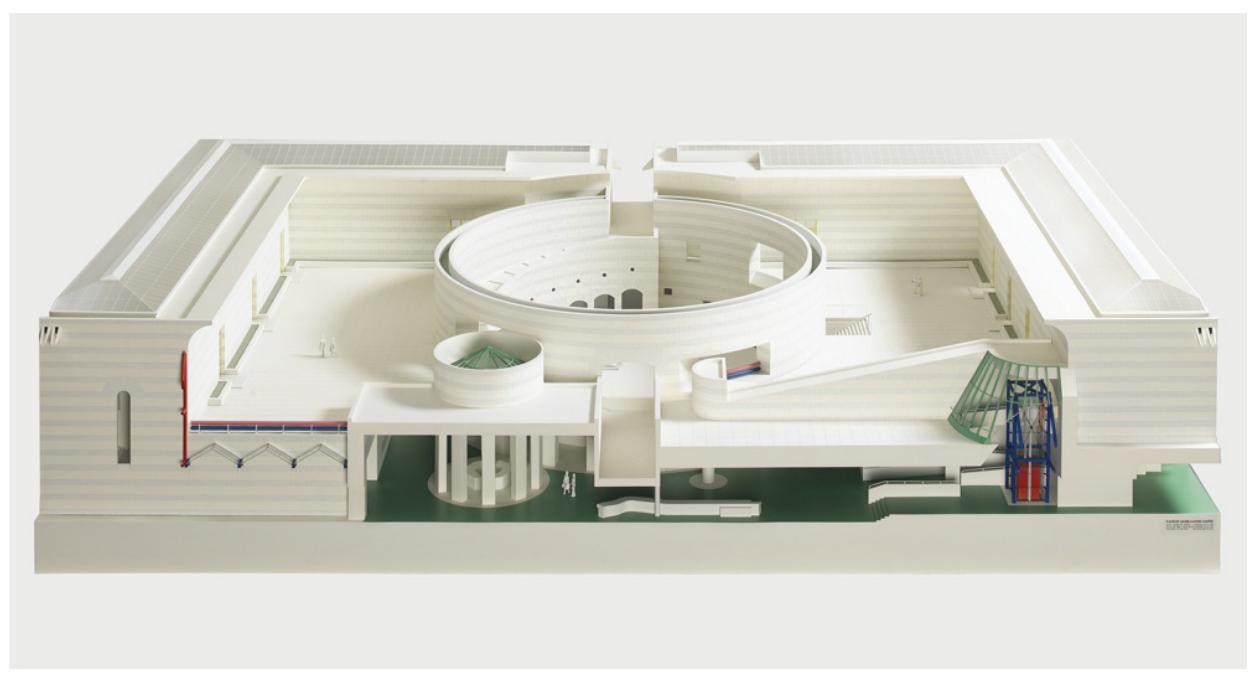

Fig. 17: Neue Staatsgalerie Stuttgart, presentation model, James Stirling, Michael Wilford and Associates 


\subsection{Dynamic Structures}

With the advent of technological innovations in the field of kinetics, architects have discovered a new dynamic that moves beyond Modernism's space as a physical vessel, exploring the relationship between space and actual movement. Here, architecture is no longer considered to be autonomous and passive, but instead a system that adapts its behaviour to data obtained from users; this includes one's body movement, touch, and temperature. Other external information to the building (system) could also be incorporated into the parameters such as weather data and demands of adjacent buildings; in this case, architecture is capable of responding to a number of fluctuating parameters with time. Interactive and responsive designs not only embrace computation and kinetics in the fabric of architecture, they also have been instrumental in creating a novel relationship between people and buildings.

The concept of interactivity in architecture could be traced back to the era of Megastructures \& Mobility in the 1960s; during this time, flexibility and freedom of choice was made possible with plugged-in and disposable architectural elements capable of being reconfigured by the inhabitants. However, concepts such as Peter Cook's Plug-In City and Yona Friedman's Mobile Architecture dissipated, allowing for responsive software to supersede reconfigurable hardware in the development of adaptive architecture (Mitchell, 2003).

The cybernetics movement became the next wave in responsive architecture dominated by artificial intelligence, where humans and their shared environments could coexist in a mutually constructed relationship (Reichardt, 2007). Cyberneticians, including Gordon Pask, began to redefine the machine as a biological notion, ultimately adopted by architects. This theory was picked up by Charles Eastman in his work Adaptive Conditional Architecture, in addition to John Frazer's built prototypes that define architecture as a "living, evolving thing" (Fox \& Kemp, 2009, p. 15). Cedric Price was also one of the most influential architects of the pre-digital age to embrace cybernetics and broaden it to the architectural concept of "anticipatory" architecture, where buildings are conceived to be constantly changing. 

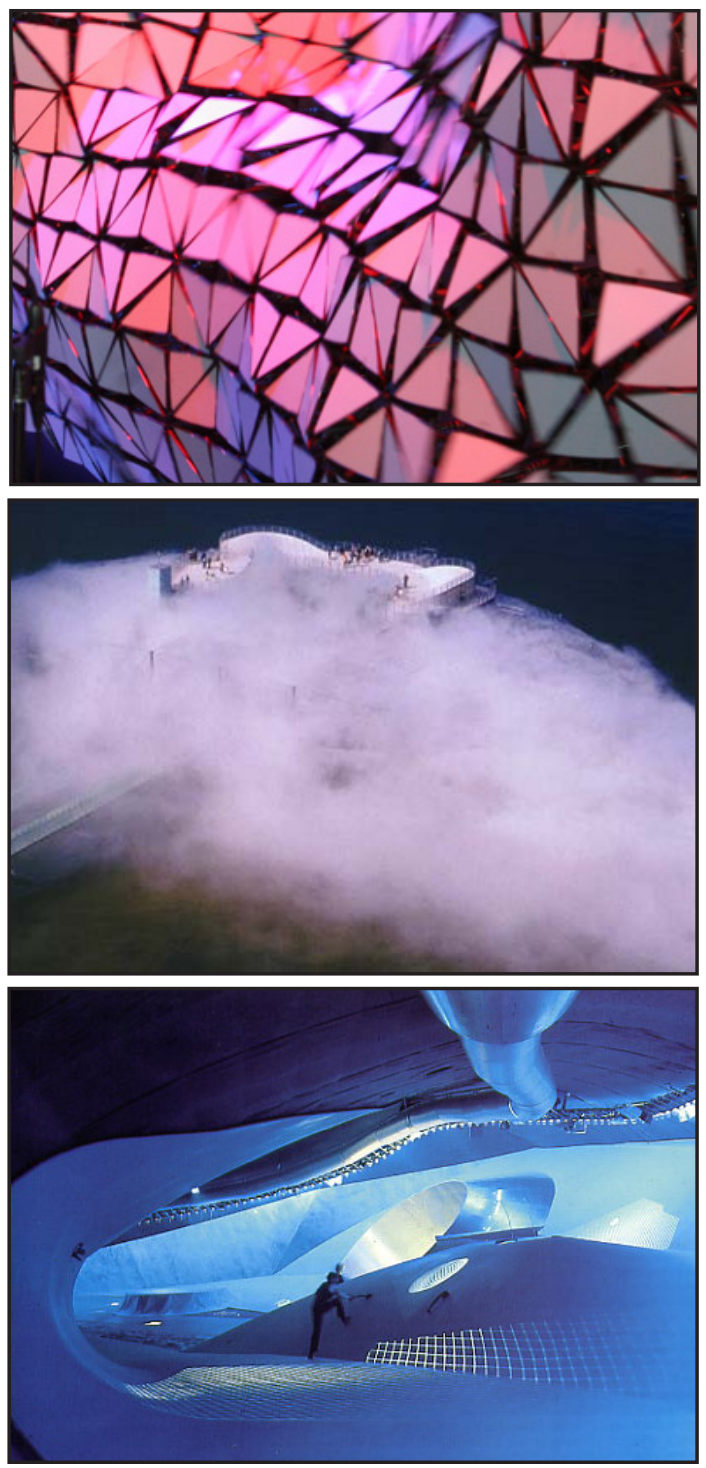

(Top) Fig. 18: Aegis Hyposurface (dECOi)

(Middle) Fig. 19: Blur (Diller \& Scofidio)

(Bottom) Fig. 20: Freshwater Pavilion (NOX)

The 1980s-1990s became the decade of smart environments where embedded computation and technologies enabled computers to become involved with the needs of the participant in the space, evident in works of Michael Mozer's Intelligent Adaptive House and MIT's Intelligent Room Project by Michael Coen. In the 1990s, a sudden burst of technological advancements

brought interactive and responsive architecture into the limelight, as it became economically and technologically feasible to utilize "do-it-yourself" electronics, programming and smart materials for interactive architecture prototypes (Jaskeiwicz, 2013, p.3). At the same time, kinetics in architecture was re-evaluated from the perspective of performance, seeing that computational information and processing could drive physical adaption in response to contemporary culture.

In the late 1990s, Robert Kronenburg created exhibitions of transportable architecture that compared traditional problems of movable infrastructure to the development of new strategies and technological innovations in the field of kinetics (Fox \& Kemp, 2009).

Within the last two decades, there has been an increase of innovation in manufacturing and fabrication techniques, heavily influenced by the intersection of adaptive architecture and embedded computation. Built works 
of interactive and responsive designs have been developed at various scales by both researchers and practitioners worldwide. The projects of dECOi (Aegis Hyposurface), Diller \& Scofidio (Blur) and NOX (Freshwater Pavilion) are all examples of responsive architecture typologies (Diller \& Scofidio, 2002; Liu, 2002; Lootsma \& Spuybroek, 1997). These works monitor changes in the environment and modify their form in response to environmental fluctuations. In the work of dECOi's Aegis Hyposurface (Fig. 18), a kinetic display medium deforms physically as a real-time response to stimuli from the environment. The programmable facade is driven by thousands of moving actuators deploying 3D patterns, graphic or video images in relief, using a generative algorithm program. The project titled Blur (Fig. 19), by architects Diller \& Scofidio, employs responsive technologies to monitor the shape and size of the building's envelope, a mass of fog. This method allows the magnitude of the cloud, and thus the envelope, to be directly correlated and responsive to the environment that encircles the building. Lastly, NOX's Freshwater Pavilion (Fig. 20) has an interior that employs responsive virtual environments where the users' body movements can change lighting and sound conditions through active sensors. In all three projects, these works rely on sensing and computing external environmental factors that ultimately shape the architecture (Sterk, 2003).

While responsive and interactive architecture embraces active movement in our built environments, it should also be acknowledged that elements in a building do not necessarily need to move in order to convey motion. Architects Sarah Bonnemaision and Christine Macy believe there is a deeper curiosity for the very idea of movement in architecture, beyond actual movement: "We can think about the way the potential of movement was depicted in the tendrils of Art Nouveau, or the memory of motion in the grotesque earth-like pillars of Antonio Gaudi, or the mechanisms of movement in the designs of the Futurists and the Constructivists." They further this notion by stating: "The very idea of movement in a building is what gives it vitality and liveliness" (Bonnemaison \& Macy, 2006). Similar to how dynamic forms were examined earlier in this chapter, the investigation of dynamic processes that infuse motion into its conception should also be explored in the discussion of movement in architecture. 


\subsection{Dynamic Processes}

Movement in architecture can be expressed by applying dynamic models and processes that inform the conception of the architectural subject. To further this notion, the following design methods will be discussed: Architecture as Event (Bernard Tschumi), Cardboard Architecture \& The Eisenman Fold (Peter Eisenman) and Animate Architecture (Greg Lynn).

\section{Architecture as Event}

Bernard Tschumi's Manhattan Transcripts explored the entangled relationship between architecture, choreography, events and movement, in which all are independent yet share a new relation to one another: "It's not a question of knowing which comes first, movement or space, which molds the other ... After all, they are caught in the same set of relationships; only the arrow of power changes direction" (Tschumi, 1994, p. 74). Tschumi dismantled conventional components of architecture and rebuilt them for a new means of representation. This breakdown allowed for independent manipulation of each part in a story or formal consideration. His method of using a tripartite mode of notation (spaces, movements and events) introduced the order of experience and order of time (sequences, intervals and moments) in the reading of our built environments. He identified architecture as a discourse of events and spaces, which in turn becomes activated through the movement of bodies. Tschumi's process of transcription, where he records episodes of city experience, reveals the dynamic activity architecture is supposed to become. His work goes as far as depicting the reason for choreographic notation in architecture:

Rather than merely indicating directional arrows on a neutral surface, the logic of movement notation ultimately suggests real corridors of space, as if the dancer has been 'carving space out of a pliable substance'; or the reverse, shaping continuous volumes, as if a whole movement has been literally solidified, 'frozen' into a permanent and massive vector (Tschumi, 1994, p.10).

Tschumi's design ideologies concerning movement in architecture have also been explored through his built works, in particular, his design for Parc de la Villette in Paris. In this project, he investigated a dynamic process that embraces a superimposed organization, designed to encourage 
movement, interaction and exploration in the urban park. This method entails superimposing three independent ordering systems: points, lines and surfaces (Fig. 21). The first system consists of a series of points at the intersection of a 120-metre grid. The points located at each crossing of the grid denotes where a folly is built, a three-storey structure used for multiple activities such as a cafe, exposition hall or playground. The second layer is a system of lines superimposed on the grid. These serve as pedestrian paths composed in two schemes. The first includes a cross axes of enclosed galleries, and the second is a wandering promenade that presents a series of unexpected views and enclosures. These paths do not possess the same authoritarian function as seen in traditional parks, where linear narratives of sequential events are employed. Instead, the passerby encounters a game of

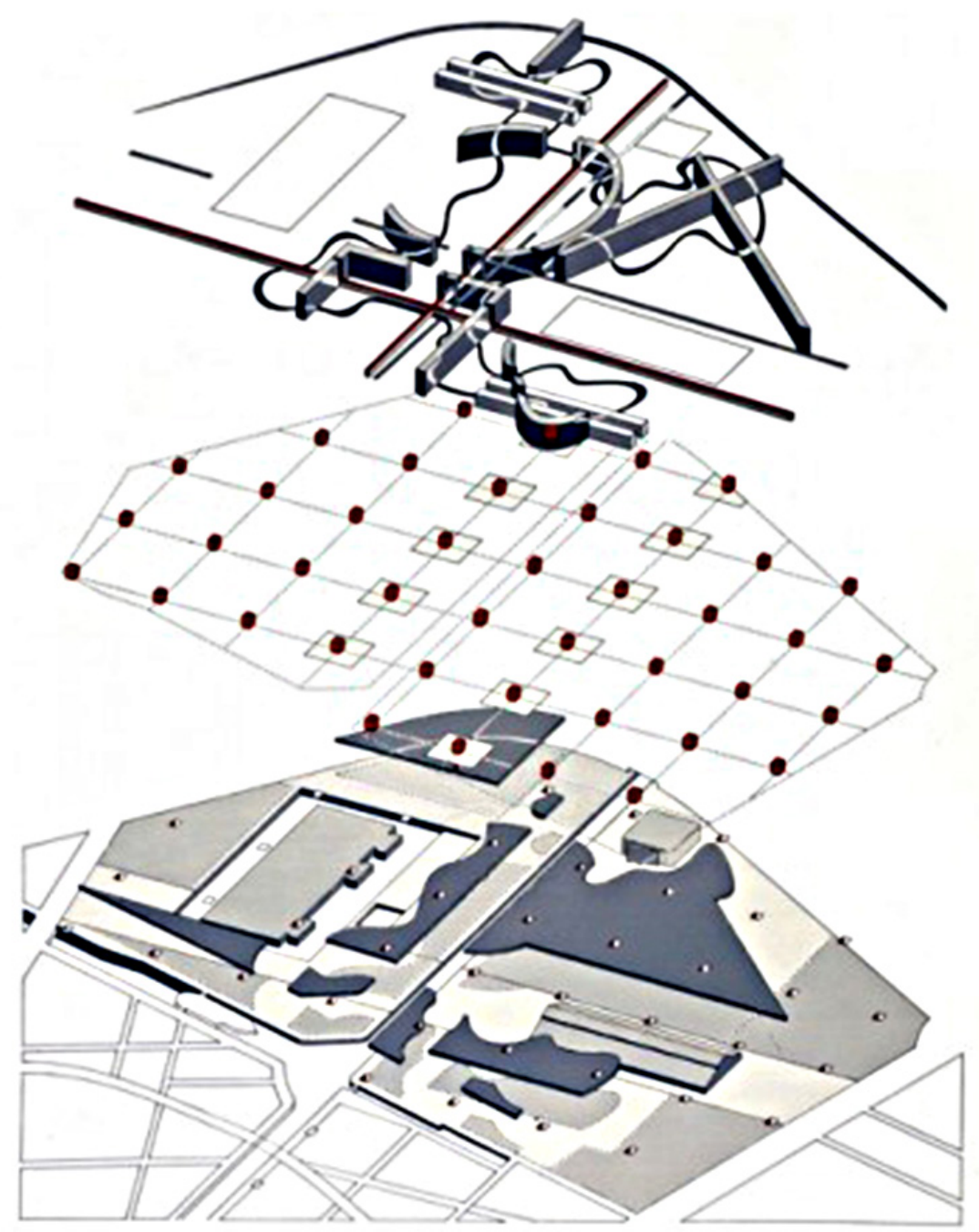

Fig. 21: Parc de la Villette: Exploded Axonometric, Points Lines Surfaces (Bernard Tschumi) 
chance and arbitrariness as the lines interact and clash between the follies and other public spaces. Here, Tschumi took pleasure in dismantling the traditional cinematic paths in a park, with the intent of creating a sense of "unbalancing expectations." The third system, the surfaces of the park, is then layered upon both the points and lines. The surface allows for all activities to occur that require large strips of land, including games, markets and sports (Straeten, 2003).

The result of this "superimposition," as Tschumi calls it, is a "series of ambiguous intersections between systems ... in which the status of ideal forms and traditional composition is challenged. Ideas of purity, perfection, and order, become sources of impurity, imperfection, and disorder" (Wigley in Broadbent 1991, p. 17). The inherent chaotic nature of the superimposed organization encourages the dweller to explore, discover and experience unexpected events and interactions within the dynamic urban park.

\section{Cardboard Architecture \& The Eisenman Fold}

Peter Eisenman also explored methods of instilling dynamism through his design processes, including his developments of Cardboard Architecture and the influence of Gilles Deleuze's notion of the "Fold" in his later works.

In Eisenman's earlier works, he searched for a method of expressing architectural meaning and an attempt to create a "linguistic model for architecture." From this period of his early career, he designed a set of houses conveying the concept that buildings are not merely physical entities, but objects with meaning or signs broadcasted along a larger social text. These houses were part of an extensive project that explored the nature of drawing, process and representation in architecture that he labeled "cardboard architecture." This method investigates the implications of his theories in built form which neglects scale, site, material and all semantics in favour of "architecture as 'syntax': conception of form as an index, a signal or a notation" (Ansari, 2013). These houses embodied what Eisenman calls "deep structure," in which he attempts to explore the idea of visual syntax. The rigorous nature of this work originated from his interest in language and semiotics, influenced by philosopher and linguist Noam Chomsky. 
Eisenman's work structures form and space in such a way that creates a "set of formal relationships" (Eisenman, 1975, p. 16). For instance, his designs often consisted of a floor plan organized by a grid of lines and slender columns as a structural framework. These were then projected in three dimensions as a series of layered planes in a cubical spatial volume. In his early concepts, these planes were situated perpendicular to each other within the volume; in later iterations some planes were disordered by applying rotational moves on the plane grid and superimposed on the original grids. Eisenman established underlying rules for his houses such as rotation versus frontality or decomposition, superposition and folding. These served as operations to be recorded in his architectural form (Jencks, 2002) (“Peter D. Eisenman,” 2004).

In Eisenman's later works, he explored the notion of the "Fold", an operation that bends and merges two distinct elements such as the vertical and horizontal, figure and ground, and inside and out. Eisenman adopted the notion of the Deleuzian-Fold that proposes a possible continuity of space, denying any form of linear sequence in favor of continuous and variable curvature (Garofalo, 1999). In his "folded projects," his strategy of embracing curvature dislocated the hierarchy of interior and exterior, and therefore, disrupts our perception of space. An example of this tactic is evident in Eisenman's Alteka Tower project where folds create an affective environment that "gazes upon the spectator" as they are both equally intertwined in space (Fig. 22). Eisenman (2007) furthers this notion, as he describes Alteka's
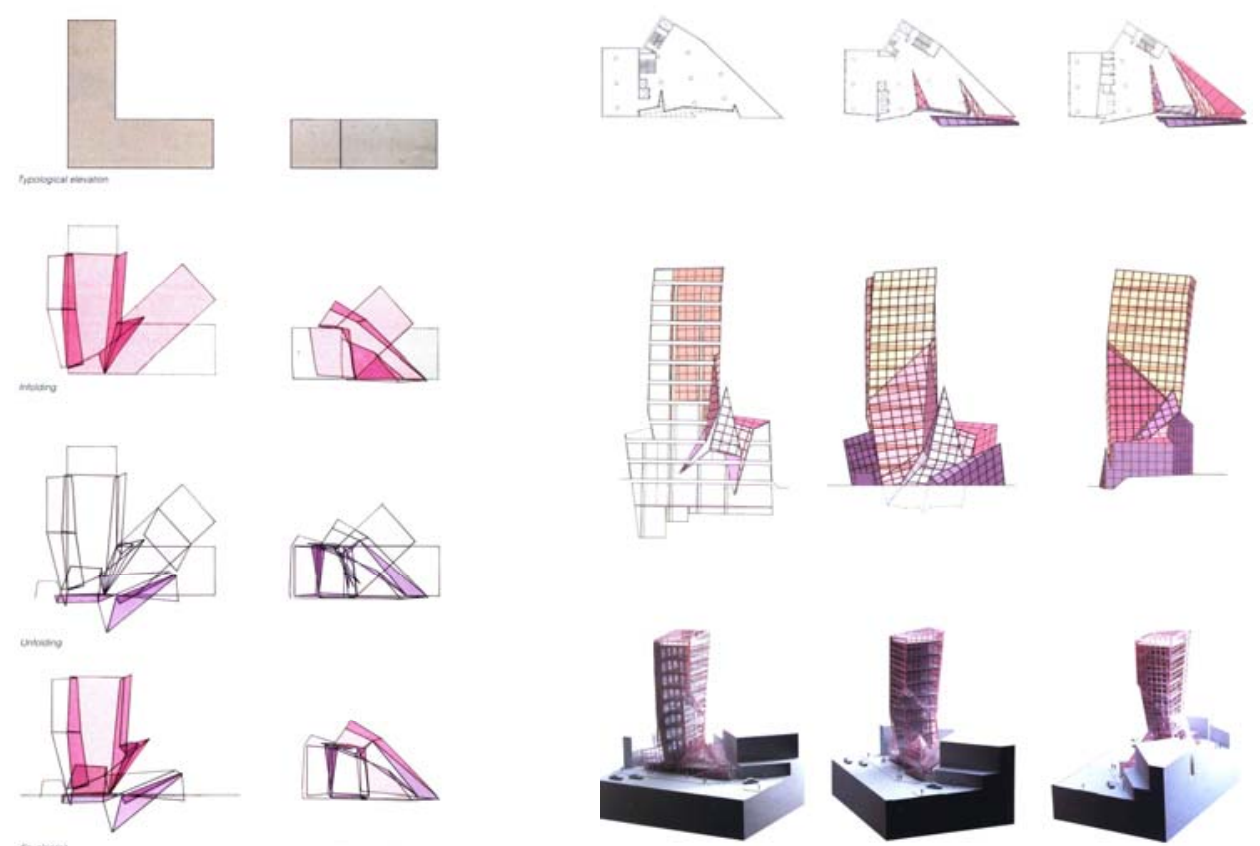

Fig. 22: Geometric Transformations - Diagram of Alteka Tower (Peter Eisenman) 
ability to create "a condition of time, of an event in which there is a possibility of the environment looking back at the subject, the possibility of gaze" (p.41). In the tower, "the subject understands that he or she can longer conceptualize experience in space in the same way that he or she did in the gridded space" (Eisenman, 2007, p.38). In this work, Eisenman outlines the possibility of conceptualizing architecture as a Mobius strip, an unbroken continuous surface between exterior and interior, where the spectator's perception is changed and adapted by the continuity of space.

\section{Animate Architecture}

Architect Greg Lynn was heavily influenced by his former teacher, Peter Eisenman, and his work on vectors. While Eisenman believes in the potential of architecture's interiority or autonomy, Lynn investigates form as a result of external forces, in particular, forces that were difficult to compute and represent before the advent of computers. Another significant difference between Eisenman and Lynn's use of computers is Lynn's approach of using the computer until the final form is achieved, as opposed to the initial abstract diagram. The similarities between the two, however, are their interest in the vector along with their influences from Deleuze and Foucault. This includes Deleuze's notion of the diagram as a "supple set of relationships between forces" and the "Deleuzian-Fold" as described above (Eversion, 2003).

Greg Lynn is most notable for exploring architecture through the lens of animation. In his book Animate Form (1999), he urges designers to embrace architecture as animate, implying the evolution of form through the input of external forces. He acknowledges the computer's ability to generate architectural form using three properties of organization: time, topology and parameters. Time is a critical factor in animation software as it enables the mechanism of key-framing, the measuring of an object's position and change of state, and for objects to move dynamically in a field of interaction. Topology is the area that permits surfaces to be manipulated using splines as opposed to lines and points. Splines are created by the continuous series of vectors that determines their shape, showcasing, "both collective qualities of continuity and local qualities of heterogeneity" (Lynn, 1998). Lastly, parameters are rules that inform how the object performs over time, whether it be changing shape or interacting with other entities. Parameters can establish a field of external factors that influence an object's performance including directional 
forces, gravity and particles. Together, the characteristics of time, topology and parameters reveal the virtual possibilities of designing for an animate architecture (Lynn, 1998).

In his early works of digital architecture, Lynn began to employ these concepts through his theoretical project: The Embryological House (Fig. 23). The house's dynamic forms are vector-based surfaces generated through a series of animations using Microstation software. In the developments of the project, he first applied a set of forces to a sphere that created a collection of "gastrulated rooms." This concept adopts the biological analogy of a process by which an embryo folds into itself to form a gastêr, the Greek word for stomach. From these initial hosts, Lynn selects six that showcase the most variation and develops a structural system for each volume. The selected iterations are further developed through an interaction of forces from the

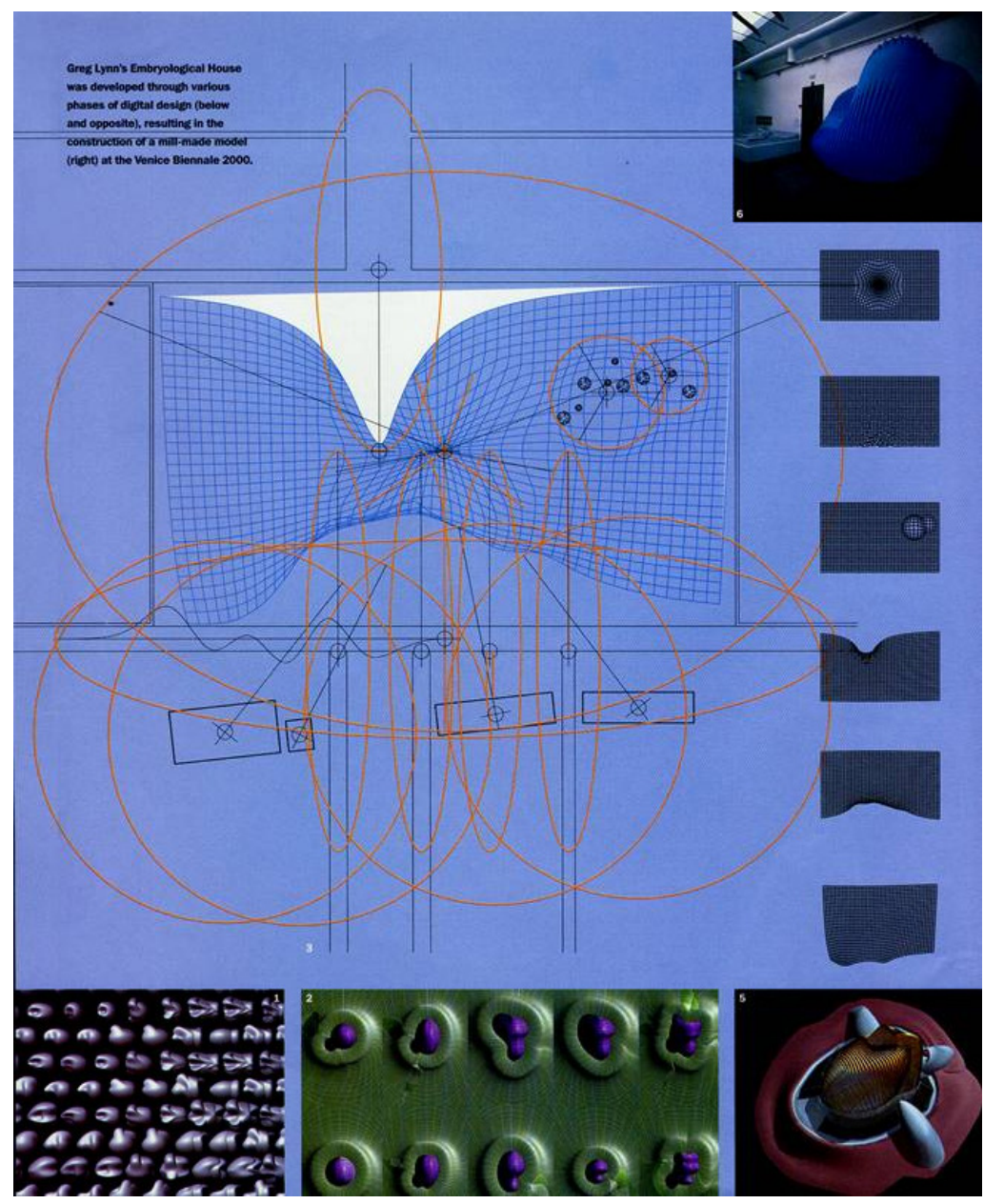

Fig. 23: Greg Lynn's Embryological House was developed through several phases of digital design, resulting in construction of a mill made model at the Venice Biennale 2000 
ground plane, where the ground shapes the volume, and the volume re-shapes the ground. Further deformations are imposed upon the nested homes once local conditions are defined. At this stage, the site interacts with each volume, creating transformations in both the ground plane and house, resulting in the formation of interstitial zones including gardens, grottos and patios. Towards the final phase of the "embryology," a series of unique houses are generated with a general proportion being 30 feet high, 30 feet wide, and 50 feet long, that bulge or contract, depending upon the site's conditions (Bergren, 2010).

\section{Reflection}

My experimental methods of a choreographic architecture are similar to how both Eisenman explored his theories through "cardboard architecture" and the "fold," along with Lynn's investigation of the animate form through external forces. Similar to Eisenman, choreographing architecture examines the intertwined relationship between the inhabitant and environment, where architecture challenges the perception of the dweller by applying the "fold" as a design vehicle. In a particular experiment discussed in Section 6, the Dynamic House, the notion of continuous and variable curvature is explored where the spectator's perception is challenged by the continuity of space, in contrast with the typical "gridded space." Similar approaches investigated in "cardboard architecture" are also applied in another experiment titled Visionary Proposition (See Section 7). In this study, elements follow a set of rules from design operations, such as attraction and superimposition. These operations are recorded through stages of transformations in the design process.

In regards to Lynn's investigations, the computer has given the ability to examine virtual forces in our environment. In the case of a choreographic architecture, the focus concerns the forces and motion of the human body. In all design experiments, human kinesis is explored as means to inform the conception of architectural form, where time, topology and parameters are ingrained in the design processes. Prior to further discussing the exploration of a choreographic architecture, it is critical to first examine the role of the human body and its influence within the discourse of architecture. By understanding the past and current roles the body has served, this thesis can then respond to how we can further this relationship between body and architecture through the analysis of human kinesis. 

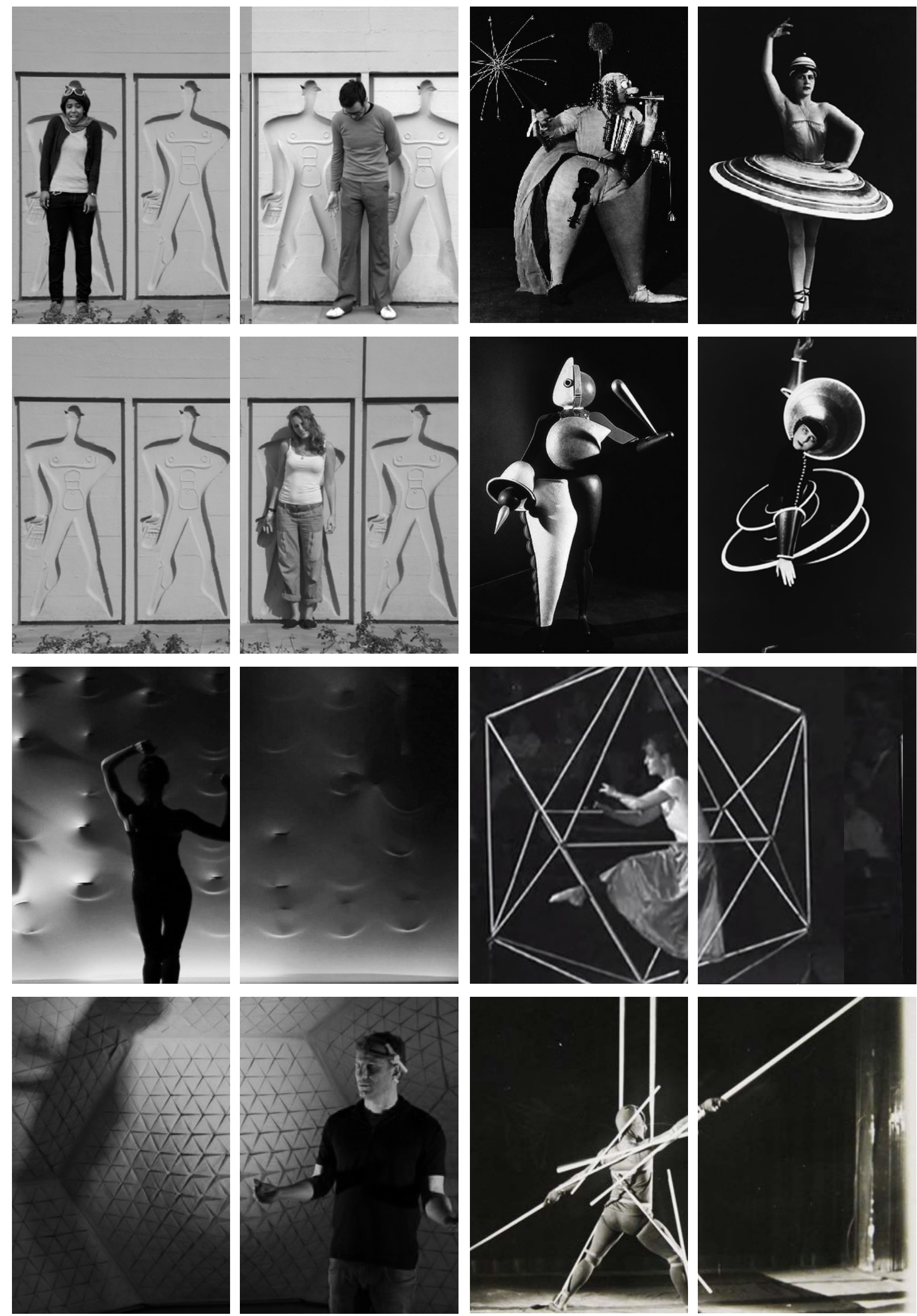


\section{Body \& Space \\ "The body is our general medium for having a world." \\ Maurice Merleau-Ponty (1945) in Phenomenology of Perception \\ Body \& Space examines the interrelationships between the human body and architecture. The human figure has played three distinct roles for informing the creation of architecture including the Ideal Body, Moving Body and Virtual Body. Beginning with the age of Vitruvius, the /deal Body has been used as a foundation for architectural order, where proportions of a well-shaped body served as a model for a building's composition. The Moving Body has been investigated as a geometrical source for form and measurement in both costume design and theatre, initiated in the Bauhaus during the 1920s. Here, particular figures, as opposed to the ideal figure, were acknowledged for the creation of forms, but have yet to be fully embraced in the discipline of architecture. In more recent years, the Virtual Body has become the centre of responsive and interactive architecture, extending our current bodies' capabilities through innovative technologies in architecture. This section will trace the evolving role of the human body in architecture, beginning with the unified body as the centre and the measure of our built world.}



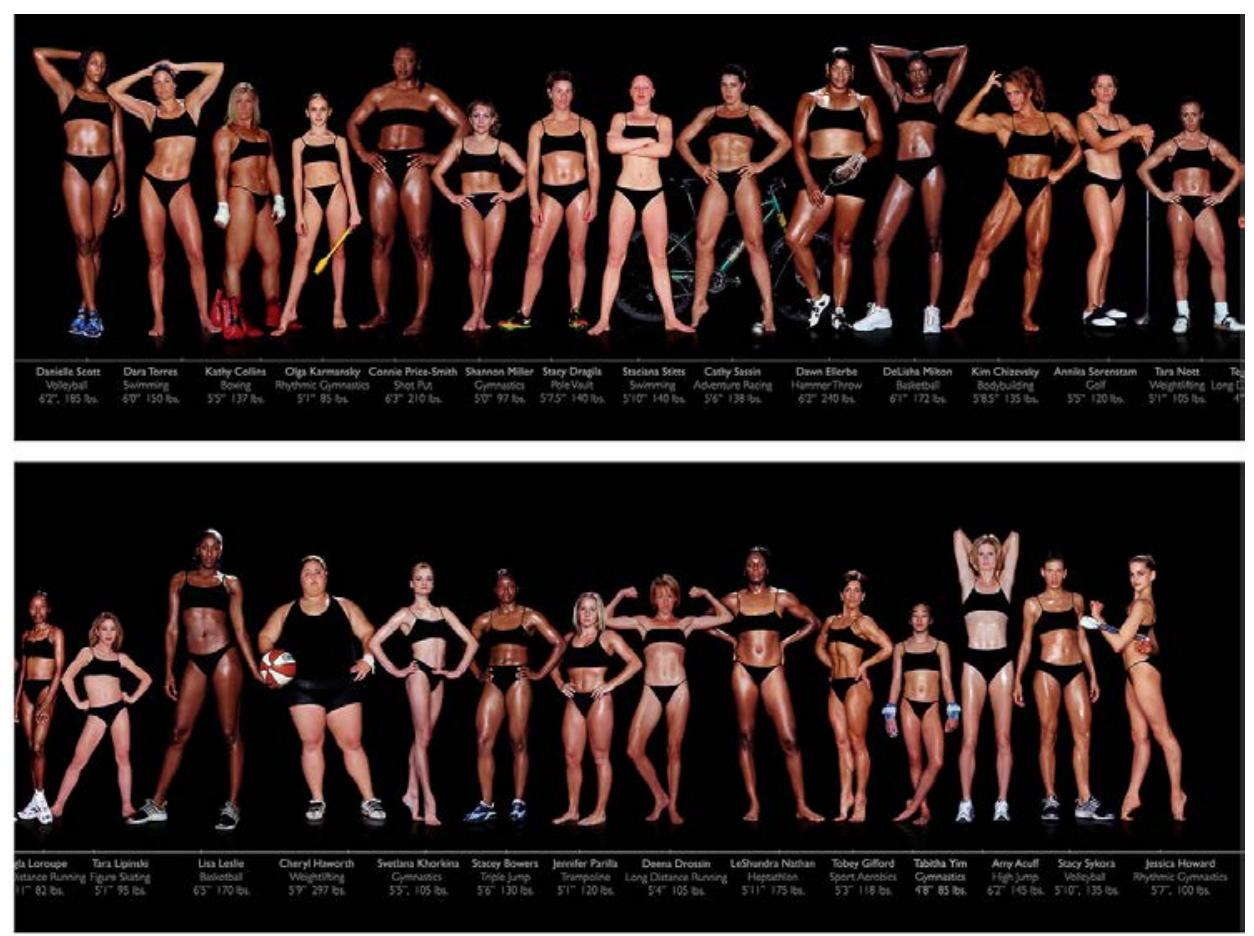

Fig. 25: Diversity of Female Bodies - Photograph taken by Howard Schatz in his book titled "Athletes"

\subsection{The Ideal Body}

All bodies are unique. While this observation may seem indisputable, architectural theory has favoured the standardized body type as the proportional basis of buildings for centuries. The ideal body, its form and movements are evidently ingrained in architectural proportional systems, treatises and theories. These date from Vitruvius' belief in the human body as the fundamental source of temple proportions, to Francesco di Giorgio and Leonardo da Vinci, to modern systems such as Le Corbusier's anthropometric scale for architecture. Since the age of Vitruvius, the entire concept of architecture was dependent upon the ideal human figure, rendering any particular body unfavourable. But what defines the perfect human figure? Vitruvius believed a "well-shaped man" should be eight heads high, and fit precisely into both a square and circle, and therefore, demonstrate the connection between perfect geometry and the perfect body (Kiberd, 2015). For Le Corbusier (1954), he admired the characters in English detective novels where "good-looking men, such as policemen, [were] always six feet tall" (p.56). This proportion was adopted for his famous Modulor Man, the "measure of all things" (Kuhlmann, 2014, p.103). 
Le Modulor (1948-1955), an anthropometric scale of proportions developed by Le Corbusier, was created as a measuring tool based on the mathematical understanding of the Fibonacci sequence, Pythagorean Triad and Duality (Fig. 26). With the development of Le Modulor, Le Corbusier hoped to relocate architecture to the human scale by embracing proportions of the human body, the golden section and the Vitruvian Man. To the architect, it became a tuned instrument that collected a "range of harmonious measurements to suit the human scale, universally applicable to architecture and to mechanical things" (Rasmussen, 1959, p.118).

Within his work, he desired to showcase the architect's ability to orchestrate a balance between man and his environment, a rather comprehensive view that evokes humanist thinking in architecture. Le Corbusier's work recalled many Renaissance architects including Alberti, who believed "the eye as the supreme organ of perception," similar to Corbusier's claim of concerning himself "only with objects falling under the jurisdiction of the eye" (Le Corbusier, 1954, p. 184). However, he believed the Renaissance architects understanding of architecture sought a more individual spiritual journey than a social or universal philosophy. This very notion of Le Modular, the "Universal Man" only considered a standardized body, an inflexible idiom that dismissed cultural, emotional and physical differences. Le Modulor was soon to be seen as an ill representation of man that was static and closed, only housing the intellect and the eye and leaving the body and the other senses homeless (Pallasmaa, 1996, p. 19).

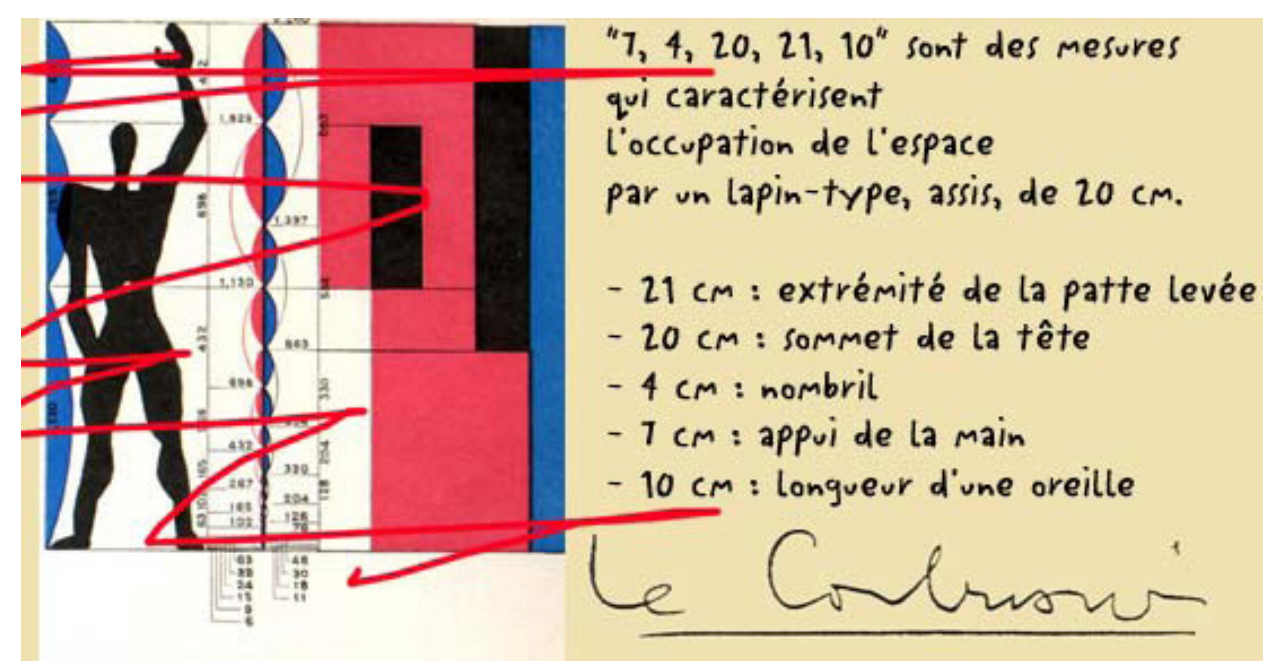

Fig. 26: Le Modulor (Le Corbusier) 


\subsection{The Moving Body}

The Moving Body has been explored throughout the 1920s starting with Rudolf von Laban's interest in human kinesis as a geometrical source for spatial measurement. Laban, a Hungarian dancer, architect and theorist, pioneered analytic methods for understanding the body in motion including the Laban Movement Analysis, Labanotation (Kinetography Laban), and other variations of dance notation that evolved from his movement studies. His theories were the result of a scientific method founded upon the observation of movements in everyday life, from working in the factory to cultural events in Germany, and dance practices in the studio. In summary, Laban's Movement Analysis explores Effort/Shape notation (decoding quality and dynamics), Effort (describing how a person utilizes kinetic energy) and shape (illustrating and recording spatial forms from body movements).

Laban perceived the human body as a static structure, analogous to levers, rods and points all subjected to the force of gravity. This concept represents the body as a tensional architecture, emanating from the center and radiating lines of force forming a kinesphere. Laban's notion of the kinesphere, or one's personal space, is defined as an open system in which the body is constantly moving within while concentrating on one's spatial intentions (Fig. 27). The body as a three-dimensional structure has length, width and depth axes within the kinesphere, in which motion can take place from upwards-downwards, backwards-forwards and from side to side. When our body and limbs are in

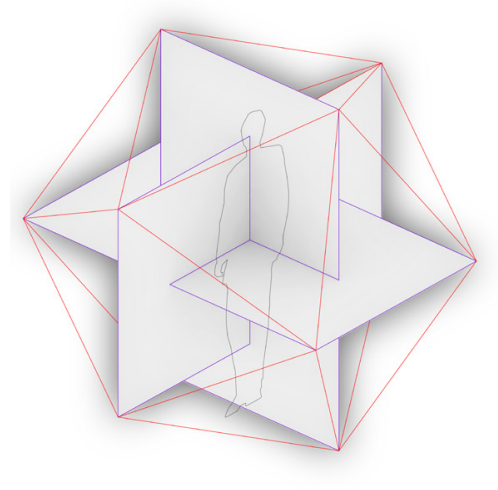

Fig. 27: KInesphere

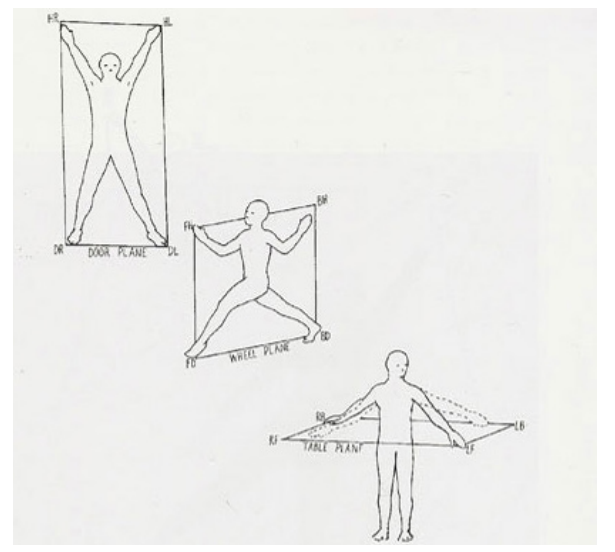

Fig. 28: Rudolf von Laban's Choreutics, an "analysis of forms in movement". The three plans.

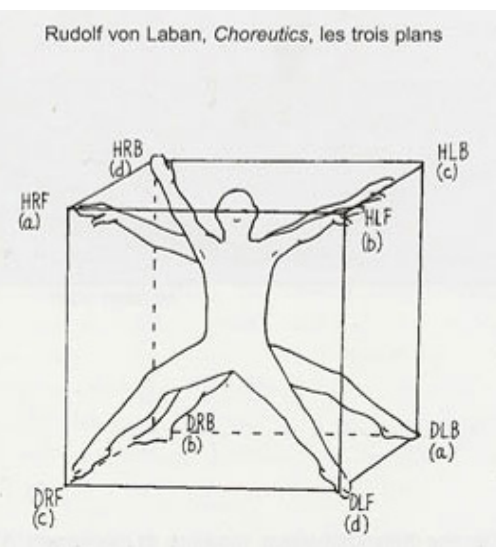

(1) 
movement, we can utilize these axes and achieve wider planes including the "door plane," "wheel plane" and "table plane" (Fig. 28). Each movement creates a distinct spatial experience, the sensation of pull in space that is defined by its axis. The perception of space outside the kinesphere informs where the body should move within (Consonni, 2014).

Around the same time period, Oskar Schlemmer investigated human kinesis through his teachings at the Bauhaus. Schlemmer, the versatile artist and Master of Form at the Bauhaus Theatre, first began his lecturing at the art school in Germany through life drawing classes. His course on "Man" (Der Mensch) focused on three sections: formal, biological and philosophical. The formal workshops explored theories of proportion, physical mechanics, kinetics and representational methods in ancient and modern art, including the study of Dürer's system of proportion, Leonardo's Canon of Proportions and the golden section. The biological segment of his course concentrated on life drawing along with theoretical seminars on the physiological, biological and anatomical conditions of the body. Schlemmer developed methods to examine the mechanics and kinetics of human kinesis in space through notation and staged diagrams. The philosophical section investigated aesthetic, ethical and metaphysical issues, from antiquity to the modern age. The entirety of Schlemmer's work underlined the importance of the human body through architectural space, where space "was less a container for the body than an aspect of the body transformed" (Feurstein, 2002, p. 229).

Moreover, Schlemmer's course encouraged an anthropomorphic theory of costume design, where costume, architecture, body and space were interweaved dynamically in a novel relationship. His theory was based on human images that negotiate within distinct constructions derived from human nature. Costumes embodied both difficult and obscure human relationships that measured and showcased the human condition. Schlemmer's perspective on "being" as an artificial construct, or an "art figure" (Kunstfigur), was a fundamental concept that defined each constructed version of the human form. The body was "clothed" in a "particular law or rule creating unique two and three-dimensional postures as exaggerated expressions" (Feurstein, 2002, p. 231). Costumes became a figural display defining concepts about the body, founded upon the intersection between body and costume. The first concept was the fabricated envelope moulded to the hidden human body, fragmenting or 
restricting movement. The interface between body and costume then formed another condition. Together, everyday living, space and movement produced a triadic relationship between four different characters, each defined by a distinctive law: "Ambulant Architecture" ("the surrounding cubical space"), the "Marionette" " functional laws of the human body in their relationship to space") a "Technical Organism" ("motion of the human body in space"), and "Dematerialization" ("metaphysical forms of expression") (Schlemmer \& Gropius, 1961, p. 27) (Fig. 29). These principles of the human body revolutionized the notion of being human, rethinking our bodies as tools for space-making.

To Schlemmer, the "felt volume" or Raumempfindung experienced by the dancers was defined by the space they occupied. The "sensation of space," a feeling of close connection with the surrounding environment, became a critical element in his work. He characterized two basic views of this relationship. In the first, he regards dancers involved in a precise mathematical and geometrical space, where mechanical motions are performed. In the second, the dancer becomes the central focus creating a grid of radial movements through organic motions. These two methods reveals Schlemmer's concept of man comprised of both organic and mechanic elements. Through the use of alienating costumes, he declared a further possibility to alter the body's relationship to the exterior space.
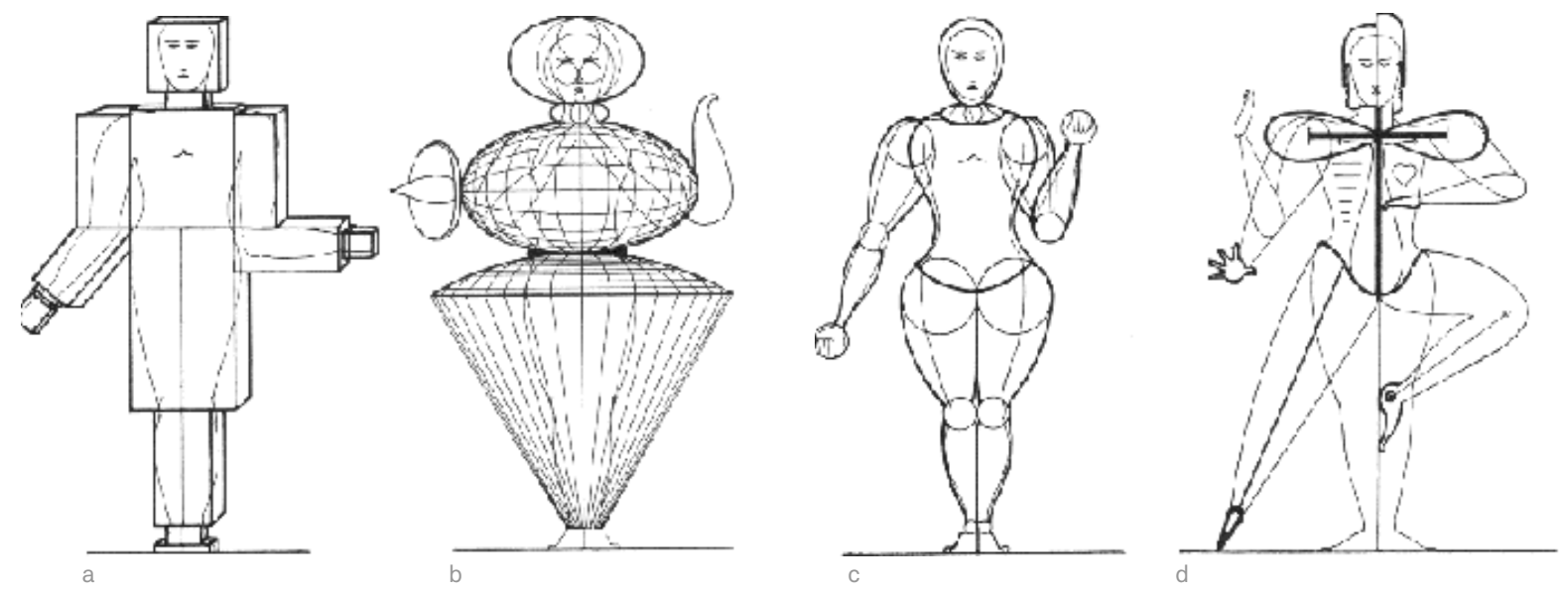

Fig. 29: Drawings of the figures in Schlemmer's Triadic Ballet

a. Ambulant Architecture, (Wandelnde Architecktur)

b. Technical Organism (Ein technischer)

c. The Marionette (Die Gilderpupp)

d. Dematerialization (Die Zeichen im Menschen Entmaterialisierung) 
In addition to costume design, movement derived form can also be traced in the field of landscape architecture. The pioneering avant-garde dancer Anna Halprin and landscape architect Lawrence Halprin together saw the world in motion in their respective professions. Lawrence expanded the discipline of landscape architecture with an emphasis on movement in design. His knowledge of human kinesis, performance and the potential of spatial formations to encourage movement concepts stemmed from his life experiences with his wife Anna Halprin. His engagement in the realm of explorative dance led him to develop a design method putting into the forefront movement-derived form. Elements that are multi-sensory are designed and implemented into his work, rendering visual principles as secondary importance. Embracing motion in the form-making process as the primary objective invited movement, exploration and physical engagement in his work. Lawrence's synergistic relationship with Anna fueled the creation of scoring, RSVP Cycles (Resource, Score, Valuation and Performance) and their design and movement notation system, Motation (Wasserman, 2012) (Fig. 30). These methods informed their landscape projects including Lovejoy Fountain Park and Ira Keller Fountain.

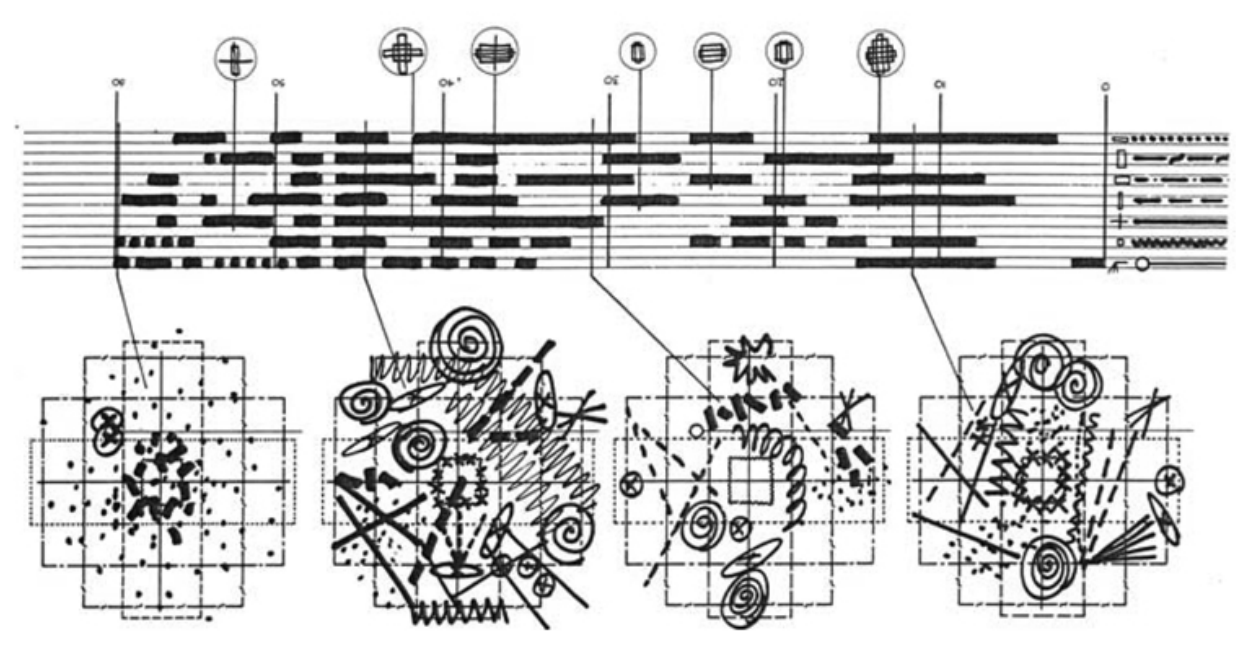

Fig. 30: An example of one type of scoring pattern-Lawrence Halprin's score for the OverhoffHalprin 1962 World's Fair 


\subsection{The Virtual Body}

Beyond anthropometric scales and choreographic notations, the role of the body for defining space has evolved within the era of responsive and interactive architecture. Over the last decade, platforms for ubiquitous computing have revolutionized how the body could change space using invisible physiological characteristics, such as sound and brainwaves. In architectural installations, such as Guvenc Ozel's kinetic Cerebral Hut, environments are being designed as "game-spaces" where the occupant manipulates the physical boundaries of one's surroundings by engaging in the act of thinking (Fig. 31). Ozel and his team hacked and reprogrammed a commercial product that measures concentration levels and blinking, allowing the data to translate the bodily motion into kinetic architecture (Ozel, 2012). Similarly, F. Myles Sciotto's Ambient Alternity is an immersive environment that explores spatial constructs being informed by mapping the user's perception through EEG data (Fig. 32). The installation uses a feedback loop in between the two programmatic models of perception and projection. The program translates data and maps in real-time, rendering the virtual environment empathetic towards its user, the space creator (Sciotto, 2009).

Tools, devices and instruments are ready to use all around us, available for manipulation in a spatial incorporation. These components constitute our environment and often disappear from our attention when used daily, given that they don't malfunction. Similarly, the organs and appendages of our body, as long as they're in good condition, often escape our explicit awareness when we are absorbed in an imagined or physical action. Thus, there is a parallel between the disappearance of the sensory organs and that of the tools we possess when proceeding in our daily lives. Drew Leder discusses this notion of absence and our desire to incorporate instruments into our body image, facilitating new abilities and settling fixed habits. Over time, these recurring habits become a definitive incorporation and disappear from our view, "enveloped within the interior of a body-structure from which [we] inhabit the world" (Leder, 1990, p.32; Teyssot, 1994, p.15). Leder's observations are analogous to Merleau-Ponty's analysis of perception when discussing the classic example of the blind man's stick: 

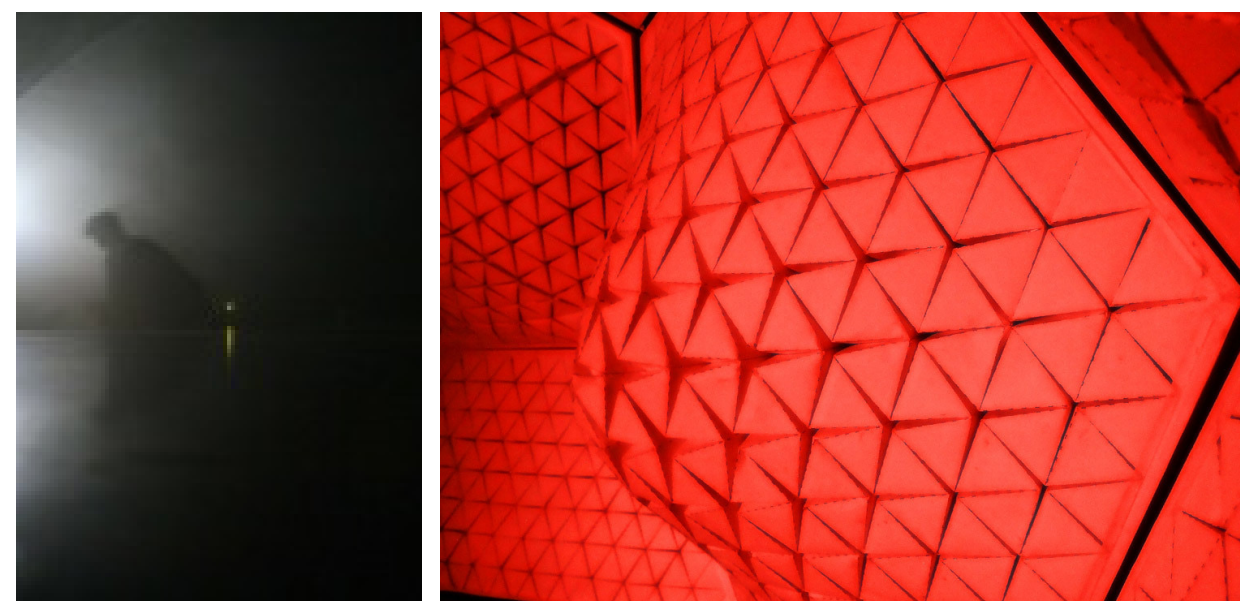

(Right) Fig. 31: Close up image of the module in Guvenc Ozel's Cerebral Hut

(Left) Fig. 32: Photograph inside F. Myles Sciotto's Ambient Alternity

The blind man's stick has ceased to be an object for him, and is no longer perceived for itself; its point has become an area of sensitivity, extending the scope and active radius of touch, and providing a parallel to sight (MerleauPonty \& Smith, 2002, p. 165).

As discussed in Diller + Scofidio's Flesh, architecture can then consider the envisaging and creation of an environment not merely for "natural" bodies but for bodies beyond themselves, absent and euphoric, through their technologically extended senses. As opposed to integrating the instrument with the body, the device will become a second type of body "incorporated into and extending our corporal powers" (Leder, 1990, p.179). Furthermore, D+S proclaim the incorporation of technology aims not to re-envision a newfound environment, but the reshaping of the body itself, reaching outward to where its artificial boundaries meet "the world" (Diller \& Scofidio, 1994, p.16).

\section{Reflection}

From the Ideal Body to the Virtual Body, what is missing in the foregoing discussion is how the analysis of the moving body could inform our design processes and methodologies in architecture. The Ideal Body dismisses any particular body with a preference for all bodies in general. The Moving Body favours any particular body, but yet to be explored from the perspective of architecture. The Virtual Body examines invisible bodily forces as mere inputs to make architecture a "second type of body," and not part of the consideration for its formation and structure. 
Therefore, what is absent is a theory to make architecture move. An architecture that moves does not suggest literal movement, or to be movable, but that it no longer be viewed as static. This notion is discussed in Bruno Latour and Albena Yaneva's (2008) essay, Give me a Gun and I will Make all Buildings Move, where they argue "the problem with buildings is that they look desperately static. It seems impossible to grasp them as movement, as flight, as a series of transformations." To make architecture move, they imply a theory must be in place to "transform the static view of a building onto one among successive freeze-frames," similar to Étienne-Jules Marey's ability to establish the physiology of a bird's flight with his photographic gun ( $p$. 80) (See Section 3). In order to grasp architecture as movement, they claim architects must embrace a human perspective and dimension of the world we reside in. My thesis begins to explore an architecture that moves, in which move, in this case, implies the embodiment of human kinesis for the creation of architecture. This research adopts the name choreographing architecture, where form is conceived by virtual movement and force from the body in motion. Architecture therefore develops an empathetic relation to the inhabitant, where our bodies internalize the sensation of virtual movement expressed by the architecture. 

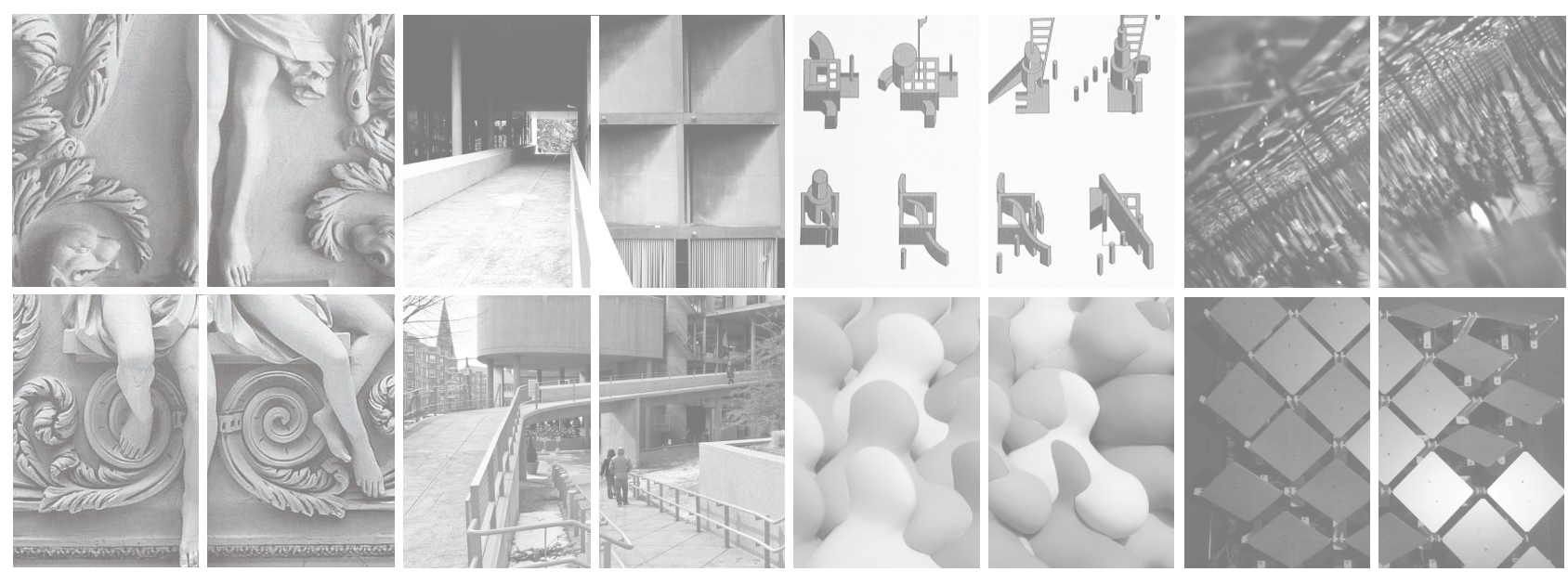

Movement + Space
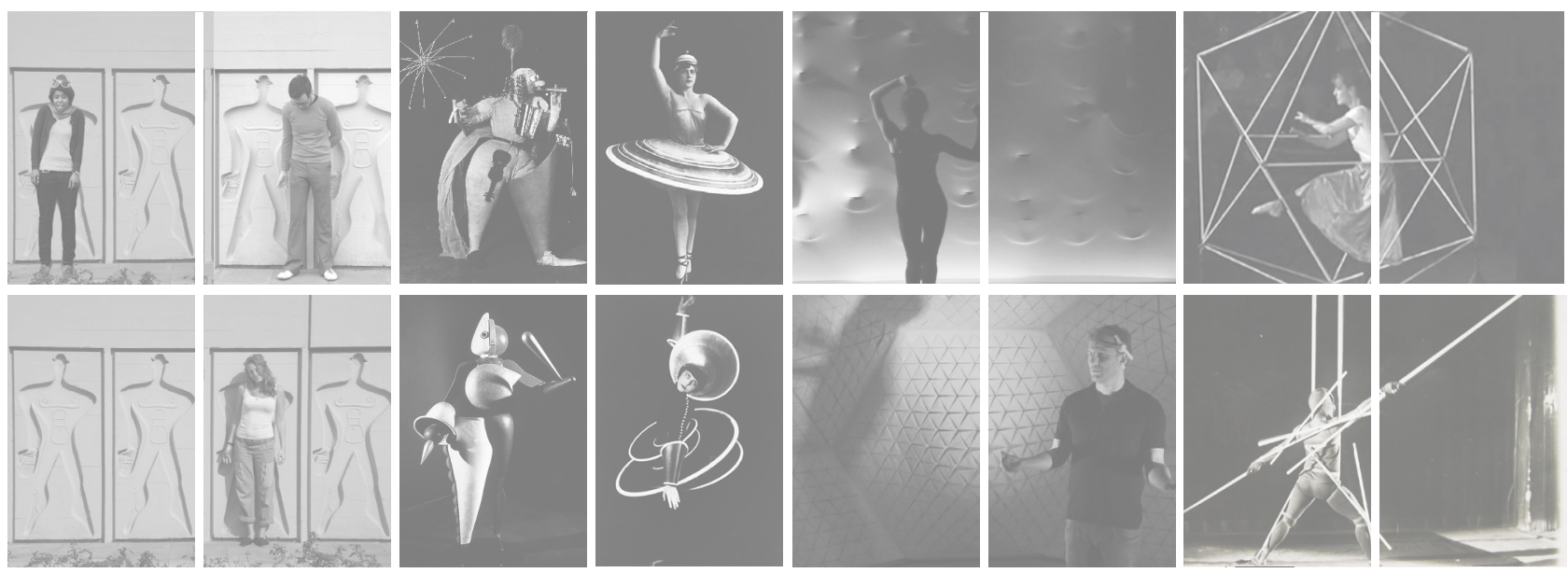

Body + Space
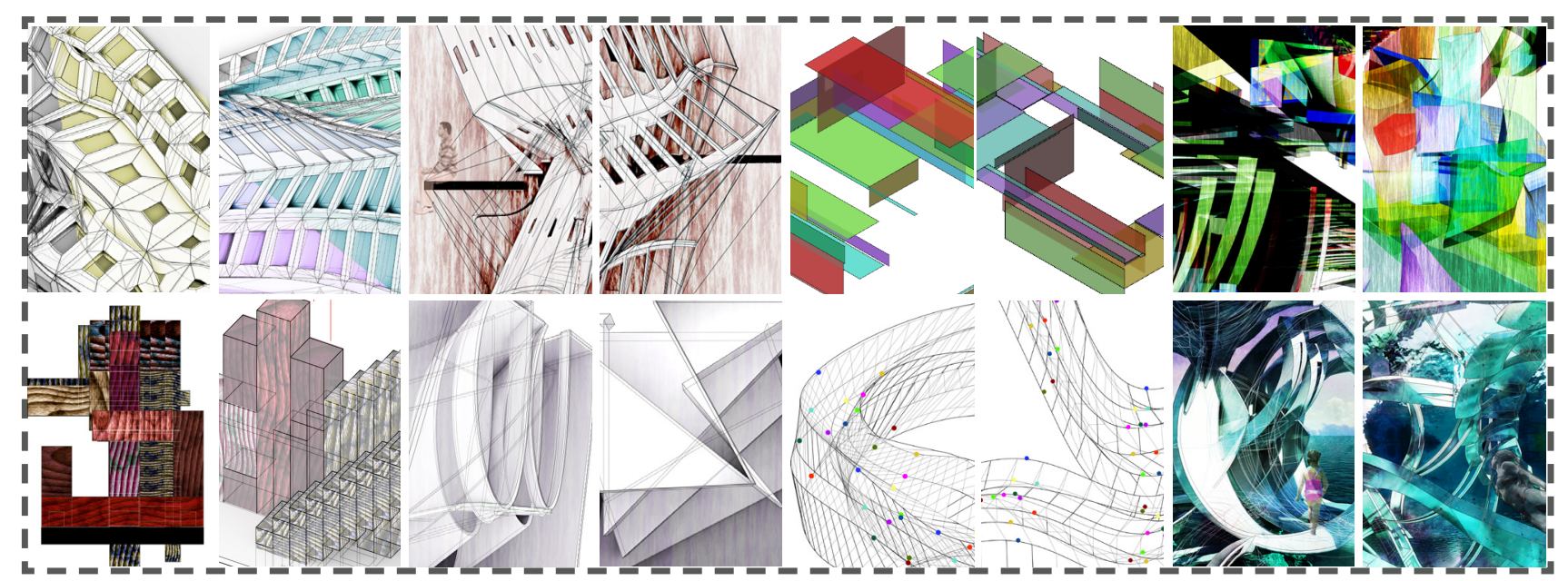

Movement + Body + Space

(Top) Fig. 33: Movement + Space

(Middle) Fig. 34: Body + Space

(Bottom) Fig. 35: Movement + Body + Space 
06 Choreographing Architecture

A choreographic architecture is designed by the body, for the body of the dweller. From its formal manifestation to its composition in space, a choreographic architecture furthers the interaction and connection between inhabitant and built environment. Here, space compels us to areas of the architecture to seek refuge or find clarity, while the body internally simulates its nuances, allowing ourselves to dwell in the building's form, shades and colors. A choreographic architecture is a spatial performance that cannot exist without the inhabitant. We bring value to the performance through the way we move, interact and construct meaning of the environment. This inseparable relationship between architecture and dweller entails the kinesthetic experience the body shares in the spatial performance. This proposition furthers Wölfflin's notion that movement in architecture is a matter of empathic relations between built form and the postural and gestural aspects of human movement. Since the perception of architecture begins in the body, we acknowledge our own bodily or emotional experience in characteristics of form; and due to human psychology, we feel sympathy for those gestures. Thus movement turns to the issue of imitation as discussed by Wölfflin: "Architecture imitates us in our capacity for movement ... the gestures through which we give movement a communicative and affective form" (Macarthur, 2007, p. 234).

Choreographing architecture reinforces these theories of empathy by thinking and conceiving space with the human body. It builds real experiences by employing and composing forms that actively engages with the spectator and awakens one's imagination with movement.

This next section begins to investigate the process of discovering a choreographic architecture through explorations with the moving body and its application in formation and organization. A wide variety of methods were developed that embrace an entangled relationship between body, form and movement in an architectural composition. These techniques include the following:

1. Empathetic Elements: Translation from Motion to Form

2. Choreographing Components

3. Choreographing Architecture as a Body + Choreographing the Body in Space

a. Dynamic Stairway

4. The Dynamic House

b. Choreographing Negative Space 


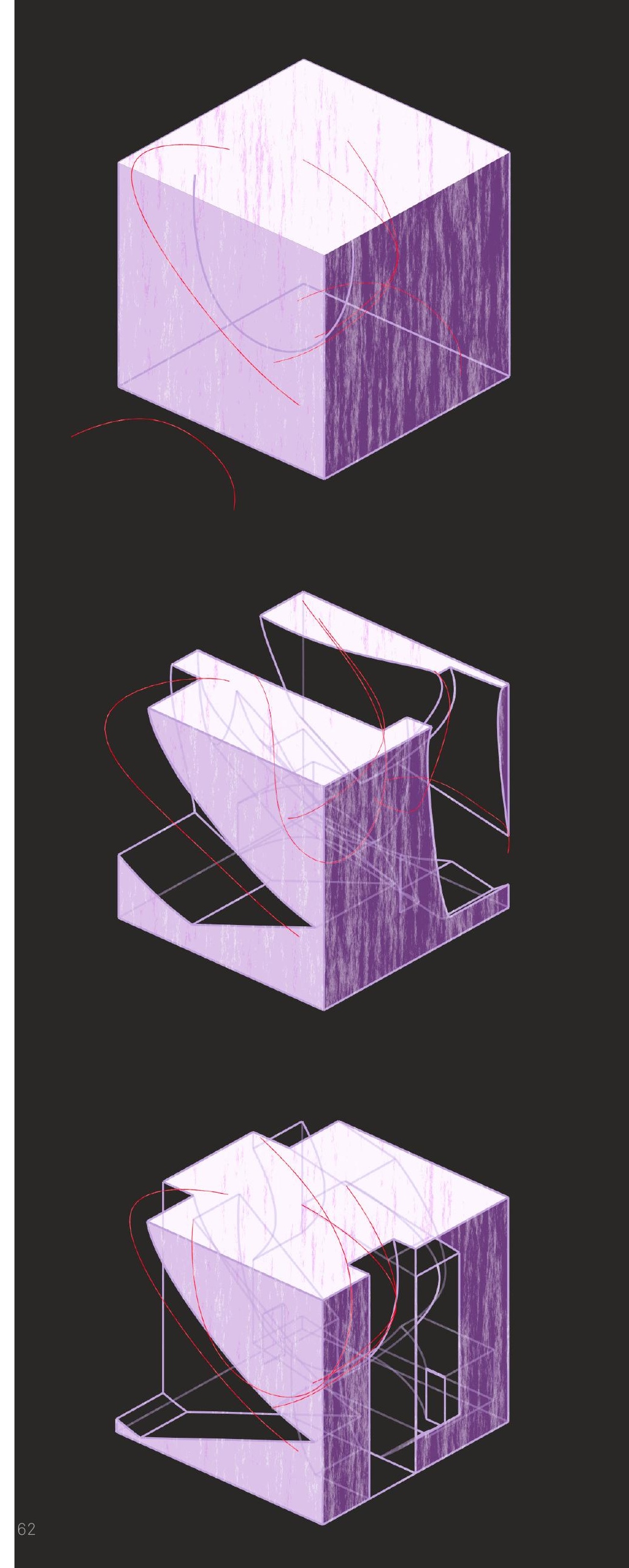




\subsection{Empathetic Elements: Translation from Motion to Form}

Mediating the human body in motion through architectural form describes, visualizes and decodes spatial qualities through the lens of the moving body. This method expands the awareness and potential of embodied expression in architecture, bringing a whole new meaning to choreographing space.

With the advent of digital technologies that can seize the activity of motion, architects have the capability of extracting this data for design conceptualization and formation. Empathetic Elements explores a formfinding process that transforms physical action into three-dimensional landscapes through points interpolated from the body. This technique entails creating positive space through defined points, captured from the body, interpolated to a line, then surface and finally, a volumetric form.

In this example, the movement of the body waking up was examined and traced to create a three-dimensional volume. The contortions of the body to the stretching of the limbs were encapsulated through the folding and stretching of a grid (Fig. 37). The mimic qualities of this movement was accentuated, creating smaller openings for expressing the feeling of the body's heaviness to the larger openings that unveil the lightness of the human form arisen (Fig. 38 \& 39). These factors reveal an architecture that indulges in the force of gravity or resists it, appearing weightless, similar to the dynamics of body movements. Other methods where the architectural form could elicit the weight of movement include defining a ratio of solid to openness in a surface, transparent to opaque, in addition to the form's material type and relationship with the ground plane. This metamorphosis of movements into architectural elements could thus expose the internal rhythm, weight and shape of human kinesis, and in turn, enrich our understanding of how bodies move through space. As a result, the Empathetic Elements render the dynamic qualities of movement through spatial characteristics of architecture.

The following design experiment explores another approach of creating space through a sequence of movements. This design phase investigates the proportions of the moving body for a component based form-finding process. As opposed to creating one continuous element from a sequence of motions, individual poses were examined as separate entities and assembled to form an architectural composition. 

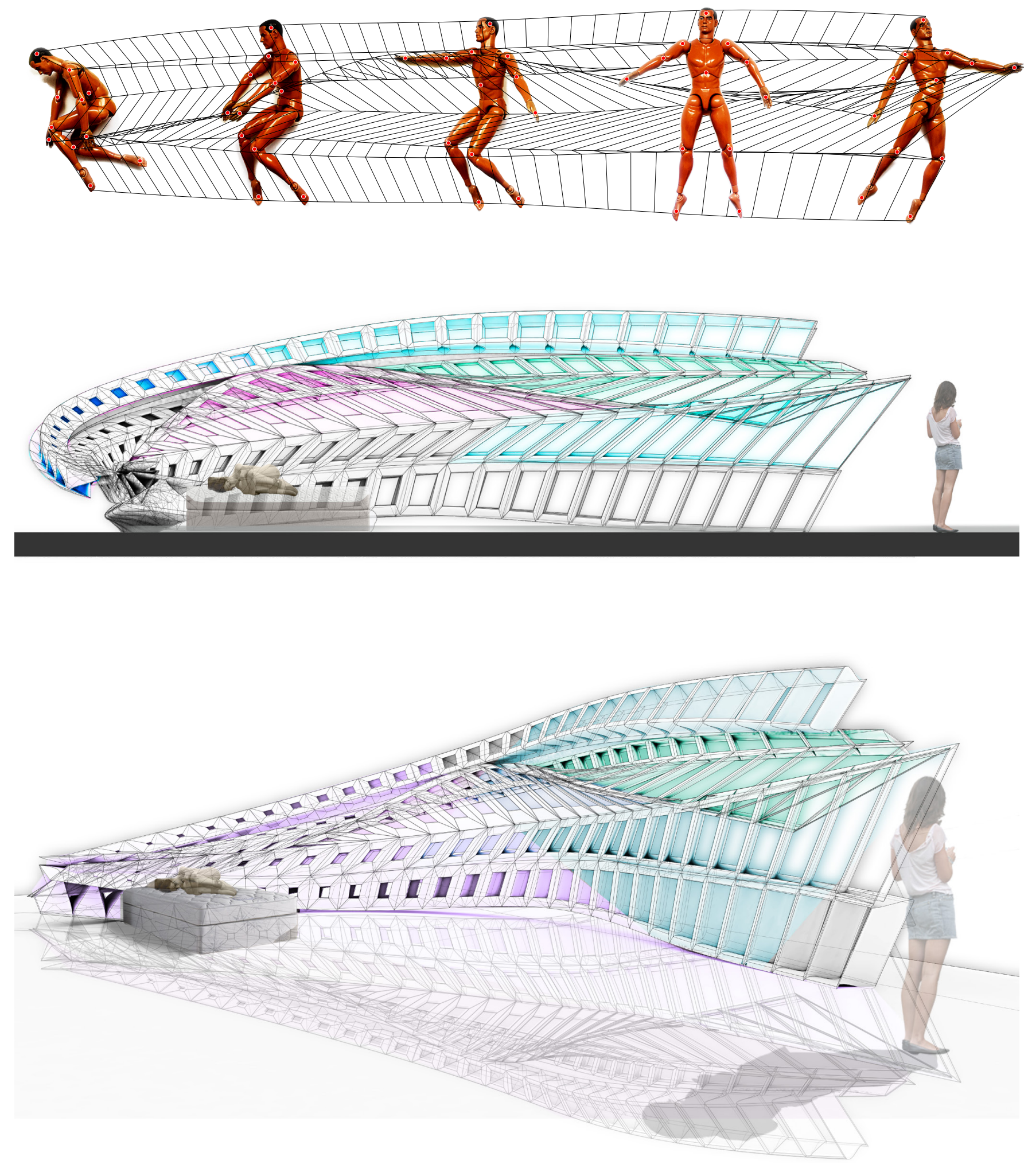

(Top) Fig. 37: Geometric outcome of tracking human movement. (Middle) Fig. 38: Elevation

(Bottom) Fig. 39: Perspective 


\subsection{Choreographing Components}

This experiment explores an additive process for choreographing space using orthogonal components derived from the human body. Each component was developed from a particular pose and assembled to formulate a spatial narrative. Through the body, the space begins to narrate a procession of movement: from lying down, to getting up, stretching, ascending a flight a stairs, and then sitting.

Choreographing Components became a turning point in the thesis experiments. From examining space as a procession of movements, this investigation led to a frame of thinking where architecture is choreographed like a body in motion, while considering the inhabitant's locomotion through space. In the next phase, Choreographing Architecture as a Body + Choreographing the Body in Space, the foregoing concept is explored through both additive and subtractive form-finding processes in the creation of a stairway and enclosure from an existing volume.

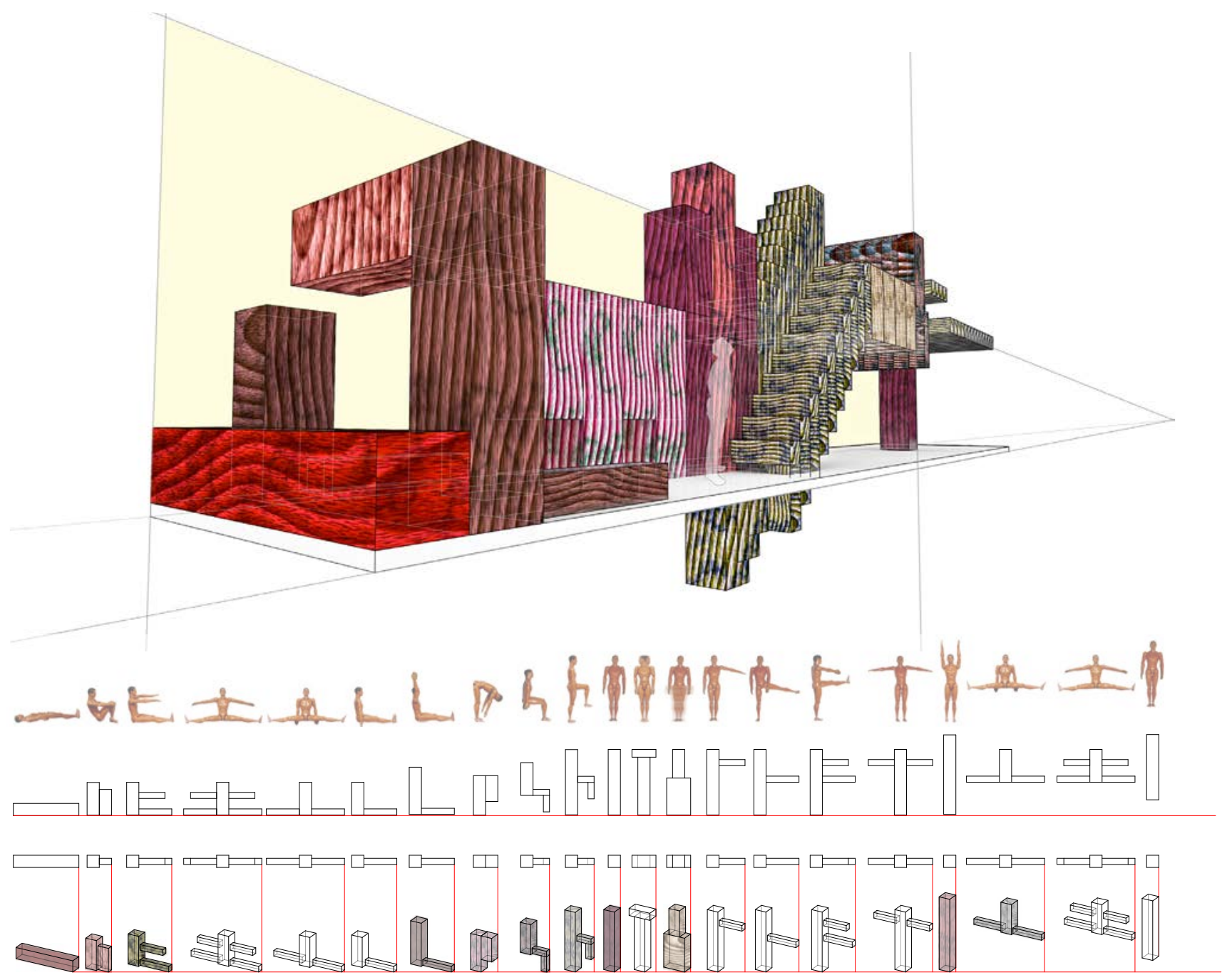



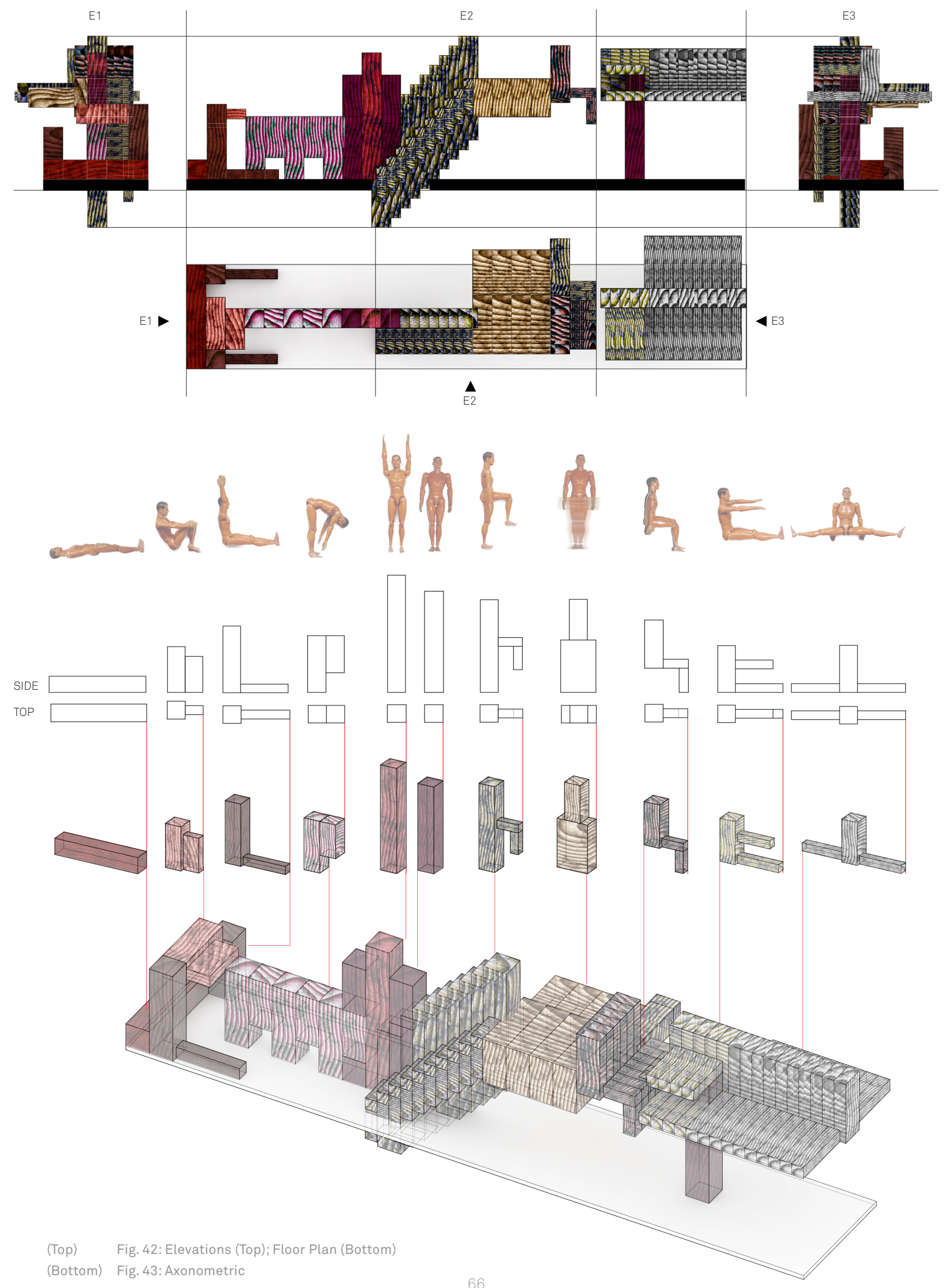
06.3

\section{Choreographing Architecture as a Body + Choreographing the Body in Space}

Within this phase of design investigations, architecture was conceived within two distinct stages: choreographing architecture as a body and choreographing the body in space. In the first stage, architecture becomes analogous to a body in movement, using a sequence of motions to generate space. Methods of this form generation include applying the motion of ascending a set of stairs for the creation of an enclosed stairway, to deforming a volume through movements of waking up, in which the figure of a body seemingly carves through a solid mass. In the second stage, how the observer moves through space is choreographed. A path or multiple paths were created for the body to experience the architecture intimately. As the inhabitant moves through the space, they are seeing and feeling the movement of the body of architecture, in other words, an architecture of kinesthetic empathy. This approach was explored through two different design experiments including the Dynamic Stairway and Choreographing Negative Space.
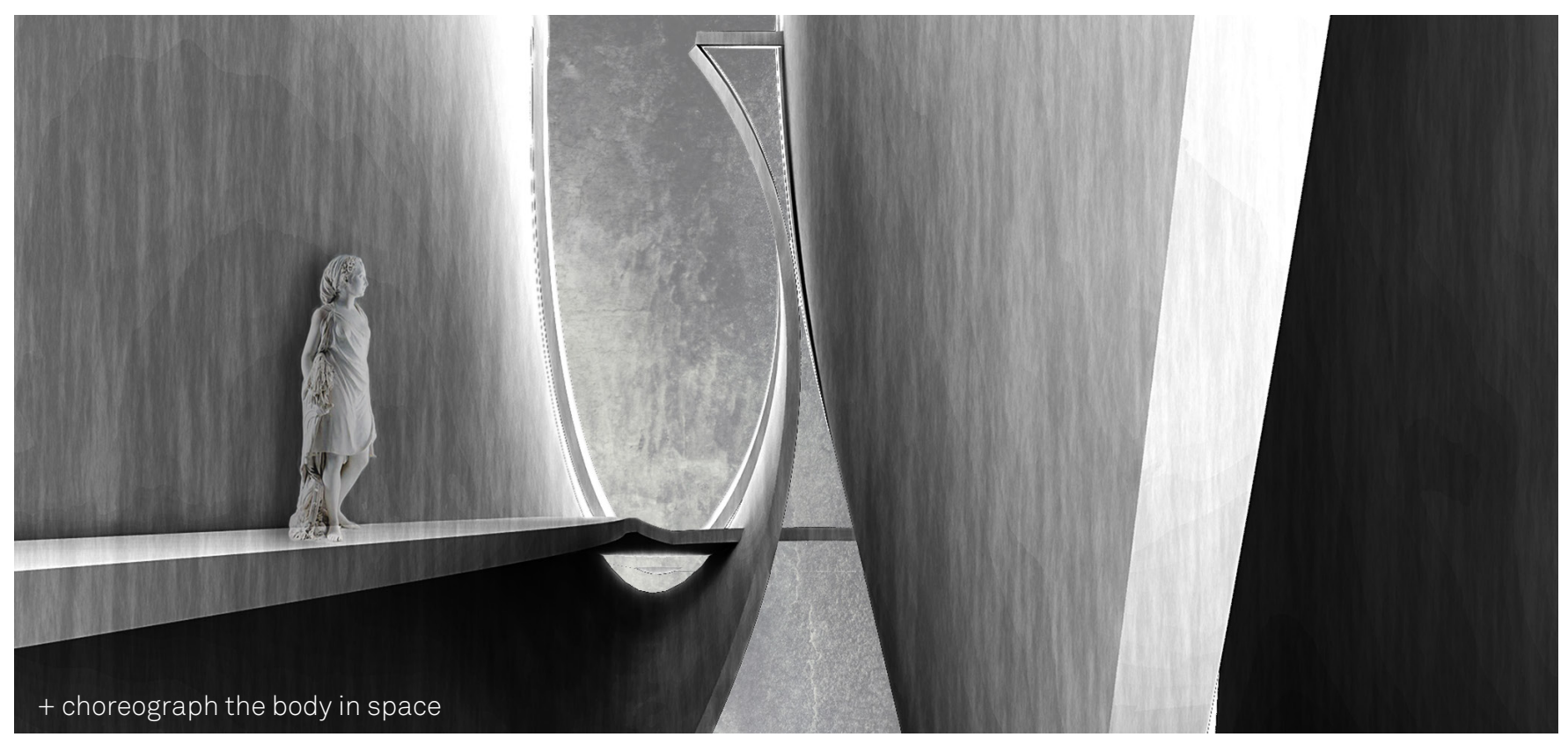

+ choreograph architecture as a body
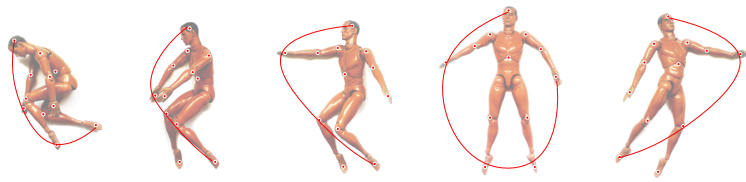

(Top)
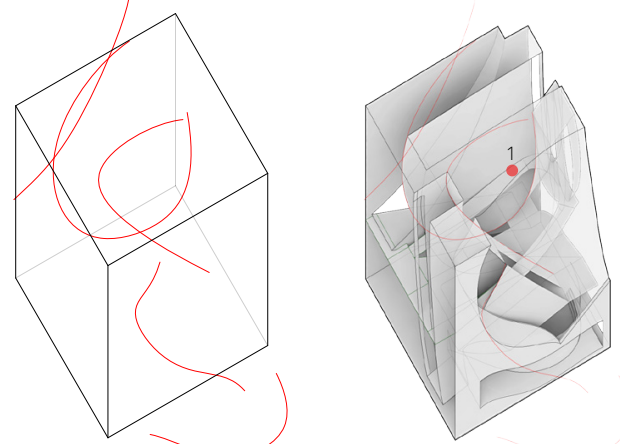


\section{The Dynamic Stairway}

The Dynamic Stairway explores choreographing architecture that influences our bodily experience in space. This relationship between body and environment has been examined in the work of Arakawa and Gins, where architecture at times challenges and surprises the inhabitant with unanticipated situations. In several of their projects including Bioscleave House (2008) and Reversible Destiny Lofts (2005), the architecture creates situations where residents must regularly negotiate with their environment, and thus always be aware of their body in space. These apartments resemble playgrounds where poles and ladders run from unexpected places, and floors are purposely bumpy and sloped (Morton, 2014). In the case of the Dynamic Stairway, a flight of stairs is explored as a means of challenging the body's movement through space by introducing interactive elements that respond to the body's movements.

In terms of ascending and descending a flight of stairs, our bodies encounter two distinct conditions. Unconsciously, our bodies indulge in gravity as we proceed downwards and resist as we travel upwards. The stairway has the capacity to provoke self-awareness of the body's dynamics and impart wonder, joy and thrill in the human experience. Yet, how might we choreograph architecture to make us consciously aware of our movements, and instill change in our bodily behaviours? We can envision a scenario where the body heightens its awareness in order to negotiate with its surroundings. In the architectural situation, proceeding down the stairs has a high impact on the steps; the weight influences the surrounding apertures to decrease in size. Likewise, ascending the stairs has less impact on the ground, allowing the apertures to remain fully open. As a result, the body becomes aware of how it performs in space, slightly adjusting the effort of each movement to shape the surrounding environment. While it may seem the occupant is manipulating the architecture, it is the architecture that is influencing one's body movement. Thus, the occupant is continuously performing mental tasks that challenge the body's proprioception when experiencing the space. 


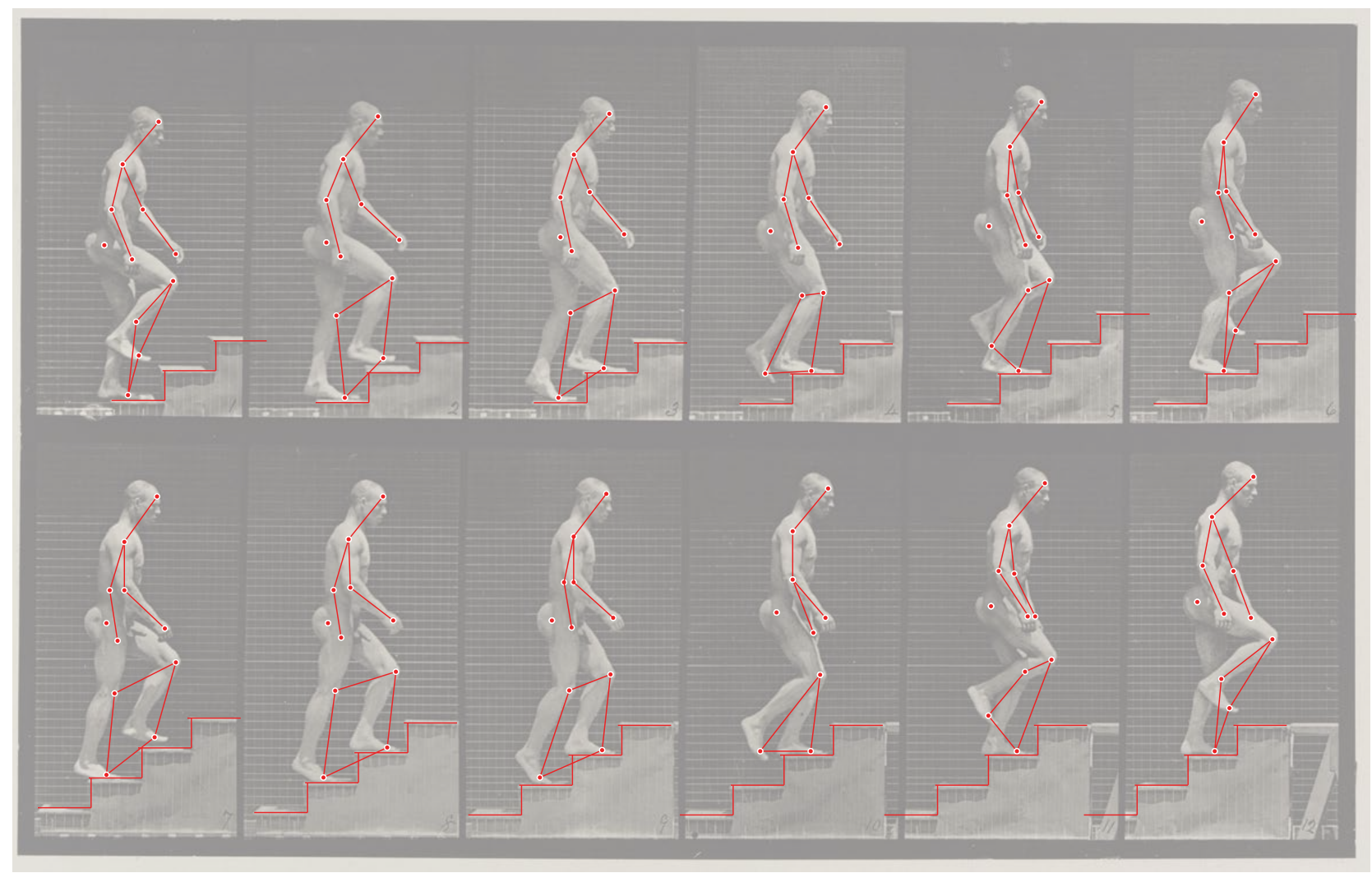

Fig. 46: Tracing movements from Eadweard Muybridge's "Man ascending stairs" (1884-1885) 
I could feel and see the heaviness of my body...

As she descended the stairs, each step became a conscious act. She tried to resist the force of gravity, stepping lighter and lighter. In the moment of each step, she felt the weight of the space in sync with her own body.

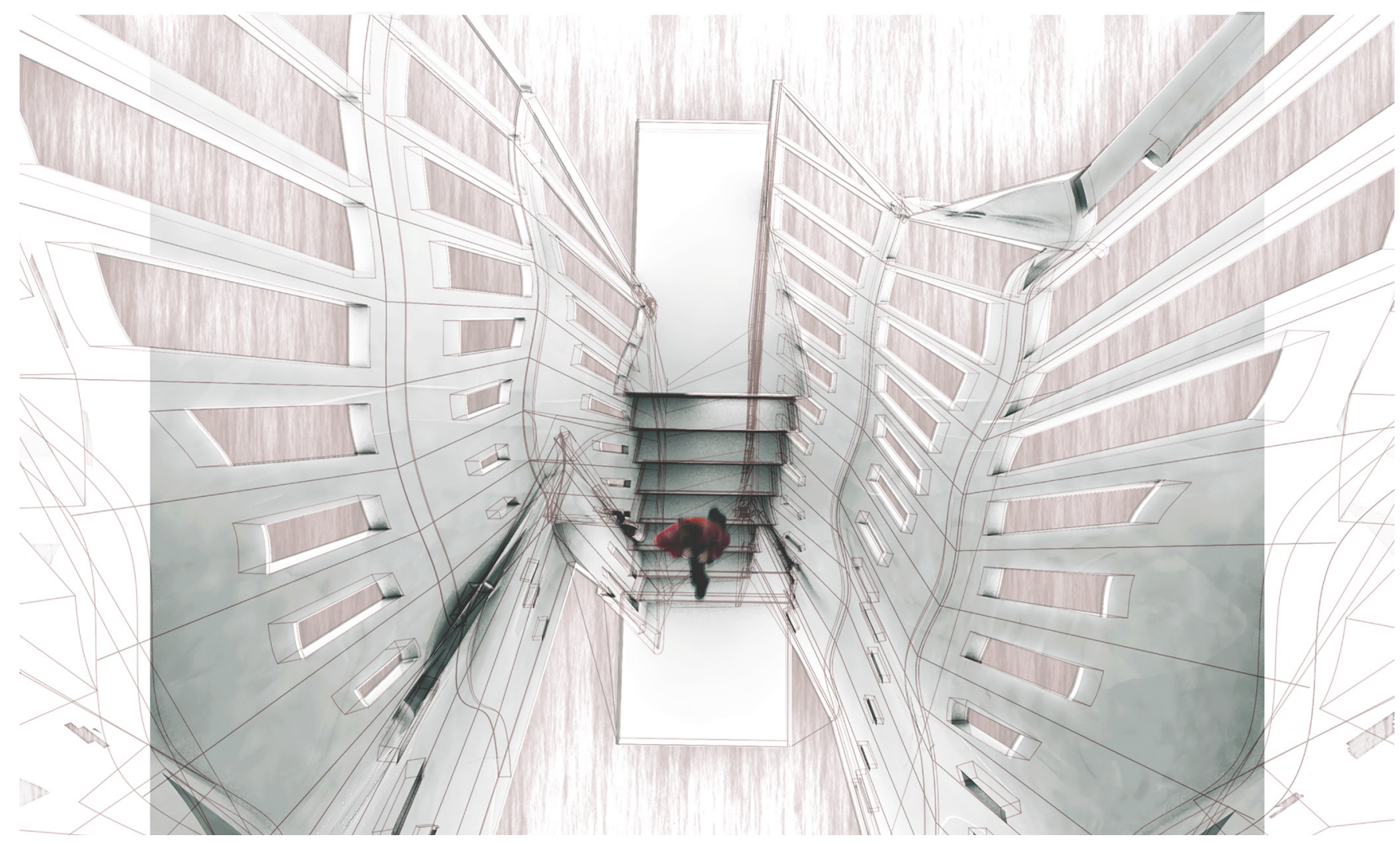

Fig. 47: The Dynamic Stairway - Plan Perspective 
The feeling lingered in her body, leaving a lasting impression even after she had left the space.

The platform detached from the stairway separates the body from all distractions. The breakaway from the space allows for the mind to reset to its reduced corporeal schema, the body alone, allowing for self-awareness and reflection.

Upon leaving and entering the stairway, the architectural experience influences how the occupant might react or behave in the environment, along with creating a lasting effect in the body even after the occupant has left the space. Here, architecture has the ability to augment the body in both physical and mental capacities through choreographed environmental stimuli.

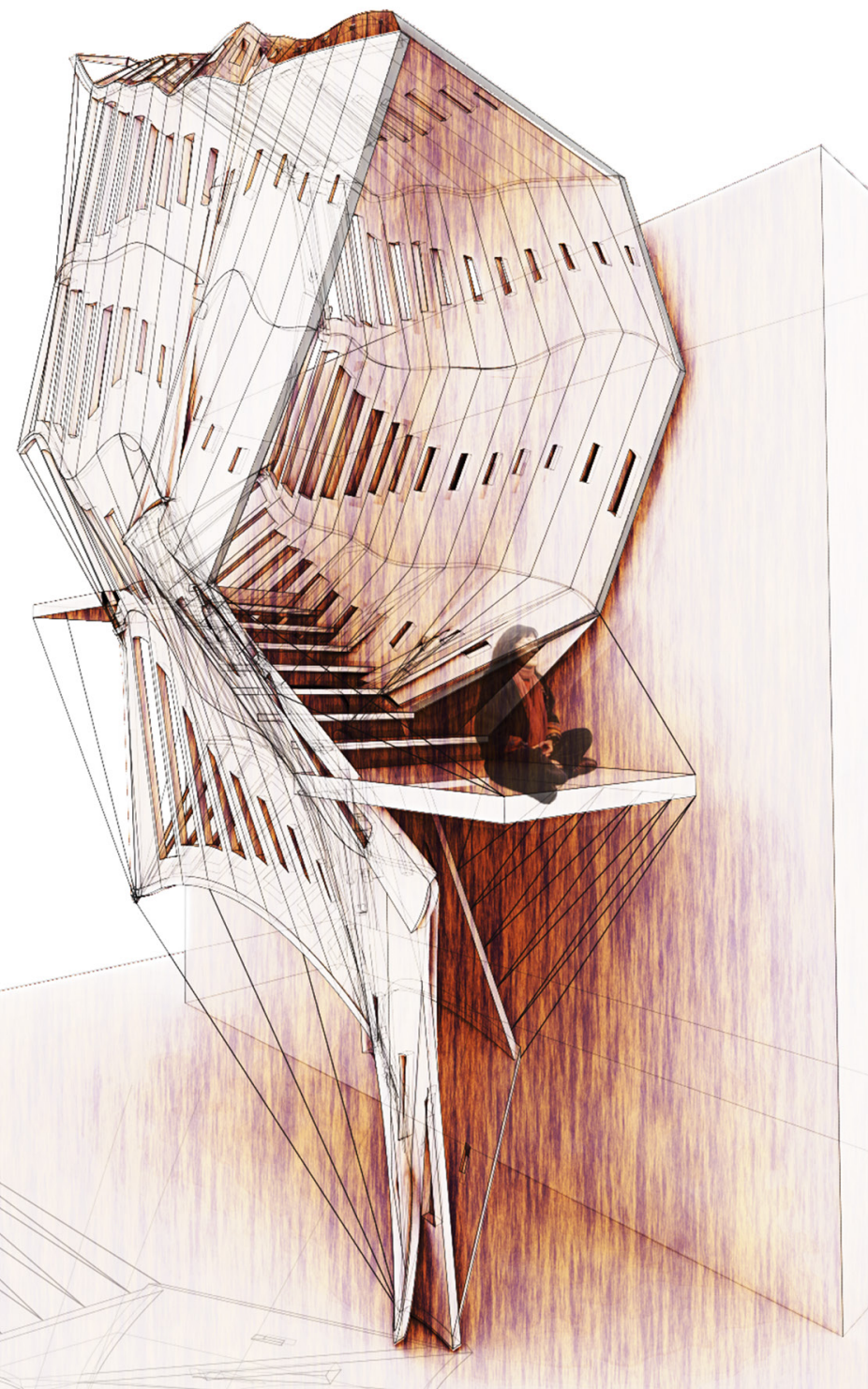

Fig. 48: The Dynamic Stair way - Perspective 

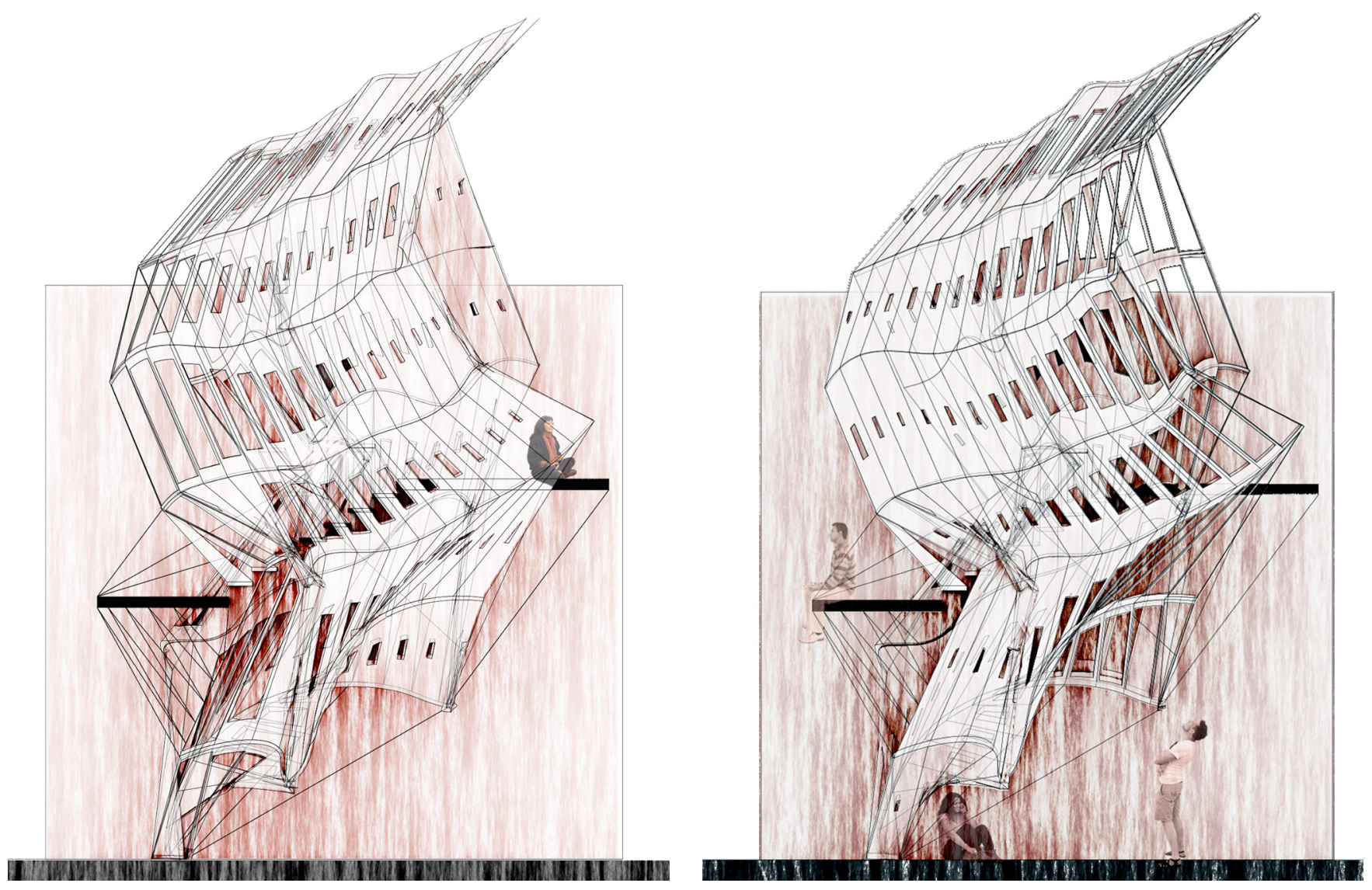

Fig. 48b: The Dynamic Stairway - Elevations

The impact of weight on the stairway influences the apertures to

change its size. (Heavier $=$ Smaller Opening; Lighter $=$ Larger Opening) 

Choreographing Negative Space 


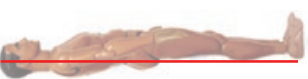

군
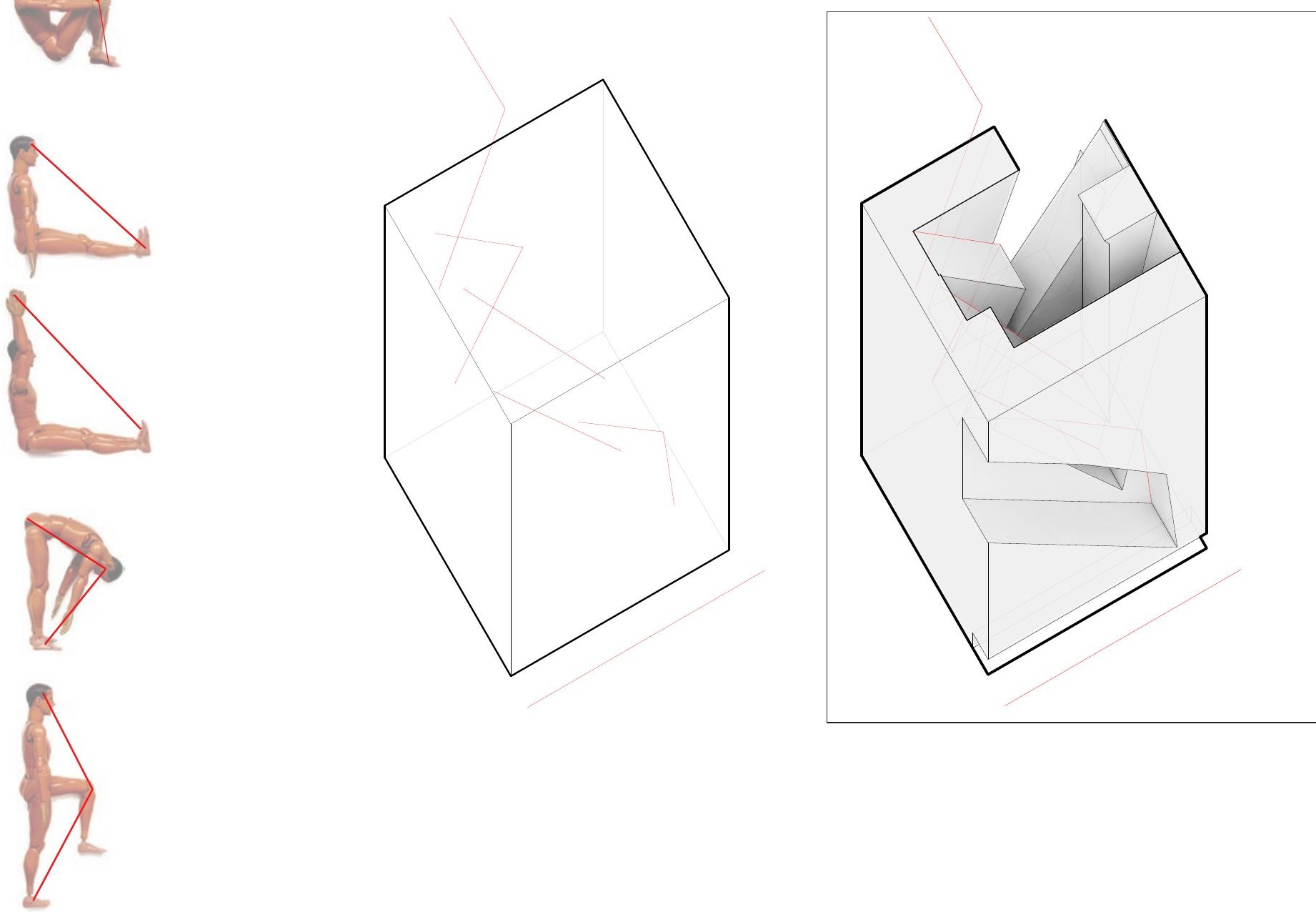
As opposed to the previous designs, this exploration concerns a subtractive form-finding process by carving through an existing volume of space. This scenario utilizes angular lines derived from body proportions to cut through the volume in a sequential progression: lying down, elevate midway, stretching, half-risen and upright position.
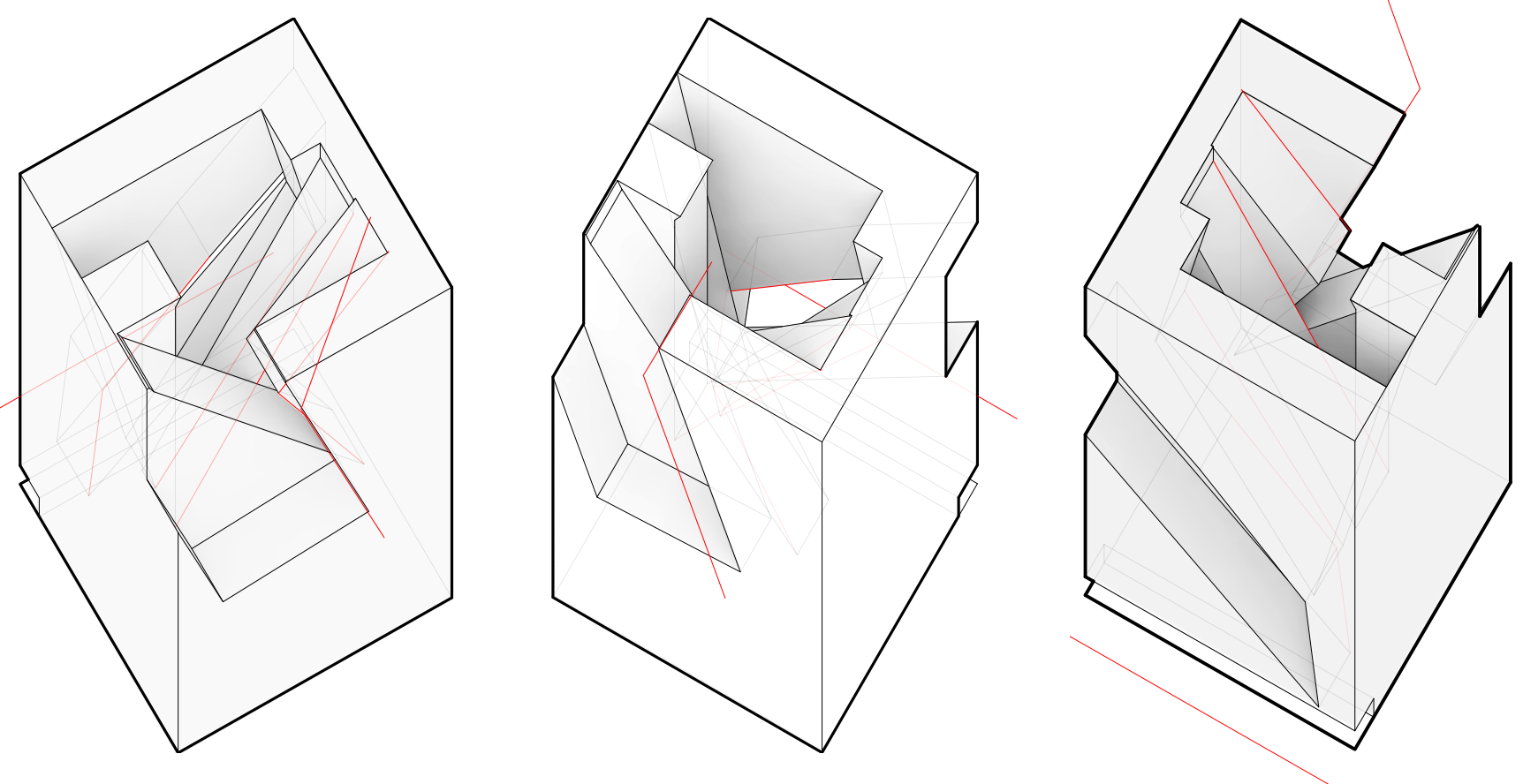

Fig. 50: Choreographing Negative Space - Isometric projection showcasing the process of choreographing the body of architecture. 

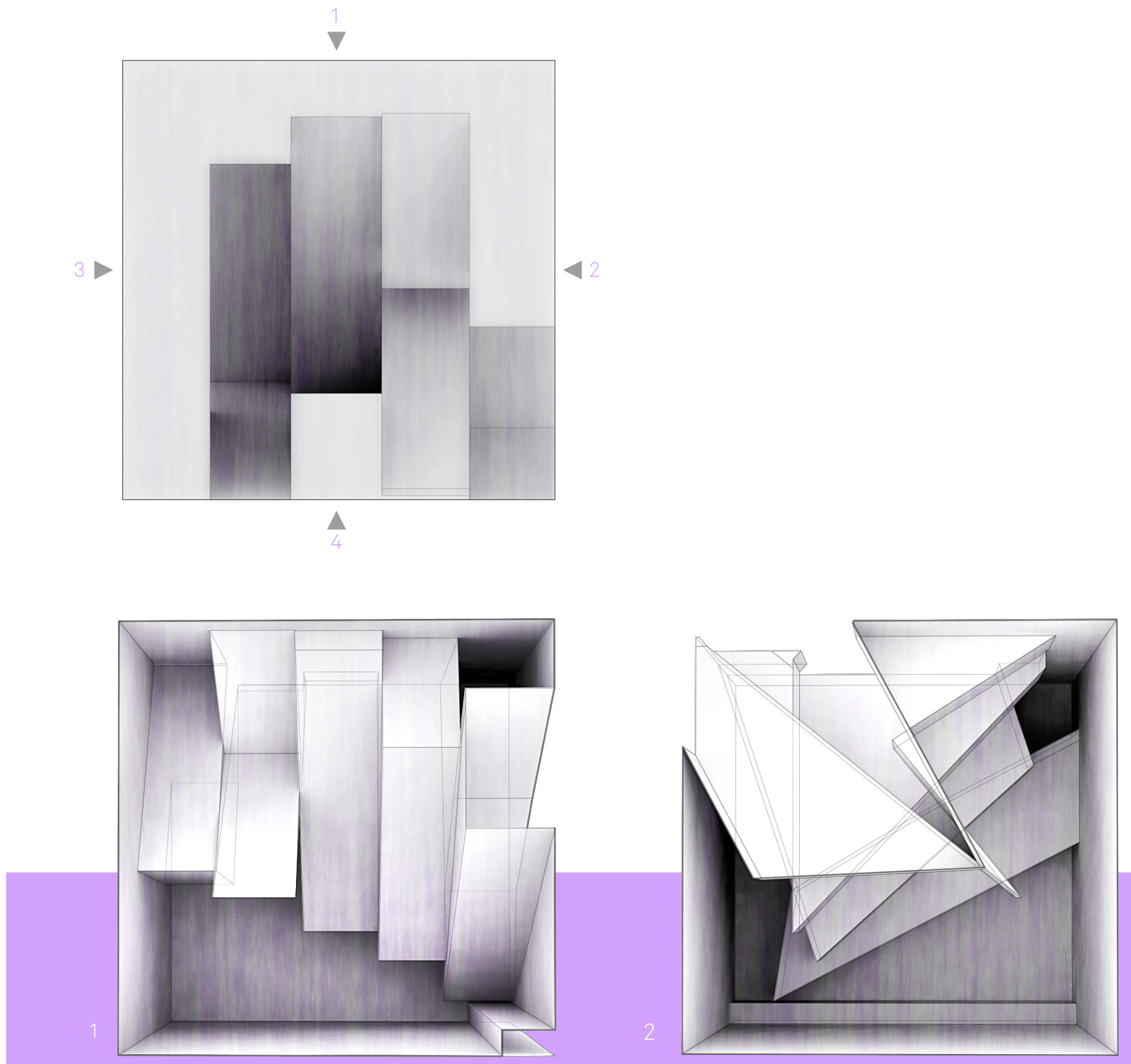

(Top) Fig. 51: Plan of Design Iteration

(Bottom) Fig. 52: Elevations of Design Iteration 
As one moves through space, the body perceives the physical environment progress from an intimate to a distant relationship with the ground plane. This relationship between the body and the surrounding negative volume is reinforced in the following design development.
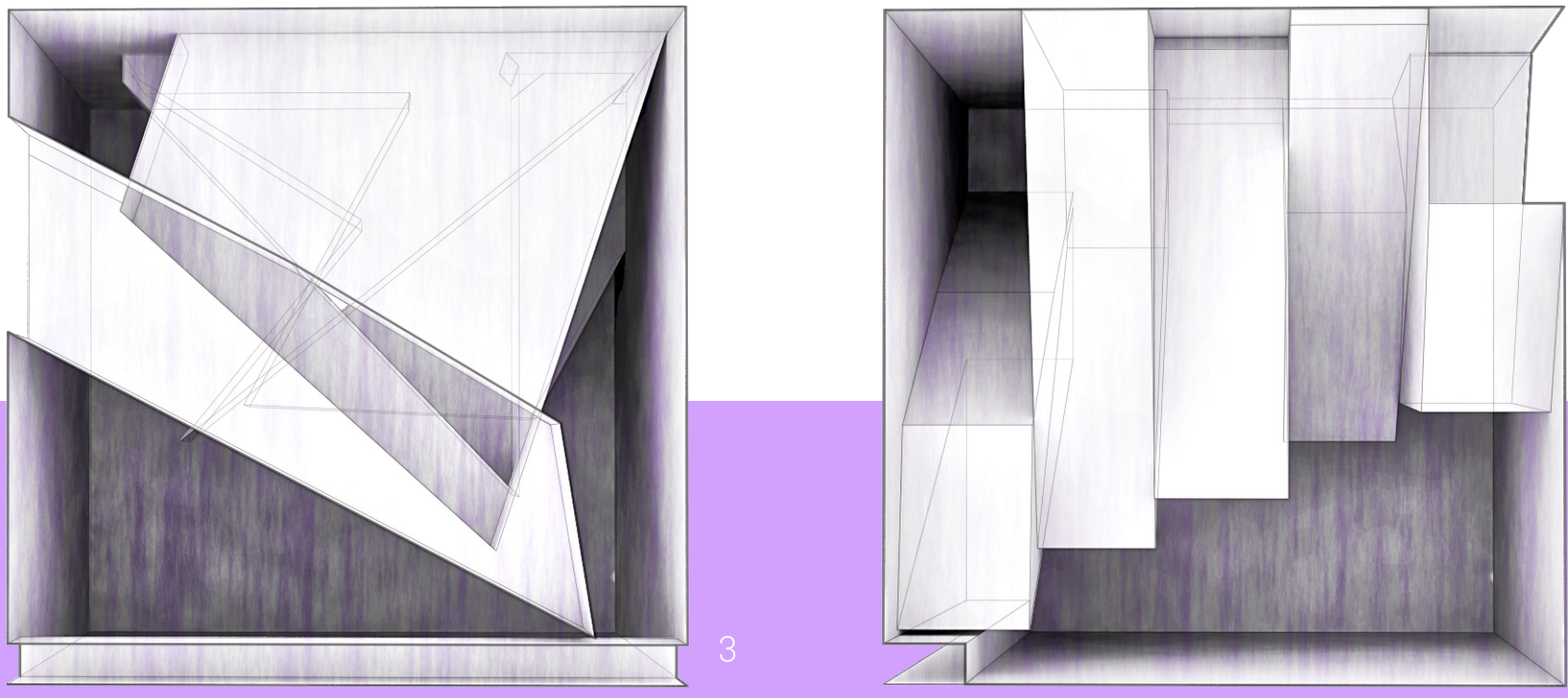
STAGE 2 DEVELOPMENT: Choreographing how the body moves through space

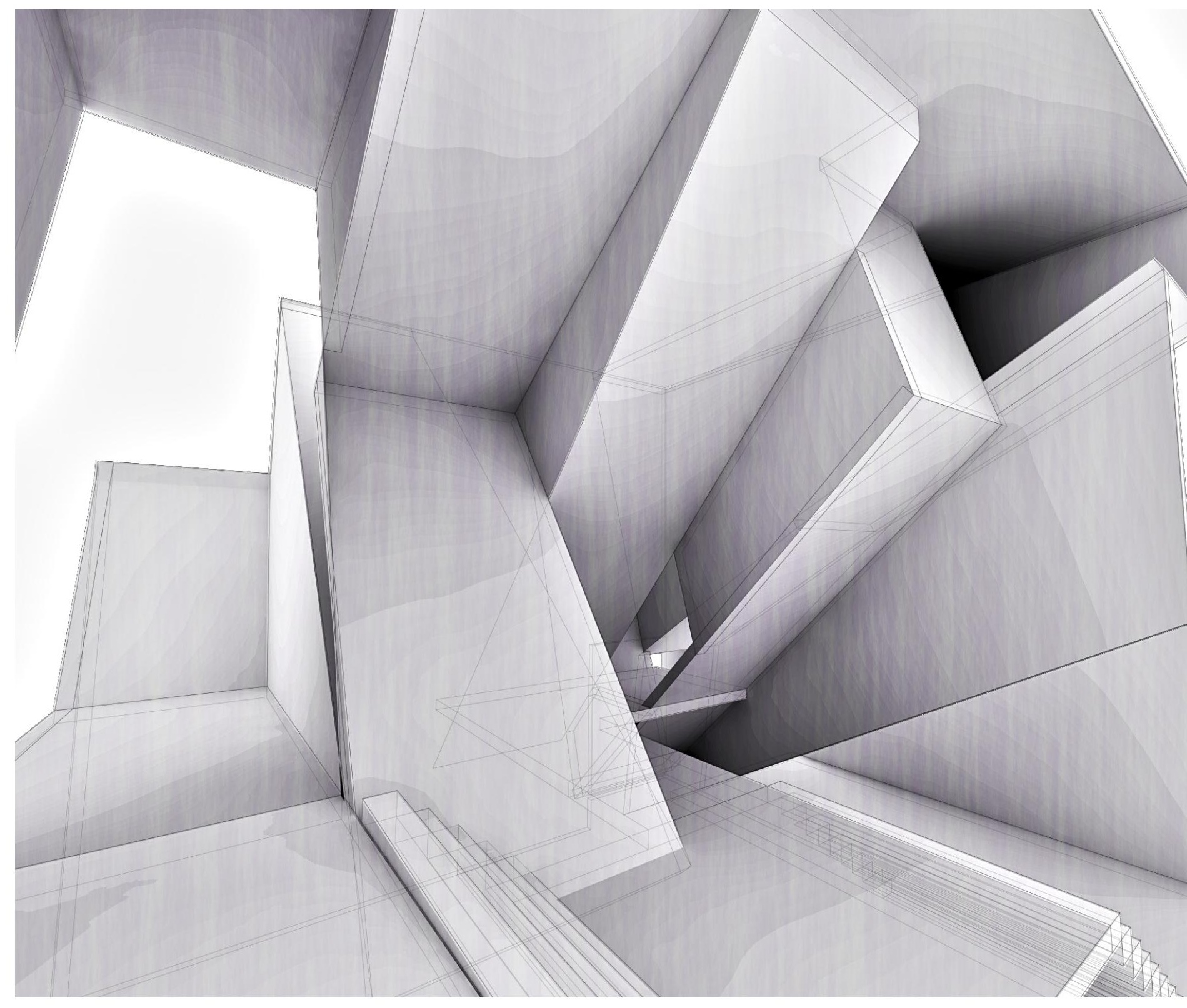

Fig. 53: Choreographing Negative Space - Perspective 
This design reveals a process of choreographing an architecture with the body and kinesthetic empathy. The body of architecture was constructed from lines derived from the human figure, progressing from the ground to an upright position. The circulation of the volume interweaves with the movement of space, giving the dweller a path to see and feel motion transferred into built form. In this experiment, the concept of movement in architecture as a spatial unfolding is similar to Le Corbusier's architectural promenade. The surrounding environment becomes mobilized through space as the surfaces follow the body when proceeding through the directed path. As the path weaves through the volume, the inhabitant experiences the architecture compress and release within vistas framed by the intersection of the interior forms.
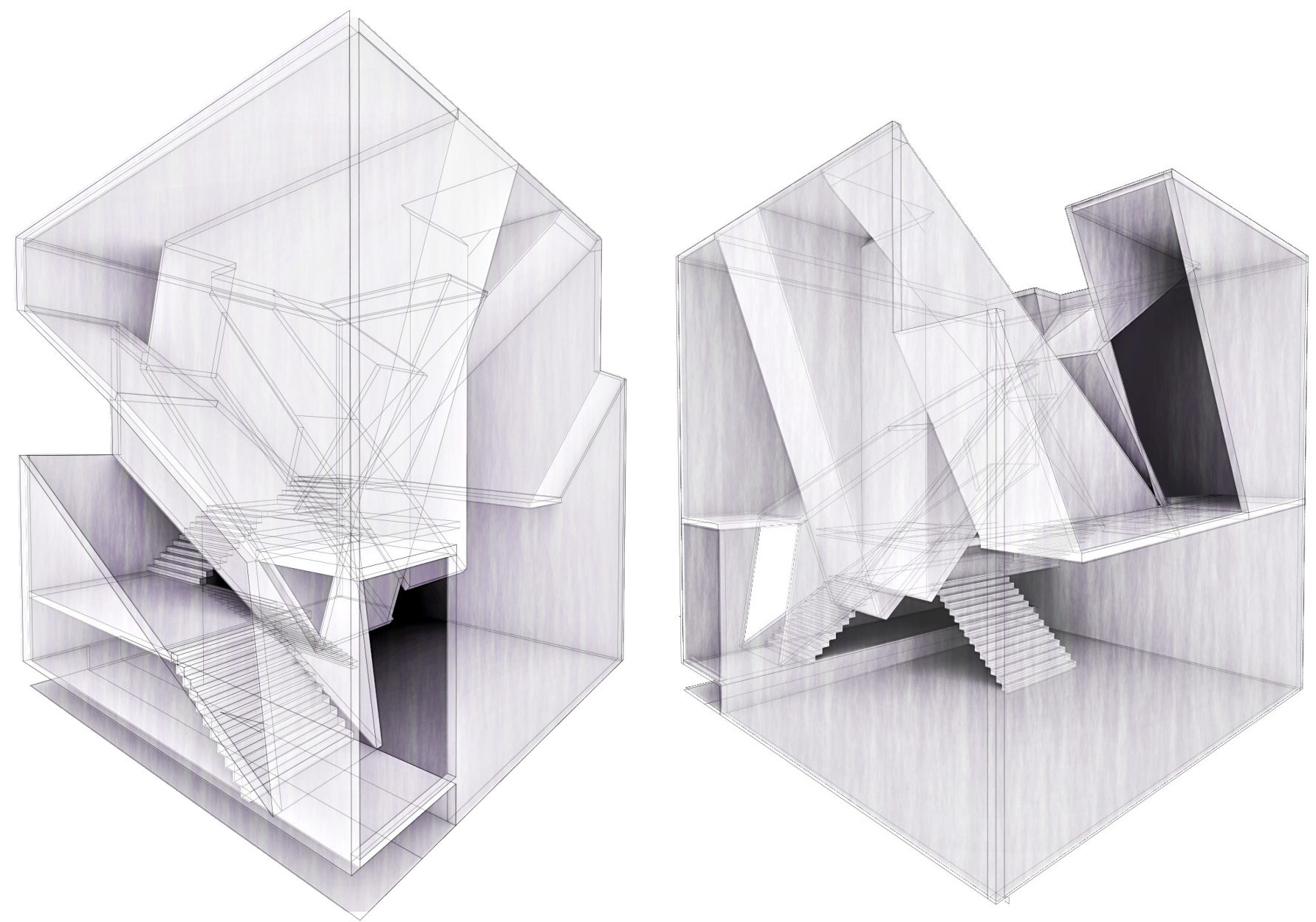

Fig. 55: Choreographing Negative Space - Perspectives

The next design phase was inspired by the processes of Choreographing Negative Space and the Empathetic Elements. Here, an existing typical suburban house was transformed by applying a similar technique explored in Empathetic Elements, where a sequence of motions was translated into continuous forms (Refer to Section 6.1). 


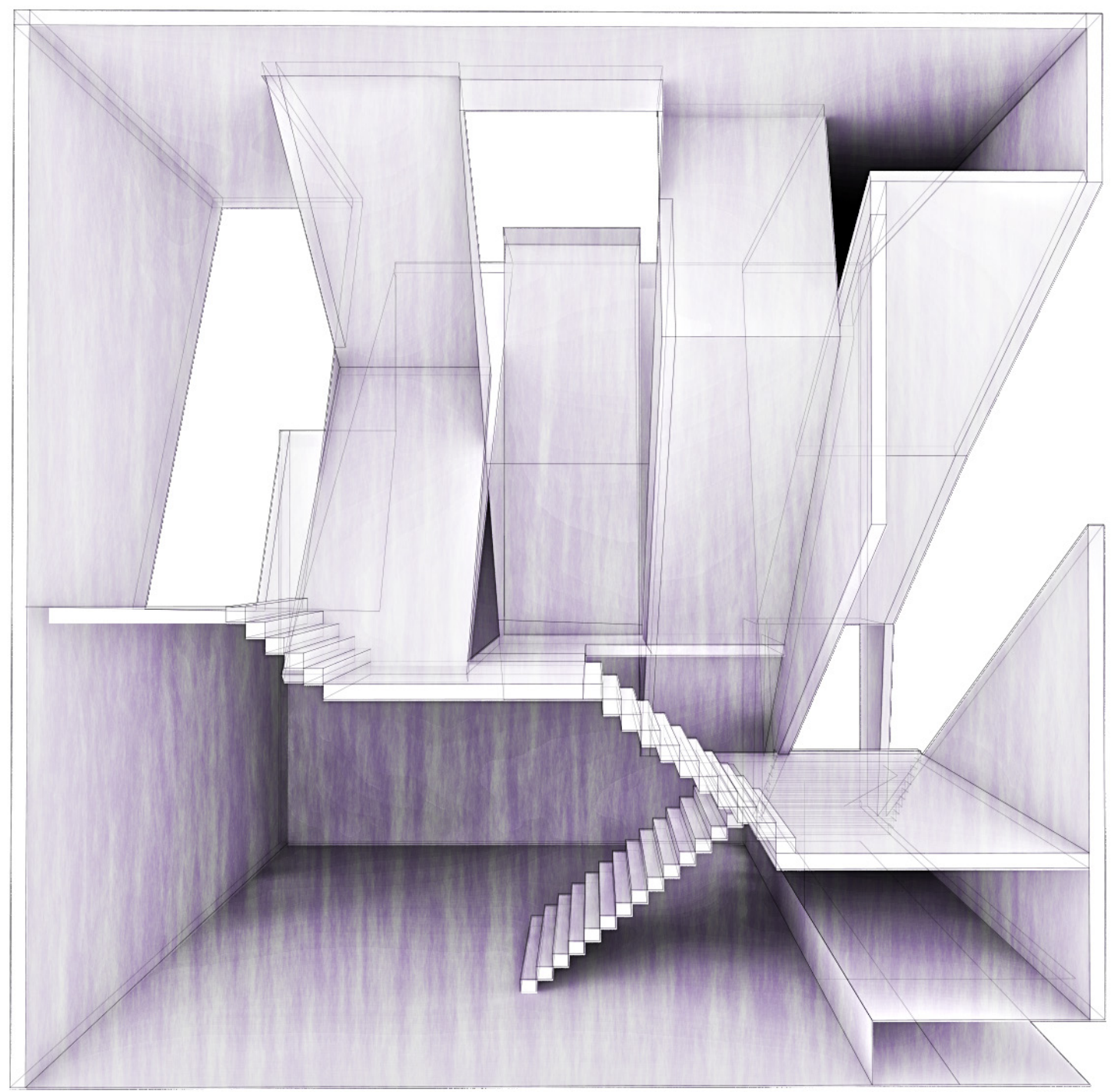

Fig. 56: Choreographing Negative Space - Perspective 
"Give me kinesthetic empathy, and I will make all buildings move."

(Quote Adapted from essay: Give me a gun and I will make all buildings move)

(Latour \& Yaneva, 2008).

From modern to traditional abodes, a typical house is designed by selecting an architectural style. As architects, how might we design a home beyond the schemes of stylistic preference? This investigation challenges the existing typologies of the traditional house and proposes a choreographic method, wherein a house is no longer defined by style but rather movement and the body in architecture.

The design method explores a narrative of transforming a suburban home into a dwelling in tune with the mind and body. Based on a conceptual framework, a house is deconstructed and redefined through a choreographic process emergent from kinesthetic empathy. Perhaps the design may initiate from the existing stair, altering the bedroom, transitioning to the kitchen, eventually reconstructing the entire built form. The design method unveils a transformation from the traditional family home into the Dynamic House, an architecture that rebuilds an increased cognitive ability in the inhabitants.

The Dynamic House embraces the art of inhabitation, the dweller's movements, mind and body. The body-tailored architecture stimulates embodiment in the dweller, offering an intimate kinesthetic experience. The house is designed based on the dweller's movements, activities and body, revealing the narrative of inhabitation through the "flesh" of the building (Merleau-Ponty et al., 1968). At times, the house will instill self-awareness, influence change in physical behaviours and make the dweller conscious of his or her movements. Other times, there will be breakaway moments in the house, with minimal diversions, allowing the mind to reset to its reduced corporeal state, the body alone.

The house was initially envisioned to be choreographed by "spaceevents," a family of movements and activities defining the dweller's inhabitation.

1. The Entrance (threshold, transition, welcoming...)

2. The Staircase (playful, effort, alluring...)

3. The Bedroom (private, contemplative, intimate...)

4. The Garden (peaceful, open, reflective...)

5. The Attic (dreams, memories, childhood...)

6. The Kitchen (gathering, engaging, efficiency...)
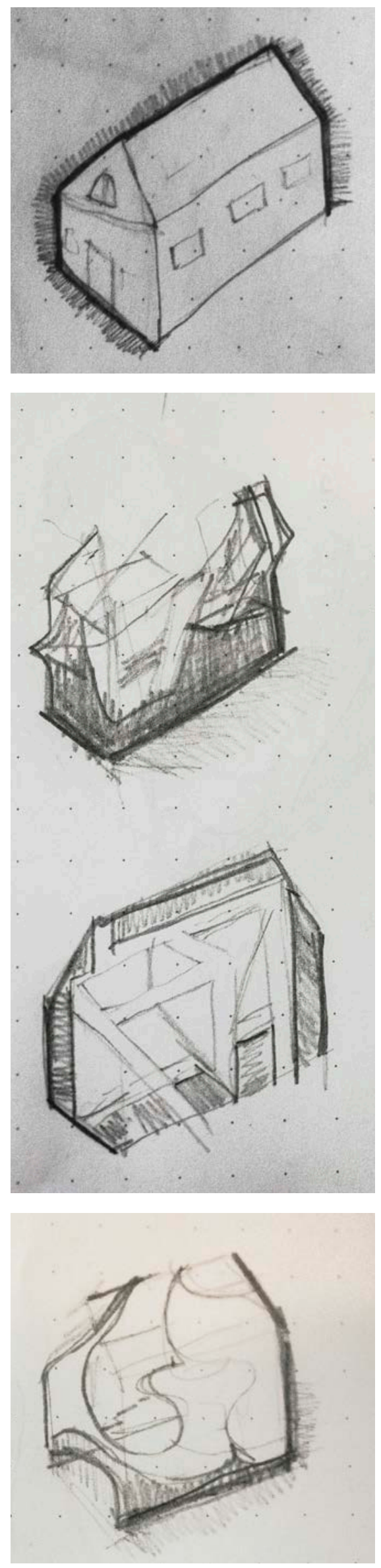

Fig. 57: Initial sketches of the Dynamic House 


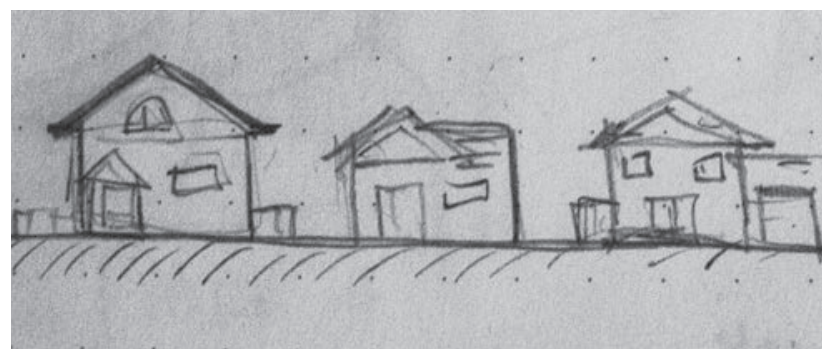

The Dynamic House fosters a tailored corporeal experience in a shared dynamism between body and space. The dweller will experience unimagined spaces, reawakening the mind and body through the phenomenon of kinesthetic empathy.
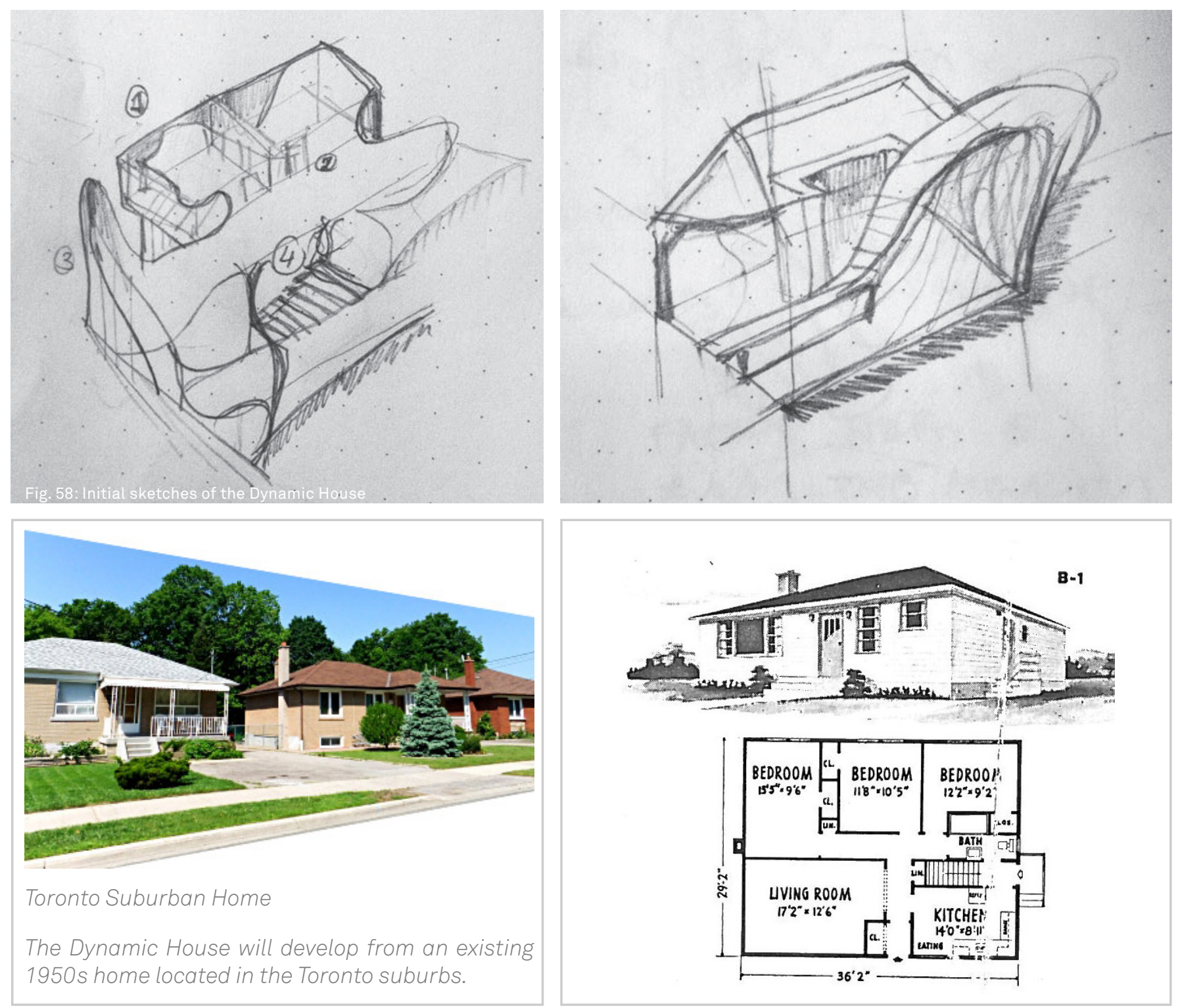

Fig. 59: Image of "Victory Housing" in Toronto neighbourhoods.

Fig. 60: Visualization of mid-century residential bungalow 


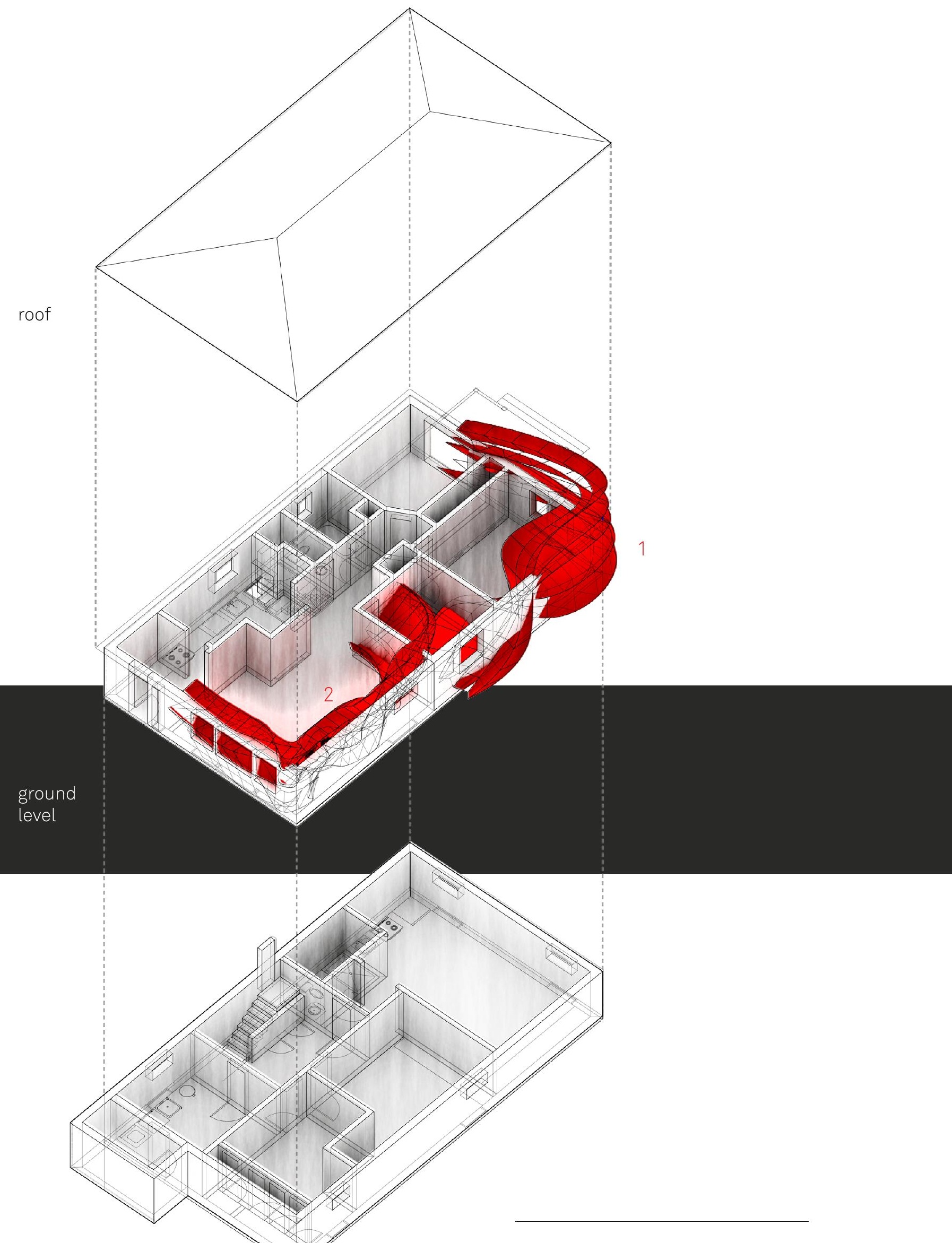




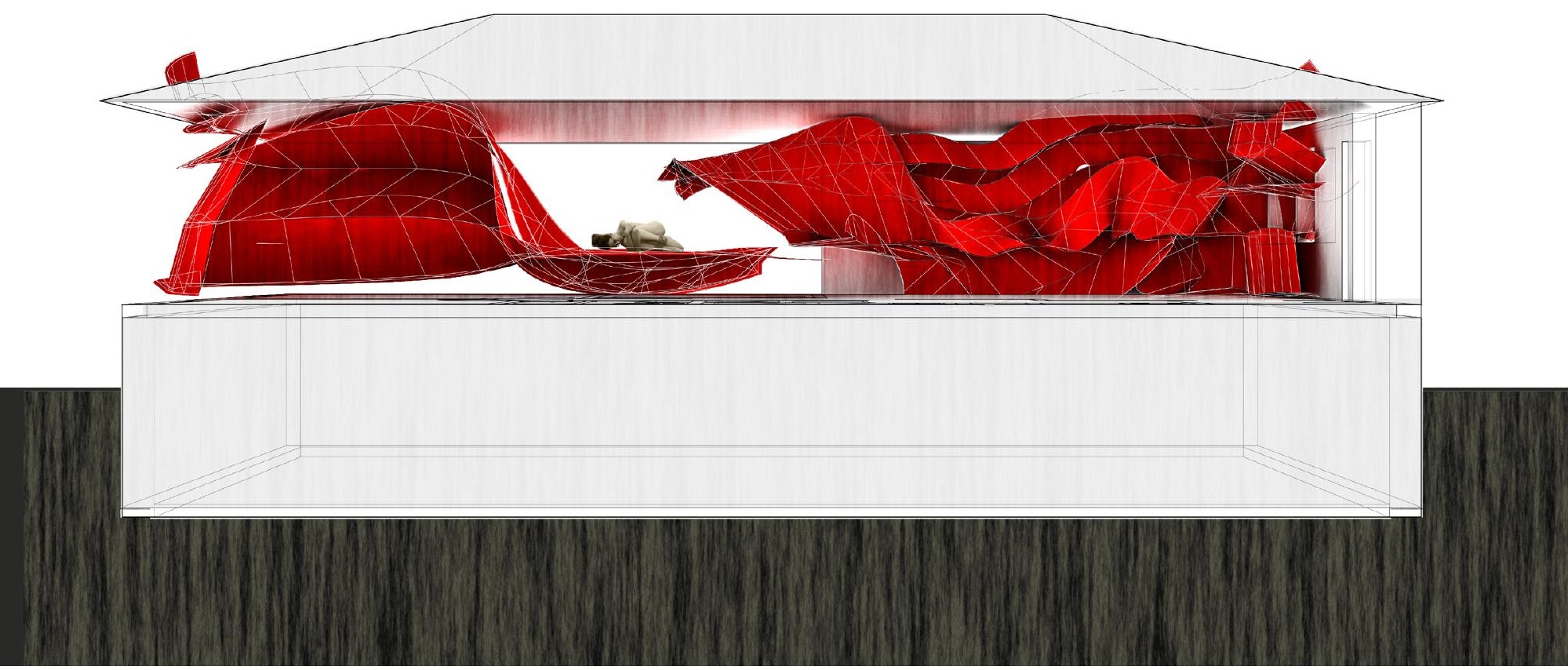

2014-2020

stage 1: bedroom

stage 2: dining room/living room

stage 3: kitchen

stage 4: stairs

stage 5: basement to garden

stage 6: facade to second floor

(continuation of stairs) 


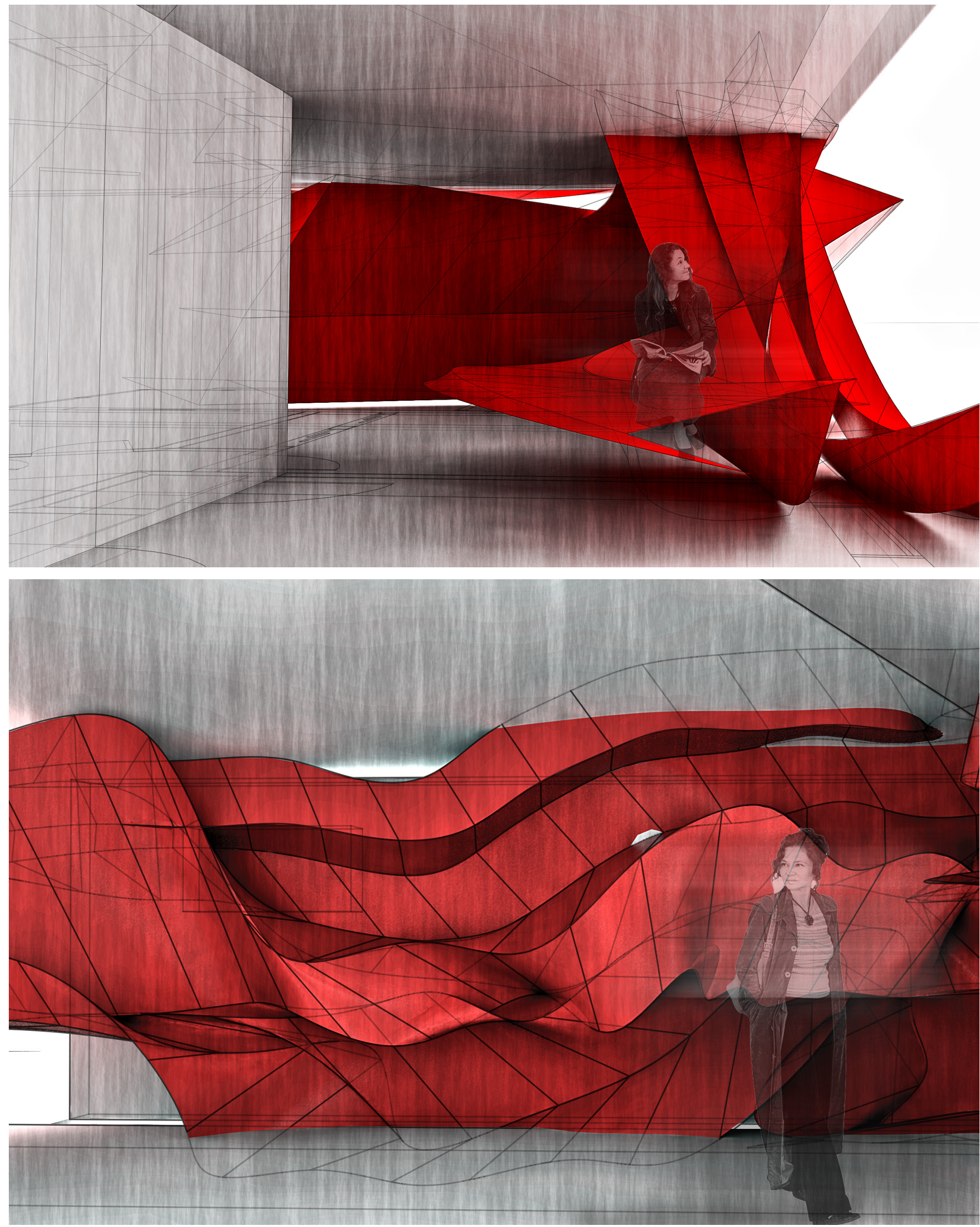



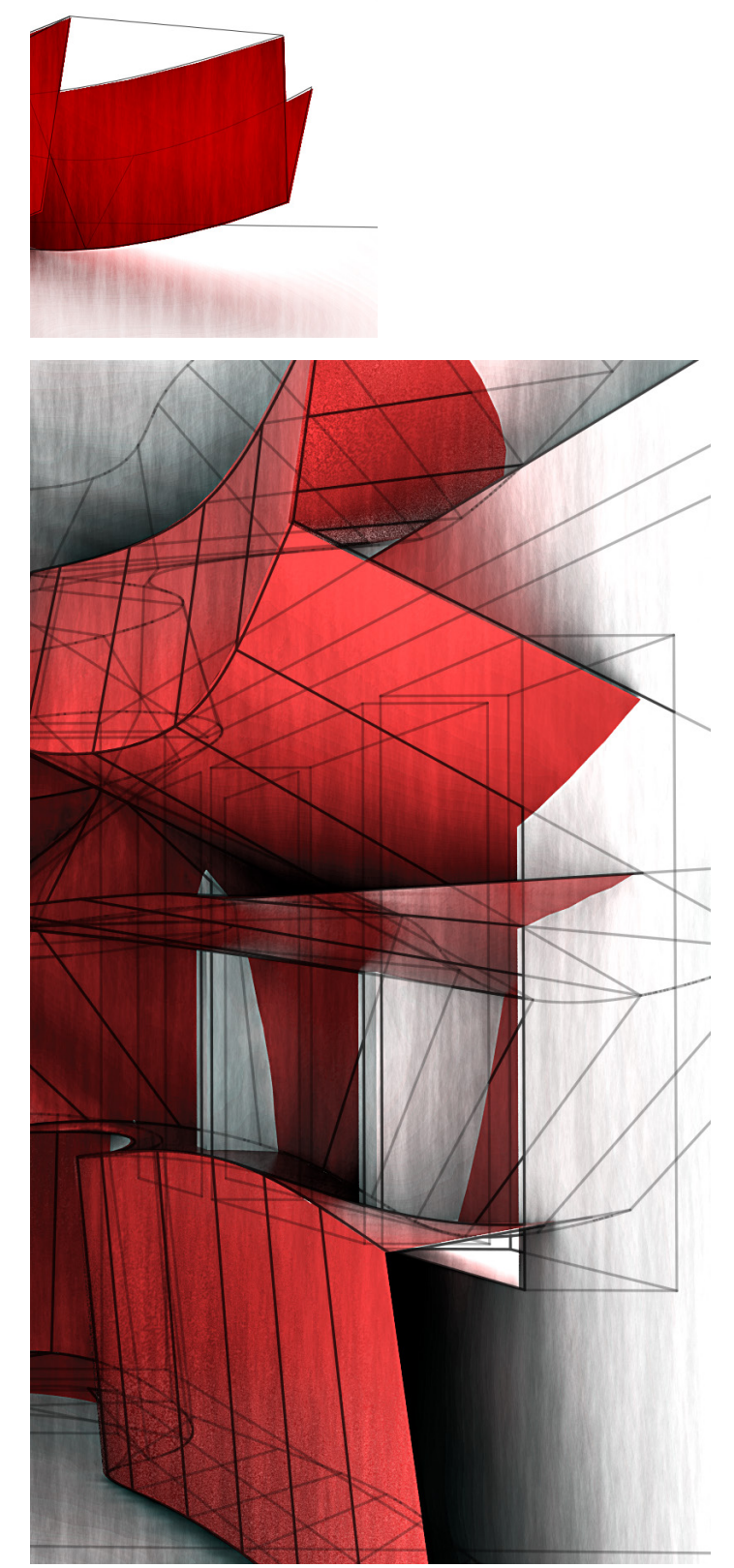

The notion of the house was examined through the analogy of neuroplasticity, in which our brains create neurons when exposed to new information or situations. In essence, the house is building new "neural pathways," diverging from the typical banal home the dweller is accustomed to, into an environment that provides neurological nourishment through the exposure of a dynamic space. This approach is similar to Peter Eisenman's exploration of the Deleuzian-Fold, a form that proposes a space shaped by a continuous surface; this effect forces the inhabitant to adapt his or her perception of space from the orthogonal gridded environment, to the continuity of variable curvature (See Section 4.4 for discussion on the Eisenman's Fold). 


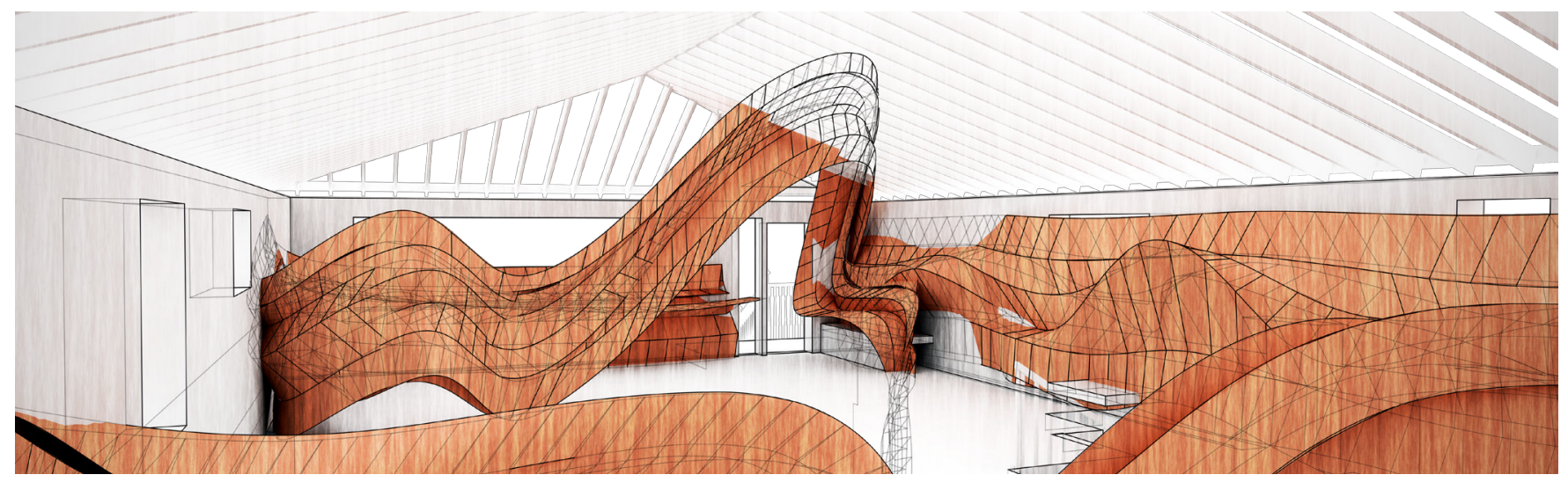

Fig. 64: Dynamic House - Interior Perspective

The Dynamic House: Further Developments

The Dynamic House concept was further developed using the Kinect, a motion sensing input device, as a means of collecting movement data for advancing the form-finding process. Sequences of movements were choreographed with a dancer and captured using this motion sensing technology. Movements included transitioning from the ground level to upper level, balletic runs, rising of the body, leaps, etc. The data obtained from the device were points of the body in movement including the head, shoulders, elbows, hands, knees and feet. These points were analyzed in space, re-organized, and connected to form surfaces that could then be introduced as a new language within the suburban home. The difficulty of creating a dialogue between the existing house and the proposed parasitic architecture stopped this design from progressing into its next stages of development.

The following design exploration abandons the existing house as a framework and explores the formation and organization of architecture through another dynamic model of choreographing architecture. 

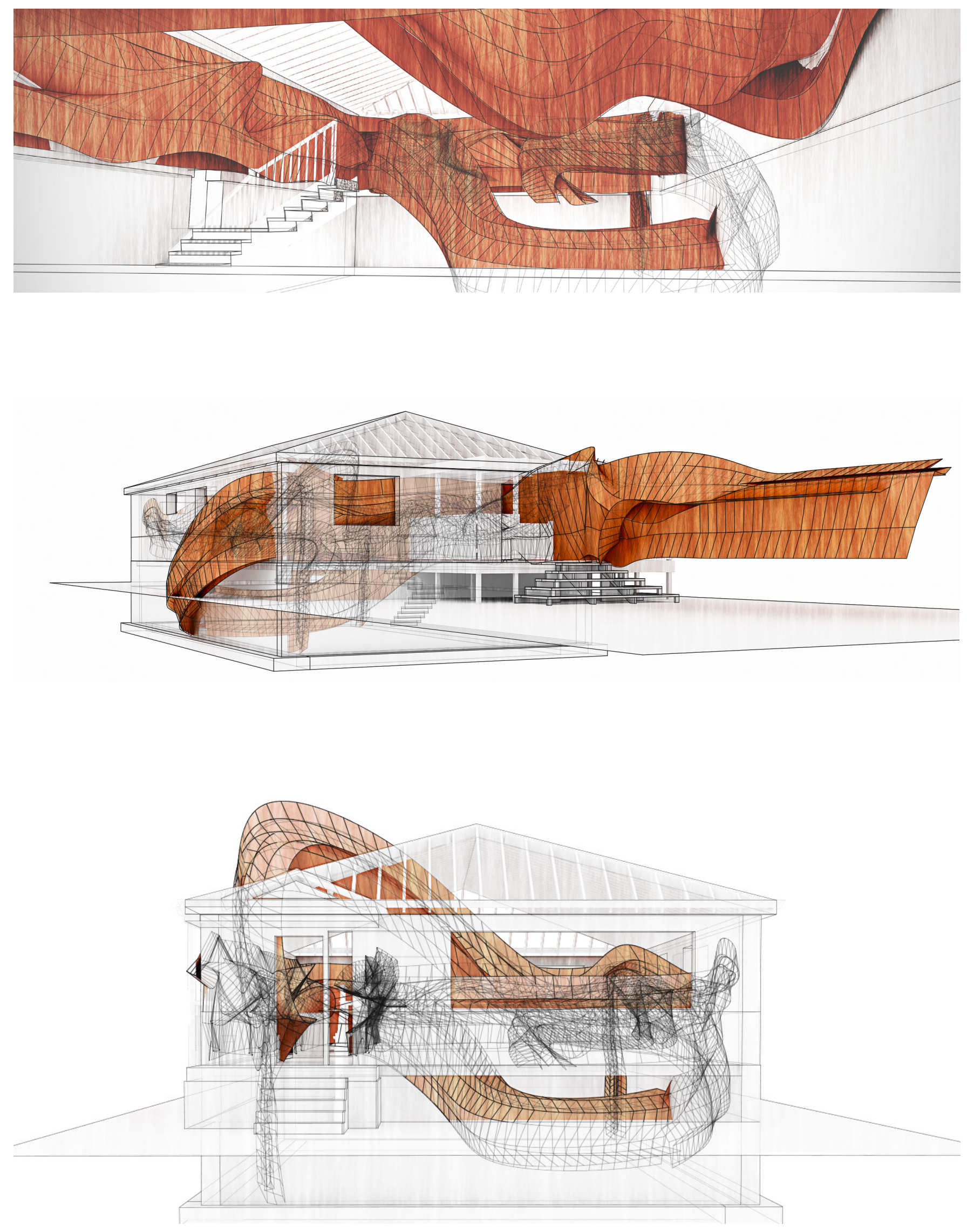

(Top) Fig. 65: Interior Perspective

(Middle) Fig. 66: Back yard Perspective

(Bottom) Fig. 67: Front yard Perspective 
Routine 1

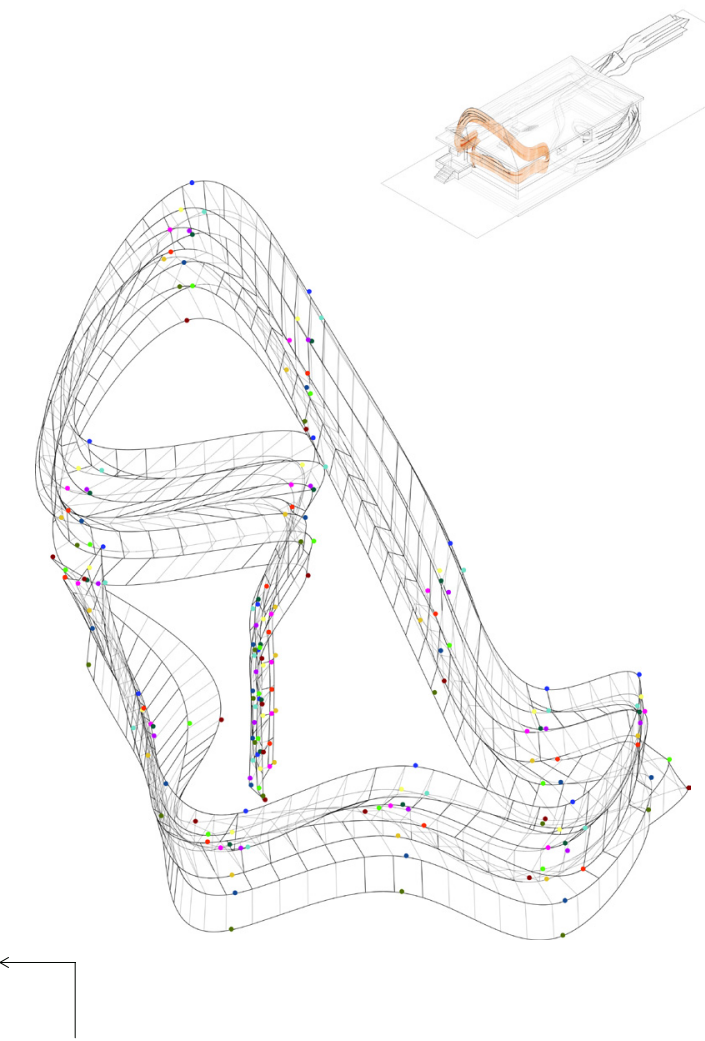

Rise of Body - Right Arm

Reach

[1/2 Scale]

Basement to Ground Fl.

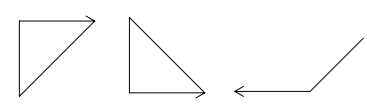

Jeté (Front Leg \& Back Leg)

[Full Scale]

Ground Fl.
Routine 2
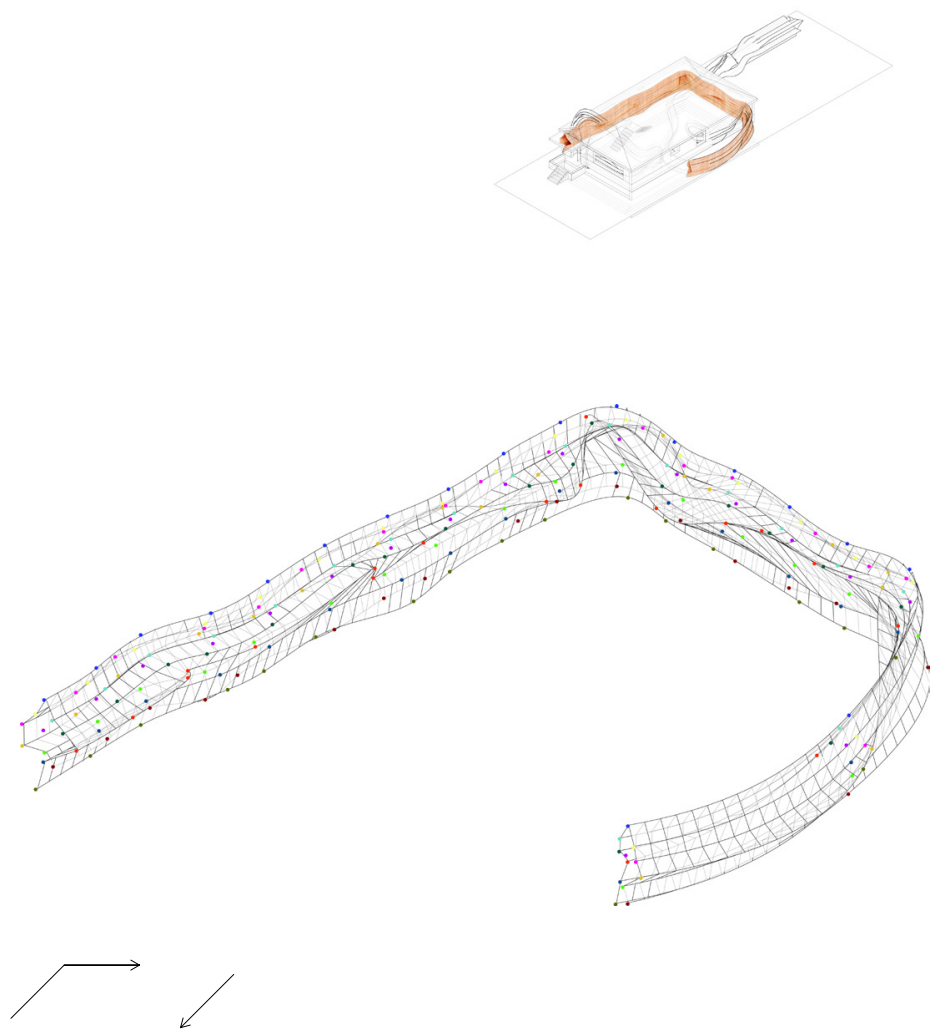

Ballet Runs

[Full Scale]

Ground Fl. to Basement 
Routine 3
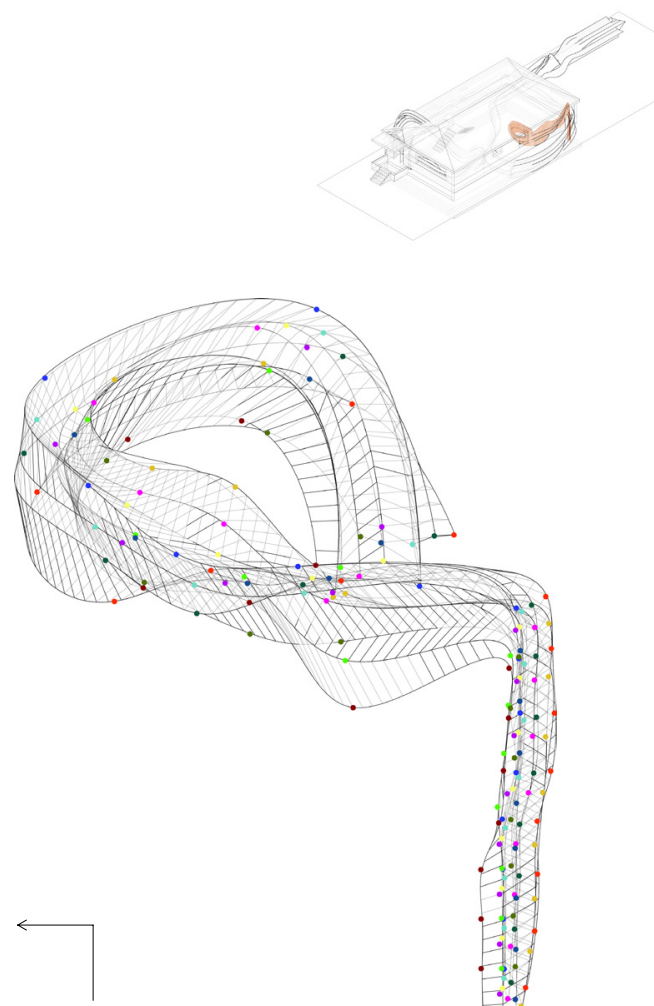

Rise of Body - Right Arm

Reach

[1/2 Scale]

Basement to Ground Fl.

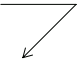

Reverse Back Bend Fall Land

[Full Scale]
Routine 4

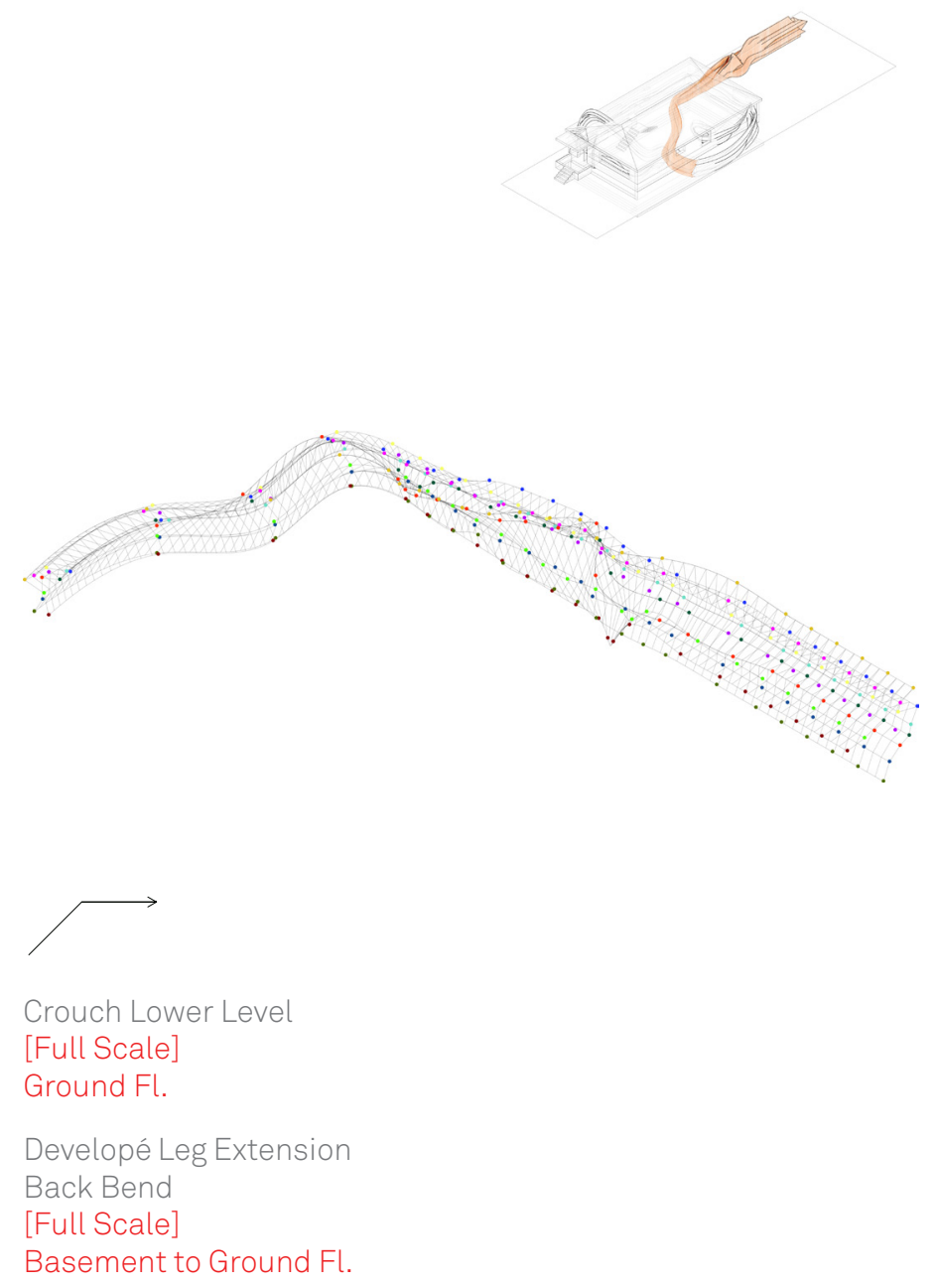

Crouch Lower Level

[Full Scale]

Developé Leg Extension

Back Bend

Basement to Ground Fl. 
This project is not a building. It's a visionary proposal for a choreographic architecture.

This proposition explores making architecture move by rethinking the way we organize and generate space using human kinesis. A choreographic architecture embraces a dynamic model for both organization and formation; where geometry is formulated by relationships between forces and motion derived from human kinesis and choreographed in space using a series of dynamic relationships. In this proposal, a choreographic architecture is a spatial performance that transforms points to planes to kinesthetic components (Fig. 69). It's a process of transformation that ultimately leads to an architecture that moves the dweller through kinesthetic empathy.

Why the moving body?

Human kinesis is highly continuous and differentiated allowing our architecture to take upon a similar nature. By applying human kinesis as the driving force of geometry, inert structures of form are transformed into dynamic bodies. Here, geometry is no longer defined as static but stable entities that store possible potentials of form defined by its relationship with the moving body. With this method, architects should acknowledge the variation of topological forms that could unfold dynamically through an analysis of movement, as opposed to understanding the geometric outcome solely as shapes.

How does it impact the observer?

Forms that instill movement make us move. The geometry innately expresses motion and force through form in which the observer can sense its mass and perceived gravity through the phenomenon of kinesthetic empathy. It pushes our consciousness off its commonplace and allows our imagination to wander away from the world of everyday realities. The forms collide, intersect, deform and unfold allowing the eye to explore various organic paths. The architecture's meanings and associations are not finite but open to further developments of individual interpretation creating multi-readings. This visionary proposal allows the inhabitant to make different kinds of relations with their surroundings, but in turn, is transformed according to one's affective and instrumental relations with the architecture. 


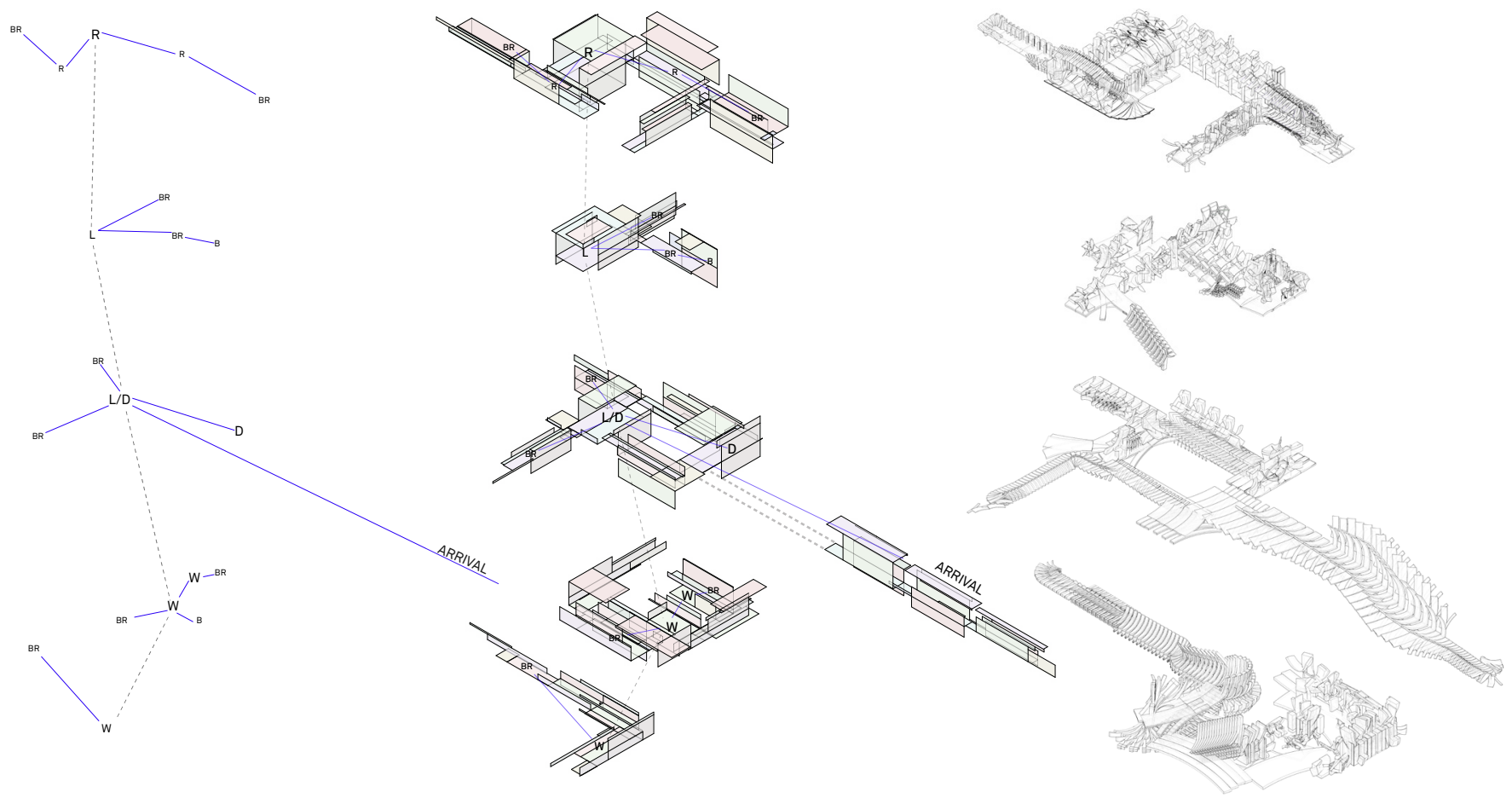


07.1 Stage \# 1: Choreographing Focal Points

To choreograph an architecture is to create a spatial performance. This architectural performance begins by identifying the major and minor focal points of the composition, followed by establishing a relationship between each point in a spatial network. In this proposal, these points serve as attractors in space that draw in assigned movement species. These species, or movement types, are defined by activities of habitation including resting, sleeping, working, eating and bathing. As discussed in the following steps of transformation, geometry defined by these movements attract their designated points. For instance, a focal point is positioned in space and assigned to draw in geometry originating from sleeping movements. All forms derived from this type of activity would thus populate its designated zone. These points are organized along a vertical axis, with activities for resting and dreaming at the top, living and eating in the centre and working below (Fig. 70). Within each level, minor focal points break away from the vertical axis, distancing themselves from the central core. These zones take up the attraction of the designated level's activity and yet break away from the high concentration of movement in the center, allowing the mind to escape and reset to the body alone.

The choreography of connections between each focal point explores alternative approaches to moving through, on and around the spaces. This choreographic method challenges and disrupts the normal usage of space, allowing for every individual to perceive their environment differently. Following the placement of points, geometry is arranged within their designated areas allowing for variation in light, privacy, openness and form that we then perceive and interpret with the sensations we internalize. Therefore, the meanings and associations in these spaces are not absolute but are open to further processes of individual interaction and interpretation resulting in multi-readings. This effect is revealed in the later stages of transformation.

(Right) Fig. 70: Stage\#1 - Choreographing Focal Points 
Focal Points

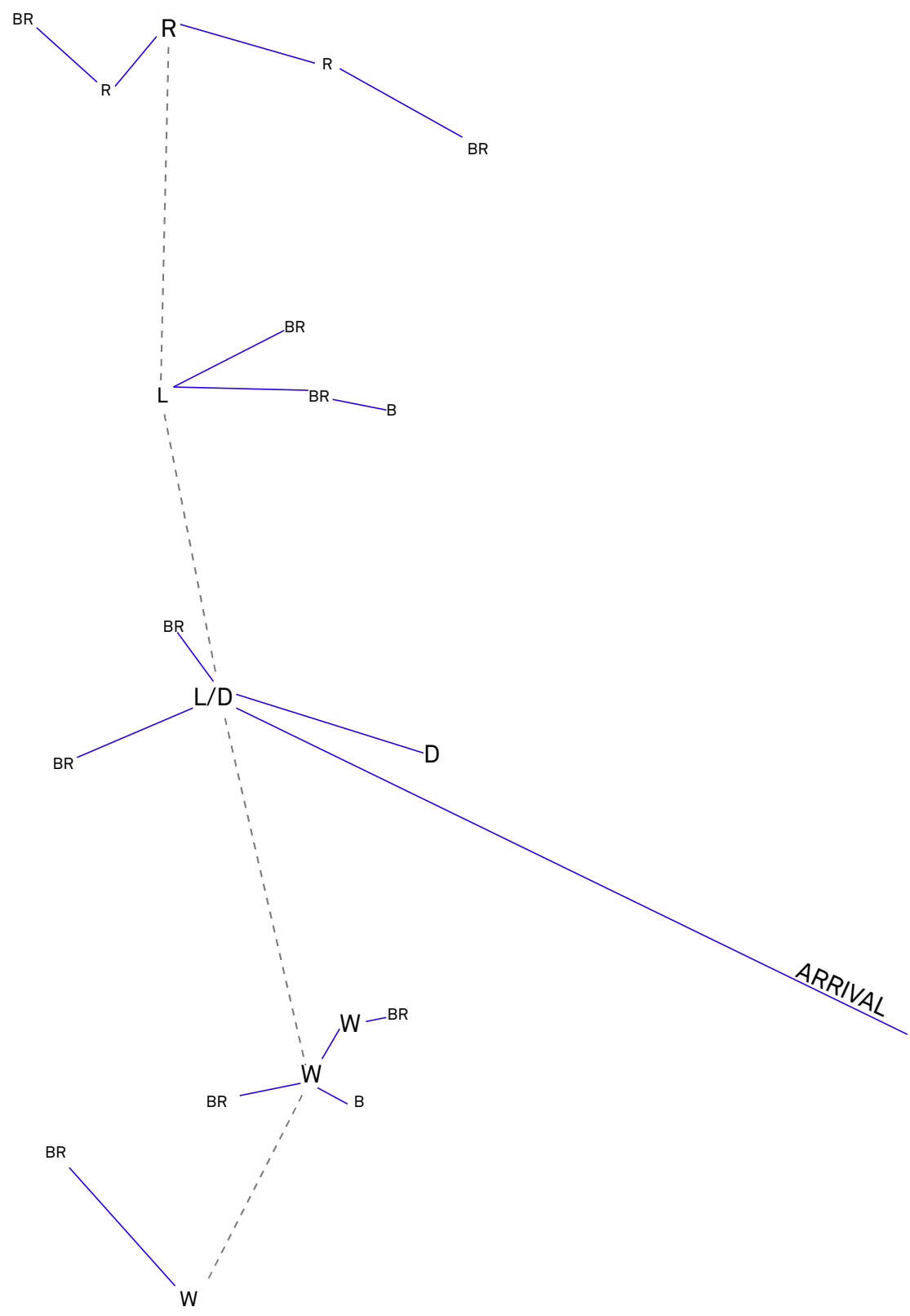

$\begin{array}{lll} & & \\ & & \text { SERTICALAXIS } \\ \mathrm{R} & & \text { RESTING } \\ \mathrm{L} & \text { LIVING } \\ \mathrm{L} / \mathrm{D} & & \text { LIVING/DINING } \\ \mathrm{W} & \text { WORK } \\ \mathrm{B} & \text { BATHROOM } \\ \mathrm{BR} & \text { BREAKS }\end{array}$




\subsection{Stage \#2: Choreographing the Spatial Framework}

Once the attractors are determined in the composition, they undergo a transformation from an abstract notion of points to a three-dimensional spatial framework using an emergent design process. This process begins by assessing the focal points in space on a level, forming planes derived from human body movements based on the intended activity, followed by re-organizing the planes in three-dimensions, using the focal points as a spatial reference (Fig. 71). The framework is comprised of vertical and horizontal planes that separate, structure and organize the activities of human spatial behavior. Its role is critical for initiating the beginning stages of the choreography along with serving as a foundation for the final layer of the composition referred to as Kinesthetic Components, examined later.

1. Focal Points

(BR) W B

W
2. Movements

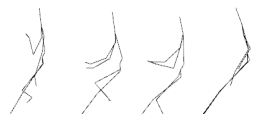

$\Uparrow$

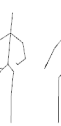

12

$+1$

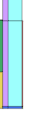

3. Orientate

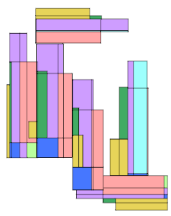

4. Explode
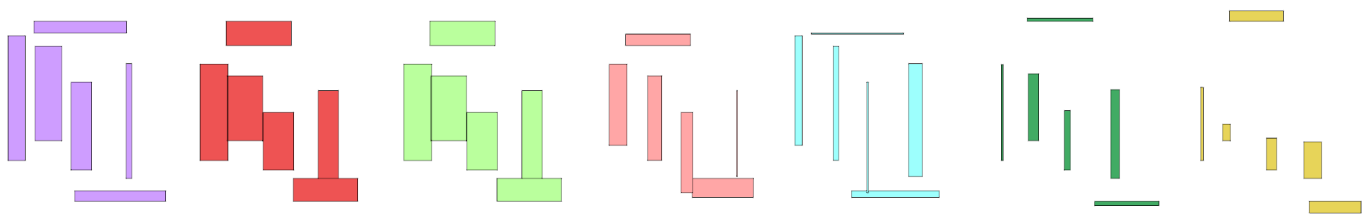

\section{Assemble}
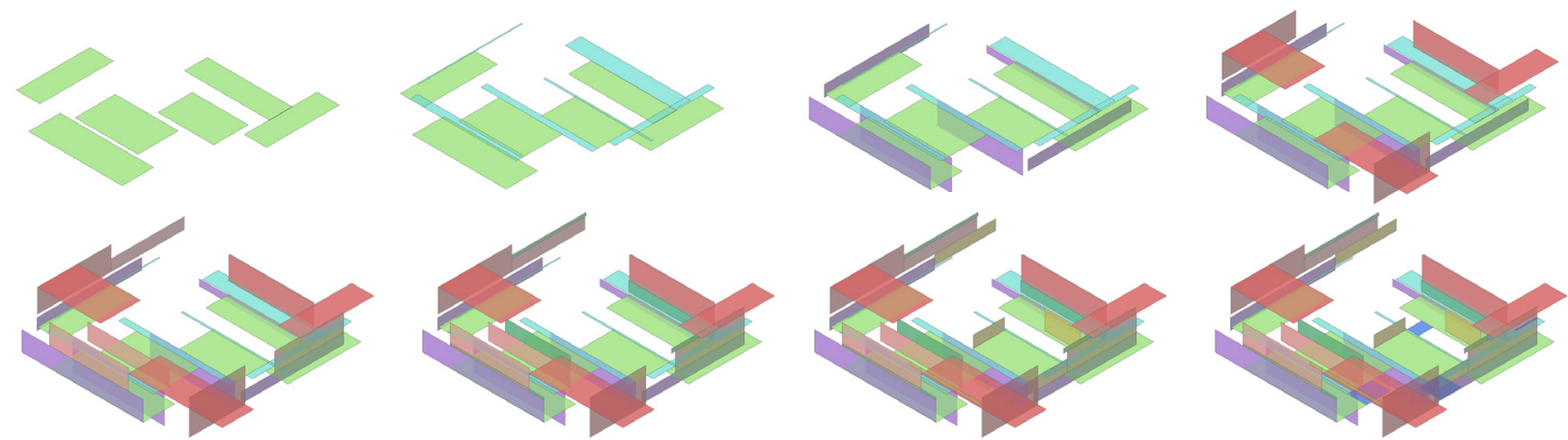

(Above) Fig. 71: Process of Choreographing the Spatial Framework

(Right) Fig. 72: Stage\#2 - Choreographing Spatial Framework 


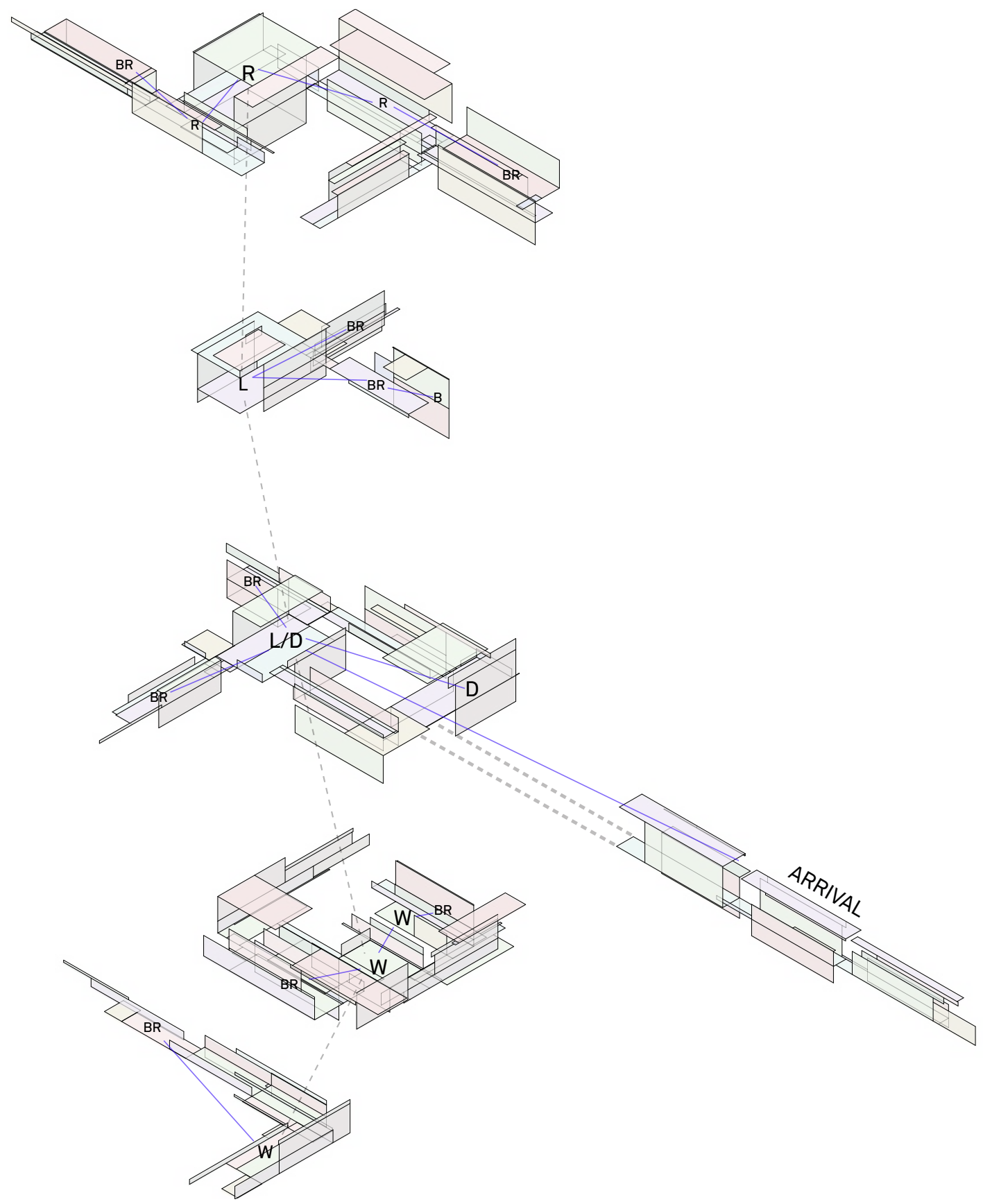

$\begin{array}{lll} & & \\ & & \text { SERTICALAXIS } \\ \mathrm{R} & & \text { RESTING } \\ \mathrm{L} & \text { LIVING } \\ \mathrm{L} / \mathrm{D} & & \text { LIVING/DINING } \\ \mathrm{W} & \text { WORK } \\ \mathrm{B} & \text { BATHROOM } \\ \mathrm{BR} & \text { BREAKS }\end{array}$




\section{Parameters of the Spatial Framework}

The spatial framework of the architecture is developed through an emergent process grounded in the proportions of the human body. Eight parameters were devised based on the relationship between parts of the body that are not physically connected, but rather could share a virtual connection. These relationships include the following: the head to right foot, head to left foot, left shoulder to left foot, left hand to left foot, left foot to right foot, right foot to right shoulder, right hand to right foot and right shoulder to left foot (Fig. 74). The two body parts that share a connection with another act as two opposing corner points that formulate a rectangular plane (Fig. 73). As the body moves, the height and width of the two-dimensional plane will change accordingly and thus generating eight unique planes simultaneously from one body movement. This method unveils the richness of human kinesis mediated through architecture and the dynamic relationship between parts of the human body in movement.

For each level in the architecture, movements based on activities are selected to generate an array of planes to use for their designated zone. For instance, movements of writing, reading and typing are chosen to generate the framework for the lower work zones. Once the planes are created, they are organized along the focal points established in the earlier stages of choreography. The planes then begin reassembling in space to formulate virtual walls and floors within the designated level (Figs.75-79). Thus, each level is defined by the richness of movements that make up our daily routine of habitation. This method explores how our movements of habitation could formulate a spatial framework and unleash a potential for human kinesis to shape our architecture.
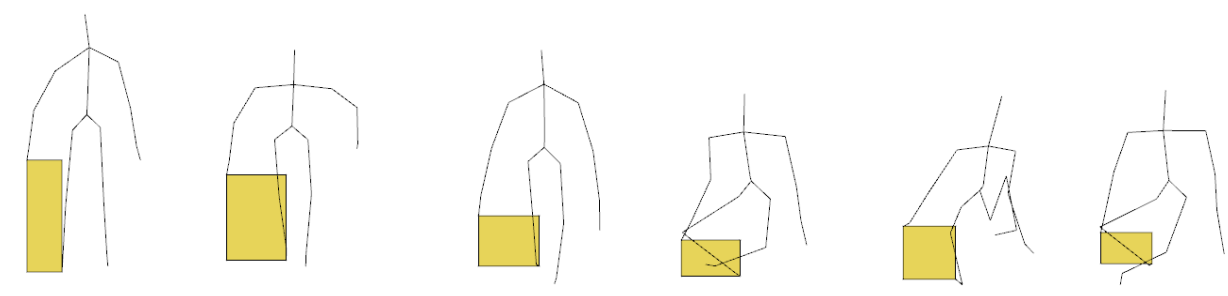

(Above) Fig. 73: Diagram above illustrates the variation of planes produced from one relationship: the hand and foot.

(Right) Fig. 74: Diagram on the right showcases the parameters derived for the Spatial Framework. Points from the body define the proportion of a plane. Eight components are produced simultaneously as the body engages in movement every 20 milliseconds. 
Geometry

Plane - Body Joints

\begin{tabular}{|c|c|}
\hline Plane \#1 - Red & $\begin{array}{l}\text { Head } \\
\text { Right Foot }\end{array}$ \\
\hline Plane \#2 - Light Green & $\begin{array}{l}\text { Head } \\
\text { Left Foot }\end{array}$ \\
\hline Plane \#3 - Turquoise & $\begin{array}{l}\text { Left Shoulder } \\
\text { Left Foot }\end{array}$ \\
\hline Plane \#4 - Purple & $\begin{array}{l}\text { Left Hand } \\
\text { Left Foot }\end{array}$ \\
\hline Plane \#5 - Dark Green & $\begin{array}{l}\text { Left Foot } \\
\text { Right Foot }\end{array}$ \\
\hline Plane \#6 - Yellow & $\begin{array}{l}\text { Right Hand } \\
\text { Right Foot }\end{array}$ \\
\hline Plane \#7 - Blue & \begin{tabular}{|l|} 
Right Foot \\
Right Shoulder
\end{tabular} \\
\hline Plane \#8 - Pink & $\begin{array}{l}\text { Right Shoulder } \\
\text { Left Foot }\end{array}$ \\
\hline
\end{tabular}


Lower Level

Working

Focal Points

(BR

W

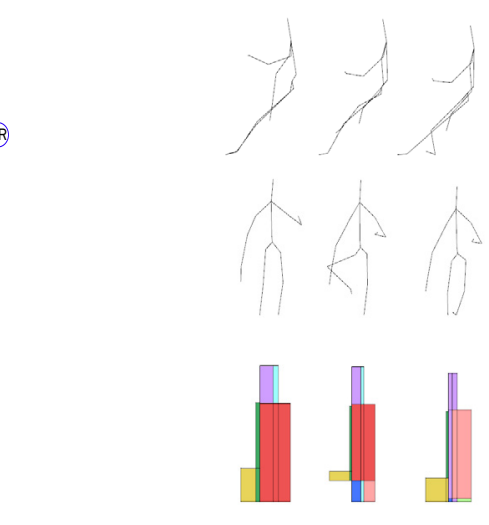

Movements

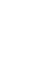

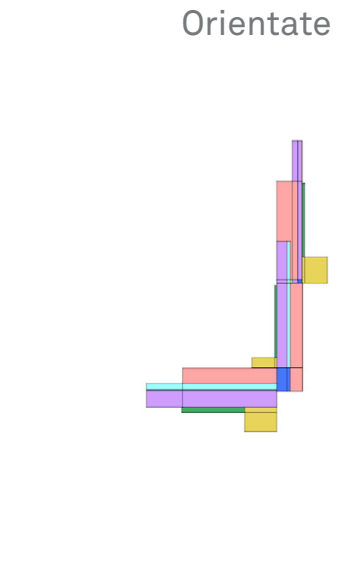

\section{Assemble}
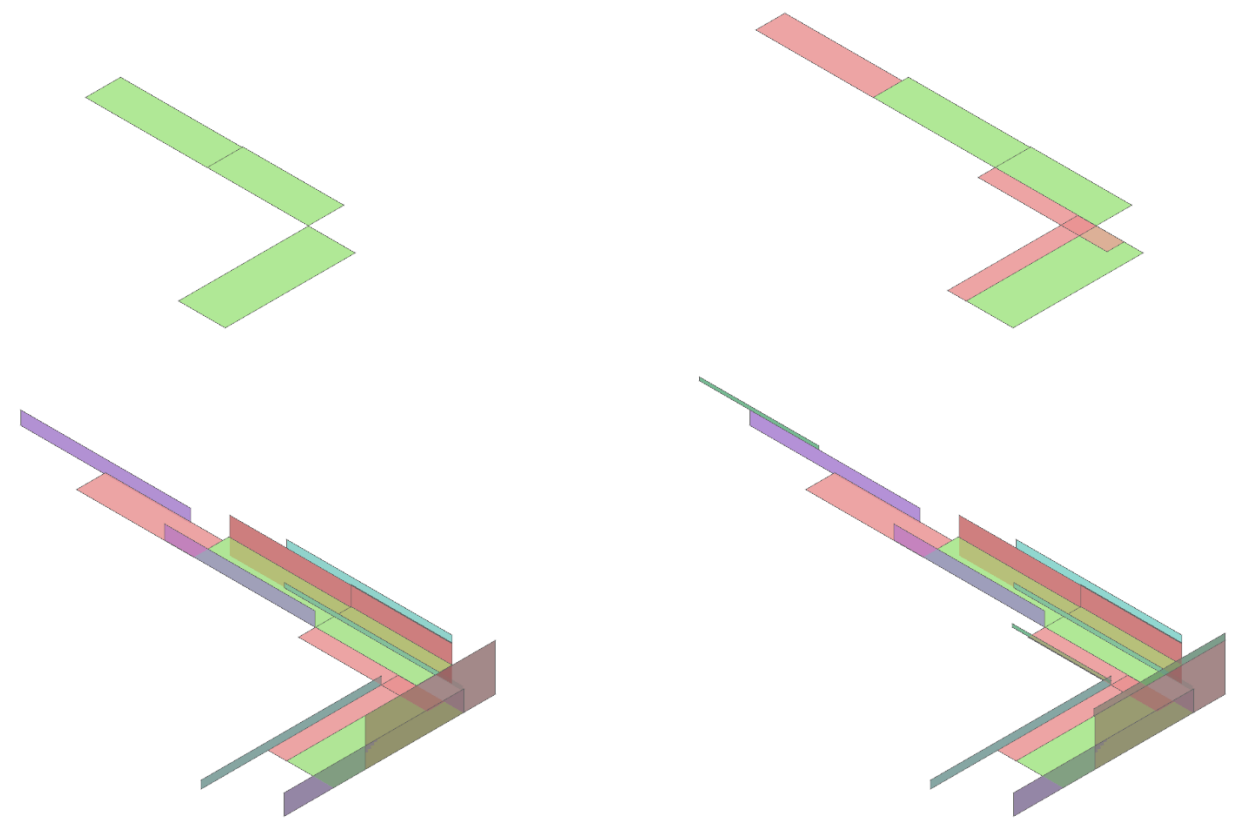

Fig. 75: Stage\#2 - Choreographing the Spatial Framework (Lower Level) Geometry is generated from working movements including reading, writing and typing. 


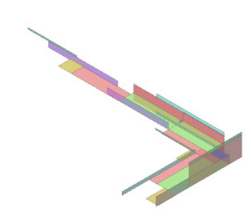

Explode
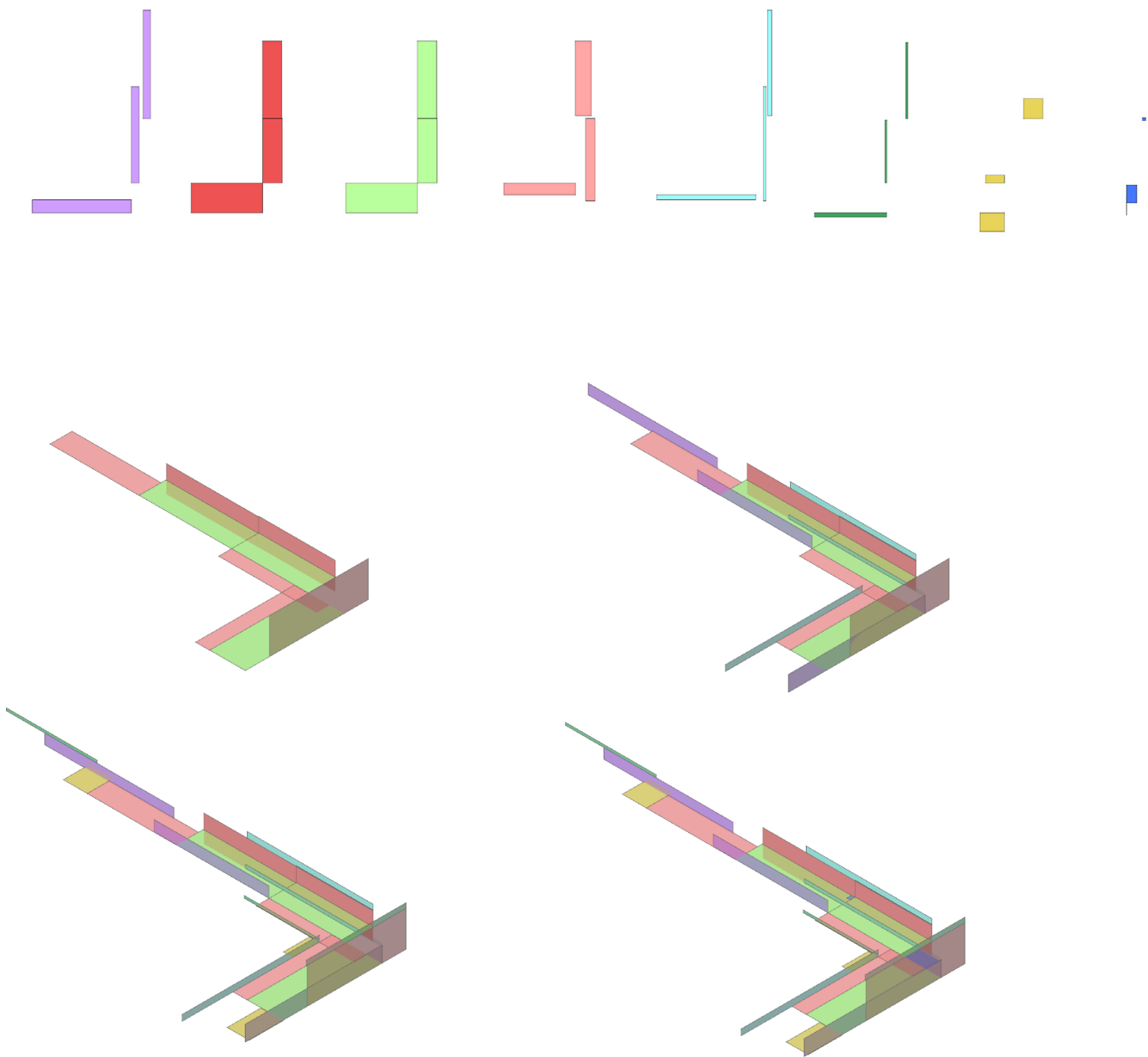
Lower Level

Working
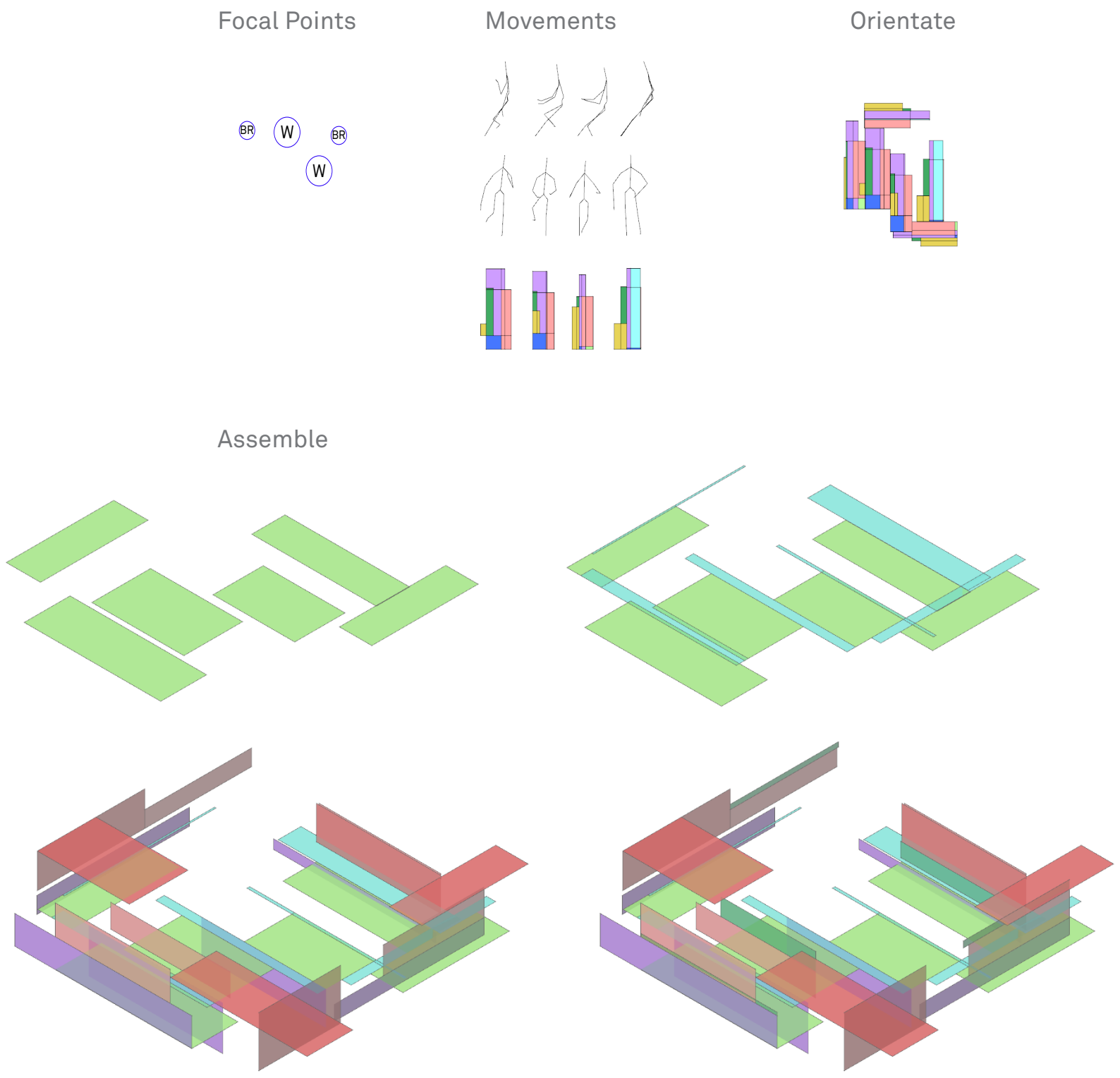

Fig. 76: Stage\#2 - Choreographing the Spatial Framework

(Lower Level) Geometry is generated from working movements

including reading, writing and typing. 


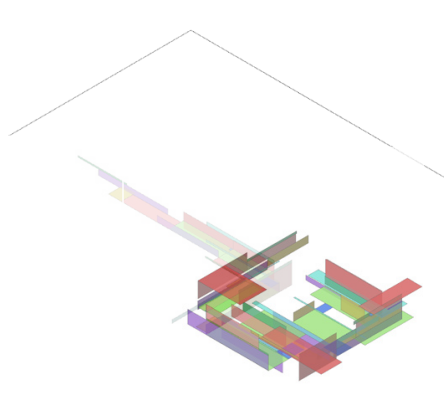

Explode
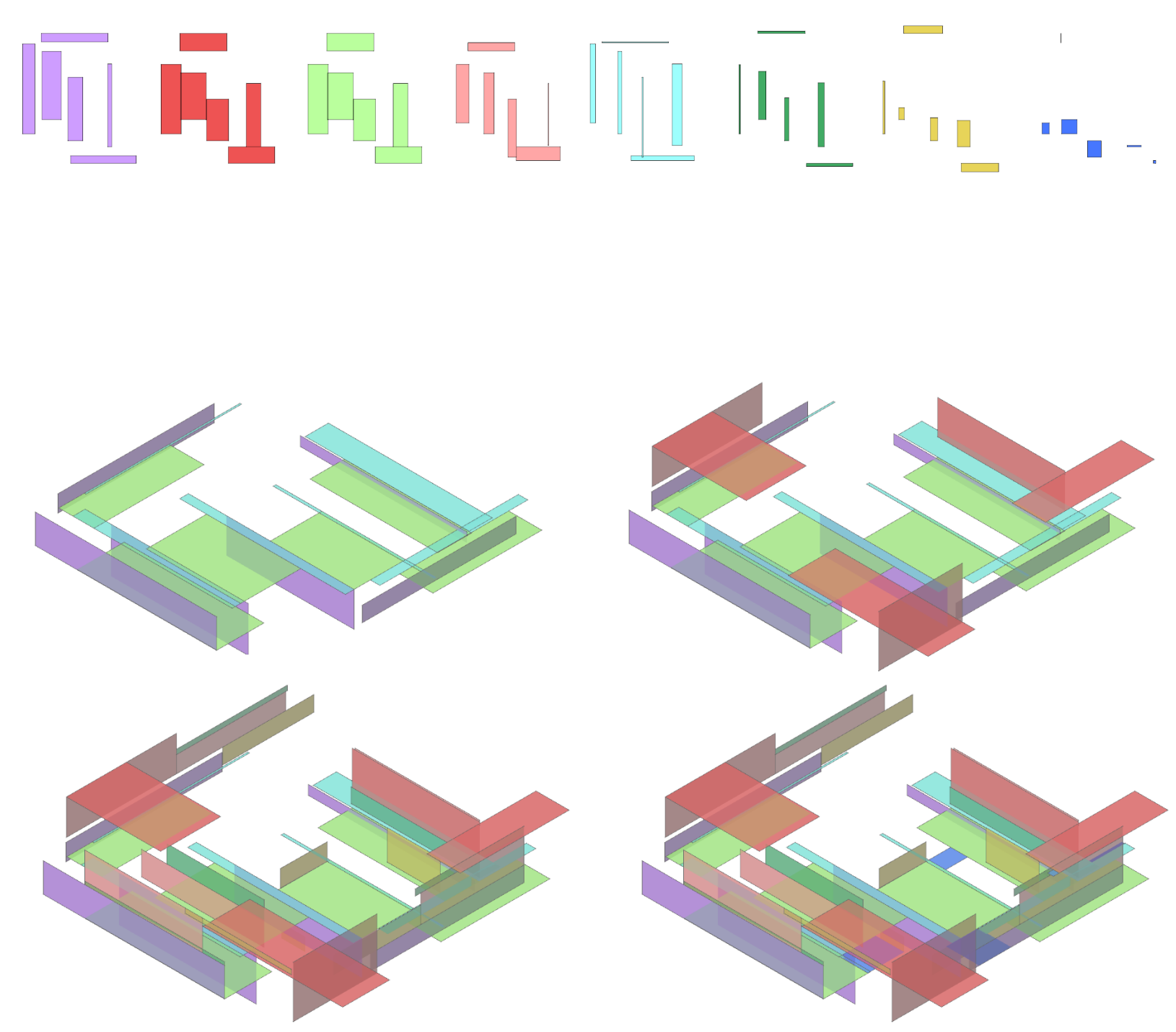
Main Level

Living \& Dining

Focal Points

(BR)

(BR) L/D
Movements

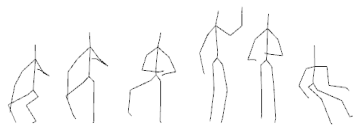

(D)

\section{Orientate}

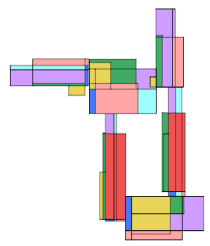

\section{Assemble}
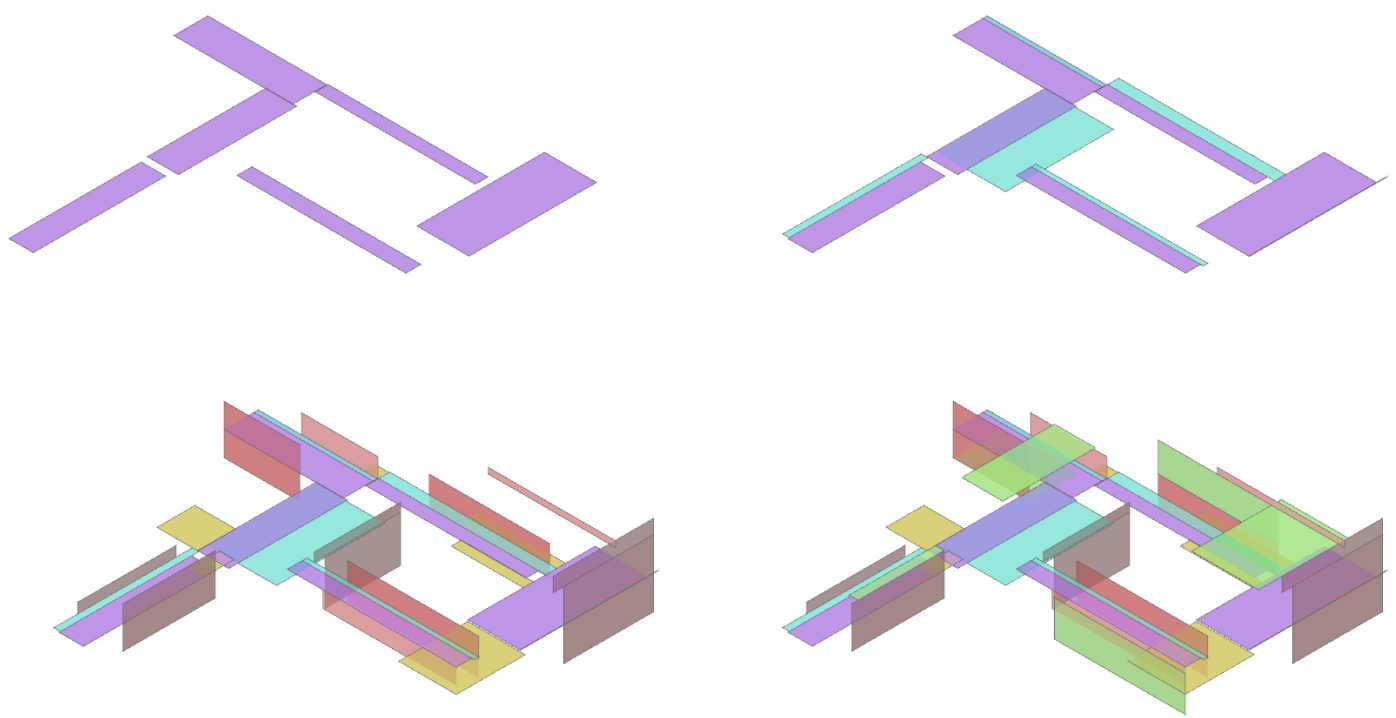

Fig. 77: Stage\#2 - Choreographing the Spatial Framework

(Main Level) Geometry is generated from movements carried out in

the living and dining room. 


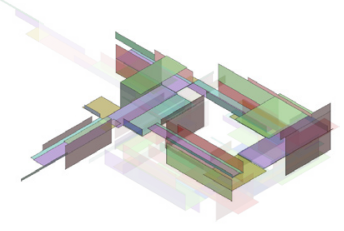

Explode
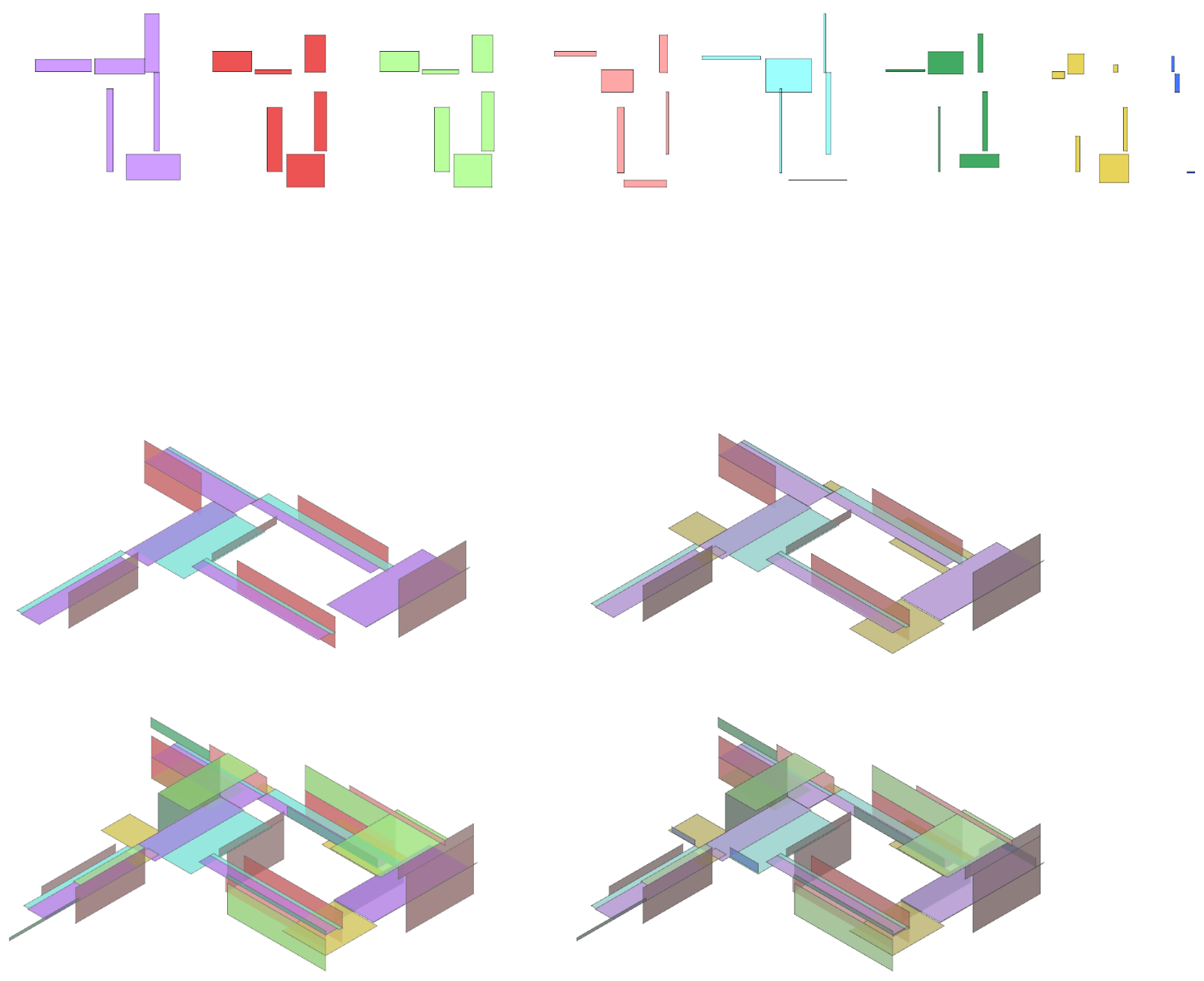
Second Level

Living
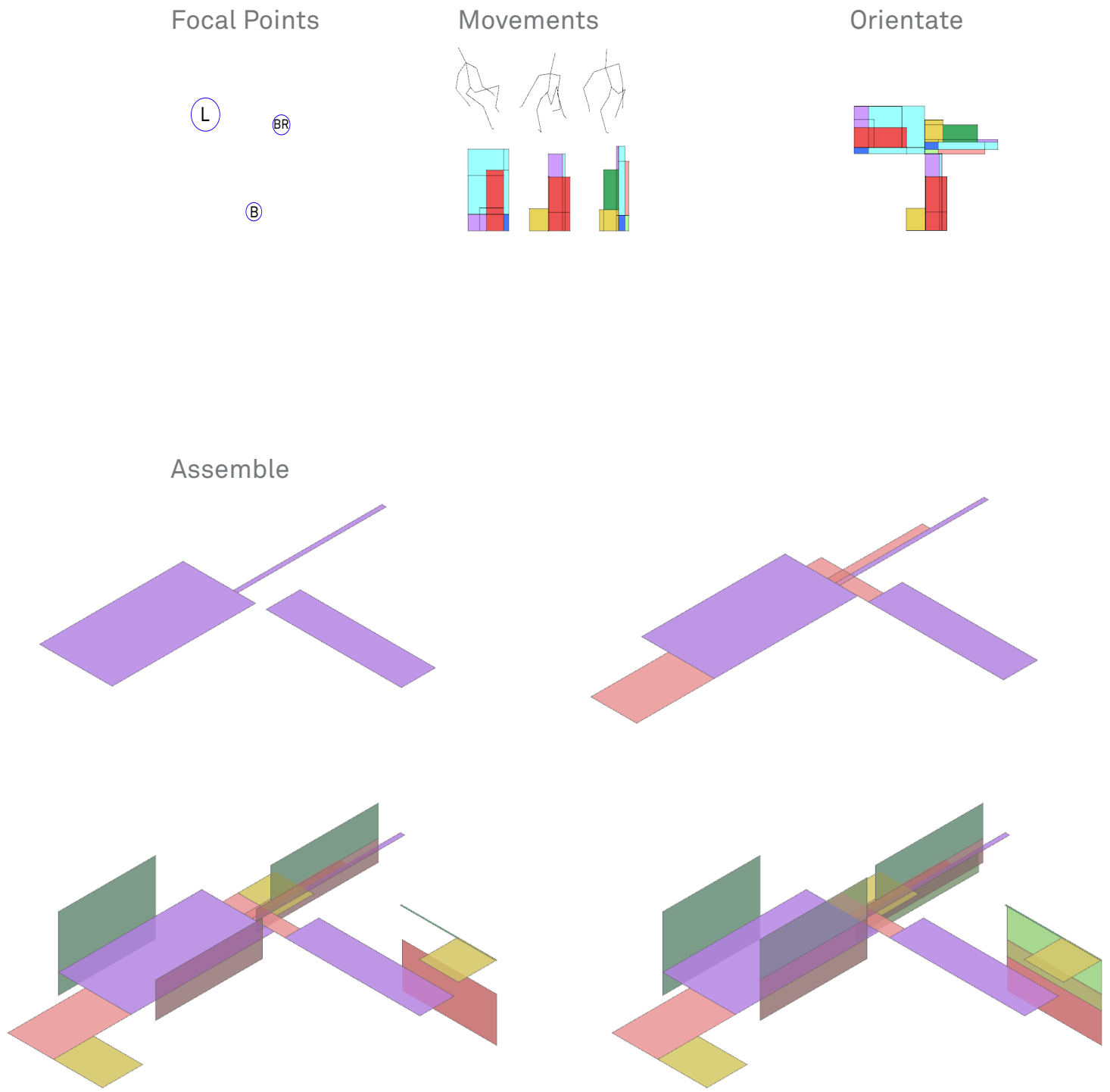

Fig. 78: Stage\#2 - Choreographing the Spatial Framework

(Second Level) Geometry is generated from movements carried out in the living room. 


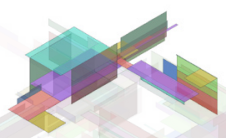

Explode

$\square+\square+\square+\square+\square+\square$
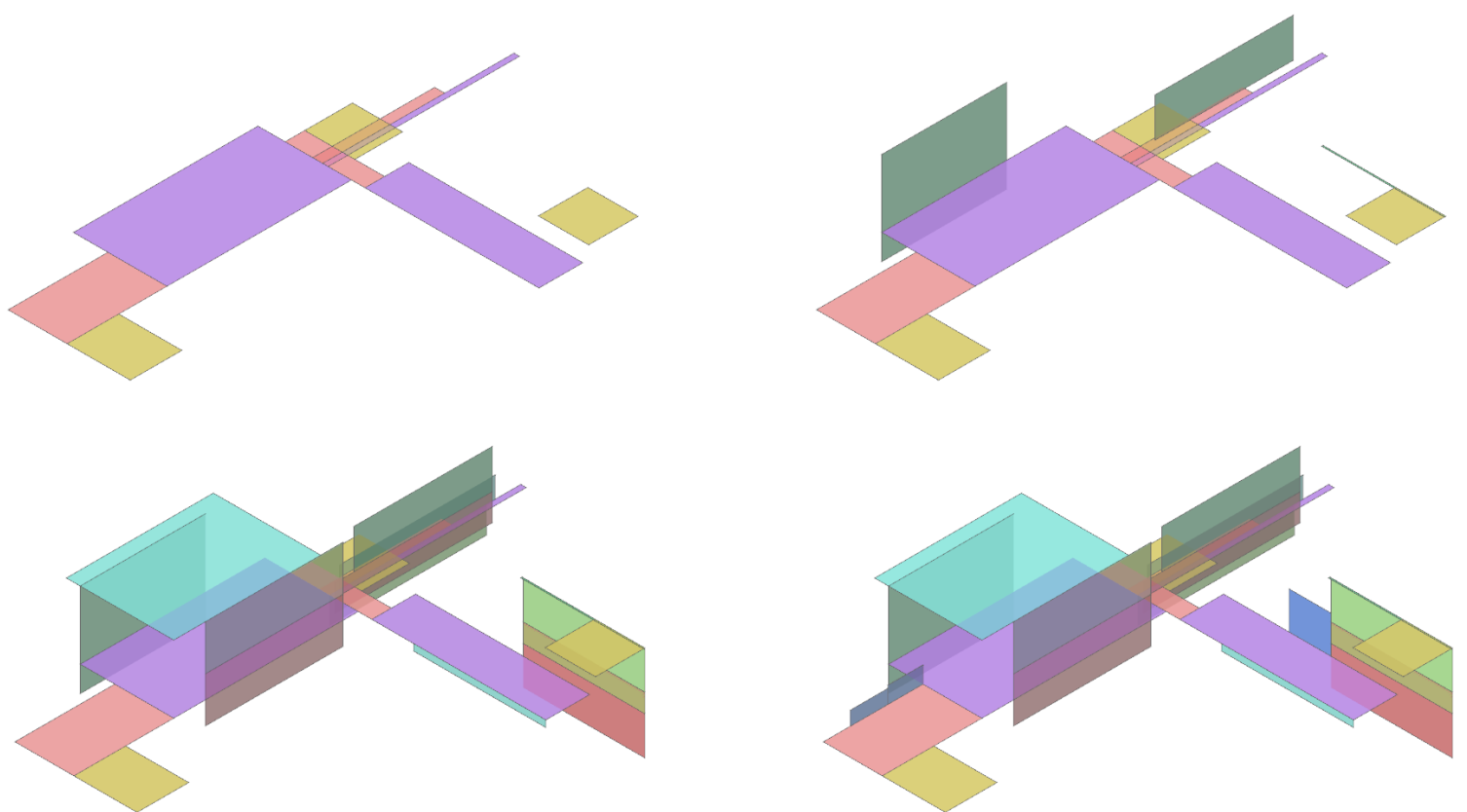
Third Level

Resting

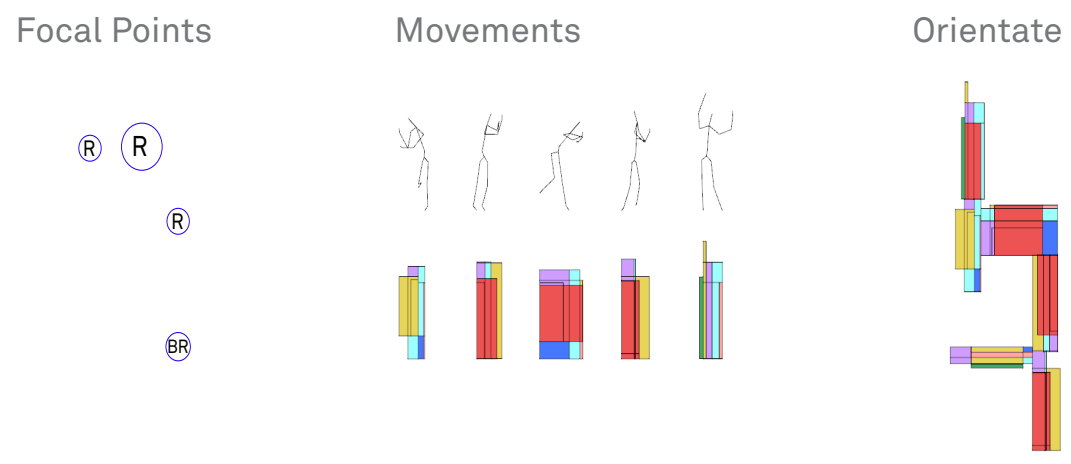

Assemble
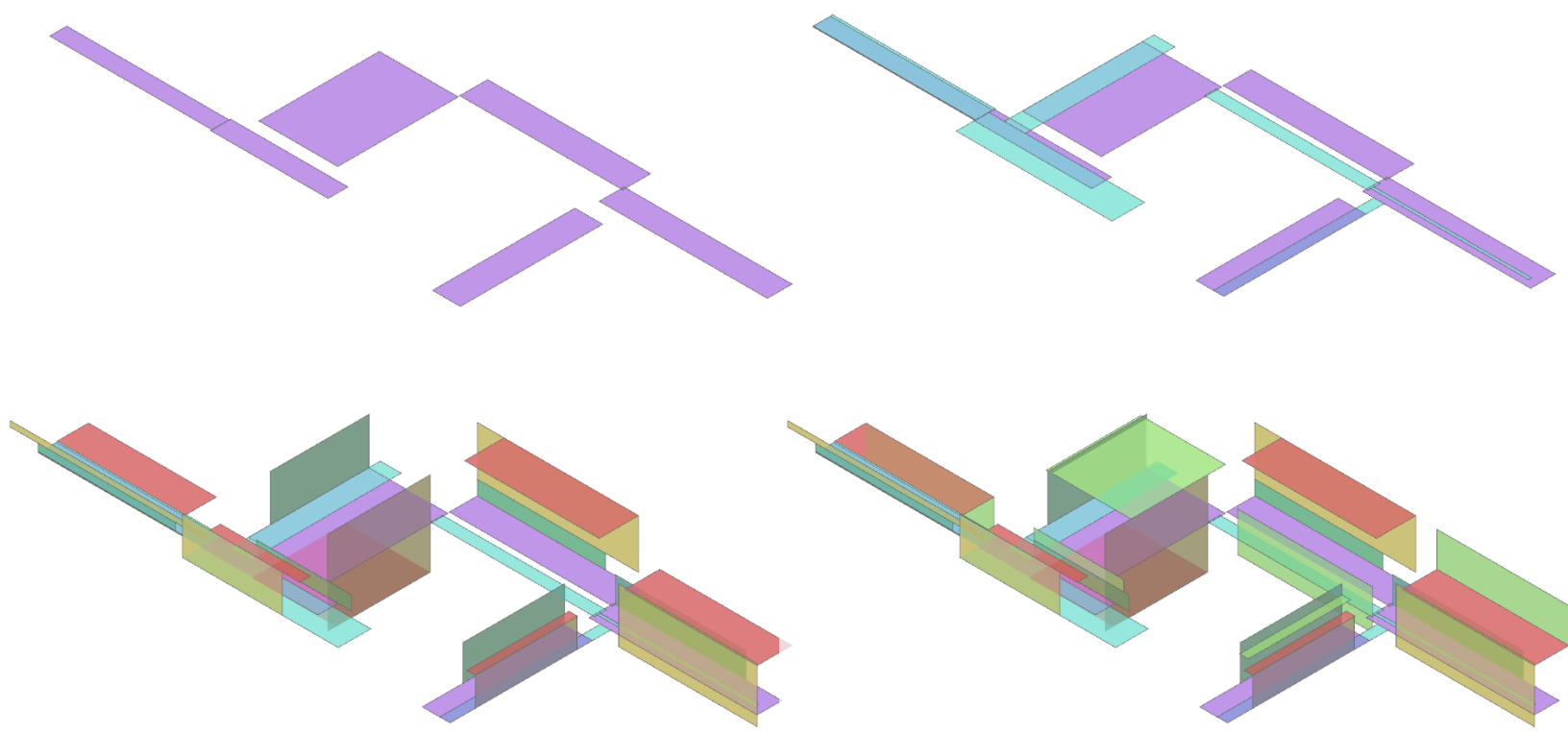

Fig. 79: Stage\#2 - Choreographing the Spatial Framework

(Third Level) Geometry is generated from movements carried out

while sleeping/resting in bed including stretching and rolling. 


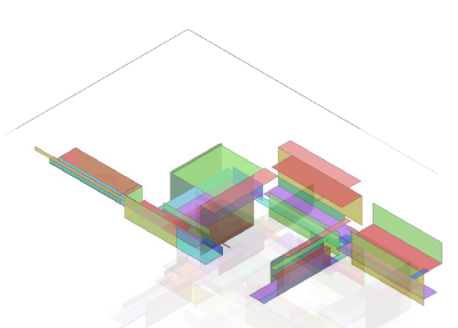

Explode
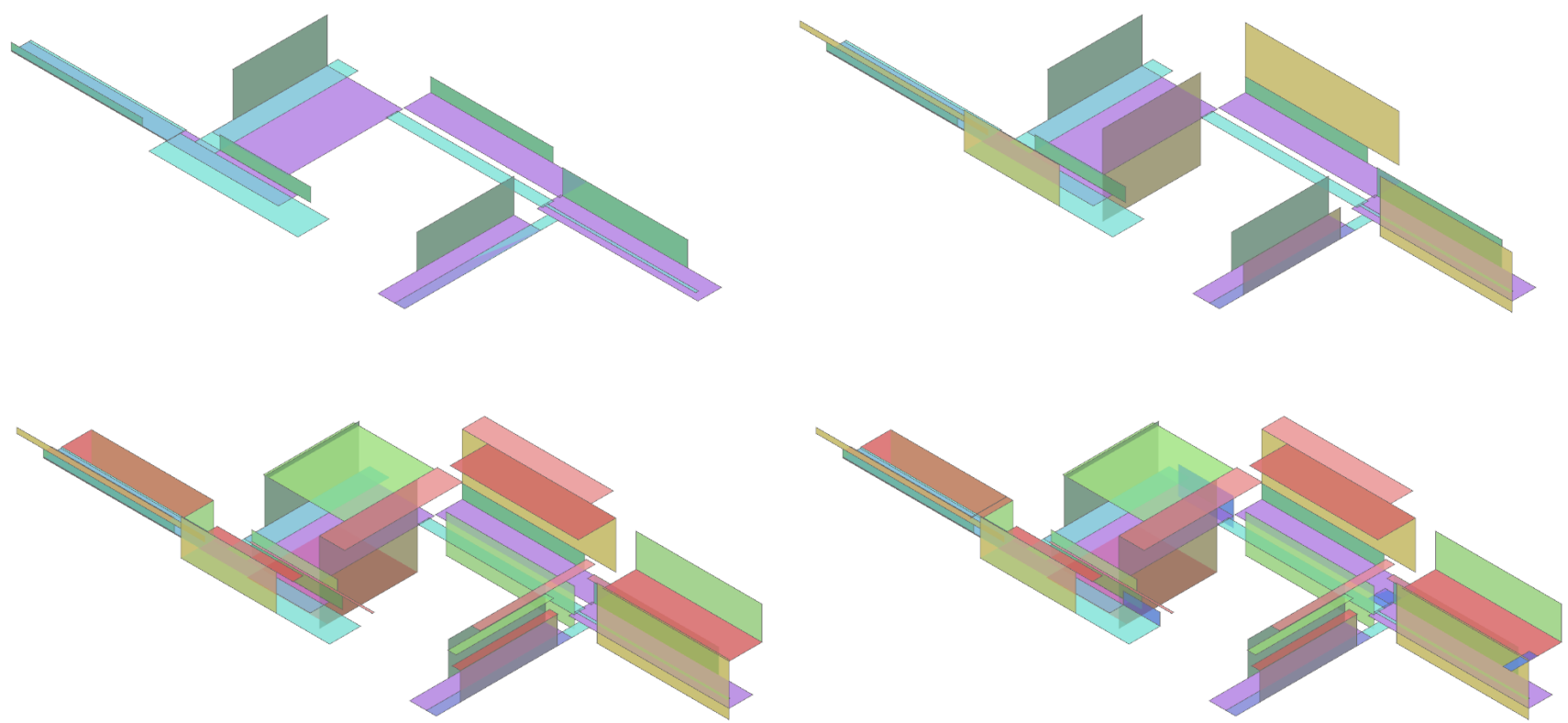


\subsection{Stage \#3: Choreographing Kinesthetic Components}

The framework serves as a spatial organizer of activities but requires an additional layer of geometry designed to provoke the dweller's kinesthetic senses when experiencing the architecture. The link between space and the kinesthetic sense is defined as an internal physical sensation of motion and engagement while interacting with space, known as the phenomenon of kinesthetic empathy (Hunter \& Victoria, 2009). In his book, The Architect's Brain, architect and theorist, Harry Francis Mallgrave (2011), discusses this liaison between our bodies with our world from the perspective of Juhani Pallasmaa:

In the case for bodily identification, every architect and spectator 'internalizes a building in his body,' when 'movement, balance, distance and scale are felt unconsciously through the body as tension in the muscular system and in the positions of the skeleton and inner organs.' Therefore, 'understanding architecture implies the unconscious measuring of an object or a building with one's body, and projecting one's bodily scheme on the space in question' (p.121).

This feeling of internalized motion can be associated with the physical aspects of scale and shape, eliciting the body in the appreciation of a form's size and character. For instance, if a building possesses an unbalanced formal expression, the inhabitant would react with a physical sensation of uneasiness as it upsets his or her bodily balance. Similarly, a kinesthetic feeling is induced when standing at the base of a large atrium, looking up through a central void to a large skylight above. A sense of motion and bodily awareness is invoked, permitting comparison of the scale of the structure with our own human form. Yi-Fu Tuan in Topophilia (1974) claims that the very words we use to explain our built and natural environments imply a kinesthetic relationship:

The existence of a kinesthetic relationship between certain physical forms and human feelings is implied in the verbs we use to describe them. For example, mountain peaks and man-made spires 'soar', ocean waves as well as architectural domes 'swell' (p. 29).

Tuan's and Pallasmaa's discussion of a kinesthetic relationship between dweller and built form is critical as it highlights the existence of a bodily phenomenon that relies on physical sensations and awareness; this feeling we encounter unveils the power of visual and formal factors that constitute our built environments. The kinesthetic experience can therefore contribute to the list of factors (psychological, sensory, cognitive and spatial) that a play a role in the experience of space and ultimately explain why people perceive their environments differently through a “process of experiencing" (Hunter \& Victoria, 2009). 



\section{Parameters of the Kinesthetic Components}

Understanding the importance of kinesthetic senses, this stage of choreography undergoes an emergent process to create spatial elements based on the proportions of the moving human body. Similar to developing the spatial framework, the Kinesthetic Components utilize the same relationships between body parts as parameters that drive the geometry. Yet, these components move beyond the two-dimensional plane considering both volume and physical morphing to instill associated feelings of tensions and impulses of motion. The established relationship between the two body parts forms a rectangular prism, as they define the two opposite corners of the three-dimensional volume. Another set of parameters is introduced that begin to re-shape the box using an arc defined by three points from the human body. The three points include the two original points from the volume, serving as the end points of the arc, with a body part located in between the two, acting as the center point of the arc. For instance, the rectangular prism defined by the head and the right foot would be deformed by an arc defined by three points in this order: the head (end point 1), right hand (center point) and right foot (end point 2). The arc serves as a virtual parameter that acts upon the ever-changing distance between the foot and the head. Using the defined parameters illustrated in the diagram to the right (Fig. 81), one movement would generate seven unique volumes that embody both the proportions of the moving body and invisible forces of each motion. 


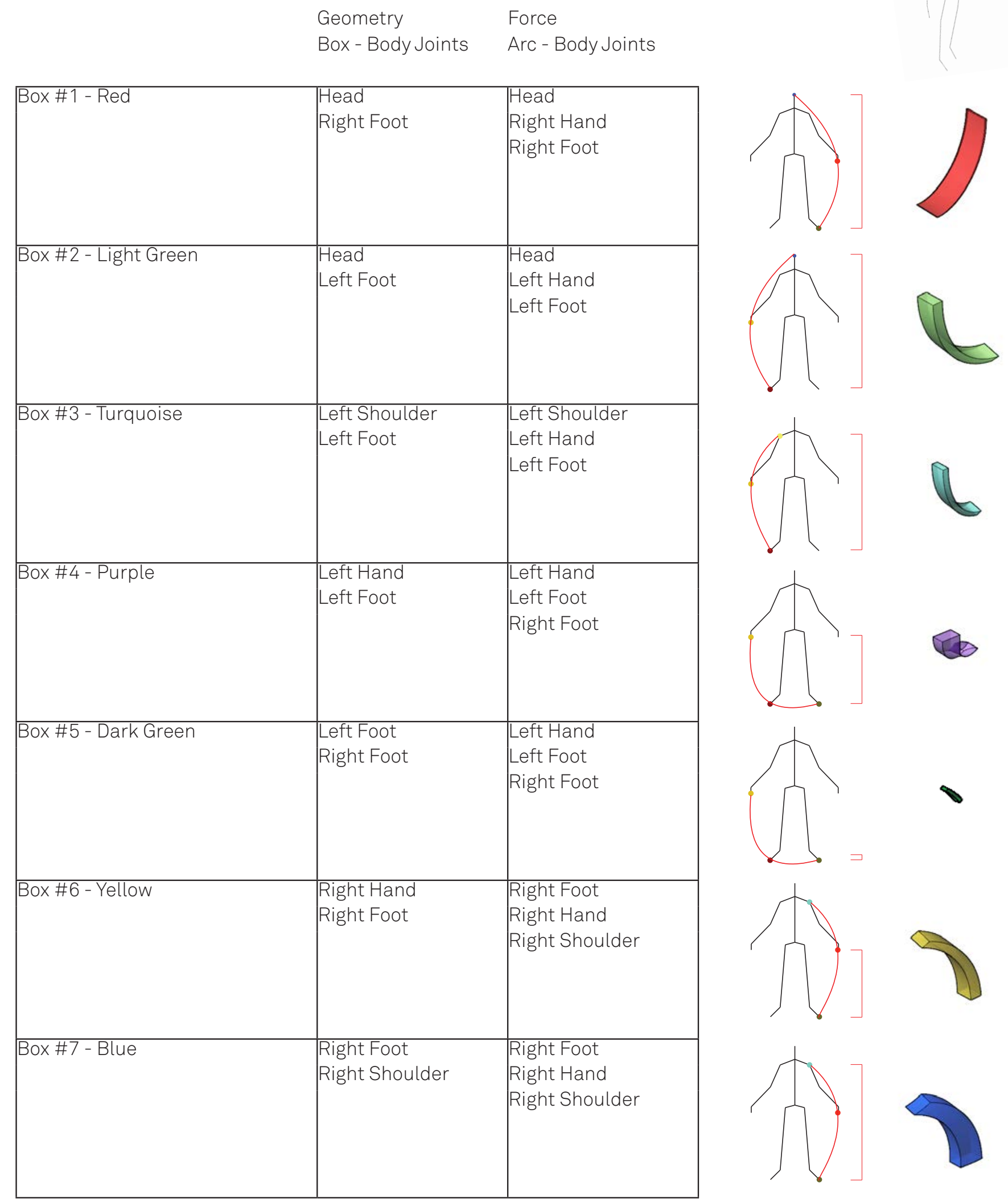


Using these parameters, movements based on the activity of space generate an array of components to be arranged within a designated zone. For instance, movements of sleeping or resting in bed are chosen to generate the Kinesthetic Components for the upper level. Once created, these components are choreographed within the architecture using the spatial framework as a guide for reference. Ultimately, the components carve through space and dissolve the existing planes of the spatial framework. They cluster, sprawl, shift and rotate to form spaces of intimacy and openness, while framing surrounding vistas and alluding to points of transition. Some elements are further refined to allow for more porosity within the space or between the boundary of outside and inside. Surfaces emerge from these elements allowing one to interpret and interact with them when perceived. Therefore, the architecture is geometrically defined by the architect but is transformed into space by the observer.

Fig. 82: Visionary Proposition - Interior Perspective 

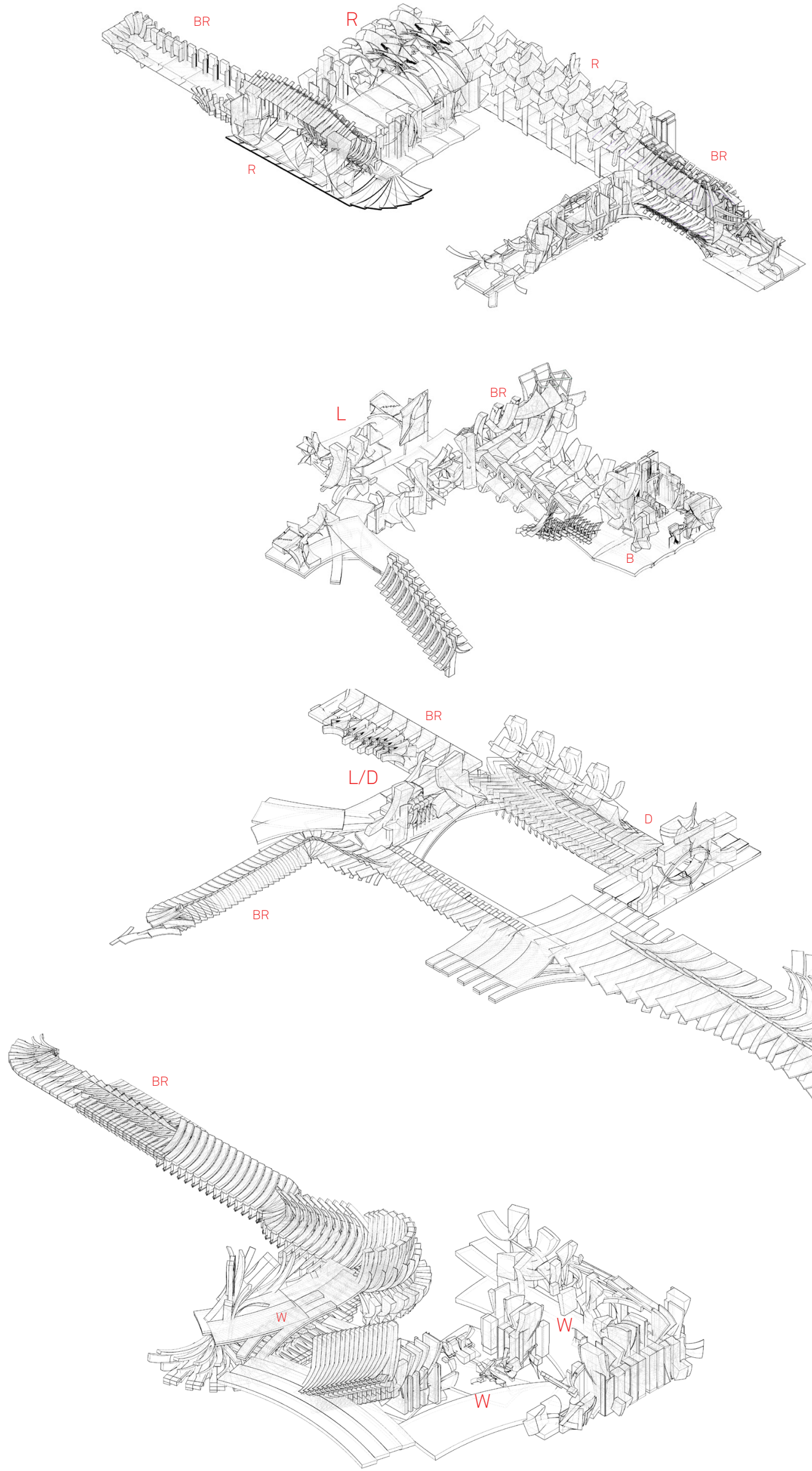

level

(movement type)

third level (rest/sleeping)

second level

(living)

(bathing)

main level

(living)

(dining) lower level

(working) 


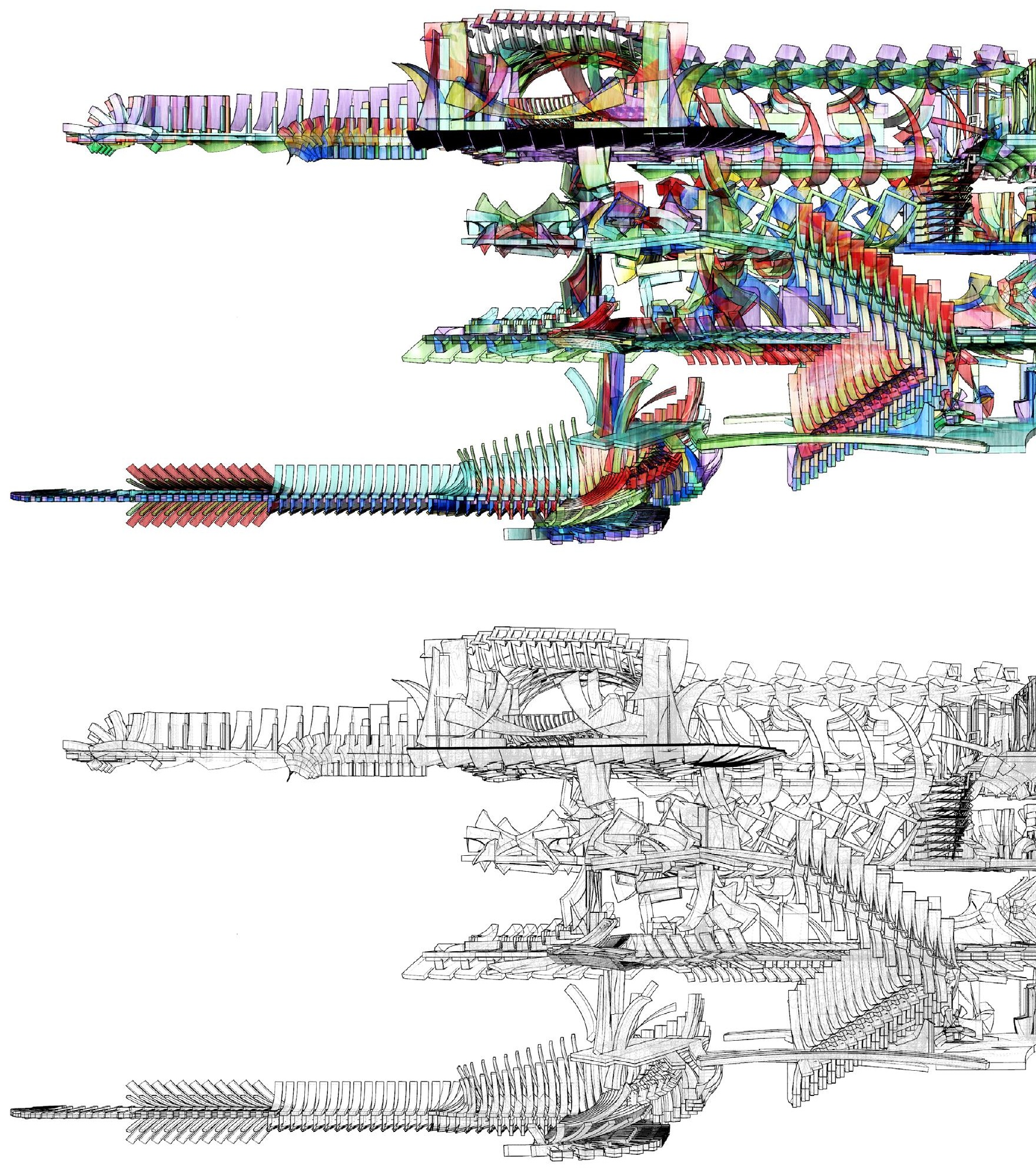




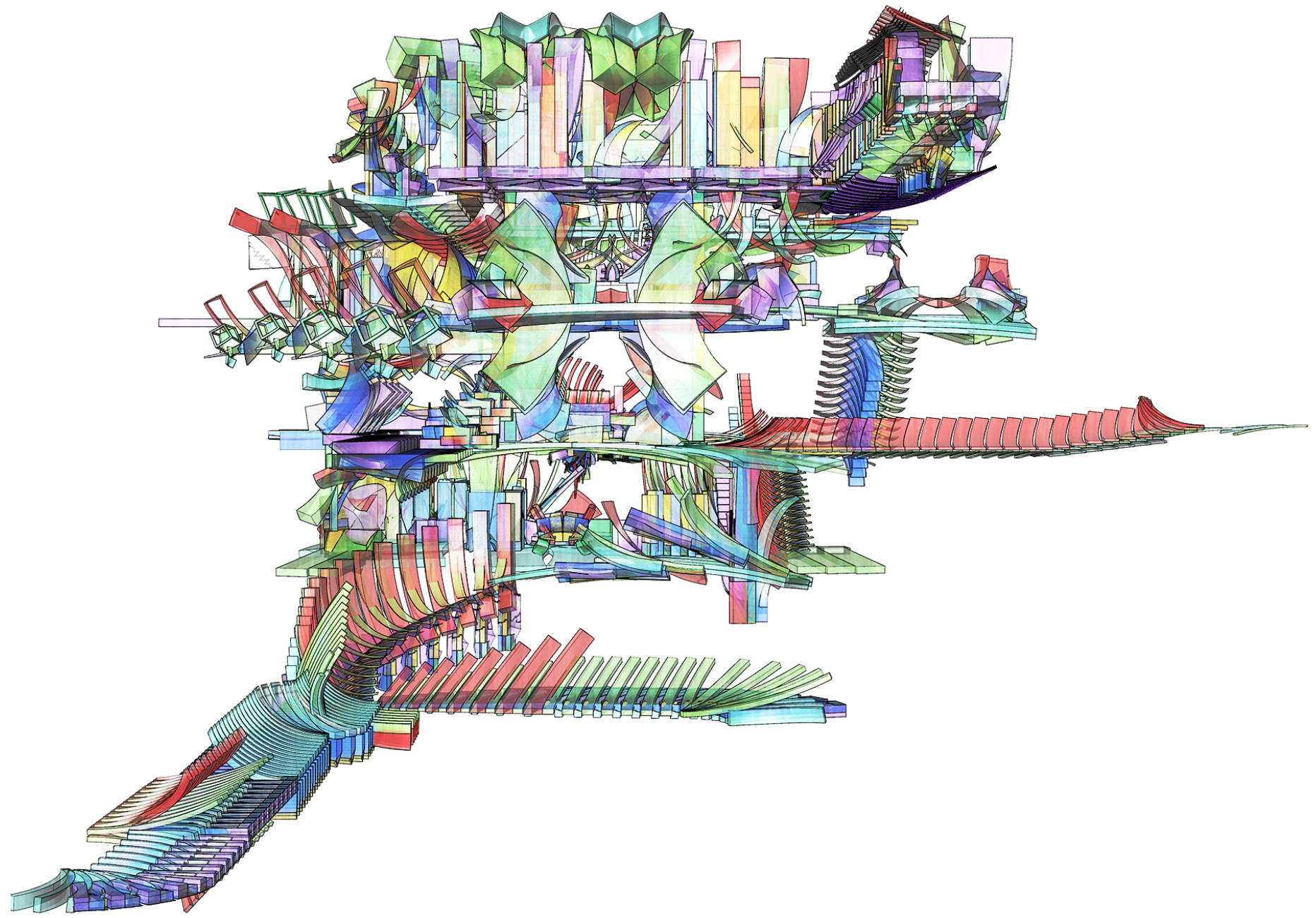




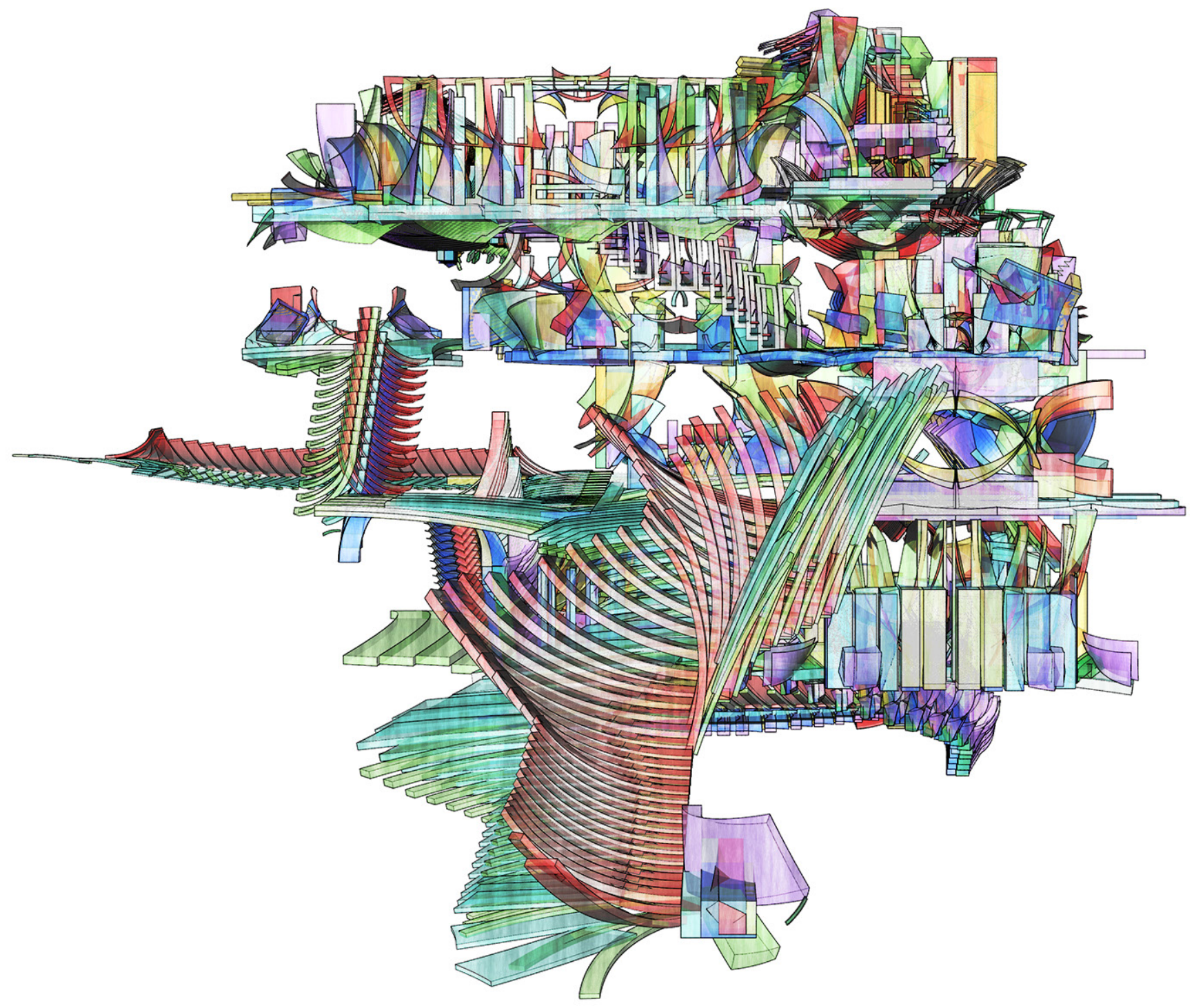


third level

(rest/sleeping)
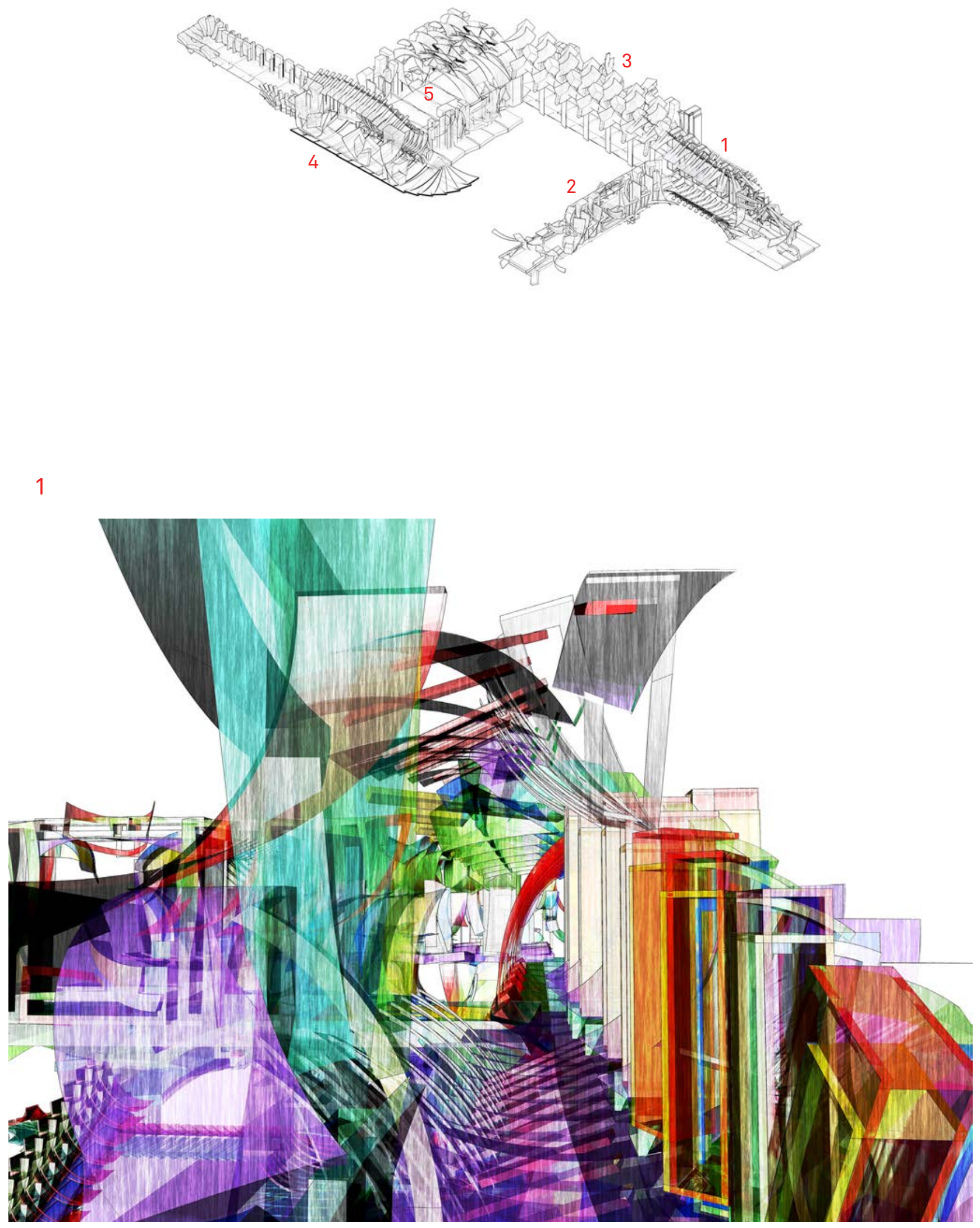


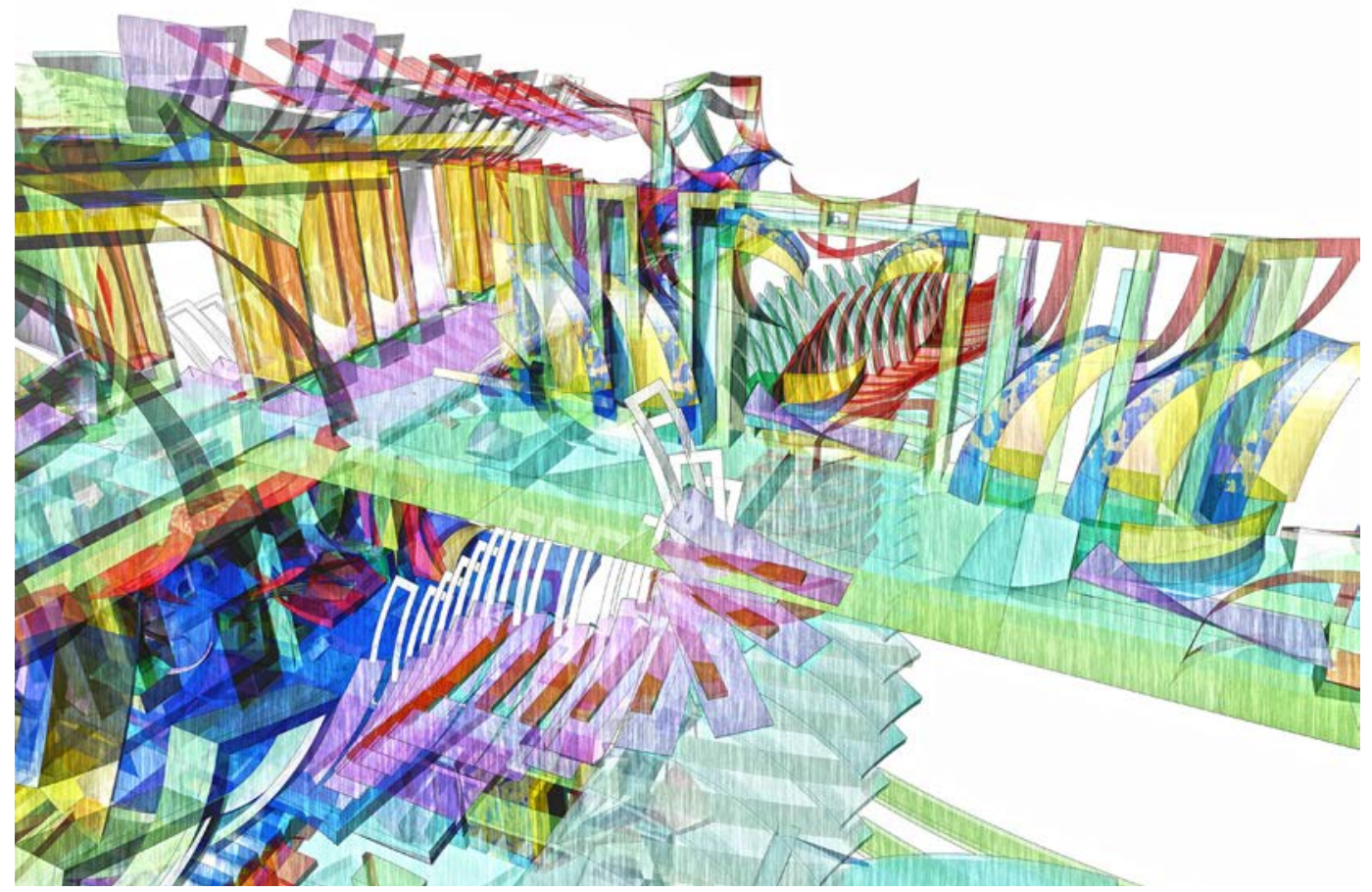

4
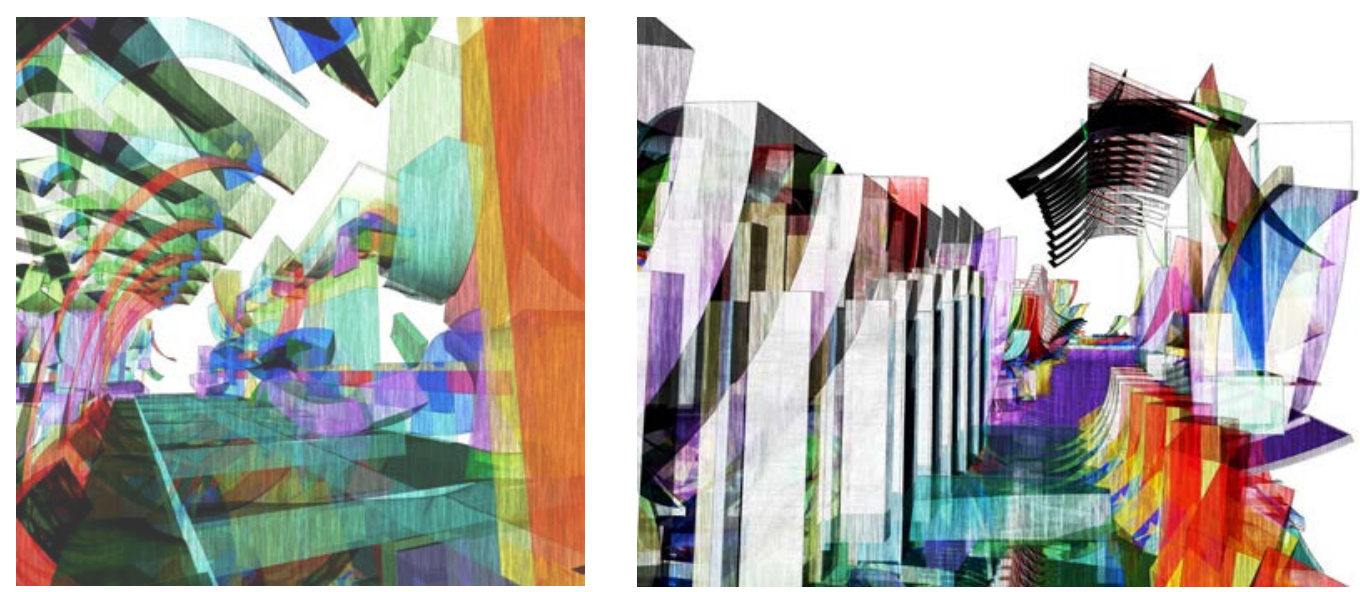

5

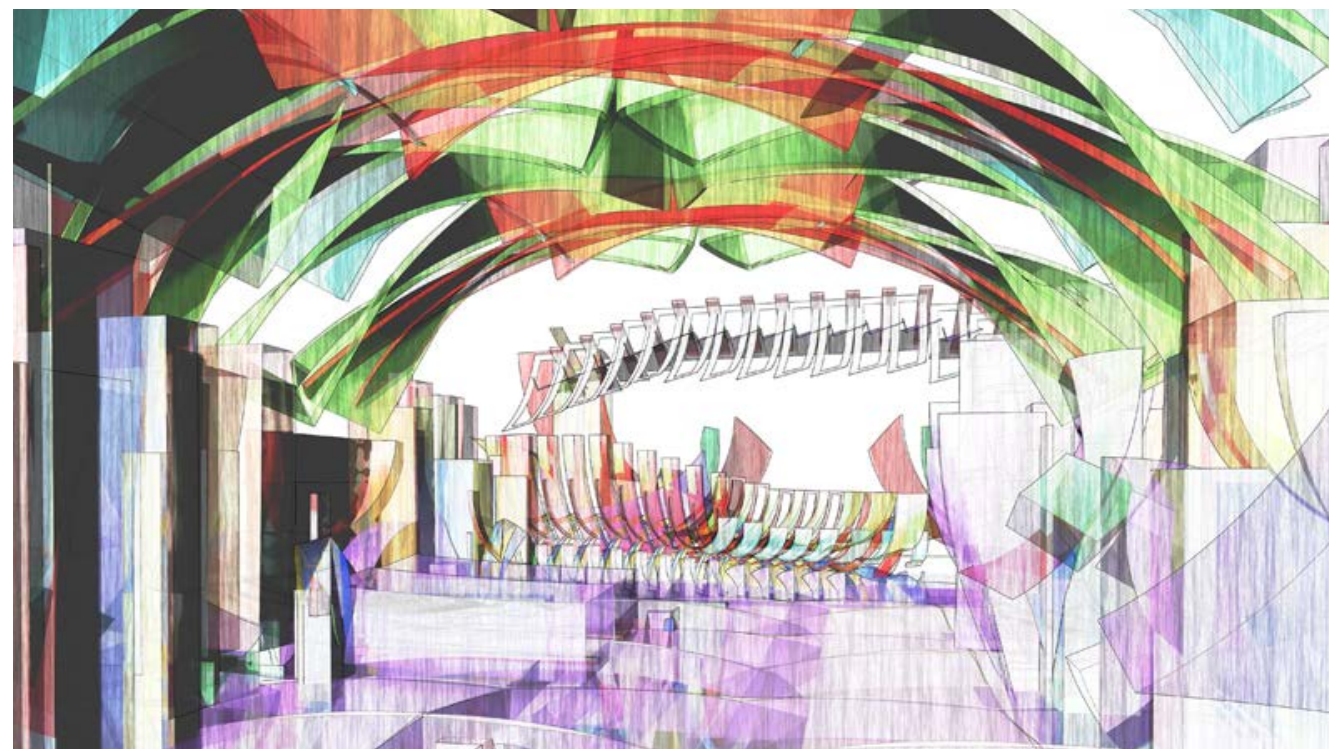




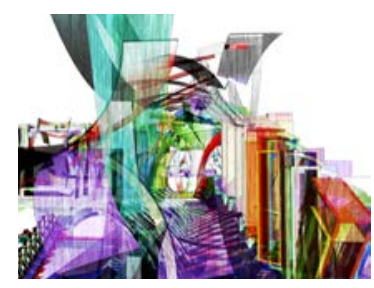

Zoomed in Perspectives of Image 1
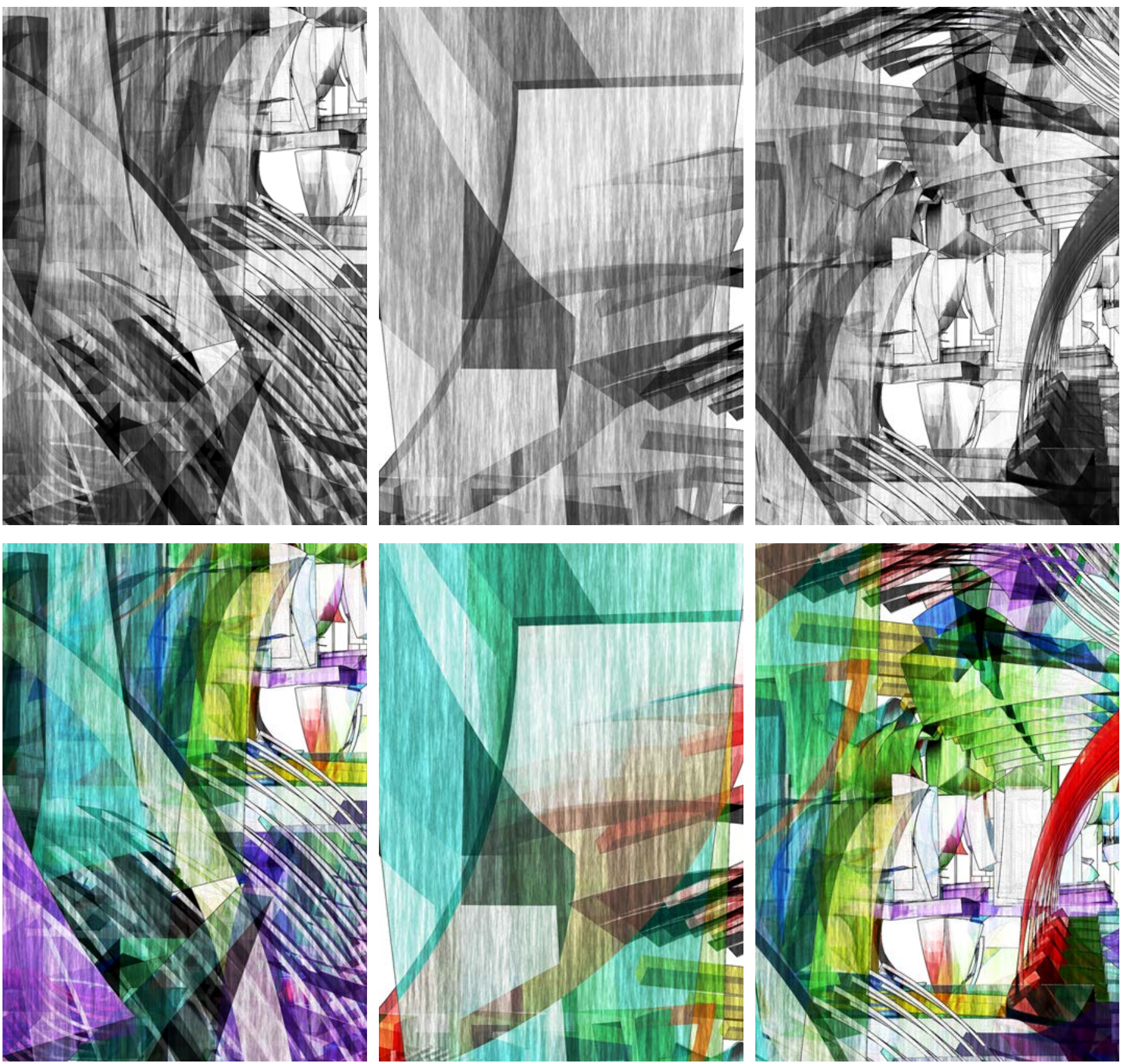

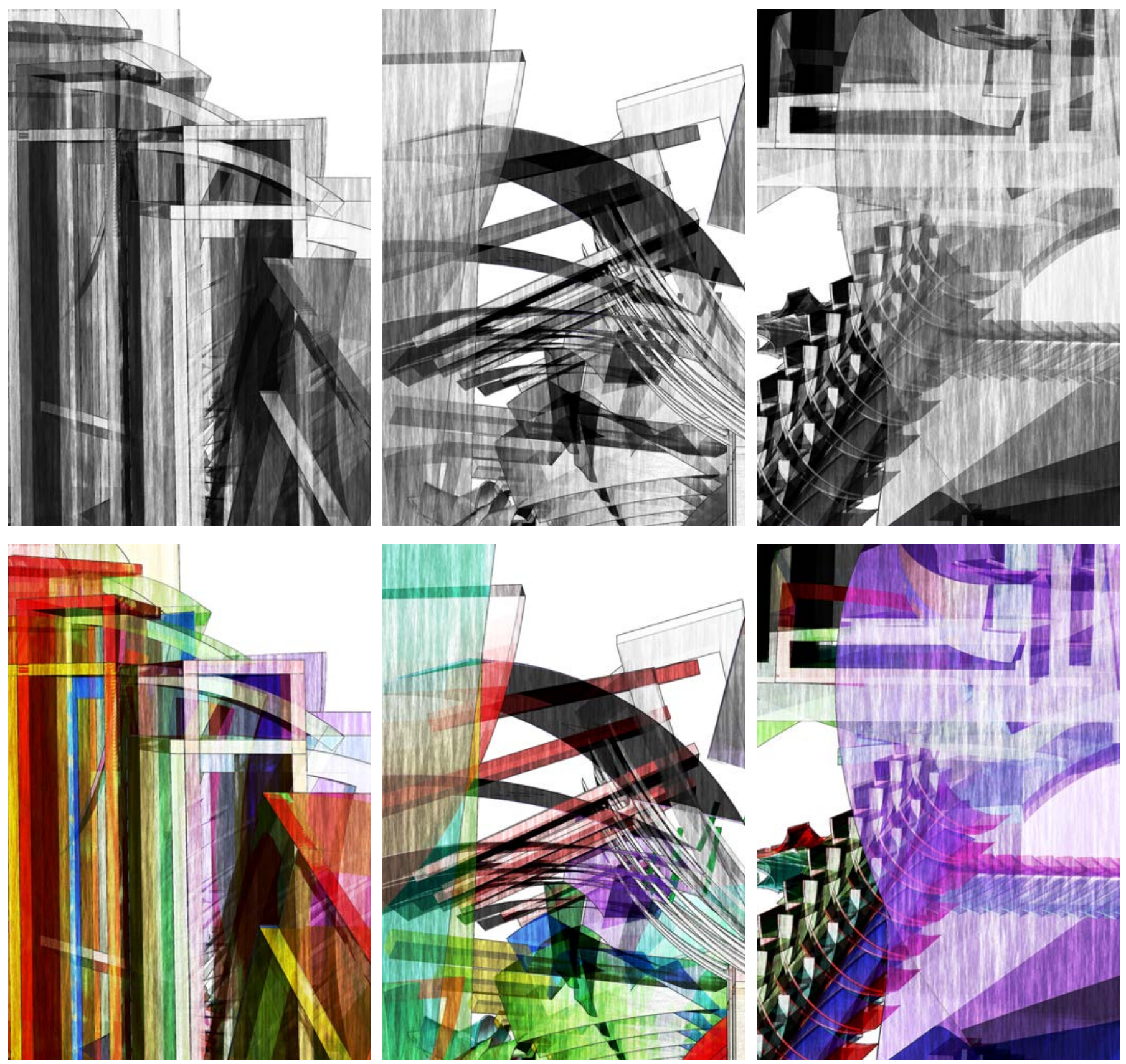


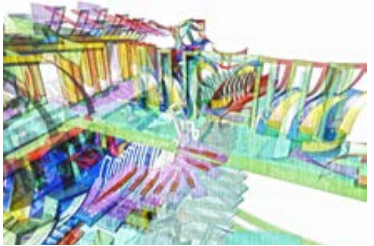

Zoomed in Perspectives of Image $\mathbf{2}$
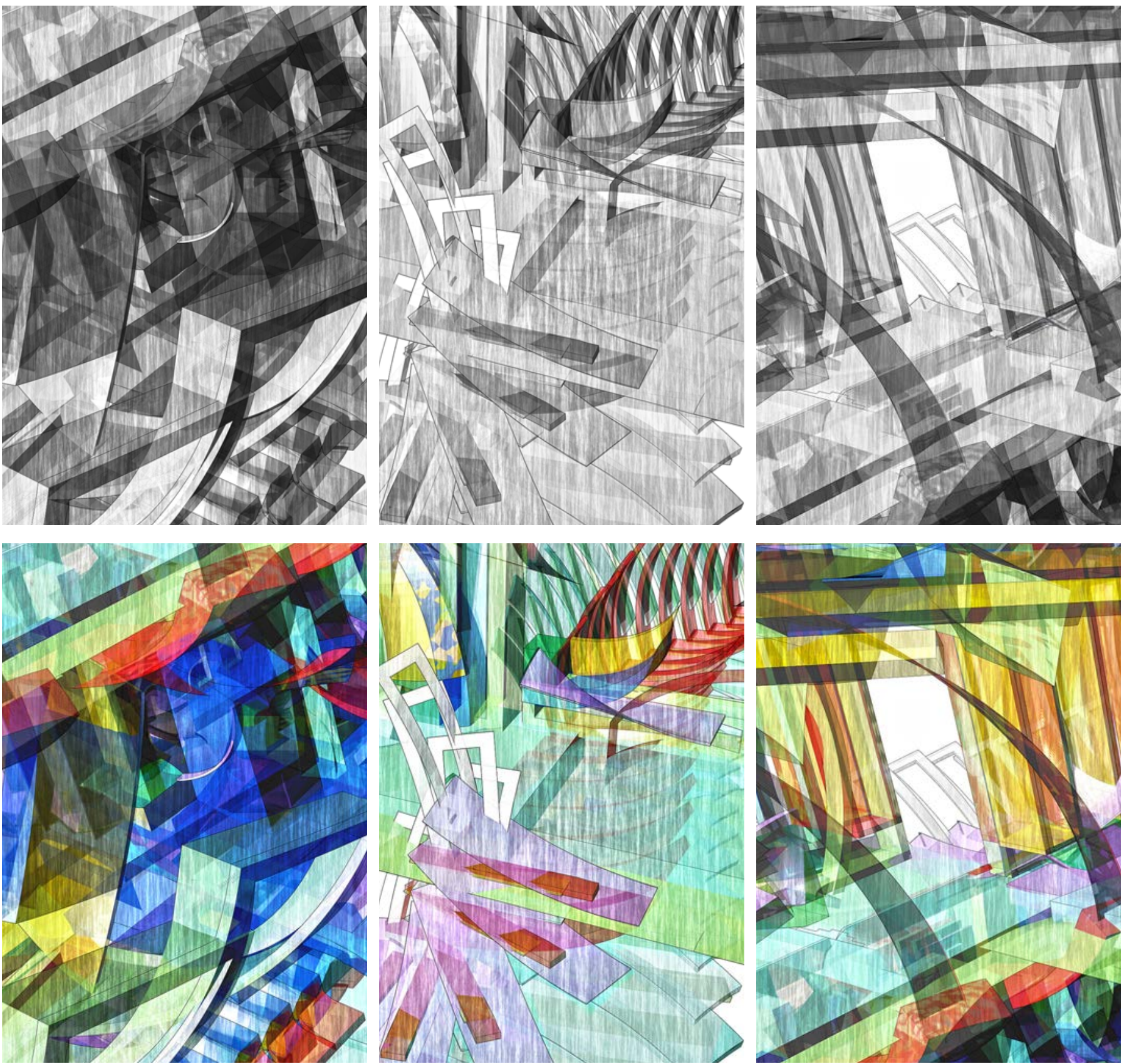

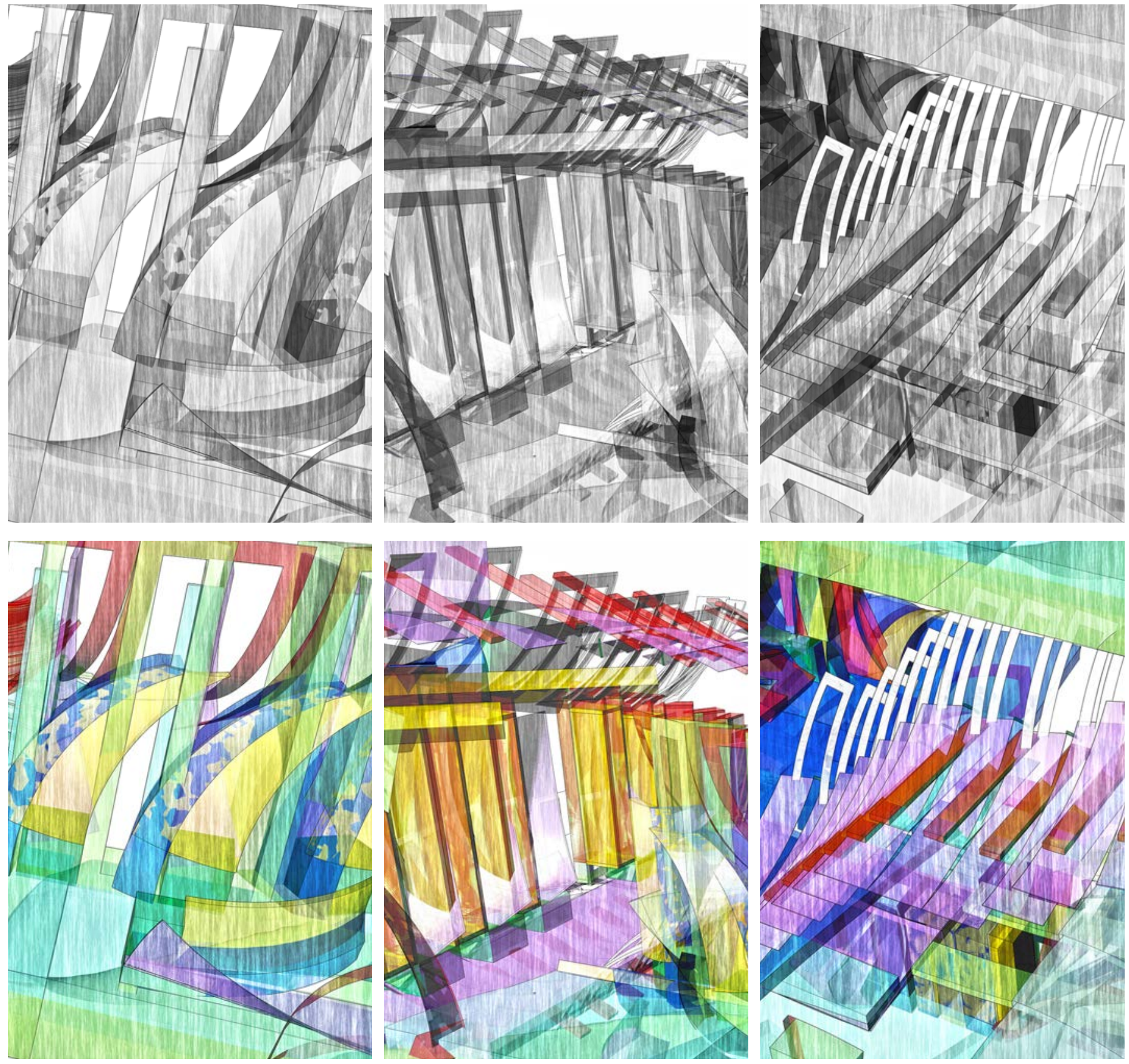
second level

(living)

(bathing)
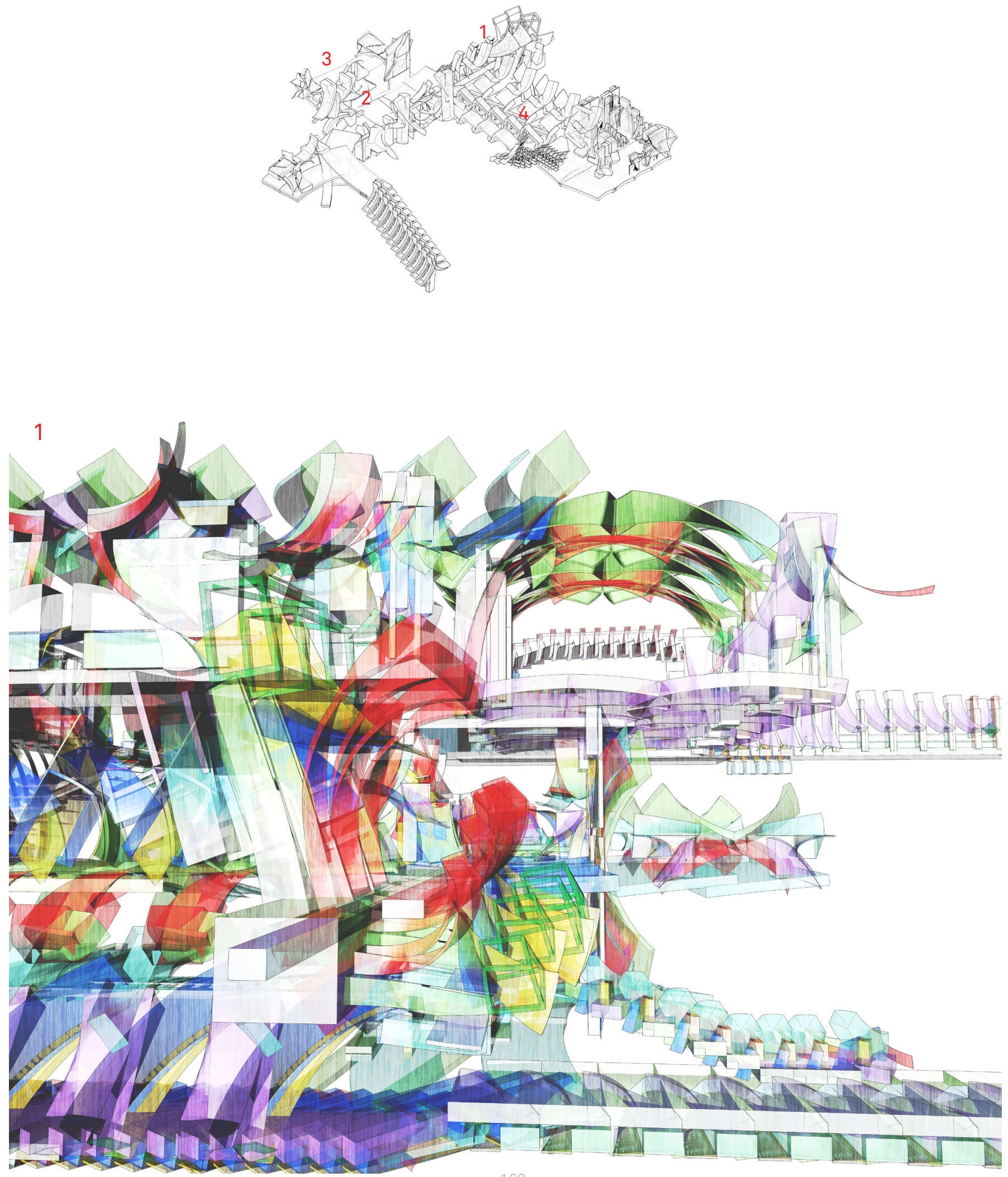


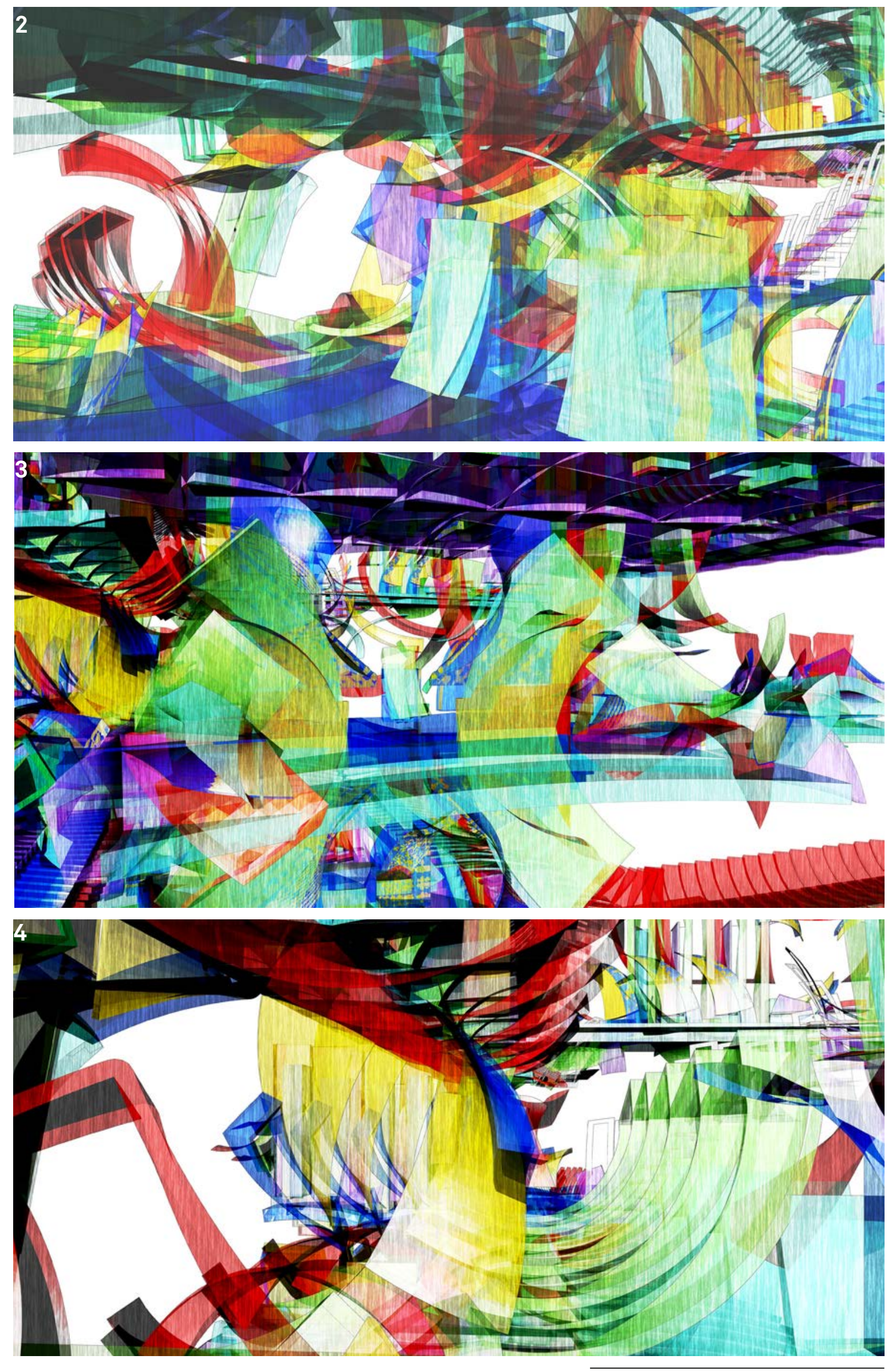




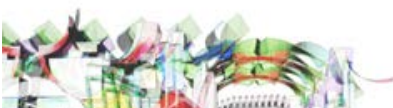

है।

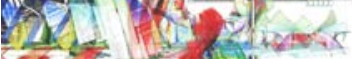

$3=2$.

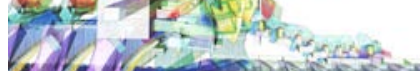

Zoomed in Perspectives of Image 1
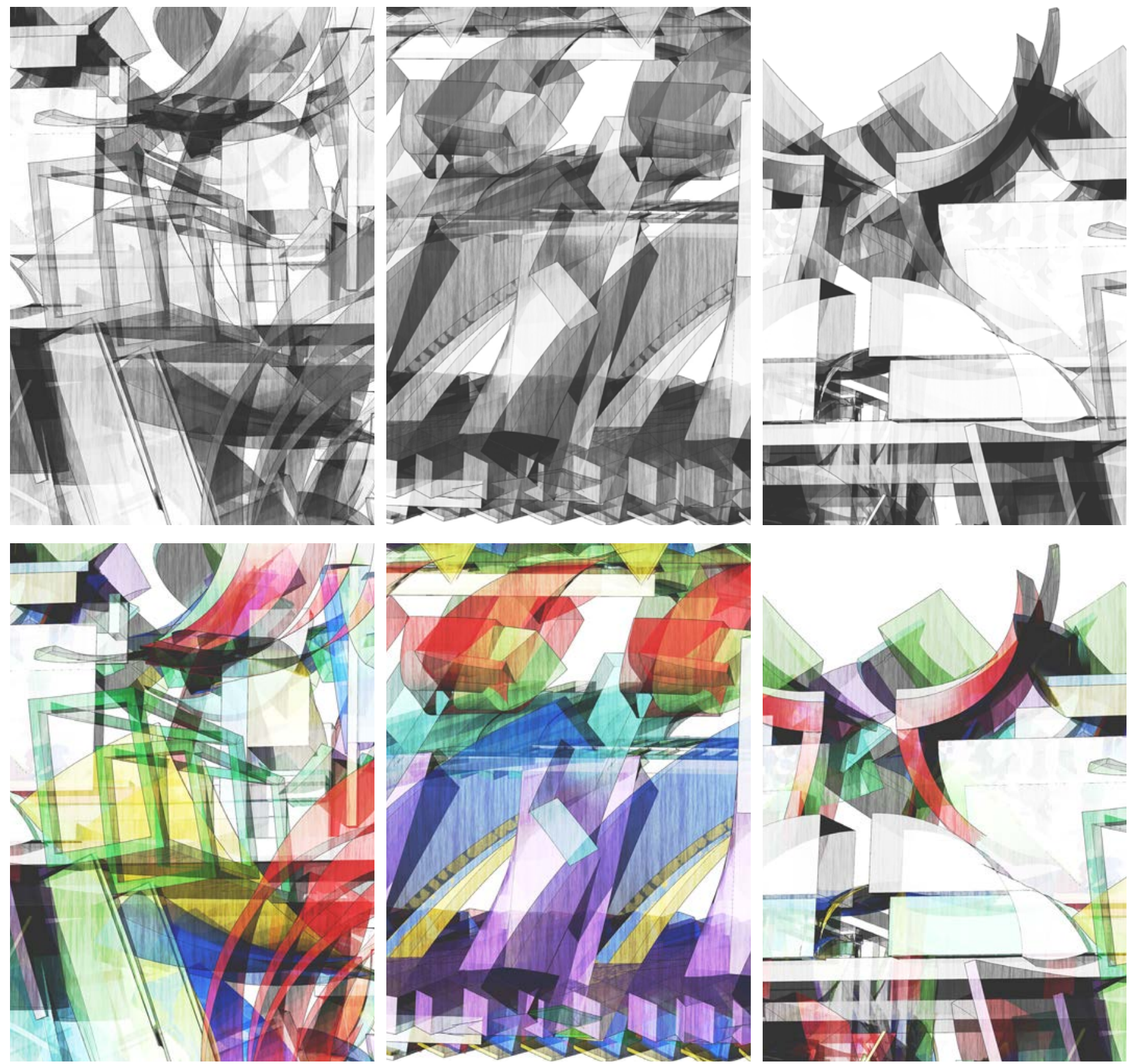

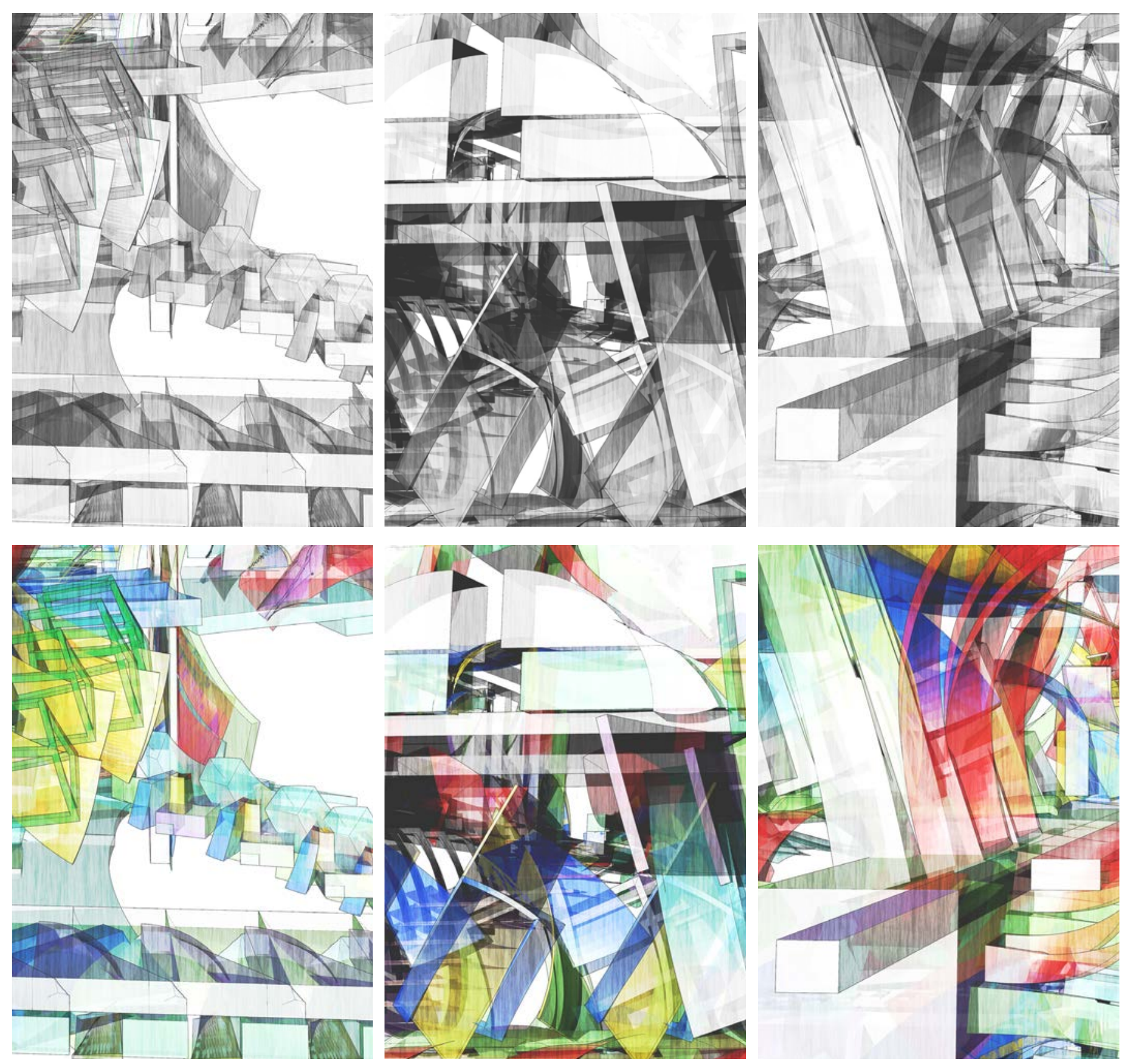


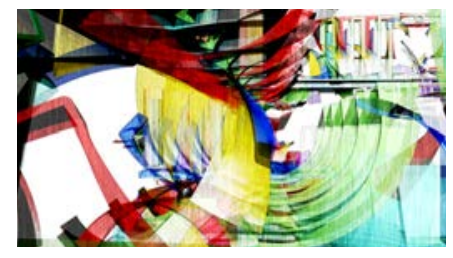

Zoomed in Perspectives of Image 4
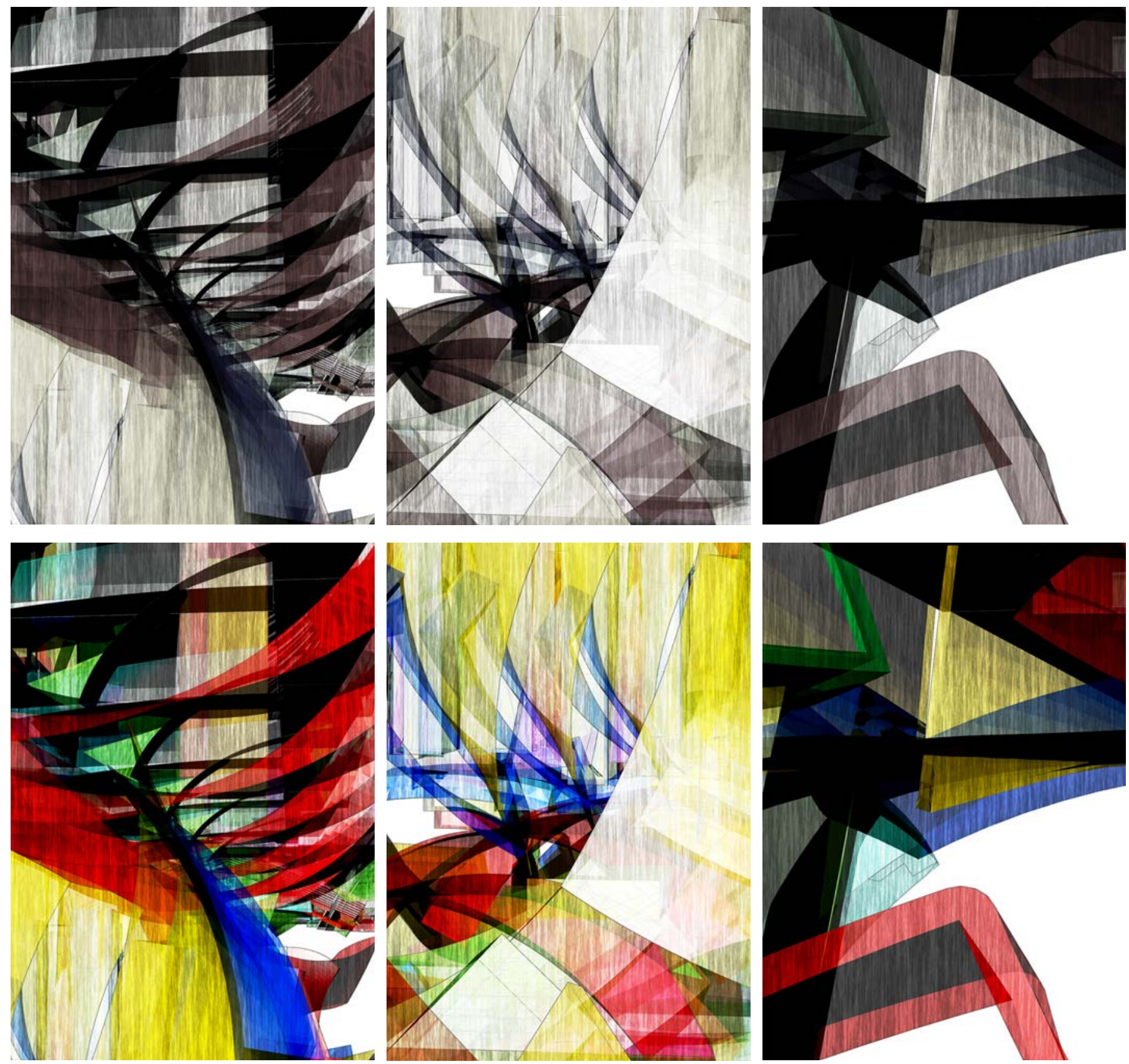

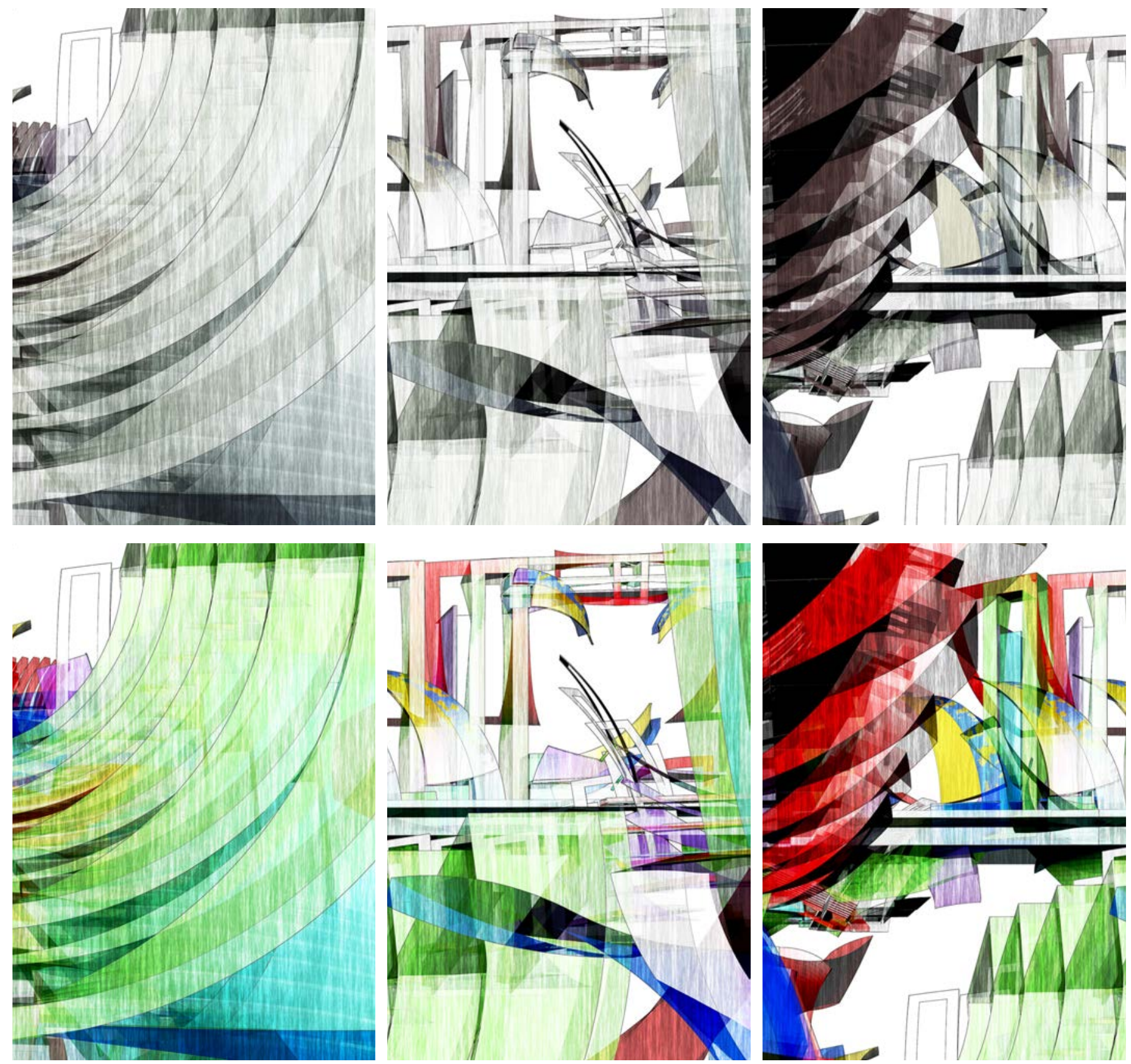
main level

(living)

(dining)
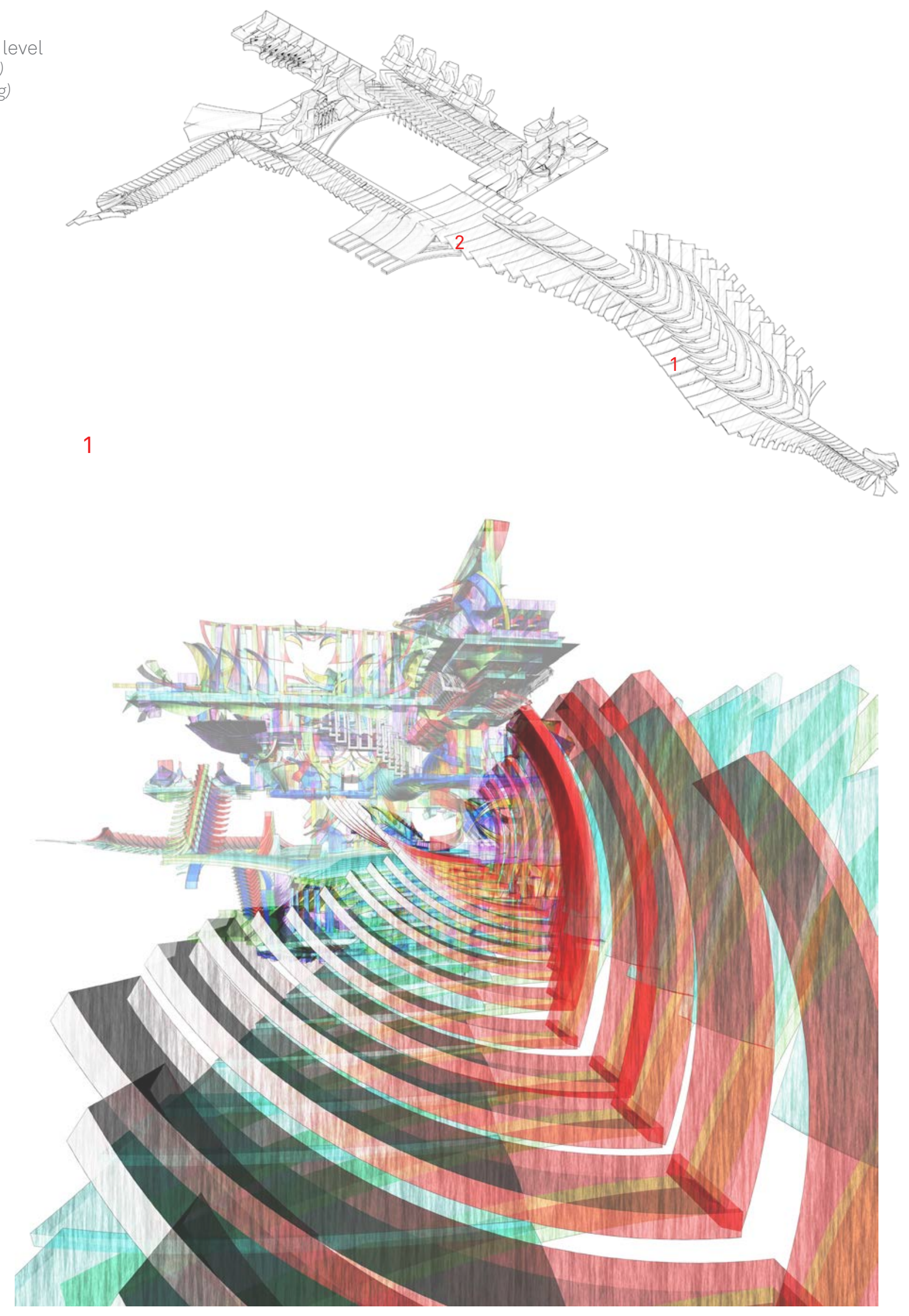


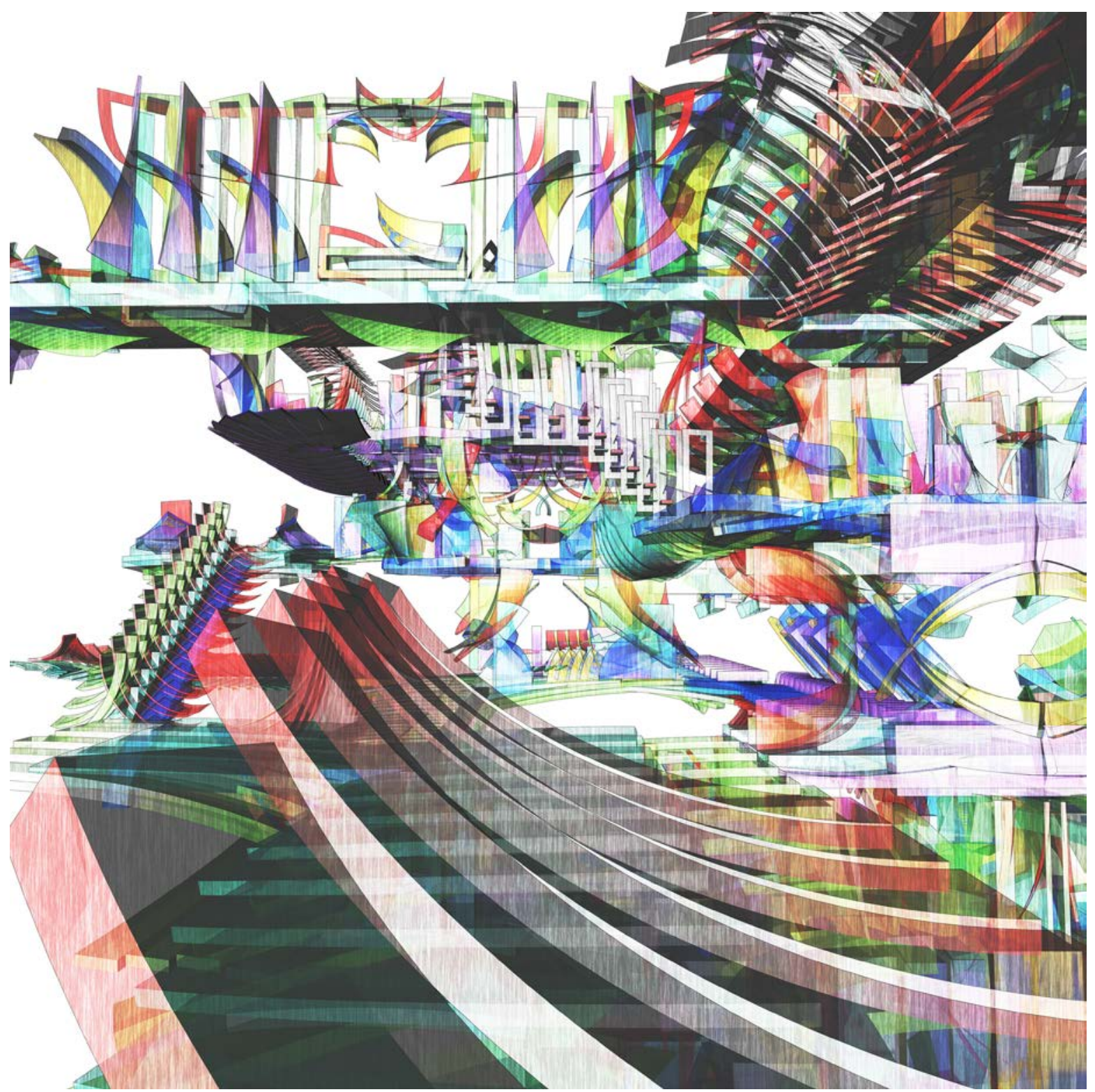

Fig. 94: Visionary Proposition - Main Level 
main level

(living)

(dining)
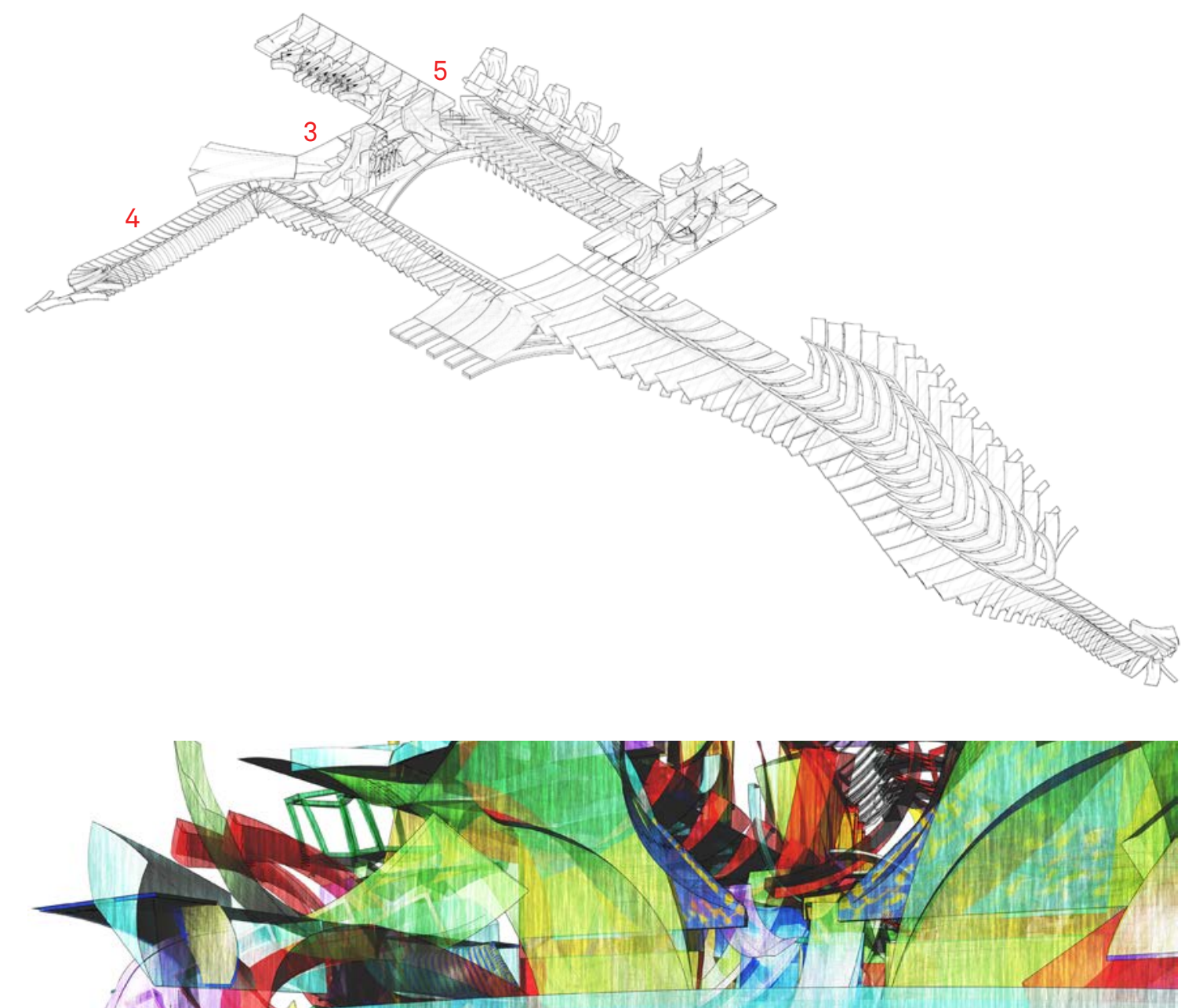

onter

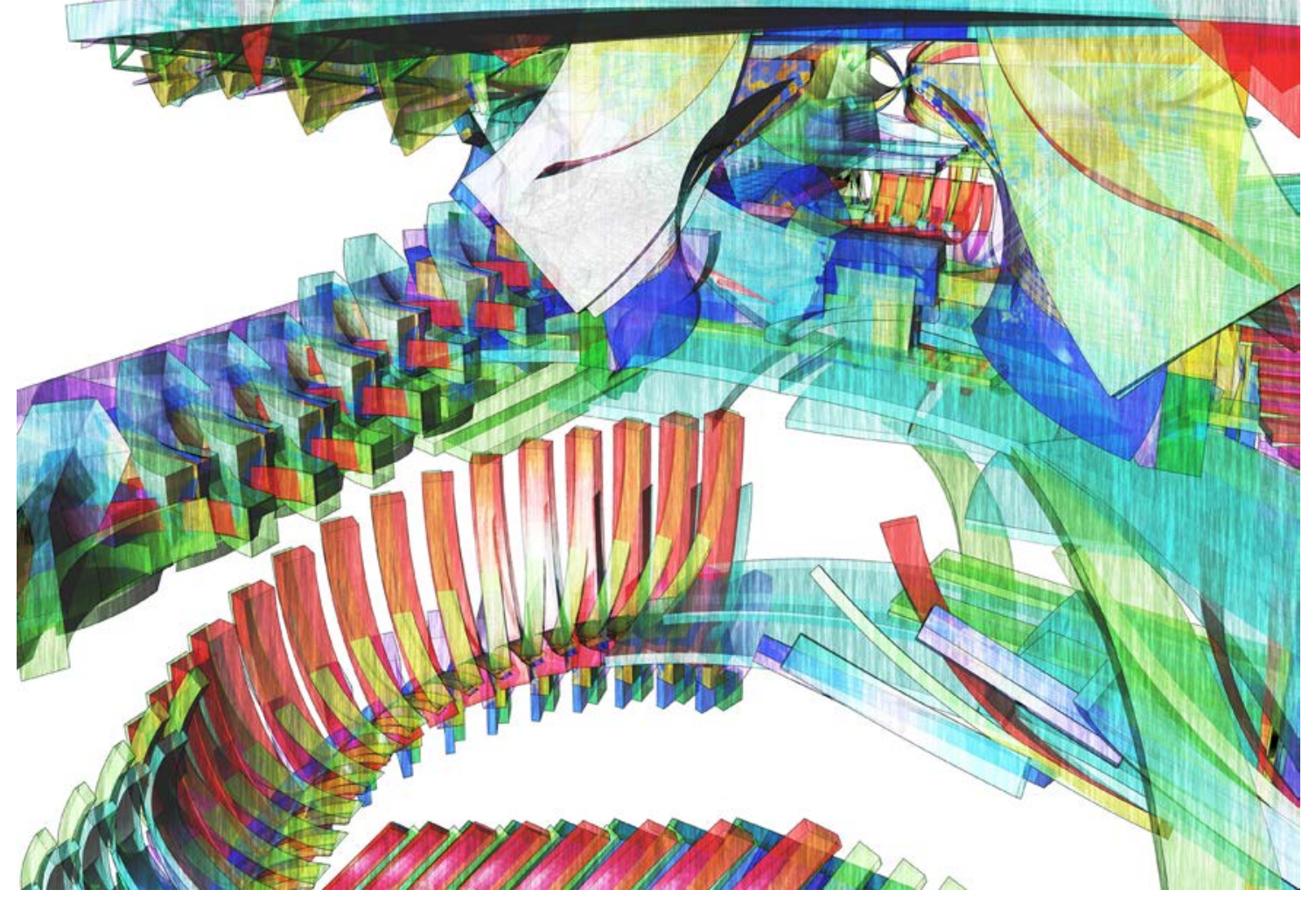




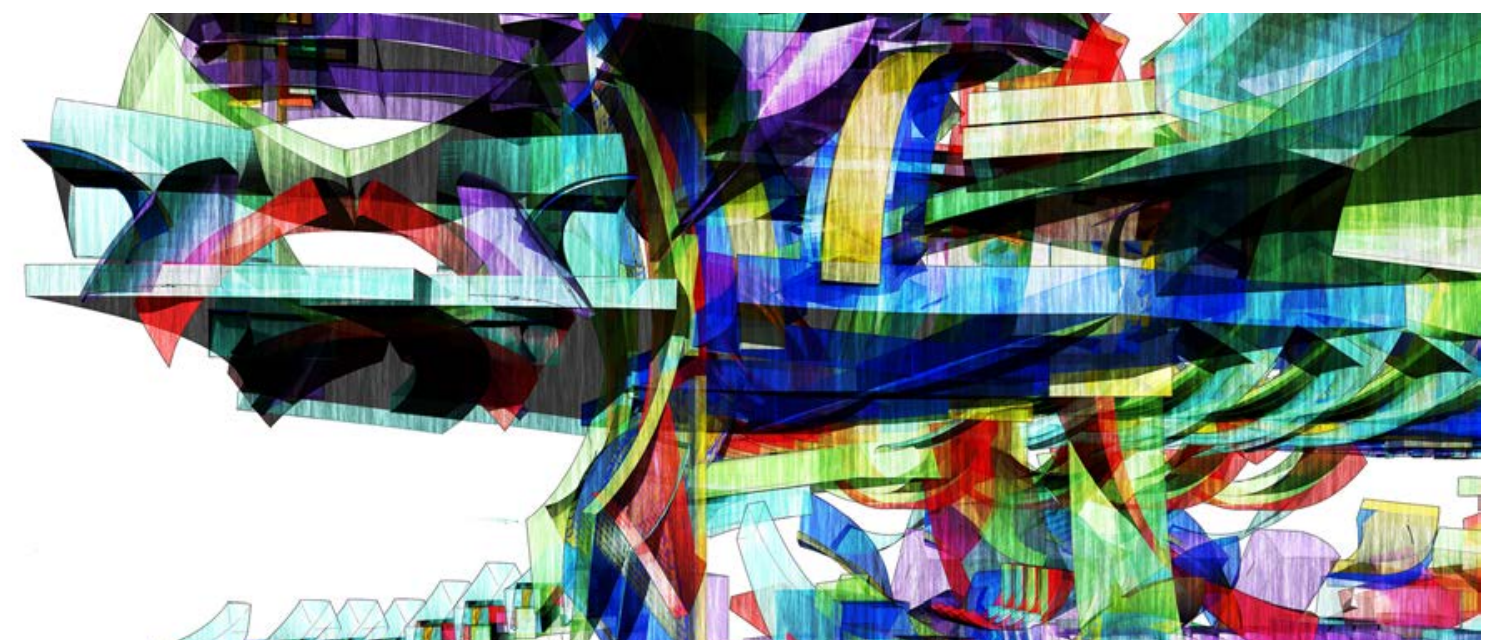

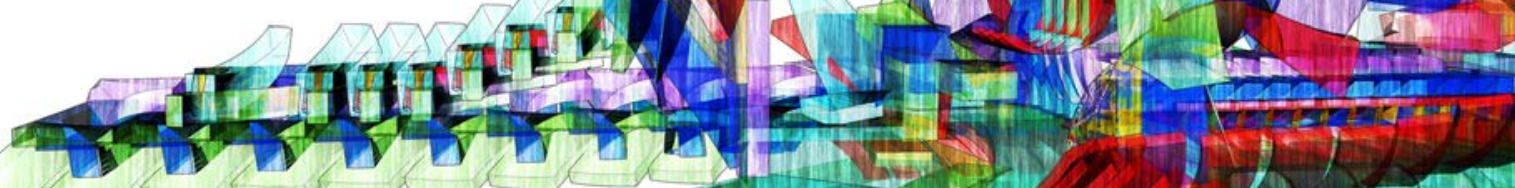

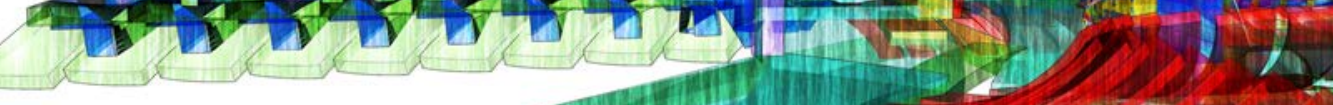

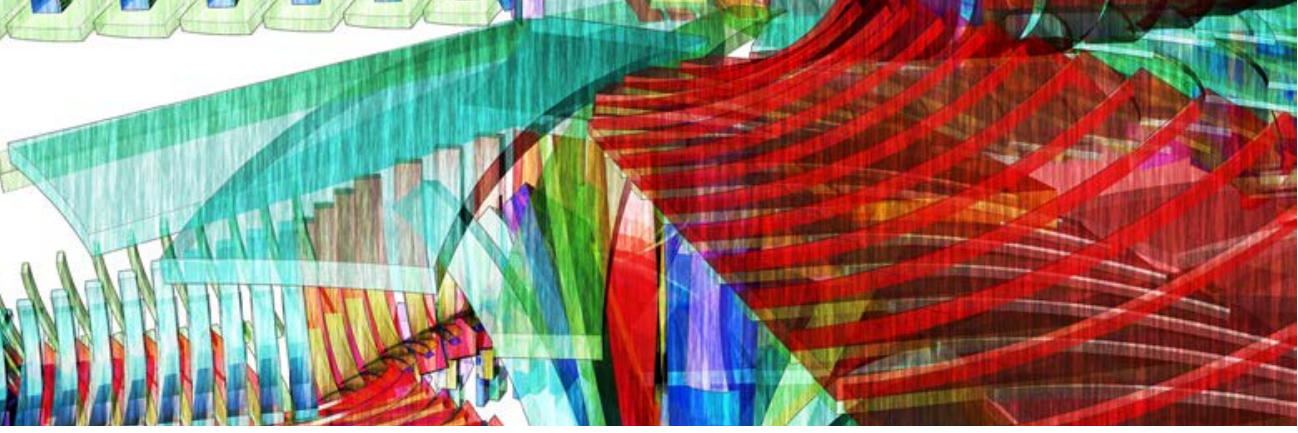

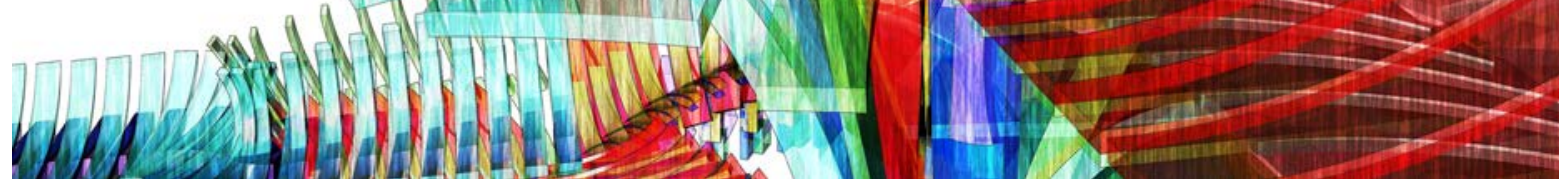

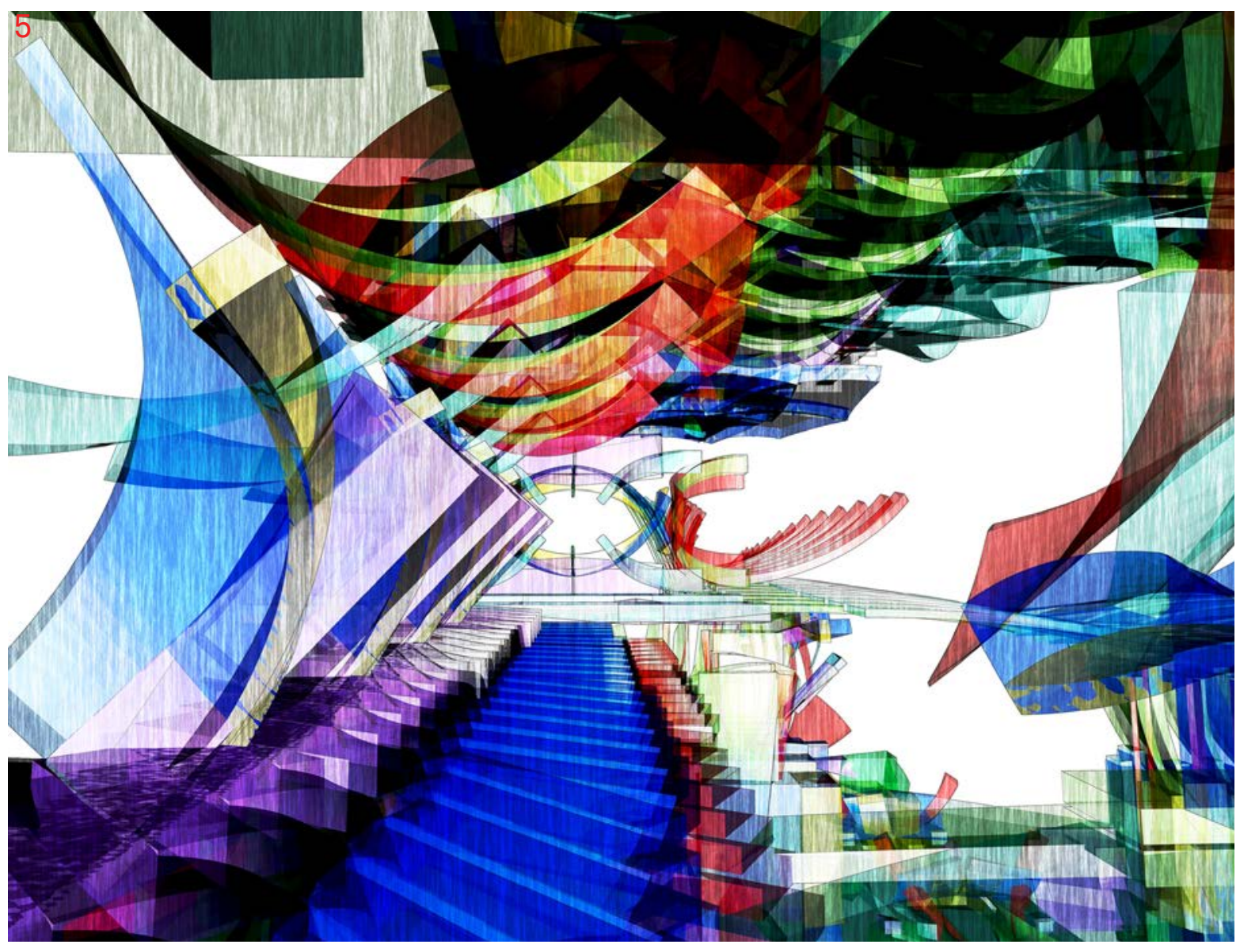




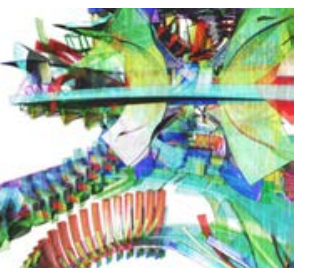

Zoomed in Perspectives of Image 3
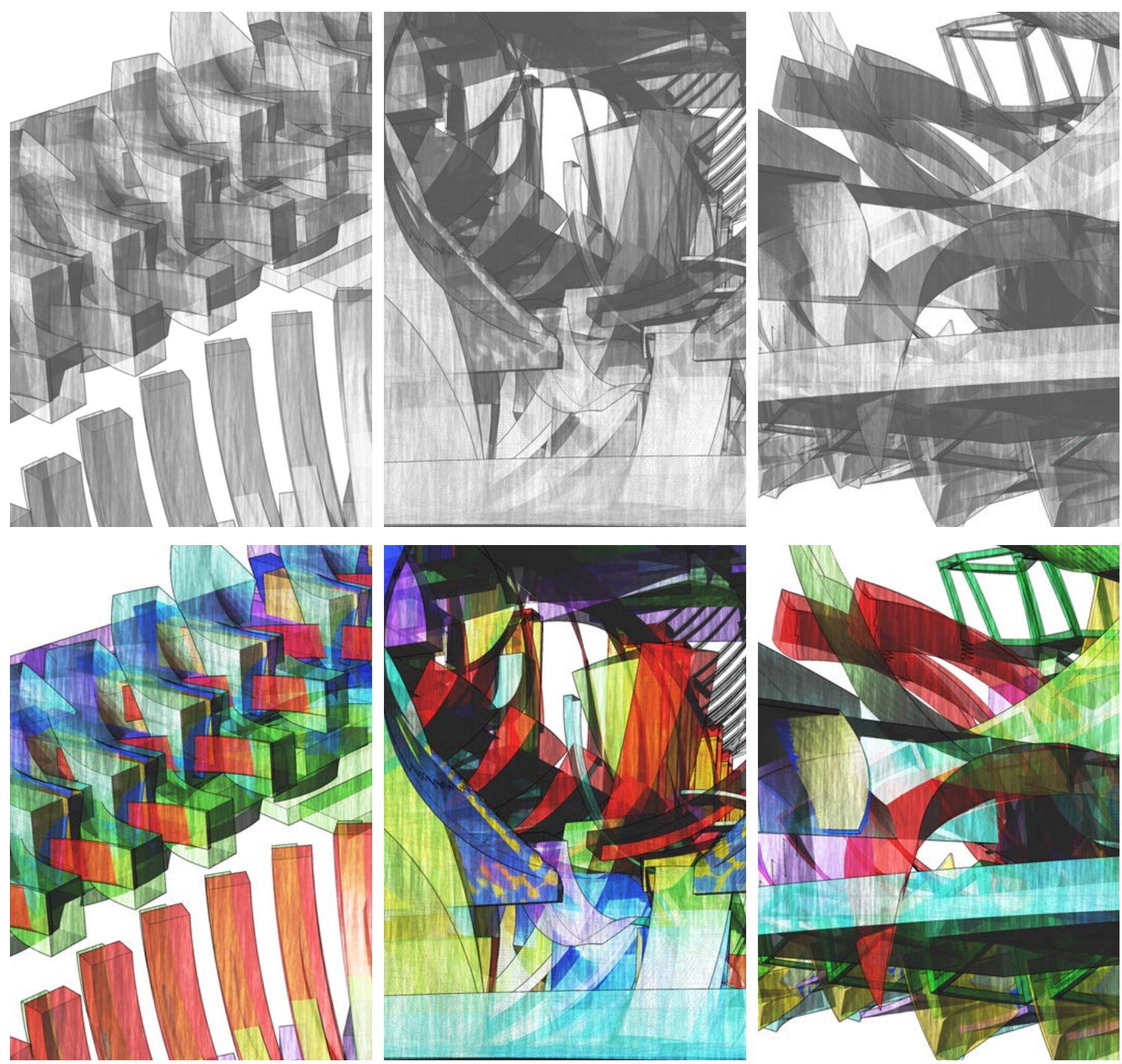

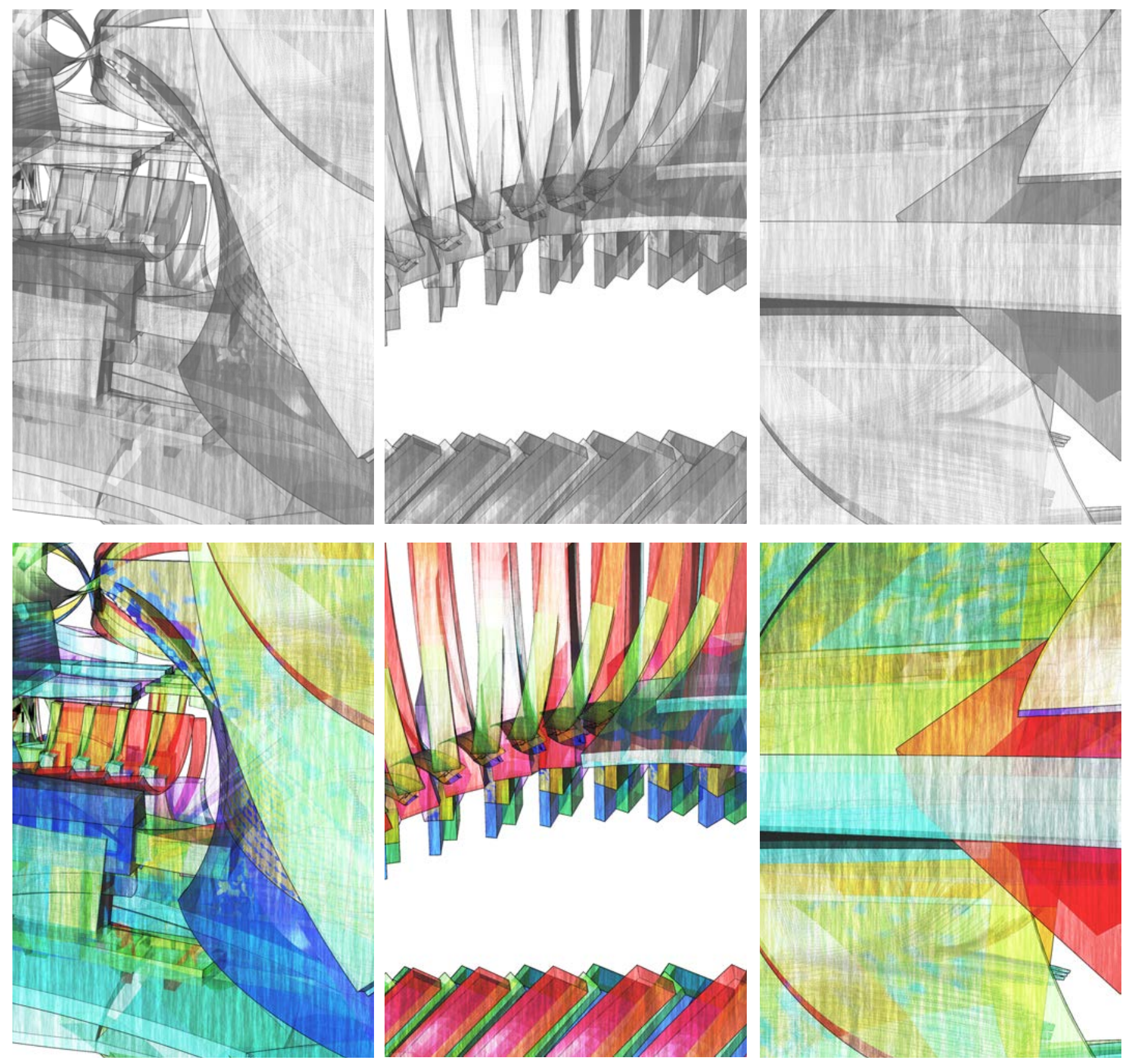


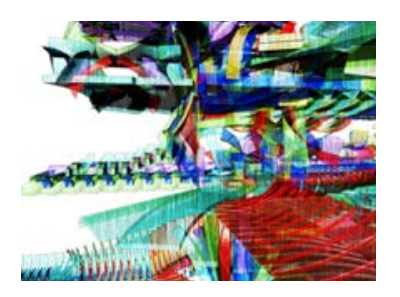

Zoomed in Perspectives of Image 4
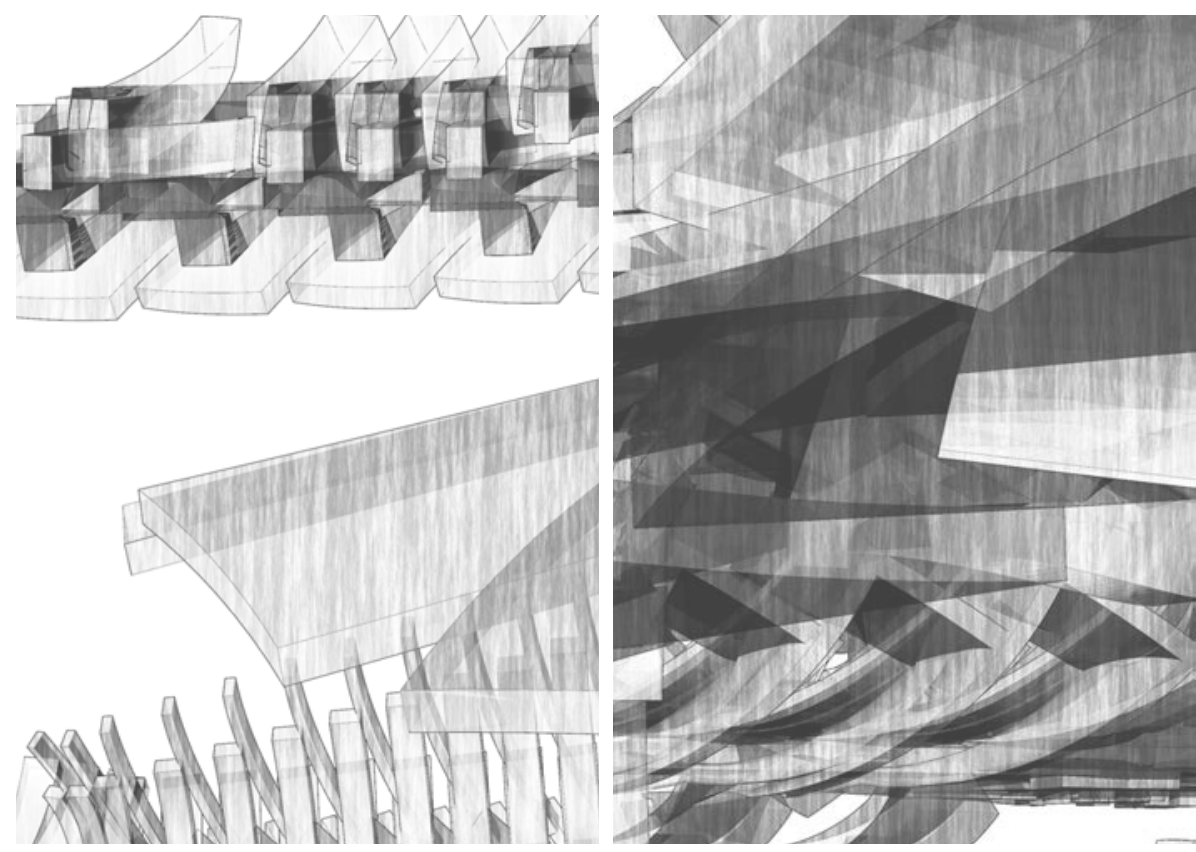

monatand
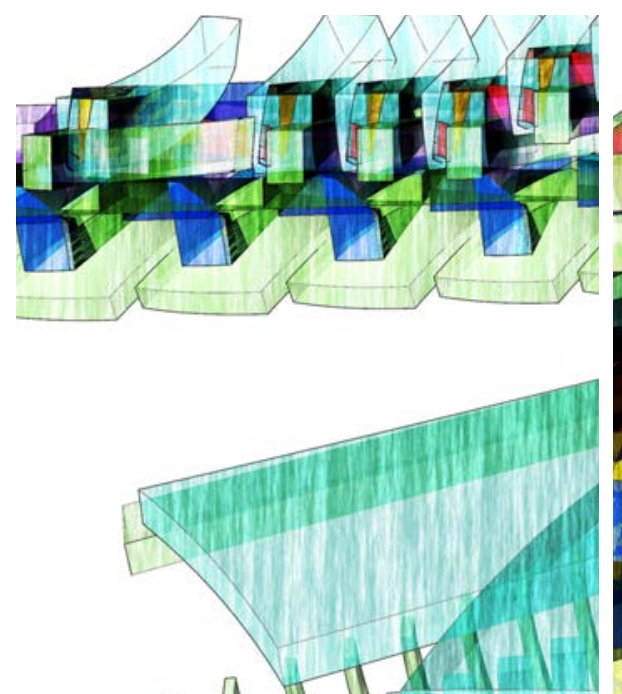

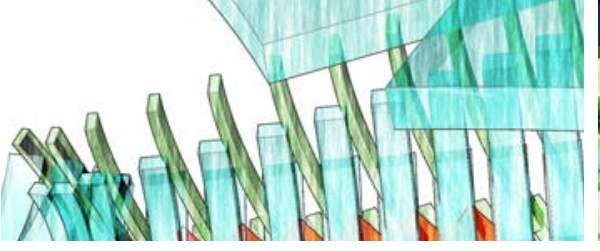
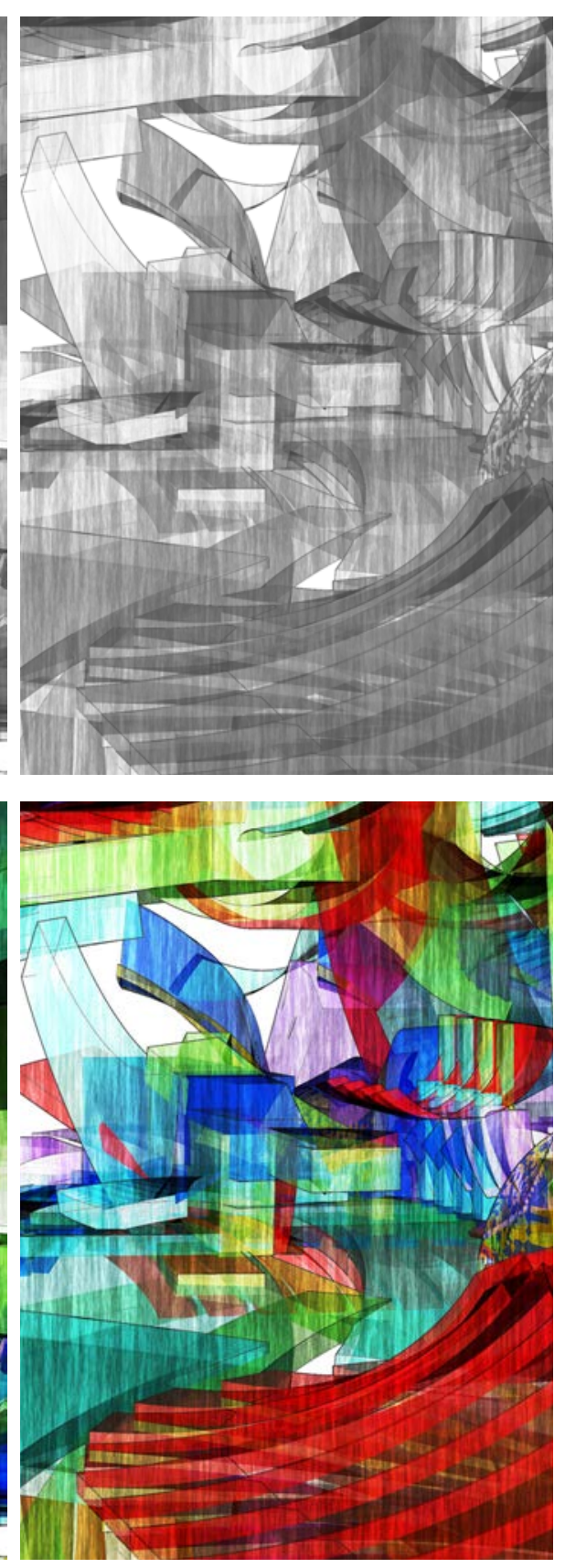

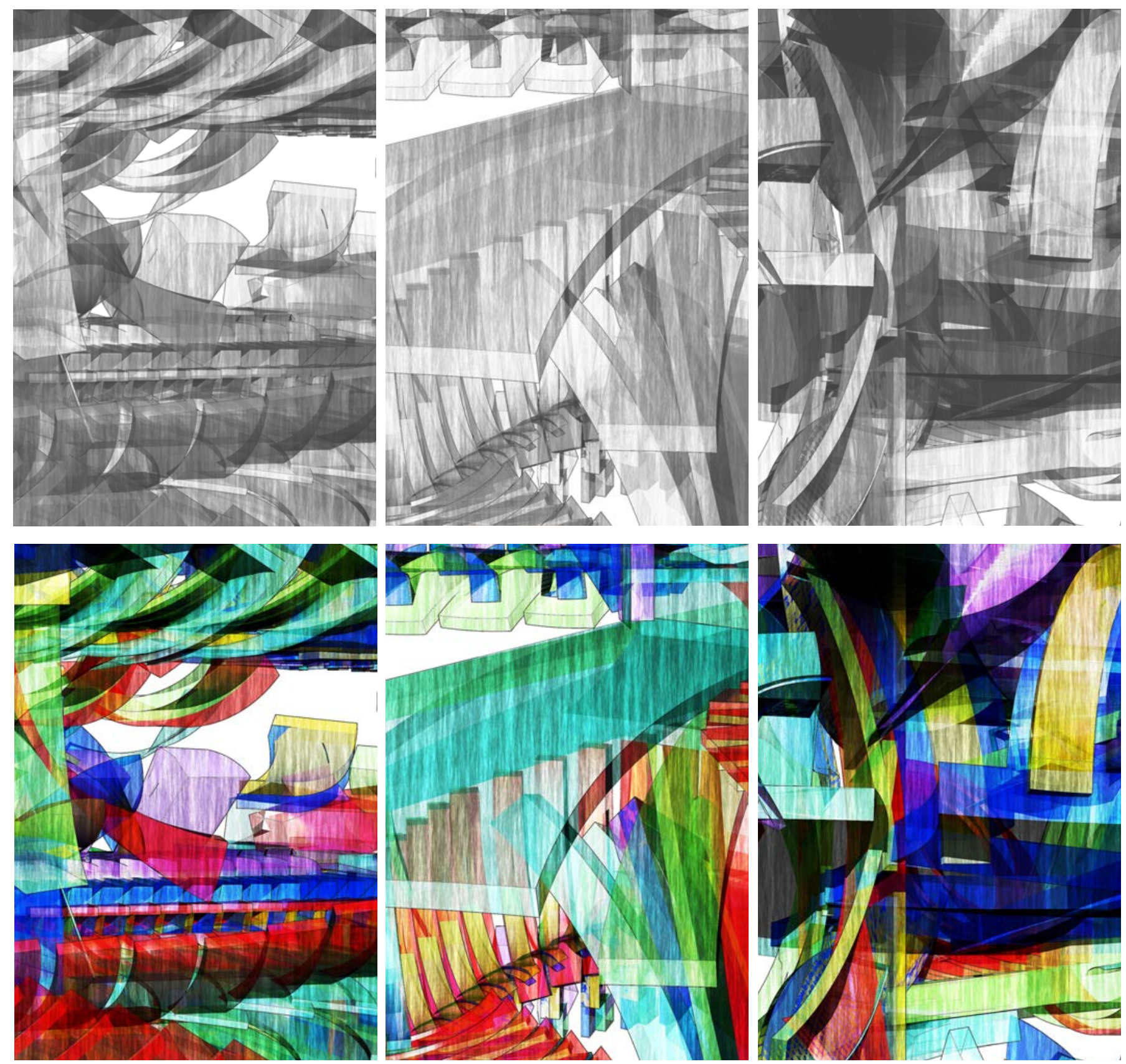
lower level

(working)
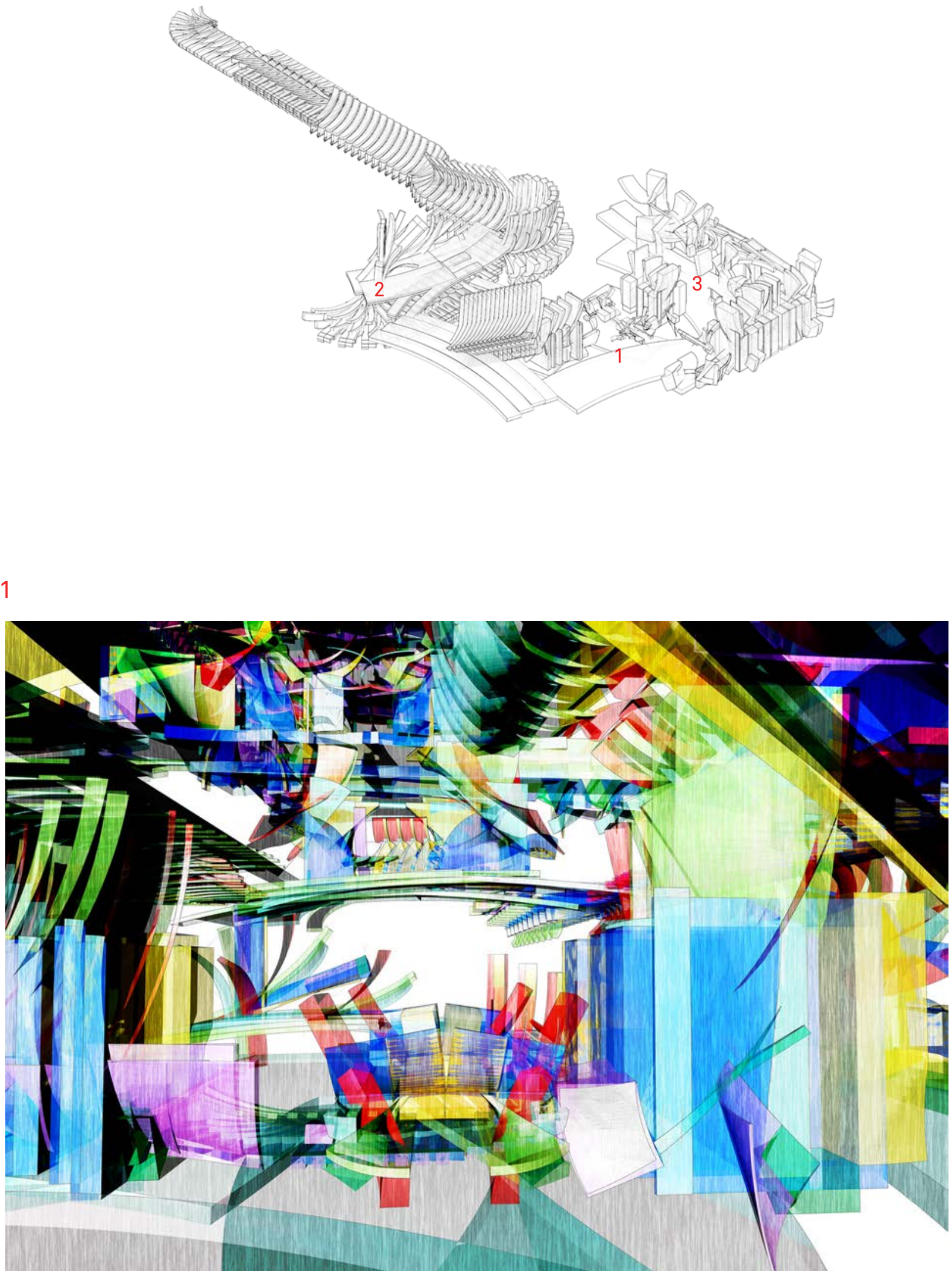


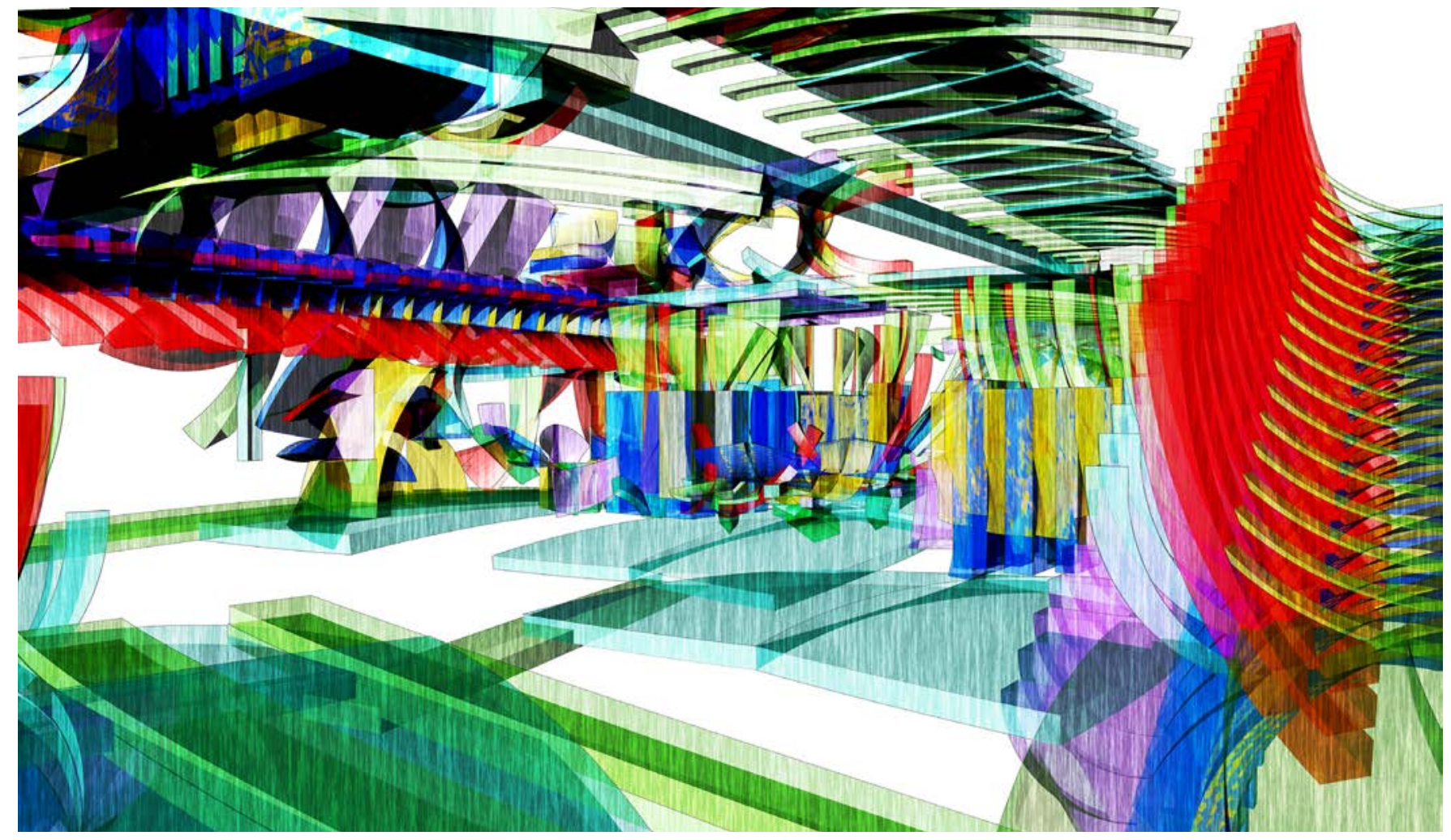

\section{3}

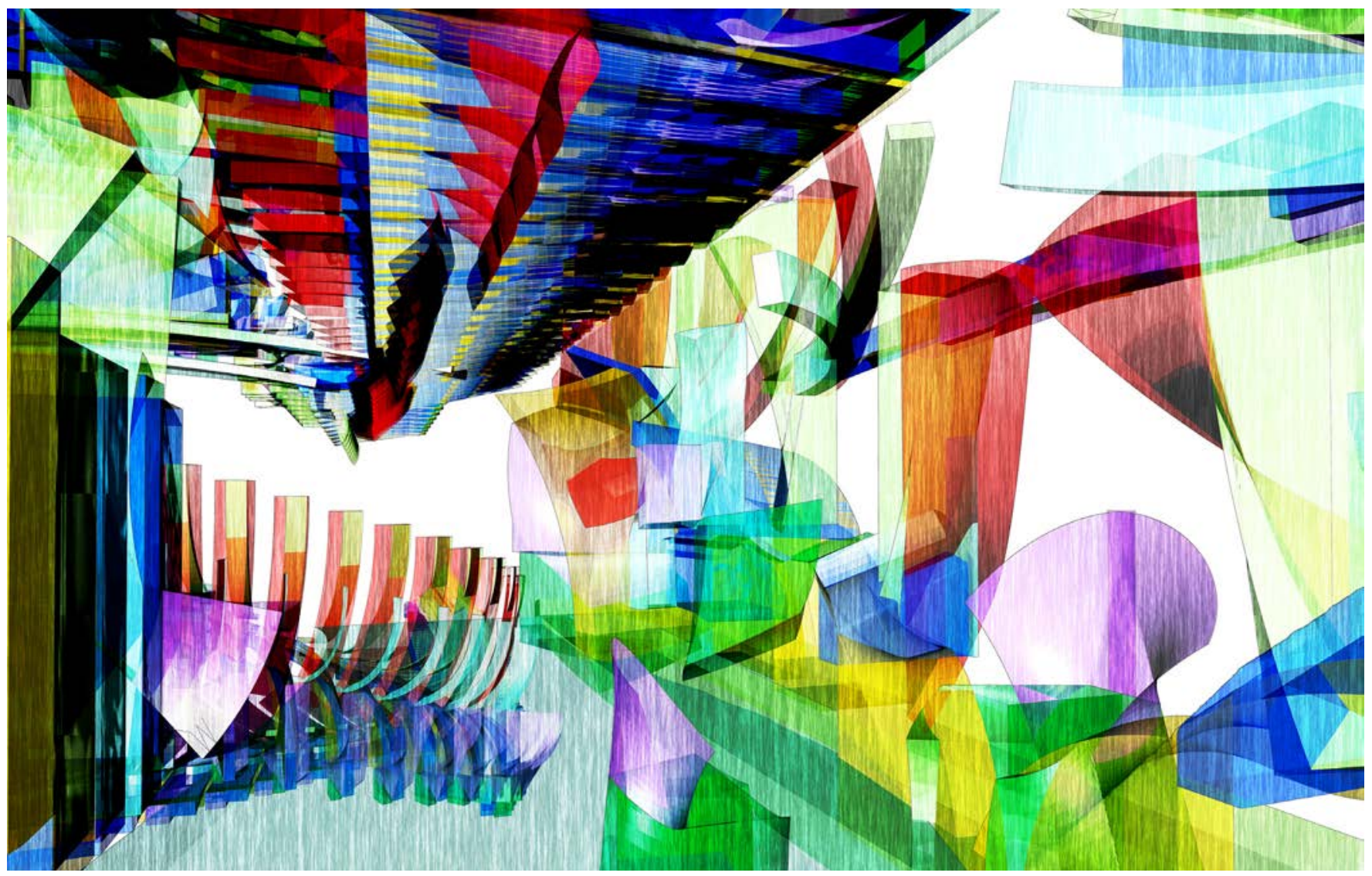




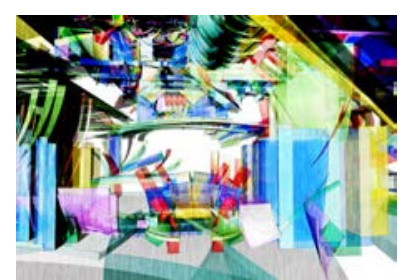

Zoomed in Perspectives of Image 1
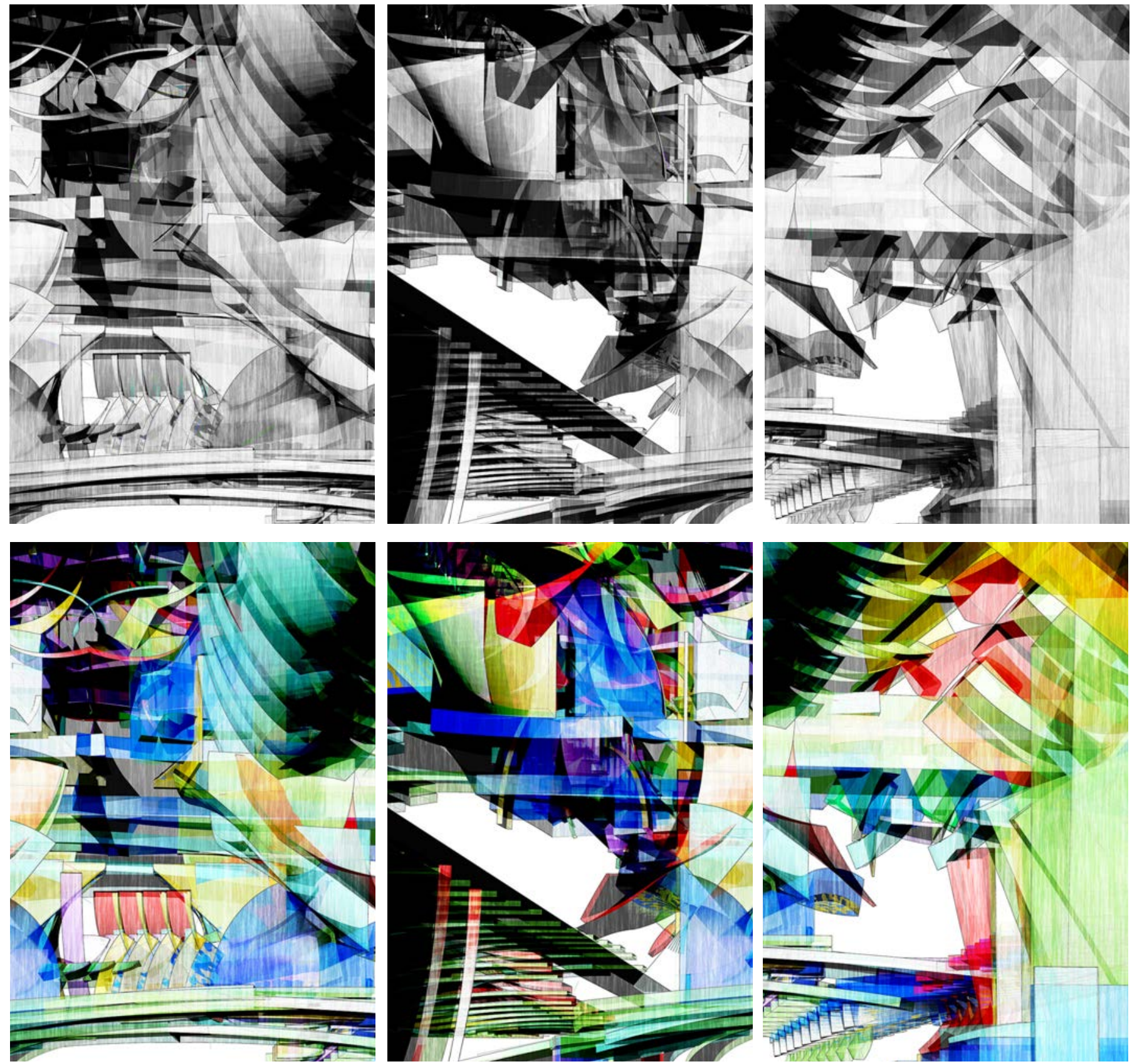

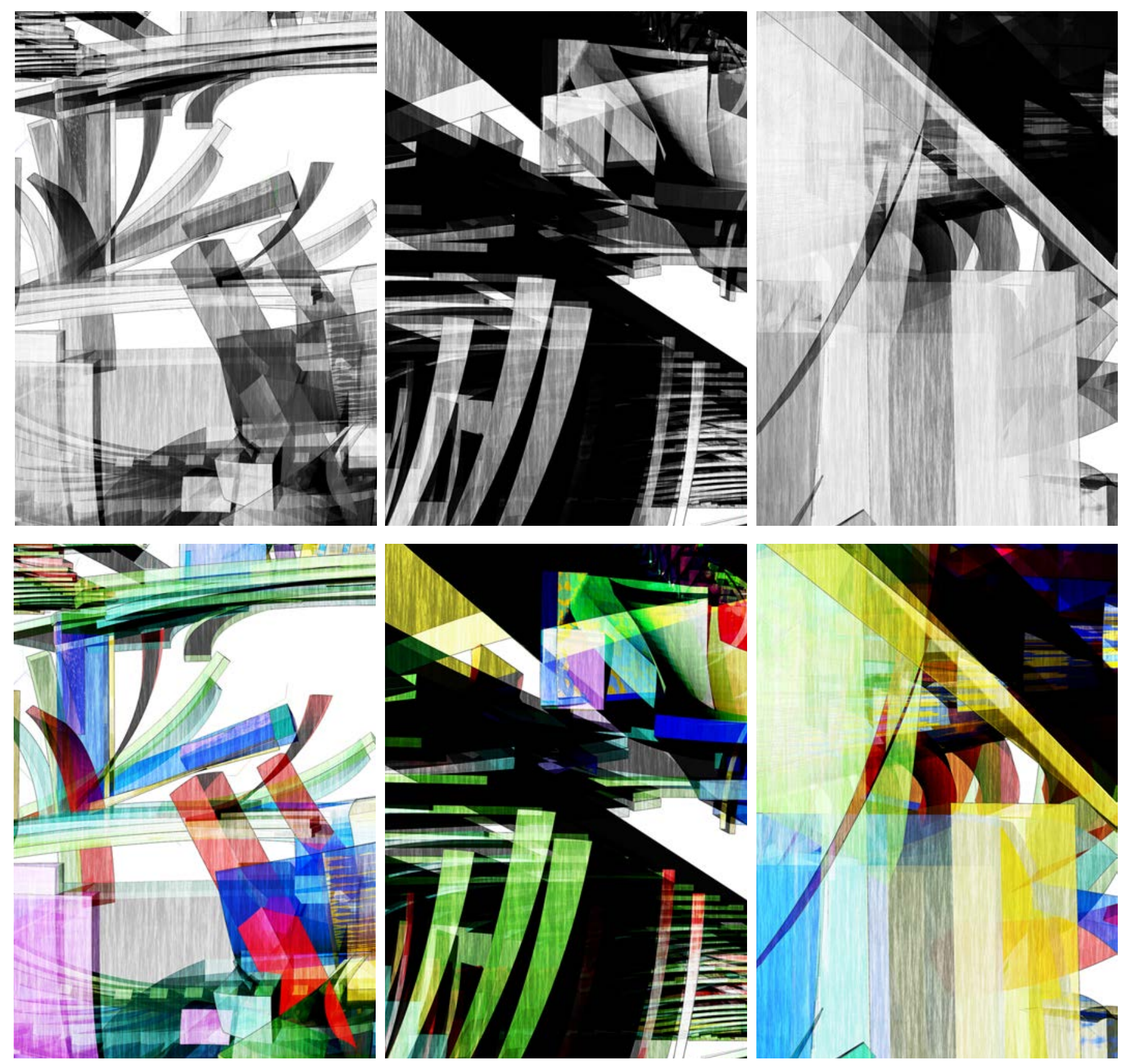


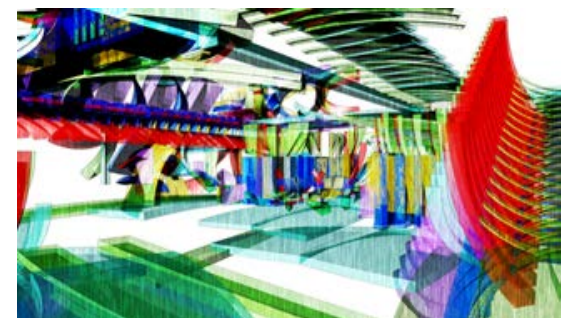

Zoomed in Perspectives of Image 2
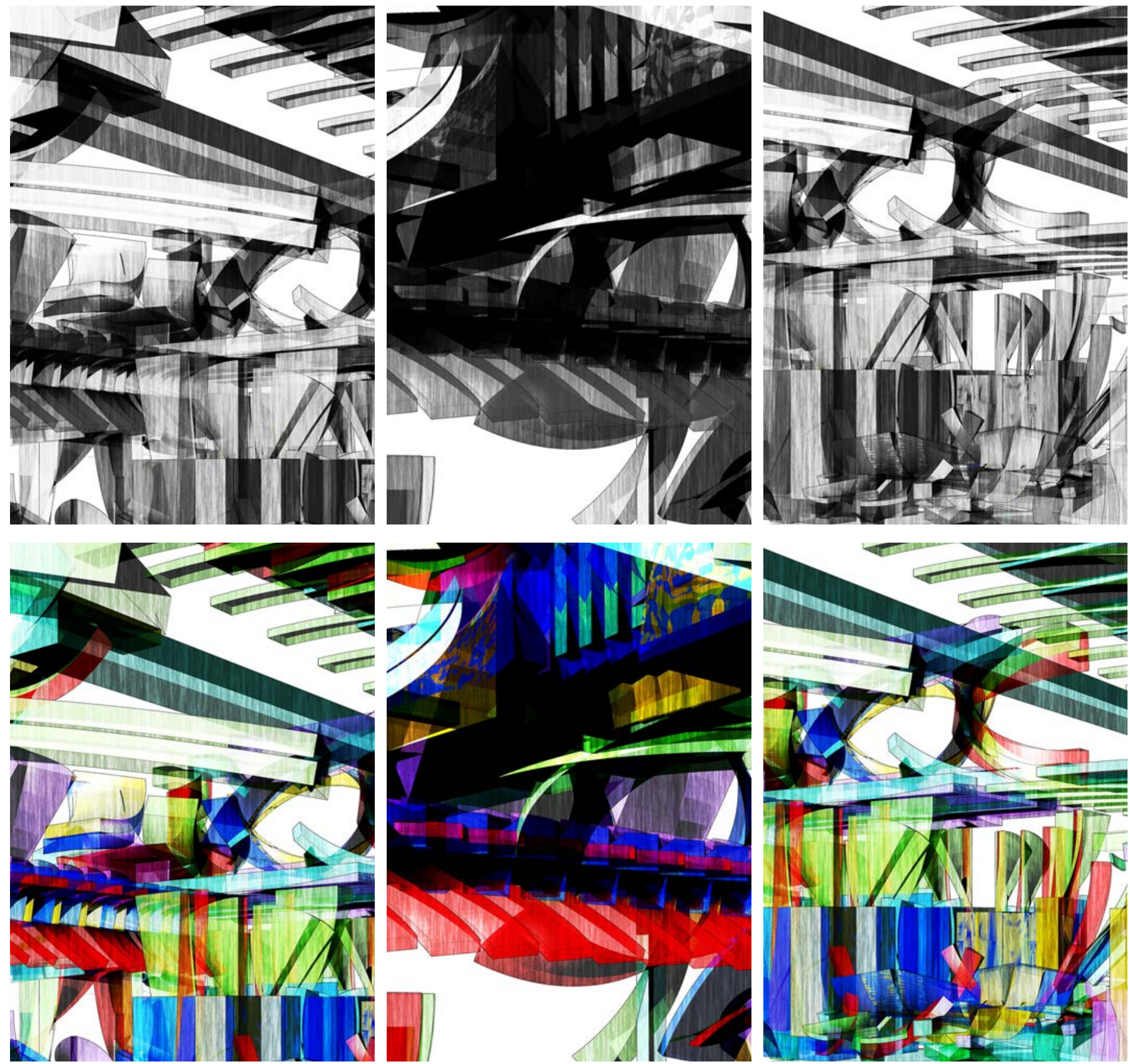

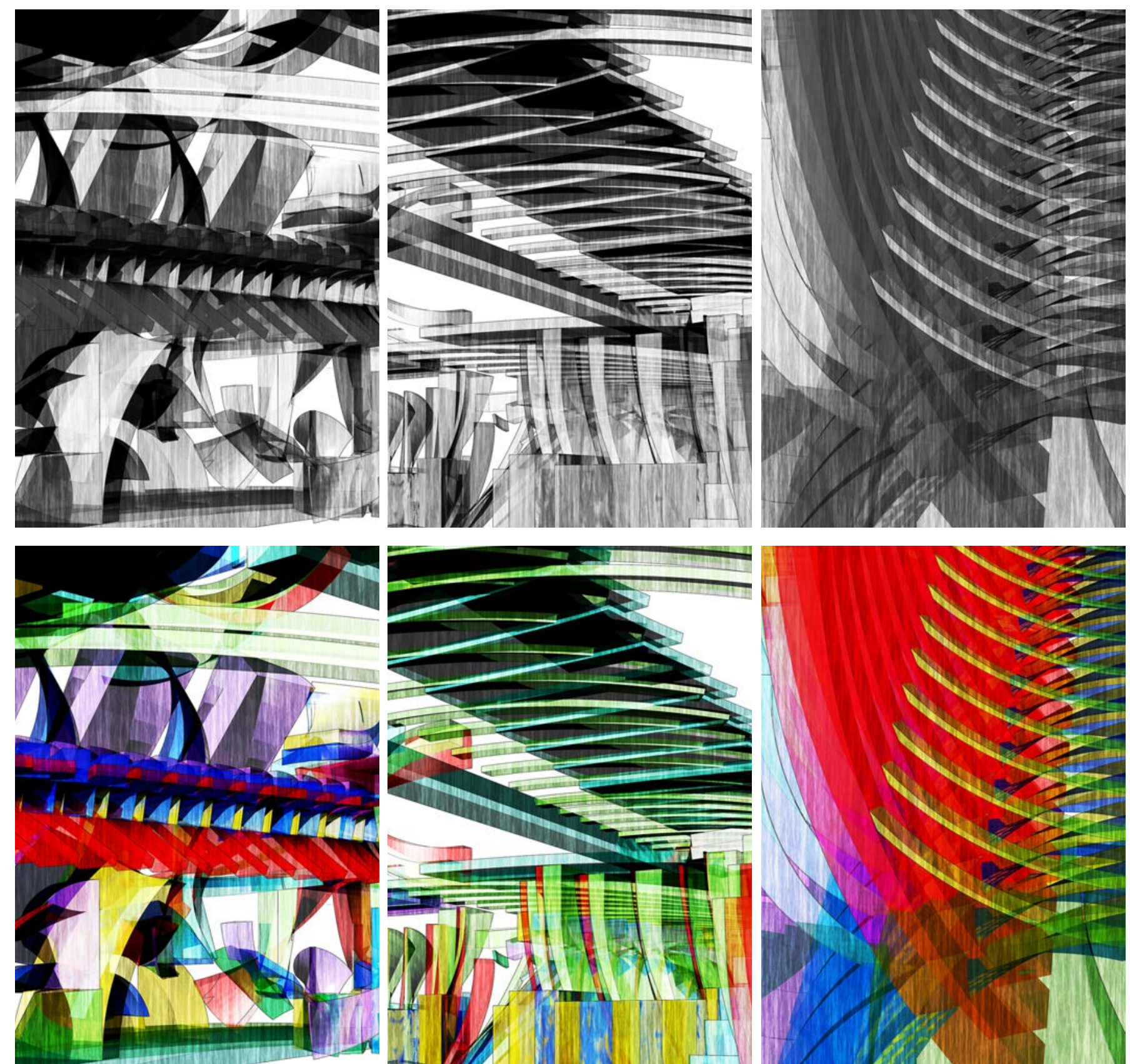


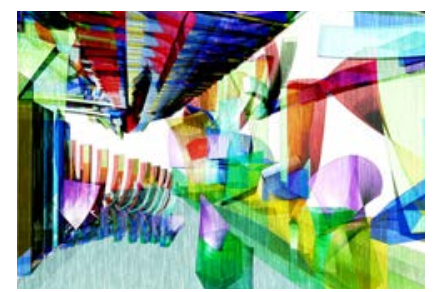

Zoomed in Perspectives of Image 3
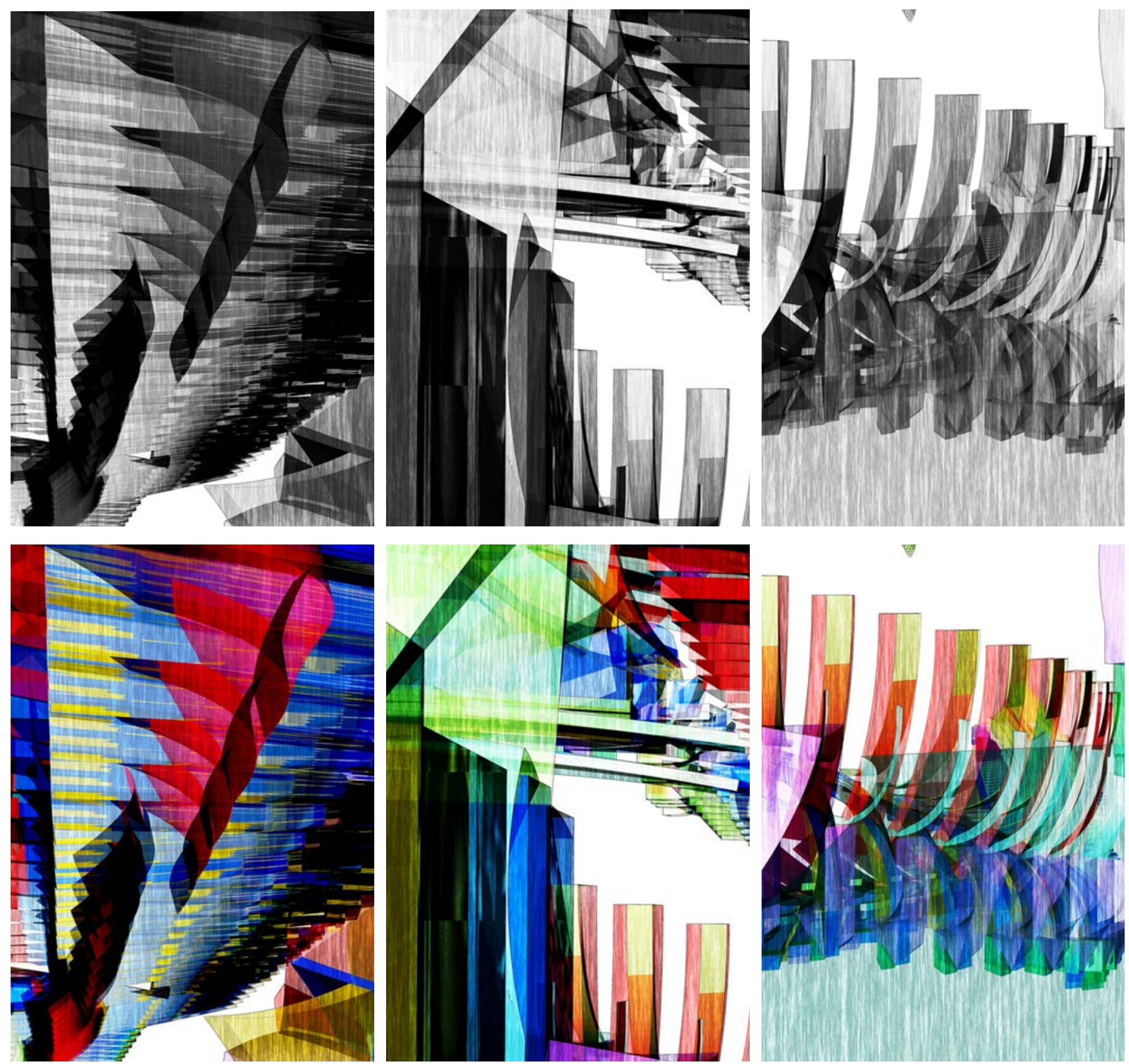

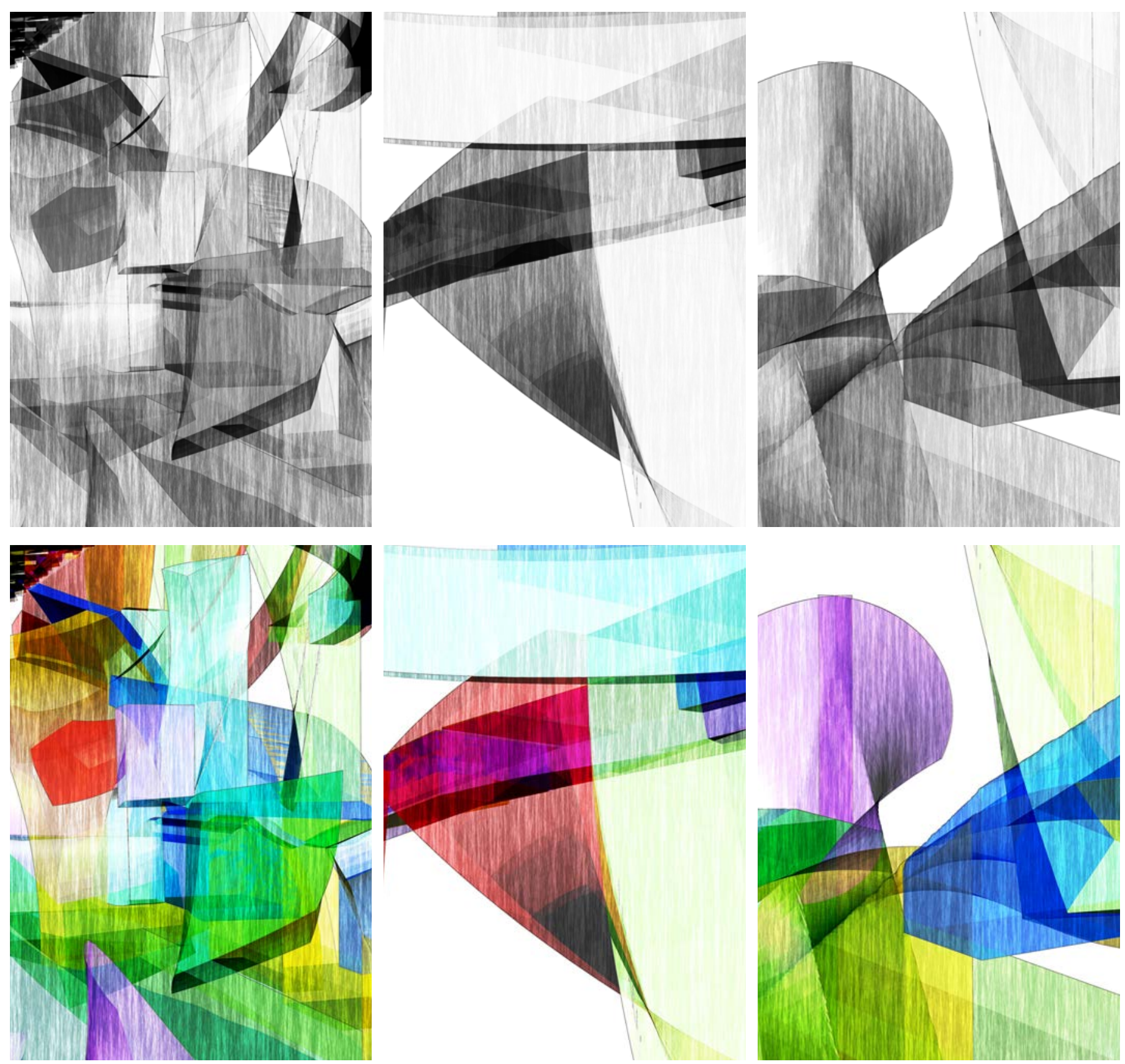


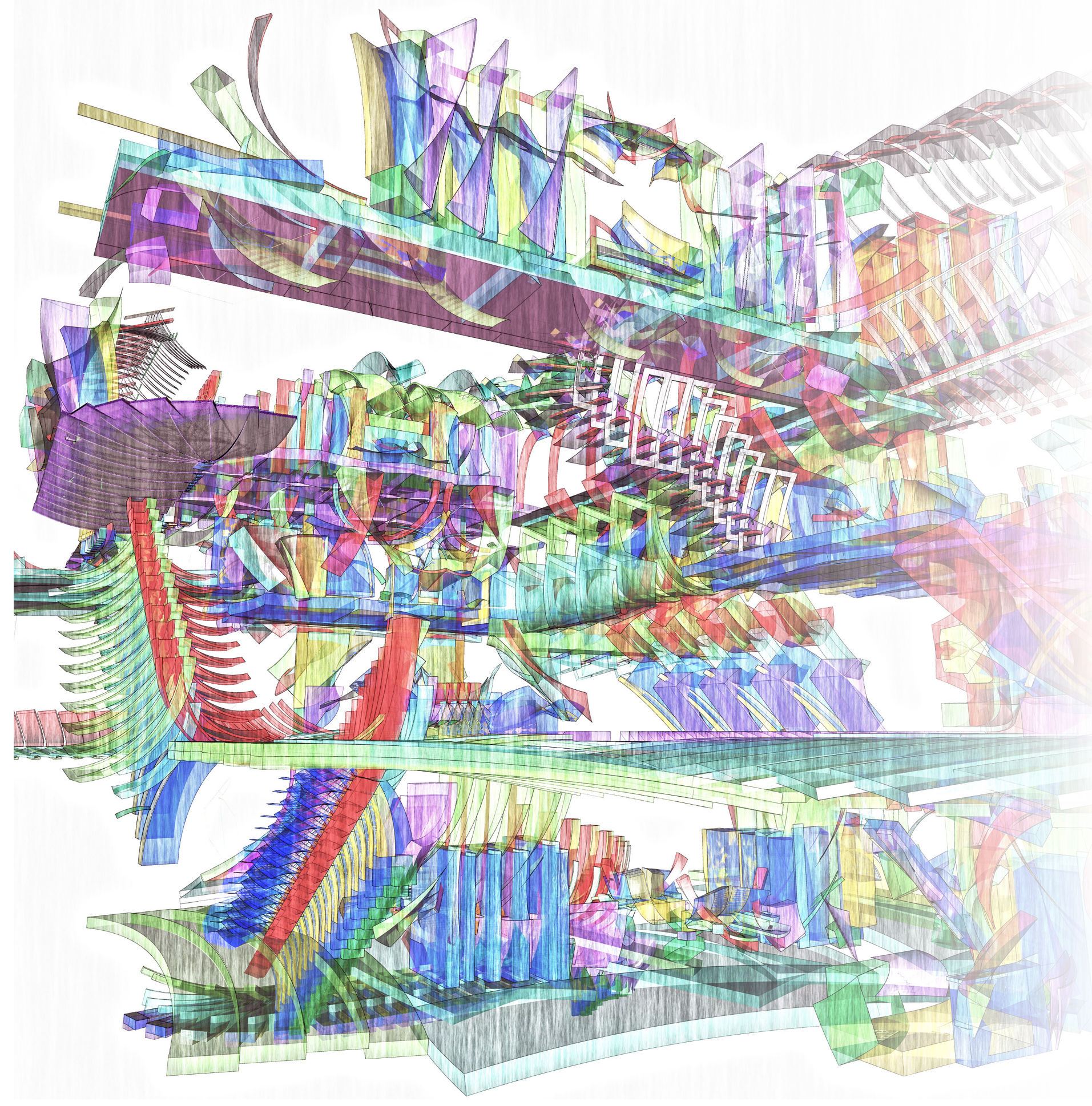

Fig. 102: Visionary Proposition - Overall Perspective 


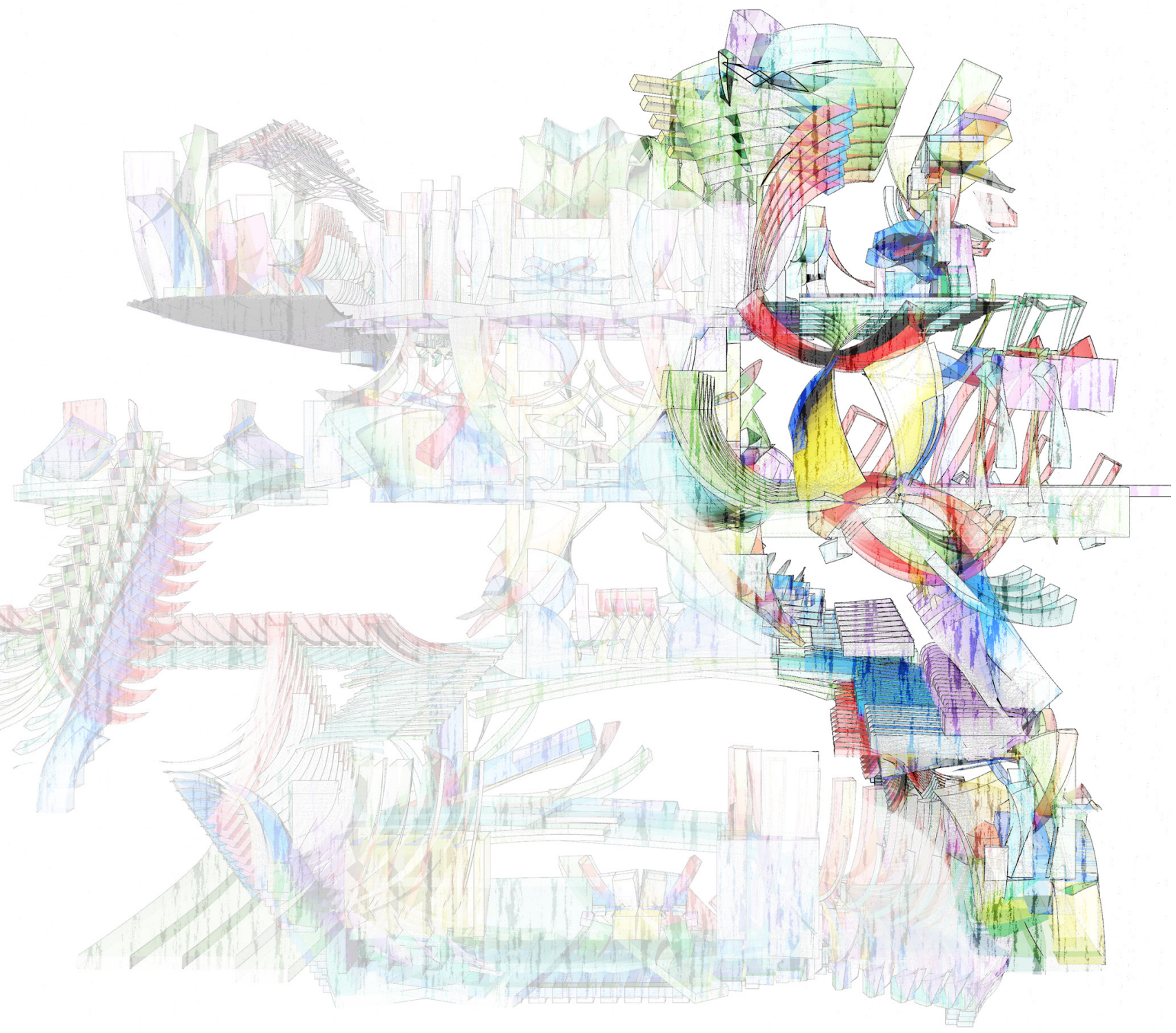

Fig. 103: Visionary Proposition - Transverse Section 


\subsection{Project Reflections}

This proposition is an investigation of an architectural subject not bounded by site, materials and function in favour of architecture as choreography: conception and organization of form as human kinesis. I started with the idea of a house, which then was abandoned as it was too restricting to sustain the exploration. This leads to the architectural subject, which allows for levels of sophistication and representation, and eventually, it uncovers the utmost potential of exploring architecture - the structure of anything. This proposal is a conceptual artifact that exists cognitively and, therefore, does not take the shape of a typical building. What this proposal reveals is an architecture rooted in motion and forces from the human body.

This work searches for a system of architectural meaning and an attempt to create a language for a choreographic architecture: an artifact that has something to say about how motion and forces of the body have an effect on the architectural object. We then create meaning for these objects as they are internalized through our bodies as we perceive them. Thus, this proposal embraces the idea that buildings are not simply physical entities but artifacts with meaning, through its ability to reveal kinesthetic empathy in architecture.

Furthermore, it is critical to acknowledge this proposal is not objecting to the importance of building. Architecture needs to see whether ideas could withstand the consideration of building, function and time in today's context. As Manfredo Tafuri once told Peter Eisenman, "Peter, if you don't build no one will take your ideas seriously. You have to build because ideas that are not built are simply ideas that are not built" (Ansari, 2013).

A building could be manifested by applying the developed theories of a choreographic architecture. This does not necessarily suggest the building would adopt the frenetic forms derived from the Visionary Proposition. The parameters of movement and form would have to be re-examined to adapt to a "real building." When referring to the notion of a real building, this implies the structure must function and stand up. What this isn't suggesting is that it has to look like it functions and stands up. It's critical to remember a choreographic architecture should not only defy the expectations of what a building should look like, but also what it should do: buildings should not become the backdrop of our lives, but the one that participates in our very existence; they should not only house other pieces, but be pieces of their own. This notion is challenged in the next section, where architecture is choreographed in environmental mediums, and designed to respond to both the surrounding conditions and the inhabitant. 


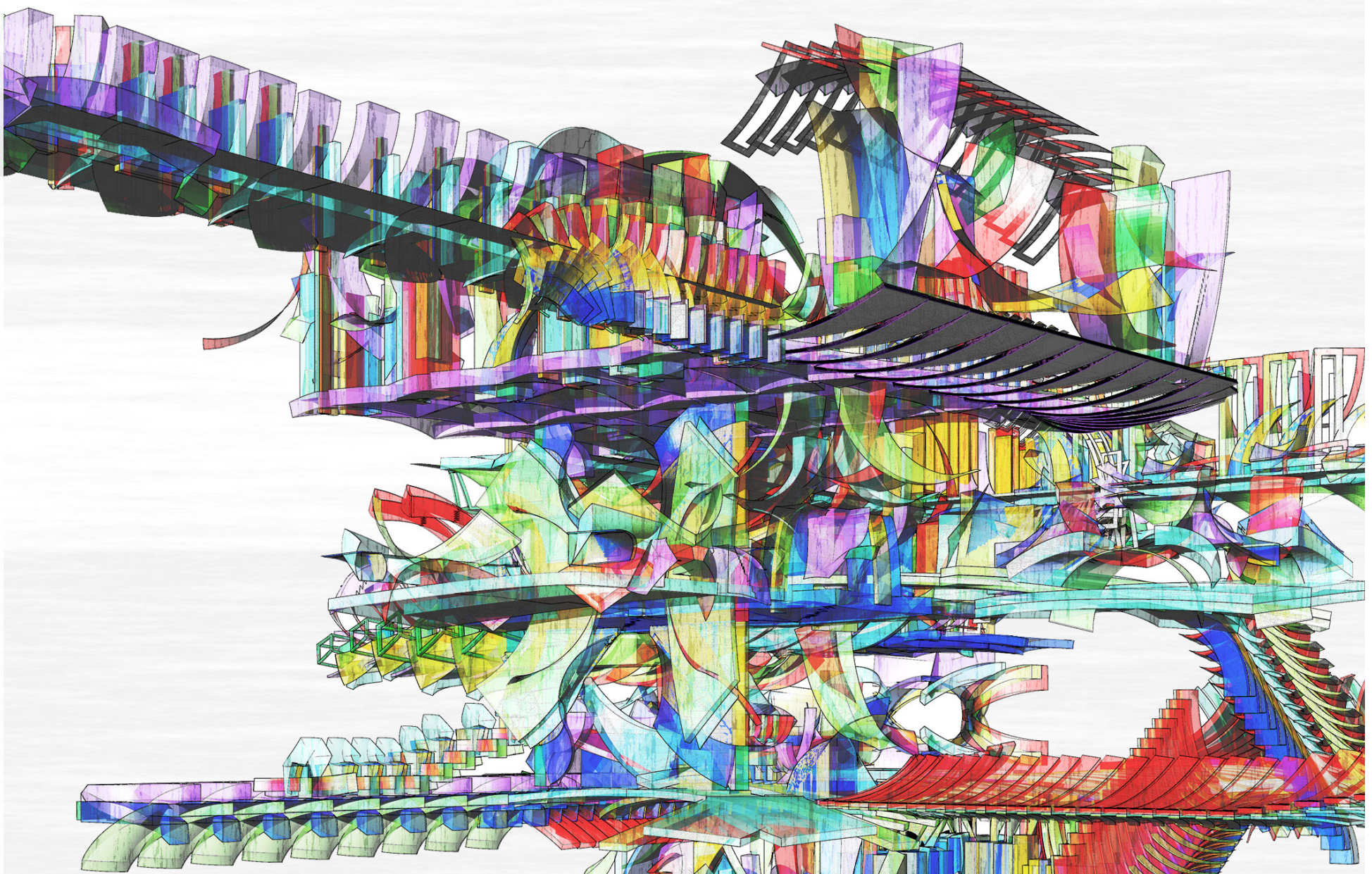

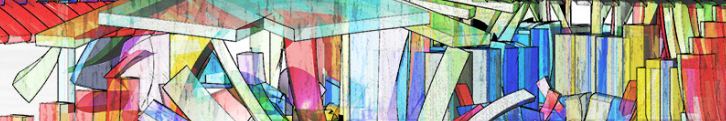

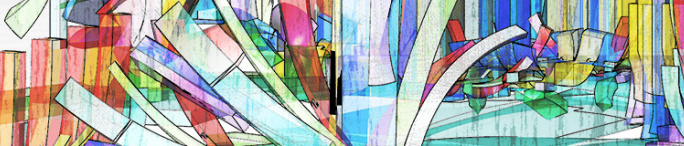

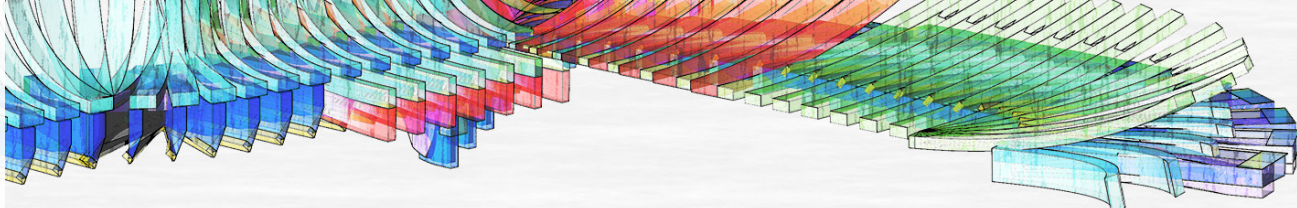




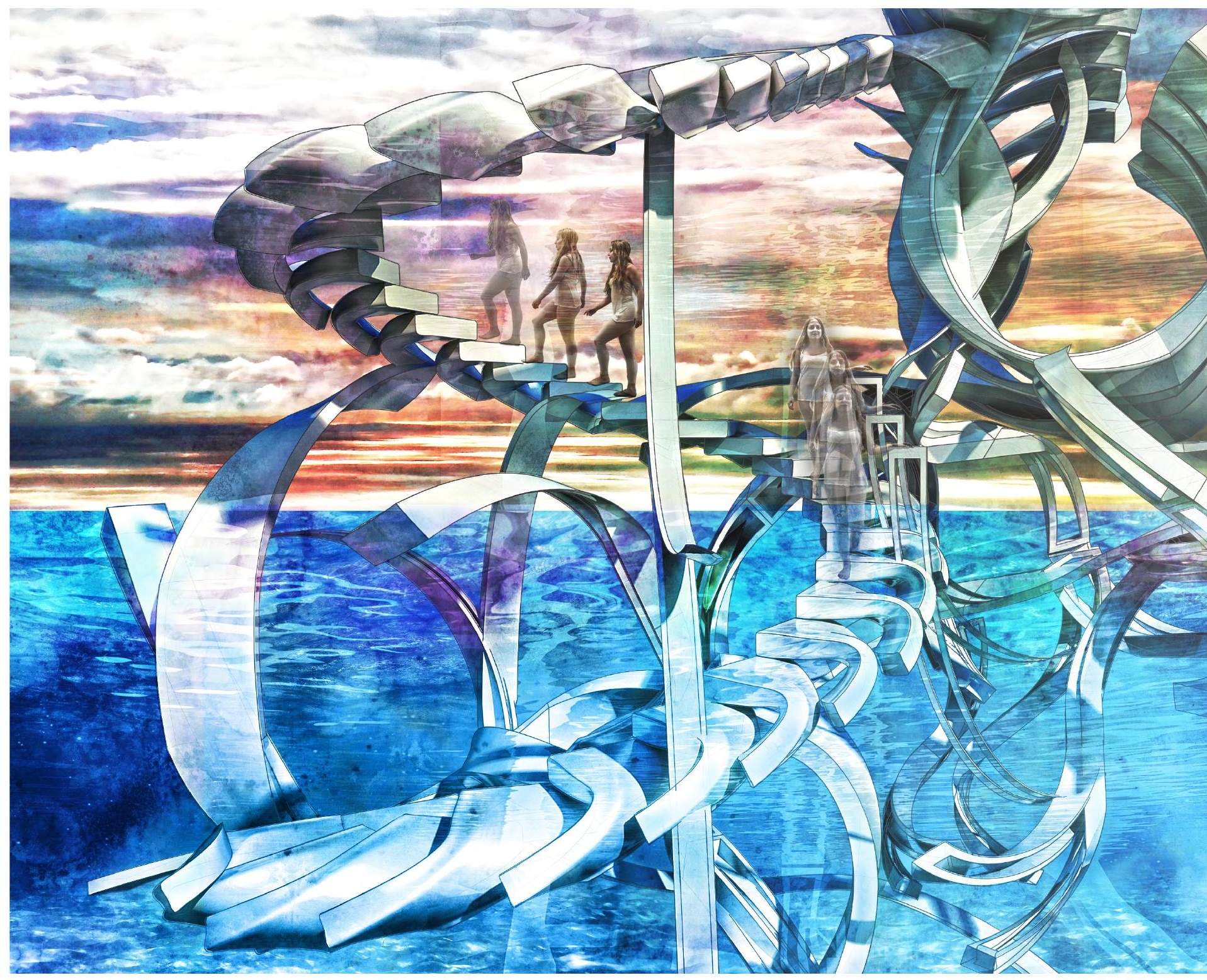




\section{Move Architecture | Move Us}

"The task of architecture is to "make visible how the world touches us'"

- Merleau-Ponty (1964)

The final thesis proposition aims to move the dweller emotionally through an architecture that moves. Similar to the previous design experiment, for architecture to move mandates the embodying of human kinesis into its formation. In this case, affective qualities and affordances are rendered into the built environment resulting in a bodily resonance in the inhabitant, whether in the form of sensations, postures or movements through space. Motion and emotion are thus innately connected: a person is moved by the potential of movement depicted in the architecture (perception, impression and being affected), and moved to move (physical action, expression or emotion) (Fuchs et al., 2014). 
This project investigates an architecture that moves through the exploration of physical movement, empathy and being moved emotionally. The formal language of the architecture was generated from forces of human kinesis and choreographed in space for the dweller to experience. When inhabiting the spatial sequence, the dweller's body perceives and internalizes the sensations of the virtually moving forms, an empathetic response towards the choreographed architecture. The built composition provides a greater connection with the dweller by embracing both physical movement of the body and virtual movement of the architecture, and thus, moving the dweller through the phenomenon of kinesthetic empathy. Here, an architecture that moves, moves us; a spatial performance created to free our minds and induce our imaginations.
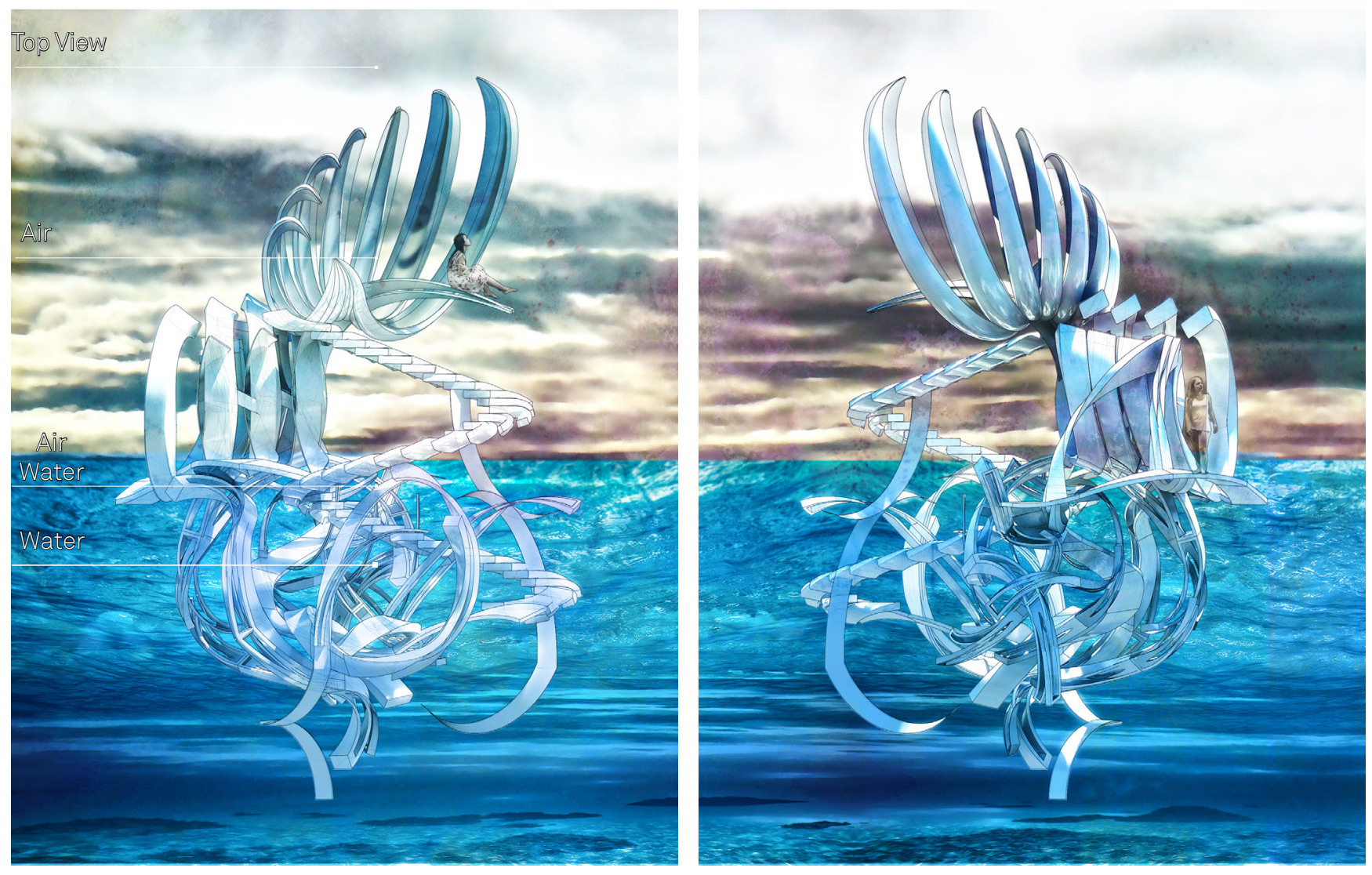
The architecture is designed to interact and respond to three distinctive environments that move the dweller, both physically and emotionally. These settings include the body being submerged underwater, positioned at the interface between water and air, and immersed within the sky above. The composition underwater is fluid and open, responding to the resistance of the waters; this condition allows space to be explored freely, stimulating the inhabitant's curiosity and imagination. At the interface of water and air, the architecture facilitates the convergence of both mediums, creating a tranquil environment for a moment of self-reflection and resting. Lastly, the summit of the structure opens up to the sky above, encouraging the dweller to daydream and wonder. In these three realms, the architecture engages with the environment above, below, and on the waterline, while allowing the inhabitant to experience these surroundings intimately. The structure's formation suggests how one moves through each setting, forming a greater bond between architecture and dweller. Together, the natural environment and the architecture are choreographed to spur a resonance within one's body when encountering the subtleties of change through space.
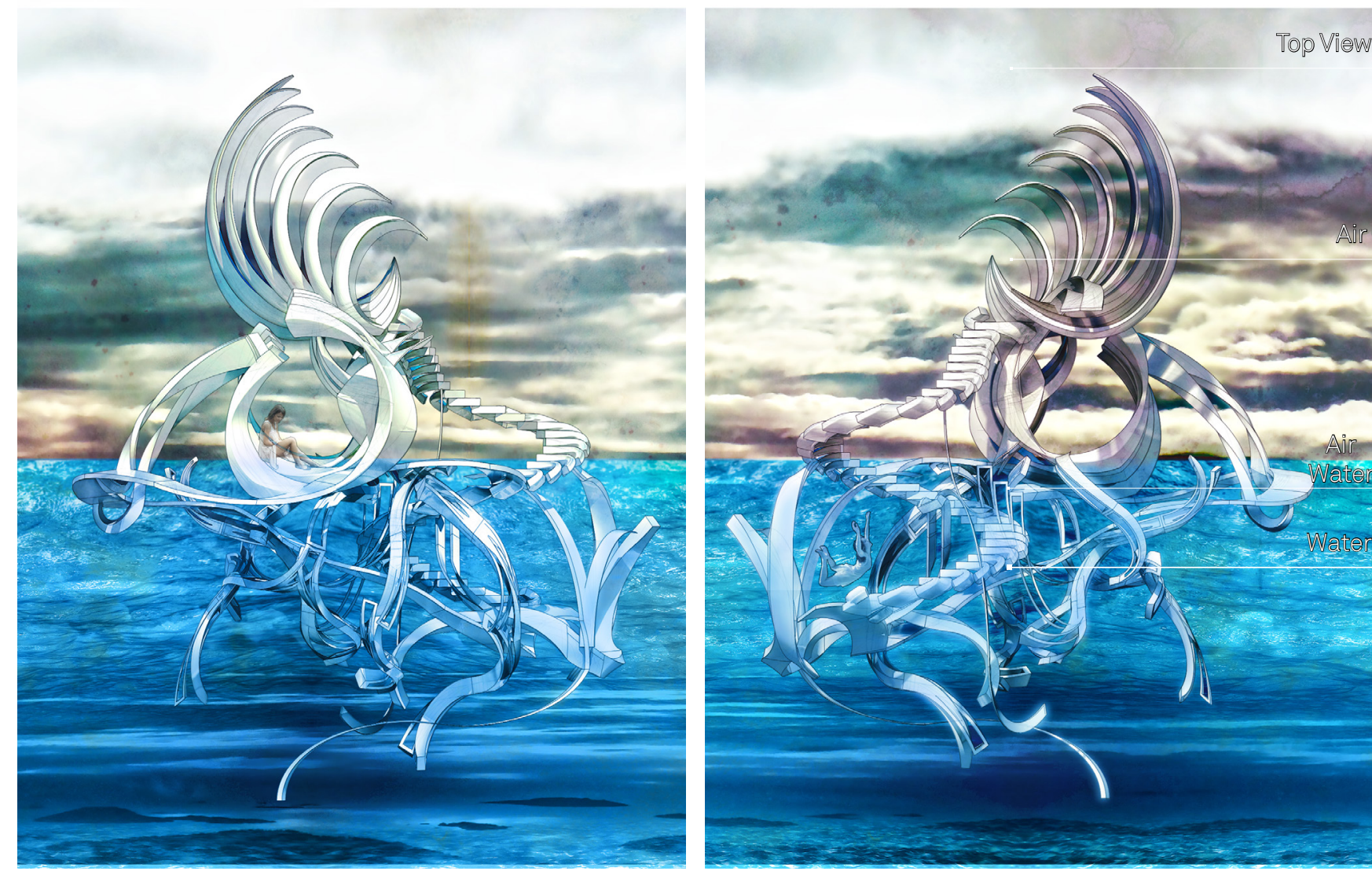

Fig. 106: Design Elevations 


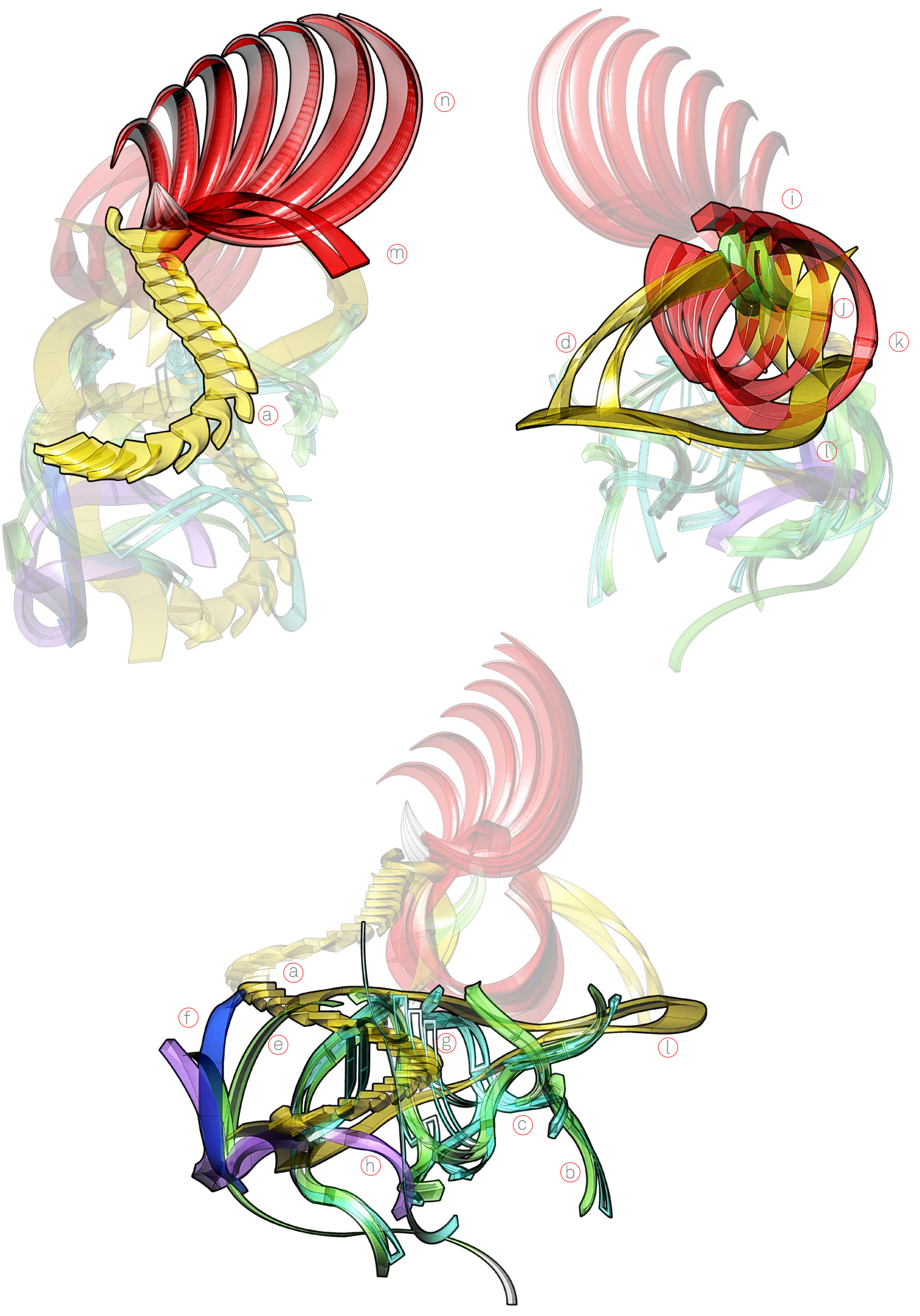


Movement Derived Components

Movement $\begin{gathered}\text { Generated Extracted Element } \\ \text { Component }\end{gathered}$
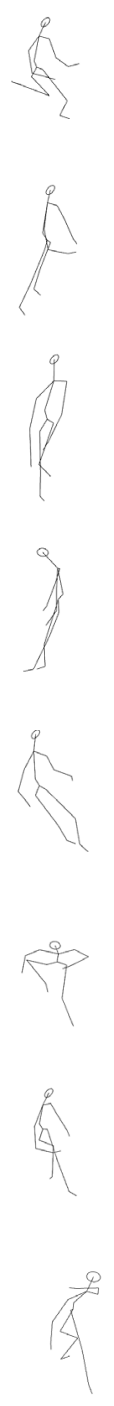
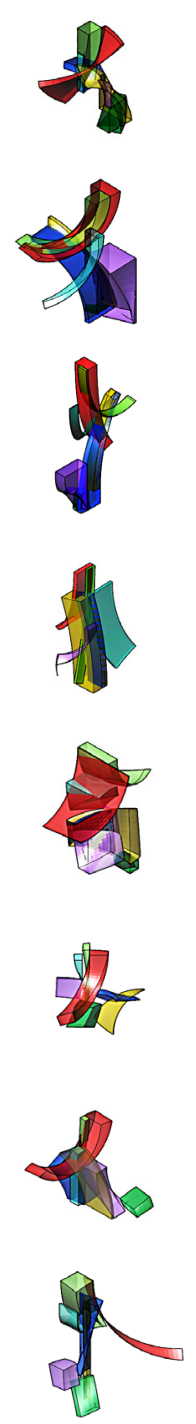
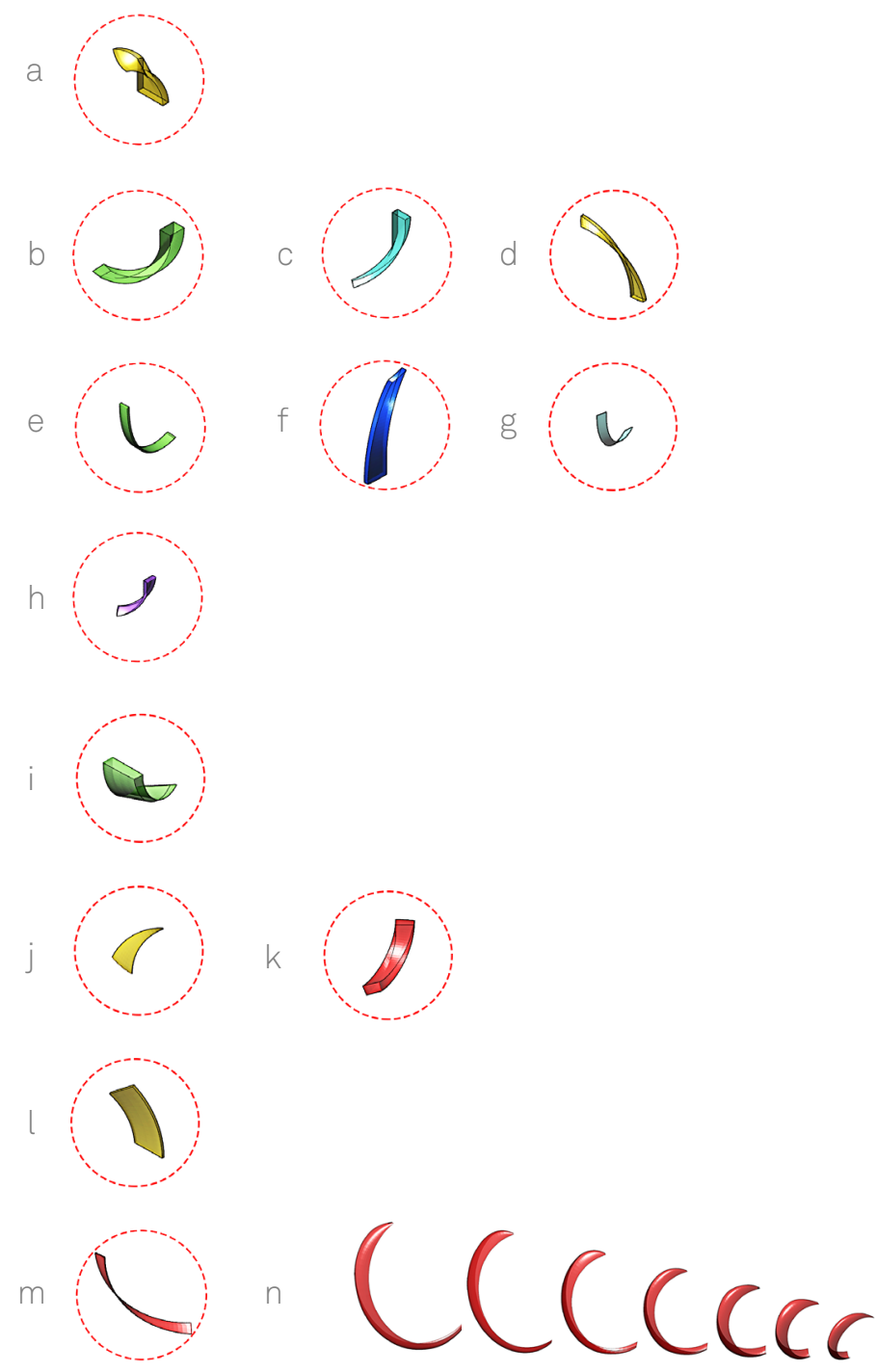

Variation Types

Fig. 107: Movement Derived Components

160 


\section{$08.1 \quad$ Materiality}

Beyond the notion of movement, the design has also considered the structure and materiality of the overall composition. In response to the design's materiality, the building is intended to be constructed in fibreglass reinforced plastic. Commonly used in the automotive and naval industries, this material composition is strong and lightweight, and can be easily moulded into complex geometries. In addition, the main elements have been composed to further reinforce the structural integrity of the design. As evident in the floor plans, the enclosure on the water's surface has been positioned towards the structure's centre of gravity (Fig. 109). The elements located on the surface of water widely spread along the horizon, providing further stability of the building. In addition, the composition is designed with a larger footprint at the bottom, gradually decreasing in footprint at the summit. This factor also further contributes towards structure's stable equilibrium (See Elevations in Fig. 106).

Additional factors that reinforce the structure's rigidity include the design of the summit's members. The elements at the summit of the building embrace a saddle-like shape of double curvature; this geometry reduces bending deformation and rotation, while taking into account all loads. This portion of the design is reinforced in the rounded enclosure below, balanced by supporting members on the water's surface. Furthermore, elements that are submerged in the waters are reinforced by the path that meanders below and along the water's surface. The path acts as a base that spreads the weight of the structure on the horizontal plane (Fig. 109).

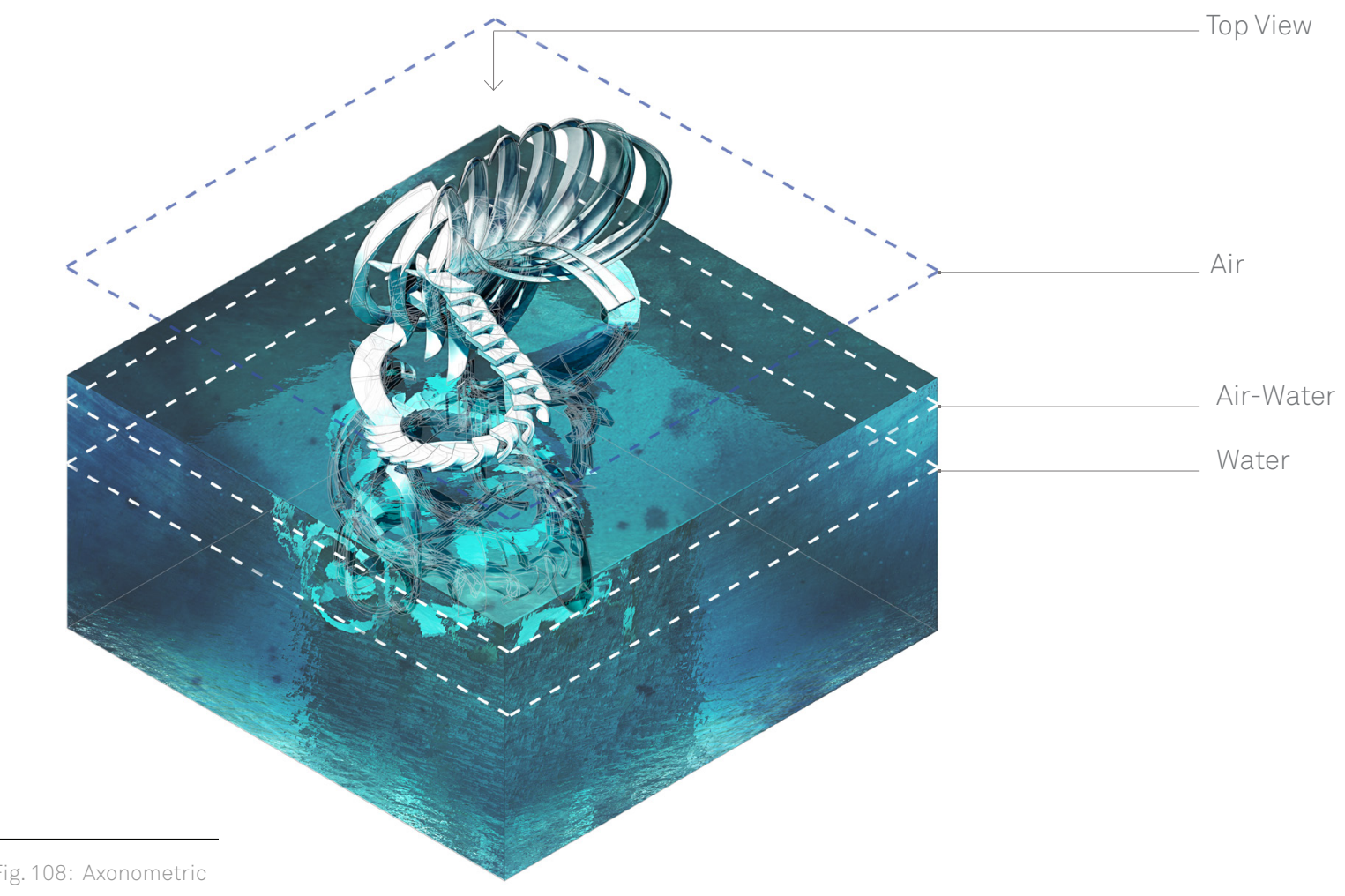



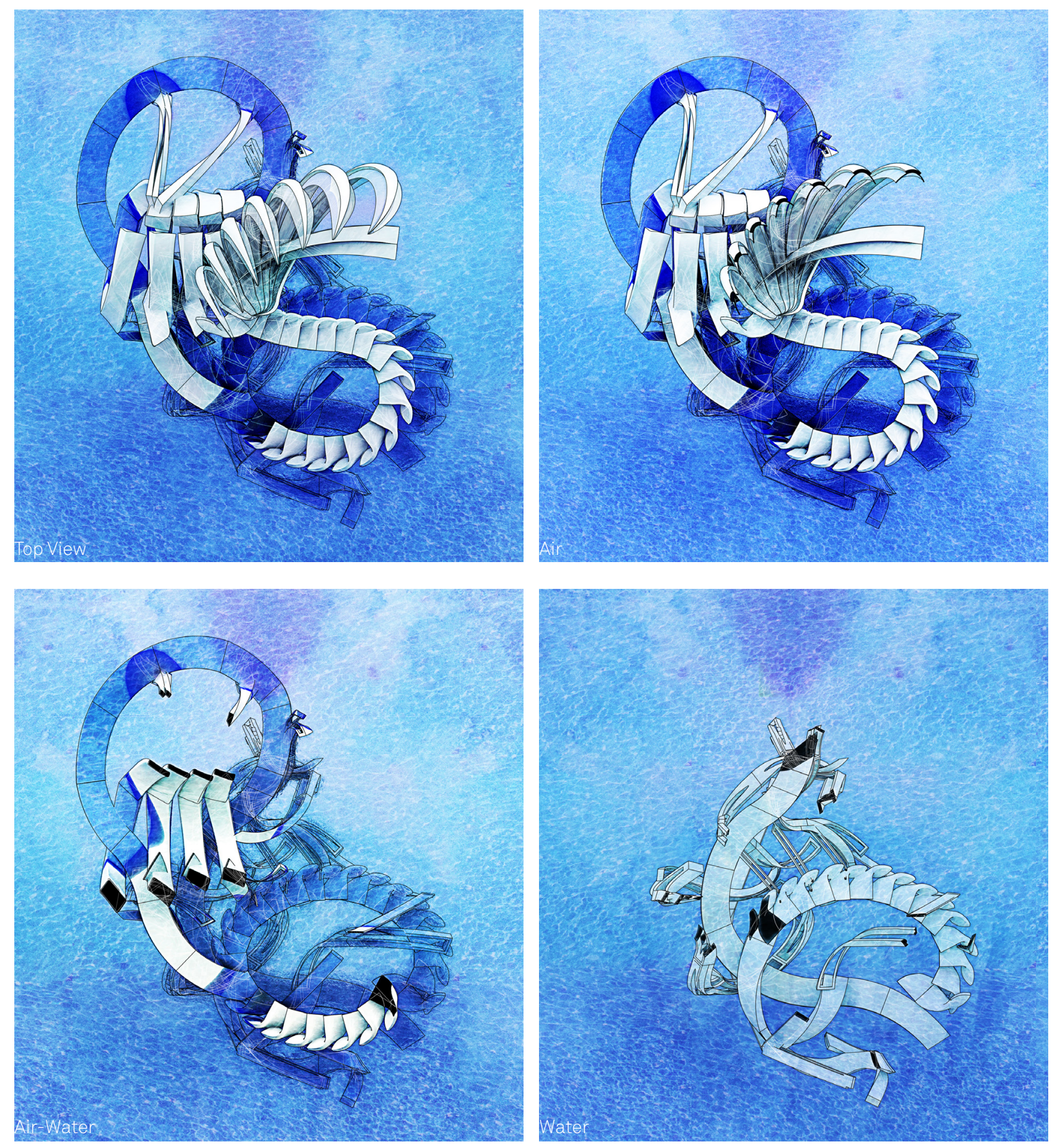

Fig. 109: Floor Plans (Top Left: Top View; Top Right: Air; Bottom Left: Air-Water; Bottom Right: Water) 
08.2 Spatial Narrative

Transition from Air to Water

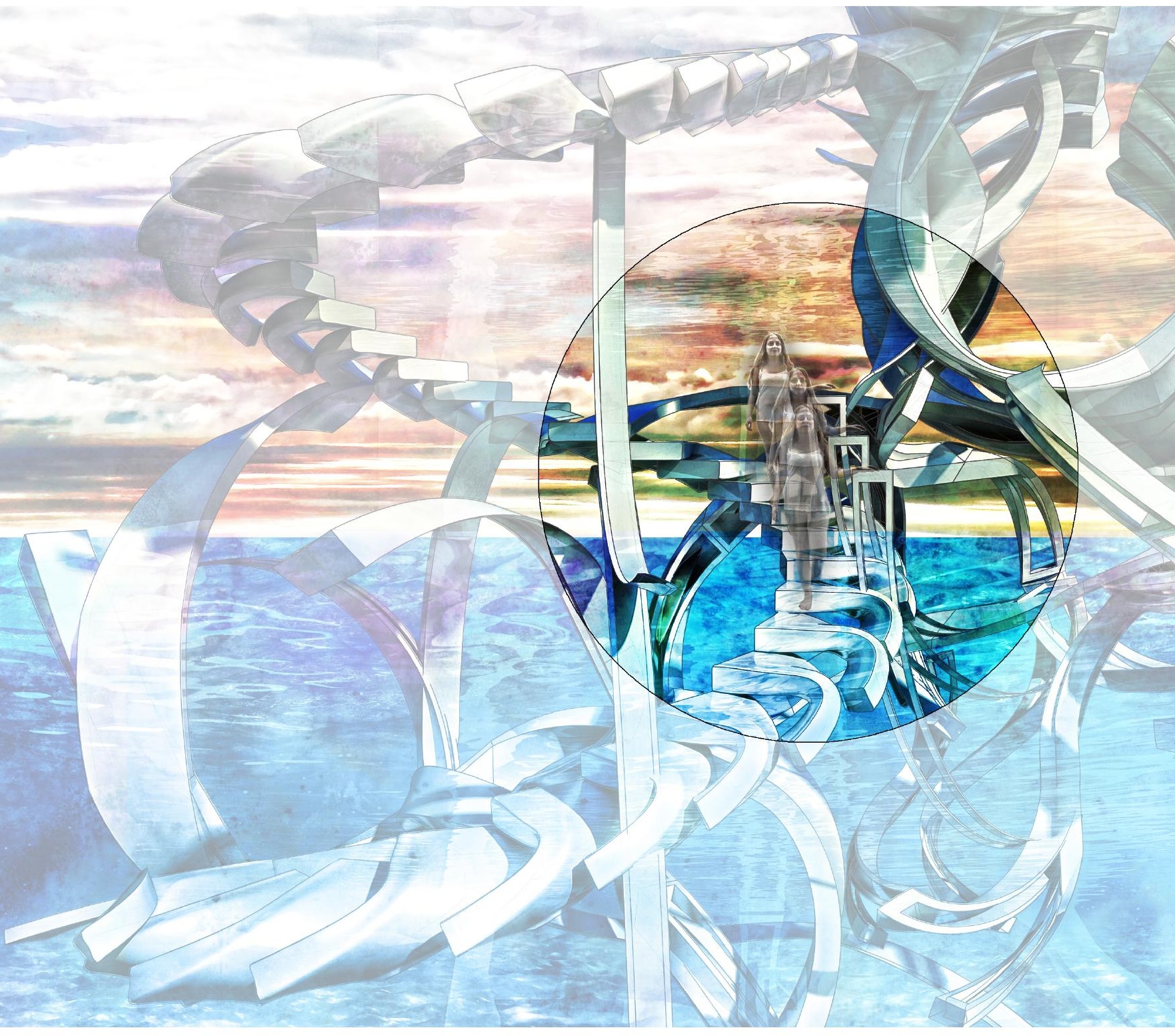




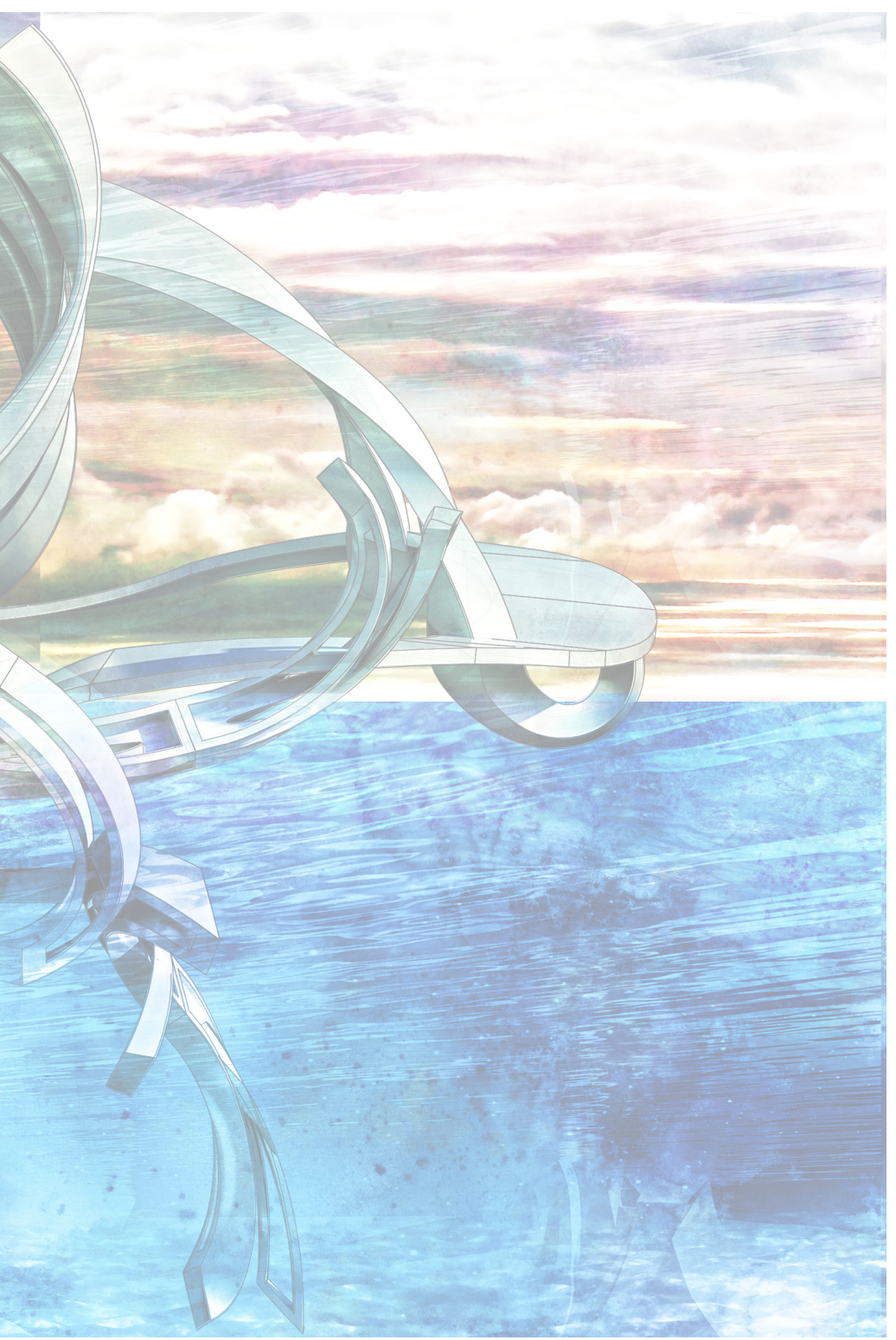

The next section illustrates the spatial experience within the three zones (underwater, the water's surface and air), along with the transitions between each space. The narrative begins by transitioning from air to the underwater realm below. 


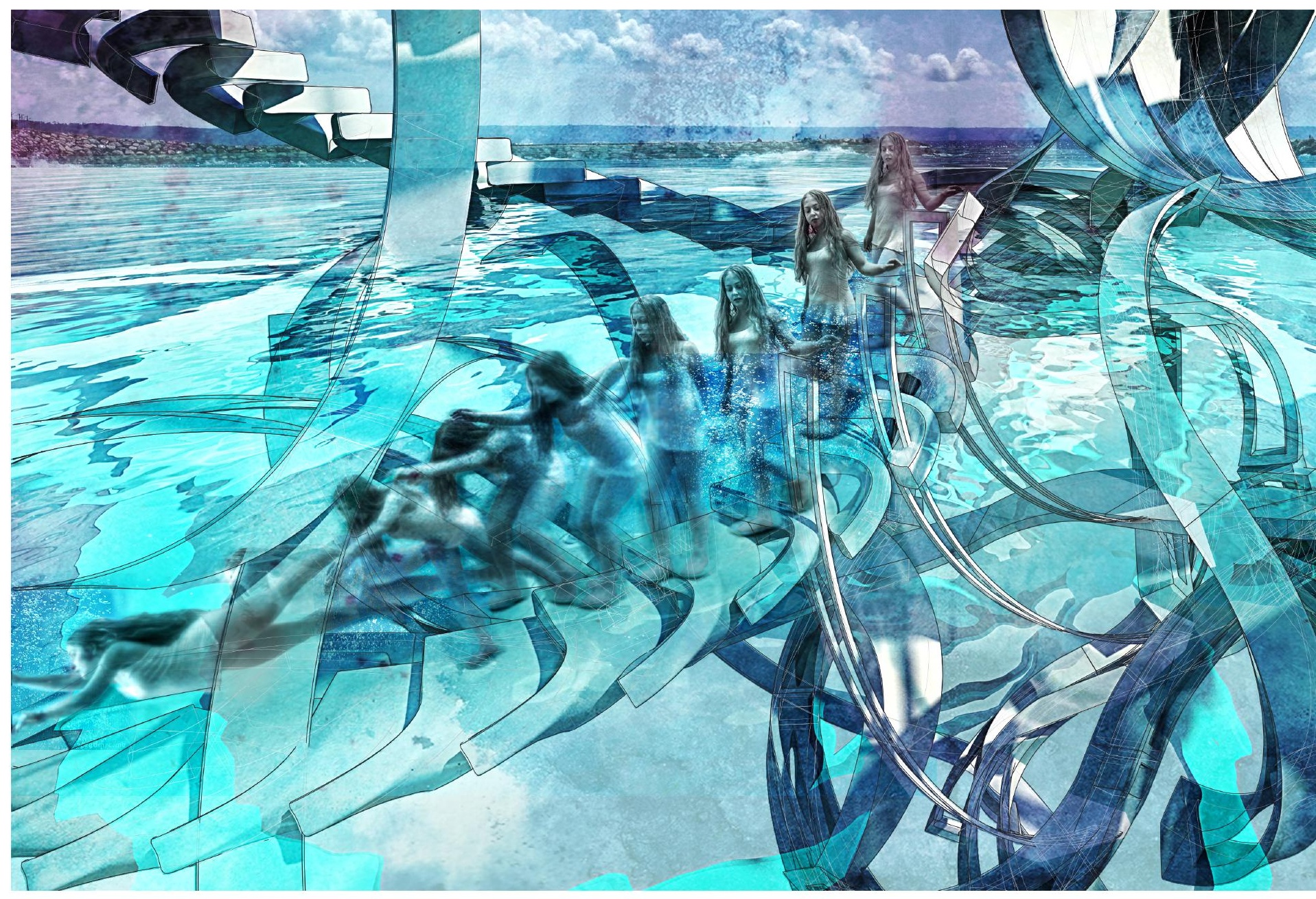

Fig. 111 : Submerging into the Water 


\subsubsection{Water}

Architecture is choreographed in the medium of water for the body to explore space weightlessly. The fluidity of the forms resists the pressure of the waters, allowing both the dweller and the water to flow effortlessly throughout the structure. The forms collide, intersect, deform and unfold allowing the eye and body to discover various organic routes. The sweeping forms wrap around the stair, guiding the dweller at the point of entrance, looping around the space and spreading outwards into the deep waters. A pathway meanders through the sweeping figures, leading the body to encounter the depths of the water below while directing one back to the surface above. The choreography and movement of the architecture elicit the sensation of buoyancy within the inhabitant. By responding to the condition of the waters, the architecture creates an empathetic relation with the dweller, provoking one to perceive and embody the fluidity, openness and weightlessness of space. The realm underwater entices the dweller to explore the choreography of architecture, only to find their imagination awakened.

Her body surrendered to the waters below as she dove beneath the arch in front of her. She swam above the last few steps of the winding stair, slowly transitioning into a delicate path. The forms that once gently grazed her hand above were now apparent below. The bending and folding of organic figures have spread throughout the waters, allowing her body to freely explore the structure weightlessly. As she roamed underwater, she could feel the sensation of the unfolding and colliding of forms that gently weaved around her. She felt in sync with her surroundings; together the forms and her body resisted the pressure of water, allowing them both to simply wander through space. As she followed the meandering path around the sweeping forms, she found her body submitting to the force of the water as she began to gently rise back to the surface above. 

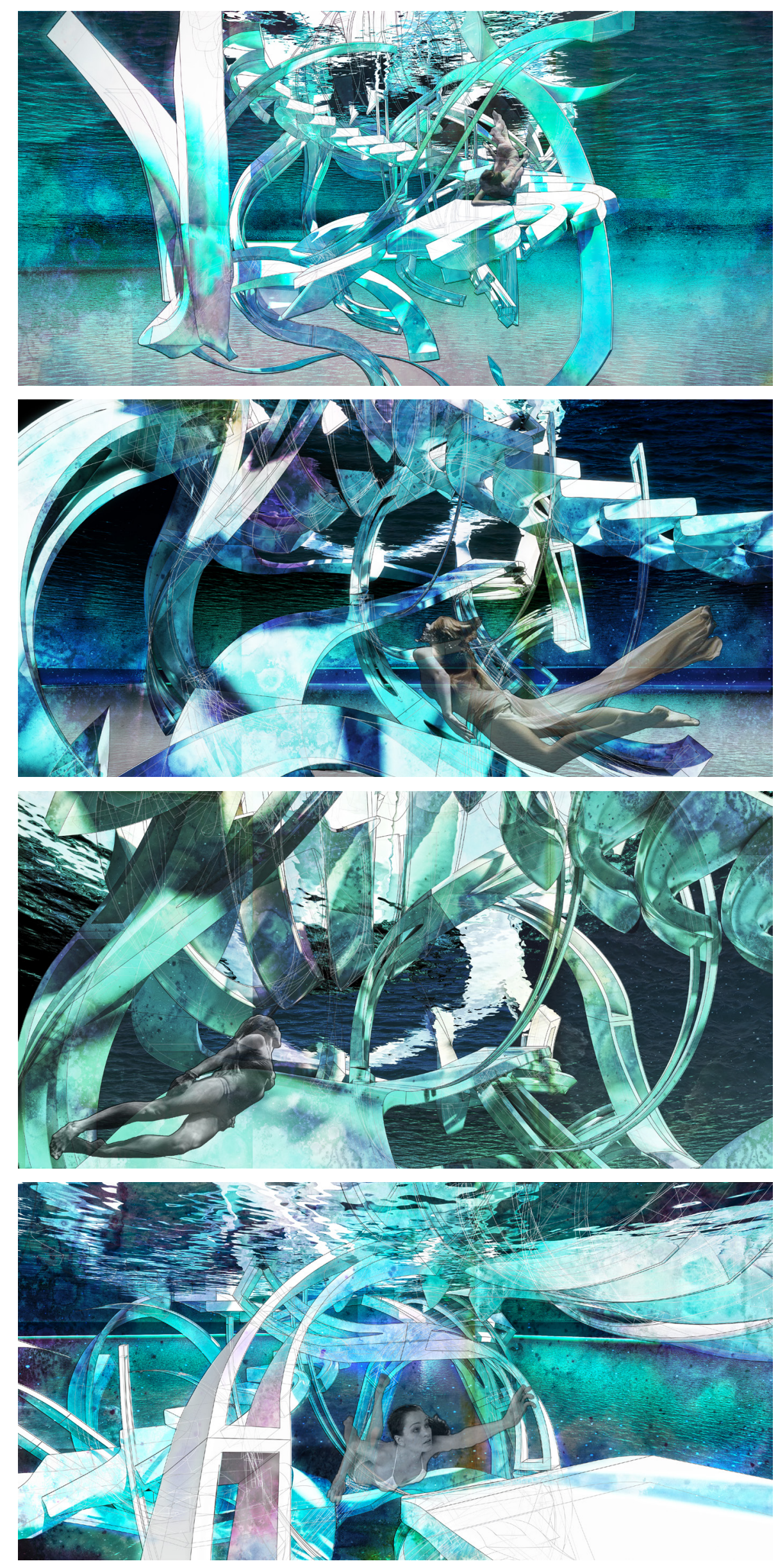


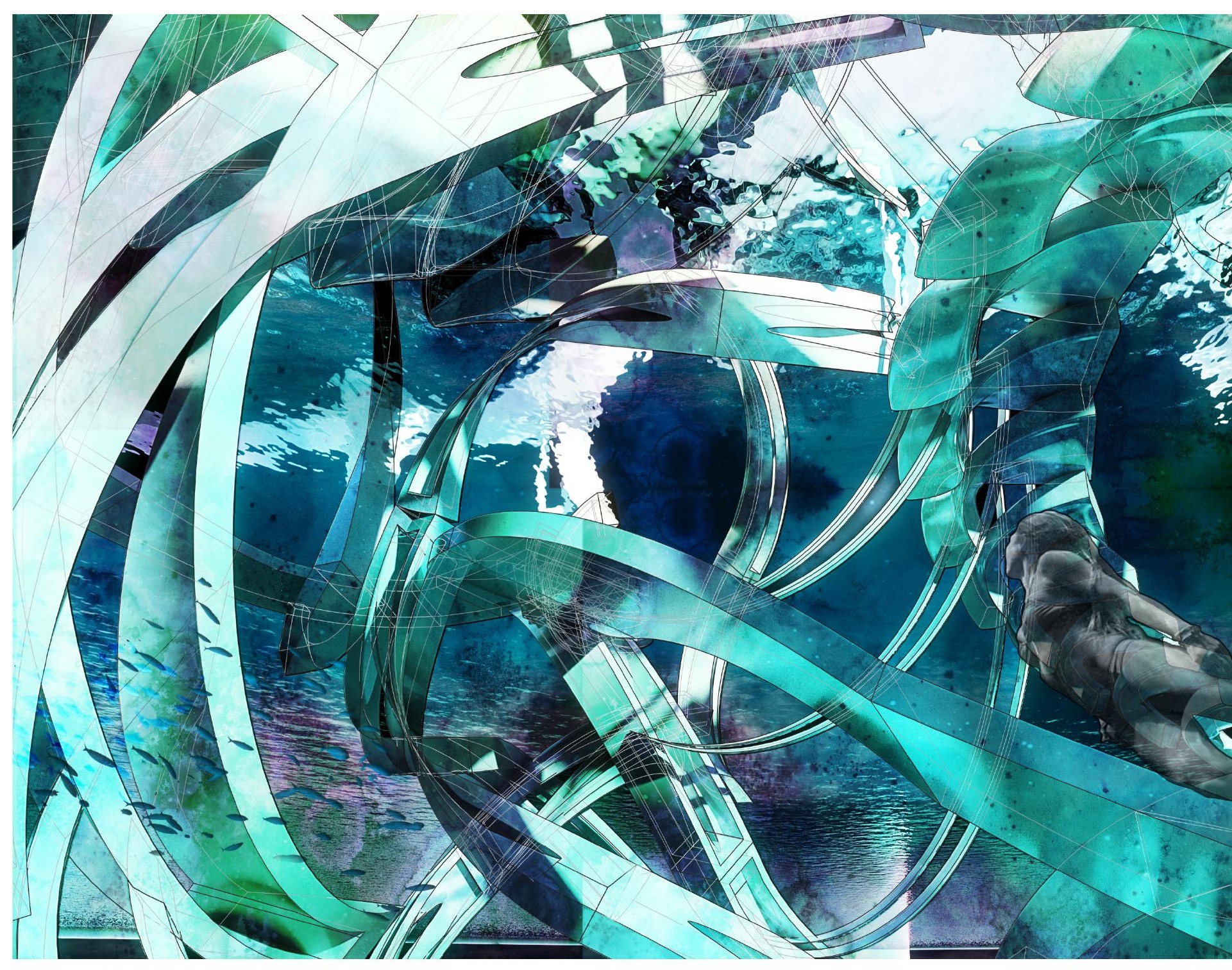

Fig. 112b: Spatial Experience Underwater 


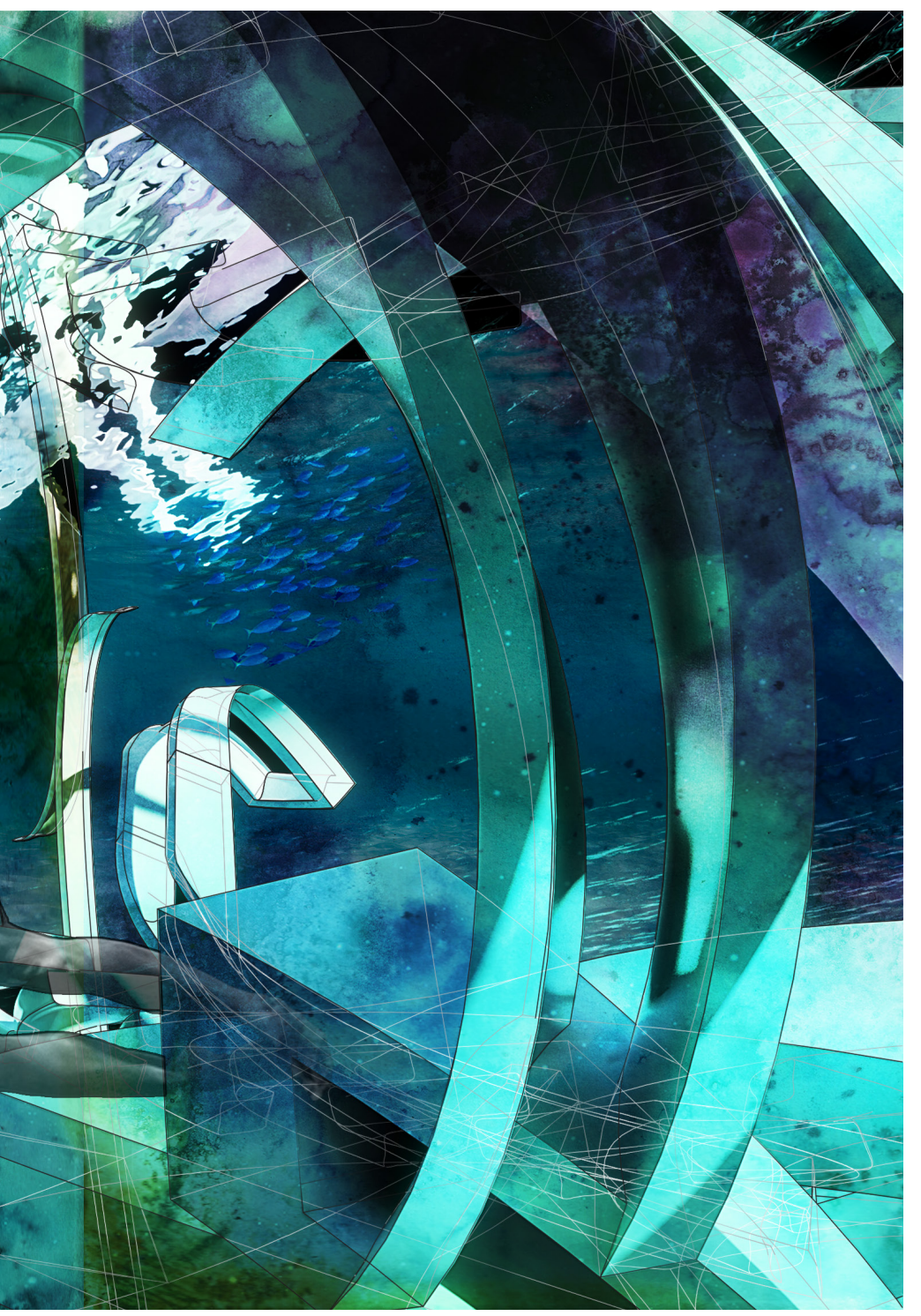




\subsubsection{Spatial Narrative}

Transition from Water to Air

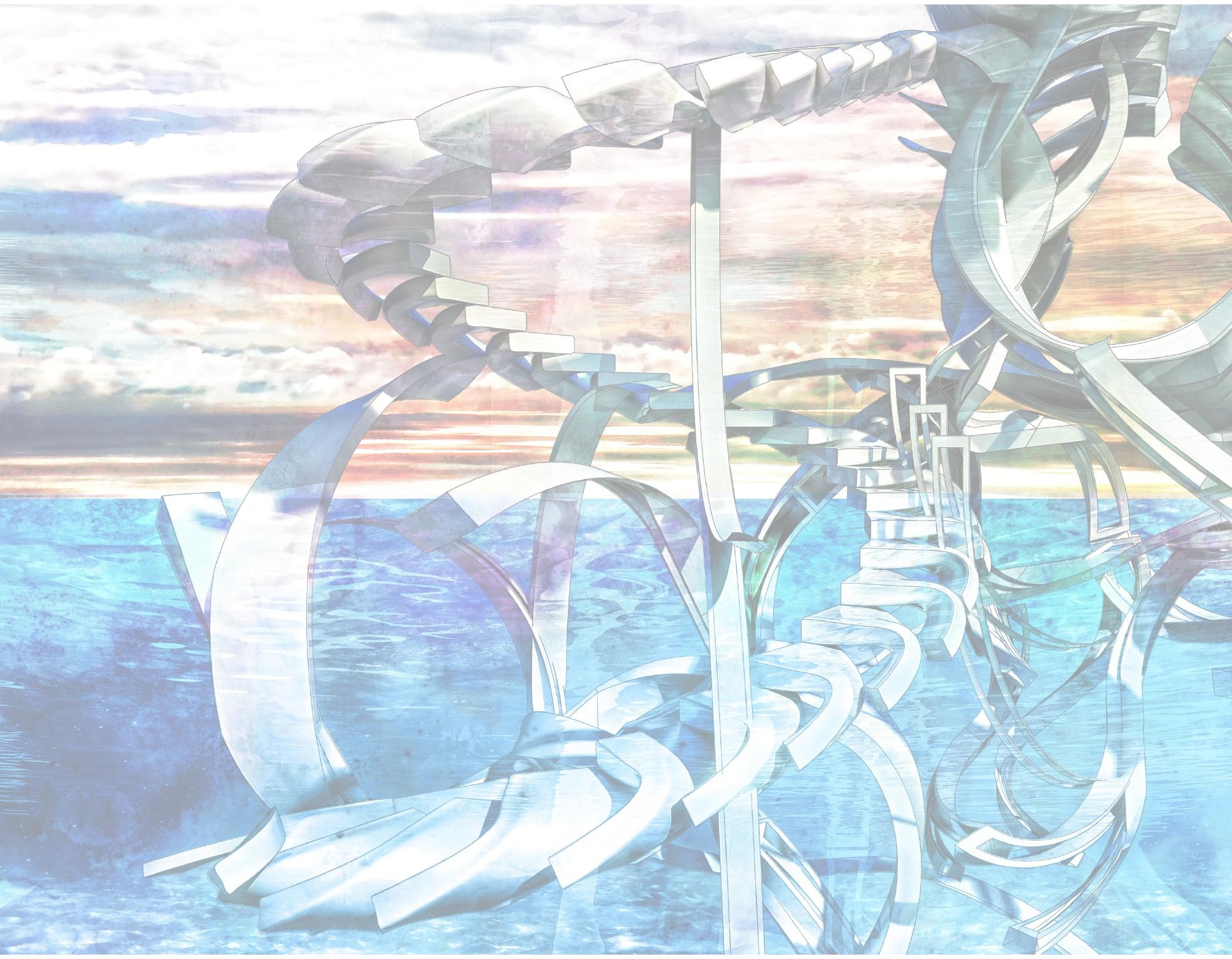

Fig. 113: Spatial Narrative - Transition from Water to Air 


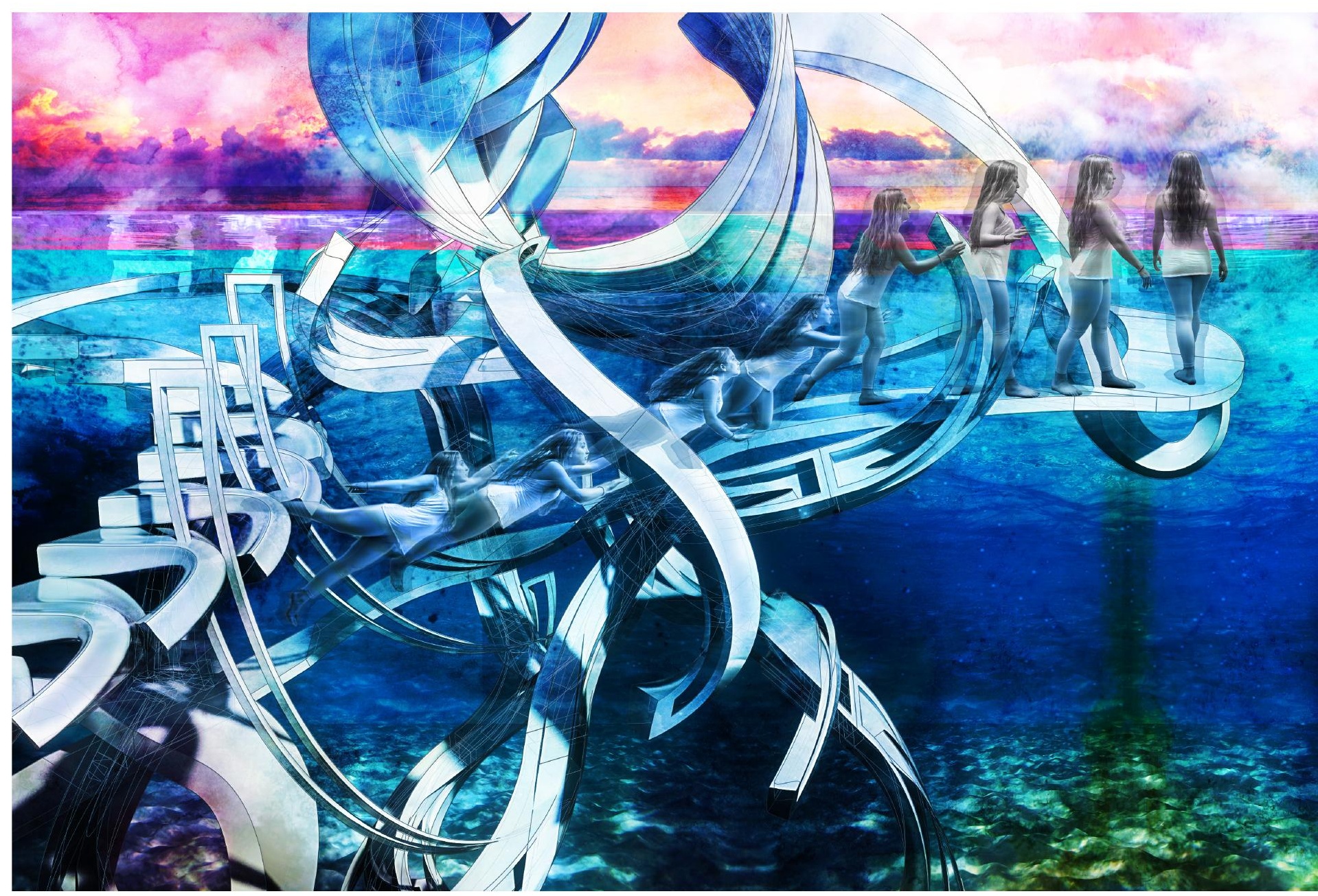




\subsubsection{Transition from Water to Air}

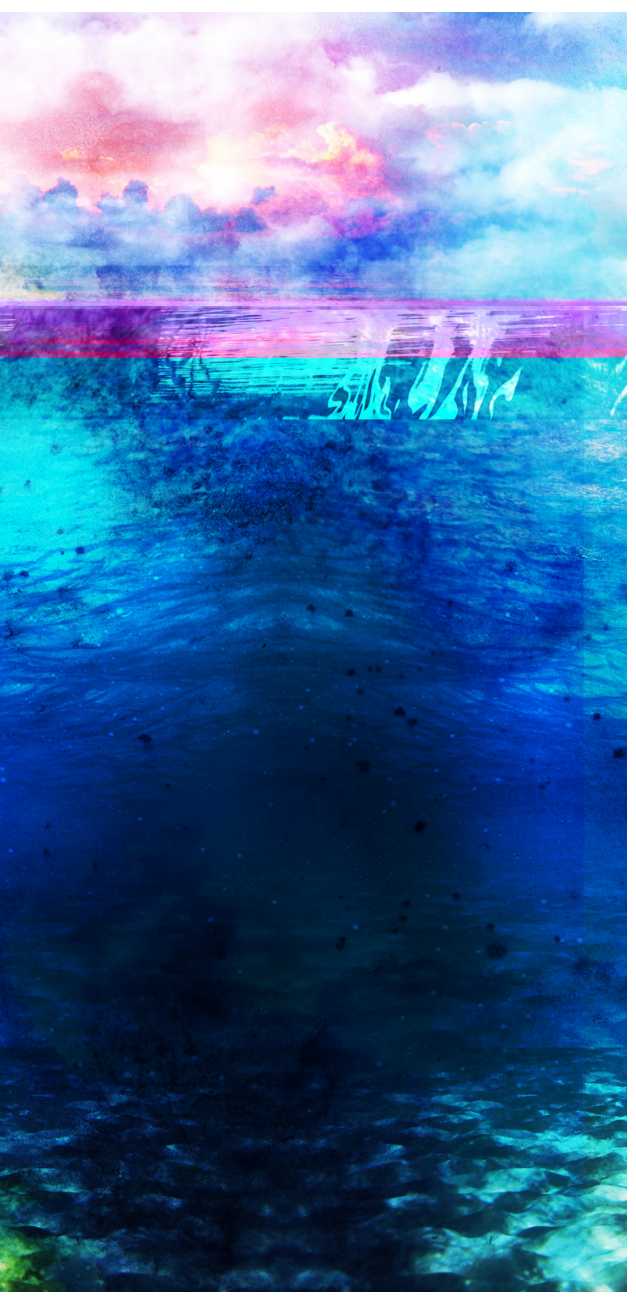

The architecture guides the body's movement in space when transitioning from underwater to the surface above. The pathway from below rises as it nears the surface of the water, allowing the inhabitant to follow its trail. Once the swimmer draws up towards the water's edge, a form in reach comes into sight. This component entices the swimmer to come in contact with it, as it facilitates the body's transition from swimming to moving on foot. When on foot, the path weaves around the enclosure positioned above water, giving the dweller a chance to observe the immediate surroundings. Eventually, the trail leads into a new space for inhabiting.

She lends herself to the path that emerged from underwater to the air above. Her body rose closer to the trail, eventually meeting the surface as they both reached the edge of the waters. A familiar form emerged beside her, guiding her hand to pull herself up into the open air. Now lifted up off the surface below, she continued to follow the path, gently grazing her feet against its presence. Her feet were timidly submerged in the waters as she continued to follow the trail that weaved around the adjacent enclosure. She found herself at the entrance of the space. She peered through and invited herself inside for a moment of rest. 


\subsubsection{Water - Air}

The architecture is choreographed at the interface between water and air, allowing the dweller to engage in rest and contemplation. The intimate enclosure is gently immersed in the waters, yet slightly open for air to penetrate through the space. The form of the enclosure is left ajar at the top and along the perimeter, delicately revealing itself to the exterior surroundings. The components of the shell fuse towards the surface of the waters, providing space for the dweller to sit and rest. The choreography of the architecture allows for a convergence of both mediums in this realm, where one can gaze upon the surface of the water and feel the air seep through the openings. When inhabiting this environment, the body comes close to a third space, a virtual meeting point between the two fluids. The calming of the waters and air slows the body and its movements, allowing a moment for self-reflection. Together, the water, air and architecture remain close to the dweller provoking the mind to reset to the body alone.

She sat still in the enclosure that embraced her body. Her feet grazed the surface of the water as she gazed upon the gentle waves that entered the space. As she sat quietly, she began to feel a breeze of air that gently swept through the enclosure. The air seeped through the openings from above, passing by her body and trickling down towards the edge of the water. She could feel the sense of turbulence as the air and water danced around her feet. The gentle movement of the fluids slowed her movements, allowing her to self-reflect, and simply be in her own body in this time. 

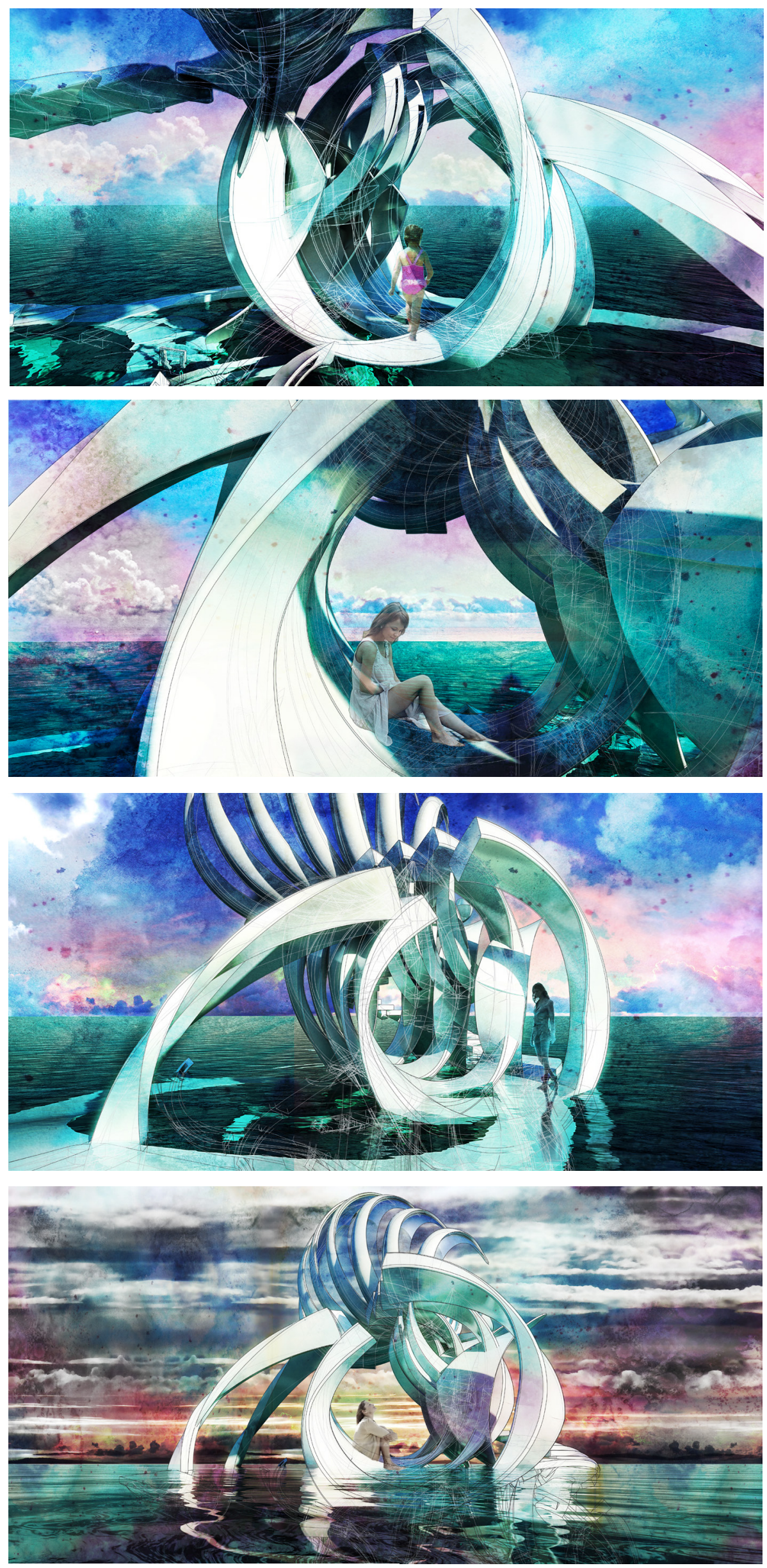


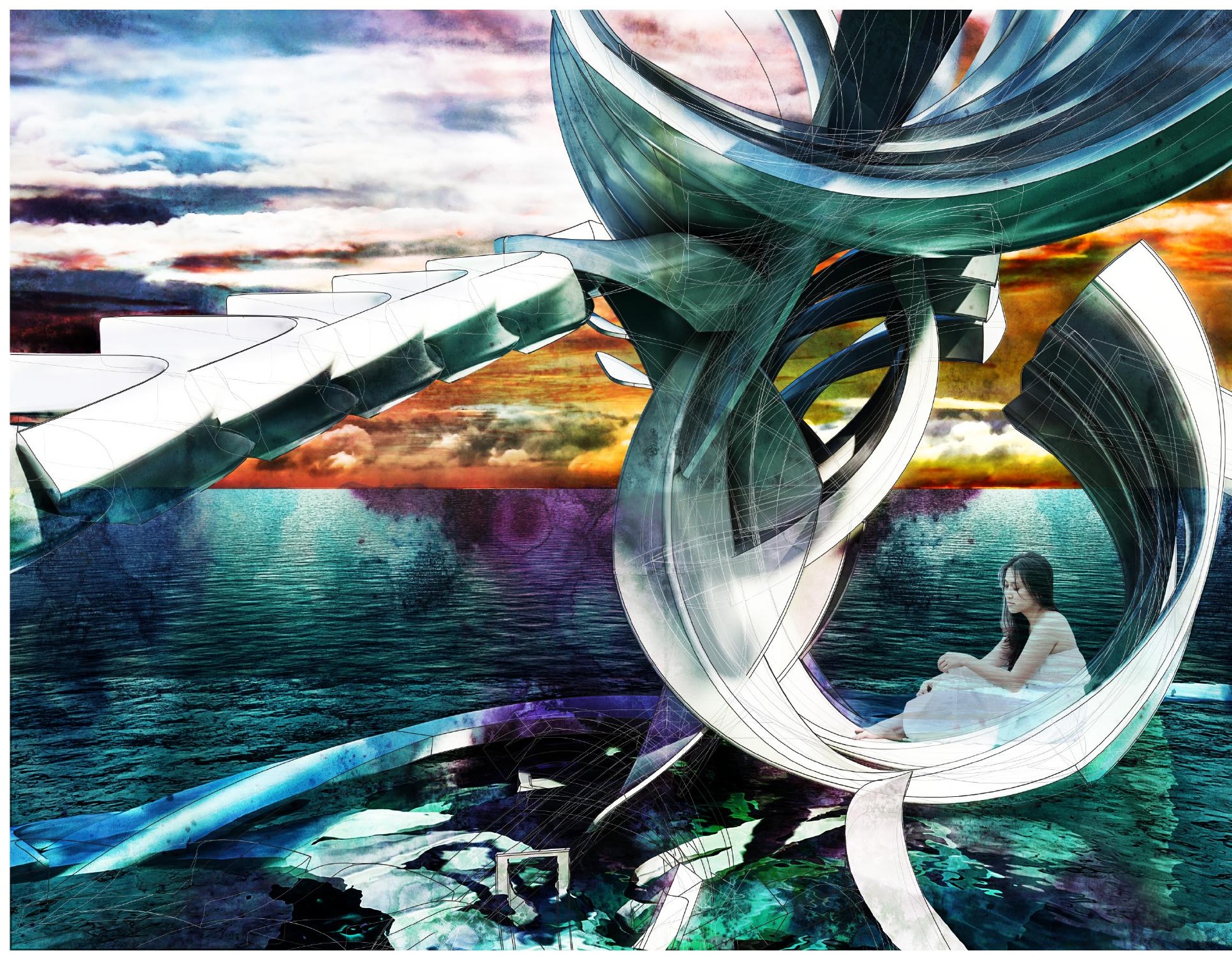

Fig. 115b: Spatial Experience on the Water's Surface 


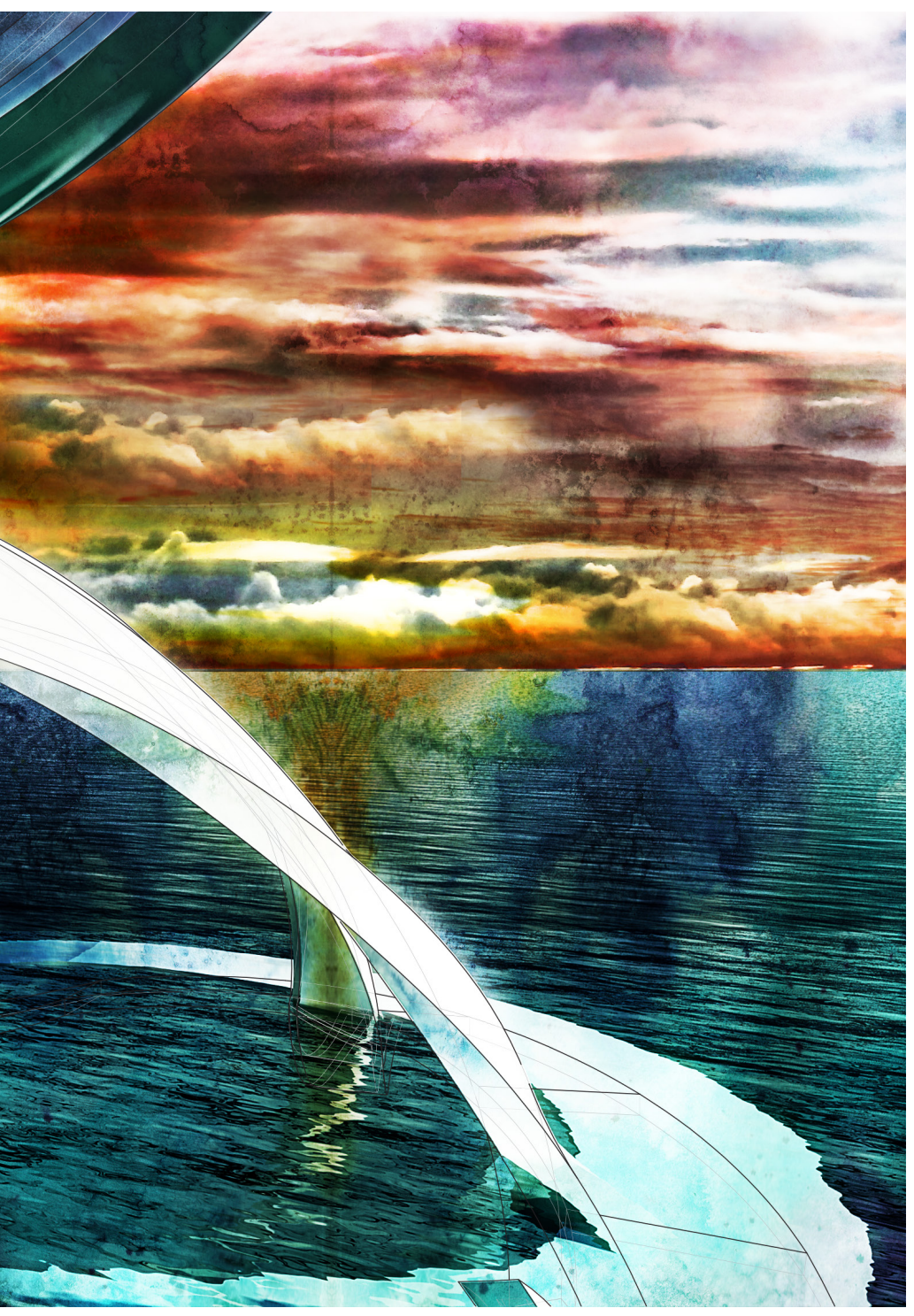


08.2.5 Spatial Narrative

Transition to the Summit

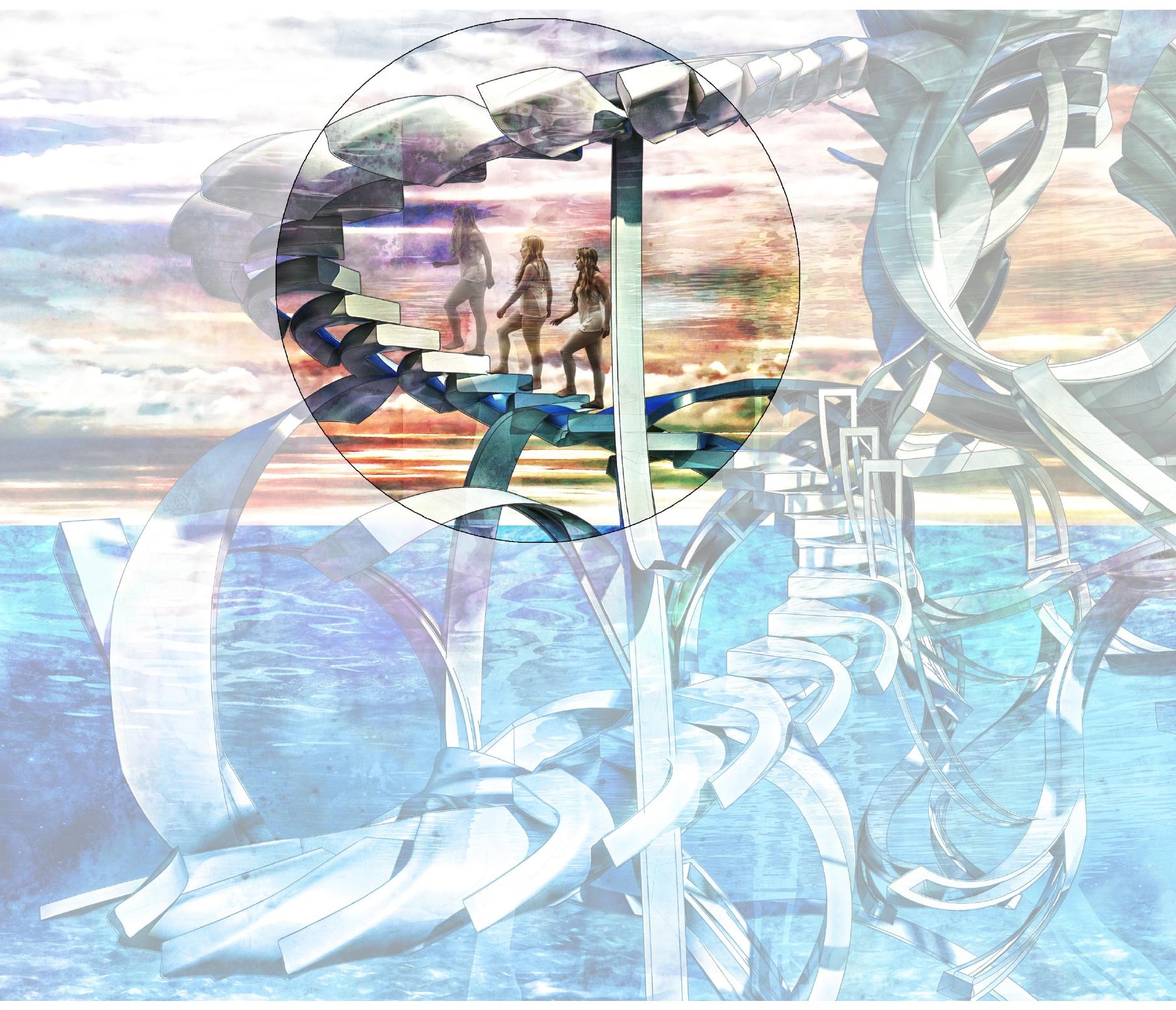




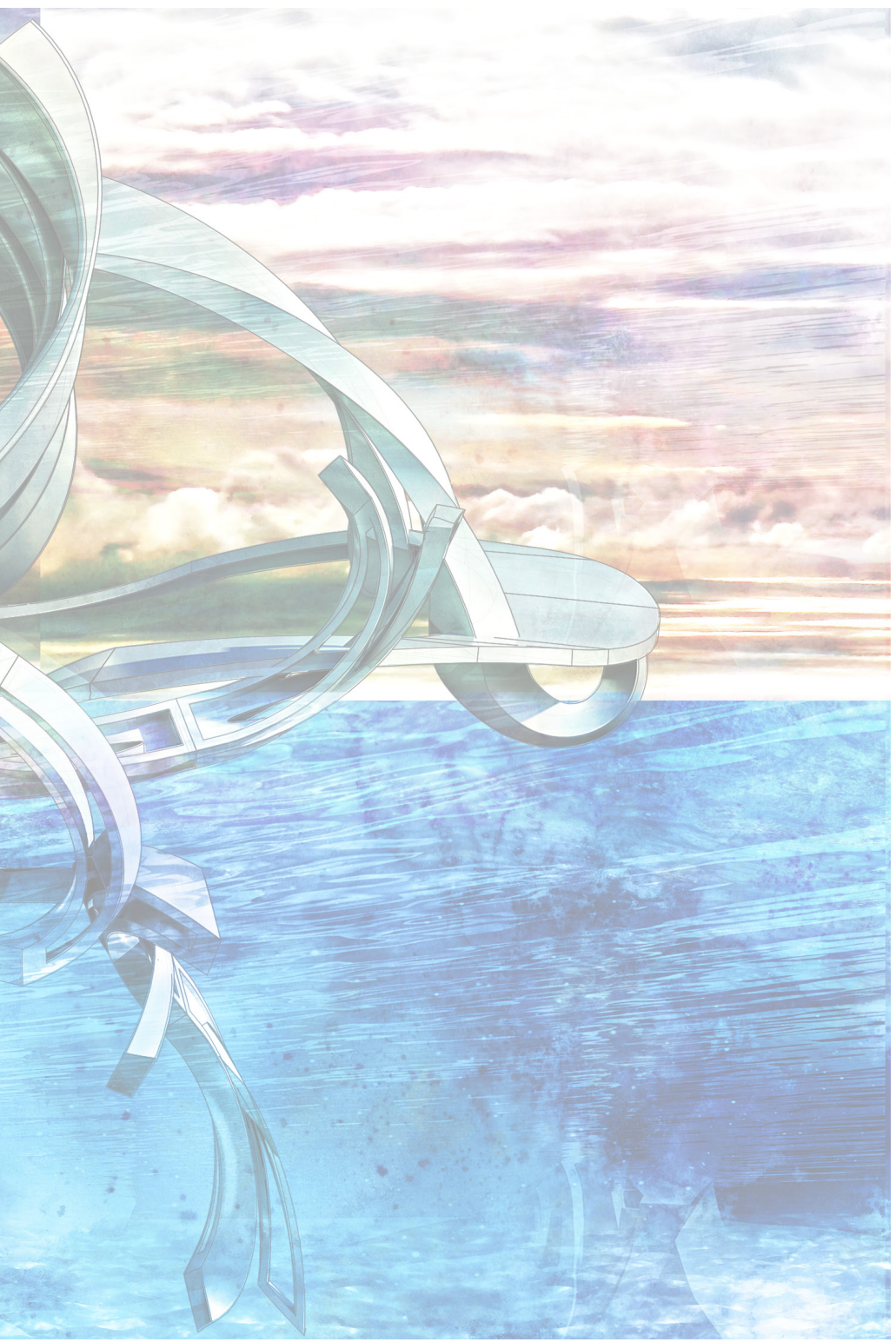




\subsubsection{Transition to the Summit}

The architecture employs spatial cues to suggest courses of travel. Within the enclosure on the surface of water, the openings allow one to catch sight of a pathway, beckoning the inhabitant to continue exploring beyond the edge of the waters. The path weaves through the enclosure for the dweller to simply transition from an intimate space to the open air. The trail still grazes the surface of the water, allowing the dweller to interact with the medium of water prior to ascending above. The formal language of the trail shifts as the path morphs into a stair that rises towards the sky.

As she lay contently within the space, she noticed a path continued far along the other side of the waters. Curious to see where it led, she decided to leave her immediate surroundings to follow the continuous trail. She emerged out of the enclosure, with her feet still slightly immersed in the gentle waves, looking up to find the stair surfacing the waters and reaching up towards the sky. As she continued to walk along the path, the surface beneath her soon morphed into the stair, taking her aloft over the waters following the warm breeze from above. The light glistened upon the summit of the structure, drawing her nearer to its presence as she ascended the stairway towards the sky. 

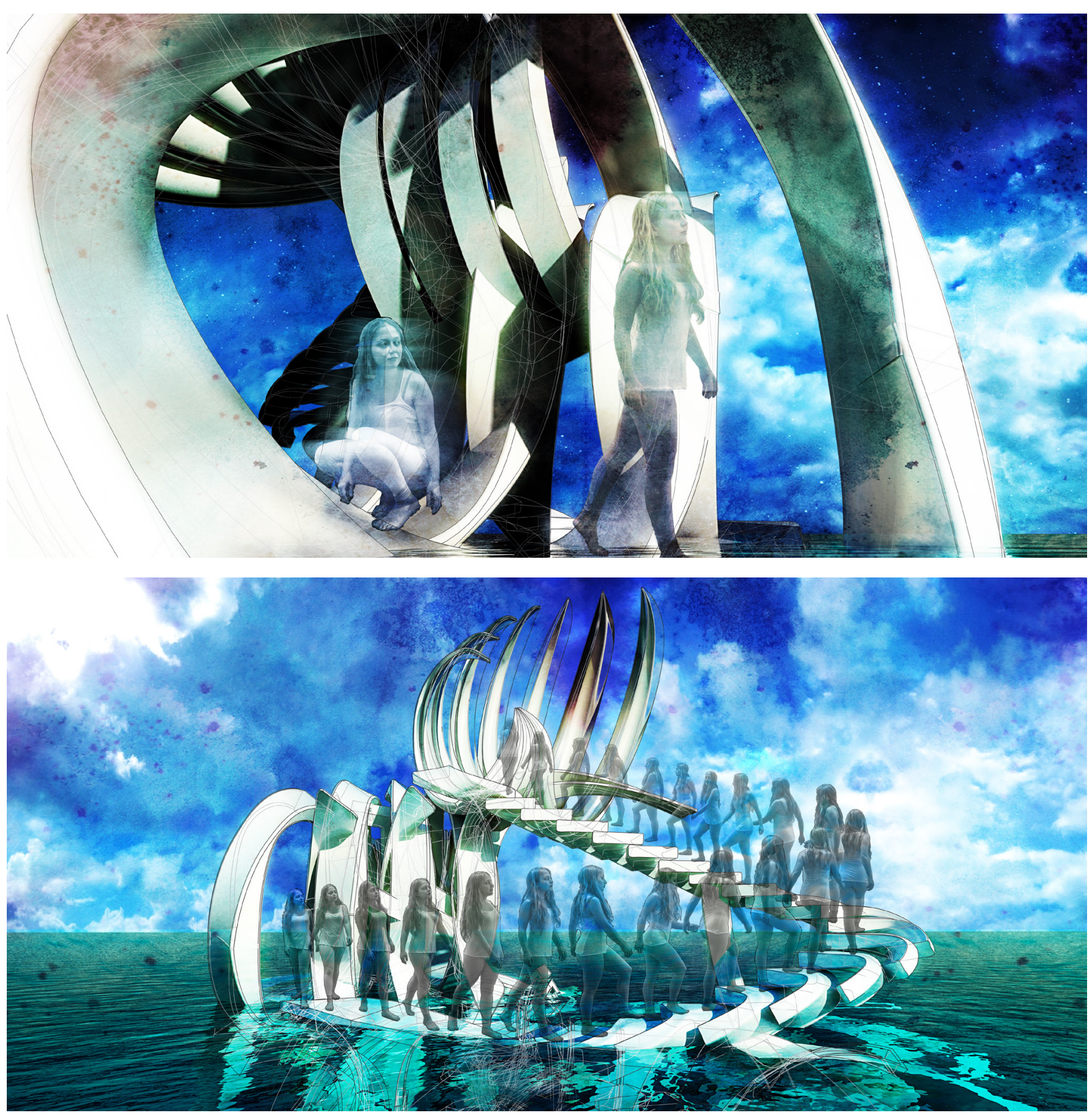


\subsubsection{Air}

At the summit of the structure, architecture is choreographed in the medium of air allowing the body to engage in the act of daydreaming. The space offers a minimal footprint making the dweller feel afloat in the sky. While sitting or standing on the edge of the platform, the pinnacle encourages the mind to wander freely and project outwards through the openness of space. The lightweight members frame the surrounding vistas of the sky and water, permitting air to pass through the openings effortlessly. A translucent inner layer is attached to the structural members, allowing natural diffused light to permeate through and maintain a view of the surroundings behind. Therefore, the space embraces the immediate landscape through its openness while giving the dweller a chance to venture underwater. The platform dips towards the surface of water, inviting the dweller to dive below to explore a new spatial medium.

Arriving at the summit, she was immersed in a new spatial realm where her mind could suddenly roam free. The forms peeled away opening up to the air, framing the surrounding vistas for her to gaze afar. She walked closer to the tip of the platform wrapped around the delicate forms piercing through the sky. She took a seat at the edge, feeling afloat above the waters. Nothing in sight was obstructing her view. She took the time to observe her surroundings while the sun warmed her body and the gentle breeze caressed her skin. She felt alive and her senses soaked everything up. At that moment, she was deeply connected to the natural world. 

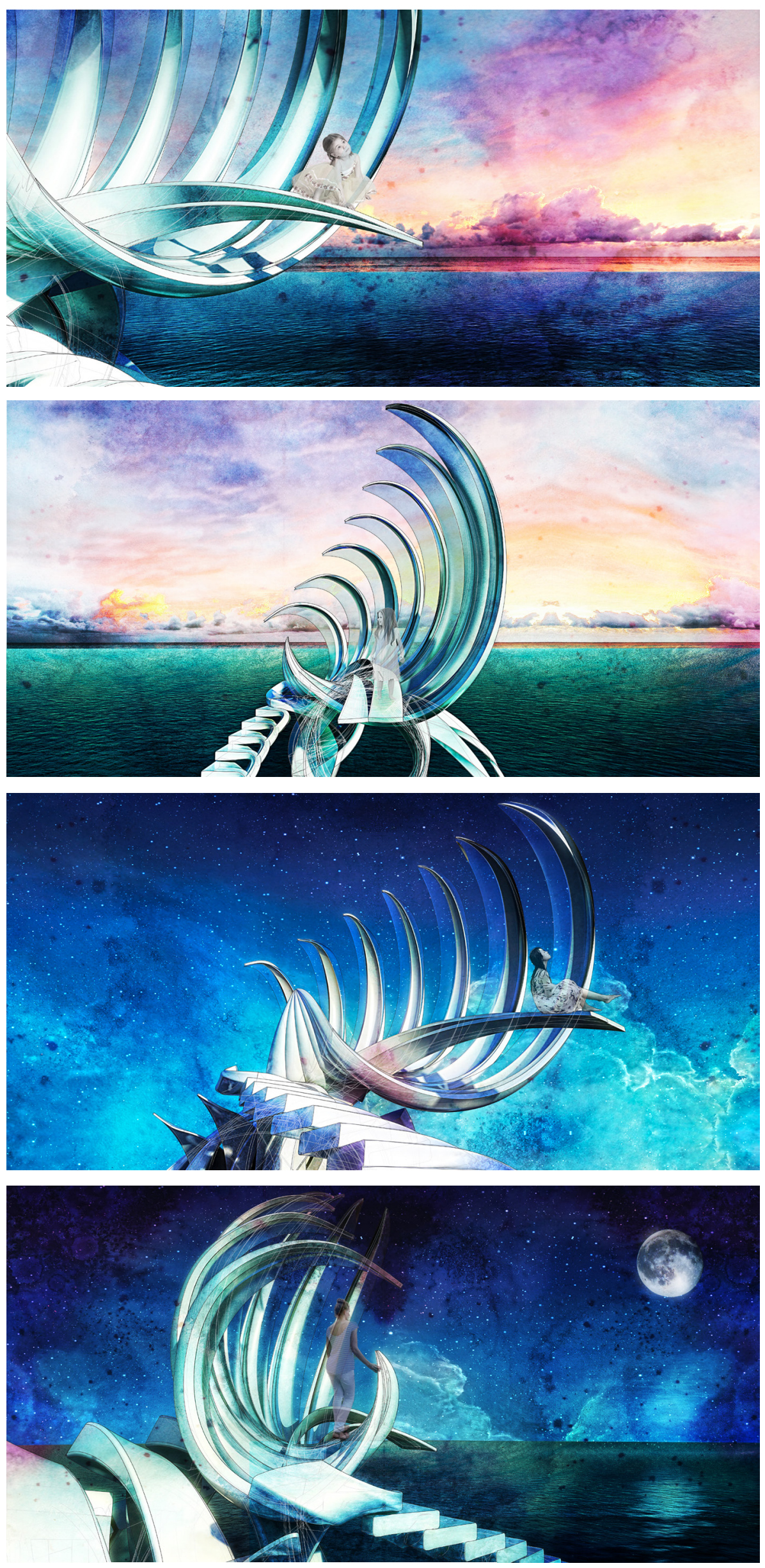


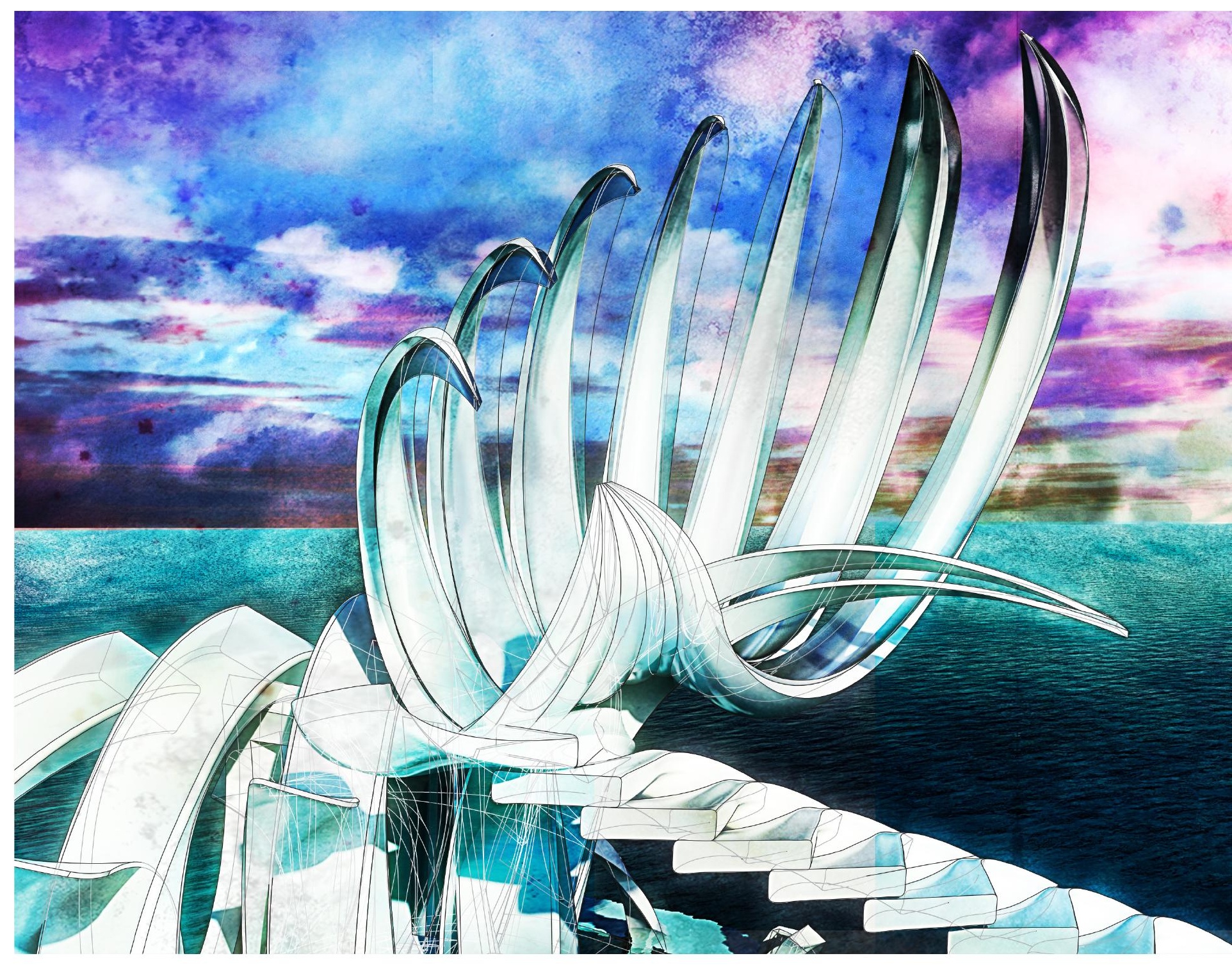

Fig. 118b: Spatial Experience in the Air 

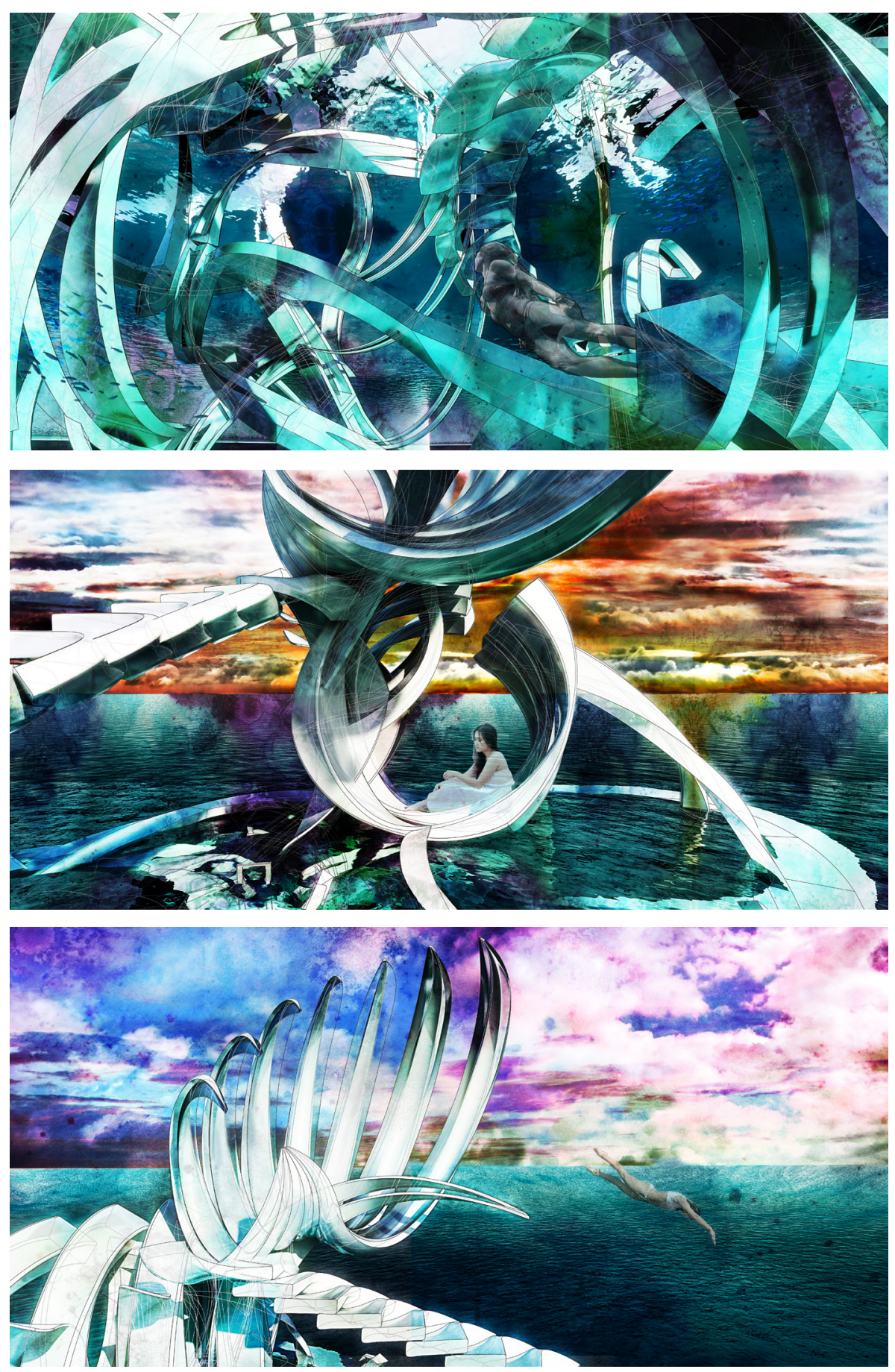

Fig. 119: Composition of three zones: Underwater, Water's Surface and Air

"Memories, dreams, and our imagination are linked inextricably with the objects of our lives and the rich associations we have with meaningful places." - Sarah Robinson (2011) in Nesting: Body, Dwelling, Mind 


\subsection{Project Conclusion}

This project reframes how we conceive and understand architecture through the moving body, empathy and being moved. Here, the choreography of architecture seeks to awaken, inspire and provoke moments of self-reflection for the dweller. Similar to a performing arts composition, a choreographer creates a piece that shares an emotional effect with both the performer and the audience, where the performer expresses an emotional state, which in turn, moves the spectators. In terms of a choreographic architecture, the architect creates a spatial performance that moves the dweller by embracing virtual movement through form, responding to the context and choreographing the body through space. When moving through the structure, the dweller experiences this interaction between virtual movement and the natural environment, triggering an empathetic relation with one's surroundings. The architecture invites the body to engage with space through movement, eliciting bodily emotional feelings that connect the inhabitant with the work.

This project explores four key concepts that provoke the dweller to experience affective feelings through space. An architect can employ these notions when designing a building to encourage a greater bond between architecture and dweller:

\section{Embrace Form as Virtual Movement}

Choreographing architecture adopts the moving body as the driving force of geometry, making architecture virtually move by encoding human kinesis through form. In this case, architecture expresses motion and force through form in which the observer can sense its mass and perceived gravity on account of the phenomenon of kinesthetic empathy:

When experiencing a structure, we unconsciously mimic its configuration with our bones and muscles: the pleasurably animated flow of a piece of music is subconsciously transformed into bodily sensations, the composition of an abstract painting is experienced as tensions in the muscular system, and the structures of a building are unconsciously imitated and comprehended through the skeletal system. Unknowingly we perform the task of the column or of the vault with our body (Pallasmaa, 1996, p. 67). 


\section{Choreograph Architecture to Respond to Context}

This project demonstrates how architecture is designed to respond towards its surrounding context. Architecture can embrace its surrounding natural or built environment for our bodies to experience when moving through space.

Kent Bloomer and Charles Moore (1977) in Body, Memory and Architecture, argue lived space begins with the landscape of the human inner world, where boundaries, coordinates and landmarks are the "only humane starting point for the organization of space around us." When architecture extends outwards towards our landscape, this leads to a "world that is a sympathetic extension of ourselves", beginning with the initial boundary, the body, to the first mutual boundary (the dwelling), and beyond that to the environment which negotiates these boundaries (p. 77). Here, a stage for 'place' is created where "transactions between body, imagination and environment" occur (Bloomer \& Moore, 1977, p.105).

\section{Choreographing Movement through Space}

How can the interaction between architecture and its context influence our bodily movements through space? This concept is concerned with choreographing how the body moves and experiences the spatial performance between the architecture and its environment, making one aware of the depths of the water below and the sensation of levitation above:

The sense of gravity is the essence of all architectonic structures and great architecture makes us aware of gravity and earth. Architecture strengthens the experience of the vertical dimension of the world. At the same time as making us aware of the depth of the earth, it makes us dream of levitation and flight (Pallasmaa, 1996, p. 67).

\section{Moving the Dweller}

Architecture has the ability to spur a resonance within our bodies. The way architecture invites us to move, in accordance with the affordances it presents in both actuality and imagination, arouses our emotions. These feelings are fundamental to our experience and understanding of our built environment, bringing us closer to architecture. The term understanding here implies our ability to unconsciously measure buildings with our bodies and project our body's schema in the world we inhabit. Body schema refers to 
the position and configuration of the body parts in space, which is constantly updating when the body moves (Haggard, 2005). Therefore, as we move through a building, we unconsciously imitate the structure's composition with our muscles and bones. We then feel pleasure and protection when our bodies experience a resonance in space.

In this project, architecture induces existential sensations that our bodies perceive and internalize. The virtual movement of form, how it responds to its context and choreographs the body's movement through space, influences our ability to be moved. This design proposition embraces the task of architecture, as suggested by MerleauPonty, "to make visible how the world touches us" (1964, p. 19). 


\section{A Future for Architecture}

The design research in this thesis reveals a future for an architecture that embraces a temporal thinking; architecture that discovers time through the body and movement. Movement is fundamental to how we experience, feel and sense our built environment: we move to experience architecture, and in turn, are moved by its presence. We must continue fostering this relationship between buildings and our bodies, in order to develop a corporeal architecture that stimulates and awakens us. It is time for architecture to consider human kinesis in the conception and understanding of our buildings, creating an environment that encourages our minds to rethink, engage and interpret the complexity of motions we sense through our bodies. This research aims to enrich the architectural discourse by rethinking the relationship between body, form and movement in a choreographic architecture.

As explored through research and design, a future of choreographed architecture would embrace the following principles: rendering our built environment as variant and stable (not static), refining the role of the body in the architectural discourse, moving architecture through virtual movement, and in turn, moving us — enriching our imaginations through kinesthetic empathy.

\section{Architecture is Variant; Stable not Static}

By applying human kinesis as the driving force of geometry, inert structures of form become stable entities that store possible potentials of form, allowing architecture to become highly continuous and differentiated. In this case, the elements of architecture do not need to move in order to convey motion. Instead, the potential of movement is depicted in the collisions, intersections and curvatures variant in the geometric outcomes of a choreographic architecture. As opposed to embracing literal motion, dynamic processes infuse motion into its conception, where the form's dynamism gives the architecture its vitality and liveliness.

\section{Refining the Role of the Body in Architecture}

The investigation in this thesis also challenges the ideal figure as a model in architecture and proposes a new kind of understanding of form and organization; one that dismisses the static body that guides a system of proportions for classical architecture's construction, with a system of parameters and forces defined by human 
kinesis for a dynamic architecture. Choreographing architecture moves beyond the inflexible idiom of Corbusier's Le Modular, Vitruvius' notion of the ideal body, among others, towards an emergent system based on the moving body.

\section{Moves Architecture: Embracing Virtual Movement}

Architectural empathy can be accomplished by embracing virtual movement through form. This thesis begins to revive the Baroque philosophy of imparting motion through mass, but furthers this notion by investigating the potential for human kinesis to inform an architecture. With the technologies available for analyzing human kinesis, we can understand its relationships as an external force that could then inform a new theory to make architecture move. Architecture that moves does not mandate literal motion, or to be movable, but that it cease to be regarded as static. Furthermore, moving architecture does not imply a cinematic model, where architecture only takes the role of the static frame through which movement proceeds. In this mode, force and motion are only introduced once the design is in place, through methods of visual processions. Whereas a choreographic architecture proposes form, forces, movement and their attendant parameters to be ingrained in the design process. Once the architectural composition is in place, the inhabitant can experience the virtual movement when moving through the stable, not static, built environment.

\section{Moves Us: Enriching Our Imaginations through Kinesthetic Empathy}

Choreographing architecture moves us through the phenomenon of kinesthetic empathy. It does not deter the mind from wandering, as would a banal building, but instead encourages our minds to engage and interpret the complexity of motions that resonate through our bodies. These dynamic forms feed our desire to seek its inner language and provide meaning to the sensations we internalize. Here, architecture is not merely a house for our fragile bodies, but a home that fosters the awakening of our imaginations. 


\section{Appendix A}

Early Design \& Research Investigations

Source: Ashley Brooke Biren

\section{a. Rudolf Laban's Effort Analysis \& The Formation of an Architectural Language}

This experiment explores Rudolf Laban's Movement Analysis and its application for an architectural context.

b. Revealing Virtual Internal Rhythm - Sudden vs. Sustained

This experiment examines sudden and sustained movement, defined by Laban's Effort Analysis, and its application through form-finding processes.

c. The Empathetic Element - Investigating the Activity of Habitation

The Empathetic Element explores movements of habitation in the context of architectural form, rendering dynamic qualities of movement through spatial characteristics of architecture. For further details, see Section 6.1. 
a

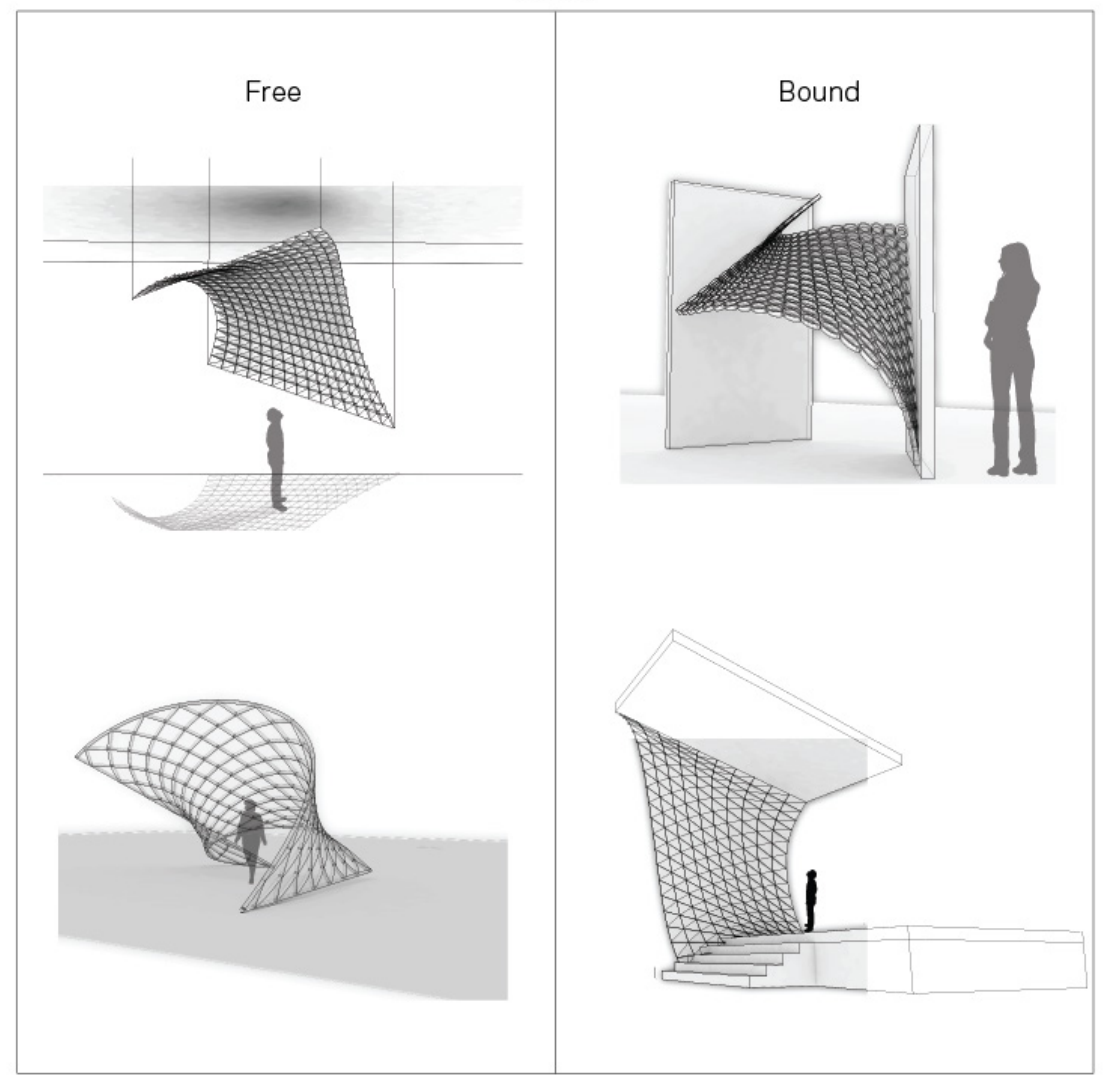

C

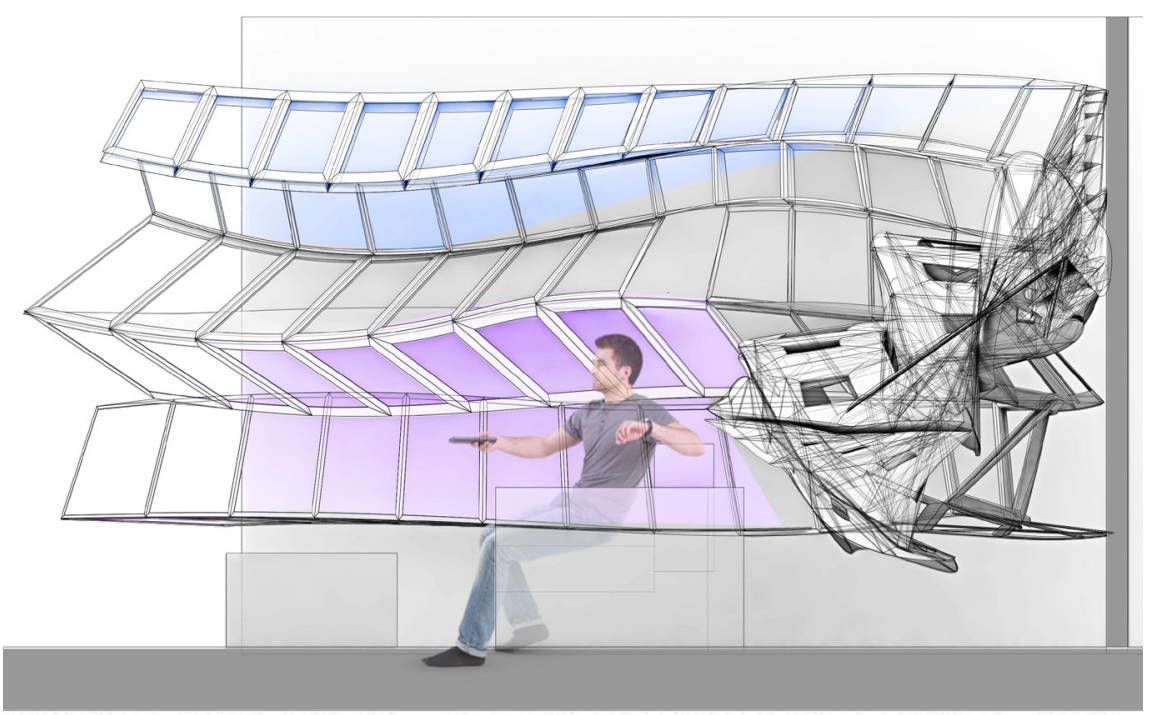

b
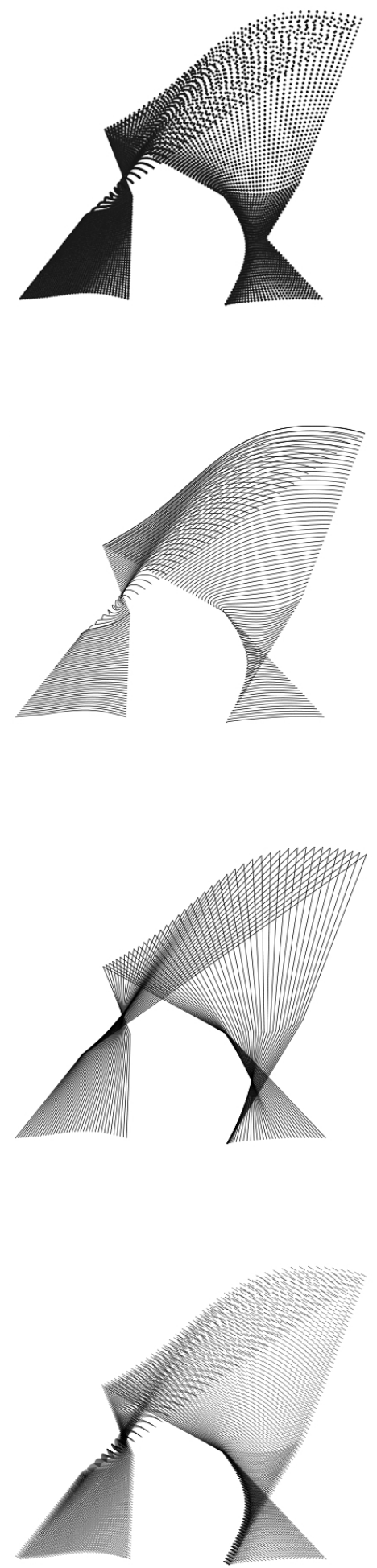

The following investigation explores Laban Movement Analysis (LMA) and its architectural application. LMA is a technique and language for describing, visualizing, decoding and recording all varieties of human movement. The focus of this study will be on Laban's category of Effort, also known as Energetic Dynamics. Effort is a method for understanding the subtle qualities of movement with respect to inner intention. The difference between reaching for a book and striking someone in anger with respect to body organization are the same, as both rely on arm extension. However, the strength, control and timing of the movement are very different. Dynamic qualities of movement facilitate in the understanding of how motion reveals a person's attitude, whether conscious or not, towards thinking, feeling, sensing and intuiting.

Effort has four factors, each of which has two opposite polarities called Effort elements (Laban \& Lawrence, 1974):

$$
\begin{aligned}
& \text { Weight | Sensing \& Intention | What? } \\
& \begin{array}{ll}
0 & \text { light-delicate, sensitive, easy intention } \\
0 & \text { strong-bold, forceful, determined intention }
\end{array}
\end{aligned}
$$

\section{Space | Thinking \& Intention | Where?}

- flexible-all around awareness

o direct-focused and specific

$$
\begin{array}{ll}
\text { Time } & \text { Intuition \& Decision | When? } \\
\text { o } & \text { sustained-leisurely, continuous, lingering } \\
0 & \text { sudden-unexpected, isolated, surprising }
\end{array}
$$

Flow | Feeling \& Progression | How?

o free-going with the flow

o bound-contained and inward

There are eight combinations of Effort Factors called Effort Actions. These actions include the following: glide, slash, press, flick, punch, float, dab and wring. Effort Actions connect with us through a physical and intuitive level; it serves as a common language that everyone can understand for illustrating a desired physical experience. 
Architecturally Mediated Human Kinesis:

An Architectural Language Defined by Body Movement

Do dynamic qualities of movement apply to architectural spatial qualities?

This investigation begins to translate qualities of movement to spatial characteristics in architecture, allowing designers to create architecture through movement.

Weight | Sensing \& Intention | What?

Weight encompasses material properties, architecture's relationship with the ground plane and the built form's solidity/openness. These factors contribute towards architecture's desire to indulge in the forces of gravity or to resist it, appearing weightless. The element of weight can be embodied in an architectural component or an entirety of a built form.

Space | Thinking \& Intention | Where?

Space is defined by the shape of the movement composed by the human body. The body can create either focused/inward bodily gestures or explore negative space in a free manner. The movement would form a plane in three-dimensional space that can be applied in the creation of an architectural element, including a wall or ceiling, or a space's entirety, such as an enclosure, room or building. A composition of multiple movements could be used to define the configuration of an interior space.

Time | Intuition \& Decision | When?

Time is expressed through the architectural element's rhythmic qualities. Whether it's sustained/predictable or sudden/irregular, the component reveals characteristics of time in space using rhythmic patterns.

Flow | Feeling \& Progression | How?

Flow is determined by architecture's boundaries of movement, typically outlined by its surrounding natural or built context. Is a wall confined by a neighbouring partition? Or does its existing context allow the movement to be free? The placement of an architectural component or building can determine its bound or free flow movement in space. 
Effort Factors

Dynanism

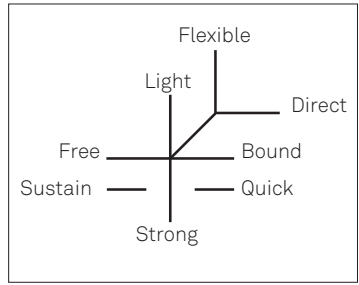

Weight

Space

Time

Flow

What?

Where?

When?

How?

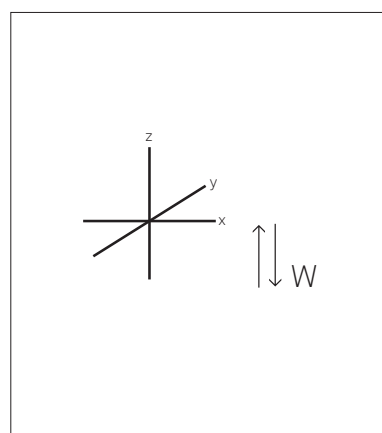

Light

delicate, sensitive, easy intention

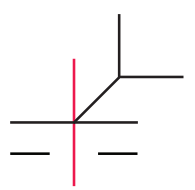

Strong

bold, forceful, determined intention

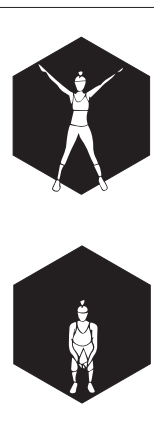

Flexible

all around awareness

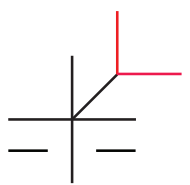

Direct

focused \& specific
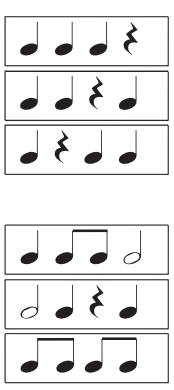

Sustained

leisurely, continuous, lingering

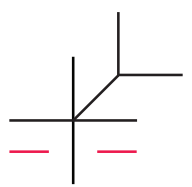

Sudden

unexpected, isolated, surprising

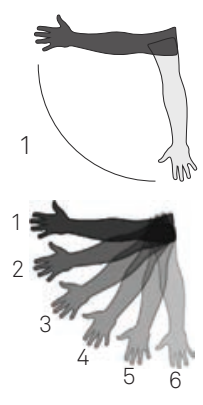

Free

unimpeded flow

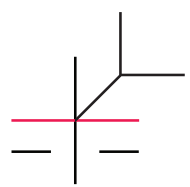

Bound

contained \& inward

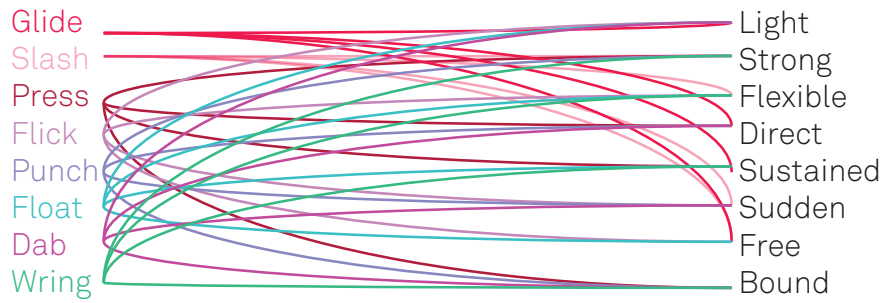


Weight

What?

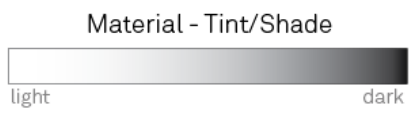

Material Physical Property

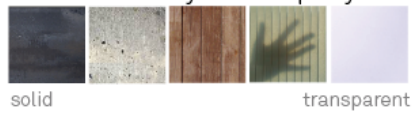

Building Form

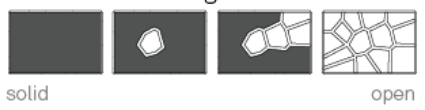

Relation to Ground

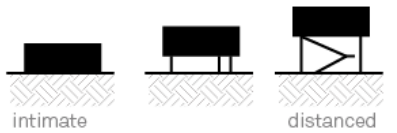

Time

When?

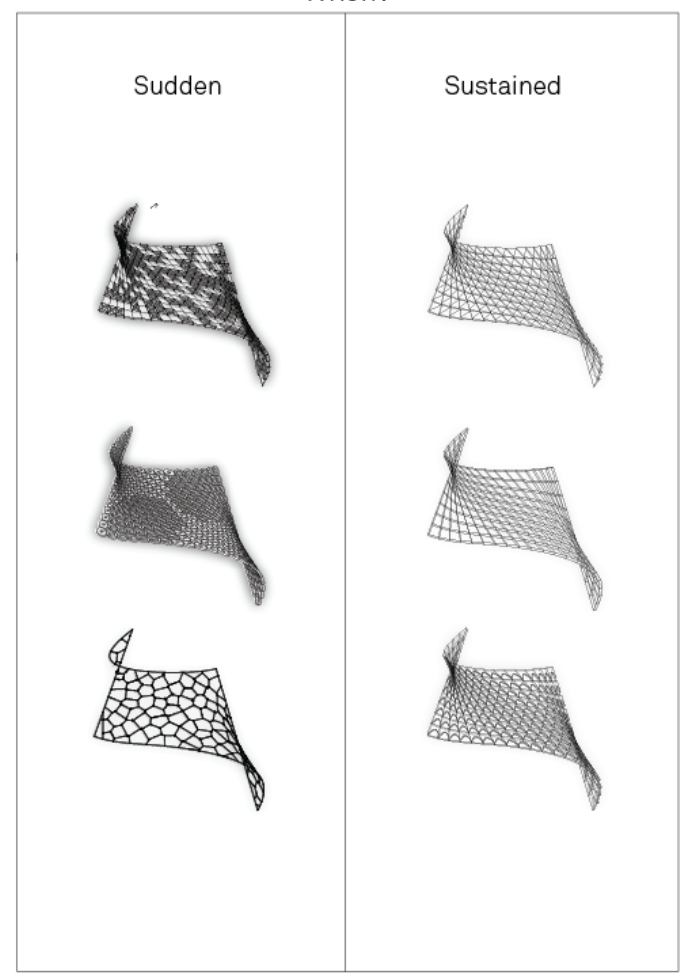

Space

Where?

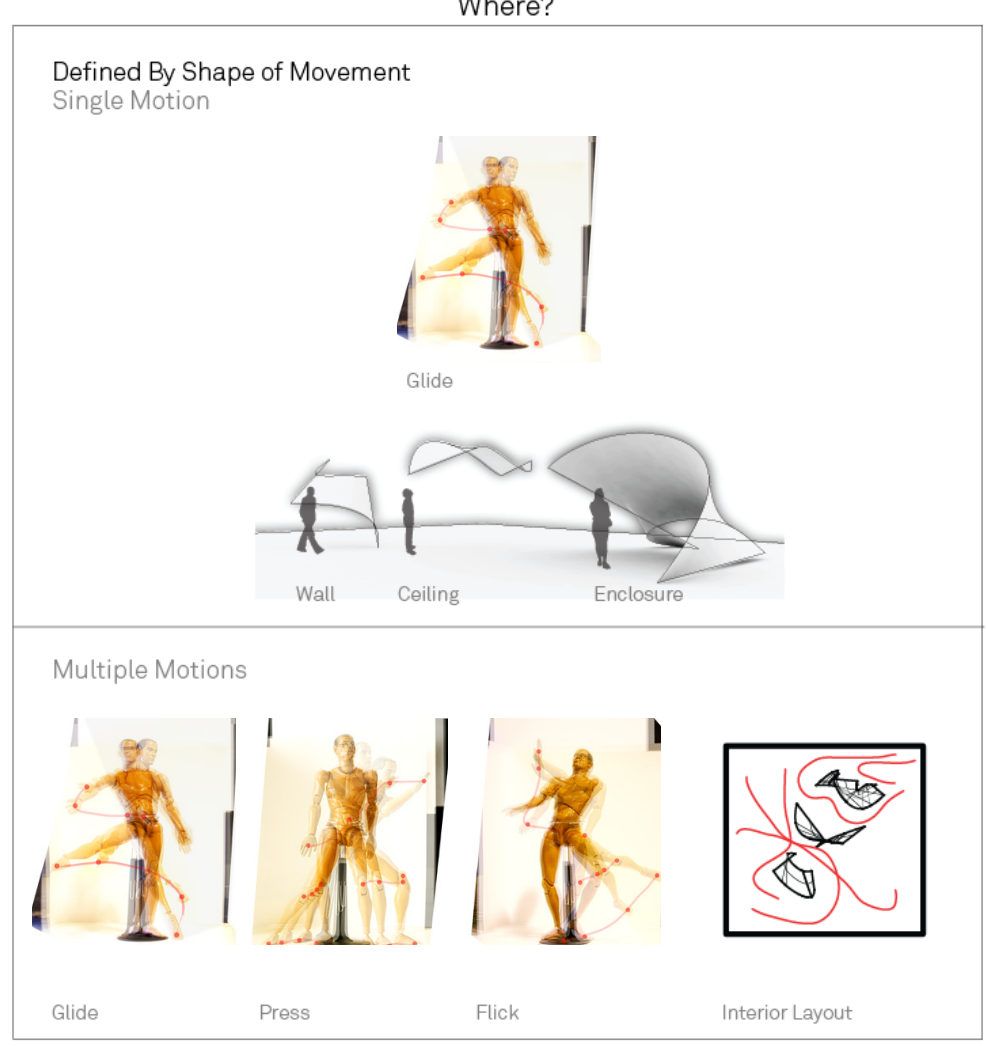

Flow

How?

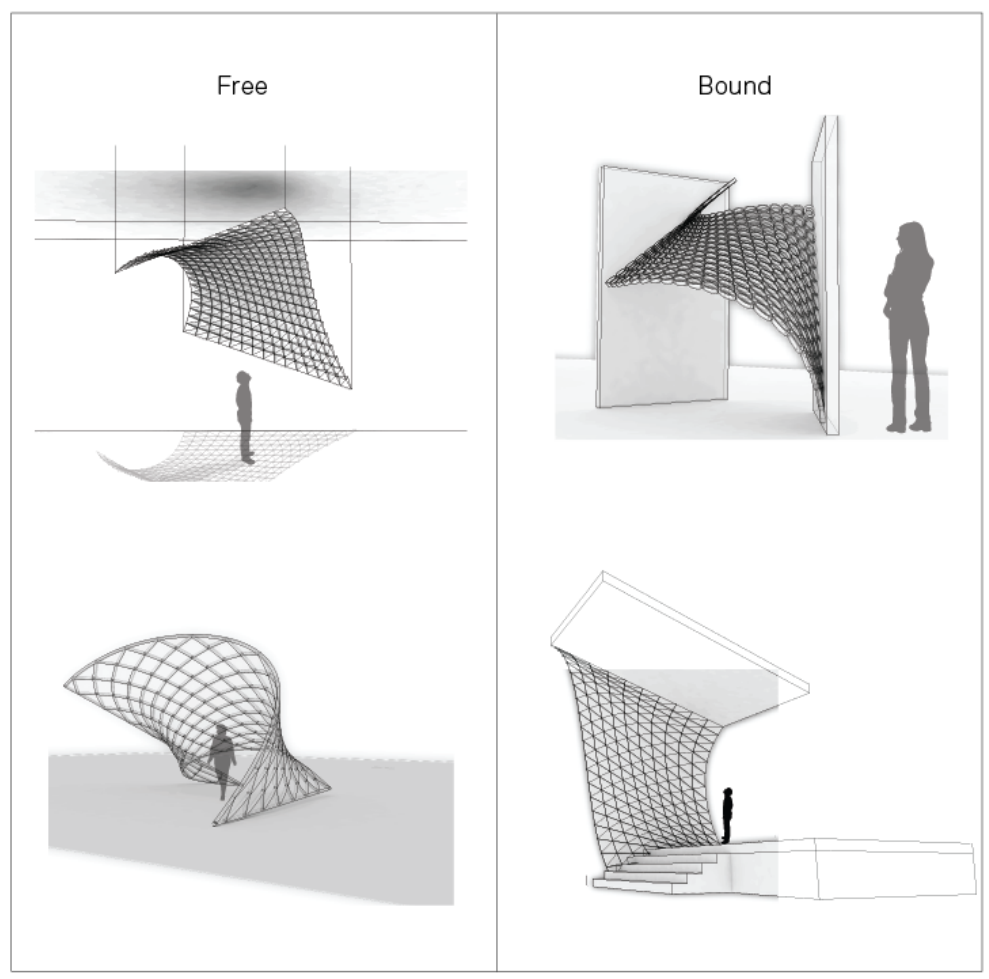





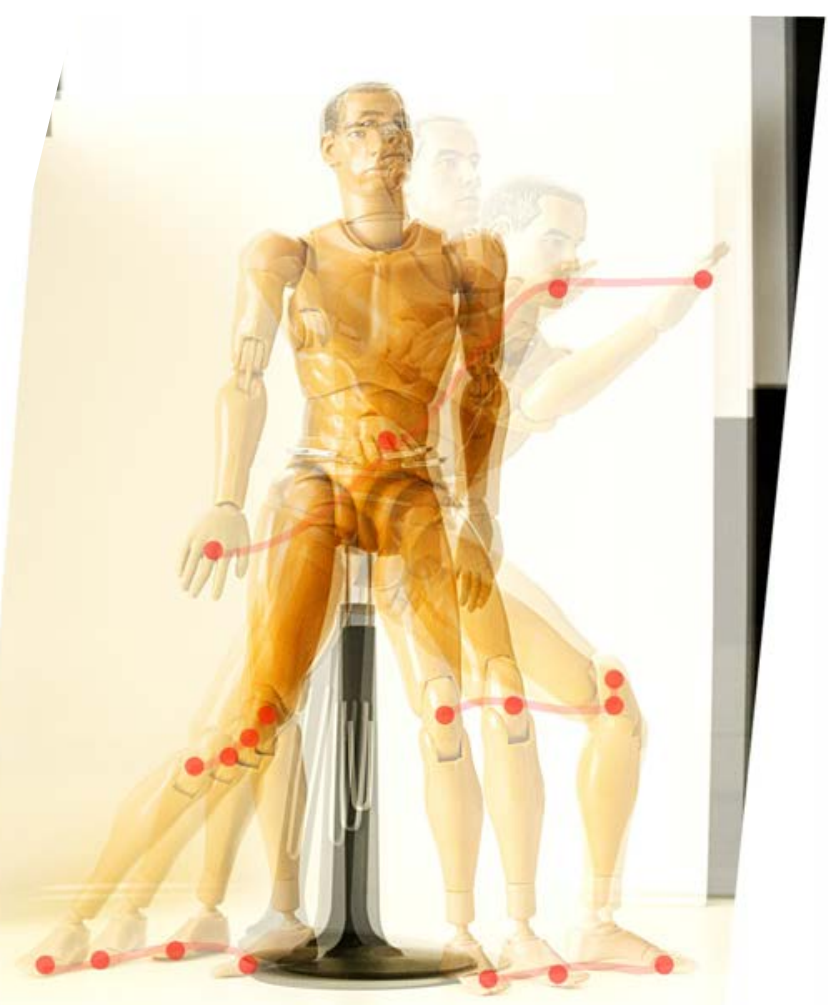

| Effort Action: Press |
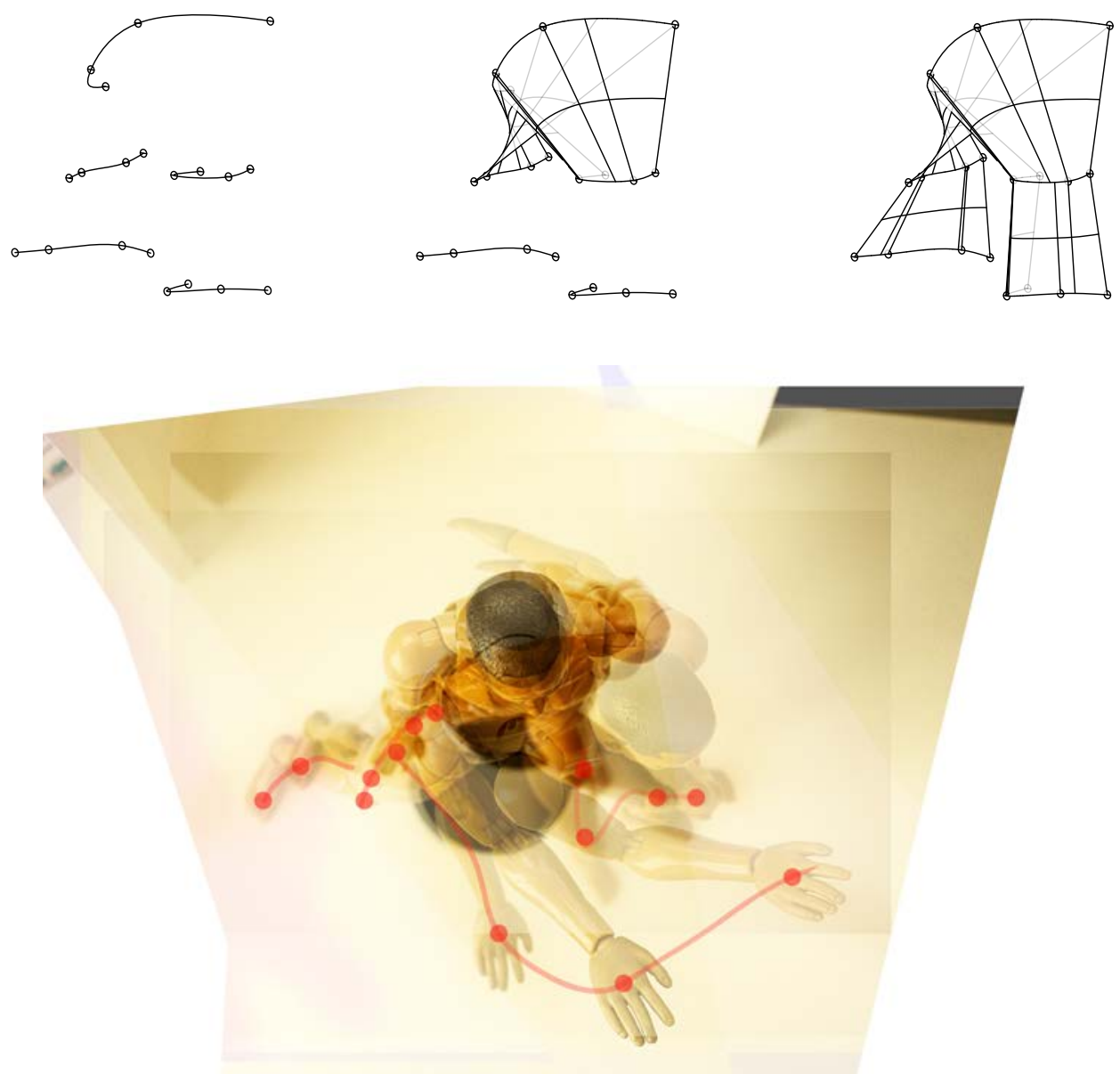


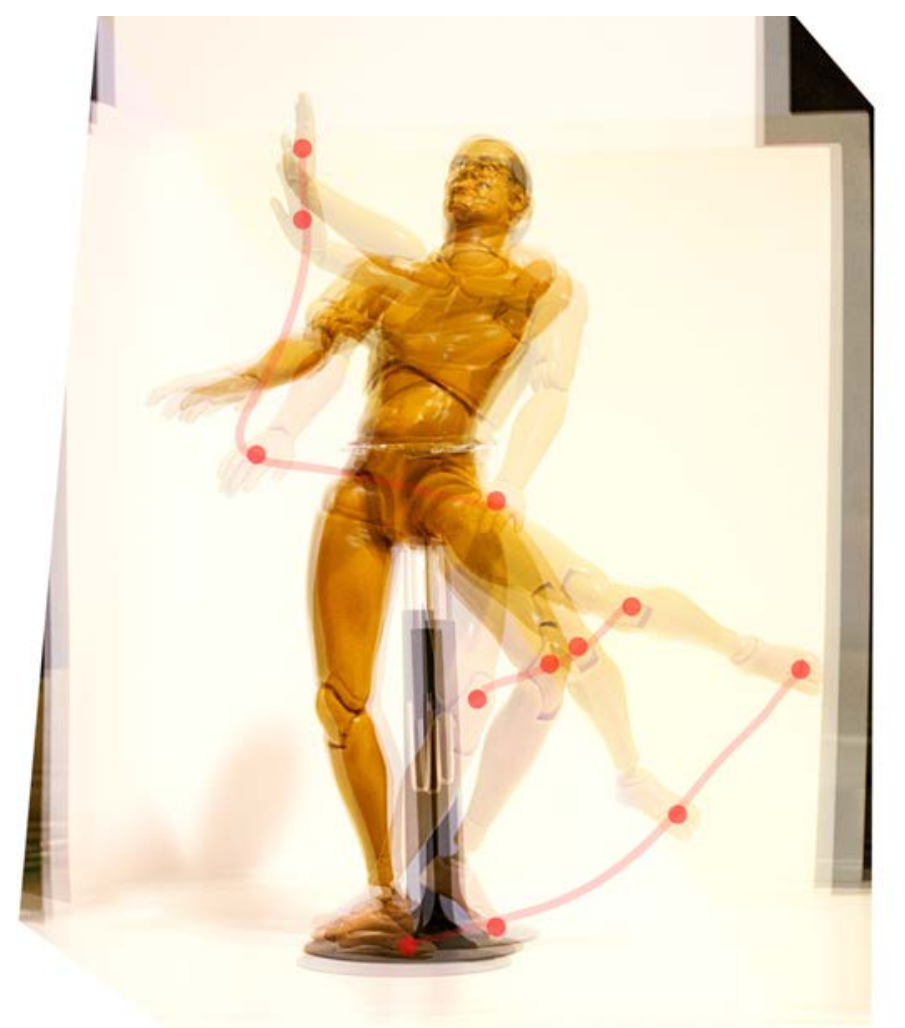

| Effort Action: Flick |
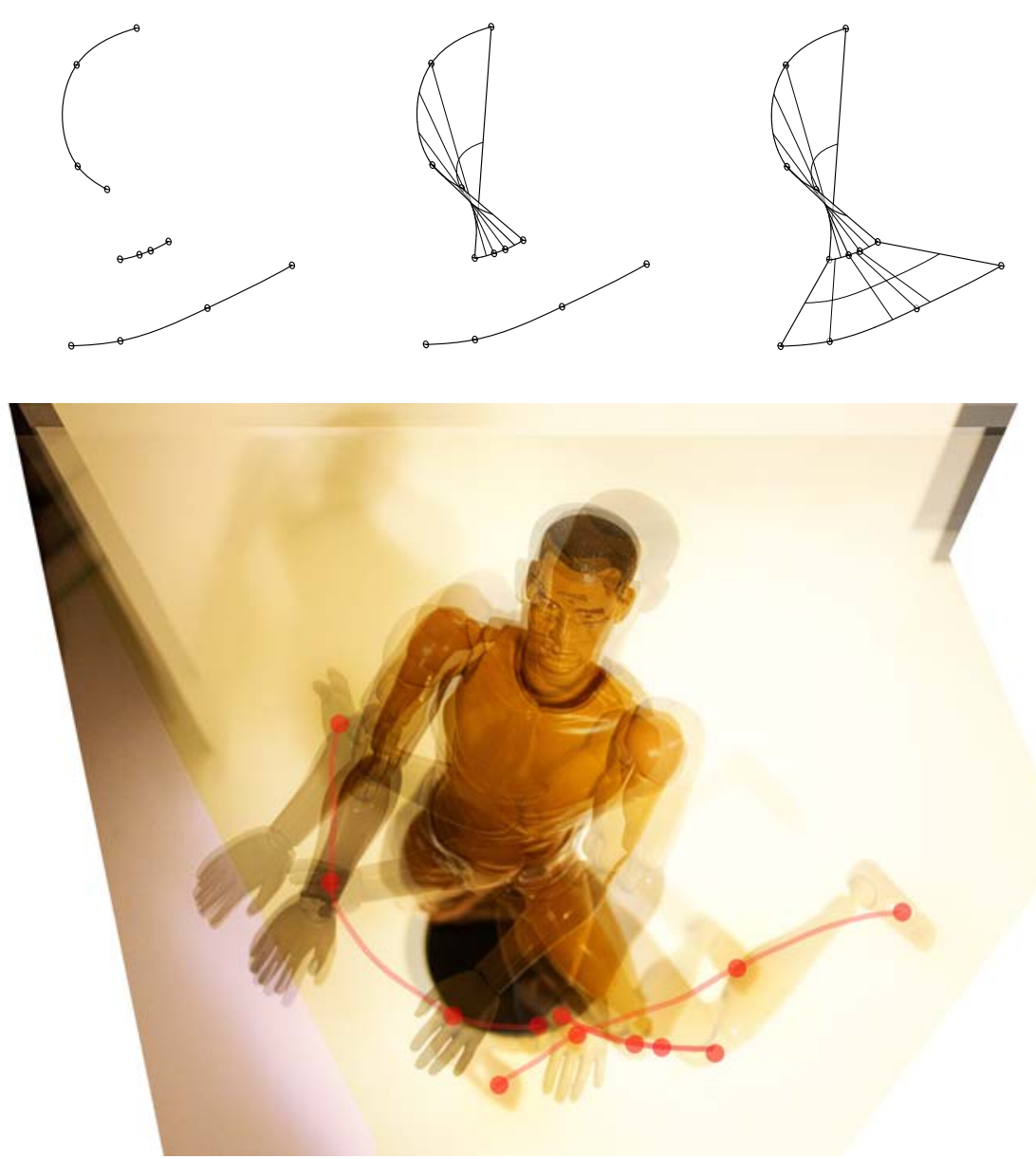
This exercise investigates the invisible effects of Laban's Sustained and Sudden Movements

This video reveals the inner intention of movement. Using the same sequence of steps, a movement is conducted in two distinct manners: suddenly and sustained. First, a stick slowly and carefully treads through water from one point to the next. Second, a stick rapidly traces the same series of points. The objective of this exercise is to reveal the invisible effects of movement's inner intention.
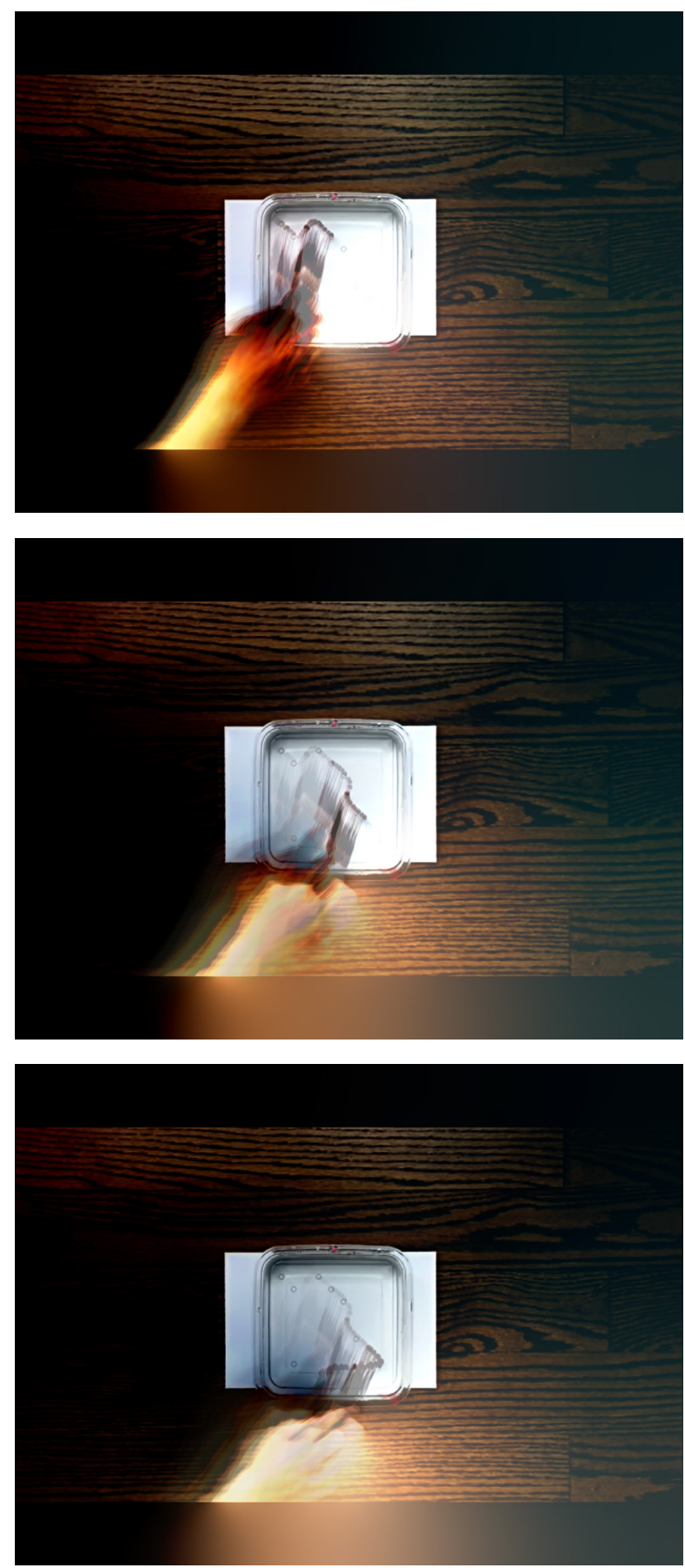
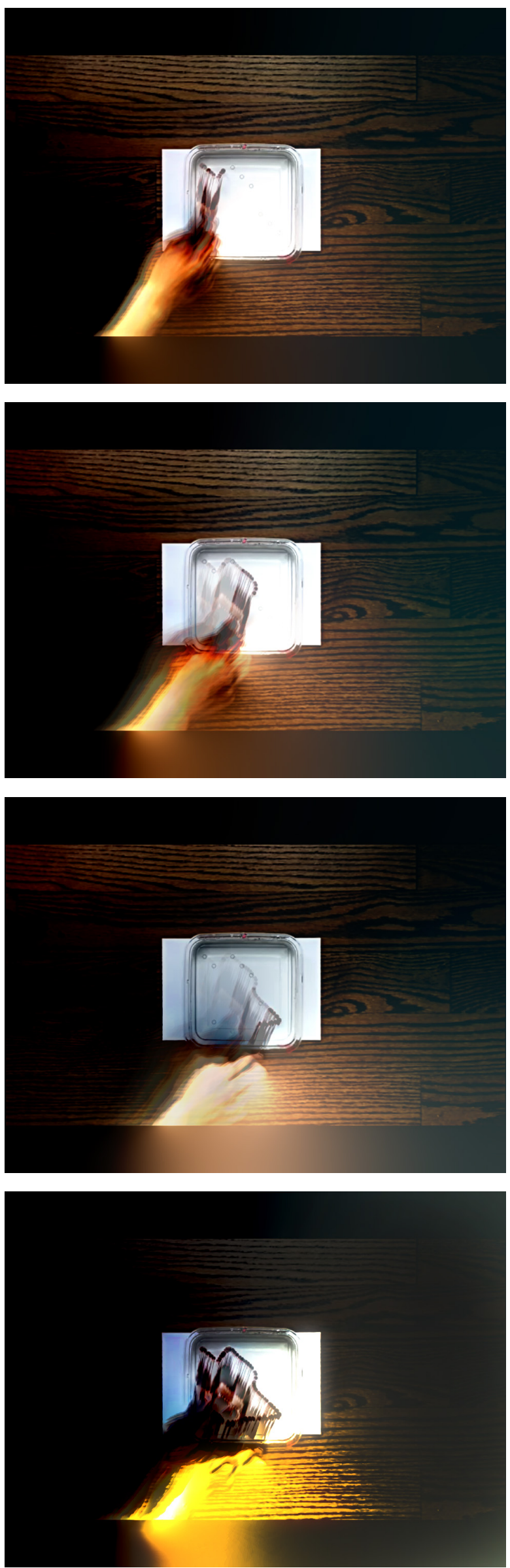

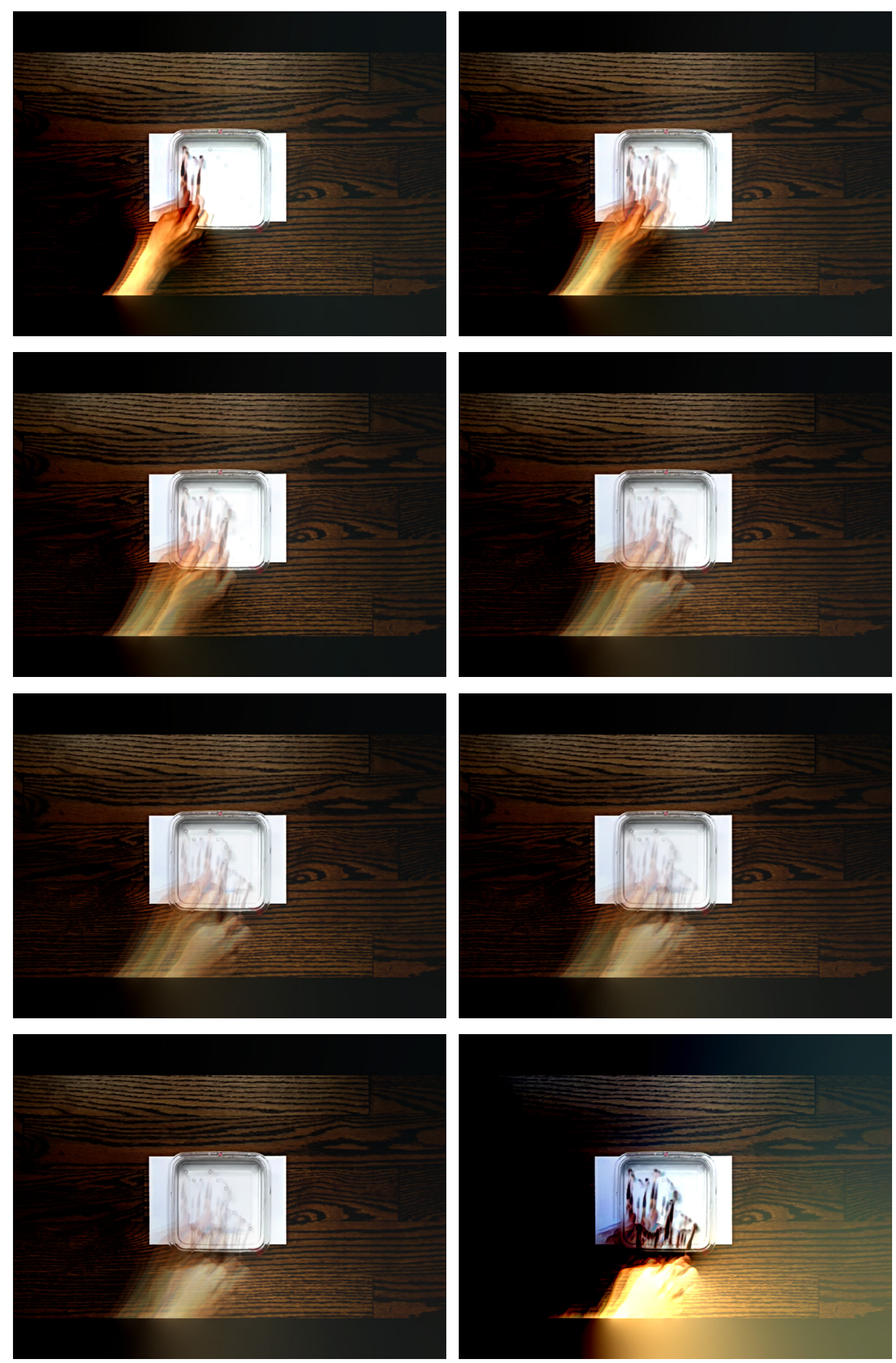

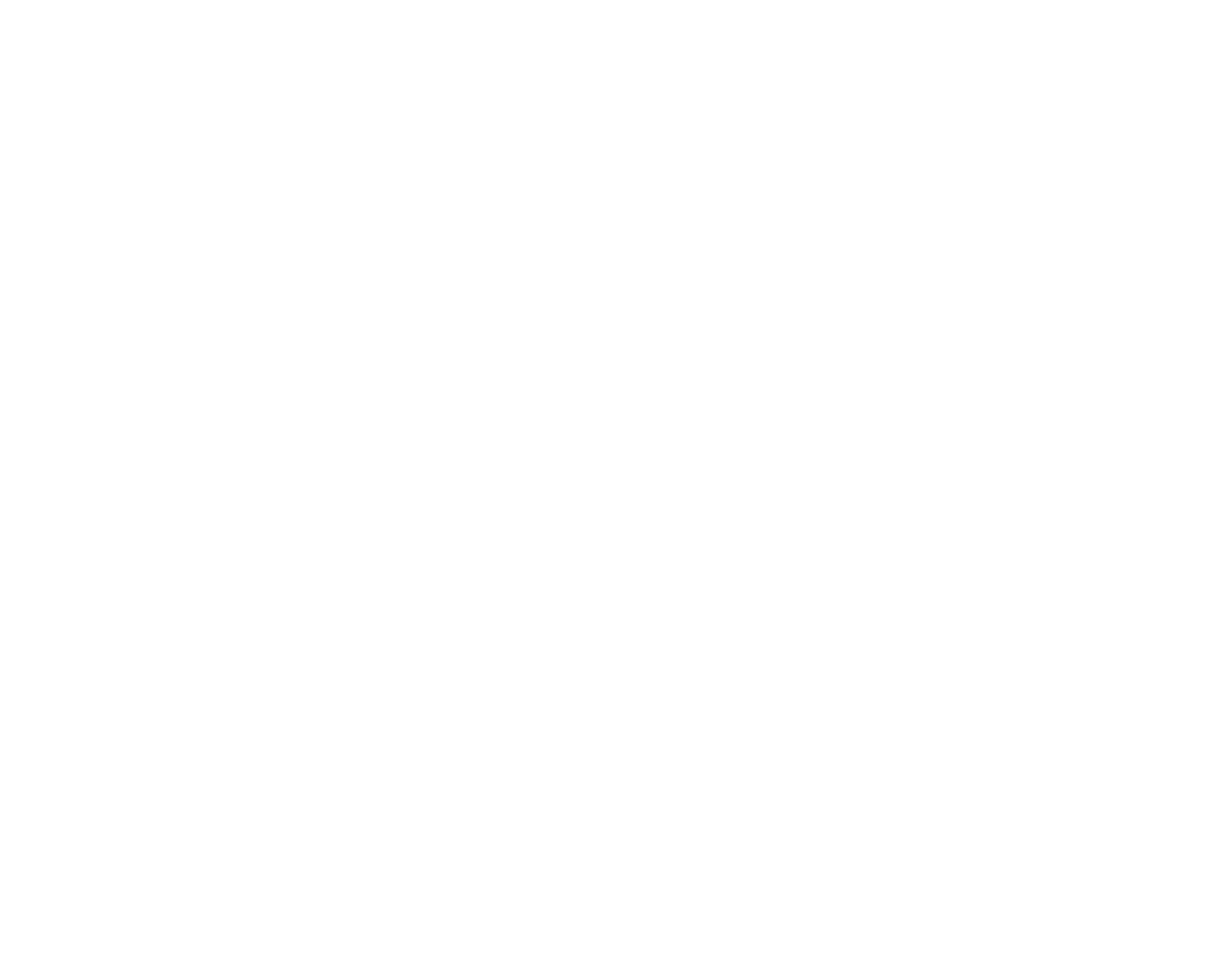

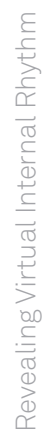

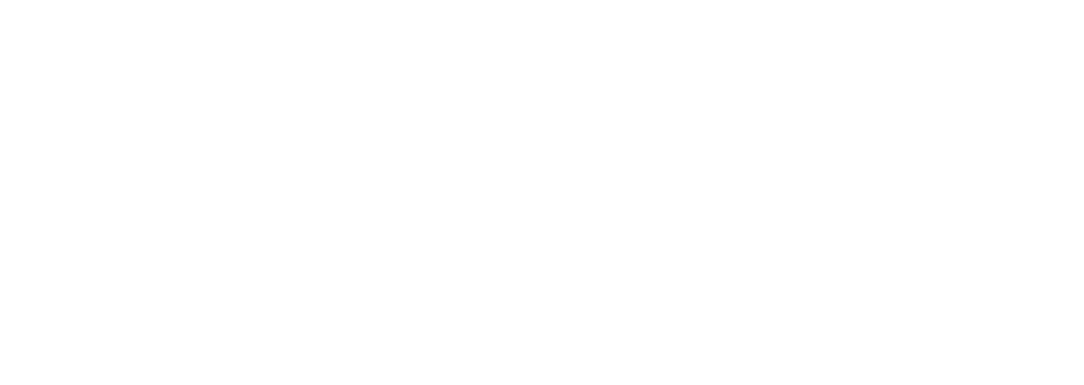




\section{motion: transfer | slight push/press/touch}

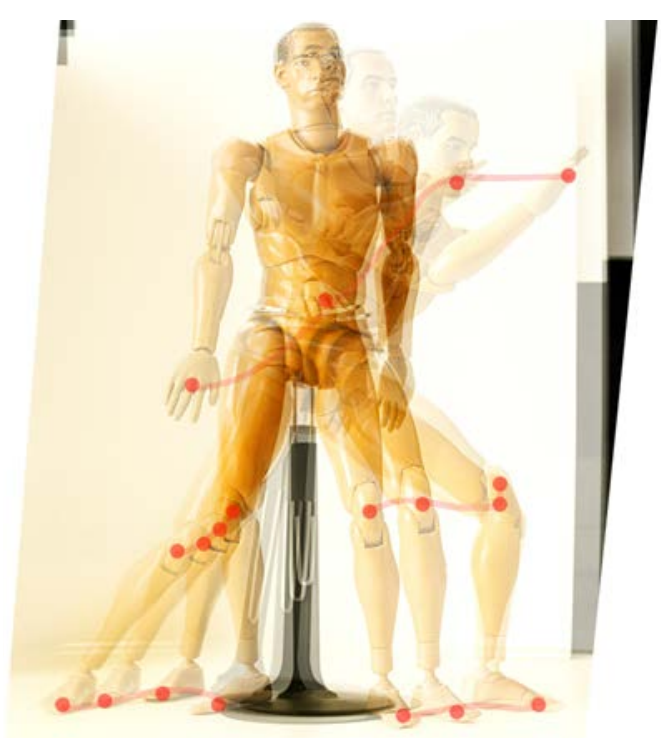

\section{[a variance of] SUSTAINED POROSITY}

The illustrations express one movement varying weight while remaining sustained in time. The movement's weight is determined by the intensity of its porosity. Its sustainment is illustrated through its continuous internal rhythm.

Sparse $=$ Light $\mid$ Dense $=$ Strong

Laban's Effort Definitions

Weight - to indulge or resist gravity

Light - delicate, sensitive, easy intention

Strong - bold, forceful, determined intention

Time- internal rhythm of movement

Sustained - leisurely, continuous, lingering Sudden - unexpected, isolated, surprising 

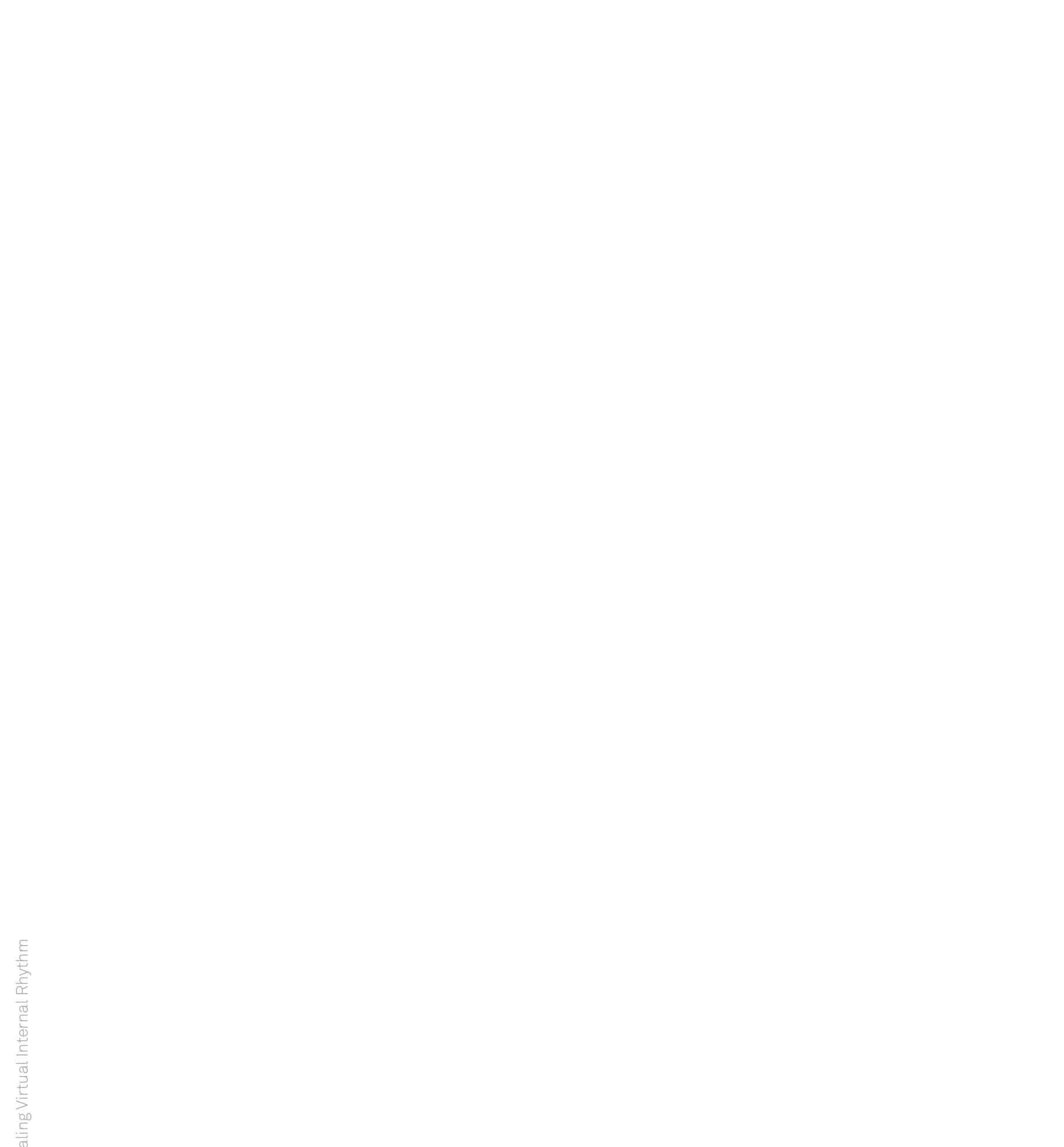


\section{motion: transfer | slight push/press/touch}

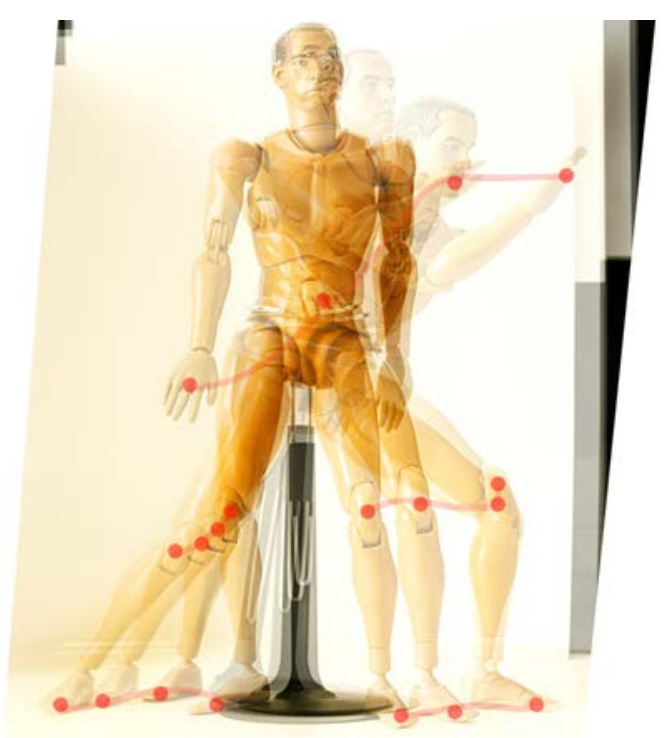

\section{[a variance of] SUDDEN POROSITY}

The illustrations express one movement varying weight while embracing sudden moments in time. The movement's weight is determined by the intensity of its porosity. Its sudden intentions are illustrated through an irregular internal rhythm.

Sparse $=$ Light $\mid$ Dense $=$ Strong

Laban's Effort Definitions

Weight - to indulge or resist gravity

Light - delicate, sensitive, easy intention

Strong - bold, forceful, determined intention

Time- internal rhythm of movement

Sustained - leisurely, continuous, lingering Sudden - unexpected, isolated, surprising 


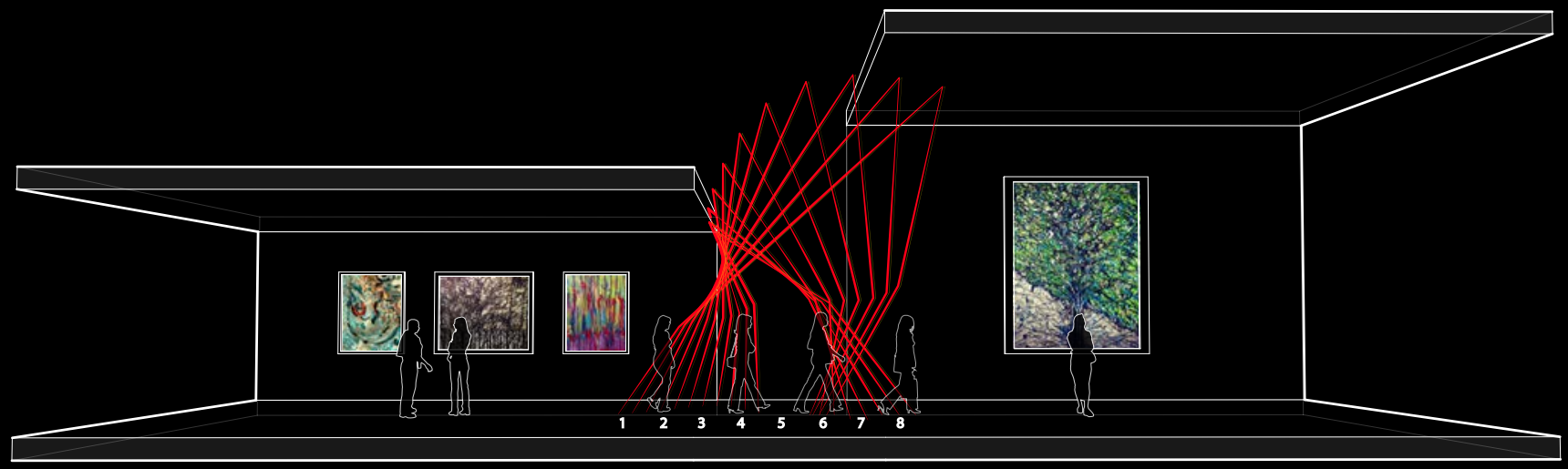

sustained | light

\section{motion: transfer | slight push | what's in the next room?}

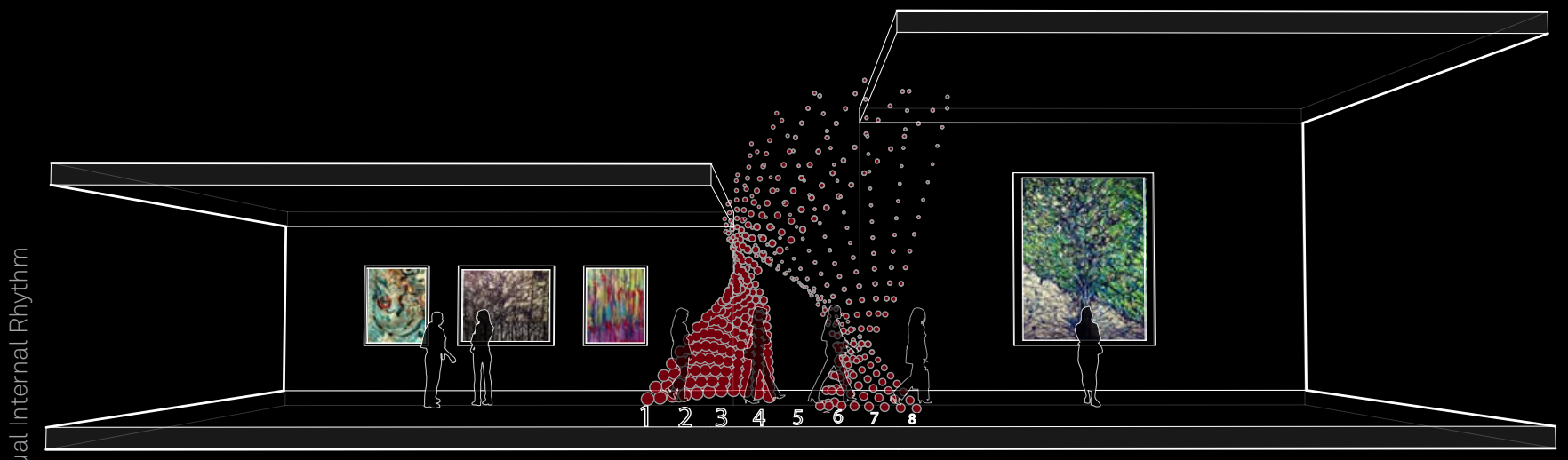

sudden | strong--> light 

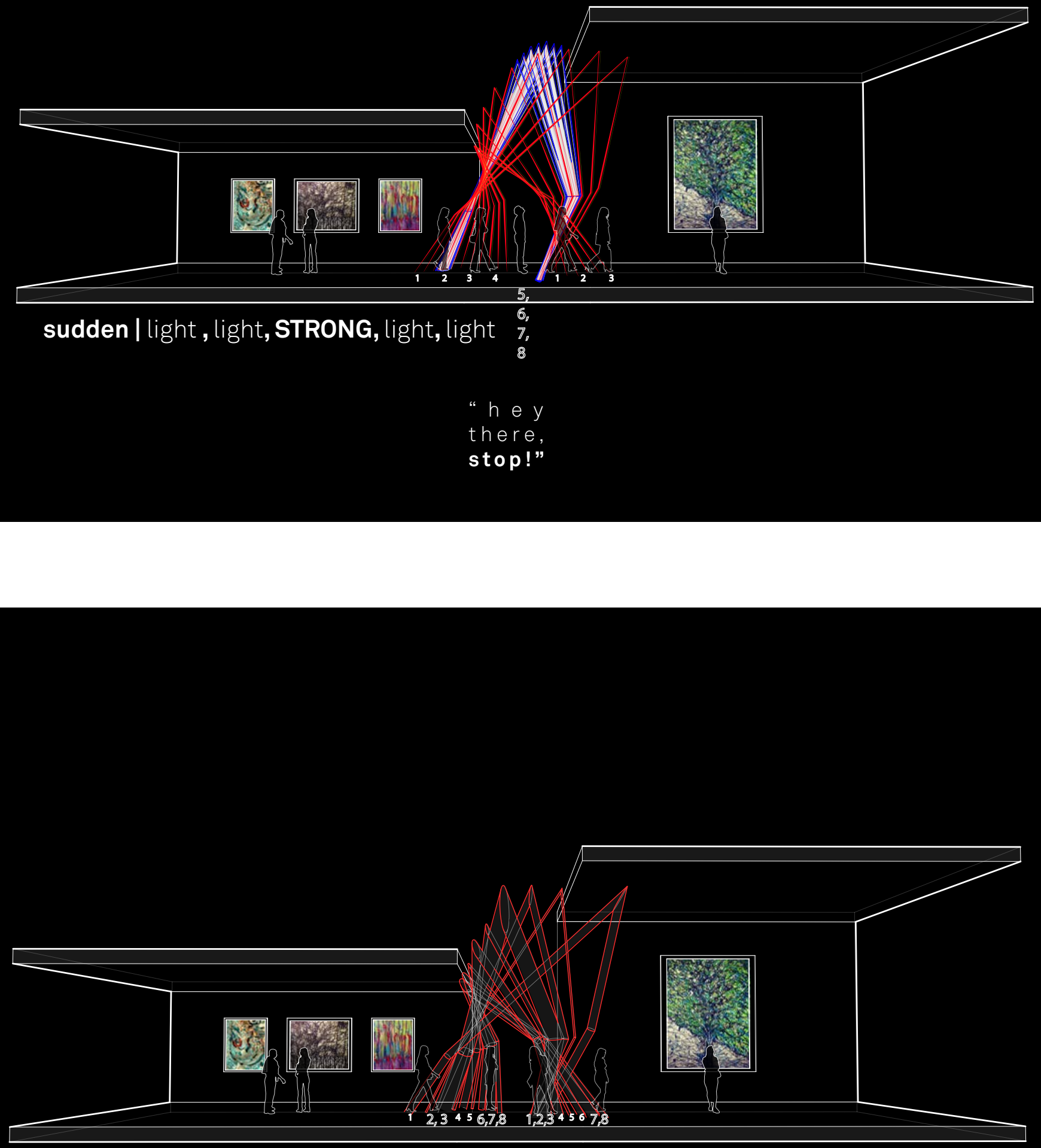

sudden | light, strong, light, light, strong, light 

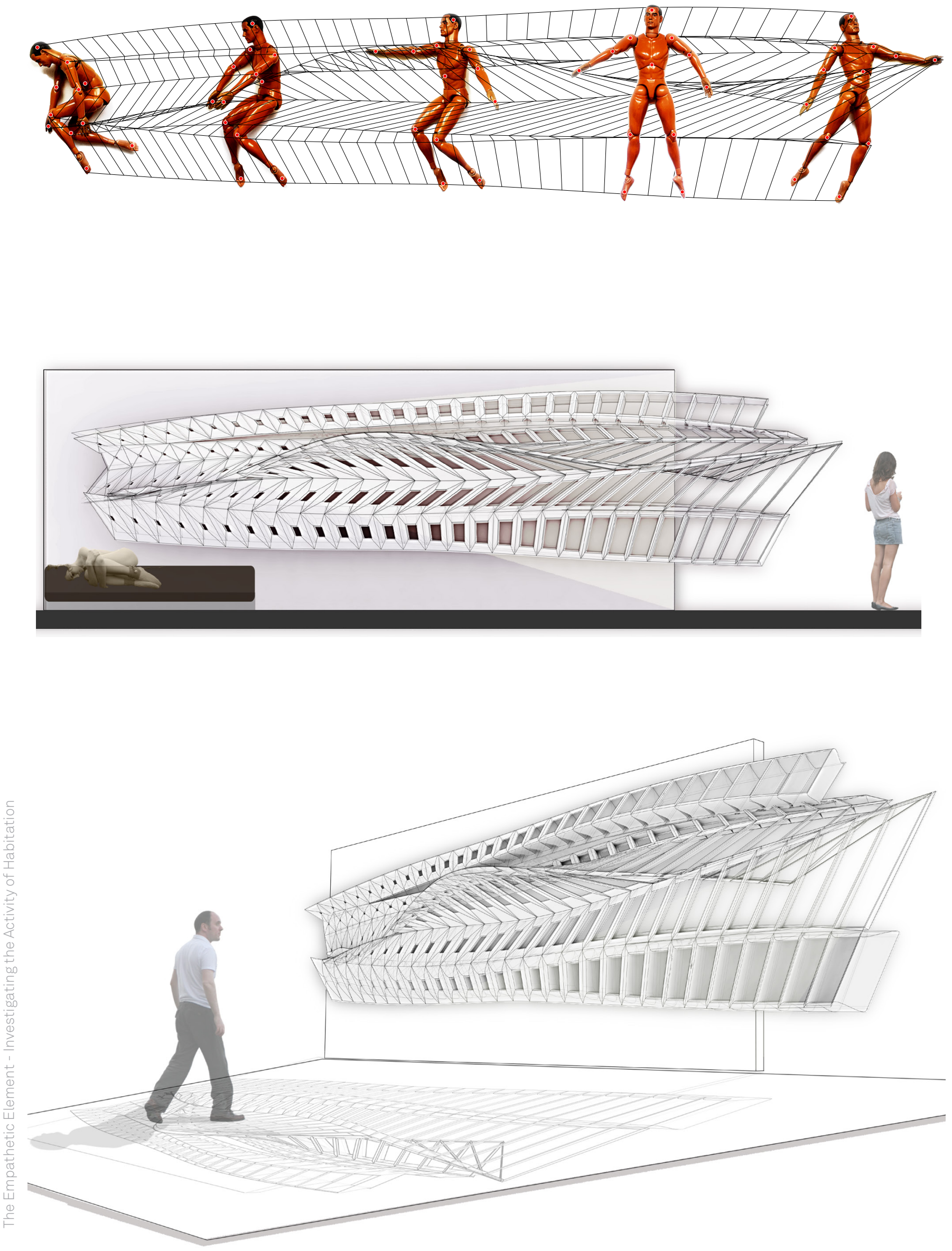

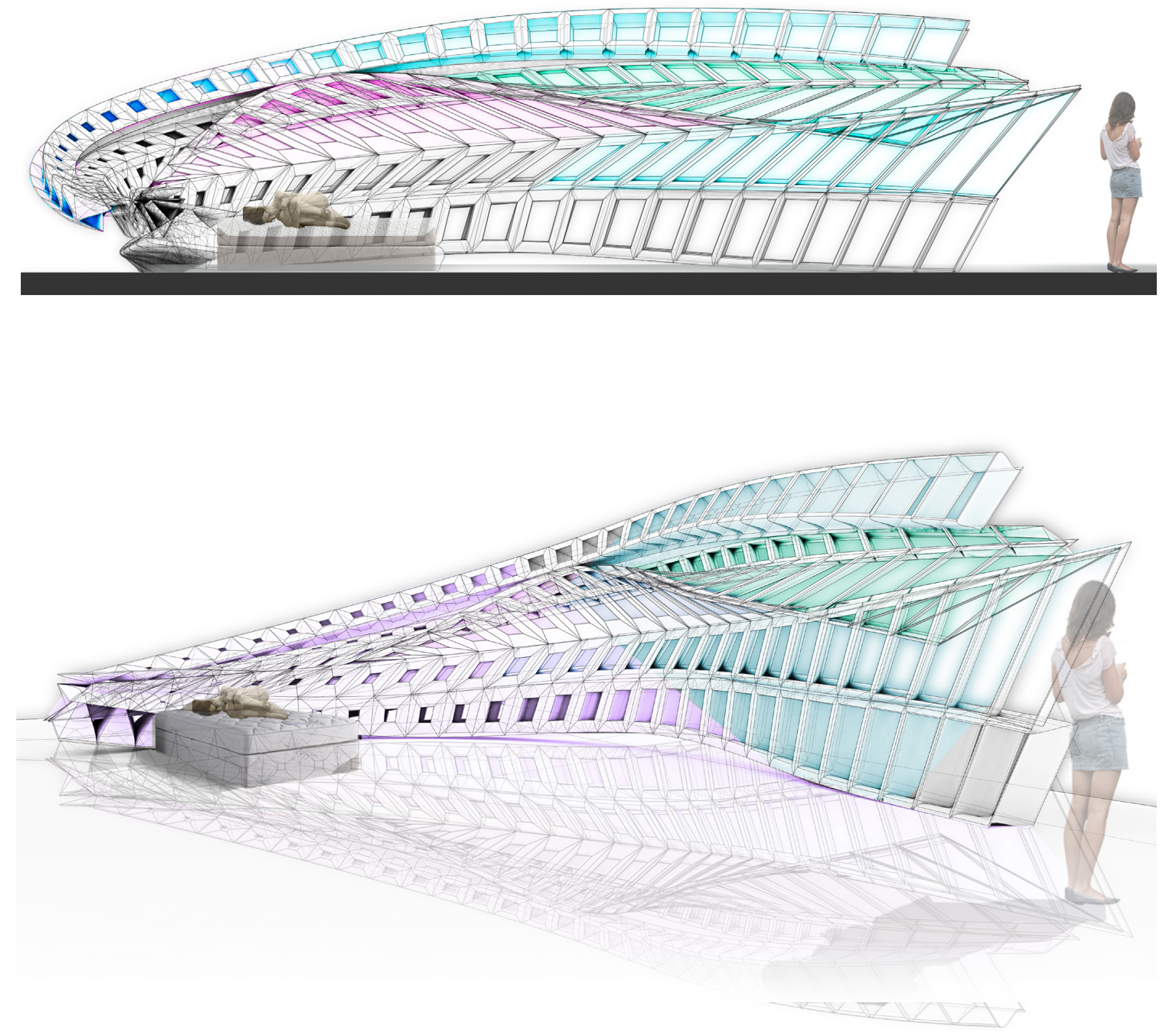

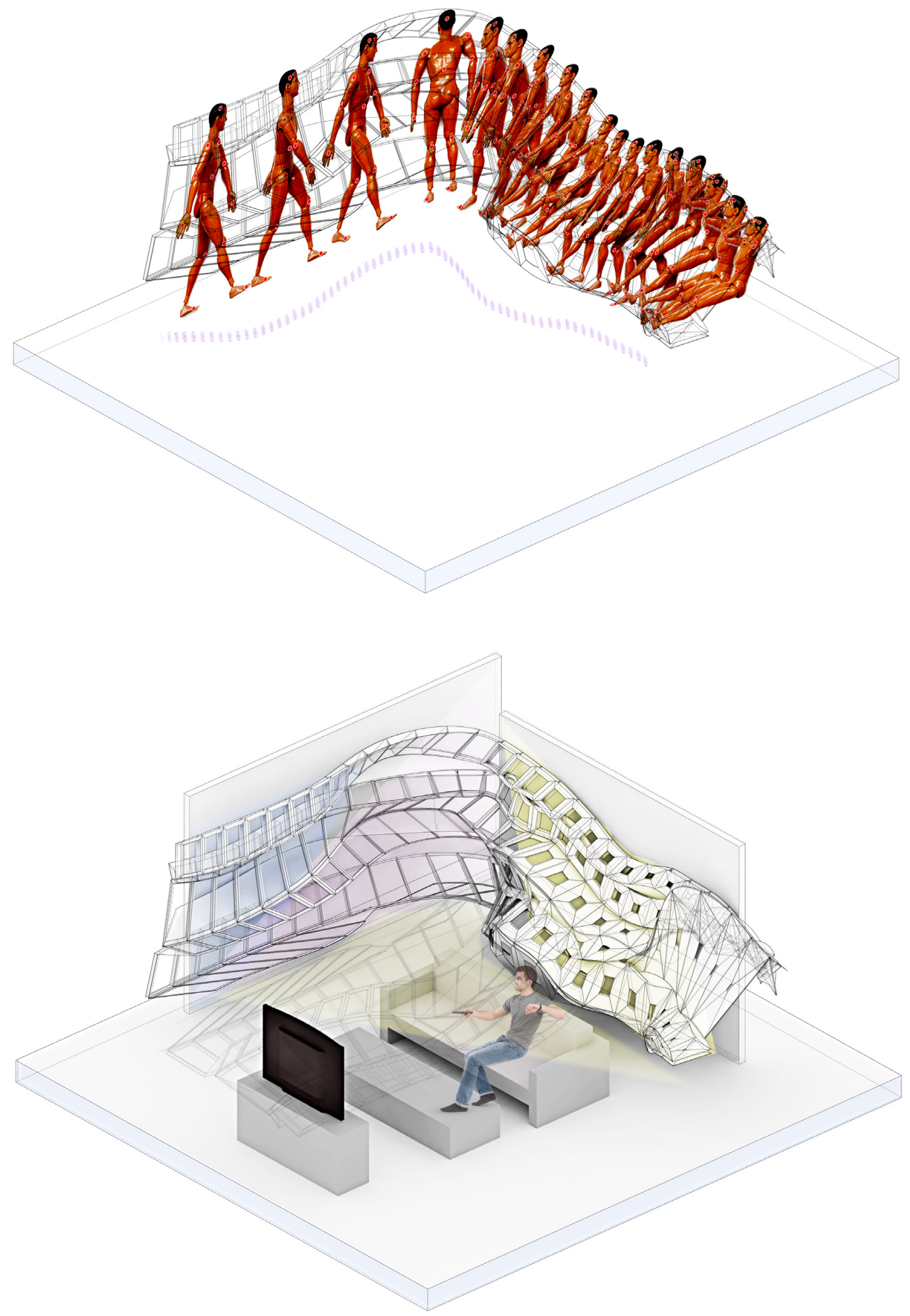

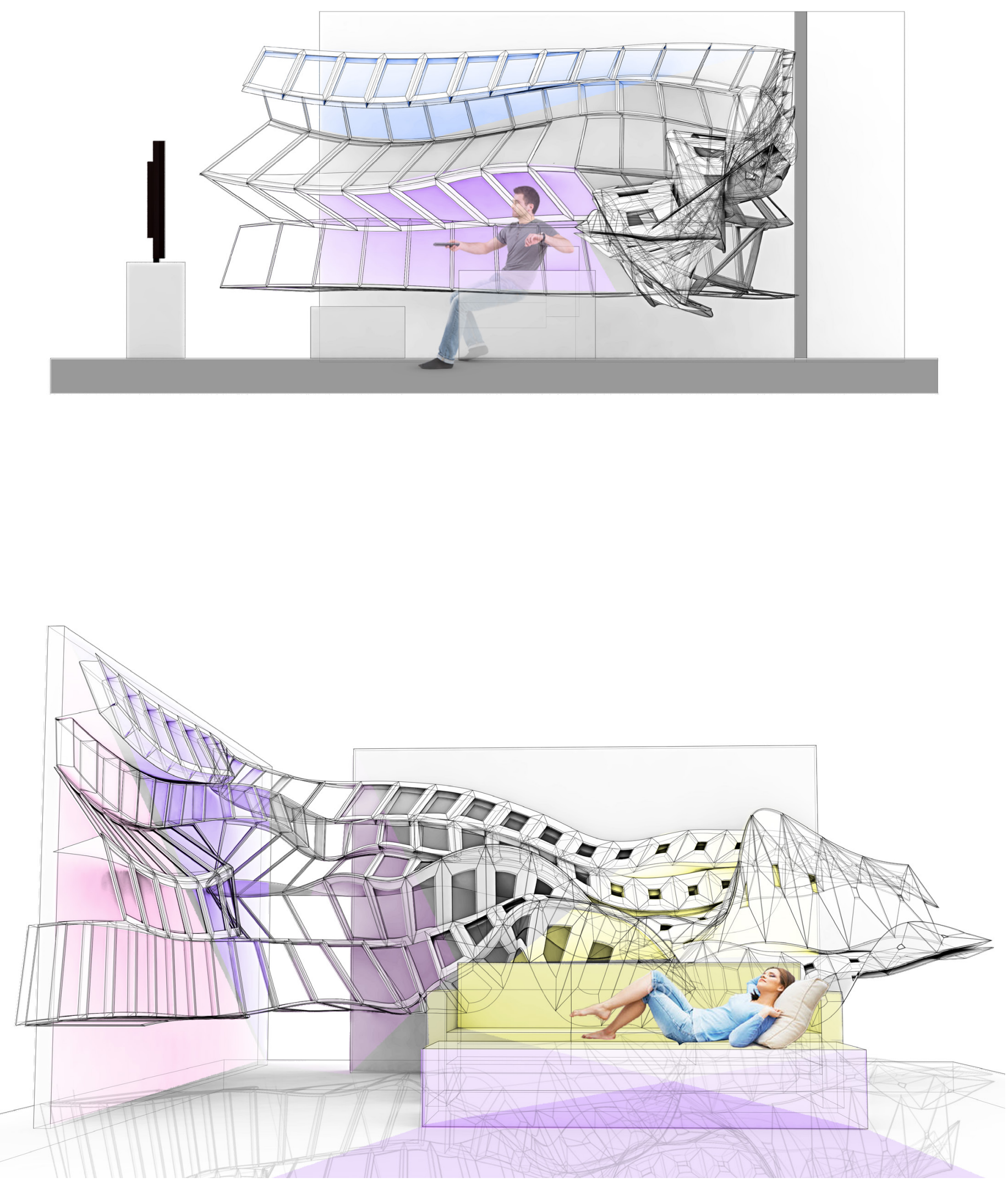


\section{Appendix B \\ Additional Drawings for Choreographing Architecture Methods}

\section{Source: Ashley Brooke Biren}

\section{a. Choreographing Negative Space}

Choreographing Negative Space explores a subtractive form-finding process by carving through an existing volume of space. Two scenarios were developed utilizing lines and curves derived from body proportions to carve through an existing volume. (See Section 6.3 - Choreographing Negative Space for details) 


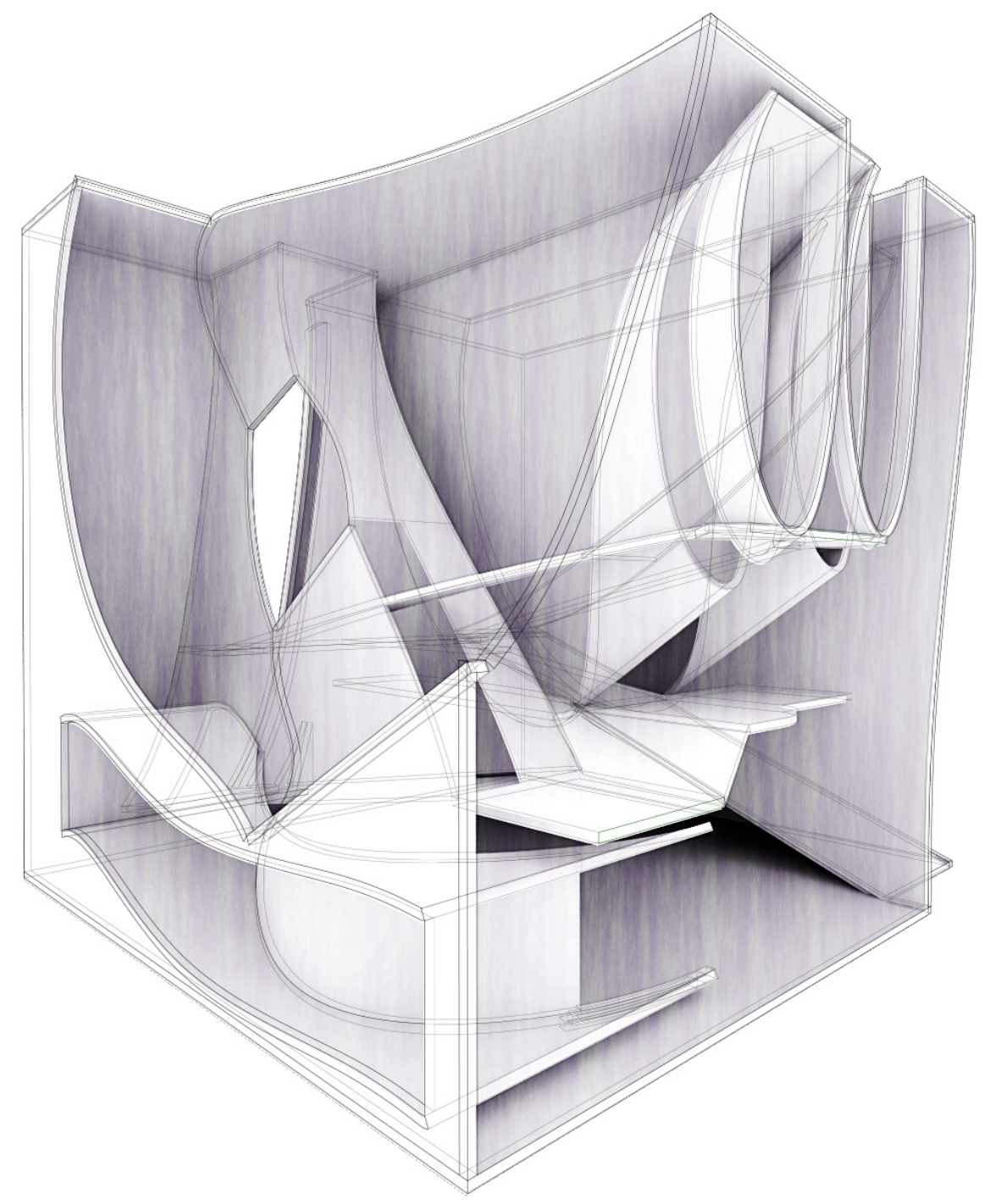


Choreographing Negative Space: Additional Drawings for Experiment in Section 6.3.

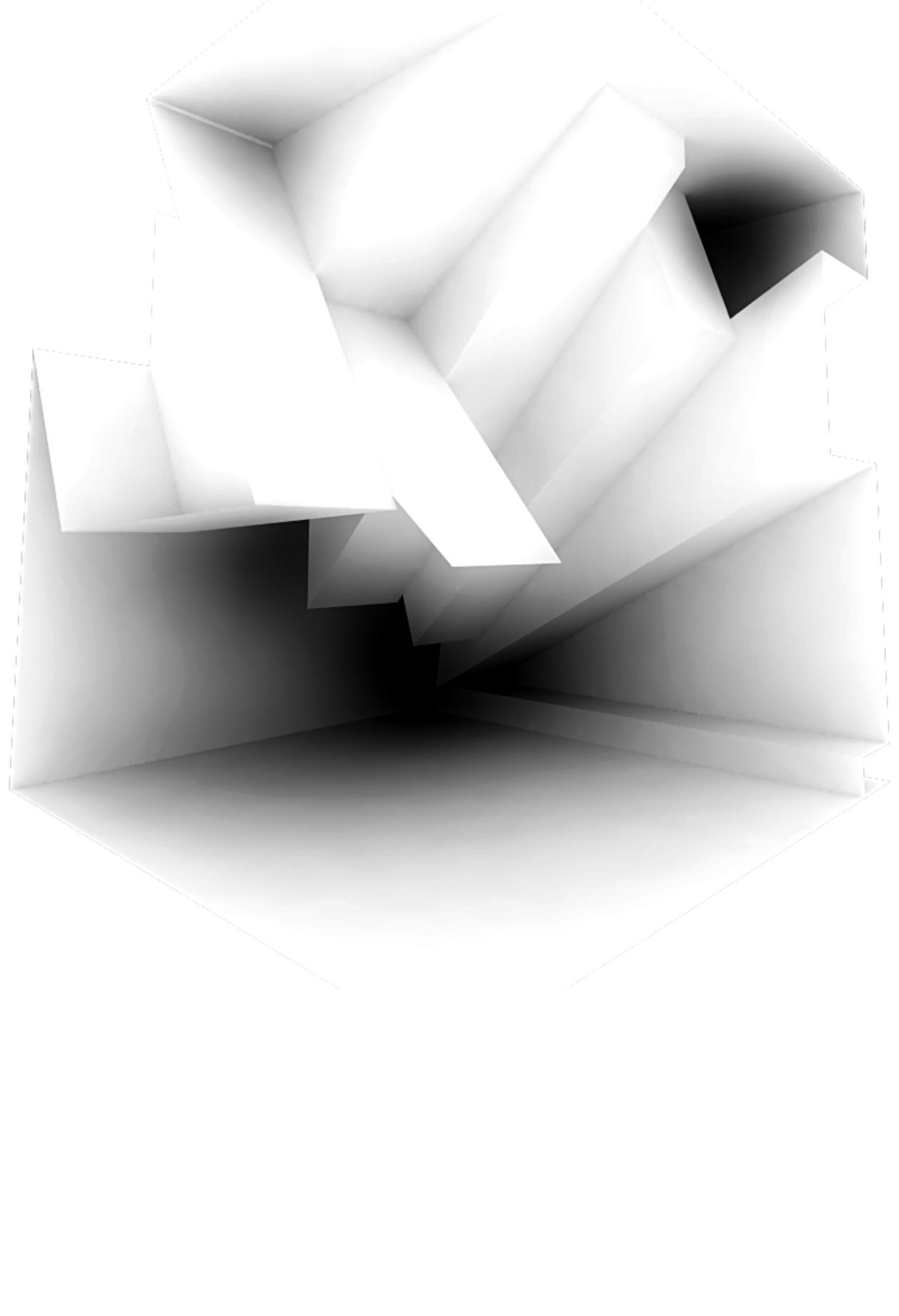



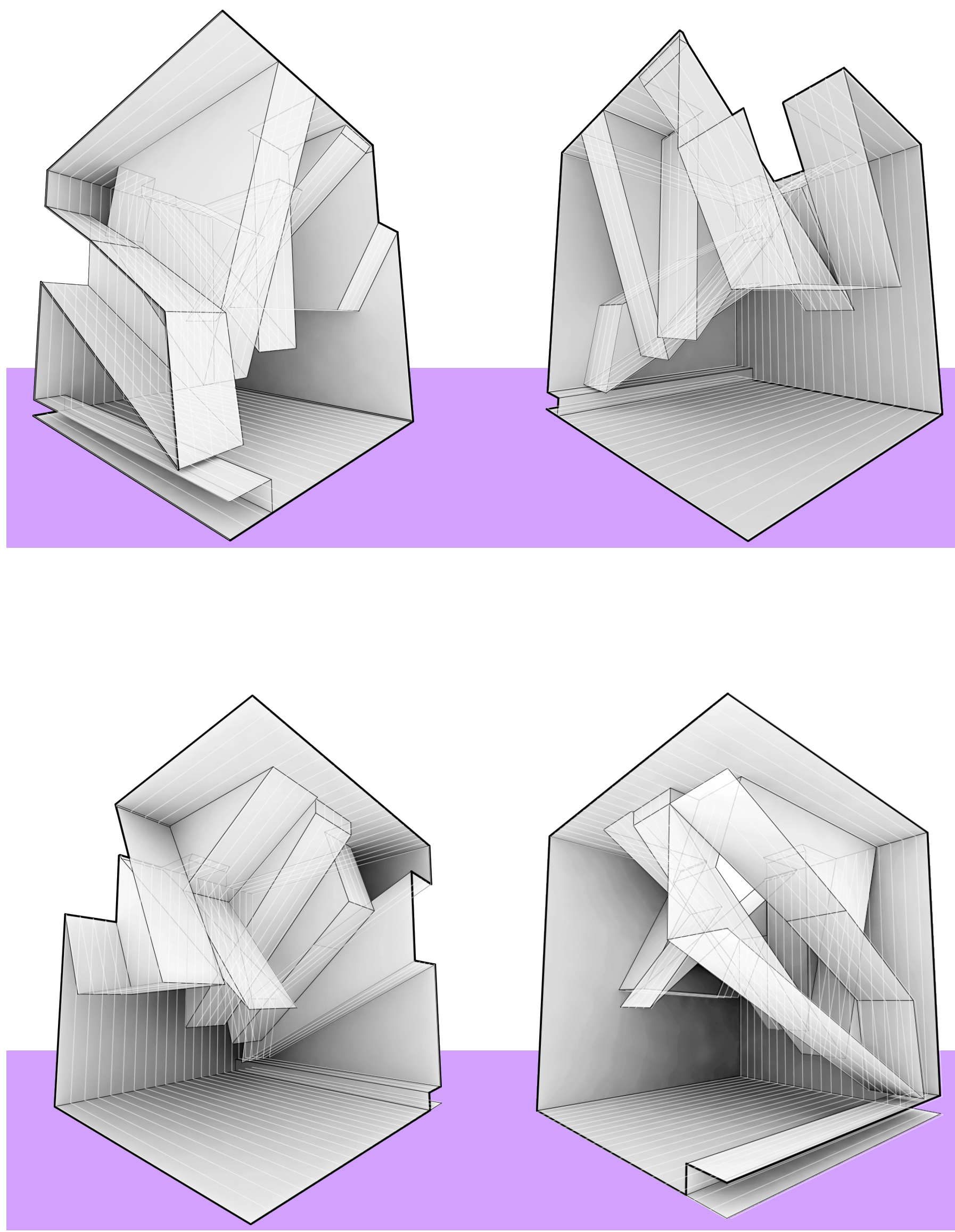

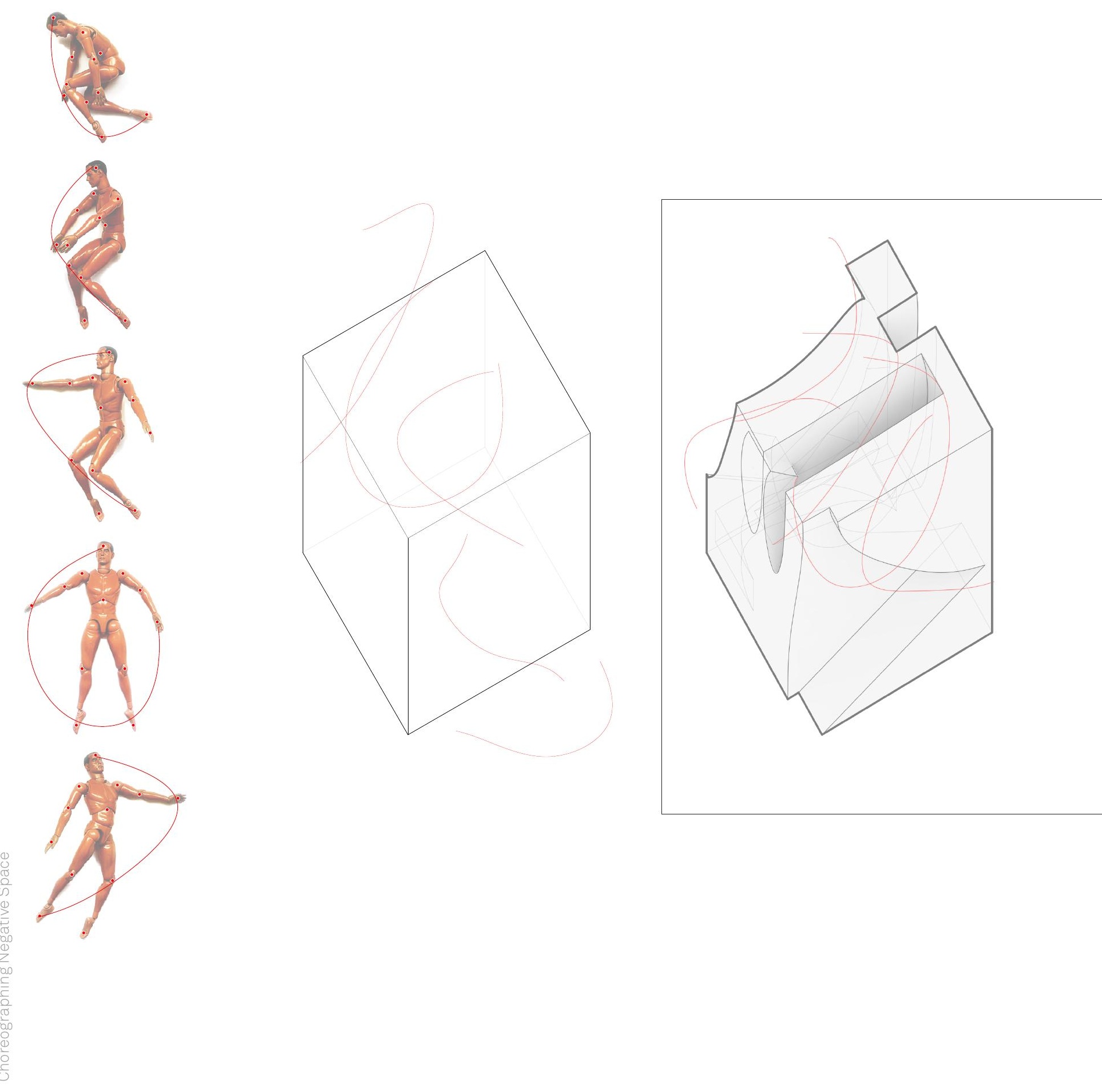
Choreographing Negative Space concerns a subtractive form-finding process by carving through an existing mass. This scenario utilizes curved lines derived from body proportions to cut through the existing volume in a sequential progression: lying down, rising, stretching and extending the body in an up-right position. Choreographing these movements allows the inhabitant to experience the body of architecture in a similar manner, beginning from a lower level, rising and wakening the body to an elevated location. Along the journey of this route, the occupant finds moments in which the movements intersect, allowing for intimate unforeseen spaces. These spatial moments are illustrated in the second stage of development.
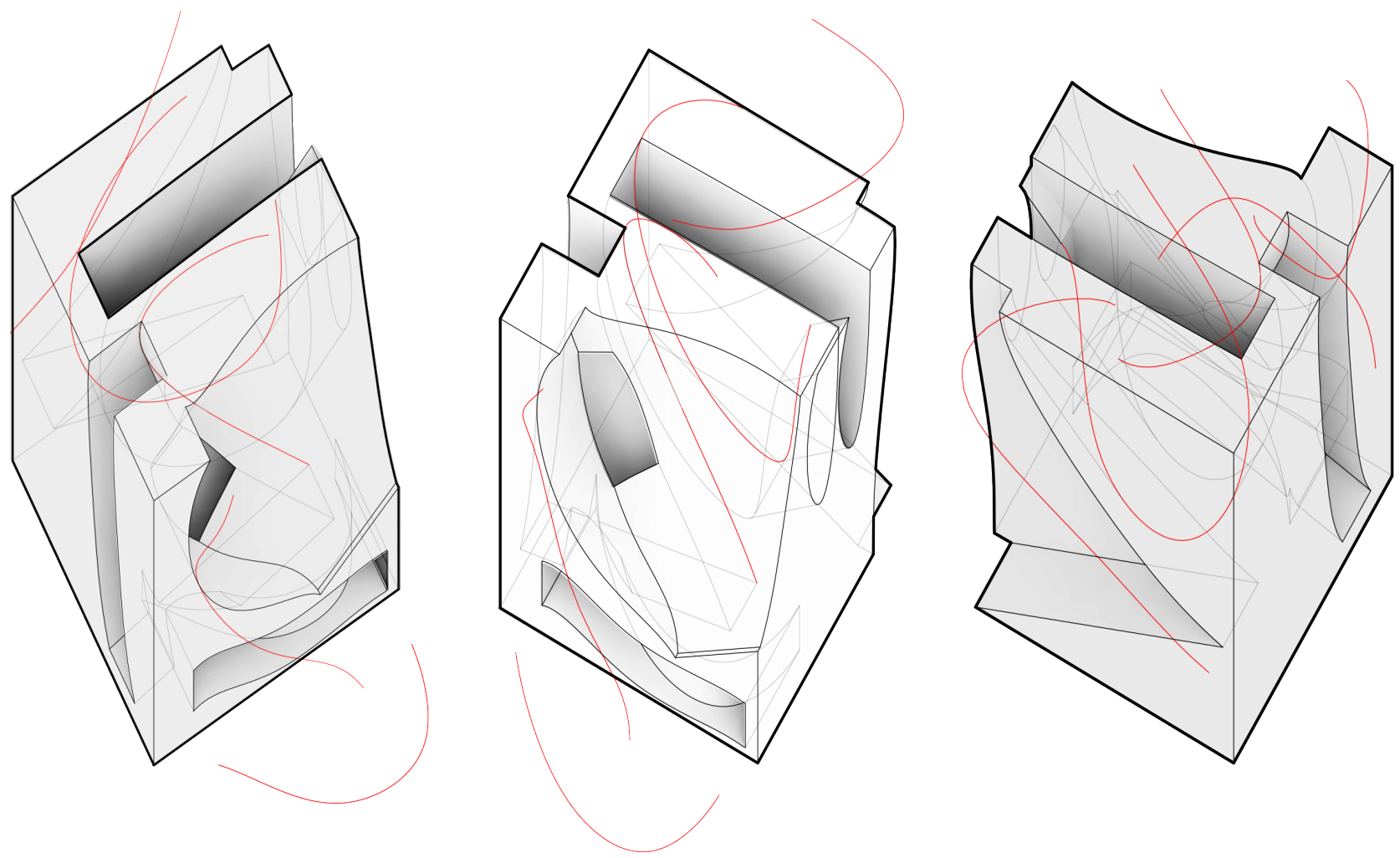

STAGE 1 DEVELOPMENT: Choreographing the body of architecture 

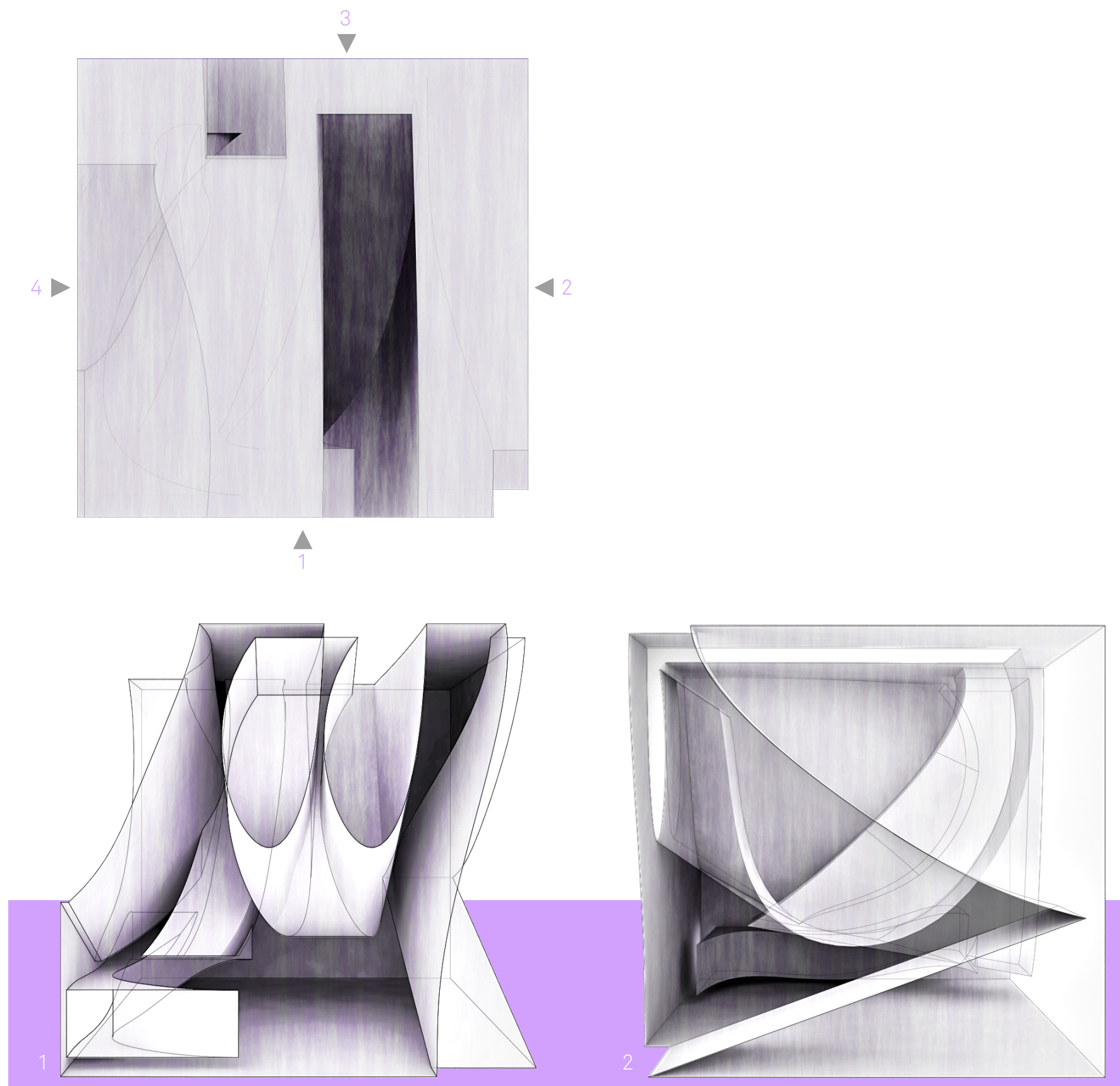

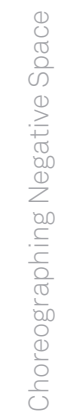



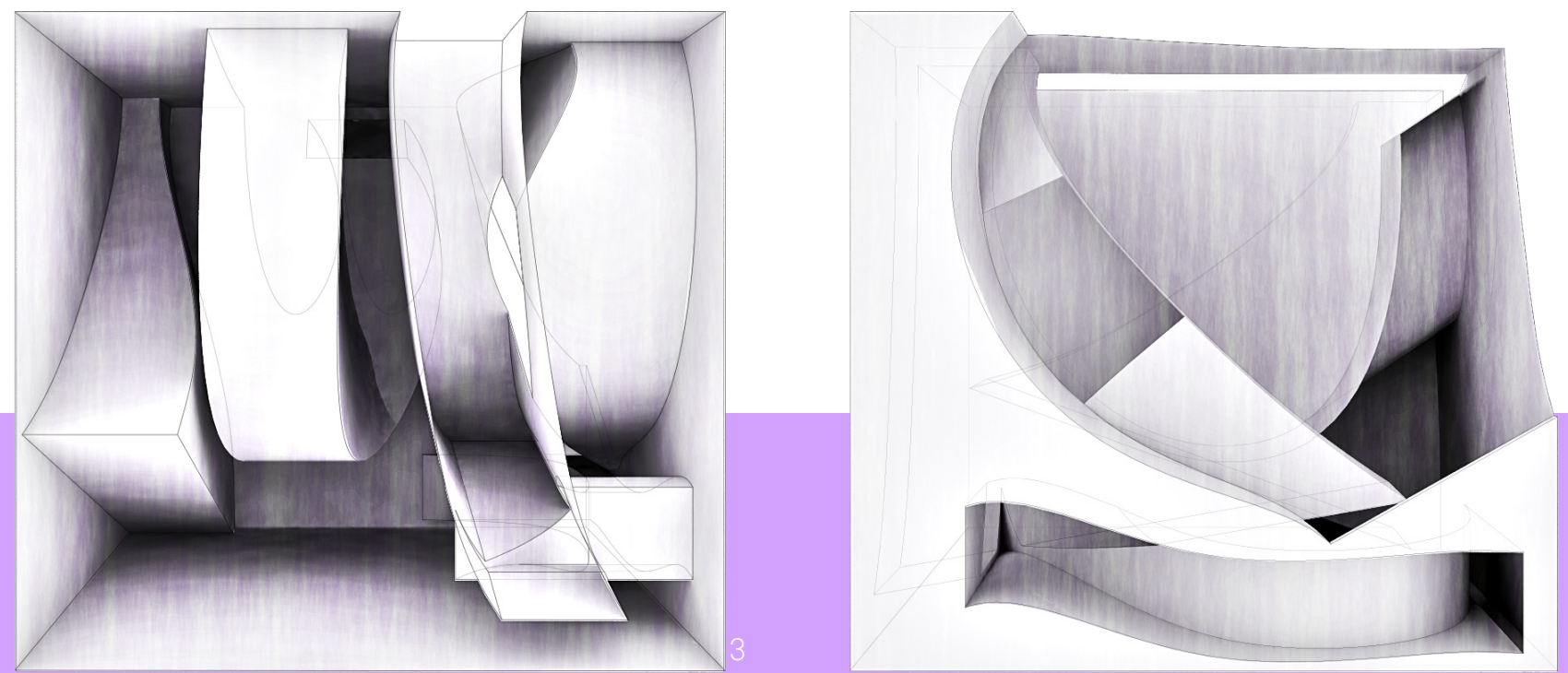

STAGE 1 DEVELOPMENT: Choreographing the body of architecture 
STAGE 2 DEVELOPMENT: Choreographing how the body moves through space

The movement of the architecture is intersected and sliced by pathways, allowing the inhabitant to experience both intimate and revealing events in space.
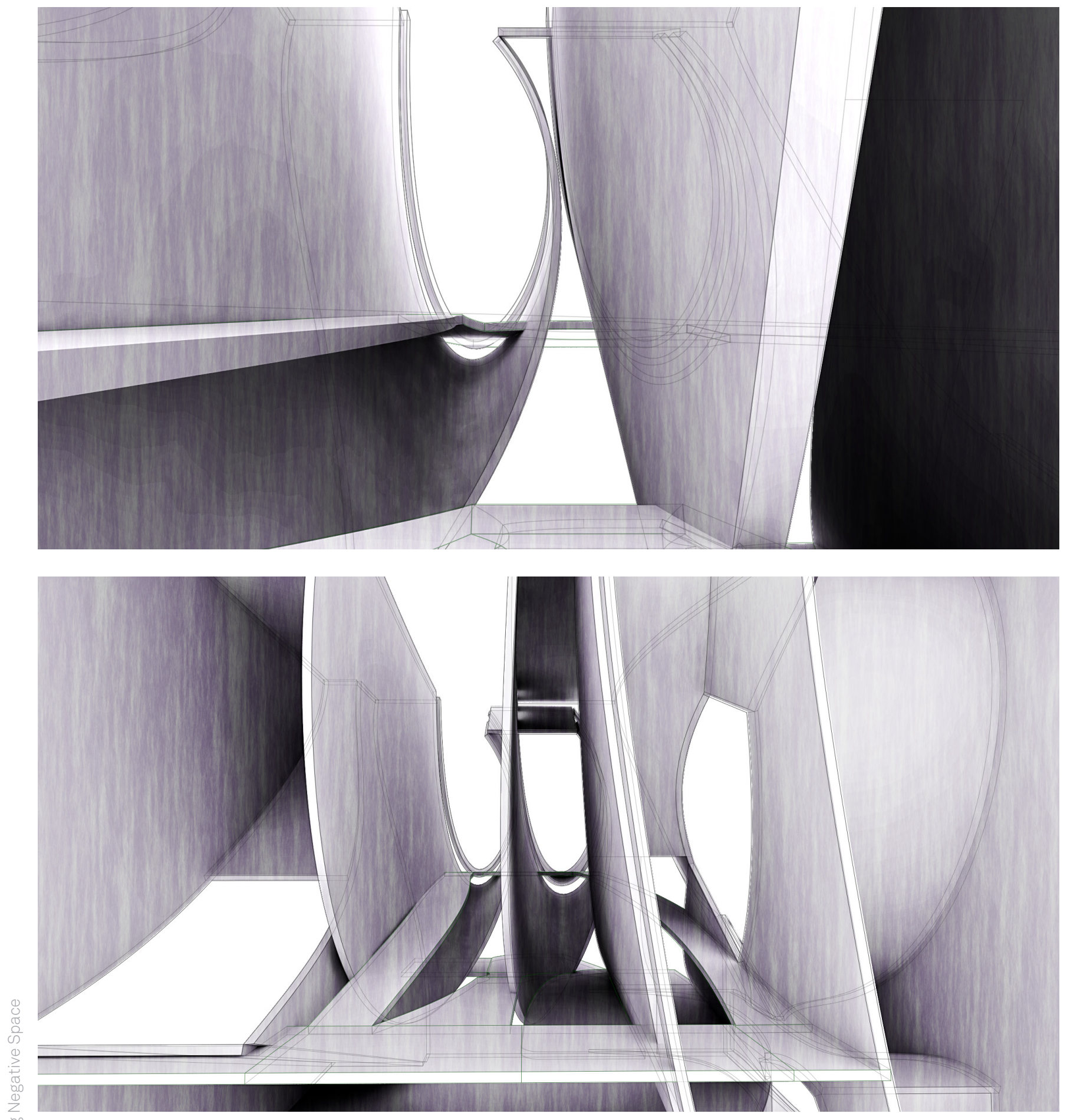

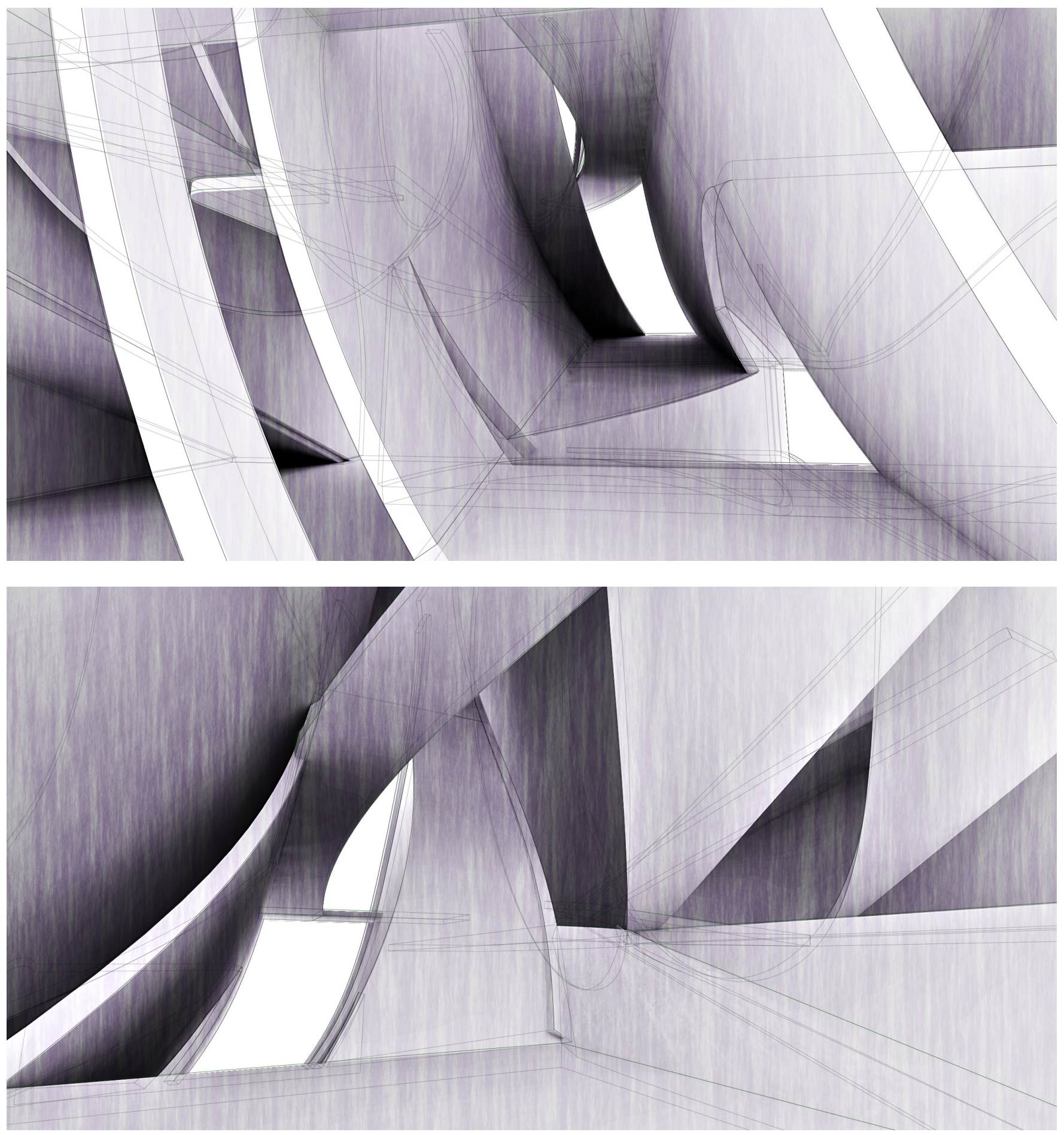


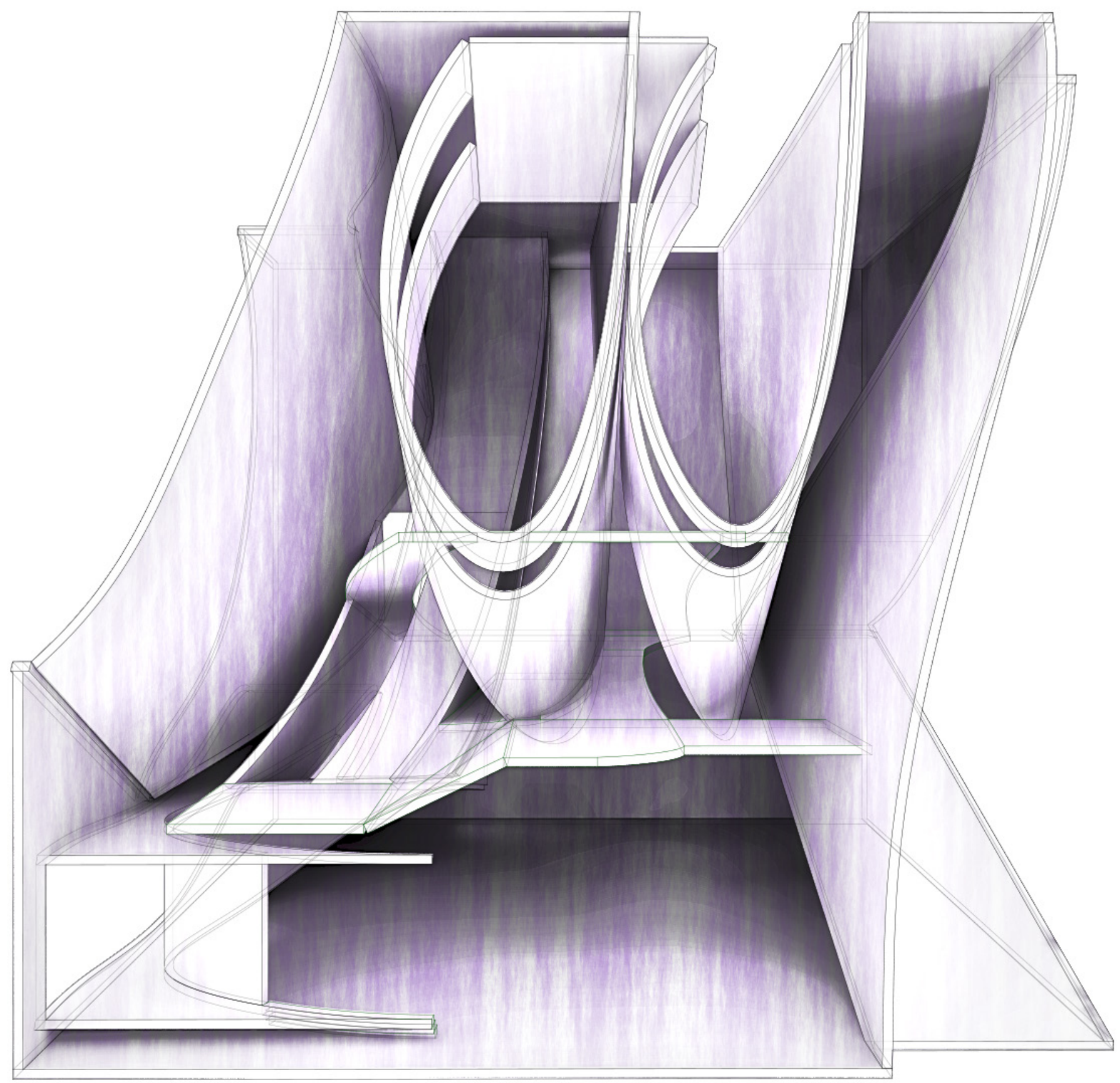



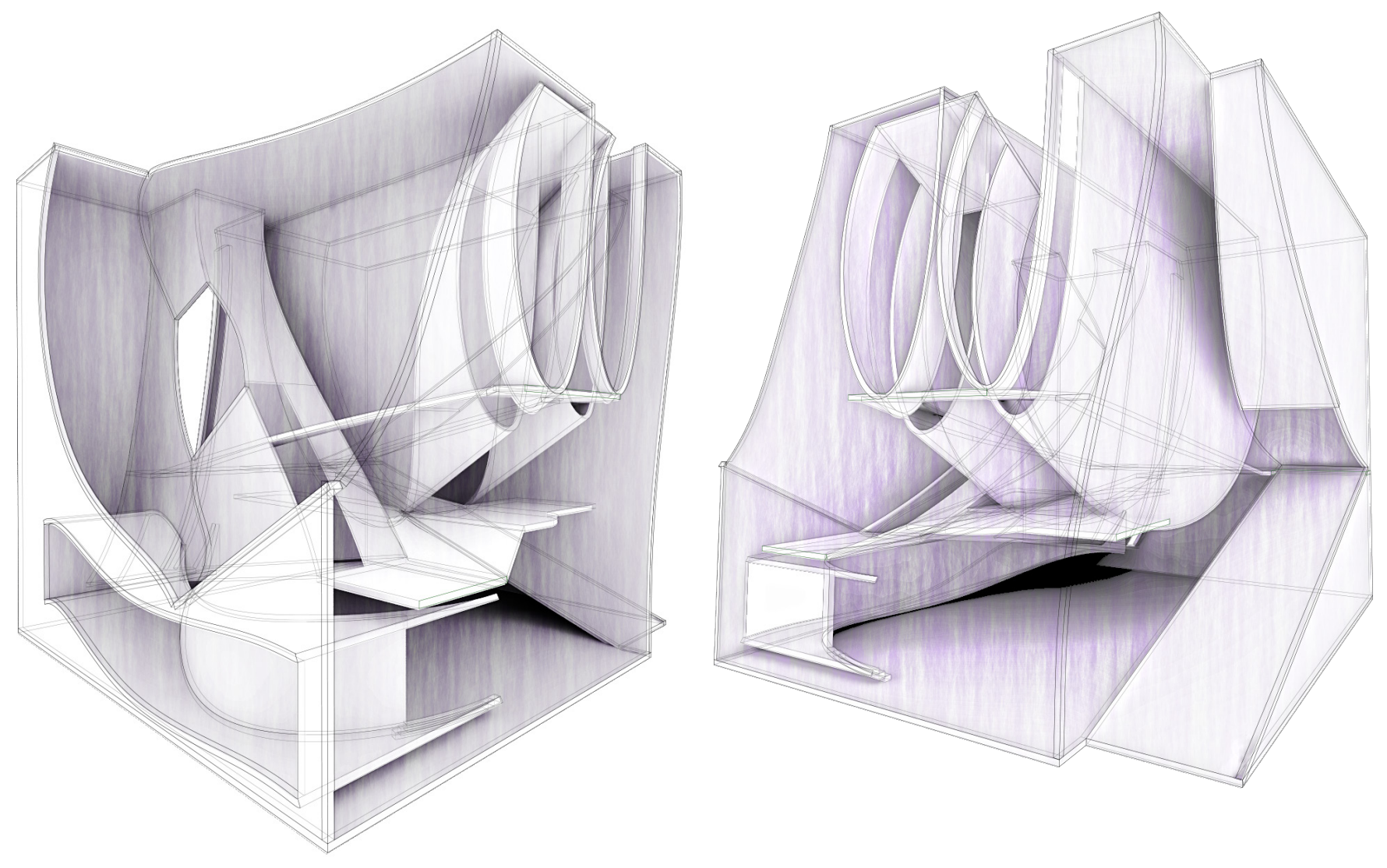


\title{
Appendix C
}

\author{
Additional Design Explorations with the Kinect \\ Source: Ashley Brooke Biren
}

\section{a. The Dynamic House - [Design Explorations with Kinect]}

The Dynamic House was further developed from its initial stages in December 2014. At this stage of development, movements were explored with the Kinect, translating points from the body in motion to lines lofted in real-time. The difficulty of developing a dialogue with the existing house and the proposed parasitic architecture stopped this design to develop into further stages.

\section{b. Movements of Habitation - Stage 1 [Design Explorations with Kinect]}

This stage of design exploration investigates the virtual forces of human kinesis and body proportions through parametric geometries. Here, the Kinect was used to explore the relationship between body parts through various geometric outcomes when engaging in movements of habitation such as activities in the kitchen, bathroom and living room. The first method explores creating rectangular volumes defined by the relationship between two body parts. The second continues this exploration by introducing a shearing force controlled by the distance between two body parts. The third investigates deforming an existing surface through defined points of the body.

\section{c. Movements of Habitation - Stage 2 [Design Explorations with Kinect]}

The second stage of design exploration with the Kinect continues to investigate the virtual forces of human kinesis and body proportions through parametric geometries. Here, rectangular volumes are defined by a body proportion, while introducing a bending force influenced by the relation between two parts of the body. An array of movements of habitation generated various topological forms including sleeping, bathing and eating. From here, methods of organizing these forms in space were investigated including duplicating, mirroring, clustering and sprawling. These exercises informed the development of Kinesthetic Components in the Visionary Proposition. 
b

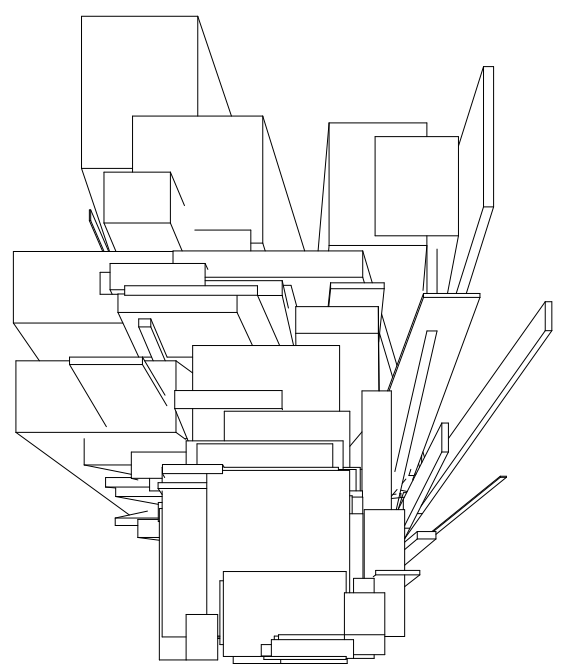

b

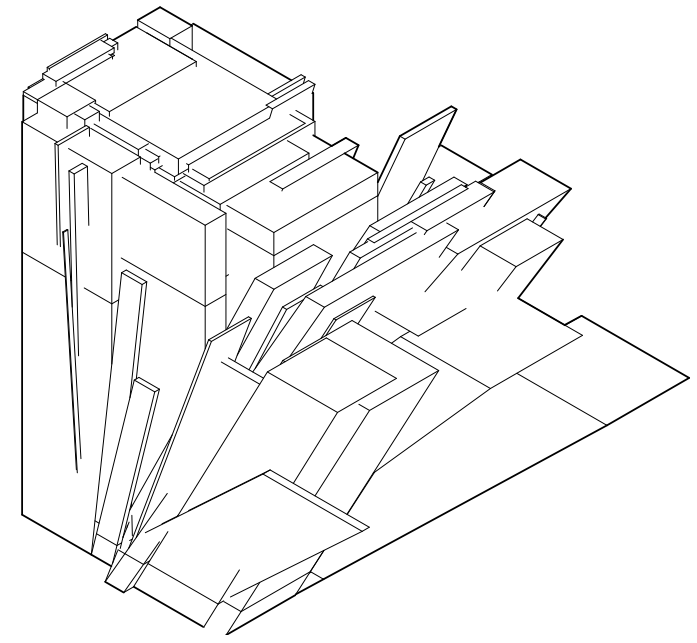

a

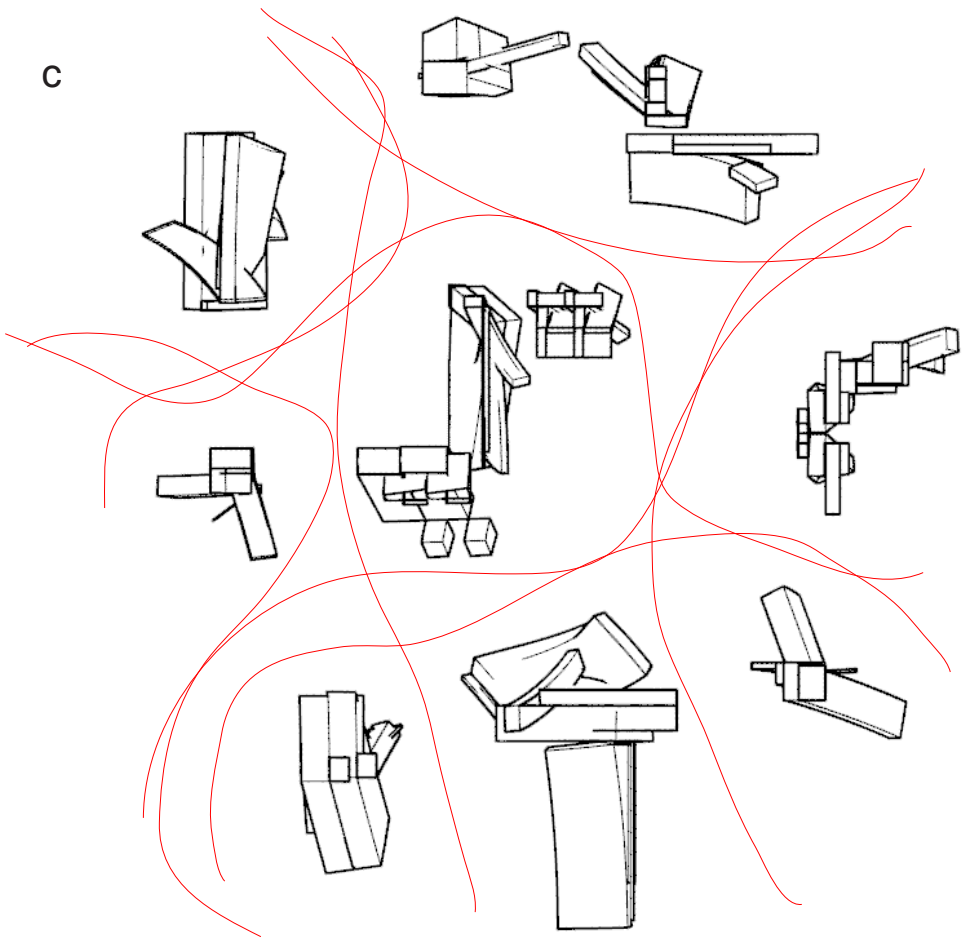

b

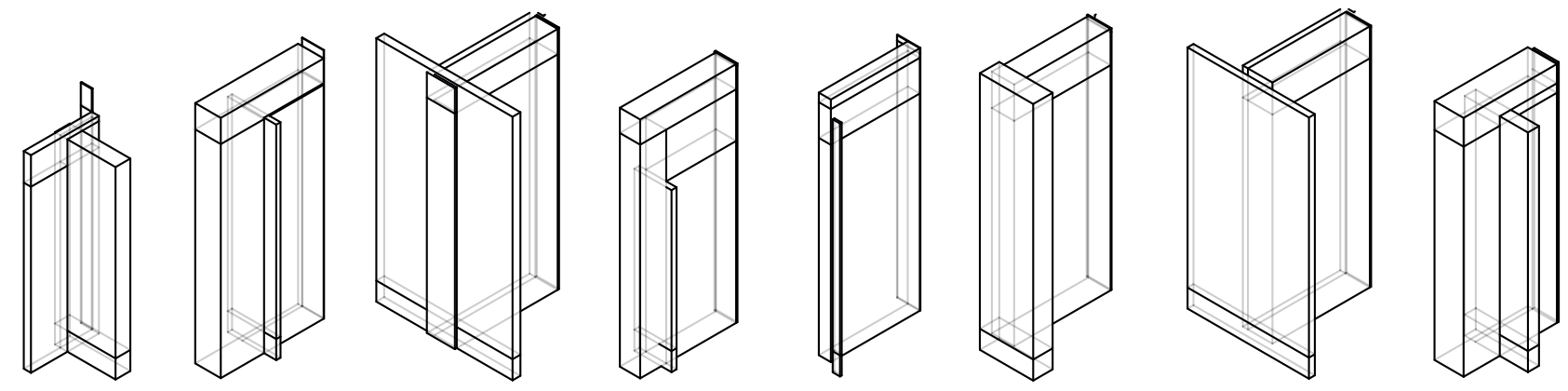


Dynamic House: Preliminary Sketches

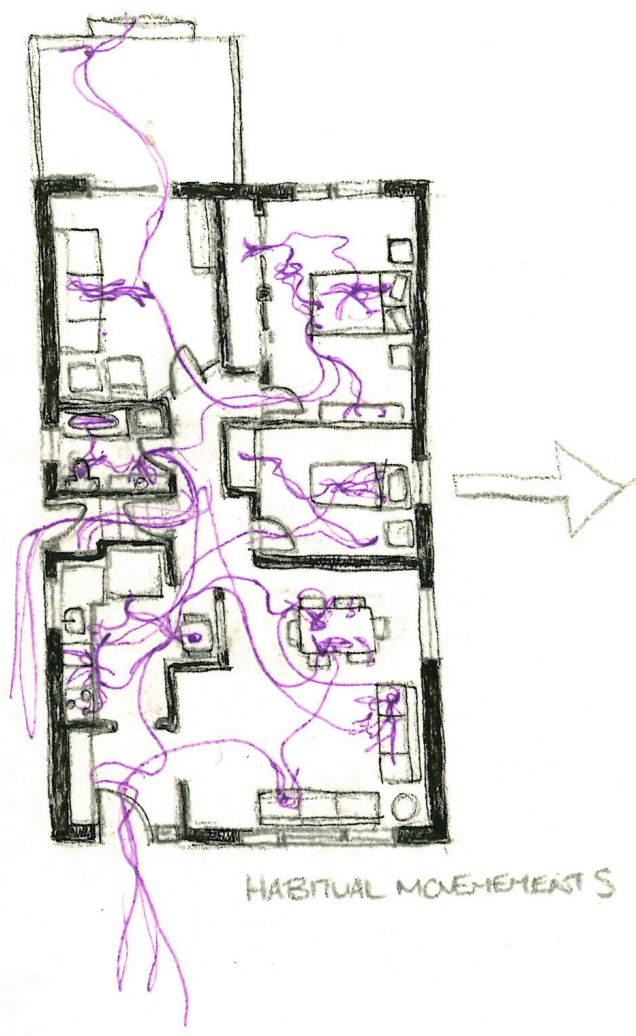

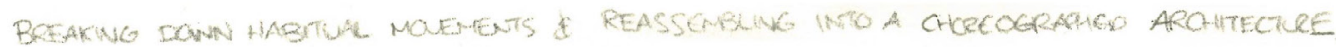

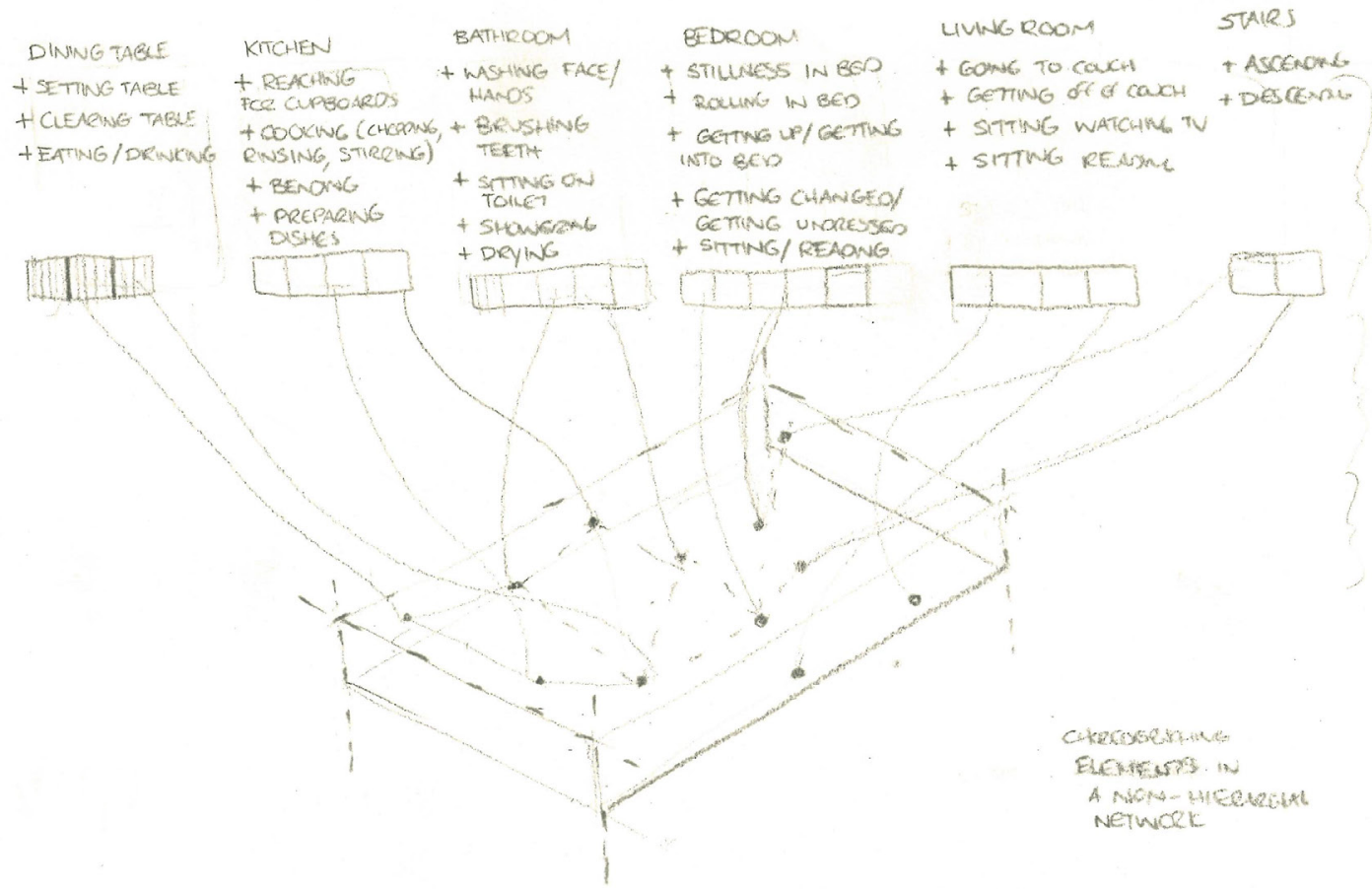

KWESTLETL

EMPATHA

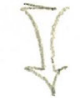

CHOREOGR<smiles>C1CC2CCC3CC(C1)C23</smiles>

ARCHTECWE 

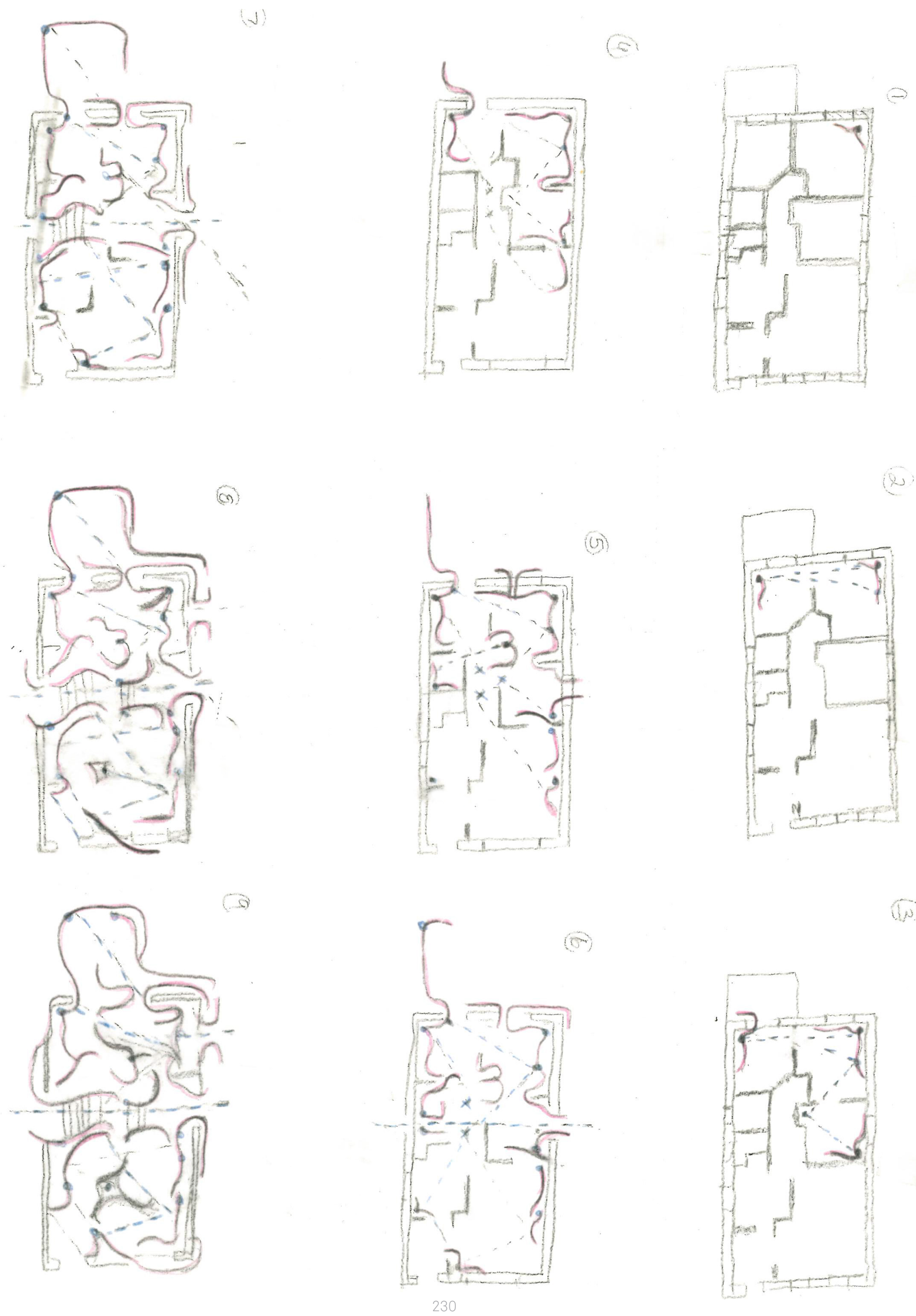

(1ij)

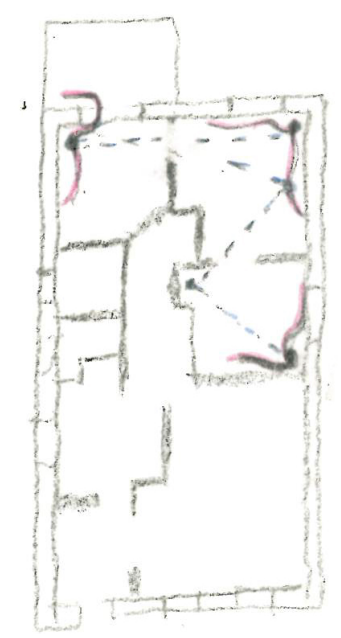



Kinect
$--\quad$ Firefly
$-->$
Grasshopper
$-->$
Rhino

[1

Untitled - Rhinoceros Corporate (32-bit)

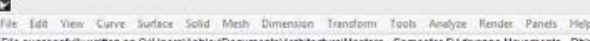

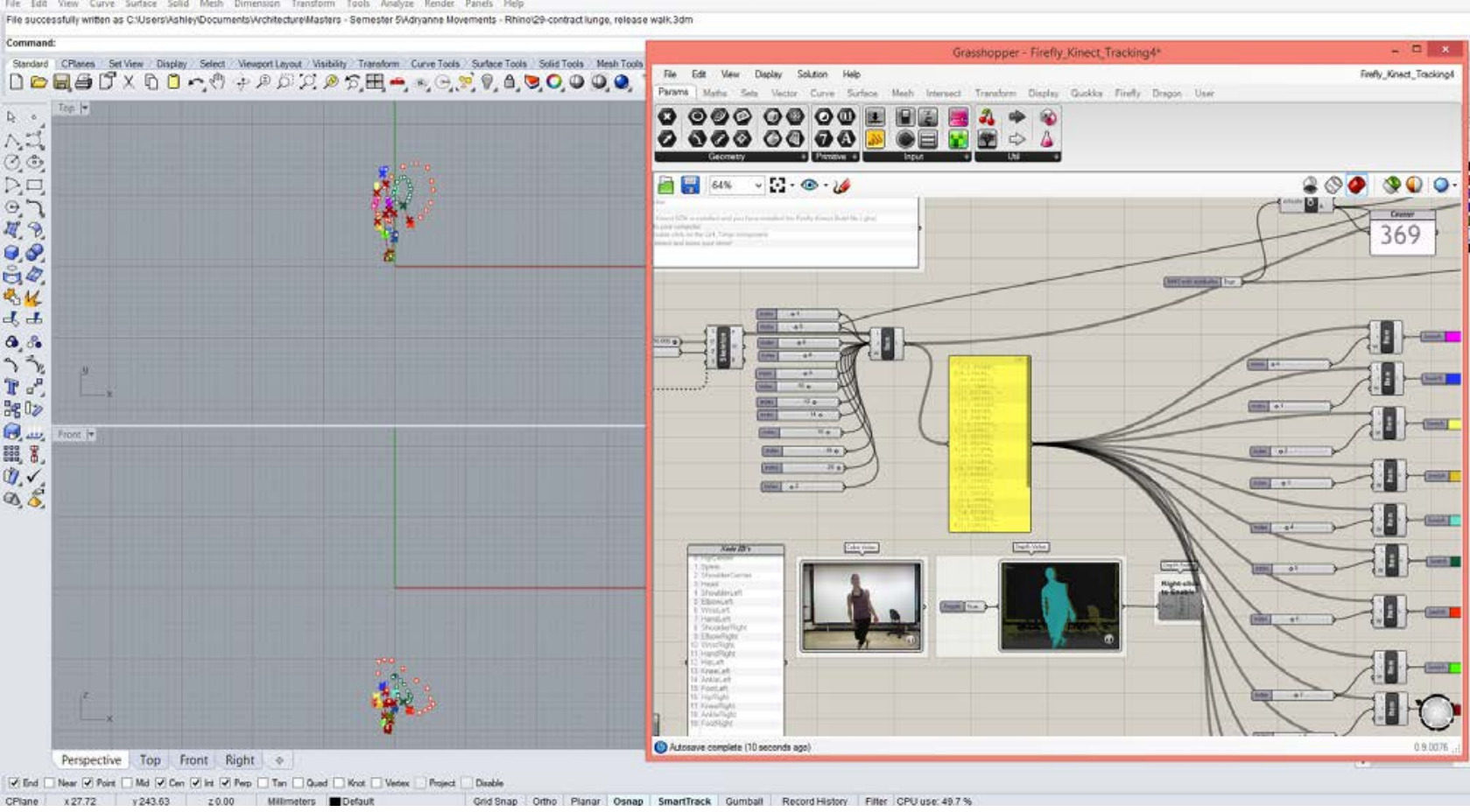

Movement Parameters

- Scale of Frames

- \# of Frames

- Distance Between Frames

- Frame Orientation

- Style of Movement

- Repetition of Frames

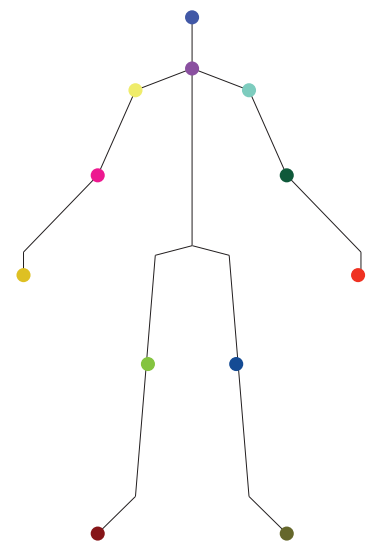




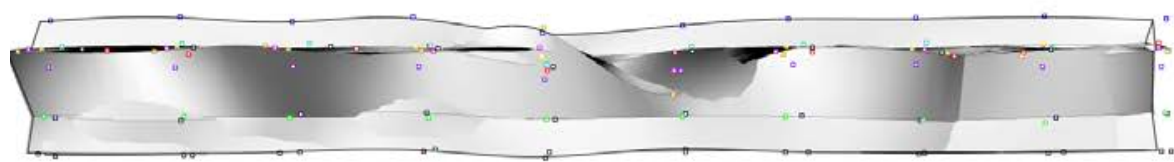

Chaine Turns

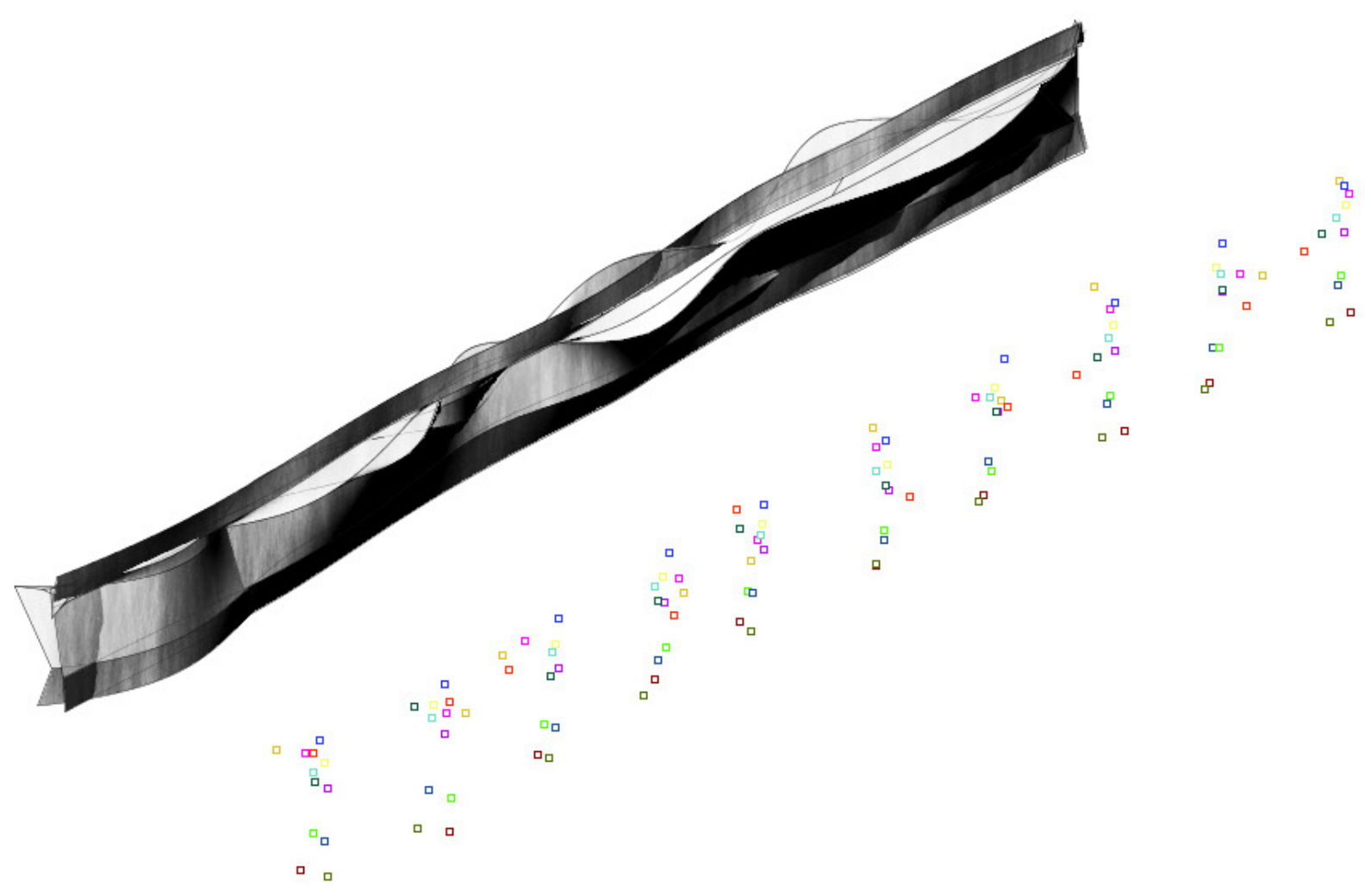




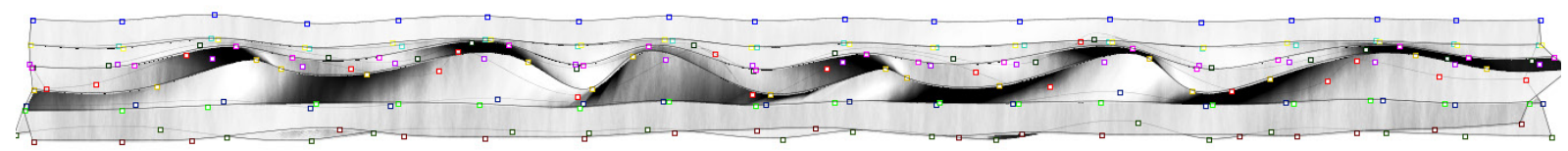

Ballet Runs

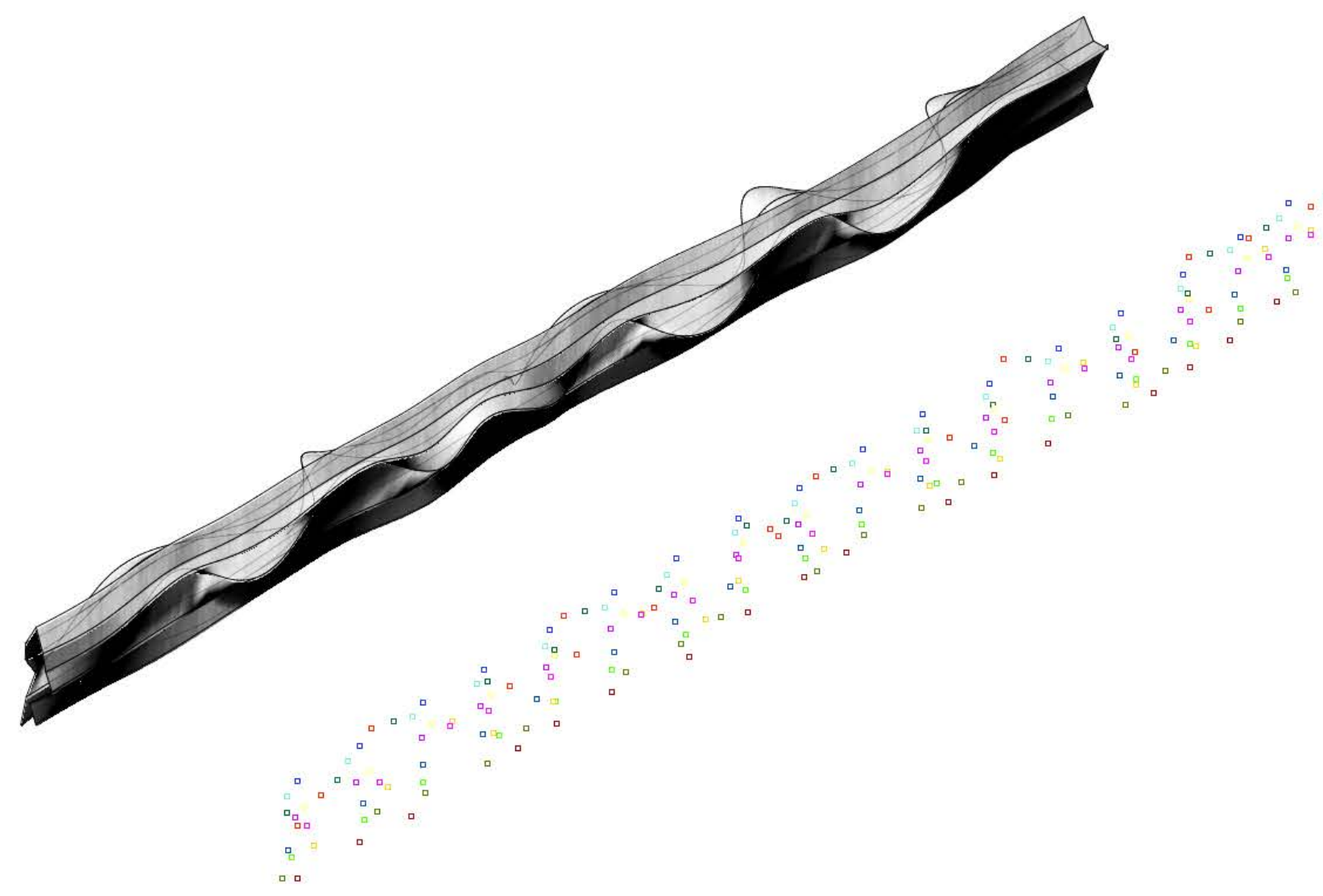



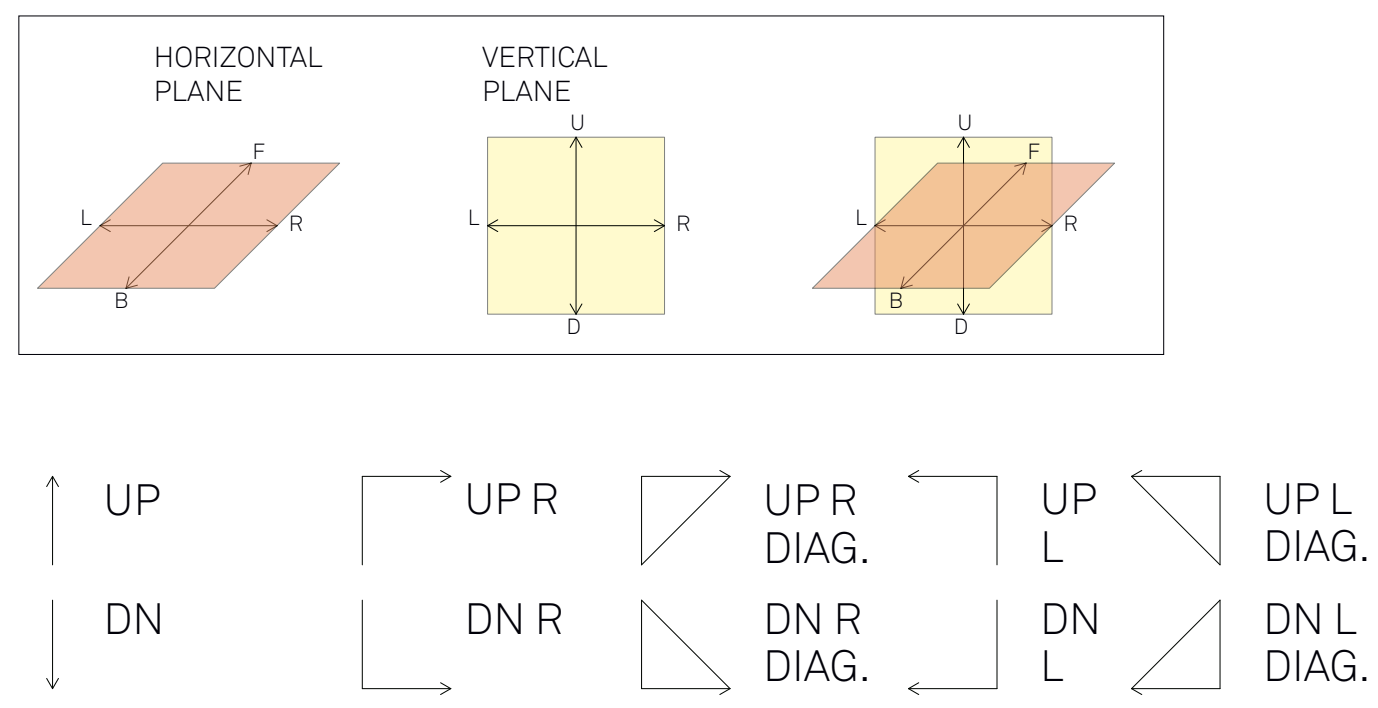

$\int \mathrm{FW}$

$\longleftrightarrow$ FWL $\longrightarrow F W R$

BW

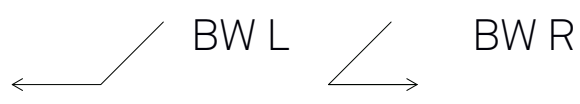

$\longleftarrow \quad L$

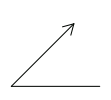

LFW

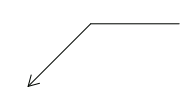

LBW
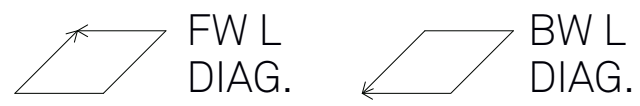

$\longrightarrow \mathrm{R}$
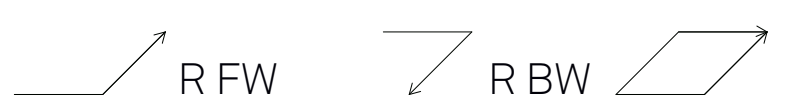

FW R

DIAG.

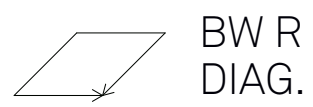


Routine 1
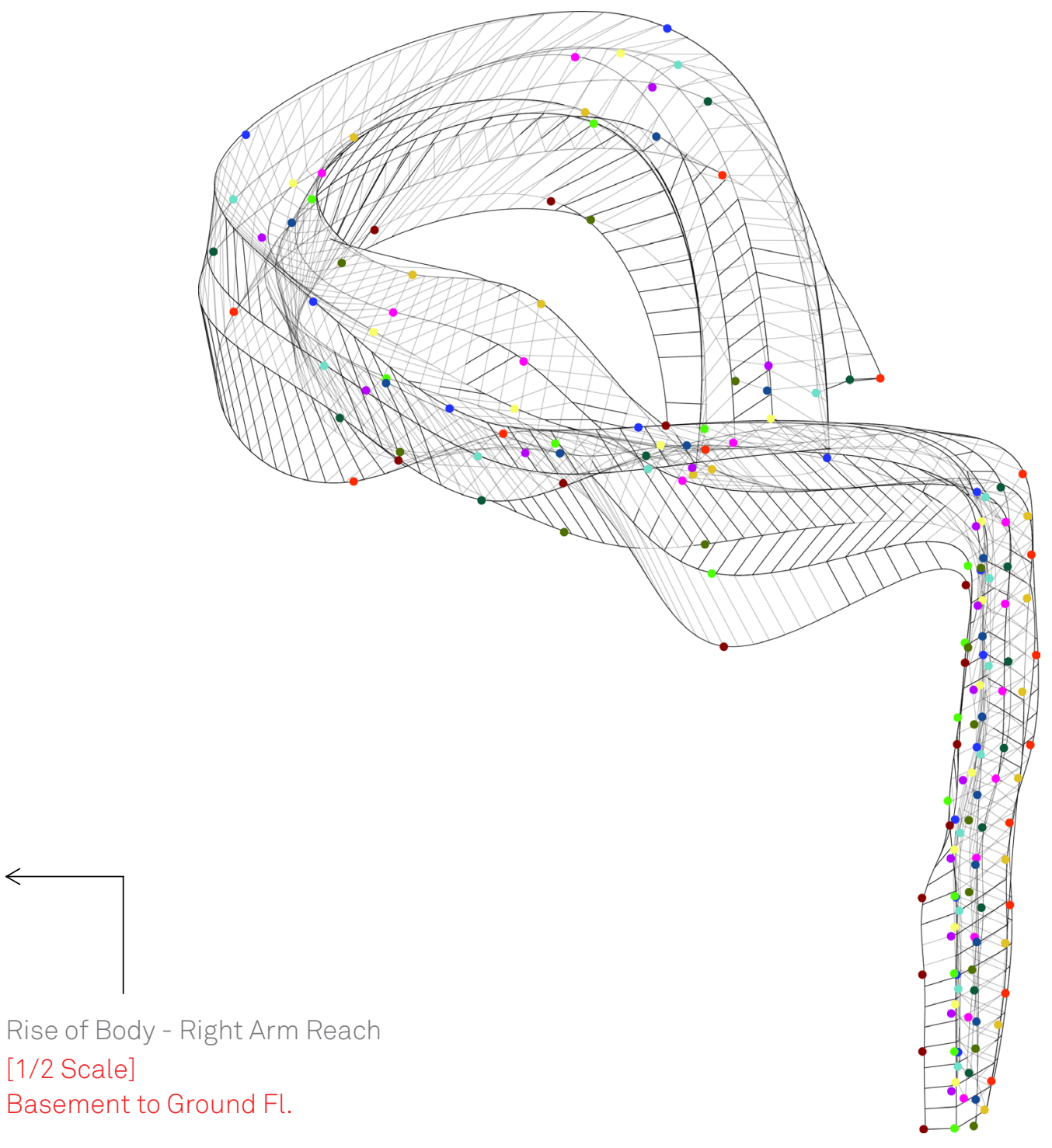

Rise of Body - Right Arm Reach

[1/2 Scale]

Basement to Ground Fl.

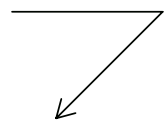

Reverse Back Bend Fall

Land

[Full Scale]

Ground Fl. 
Routine 2
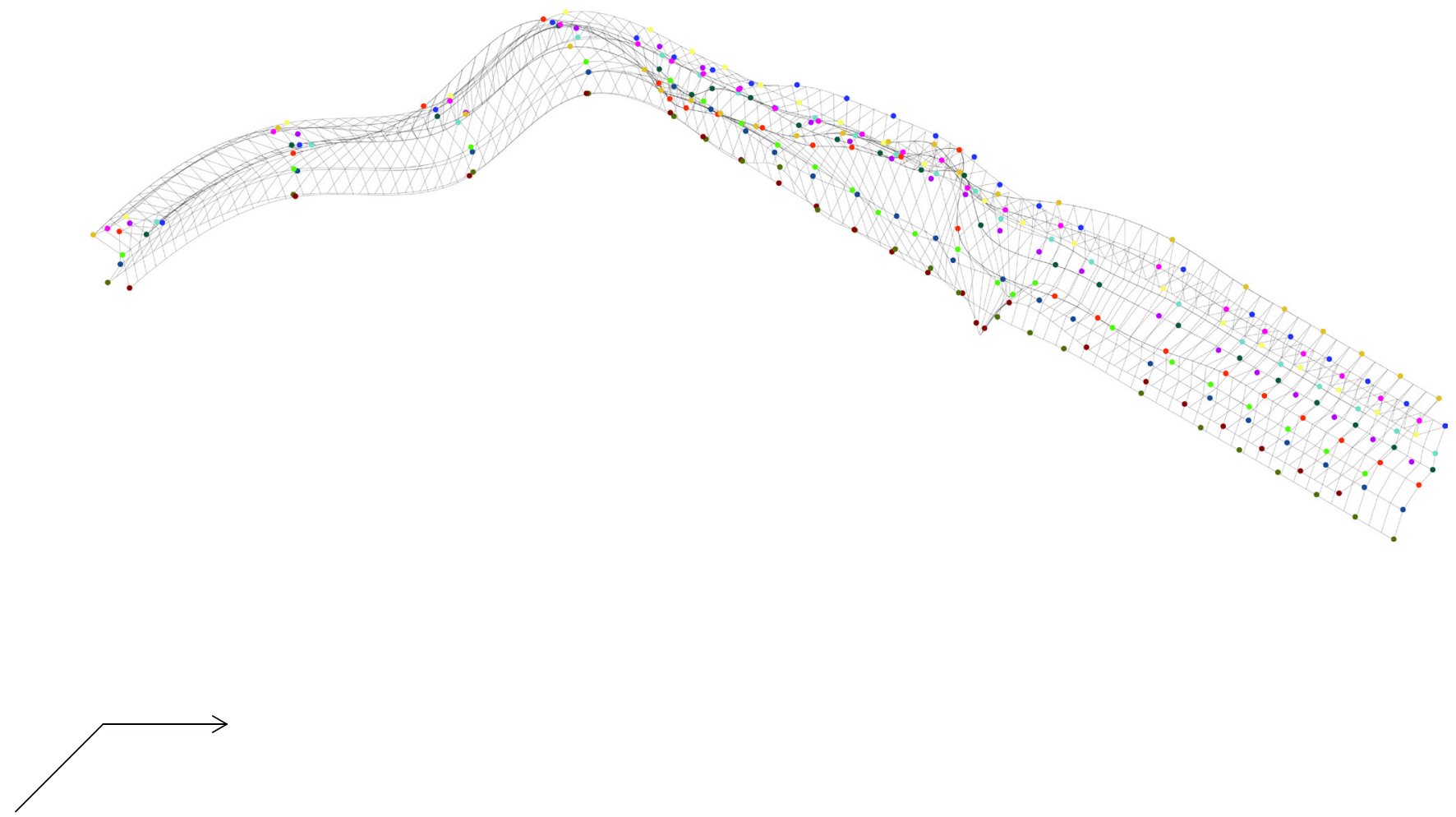

Crouch Lower Level

[Full Scale]

Ground Fl.

Developé Leg Extension Back Bend

[Full Scale]

Basement to Ground Fl. 
Routine 3

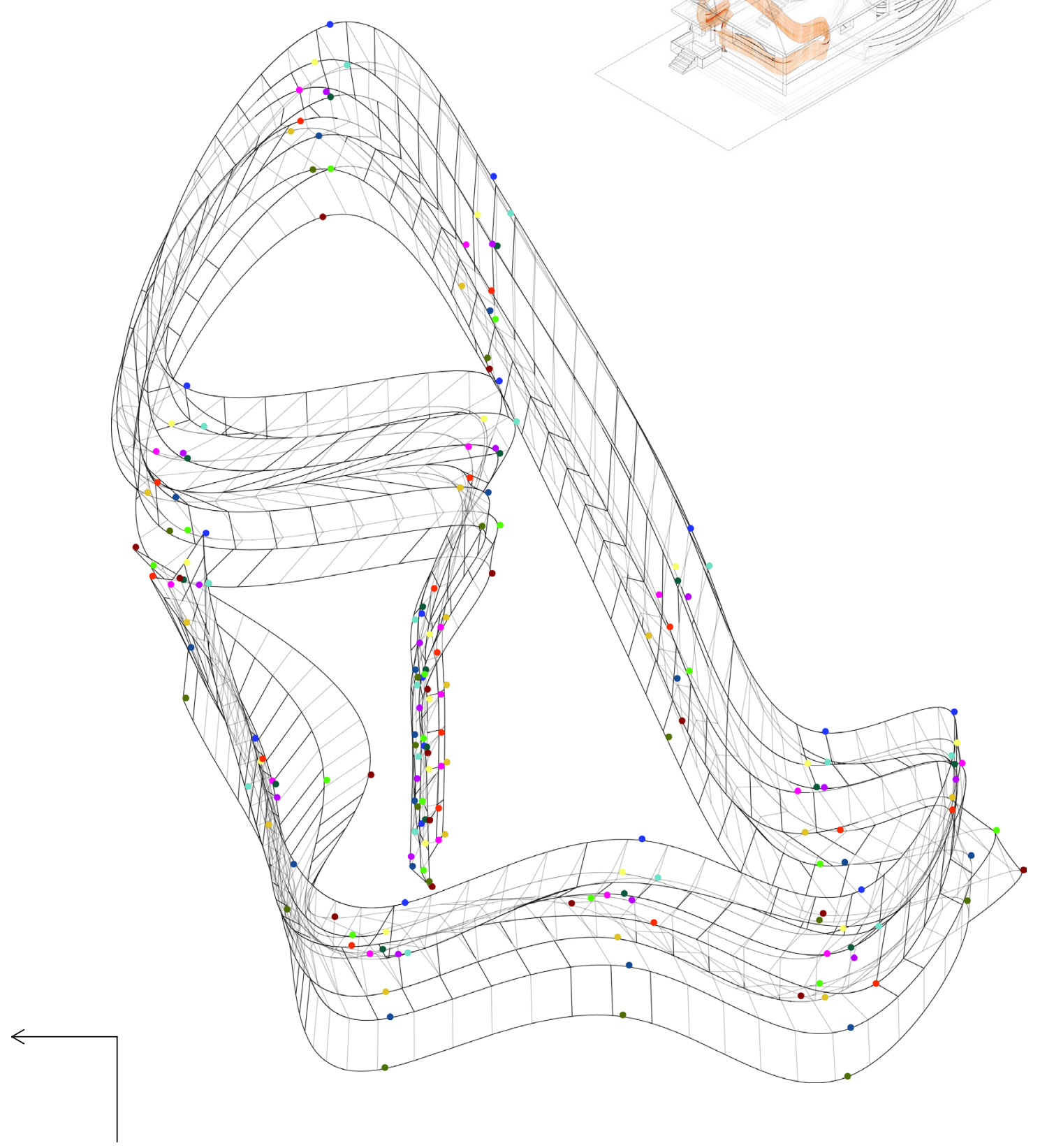

Rise of Body - Right Arm Reach

[1/2 Scale]

Basement to Ground Fl.
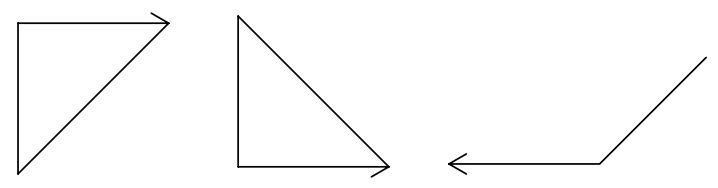

Jeté (Front Leg \& Back Leg)

[Full Scale]

Ground Fl. 
Routine 4
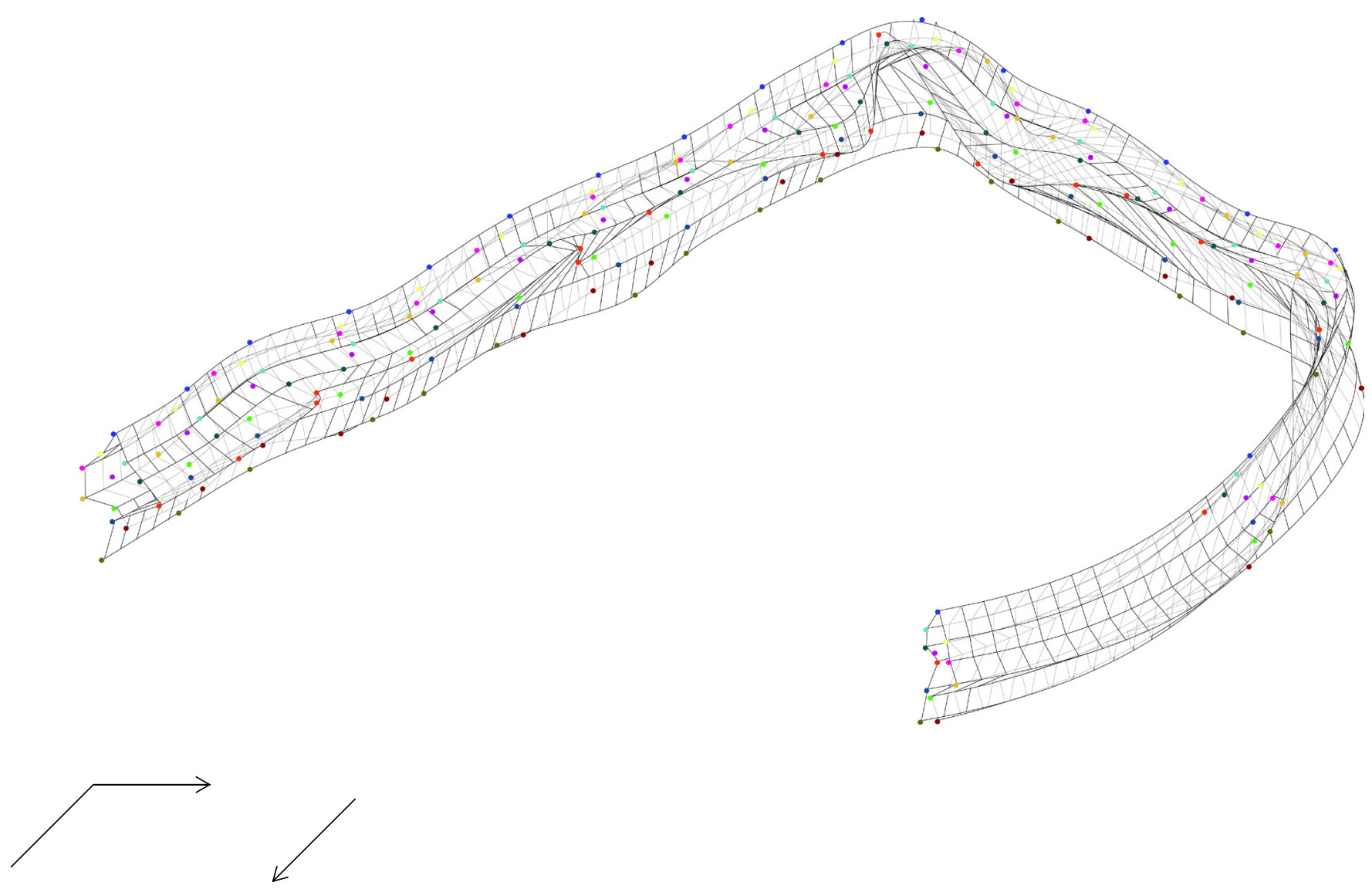

Ballet Runs

[Full Scale]

Ground Fl. to Basement 

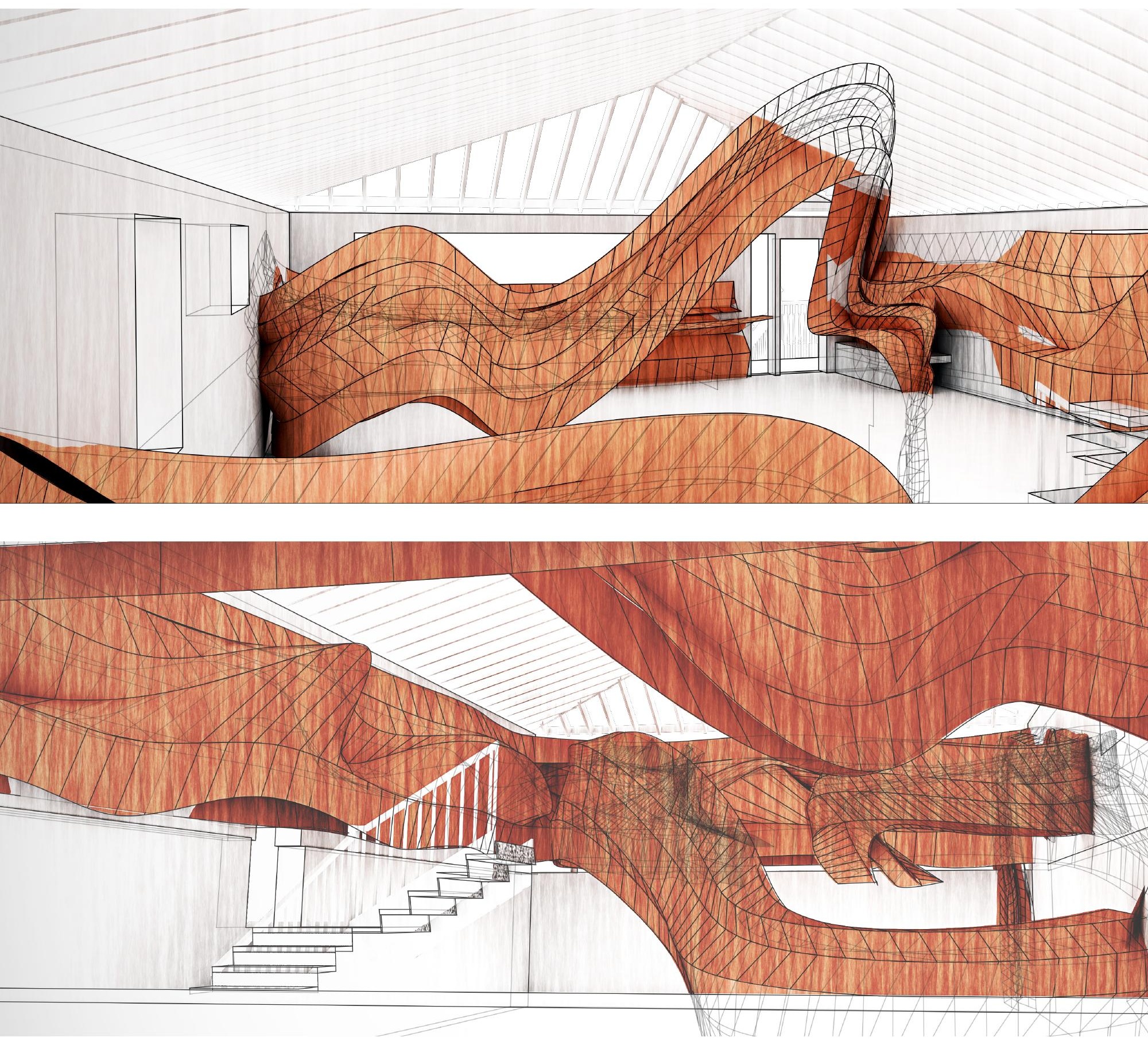
Movement of Habitation:

Reaching upper and lower countertops; moving dishes on countertop

Parameters

Box 1

- distance between right hand and left hand control height, width and depth

Box 2

- distance between shoulder right \& left foot control height, width and depth

Box 3

- distance between right foot and left hand control height, width and depth

Box 4

- distance between right foot and left foot control height, width and depth
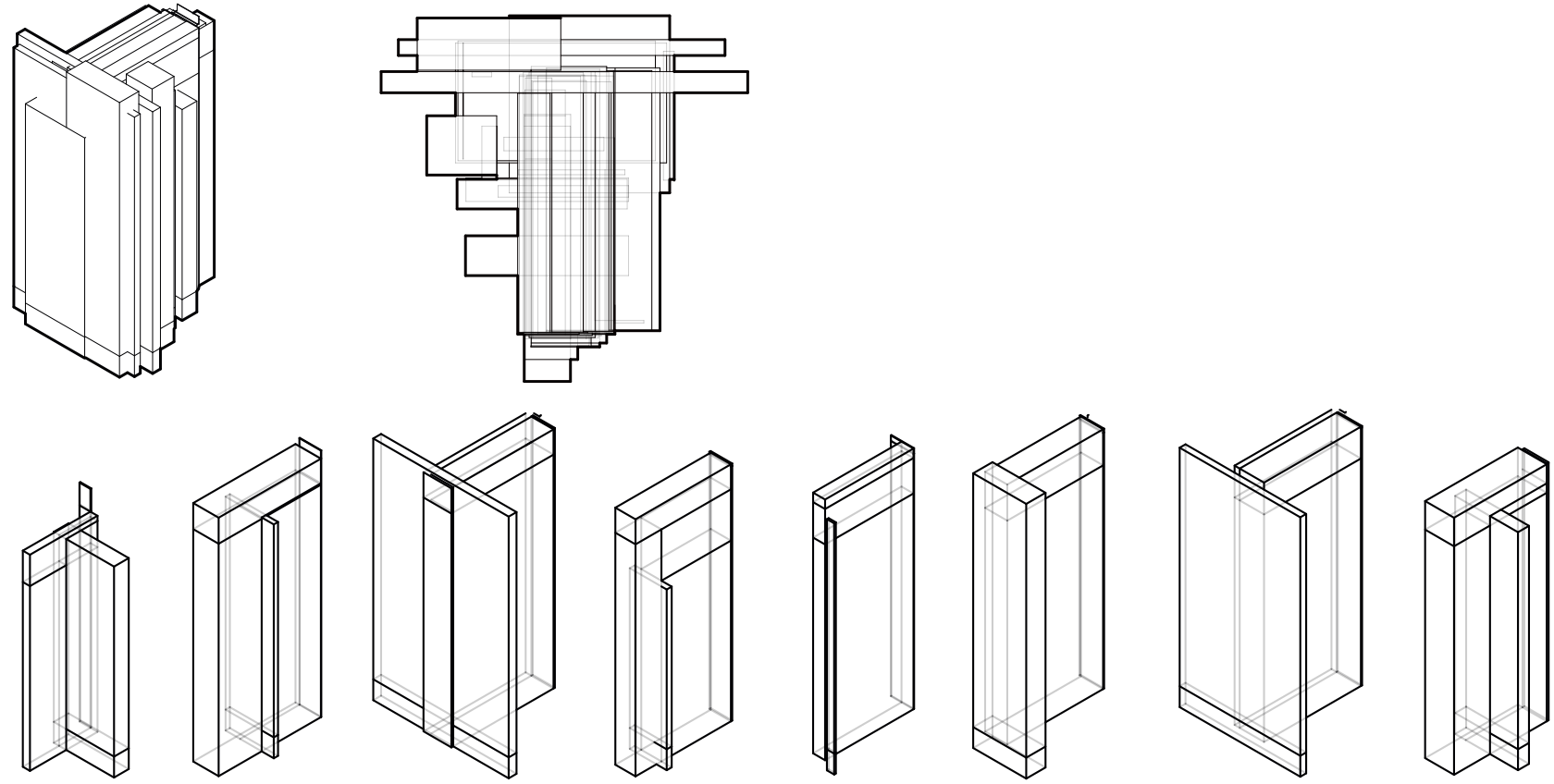

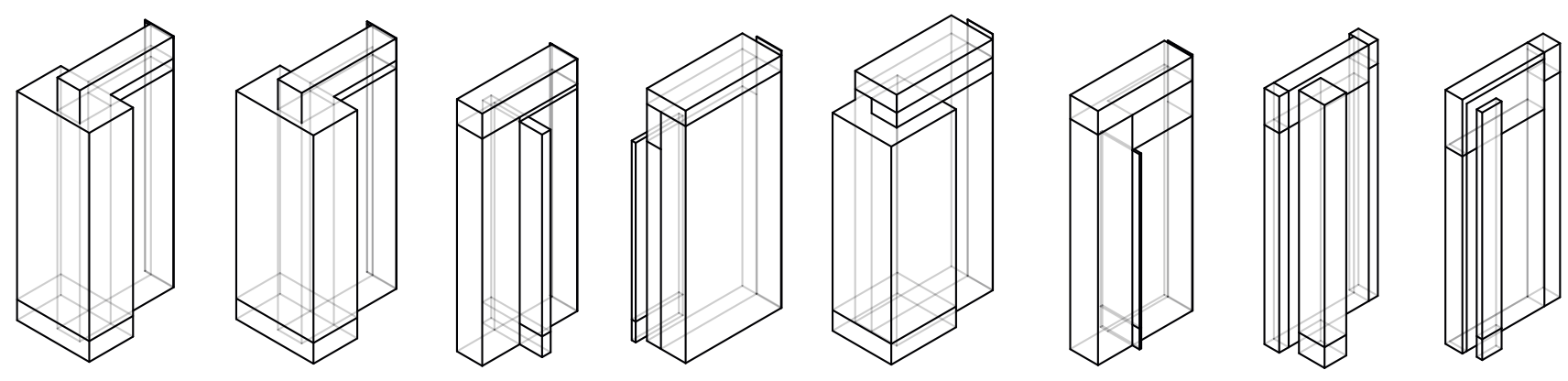

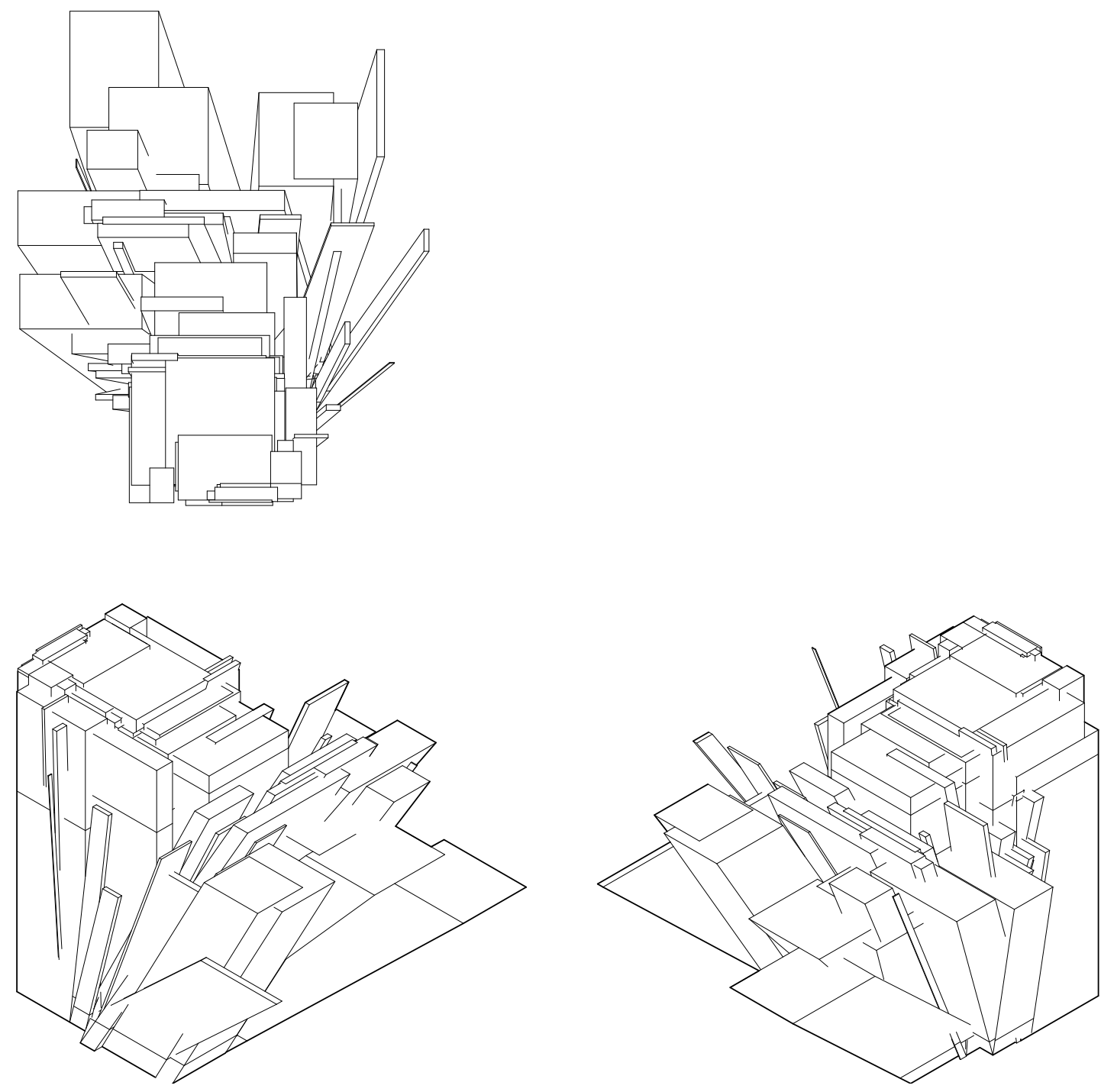

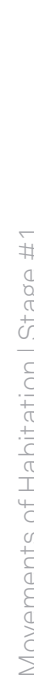
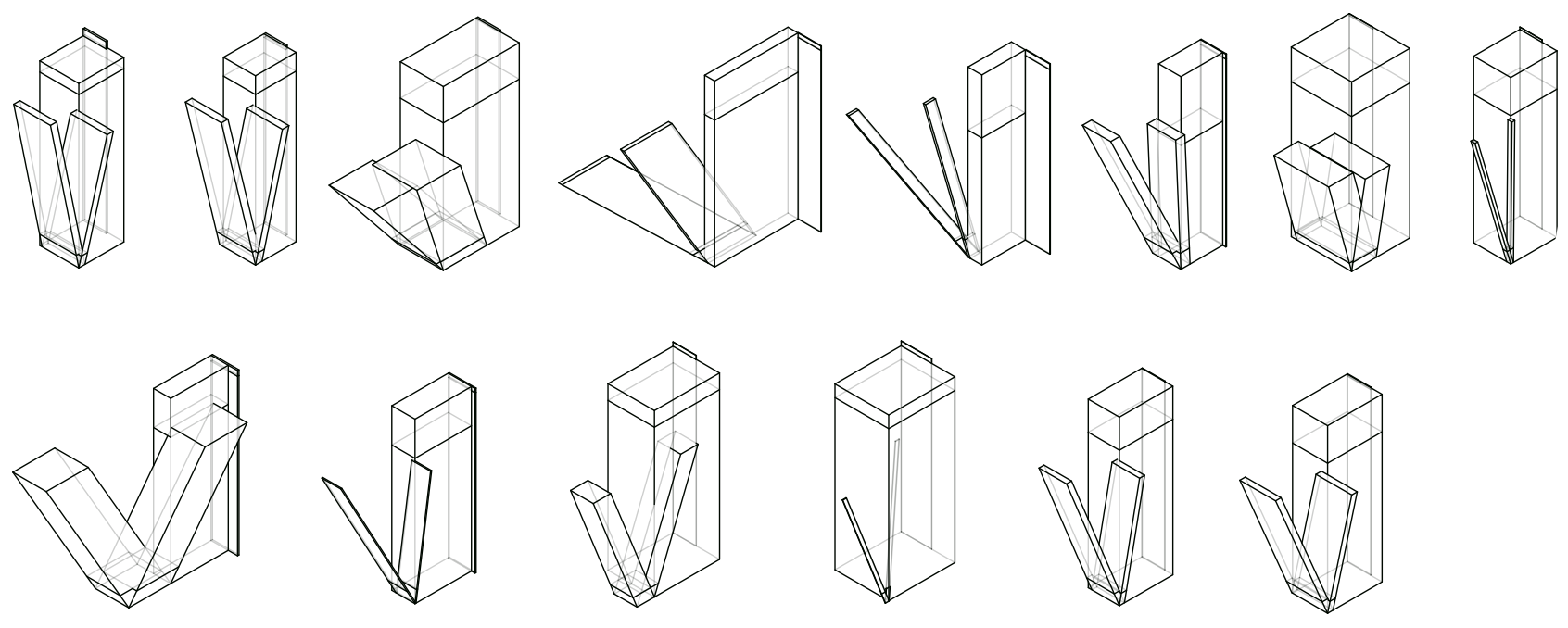
Movement of Habitation:

Reaching upper and lower countertops; moving dishes on countertop

\section{Parameters}

\section{Box 1}

- distance between right hand and left hand control height, width and depth

- shearing is controlled by the distance between right and left hand

(in the direction of the right hand)

\section{Box 2}

- distance between shoulder right \& left foot control height, width and depth

Box 3

- distance between right foot and left hand control height, width and depth

\section{Box 4}

- distance between right foot and left foot control height width and depth

- shearing is controlled by the distance between right and left hand

(in the direction of the right hand)
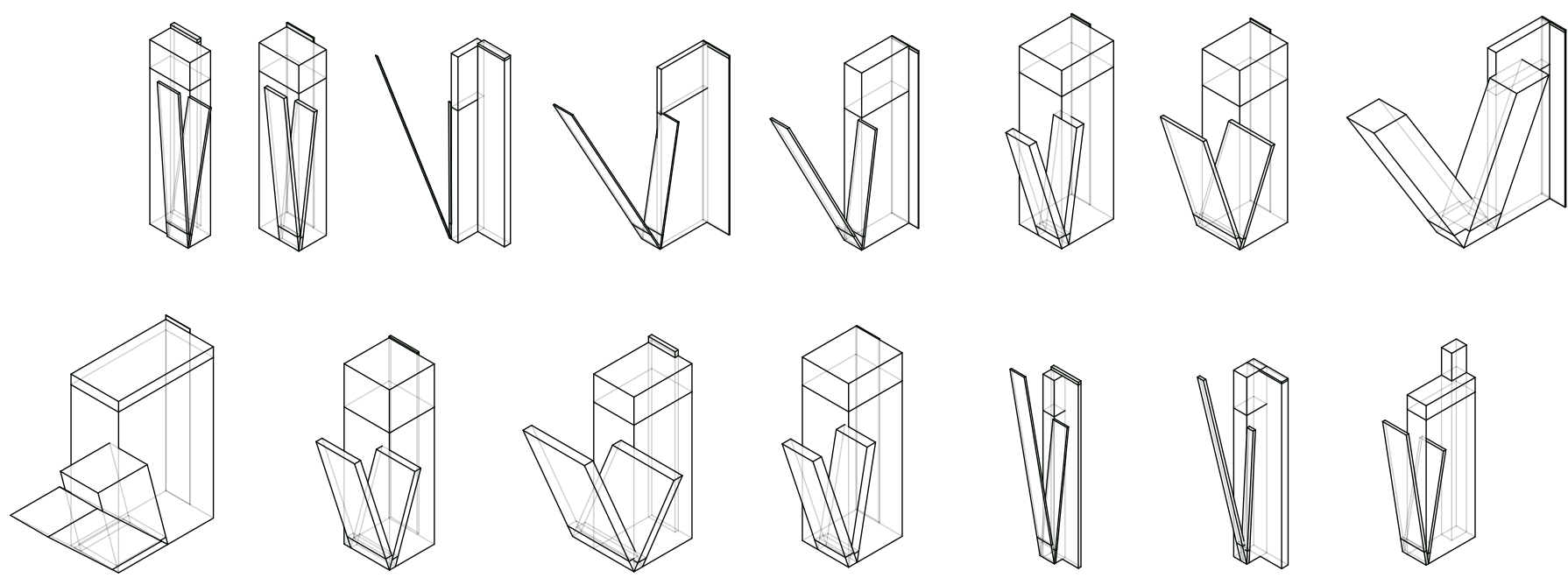


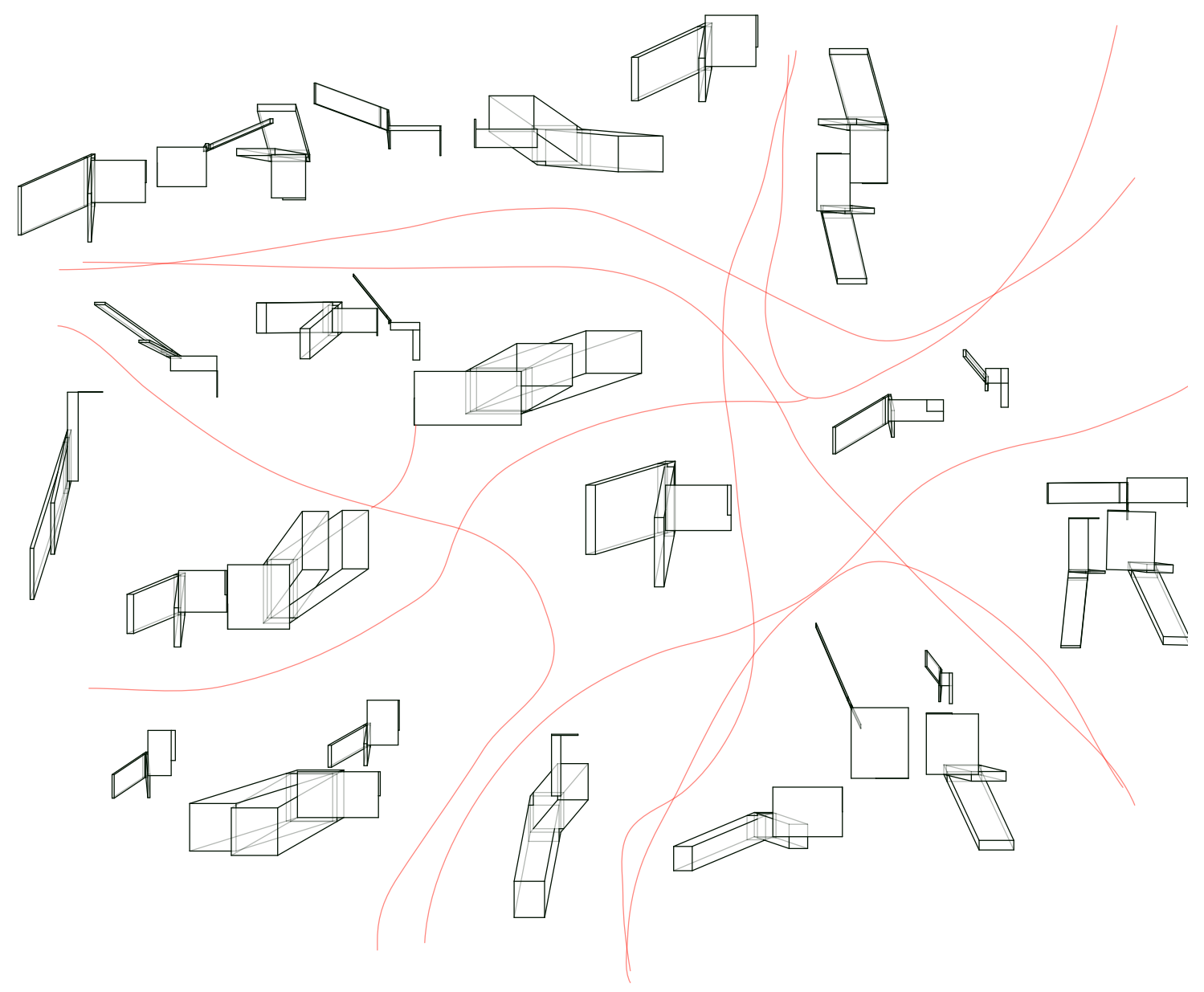




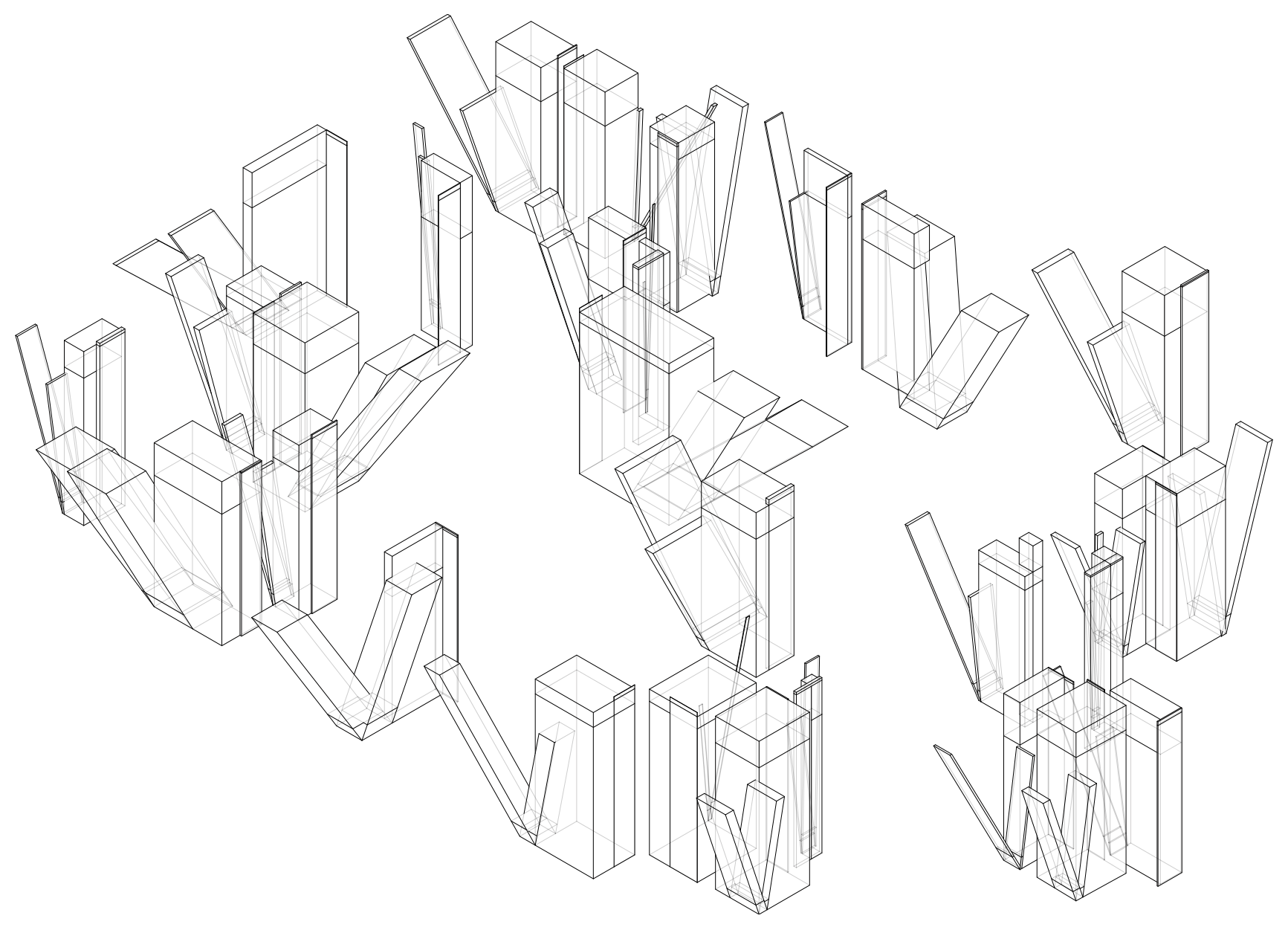


Movement of Habitation:

- Left and right hand reaching upper and lower cupboards. Moving dishes on countertop

Parameters

- Left and right hand deforms surface grid in $\mathrm{x}, \mathrm{y}$ and $\mathrm{z}$ direction.
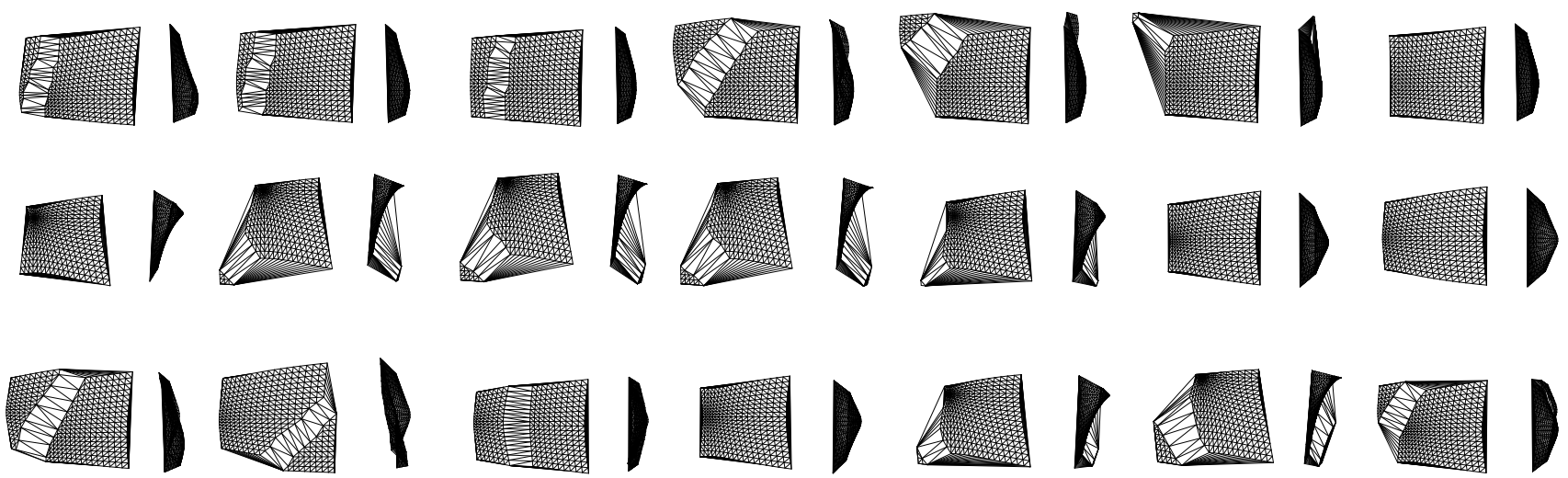

)
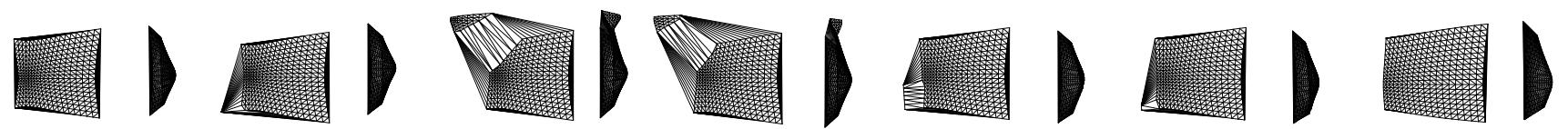
Movement of Habitation:

- Left hand reaching upper and lower cupboards

\section{Parameters}

- Left hand deforms surface determined by direction of movement in x, y, z axis
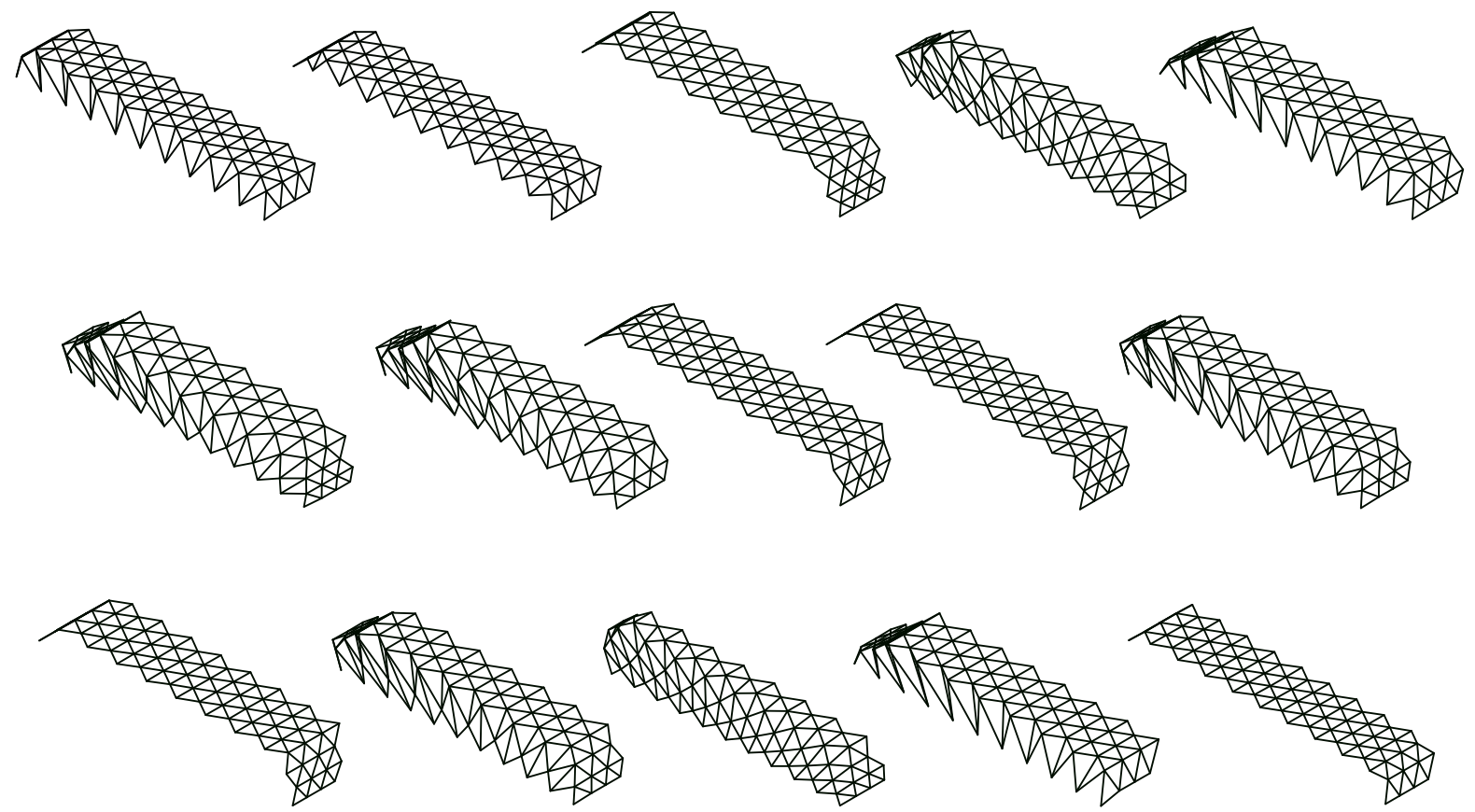


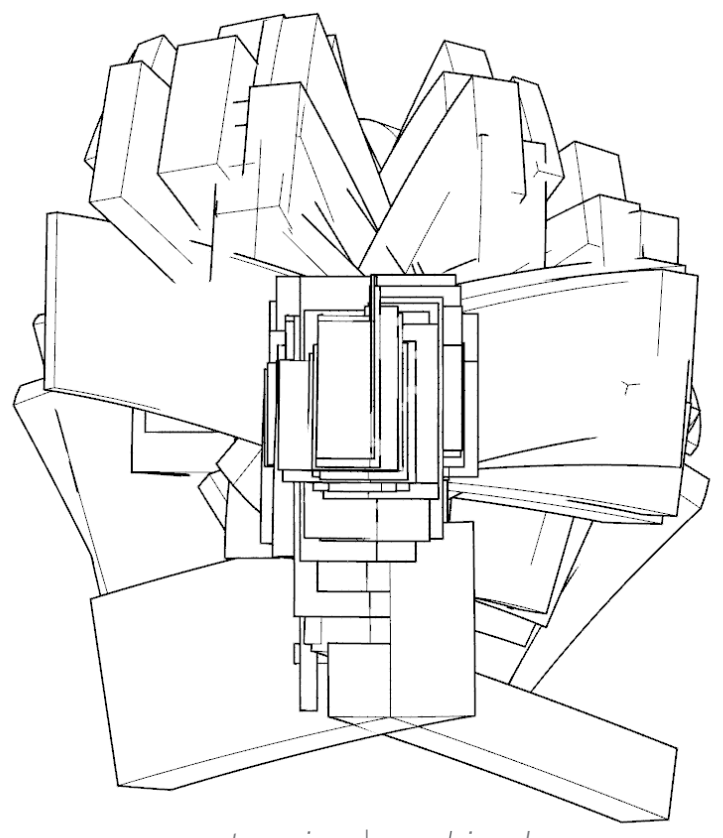

top view | combined
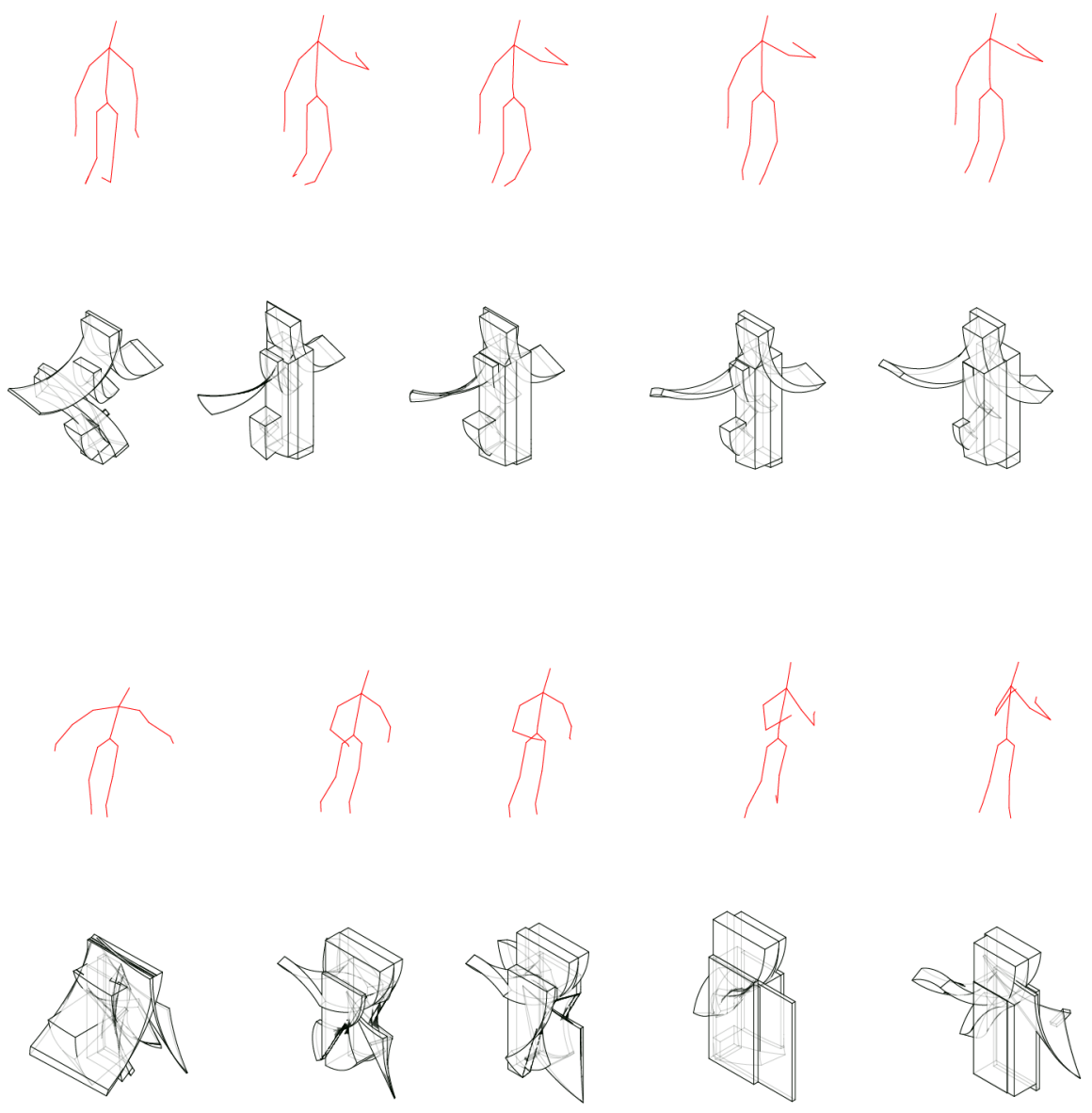


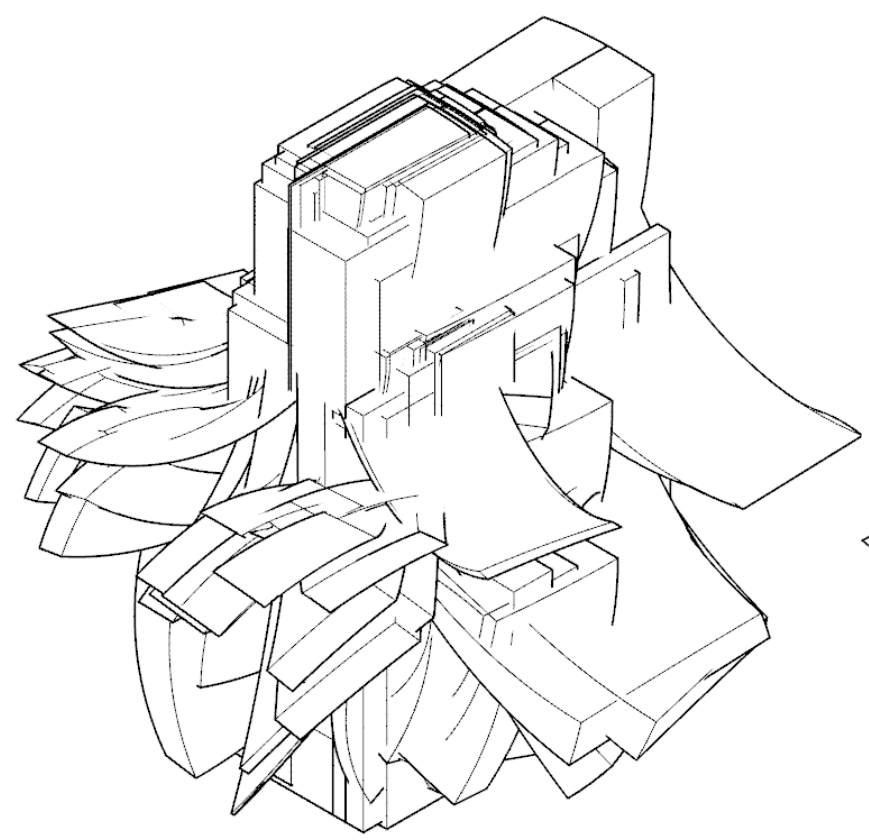

iso view 1 | combined
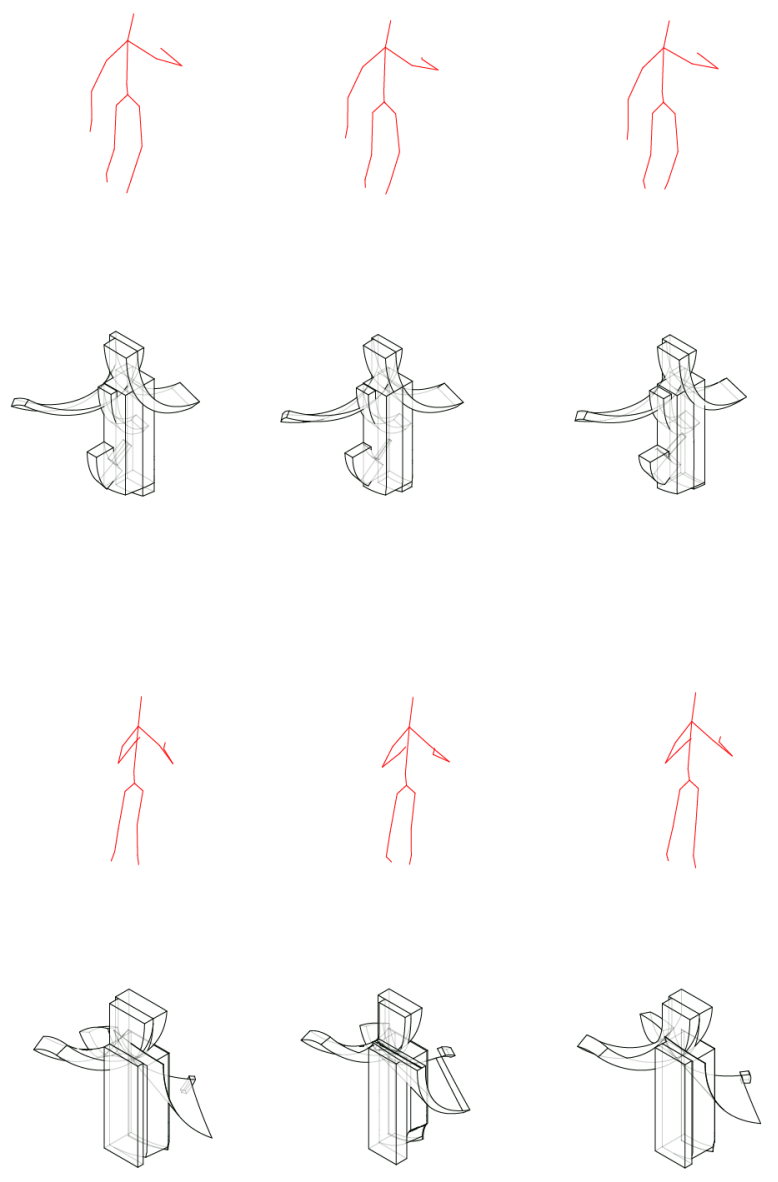

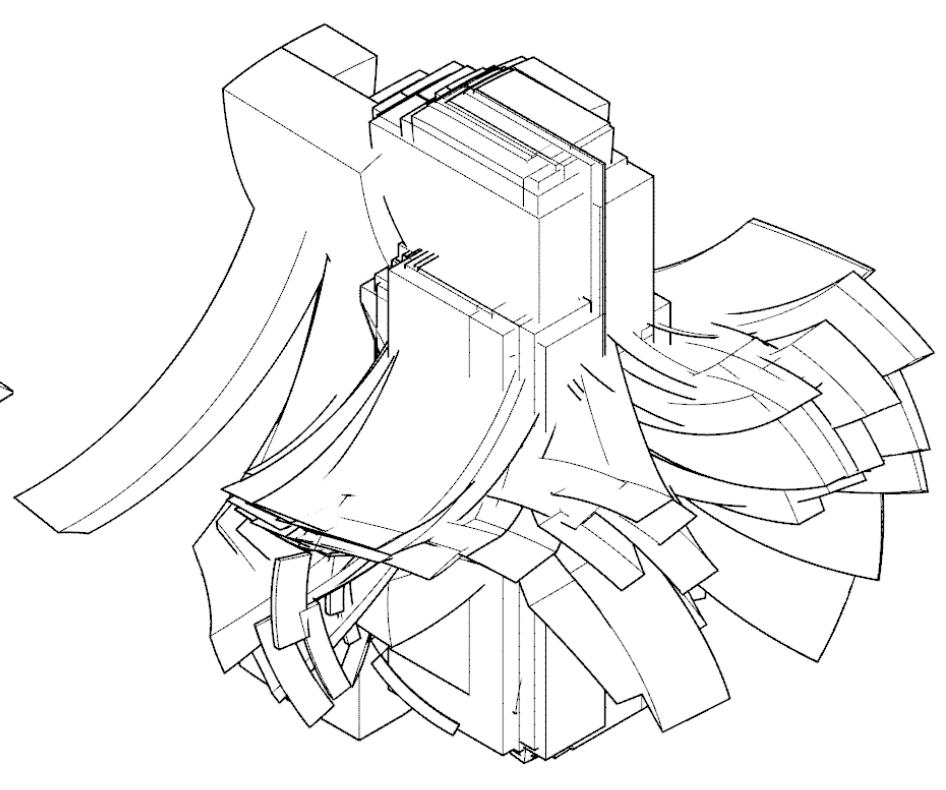

iso view 2 | combined
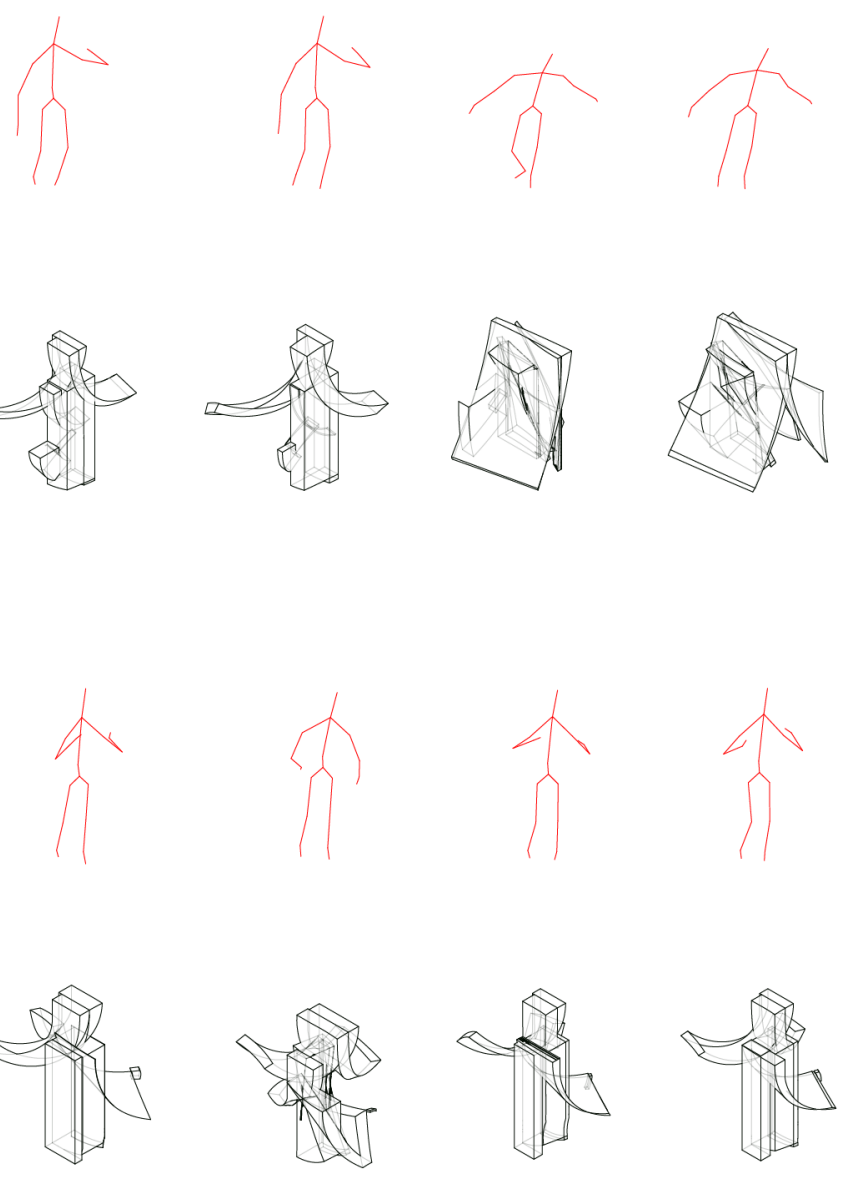
Movement of Habitation:

Sitting in Living Room; Adjusting Position on Chair

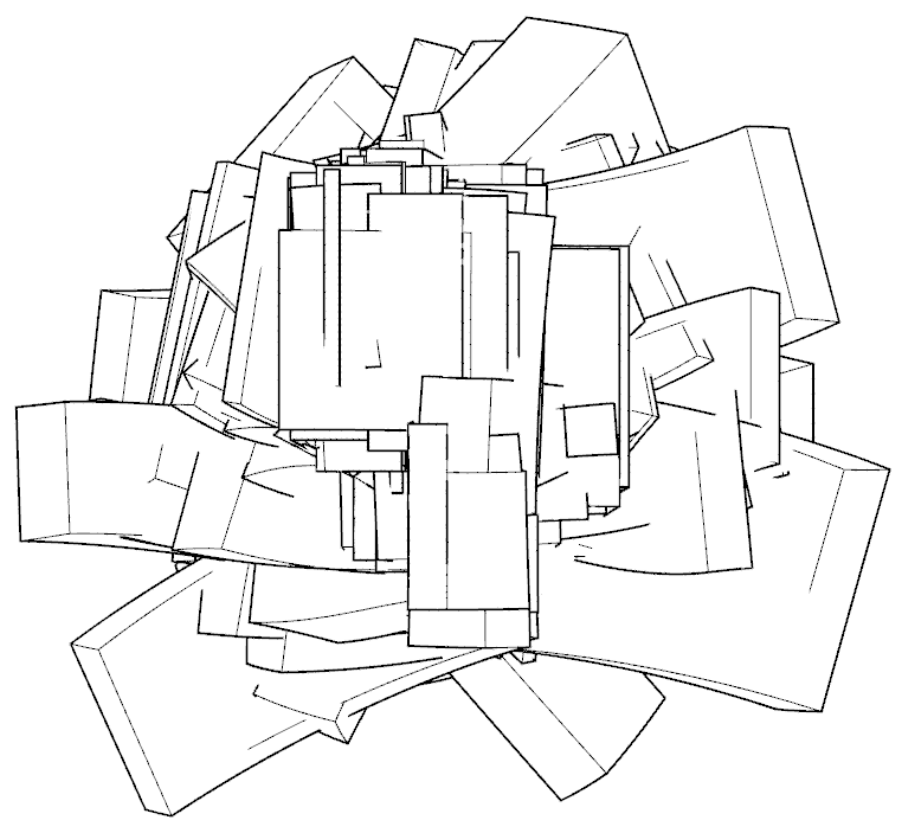

top view | combined
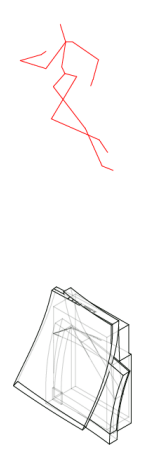
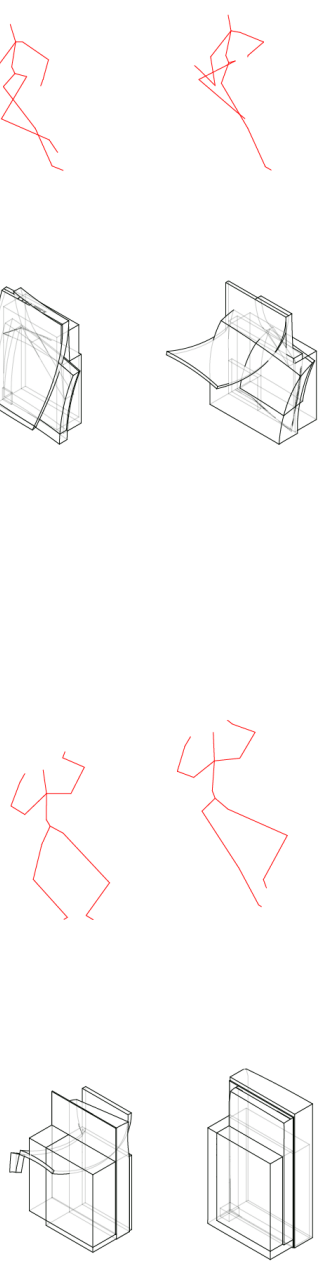
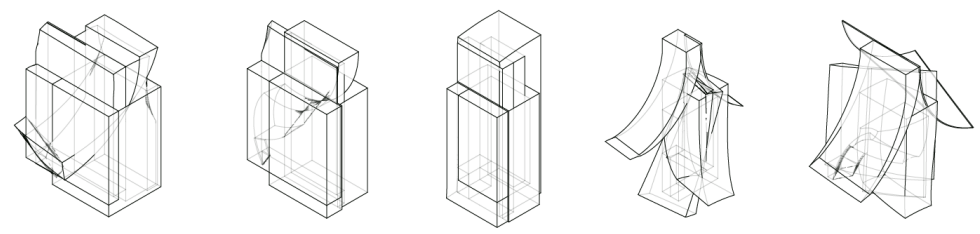

251 


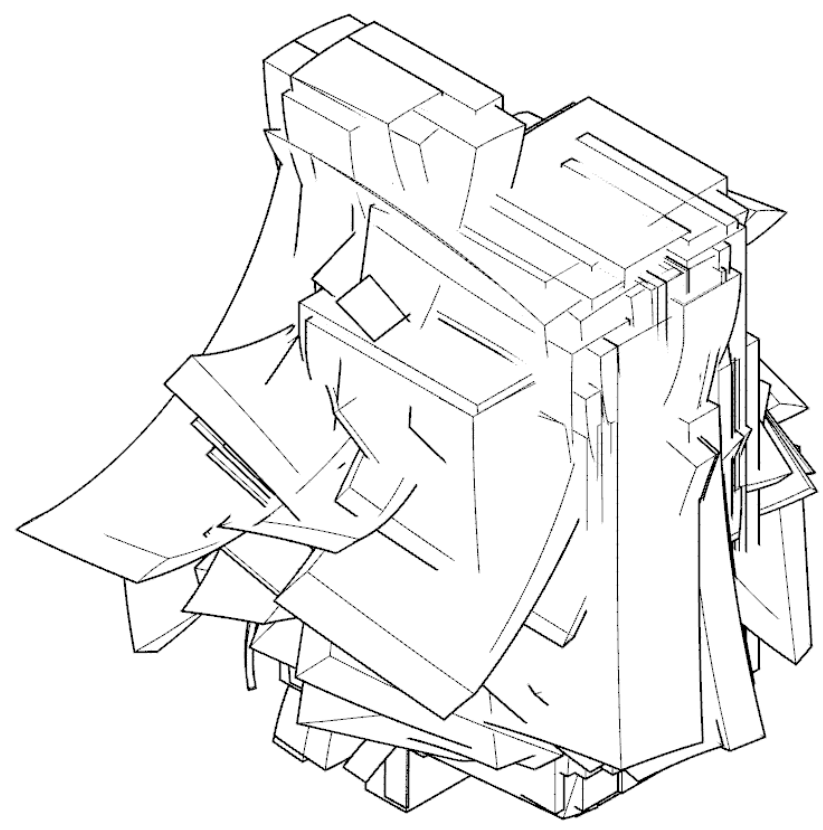

iso view 1 | combined

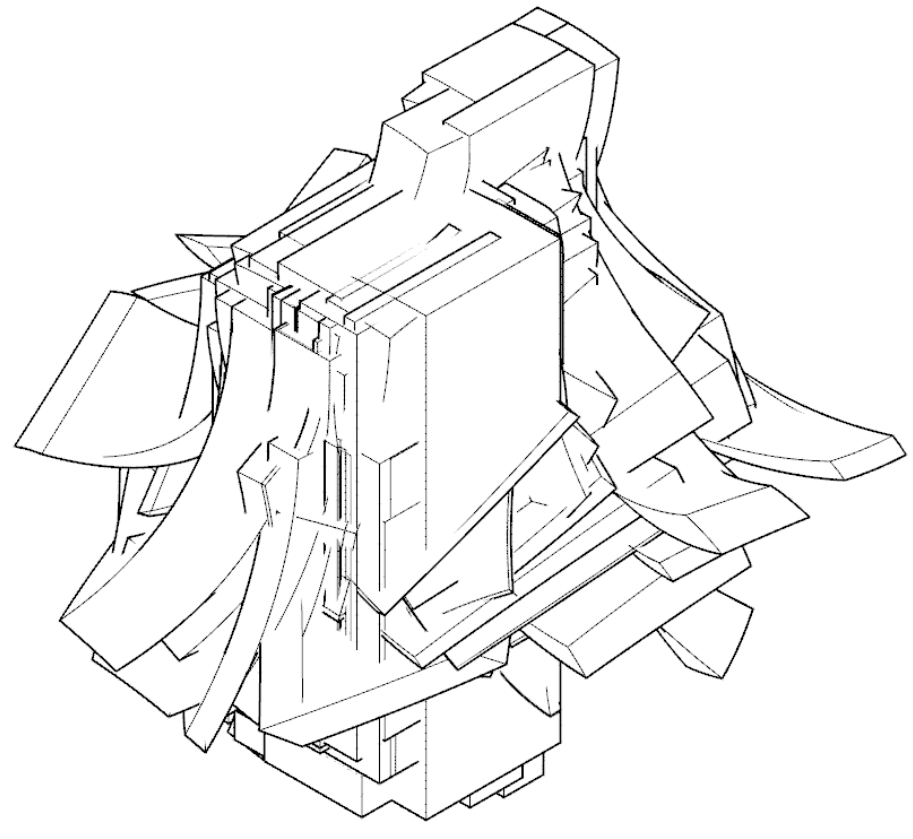

iso view 2 | combined
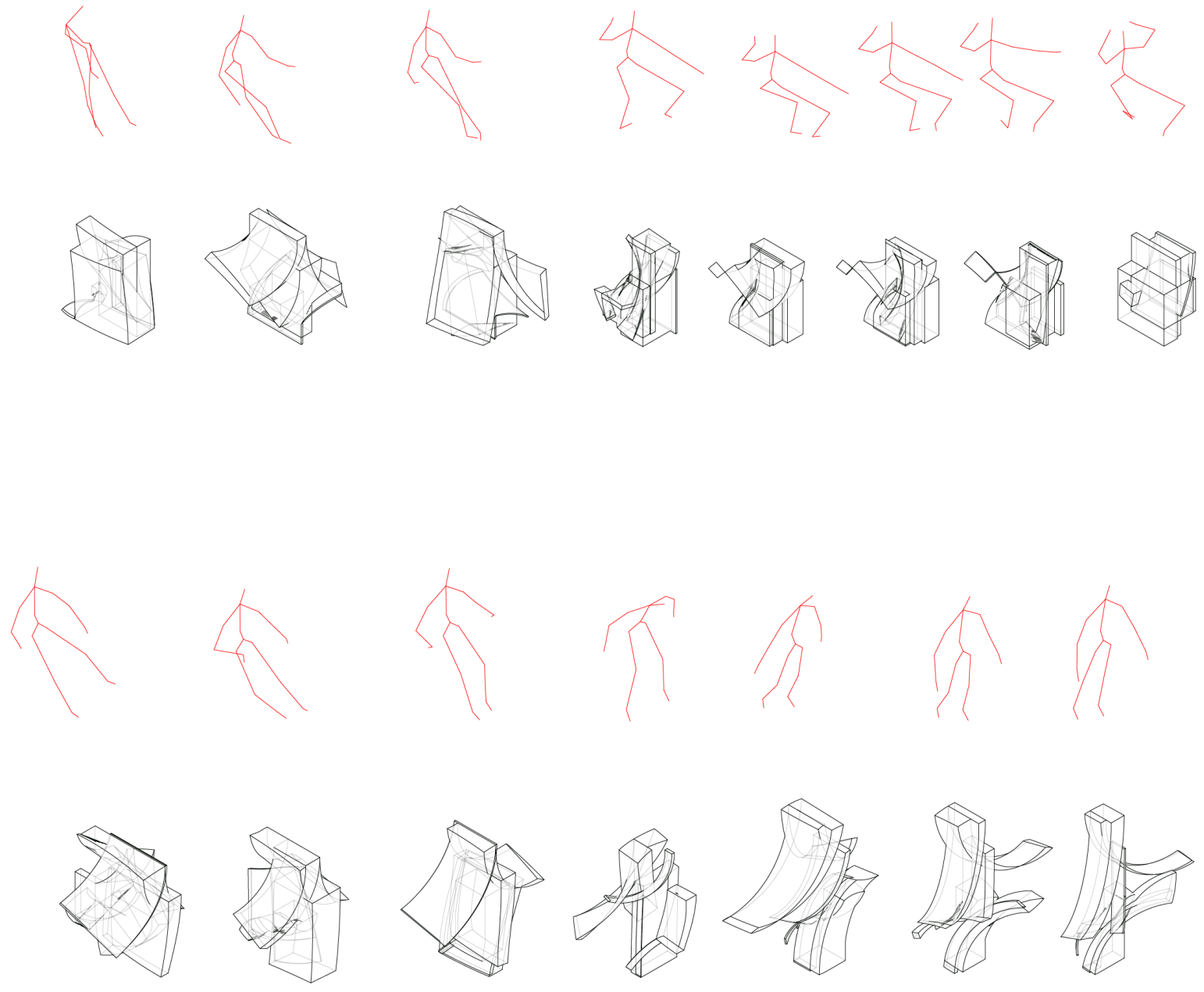
Movement of Habitation:

Showering
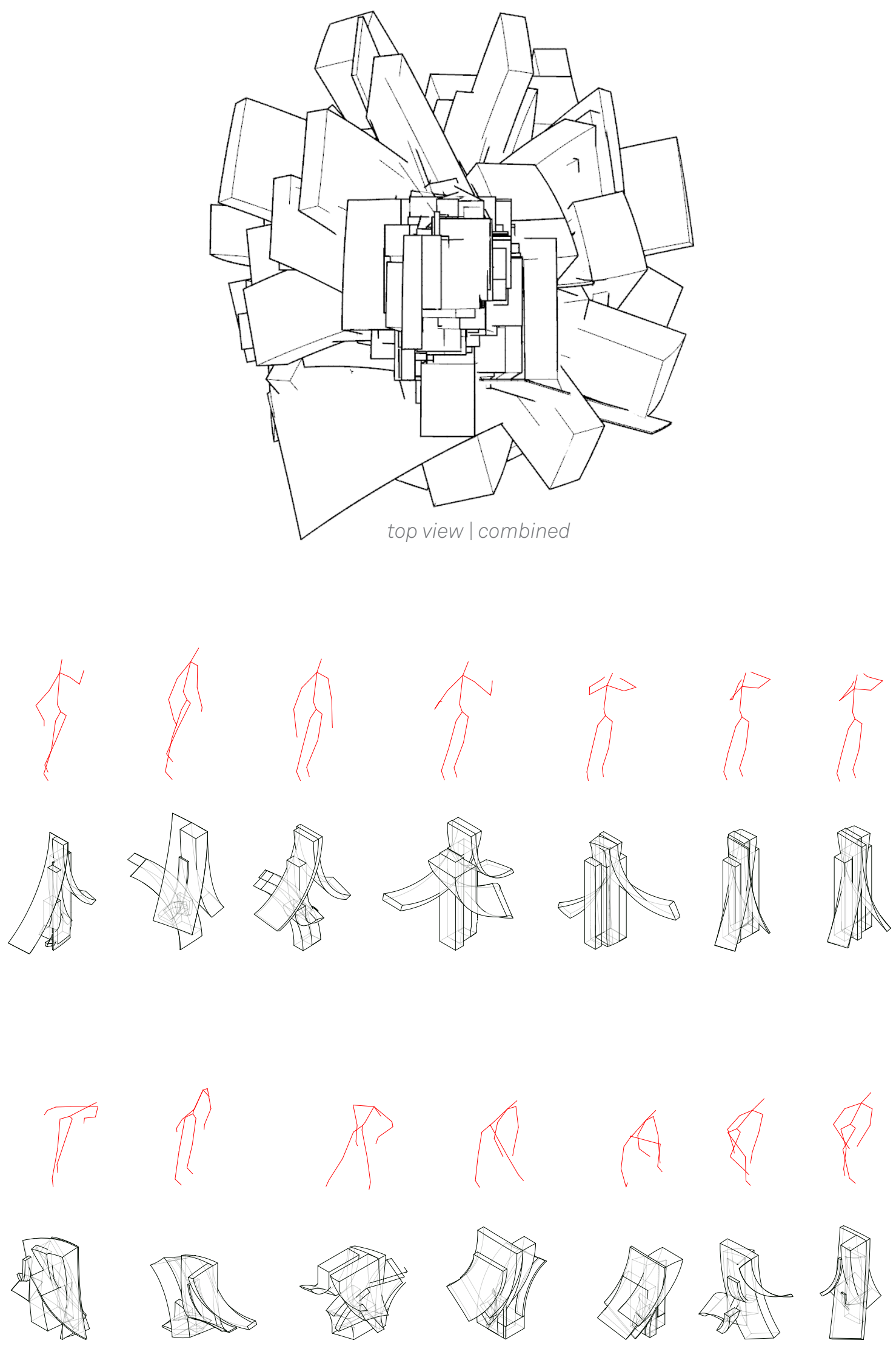


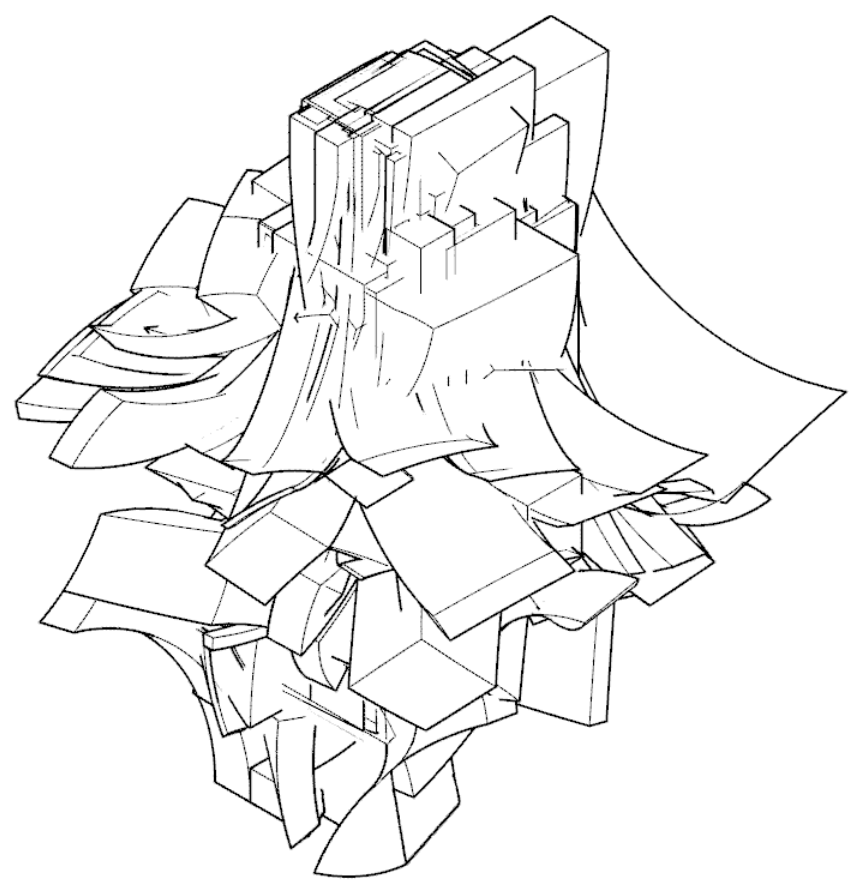

iso view 1 | combined
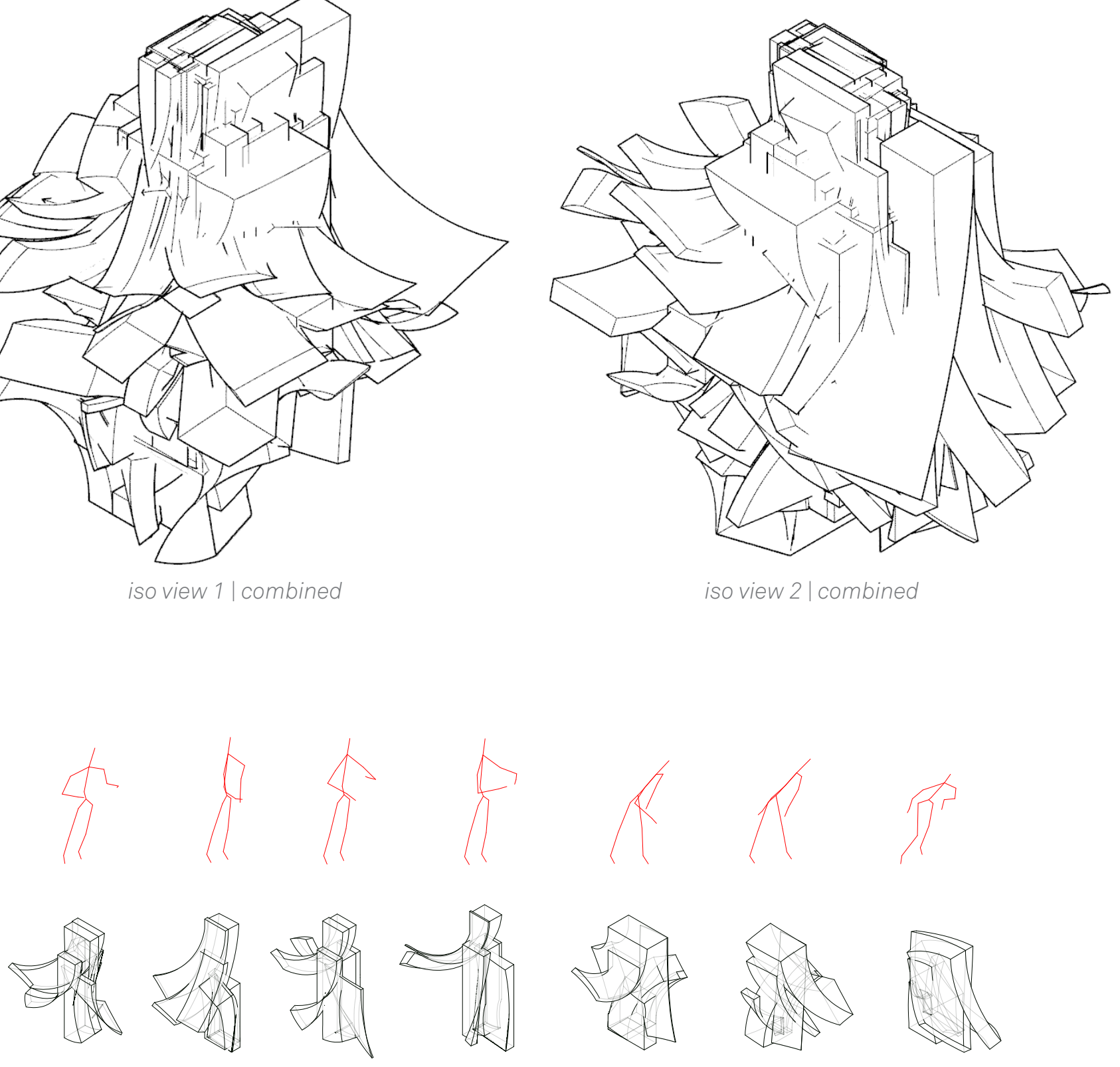

iso view 2 | combined
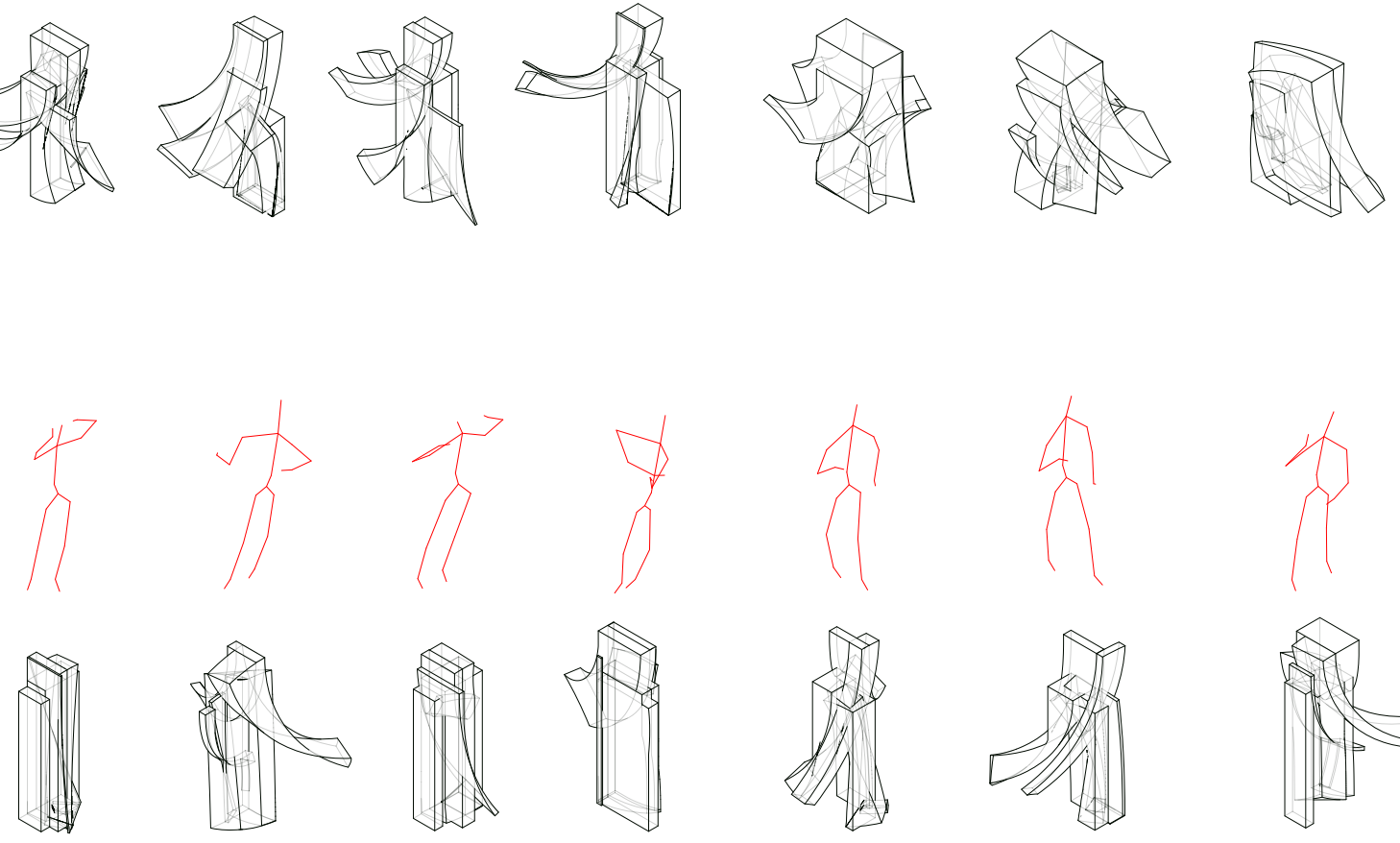
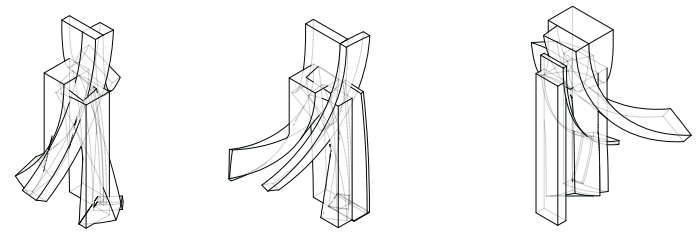
Movement of Habitation:

Sitting \& Eating

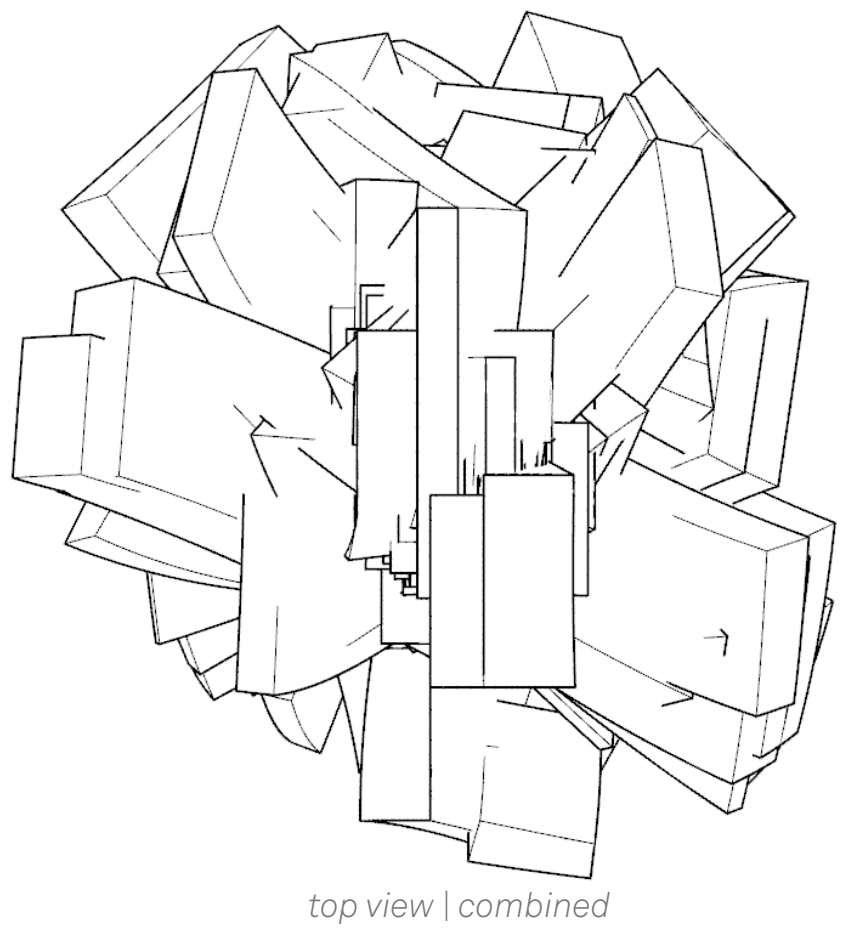

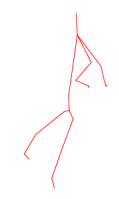
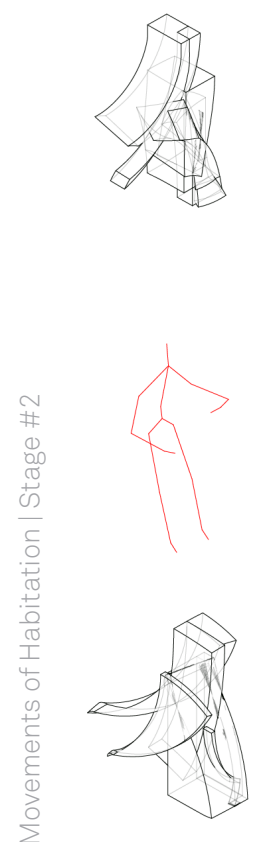
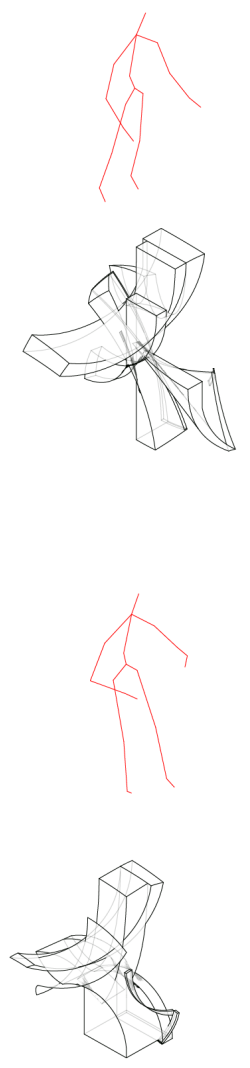
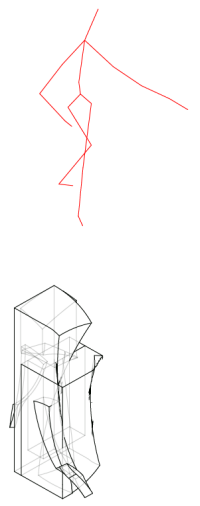
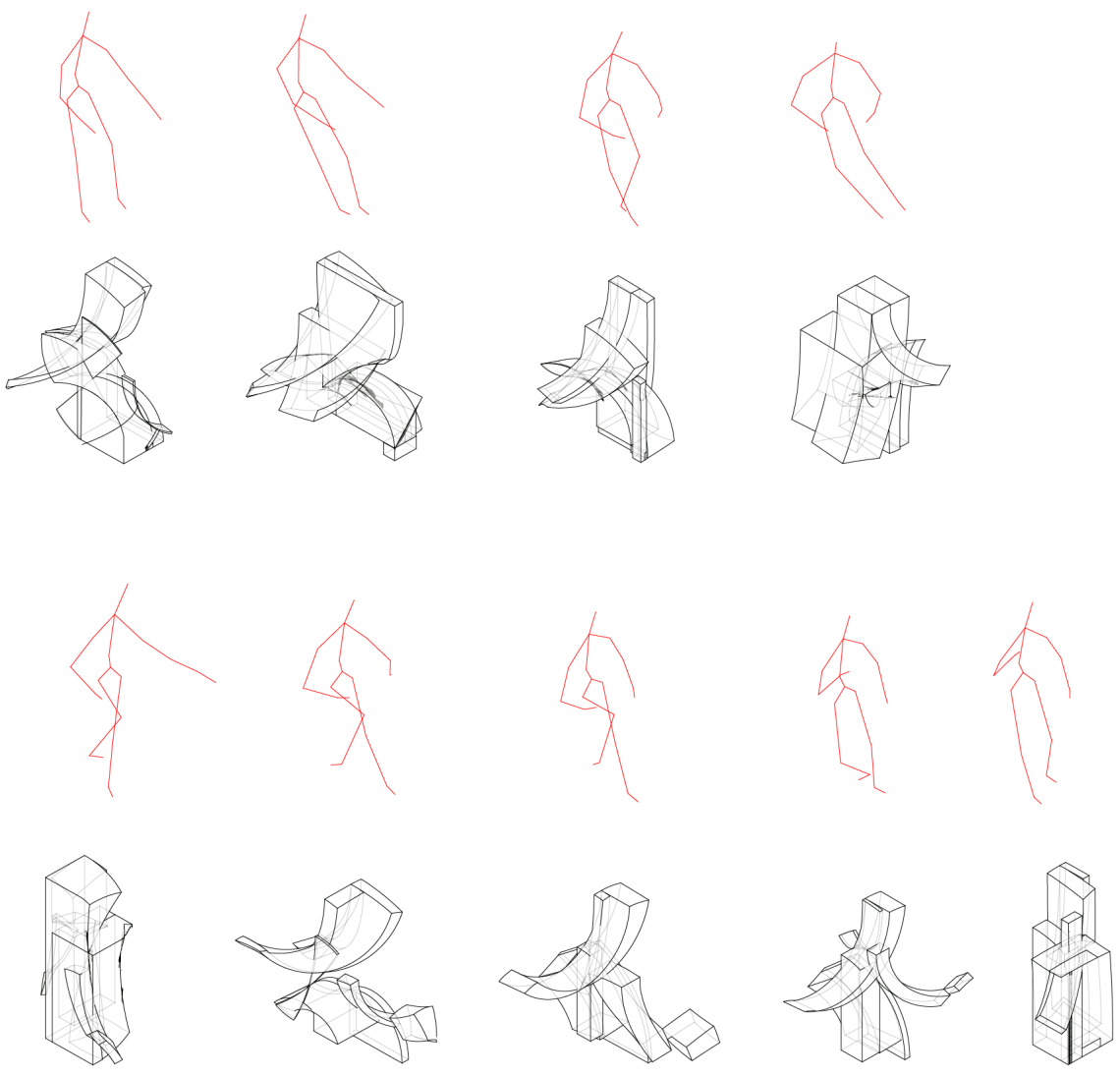

255 


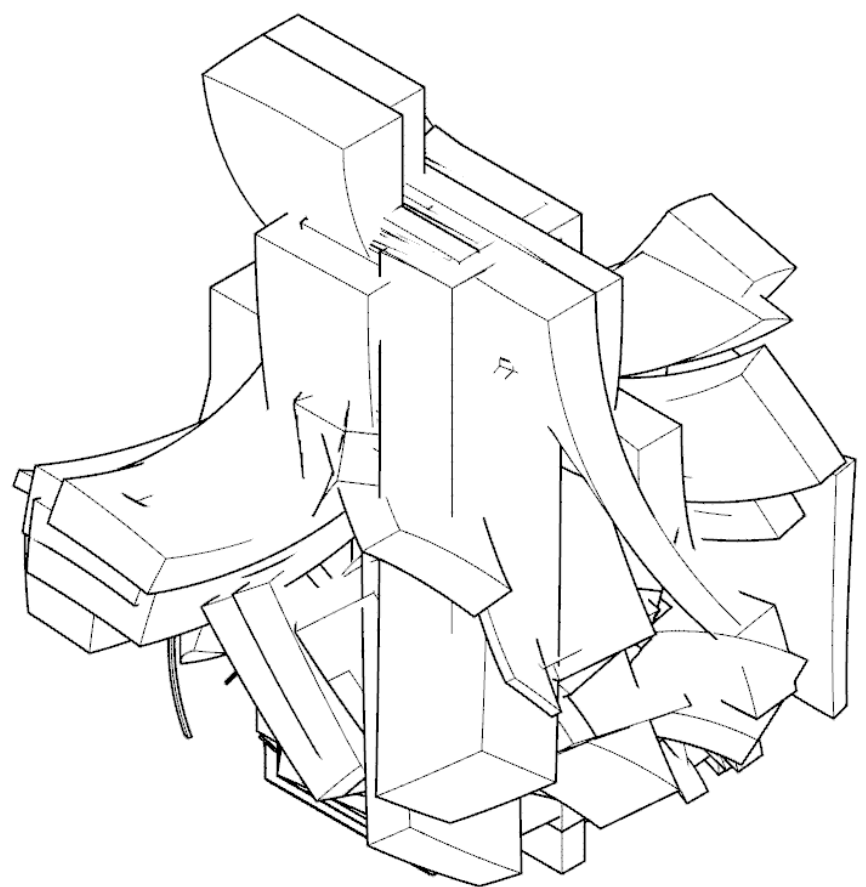

iso view 1 | combined

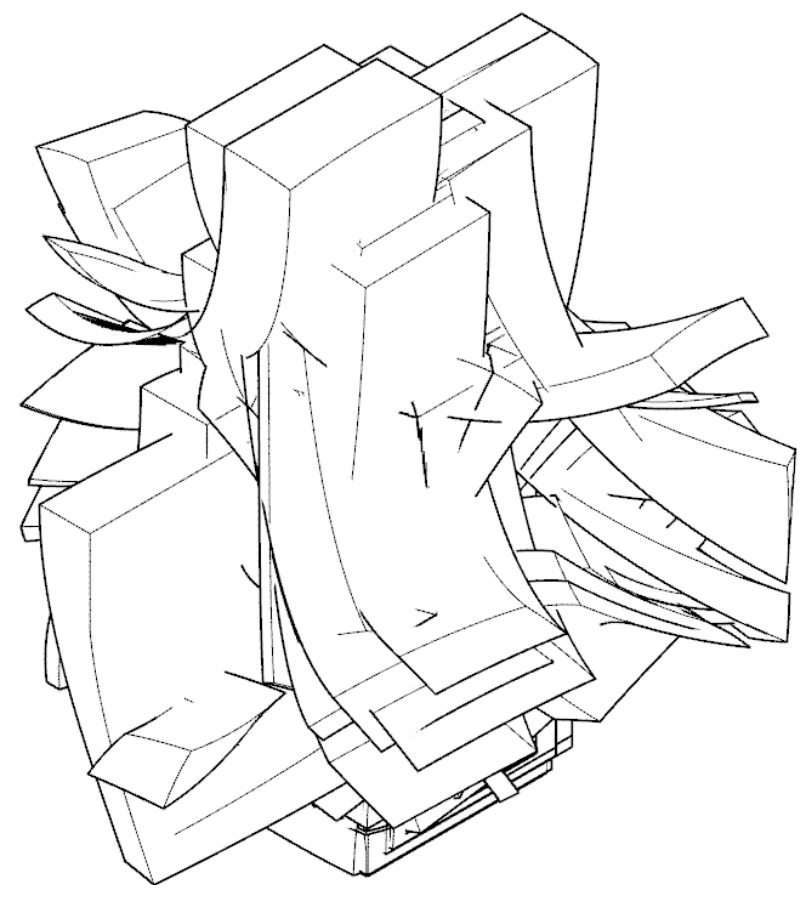

iso view 2 | combined
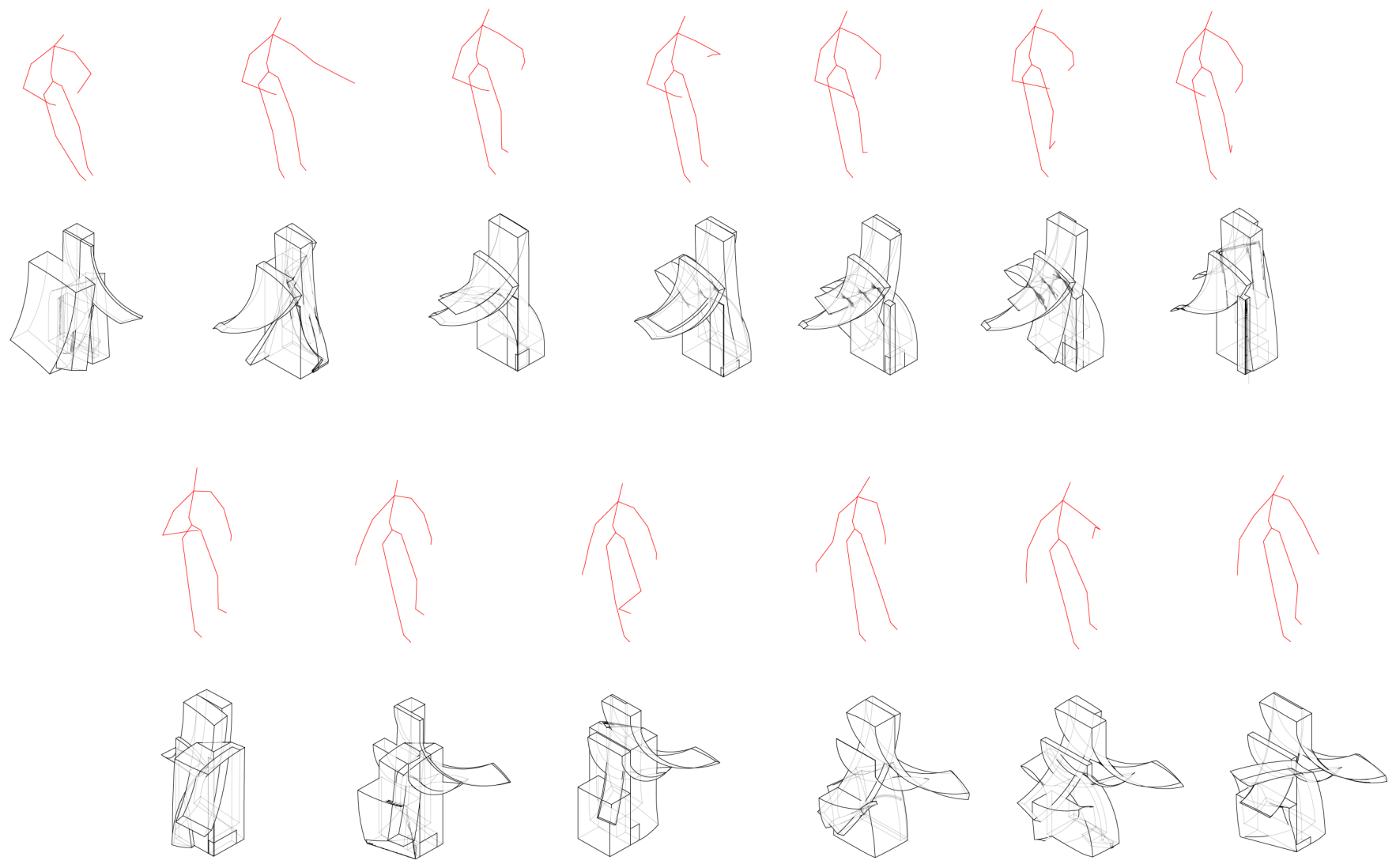


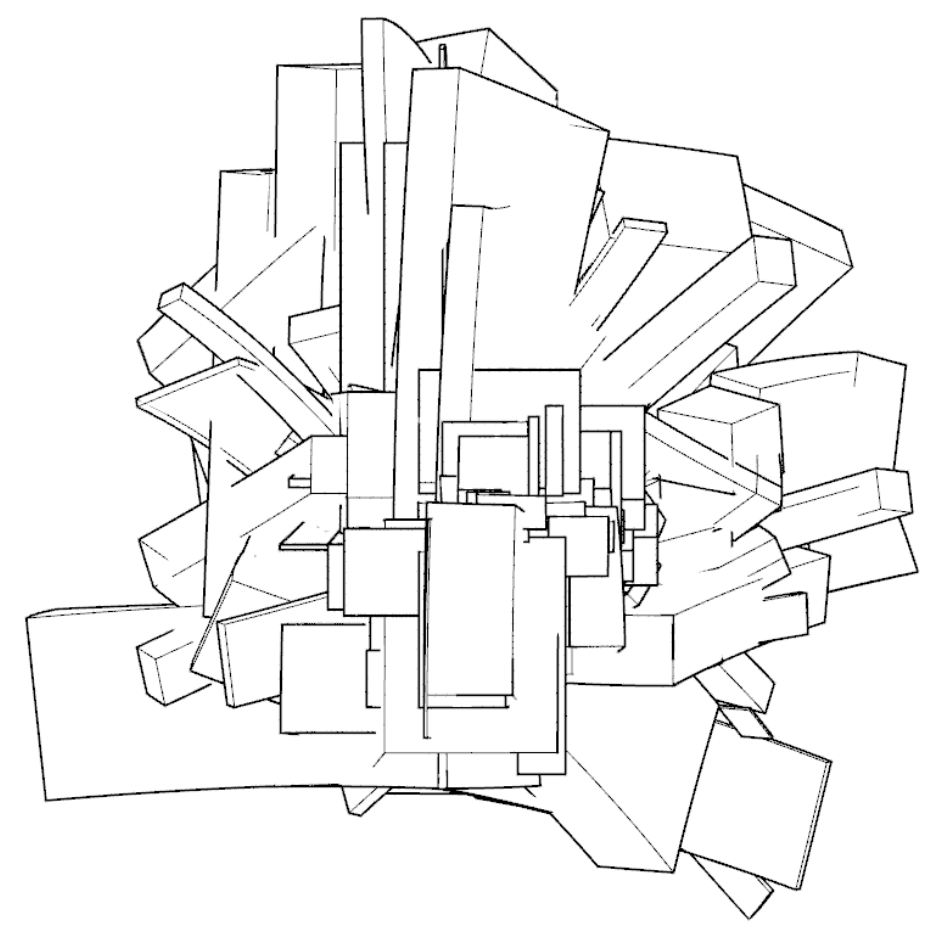

top view | combined
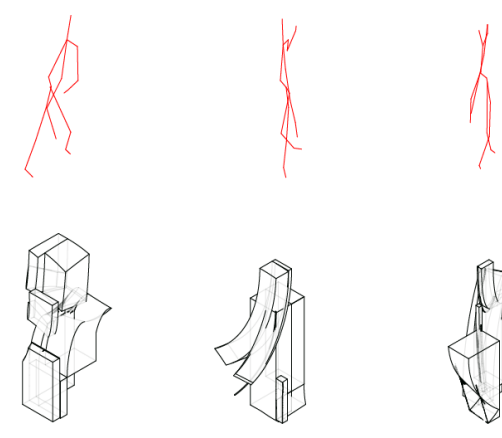
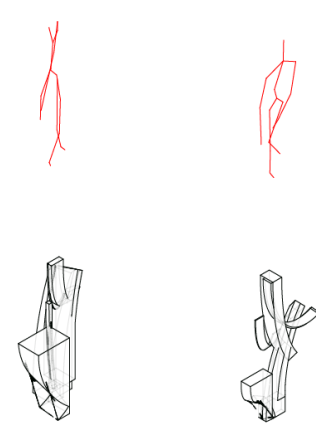
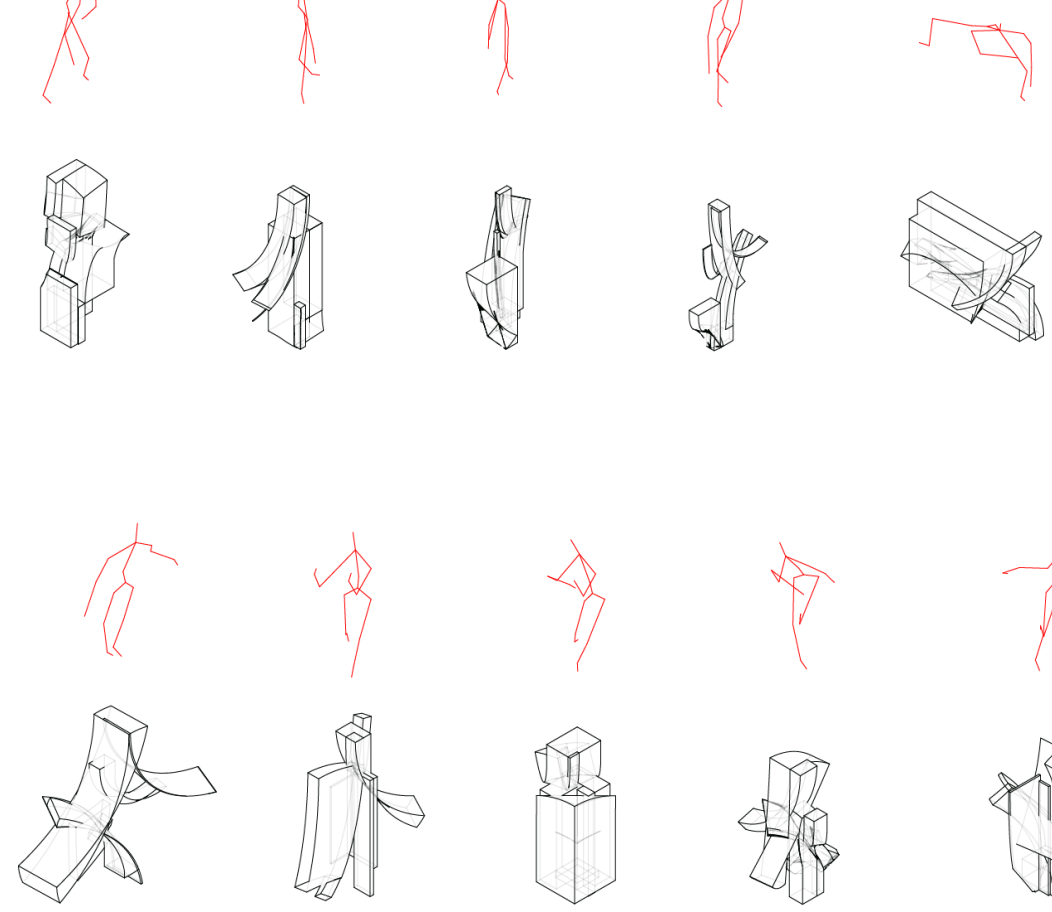
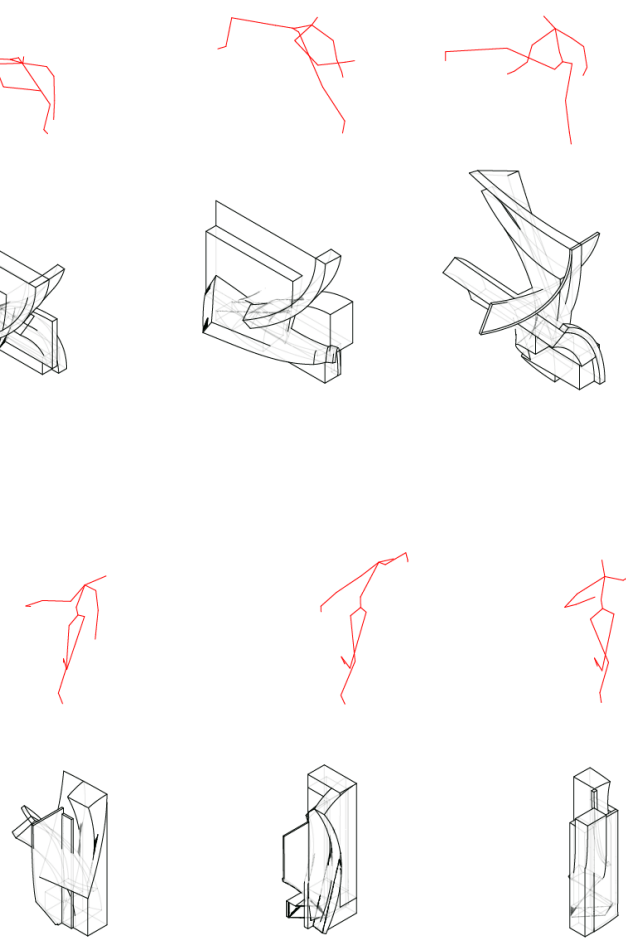


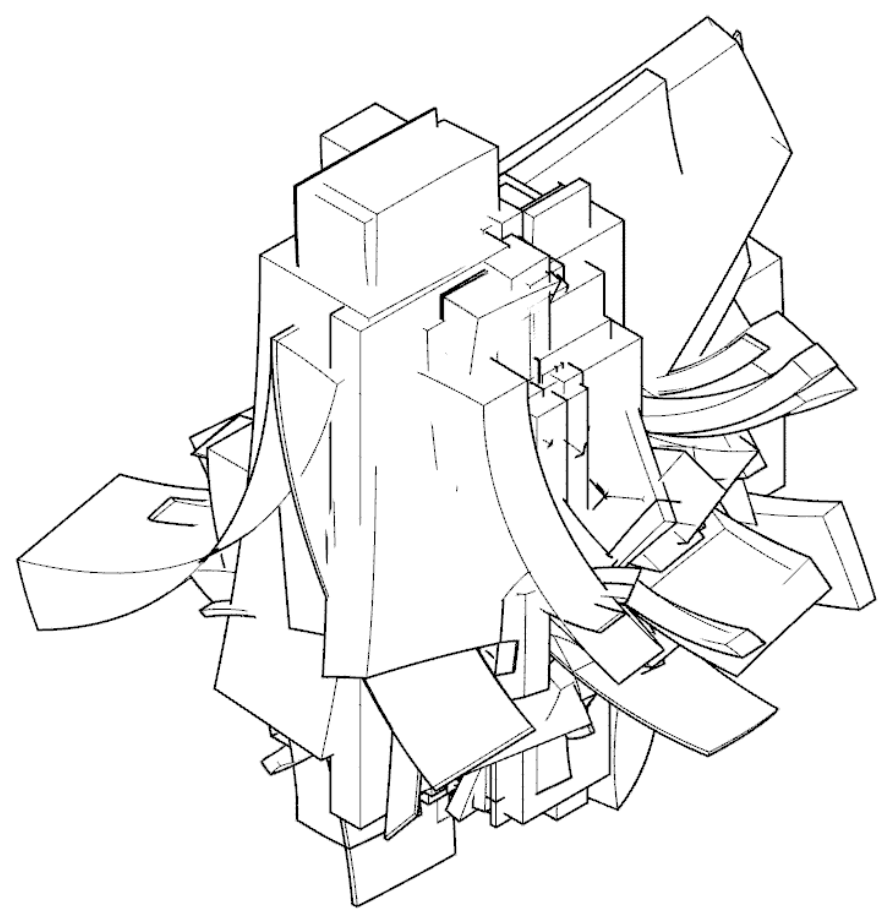

iso view $1 \mid$ combined
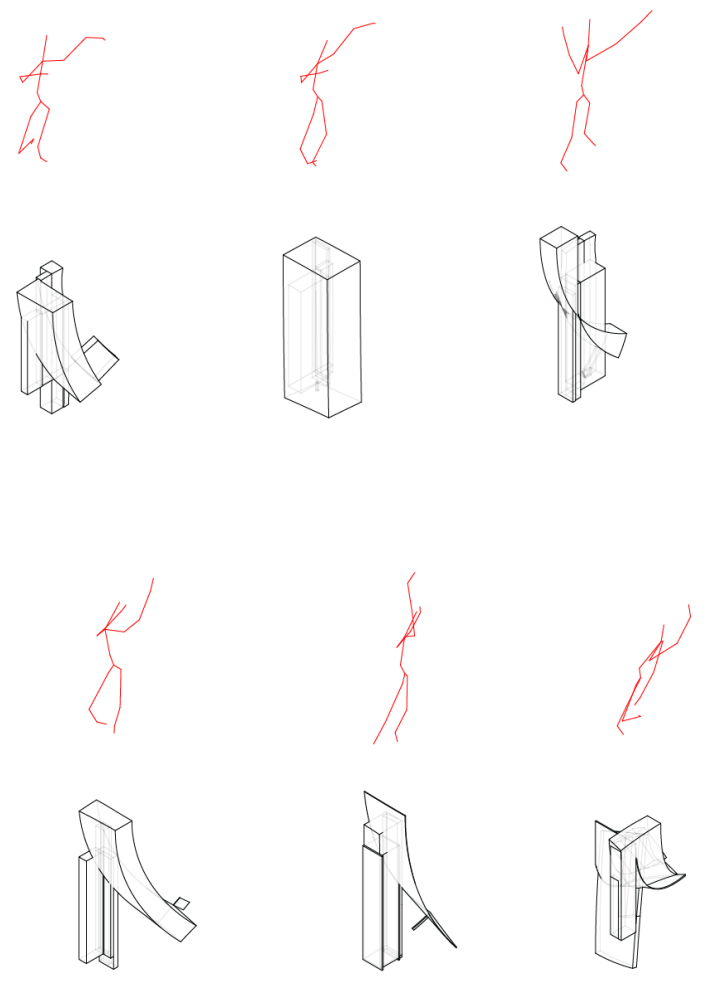

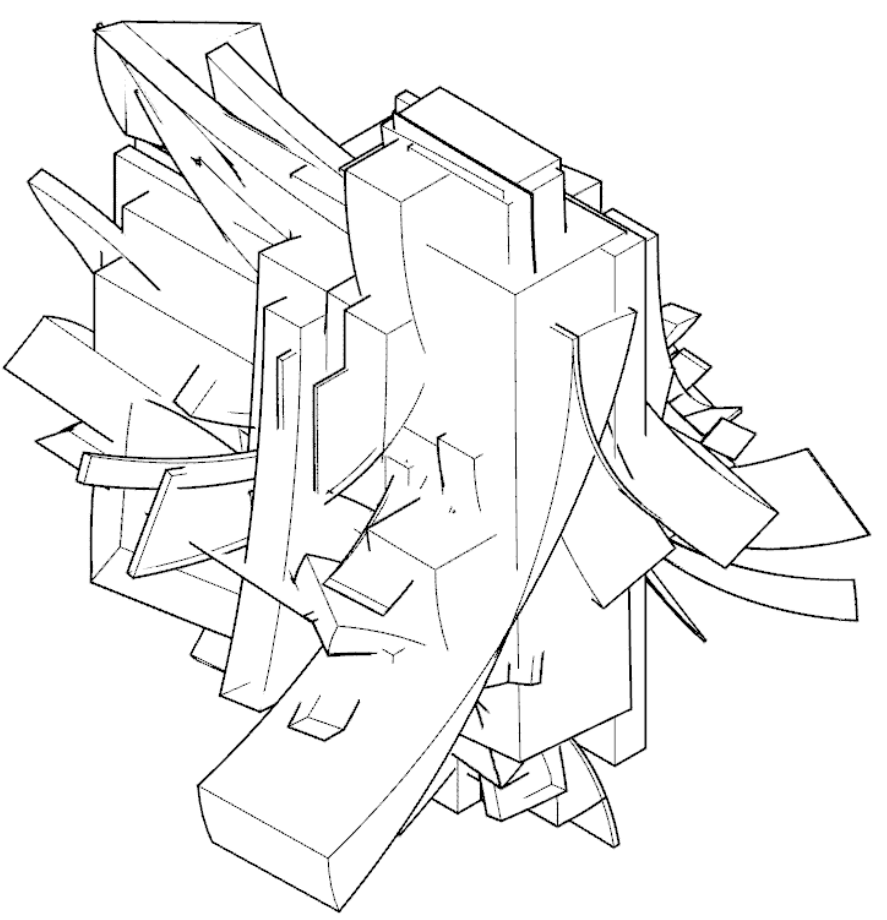

iso view 2 | combined
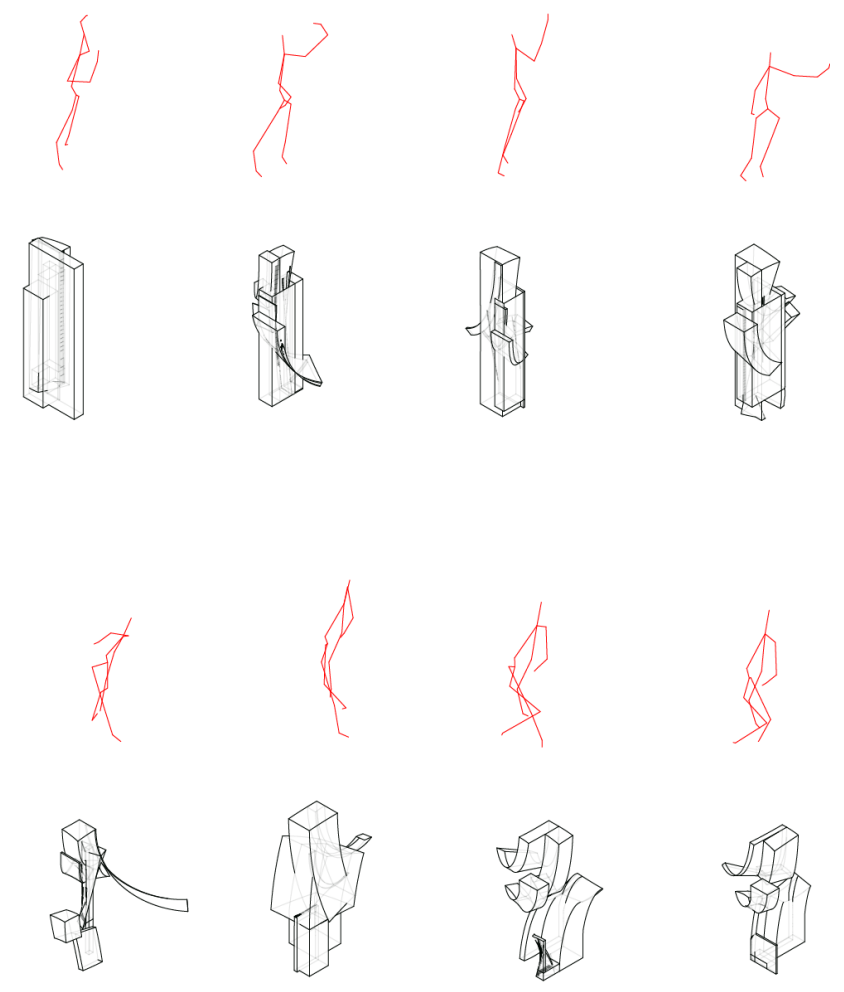
top view

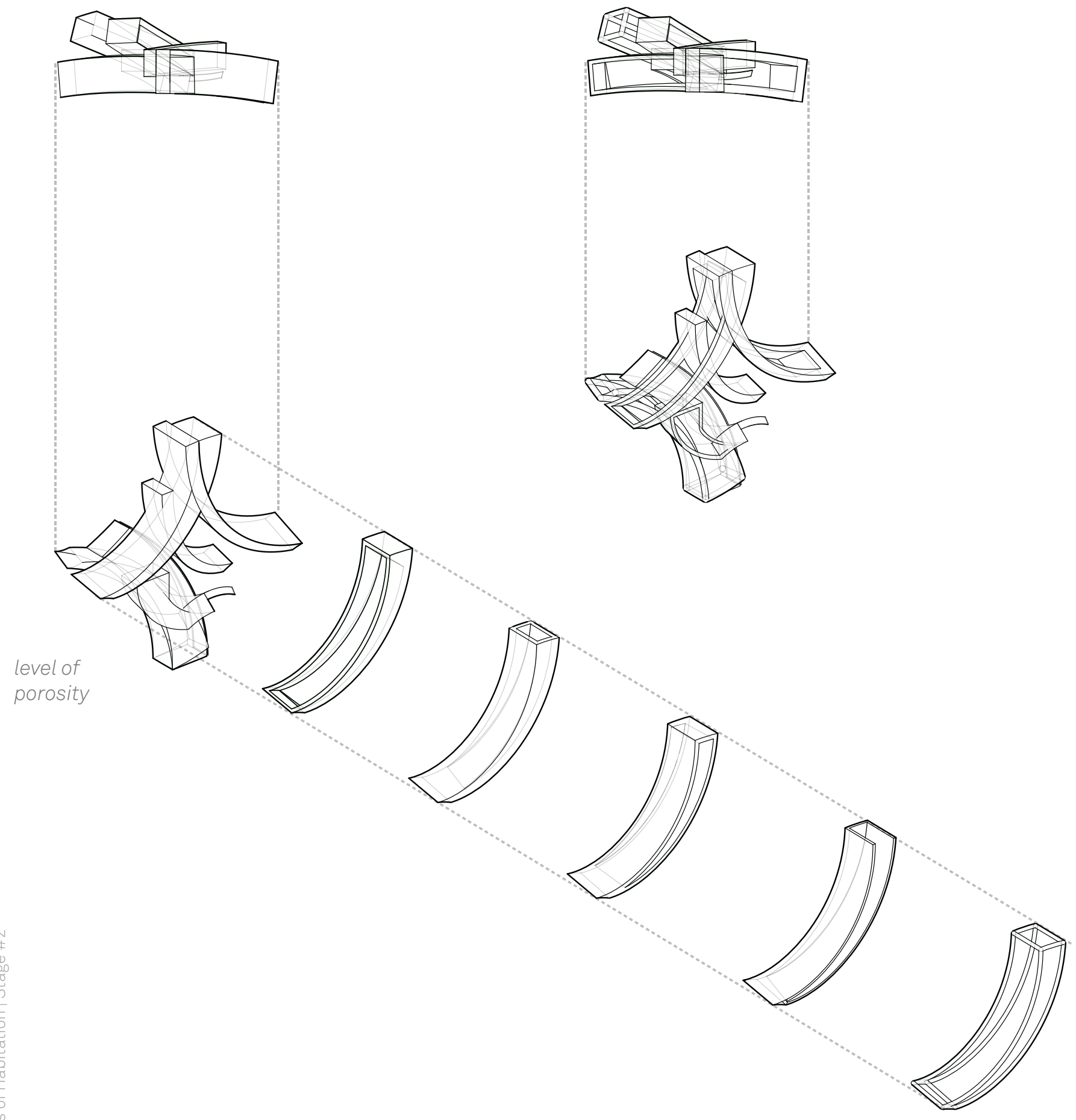



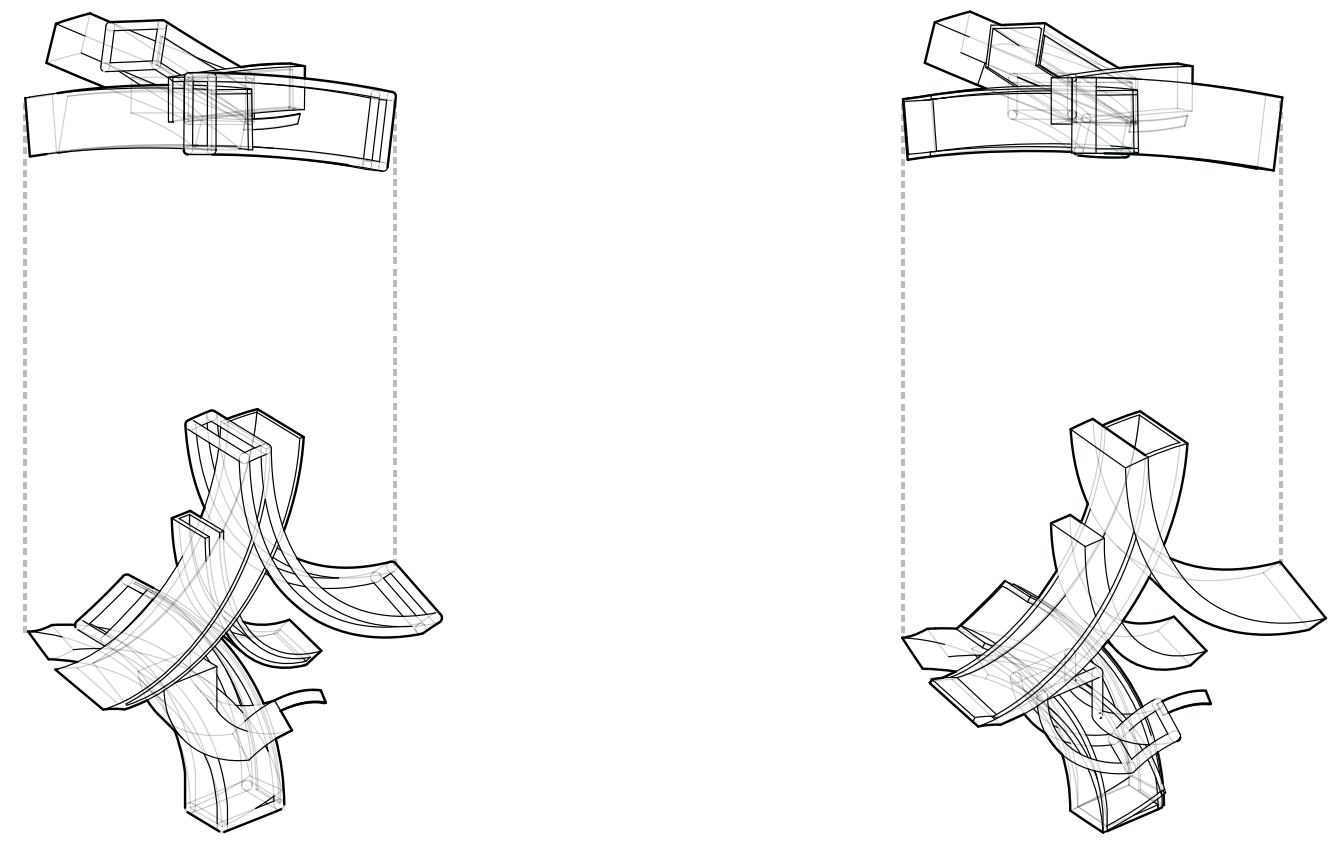

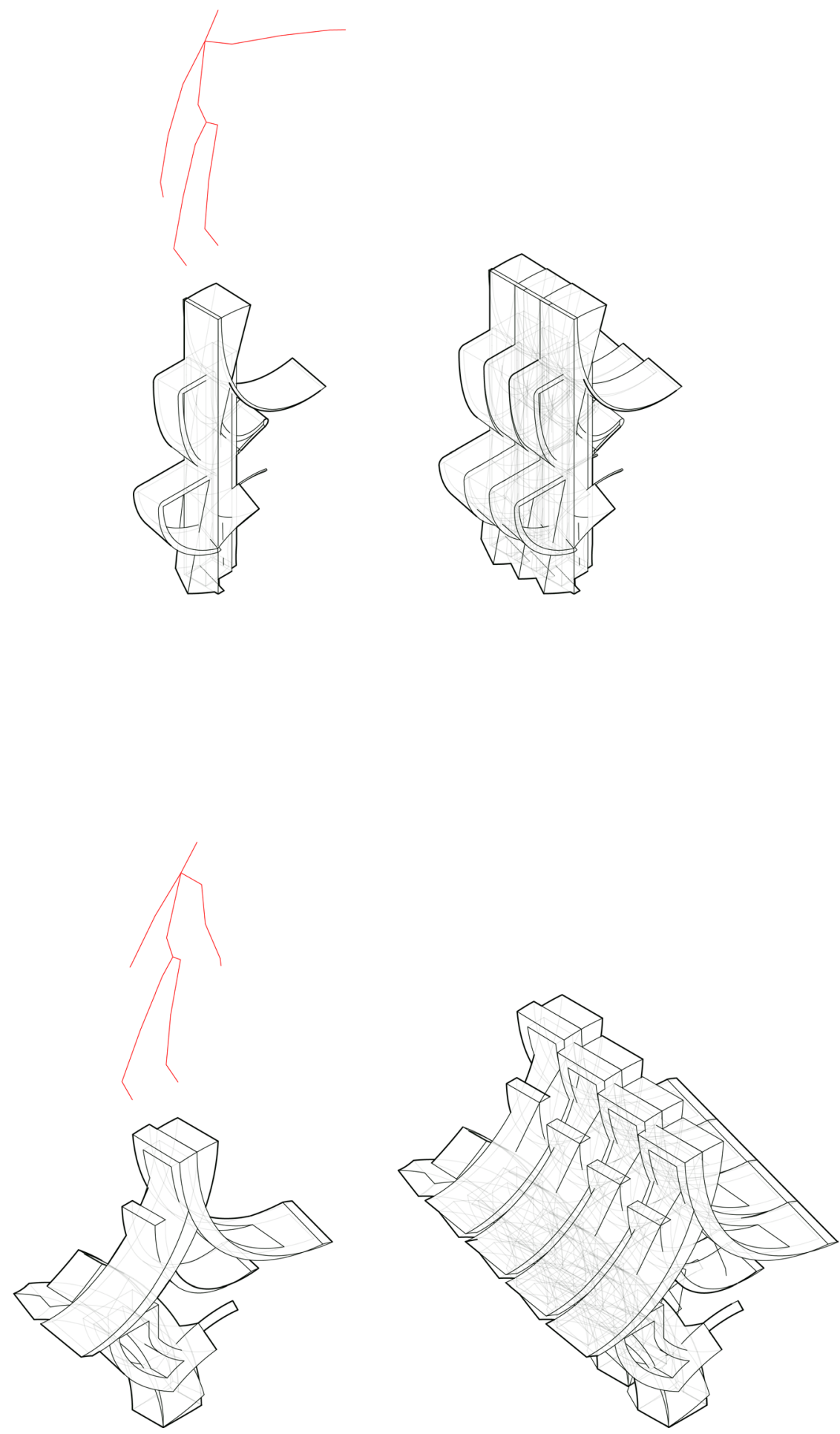

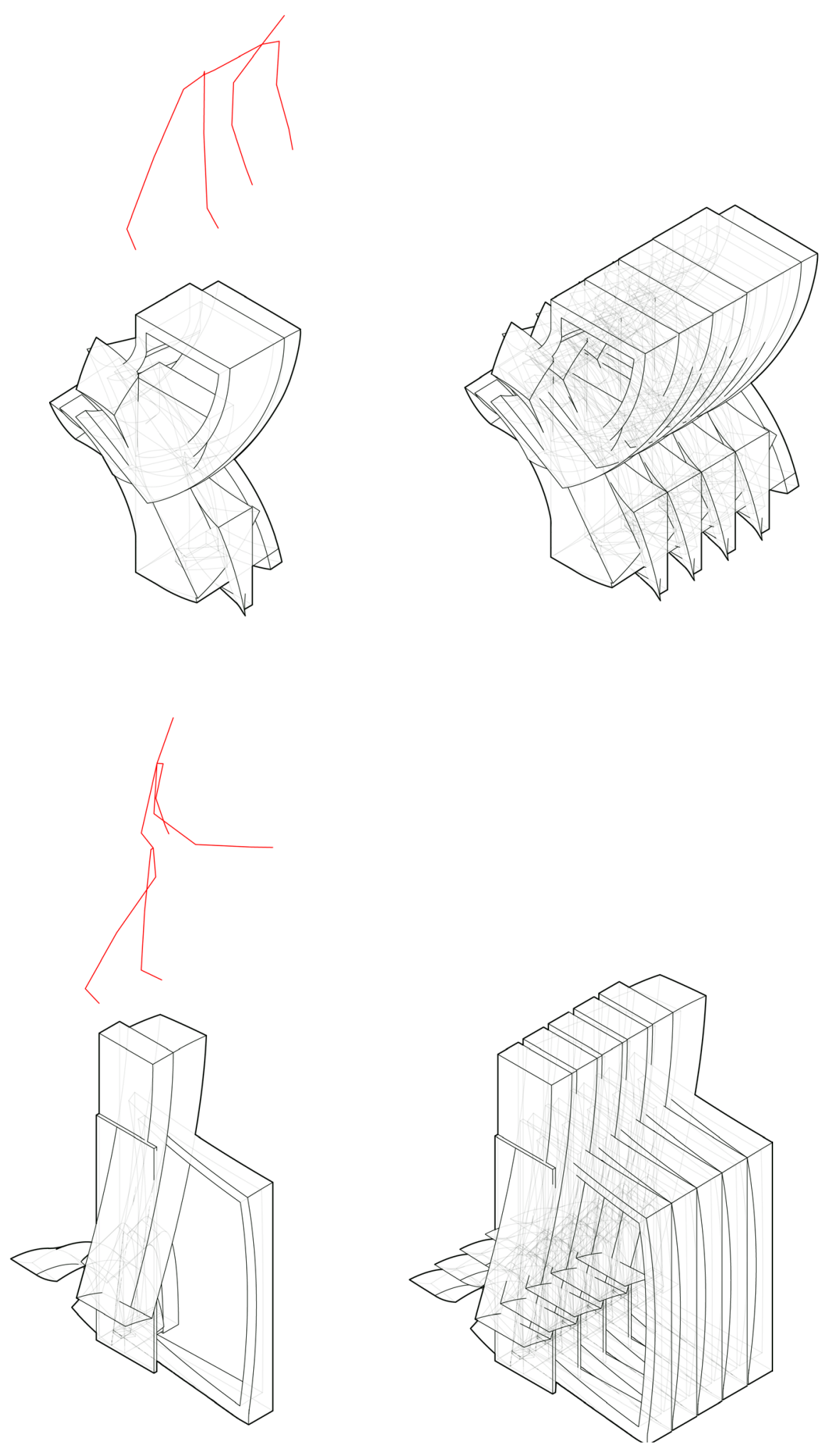

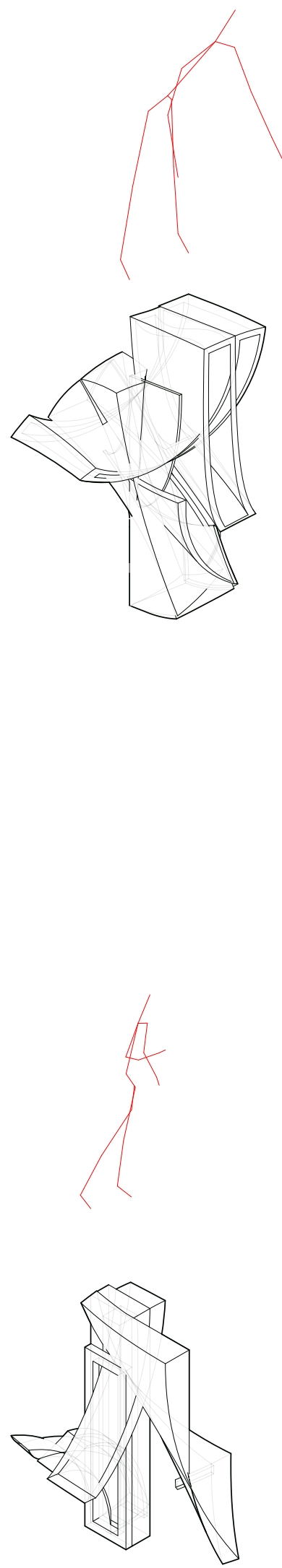

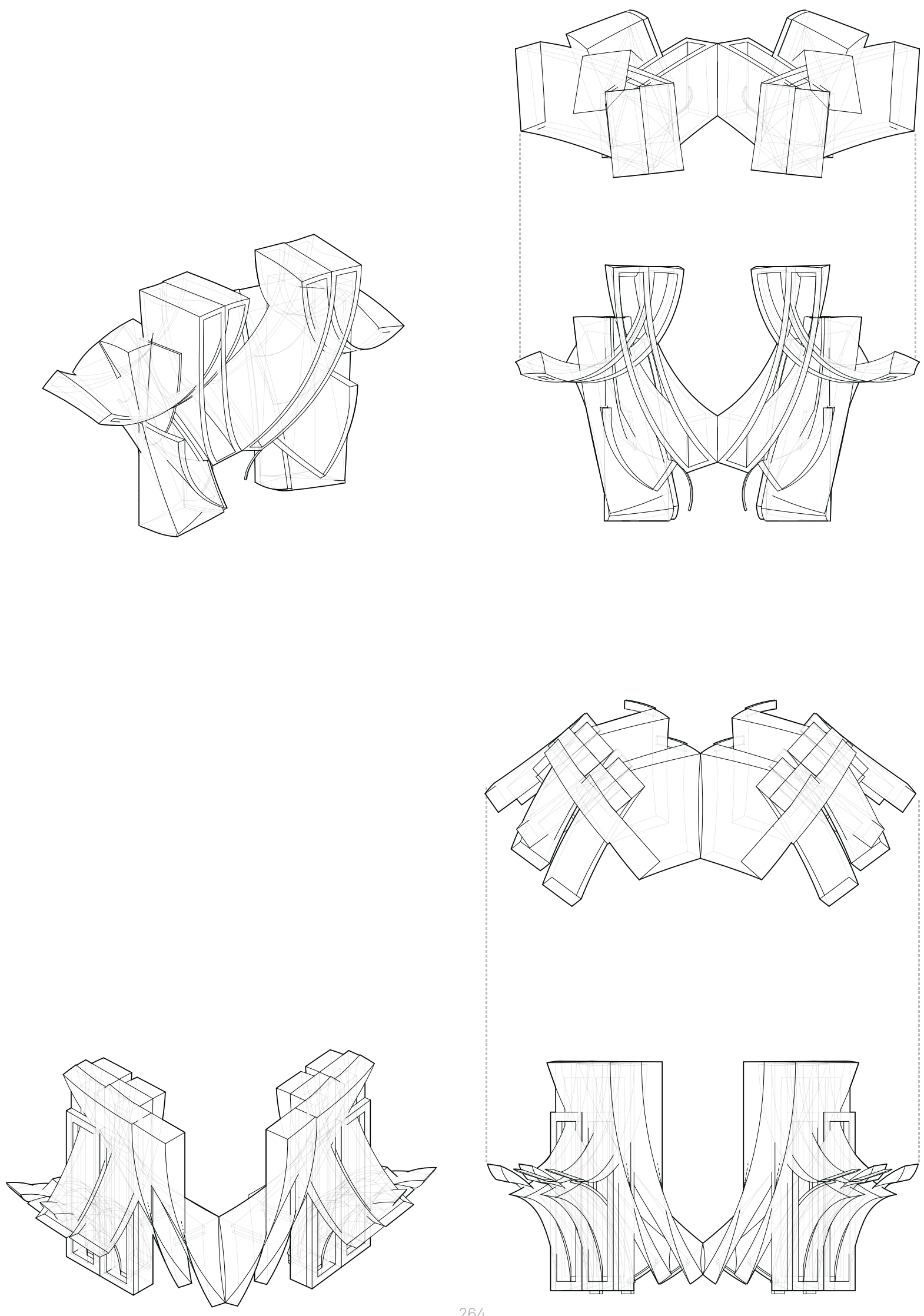
Choreographic Methods | Rotate \& Shift

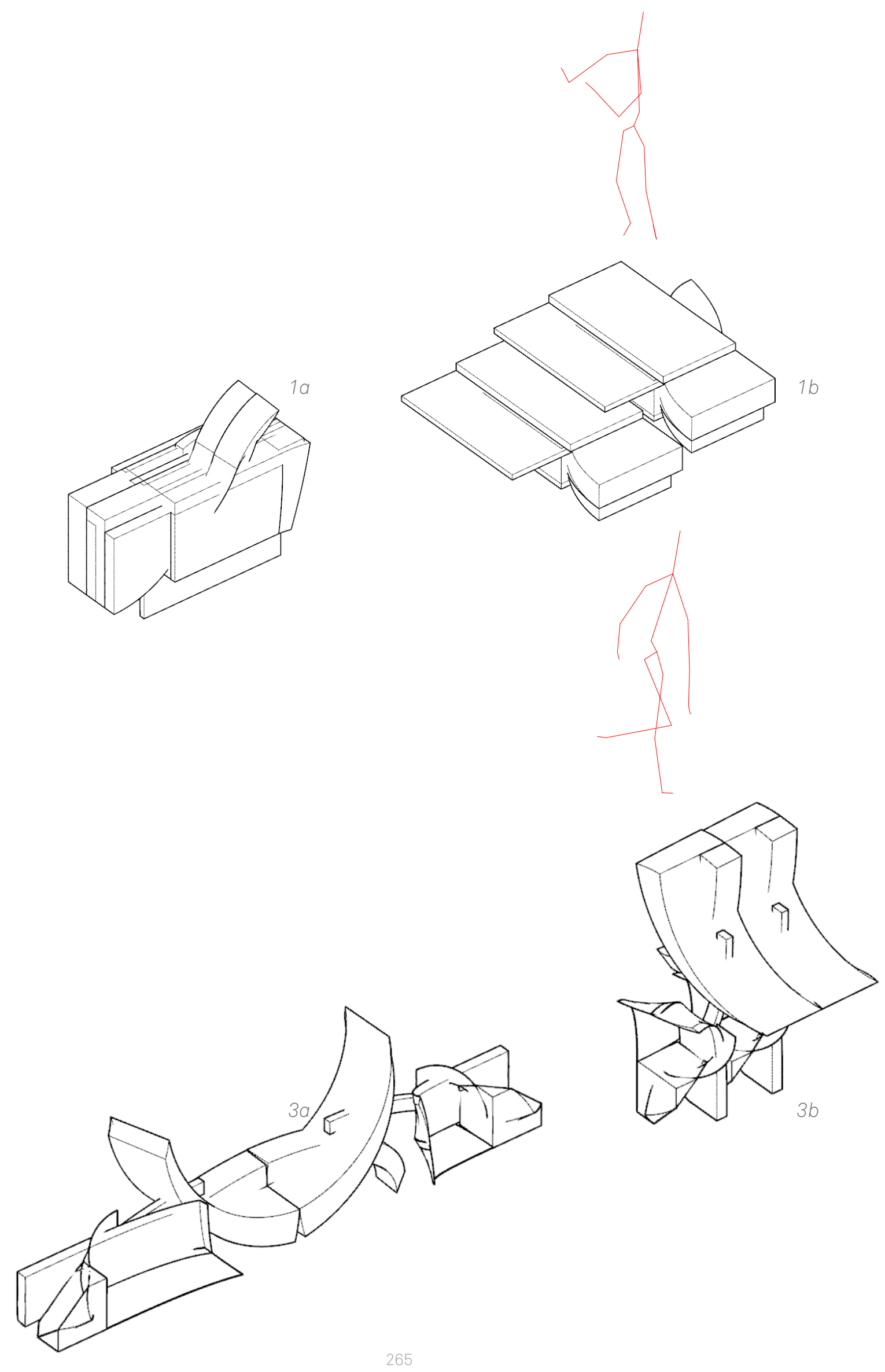




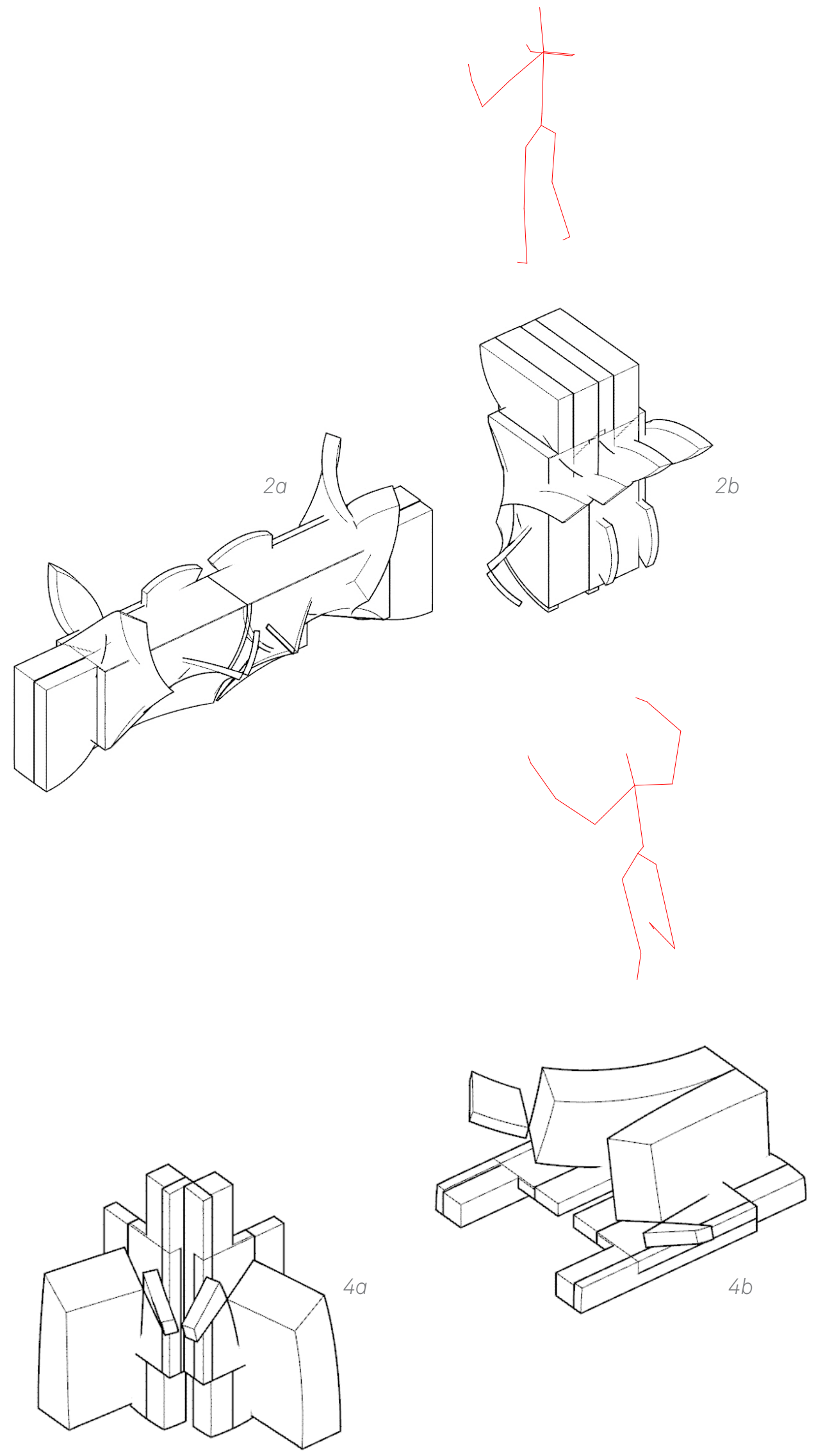




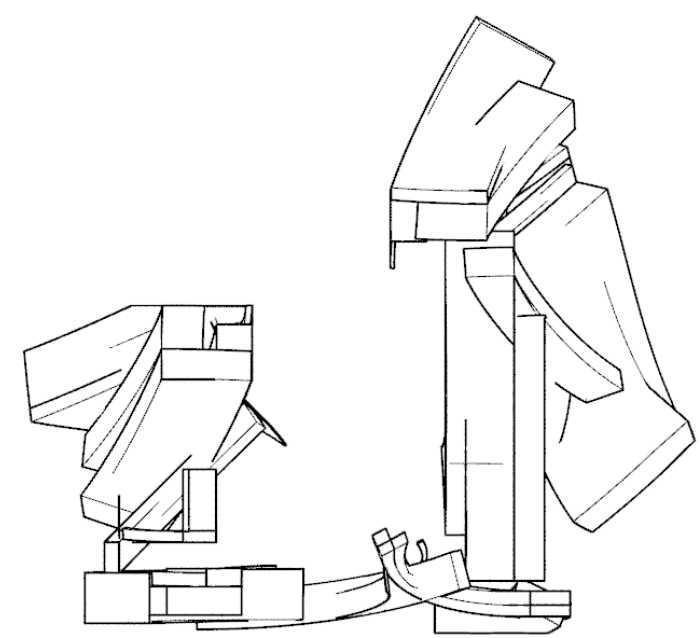

A top view

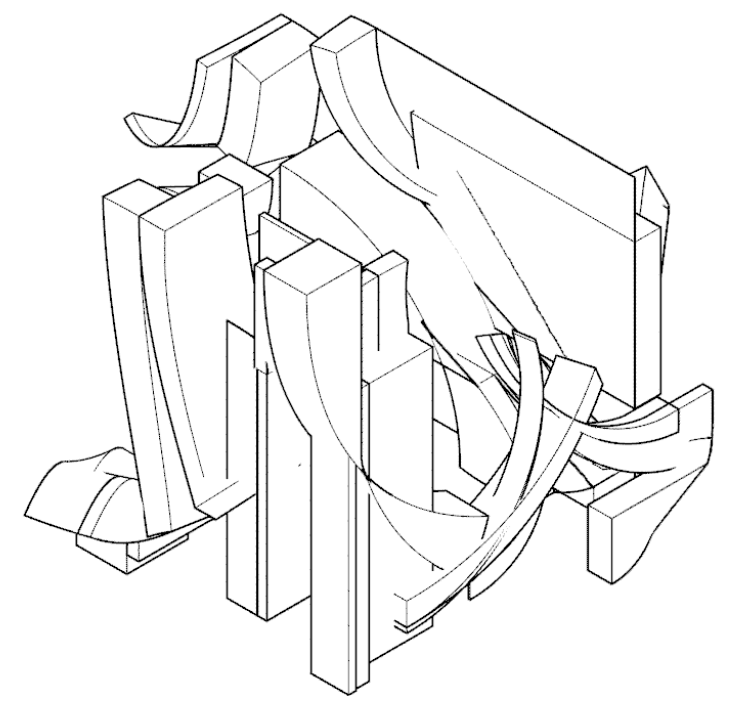

A | iso view-1

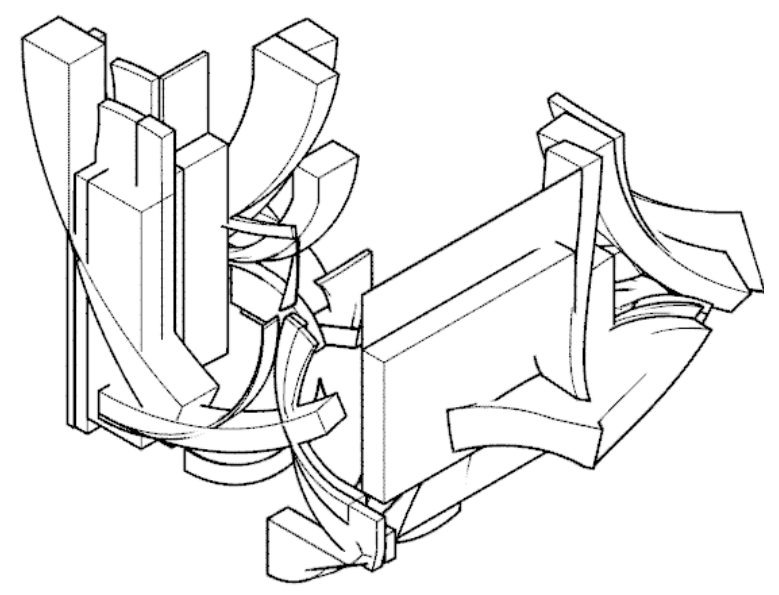

A I iso view-2

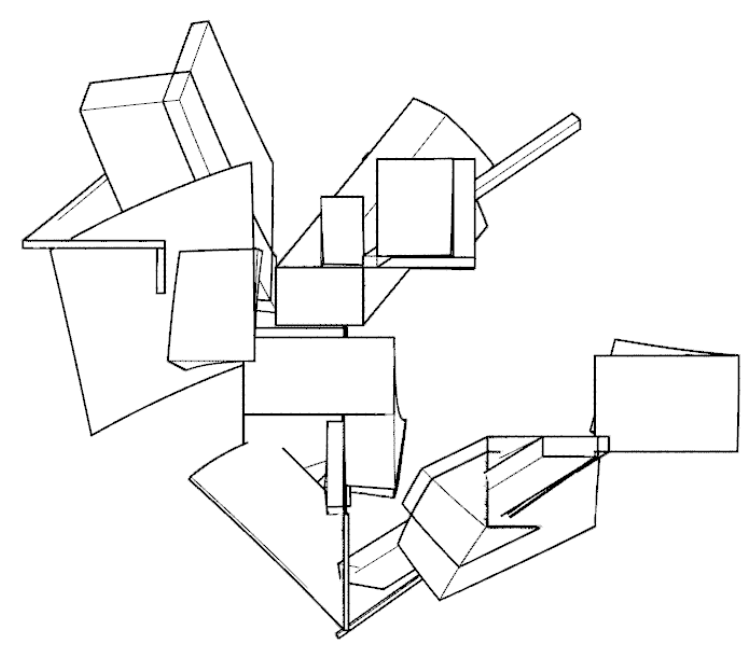

B I top view

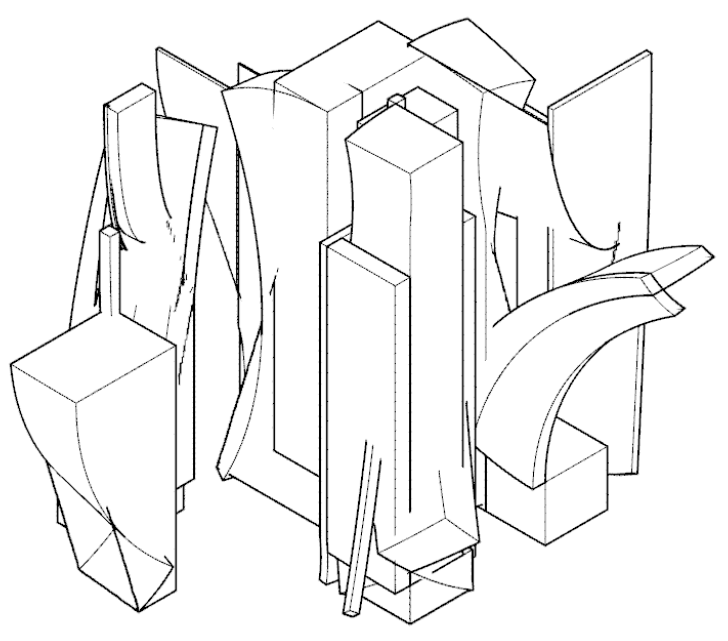

B | iso view-1

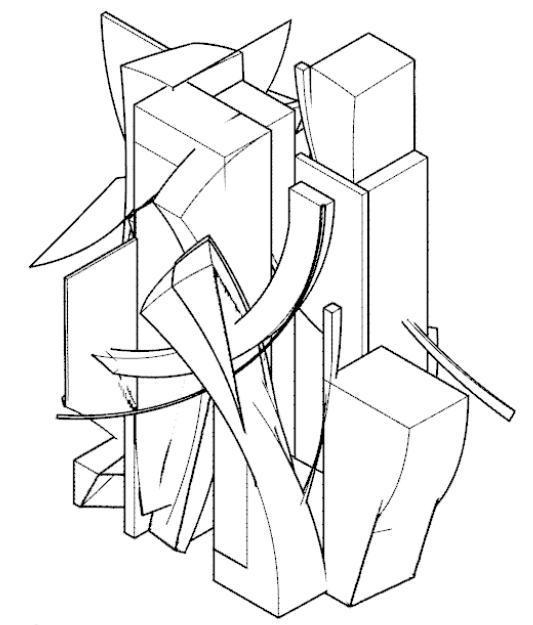

B | iso view-2 


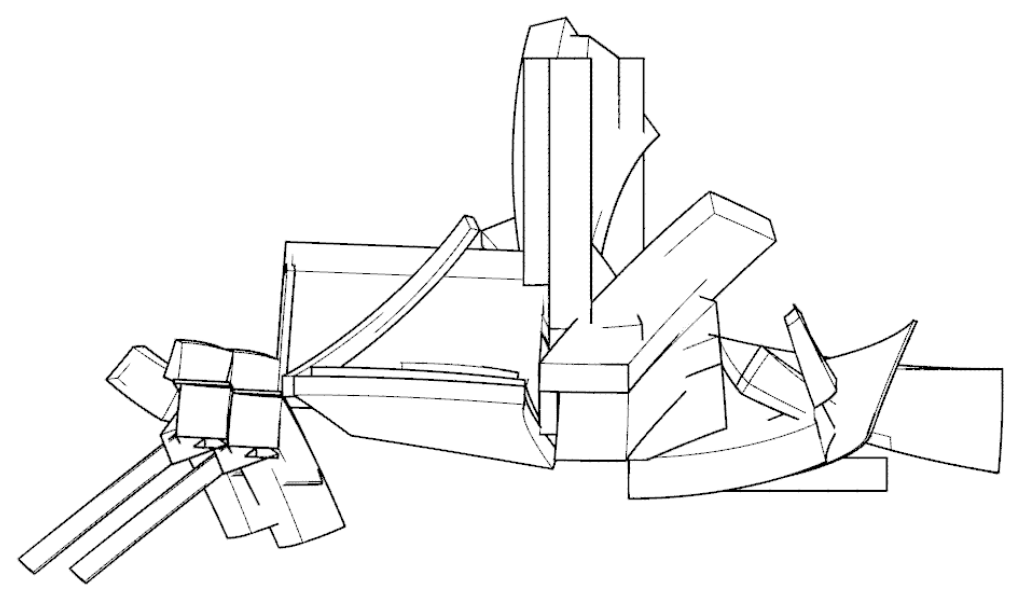

\section{CI top view}

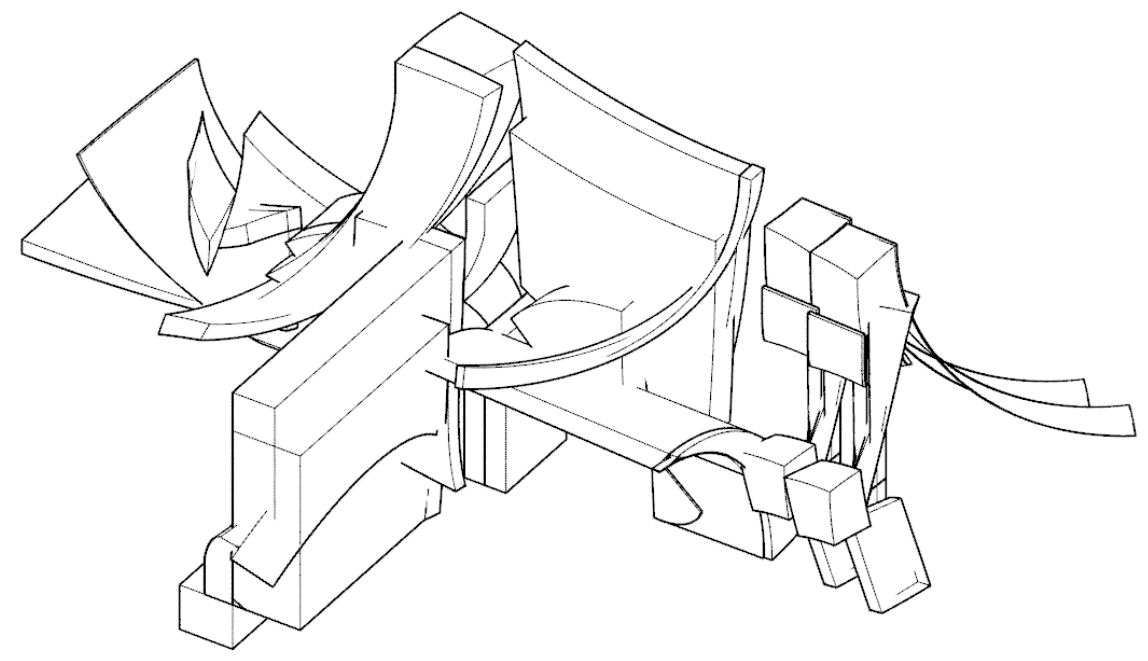

C | iso view-1

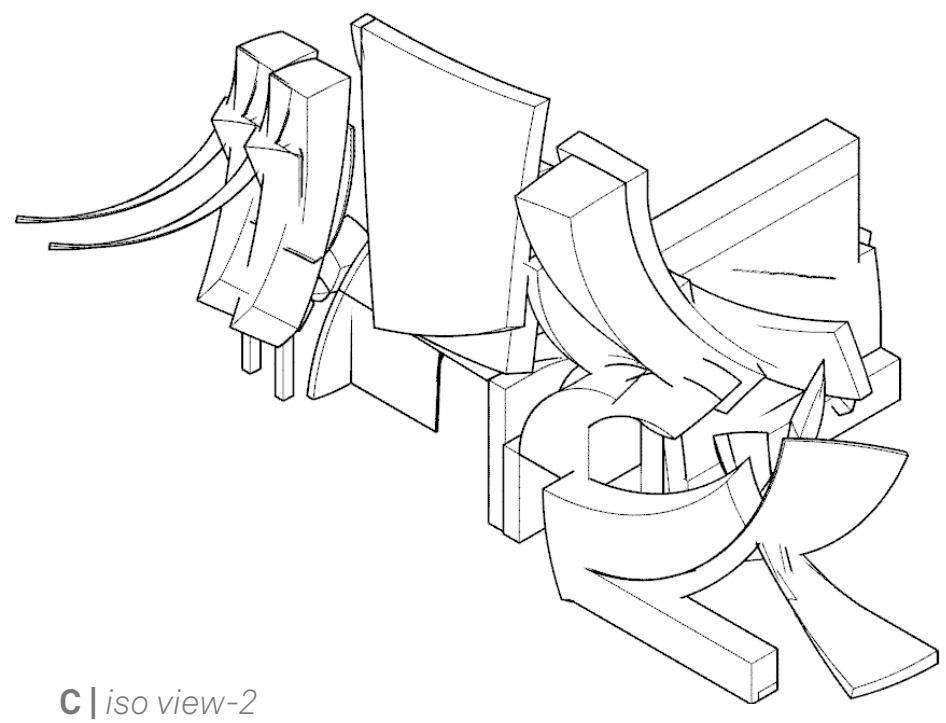




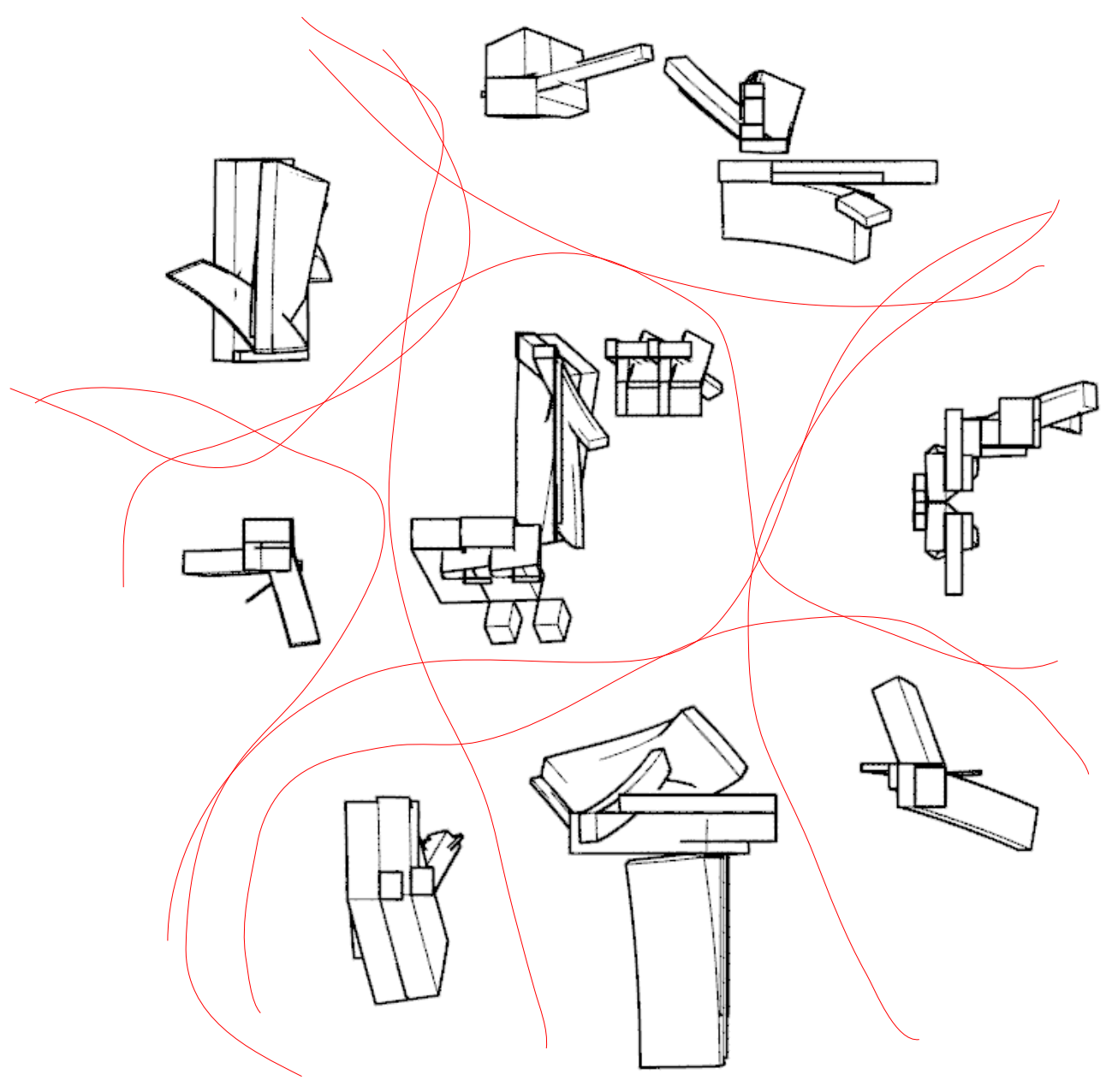




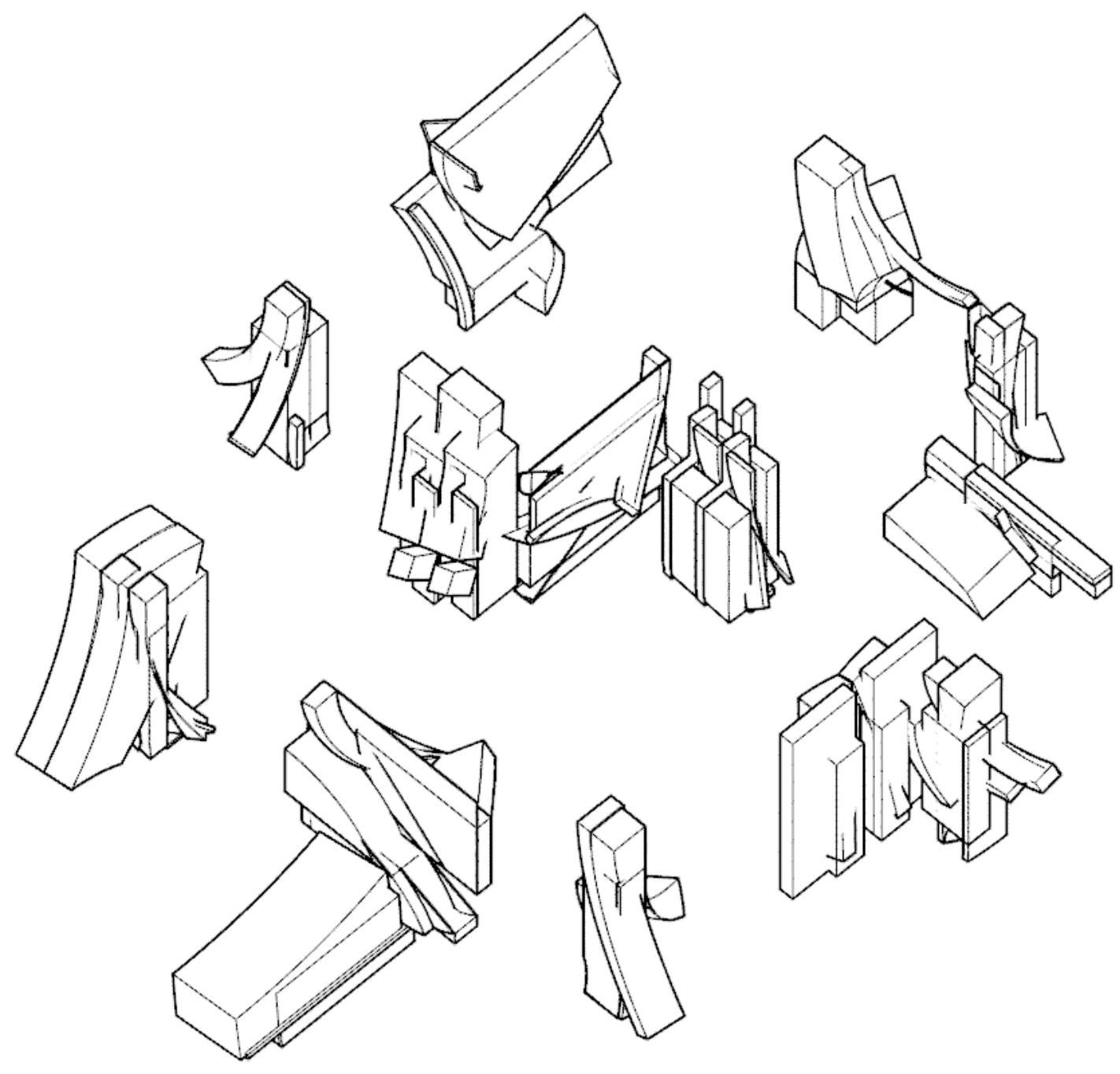




\section{Appendix D}

Design Experiments Following the Visionary Proposition (Section 7)

Source: Ashley Brooke Biren

These explorations investigate additional techniques for Choreographing Architecture, using the generated components from the Visionary Proposition.

\section{a. Design Experiment \#1}

In this design experiment, the most commonly used components in the Visionary Proposition were selected to explore additional methods of generative design techniques.

\section{b. Design Experiment \#2}

Elements from the previous experiment were further divided into parts and choreographed in space. This design iteration led to the final design proposition, prior to introducing the environmental conditions of air and water. 
a
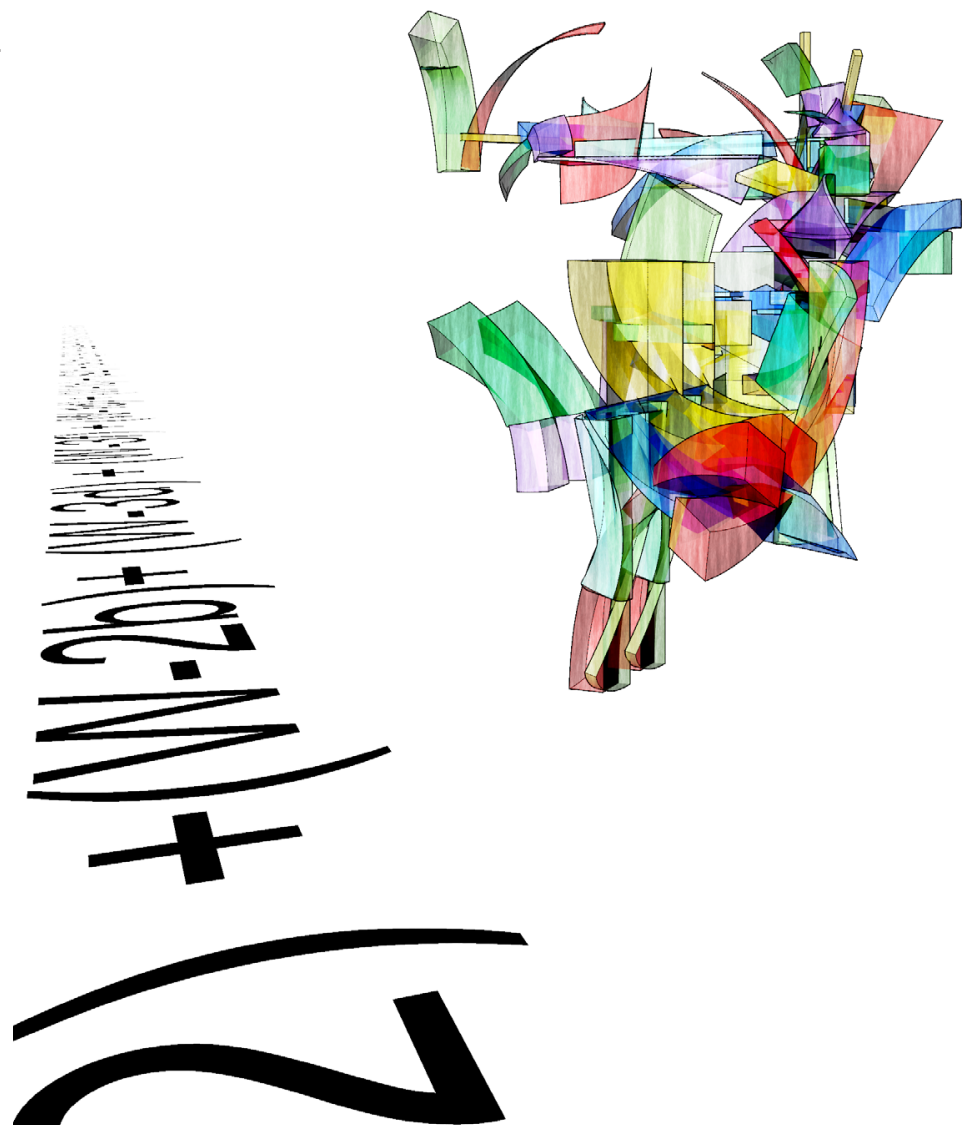

b

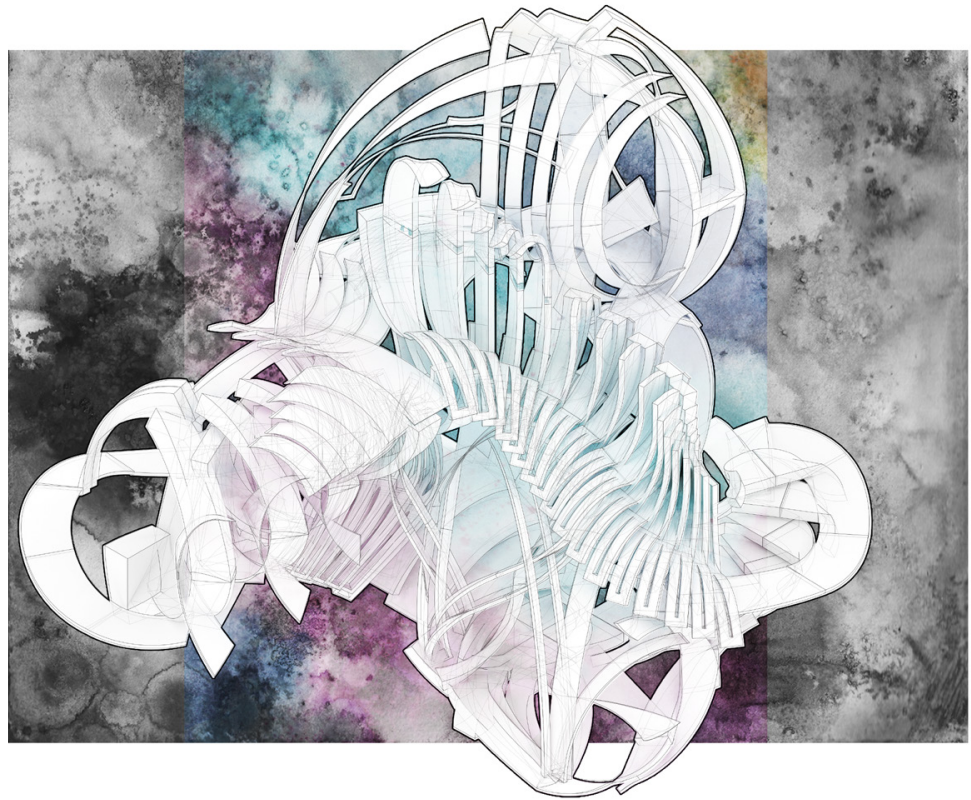


1. Vignettes of the commonly used components in Visionary Proposition
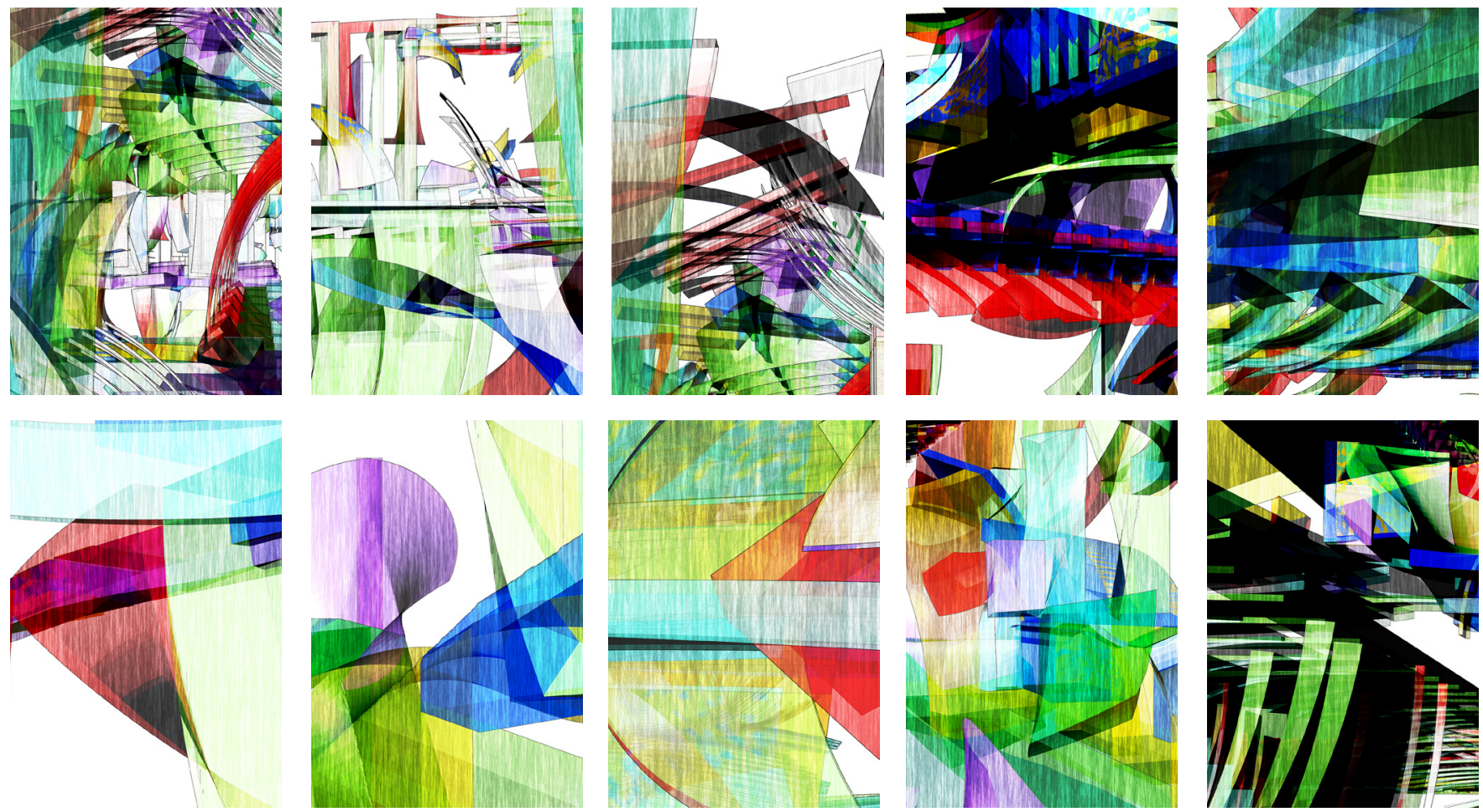

2. Extracted components from above were organized according to their "movement type" and exploded into its constituent elements.
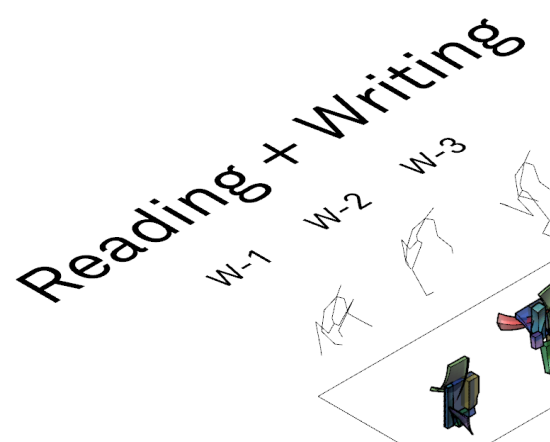

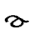<smiles>O=S1(=O)CC2CCC(CC2)C1</smiles>

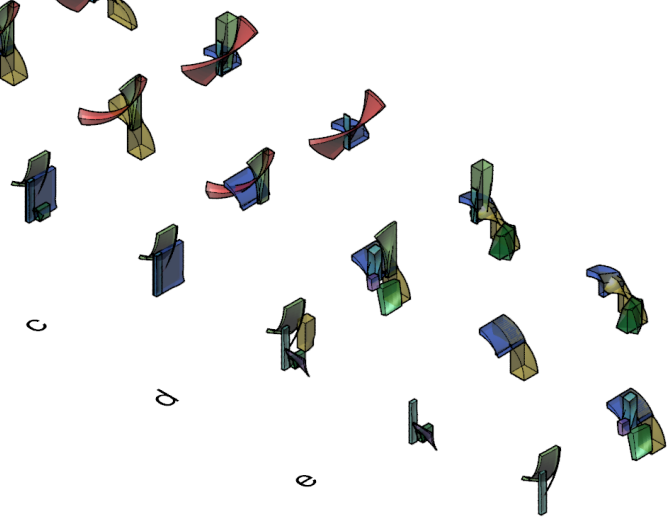




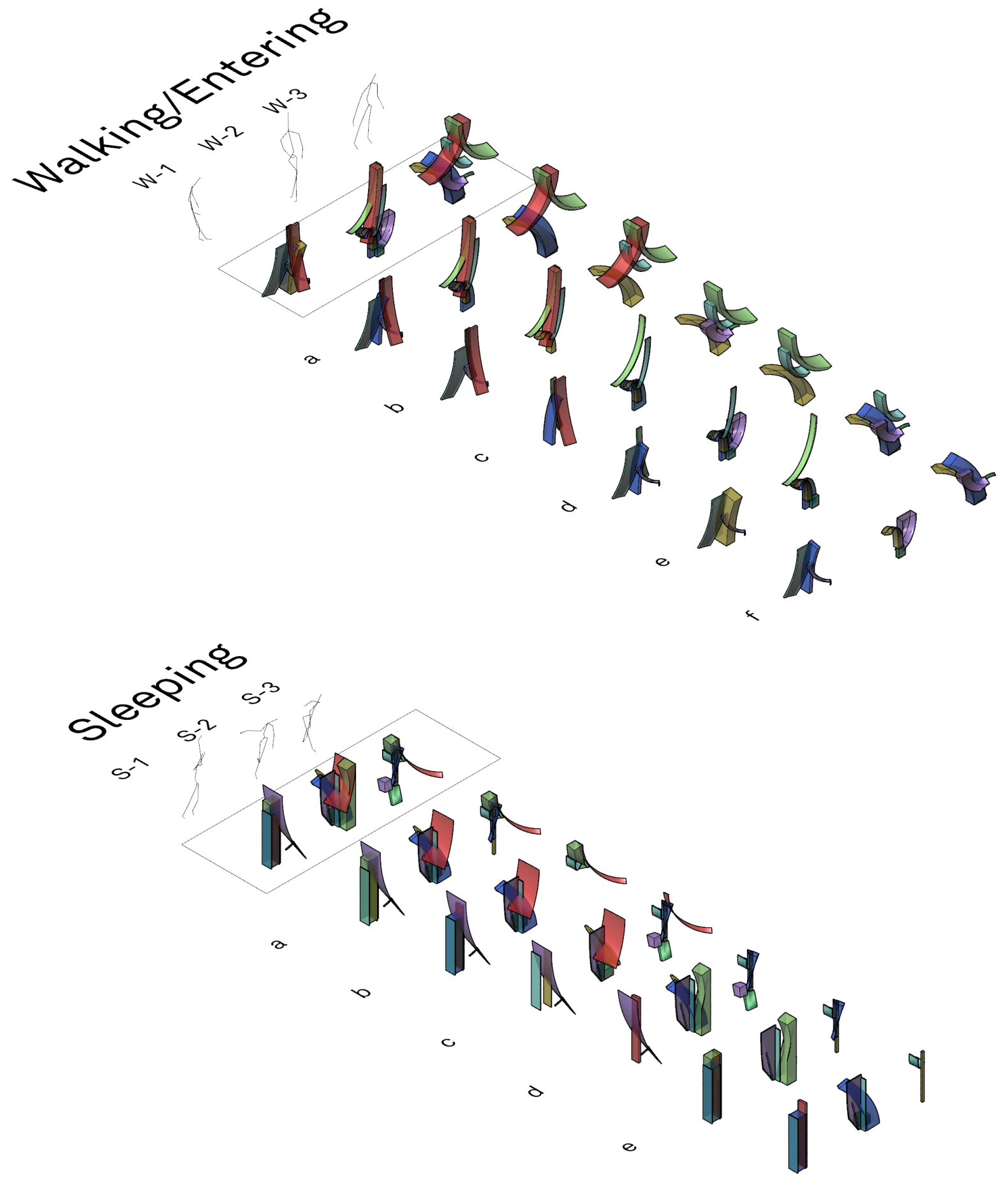

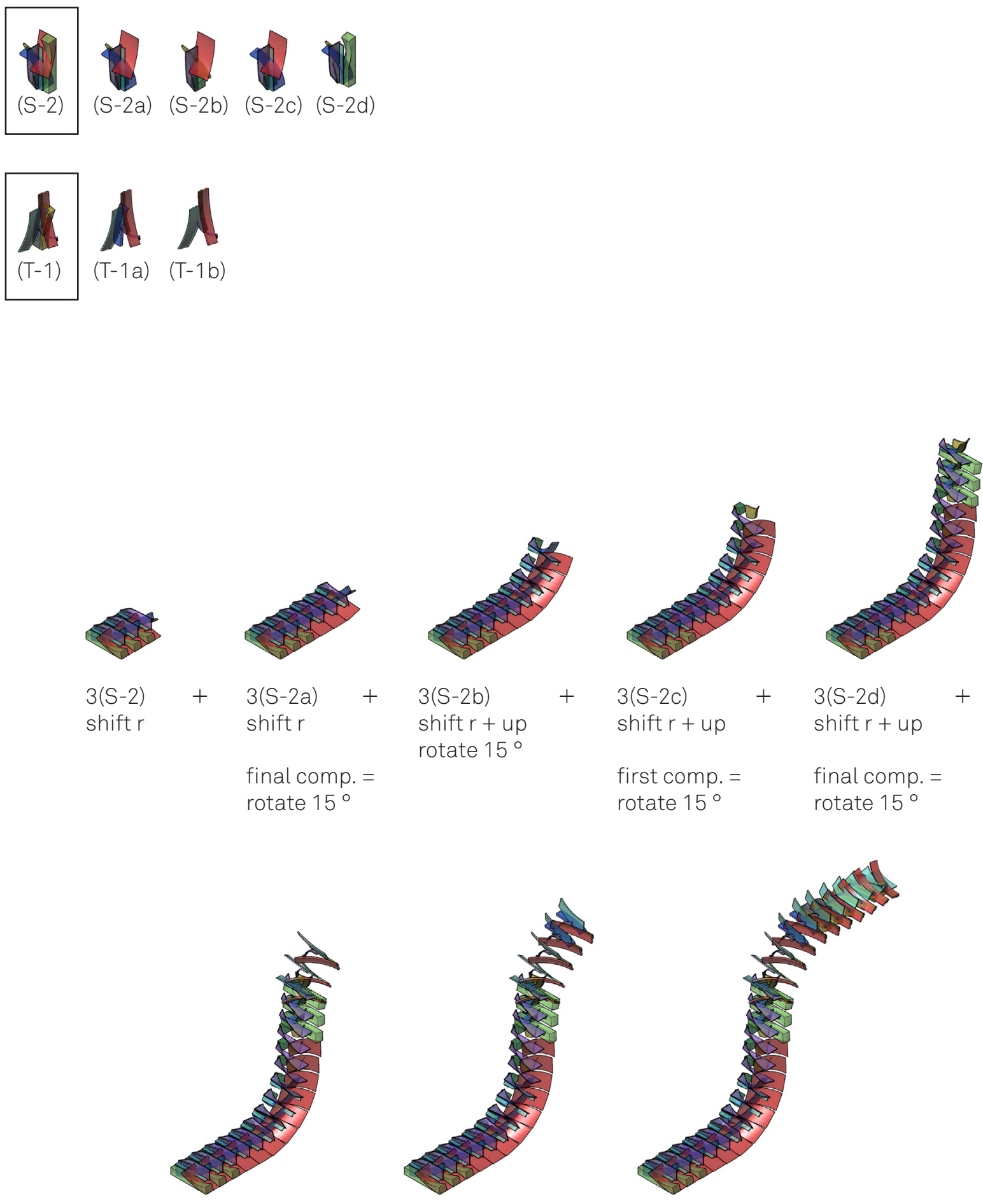

\begin{abstract}
$3(T-1 a)$
shift $r+$ up
rotate $15^{\circ}$
\end{abstract}
$+$

shift $r+u p$ rotate $15^{\circ}$ $+\quad 6(T-1)$

shift $r$

rotate $15^{\circ}$ 

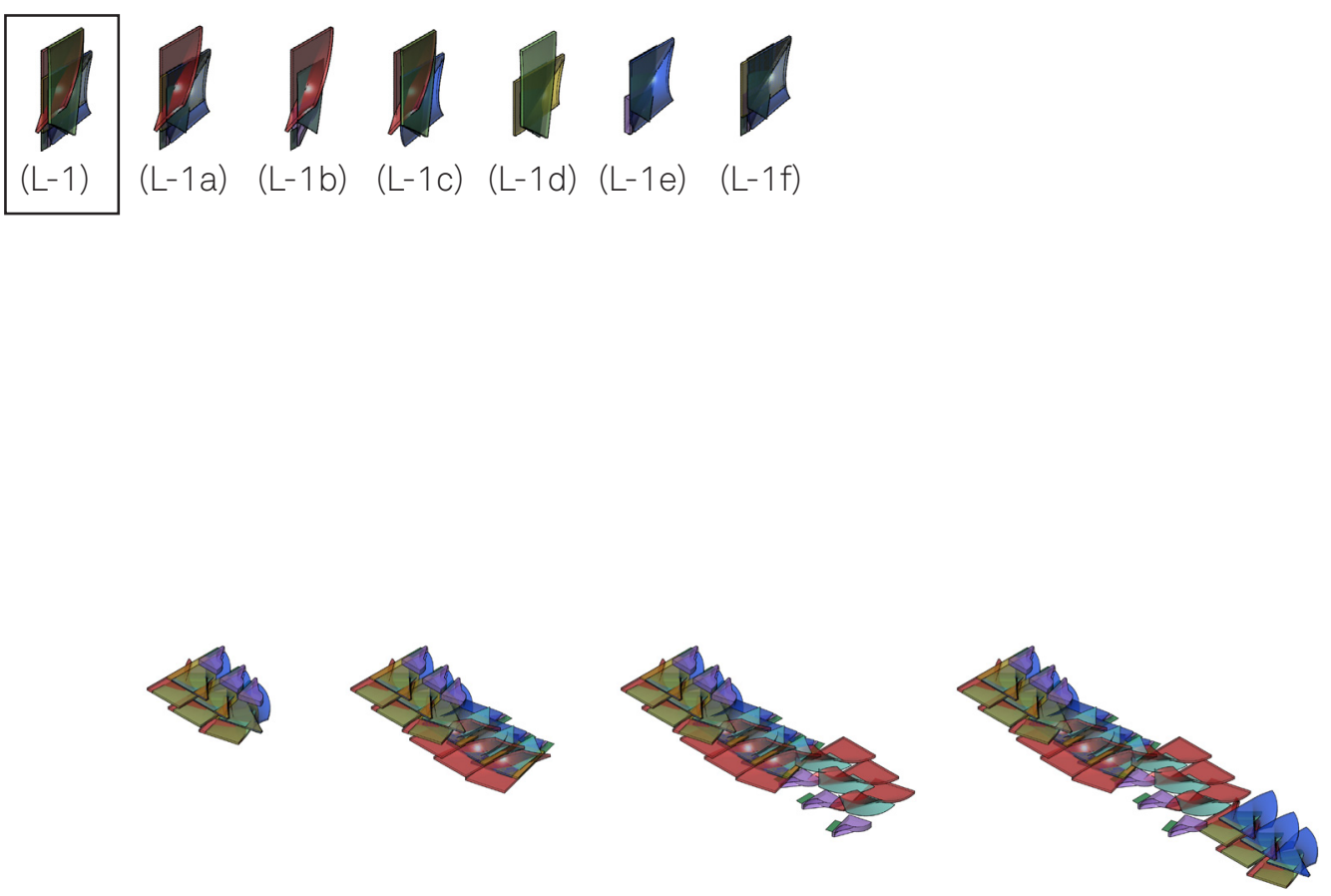

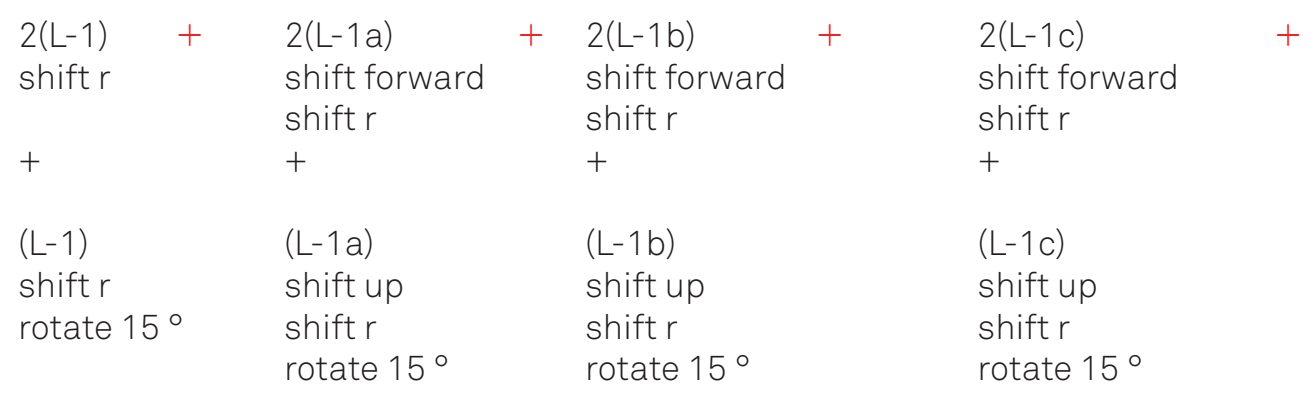
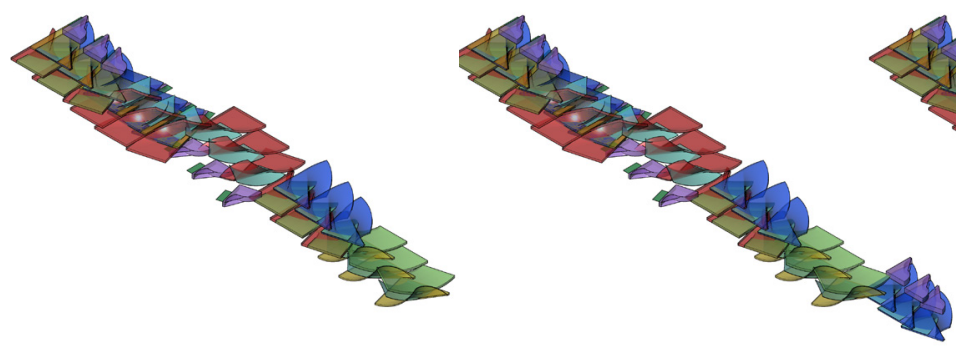

2(L-1d)

shift forward

shift $r$

$+$

(L-1d)

shift up

shift $r$

rotate $15^{\circ}$
2(L-1e)

shift forward

shift $r$

$+$

(L-1e)

shift up

shift $r$

rotate $15^{\circ}$

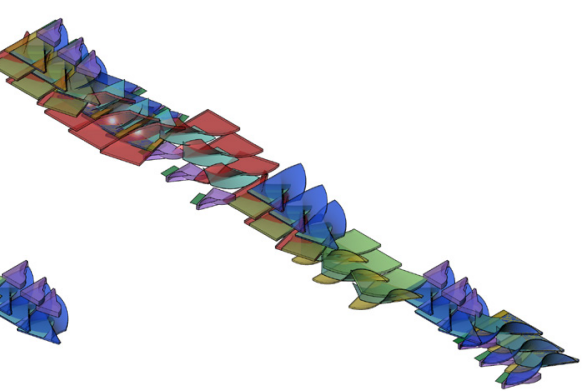

$+\quad 2(\mathrm{~L}-1 \mathrm{f})$

shift forward

shift $r$

$+$

(L-1b)

shift up

shift $r$

rotate $15^{\circ}$ 

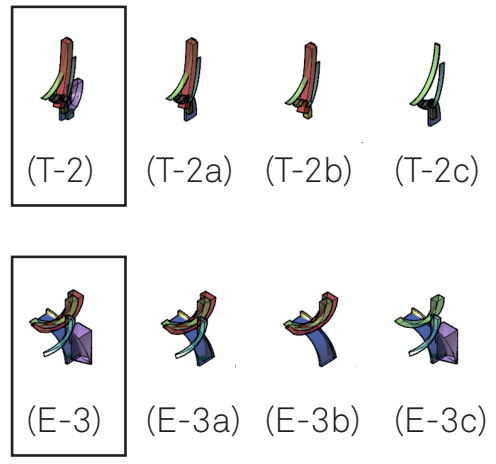
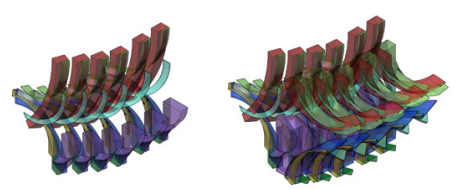

3(T-2) shift left $+$

3(T-2) shift left shift up rotate $5^{\circ}$

$3(E-3)$
shift left
+
$3(E-2)$
shift left
shift up
rotate $5{ }^{\circ}$
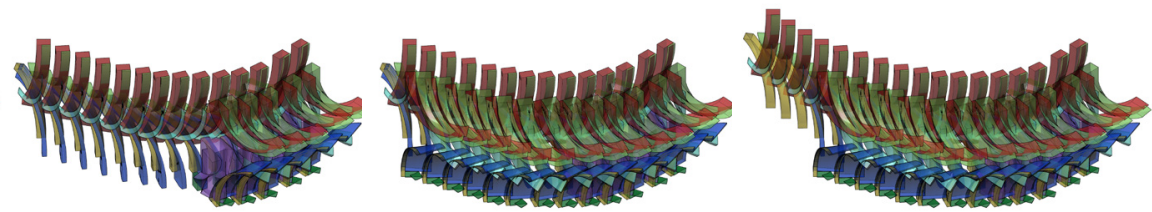

6(T-2a) shift left shift up rotate $5^{\circ}$
$6(E-3 a)$ shift left shift up rotate $5^{\circ}$
3(T-2b) shift left shift up rotate $5^{\circ}$
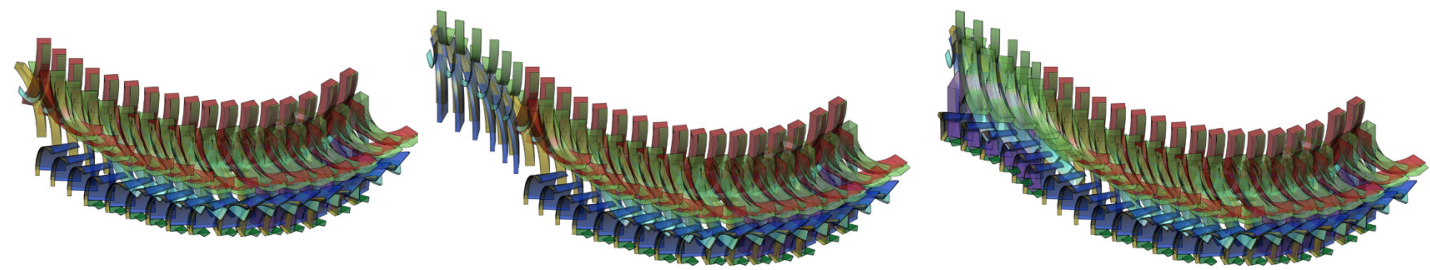

3(E-3b)

shift left

shift up rotate $5^{\circ}$
6(E-3c)

shift left shift up rotate $5^{\circ}$ 

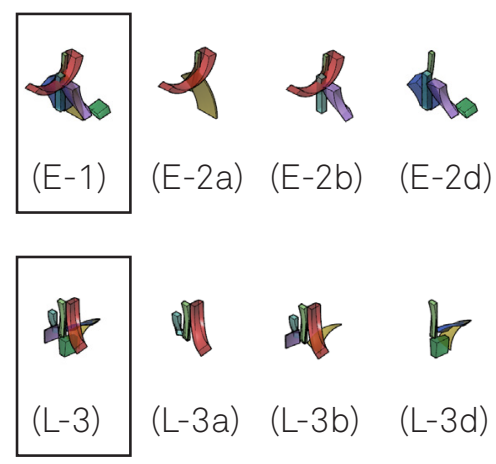

elevation
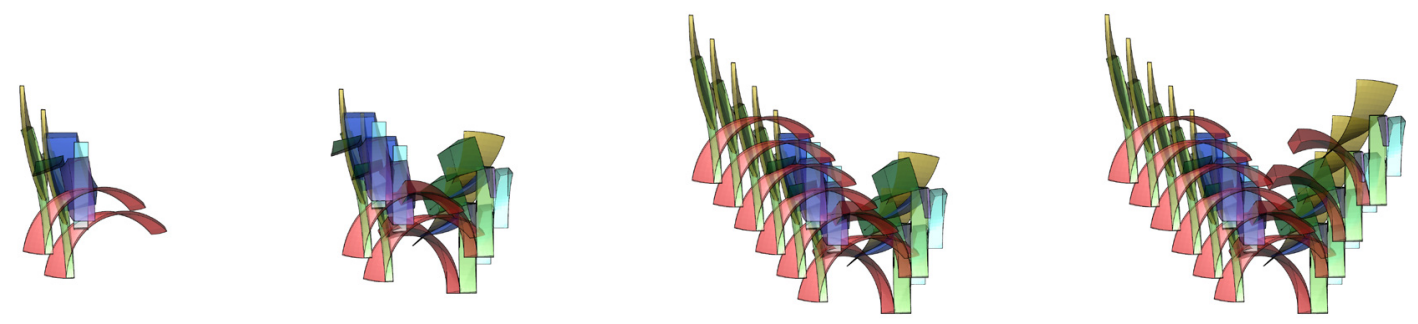

$\mathrm{axo}$
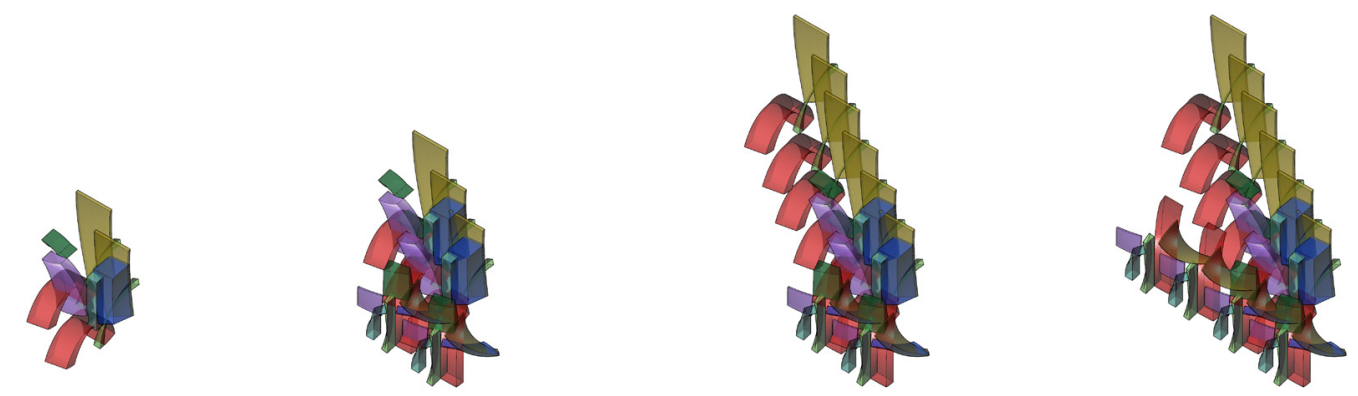

2(E-2)

$+\quad 2($ L-3)

$+$

shift up

shift forward

shift forward

shift right

4(E-2a)

shift up

shift forward

shift left

2(L-3b)

shift up

shift forward

shift right 

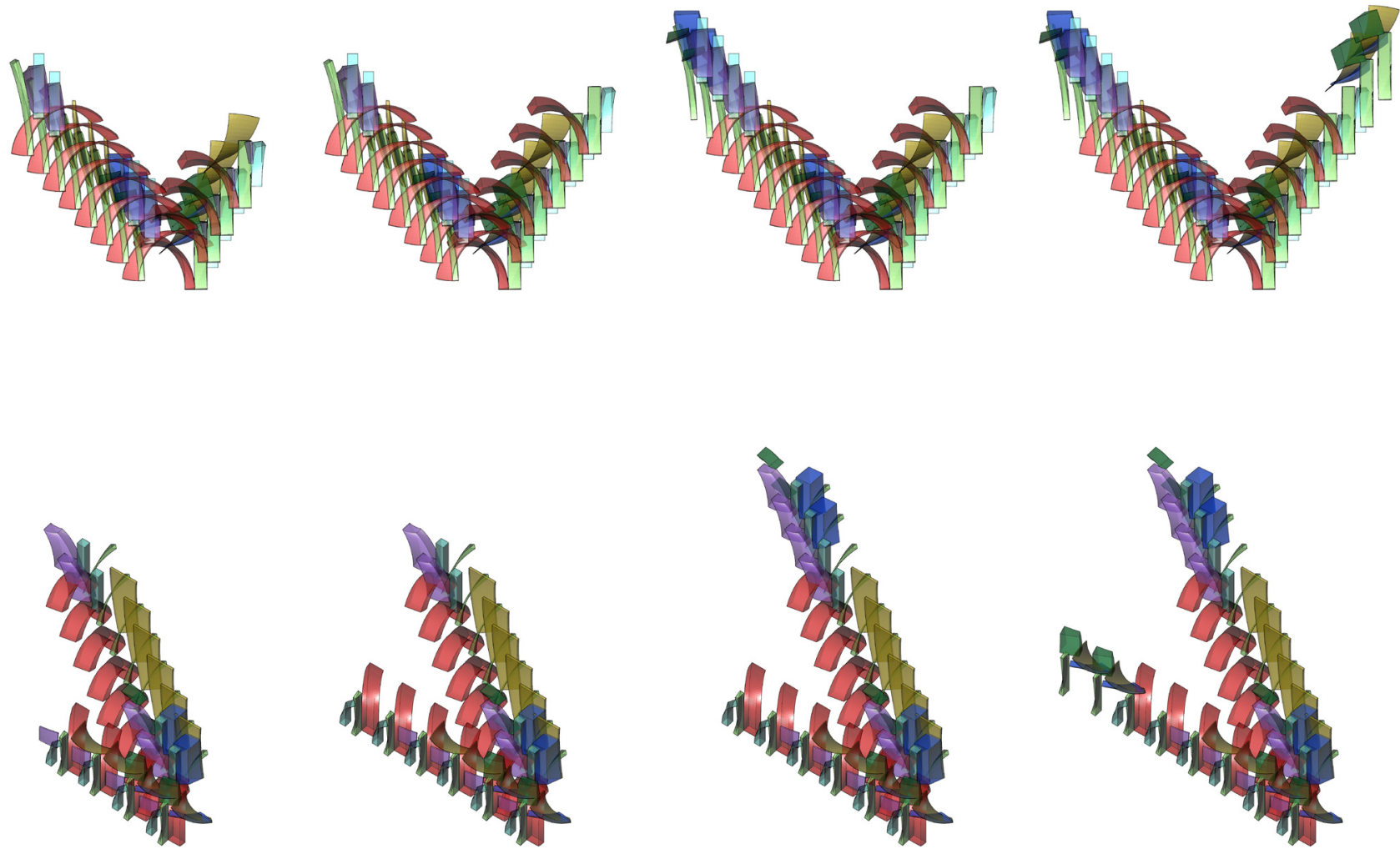

2(E-2b)

$\begin{array}{ll}+\quad & 2(L-3 a) \\ & \text { shift up } \\ & \text { shift forward } \\ & \text { shift right }\end{array}$

2(E-2d)

shift up

shift forward

shift left
2(L-3d)

shift up

shift forward

shift right 
sequence 5 - [sleeping + working movements (reading and writing)]

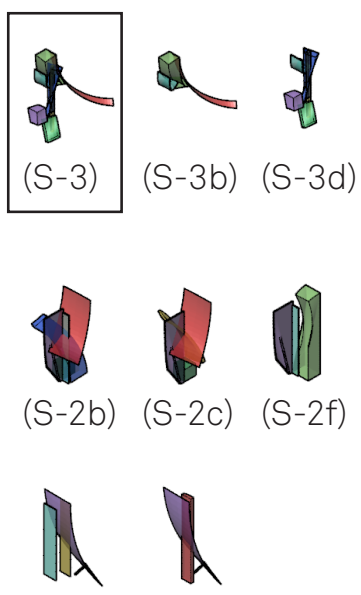

$(S-1 c)(S-1 d)$
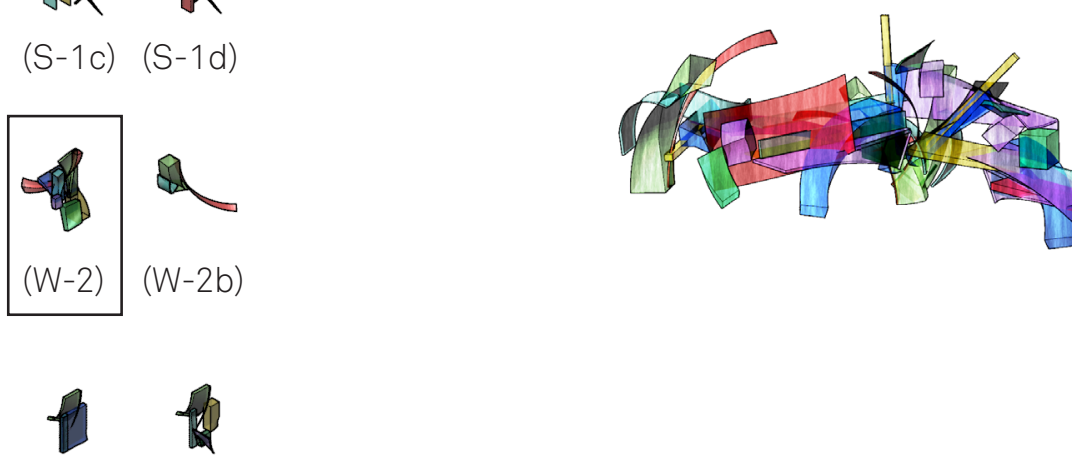

$(W-1 c)(W-1 d)$
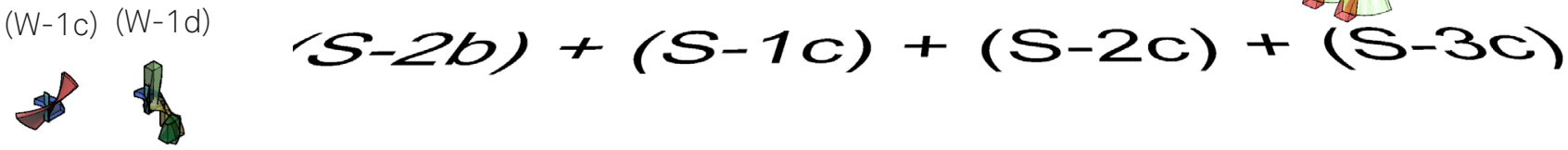

$(W-3 c)(W-3 d)$
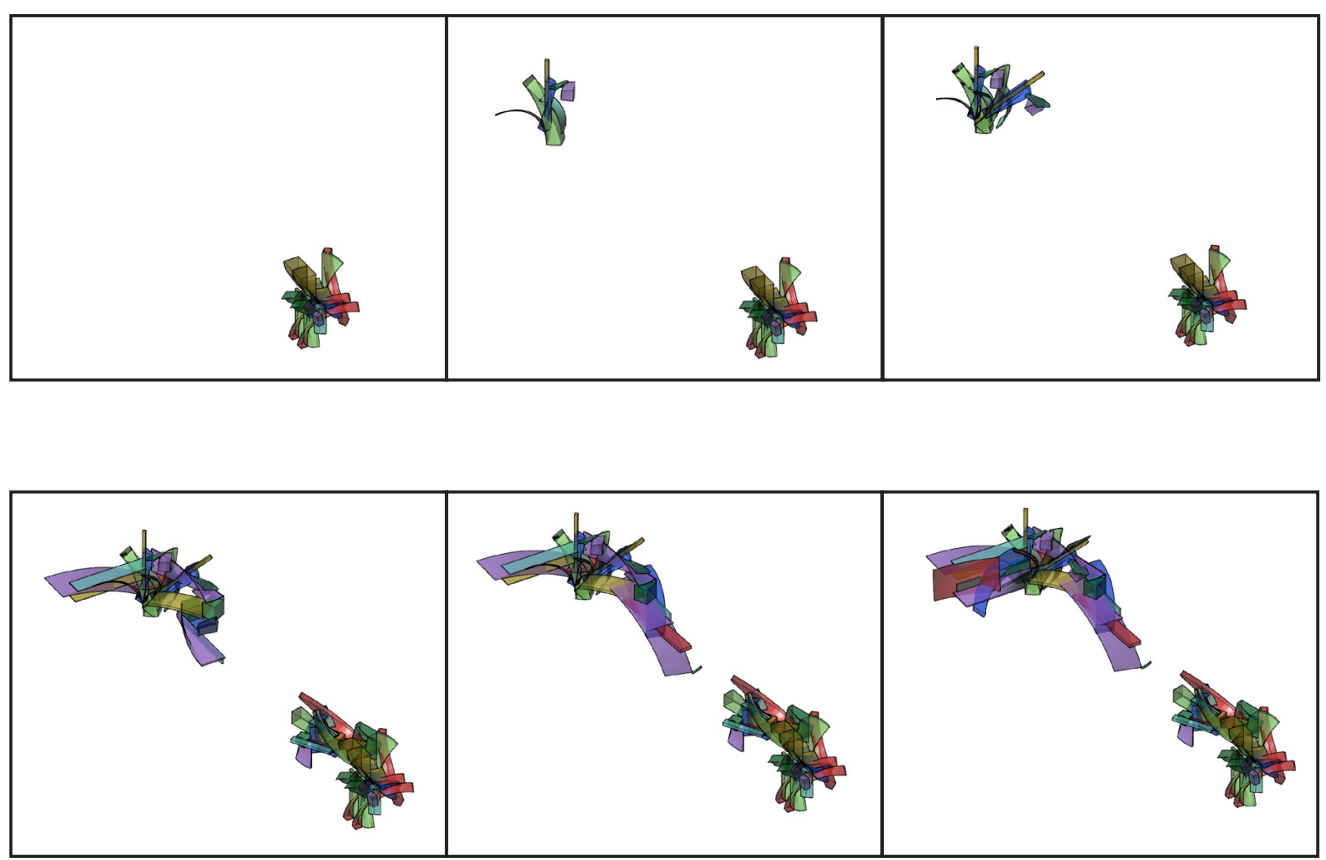

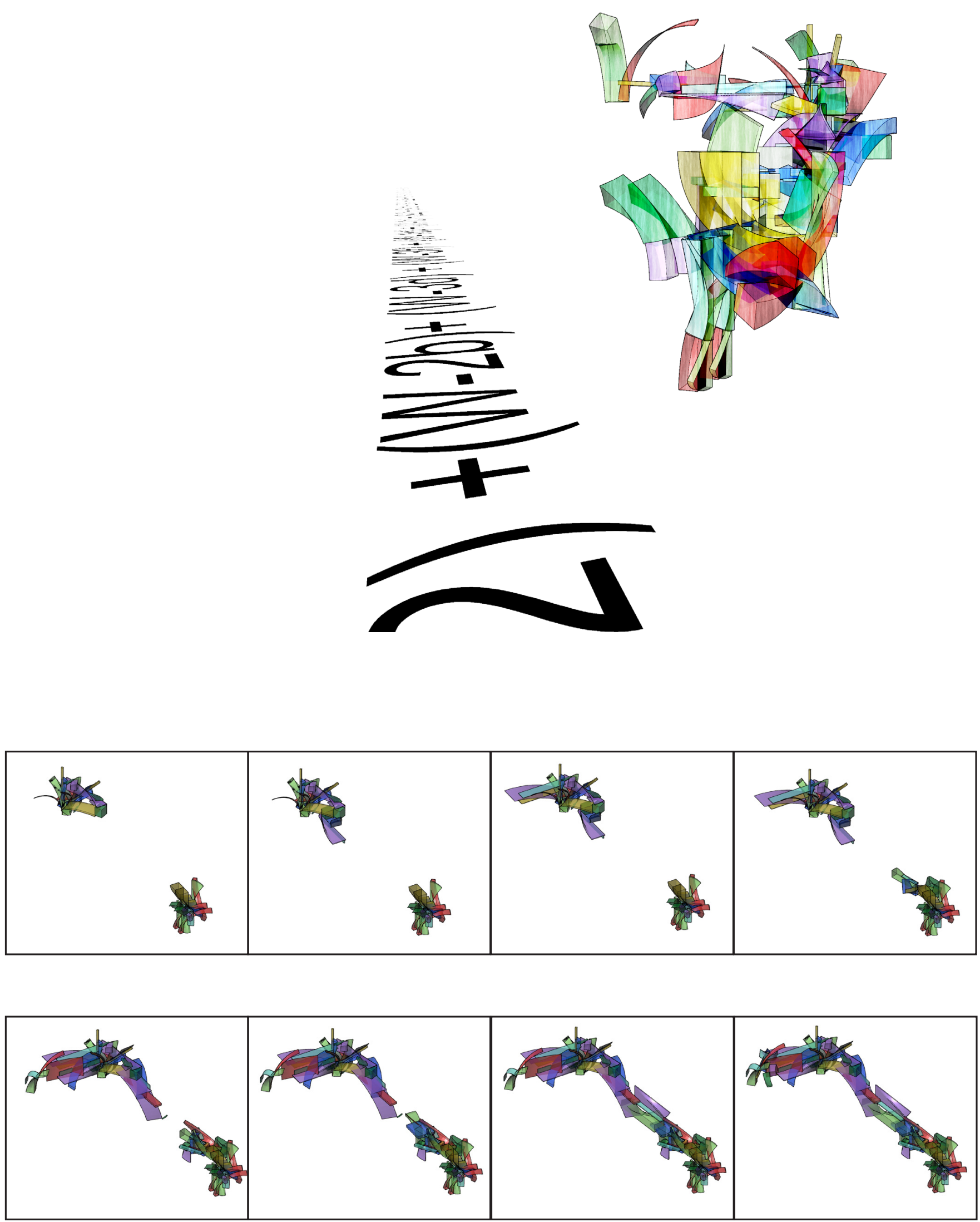

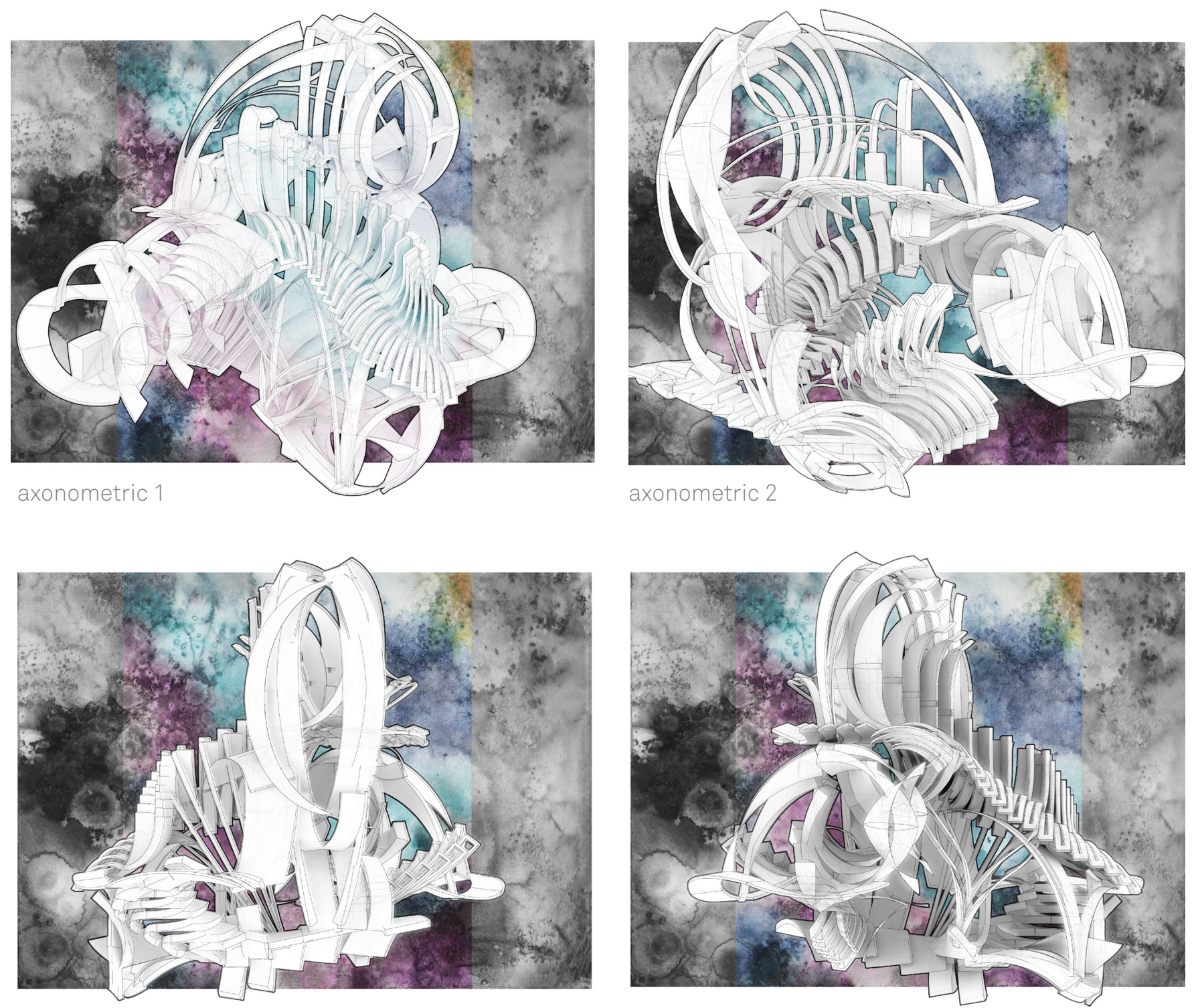

elevation\#1

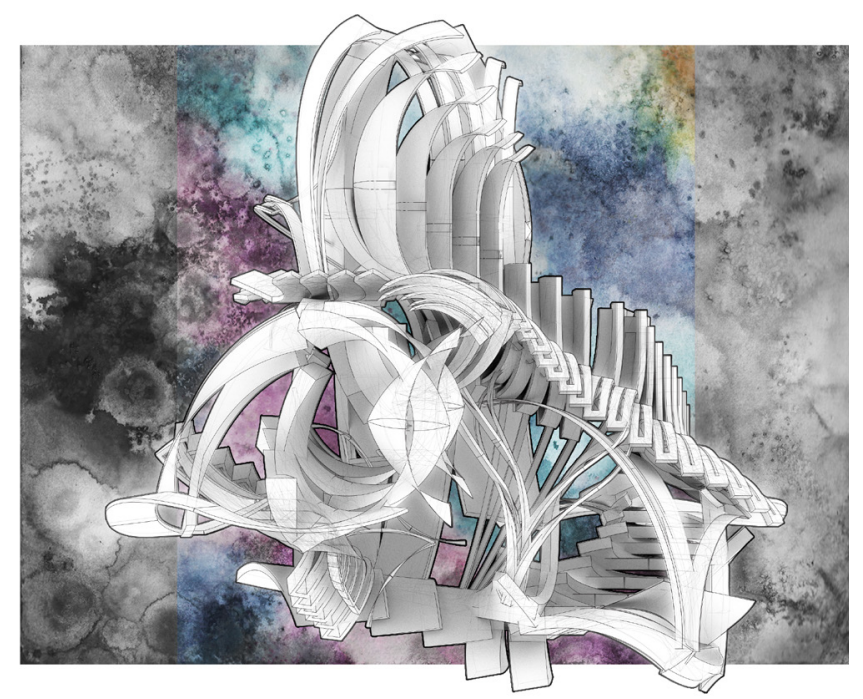

elevation\#2 

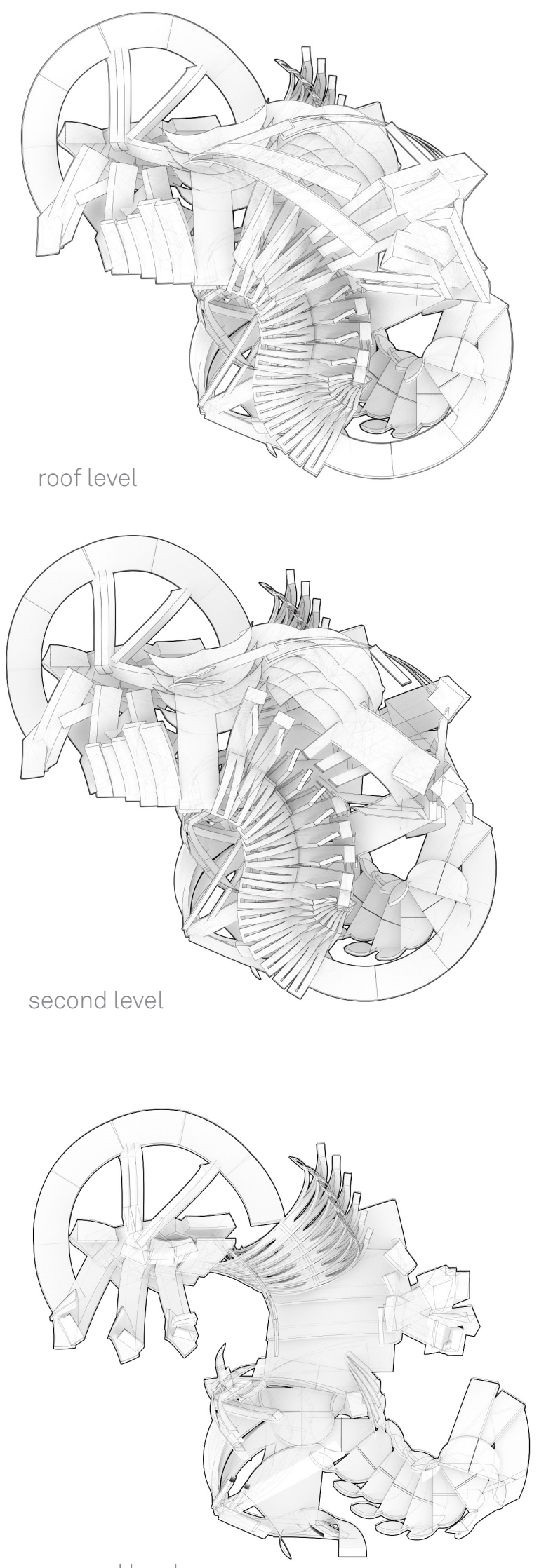

ground level 

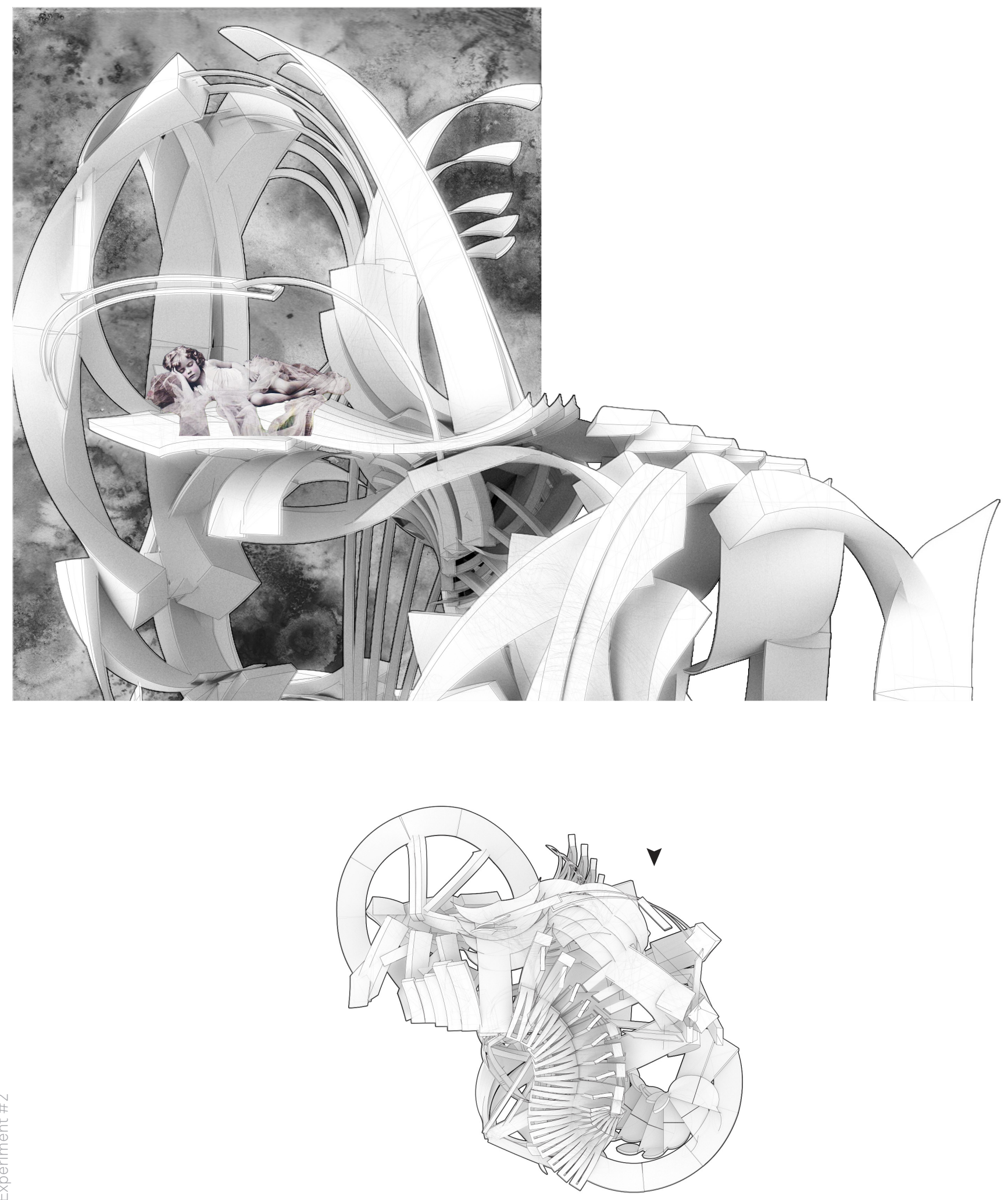

second level 

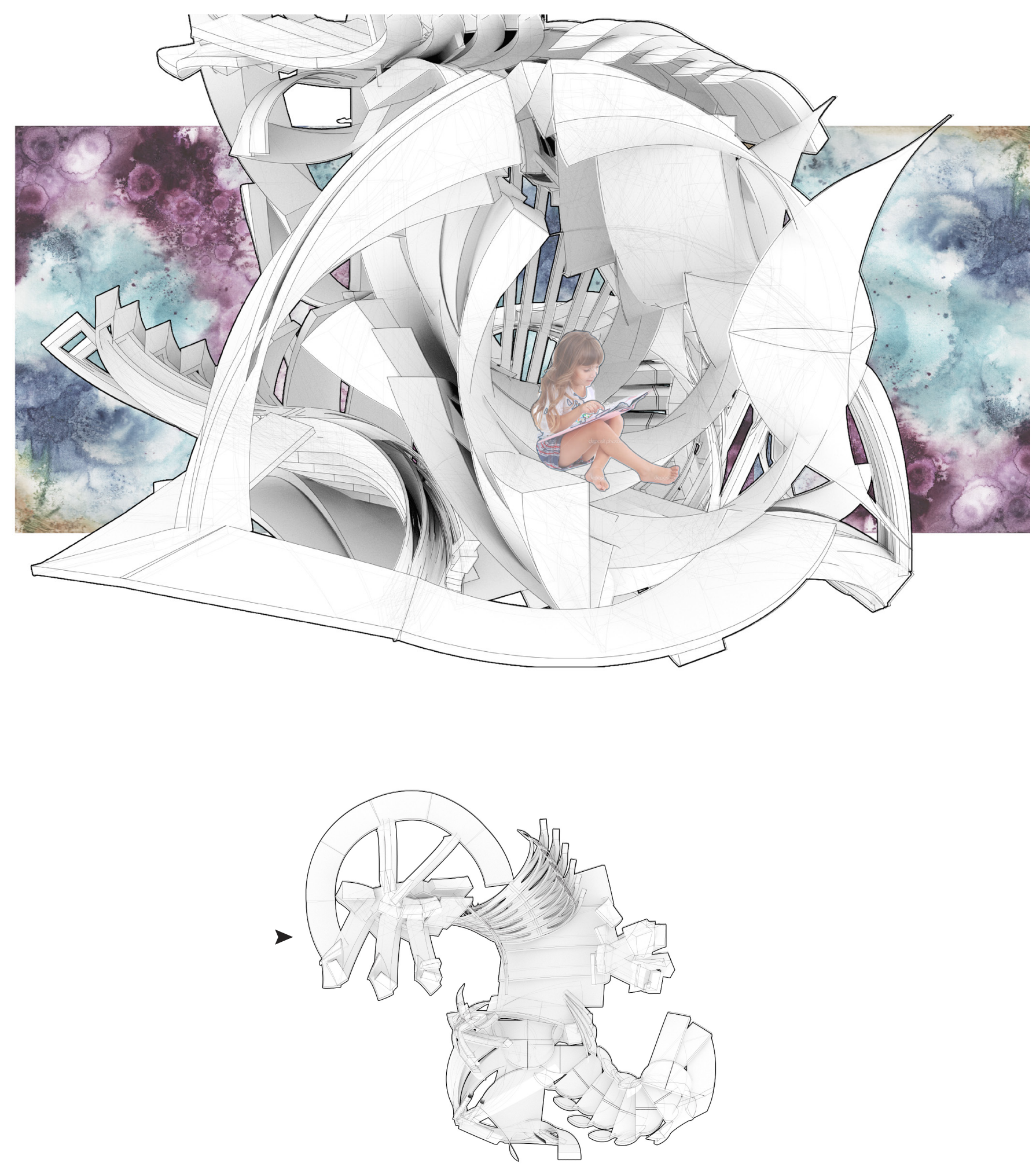

ground level 

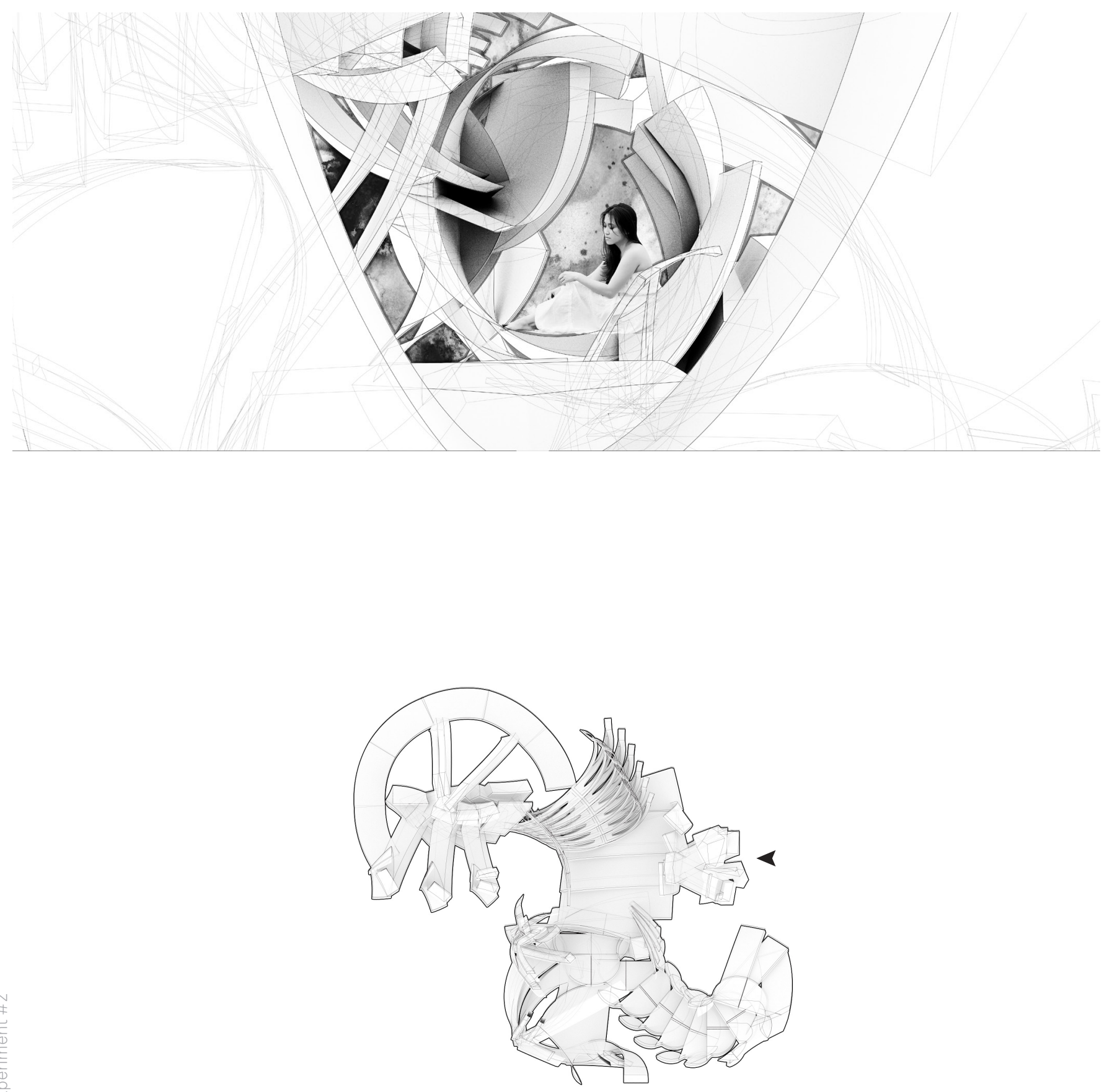

ground level 

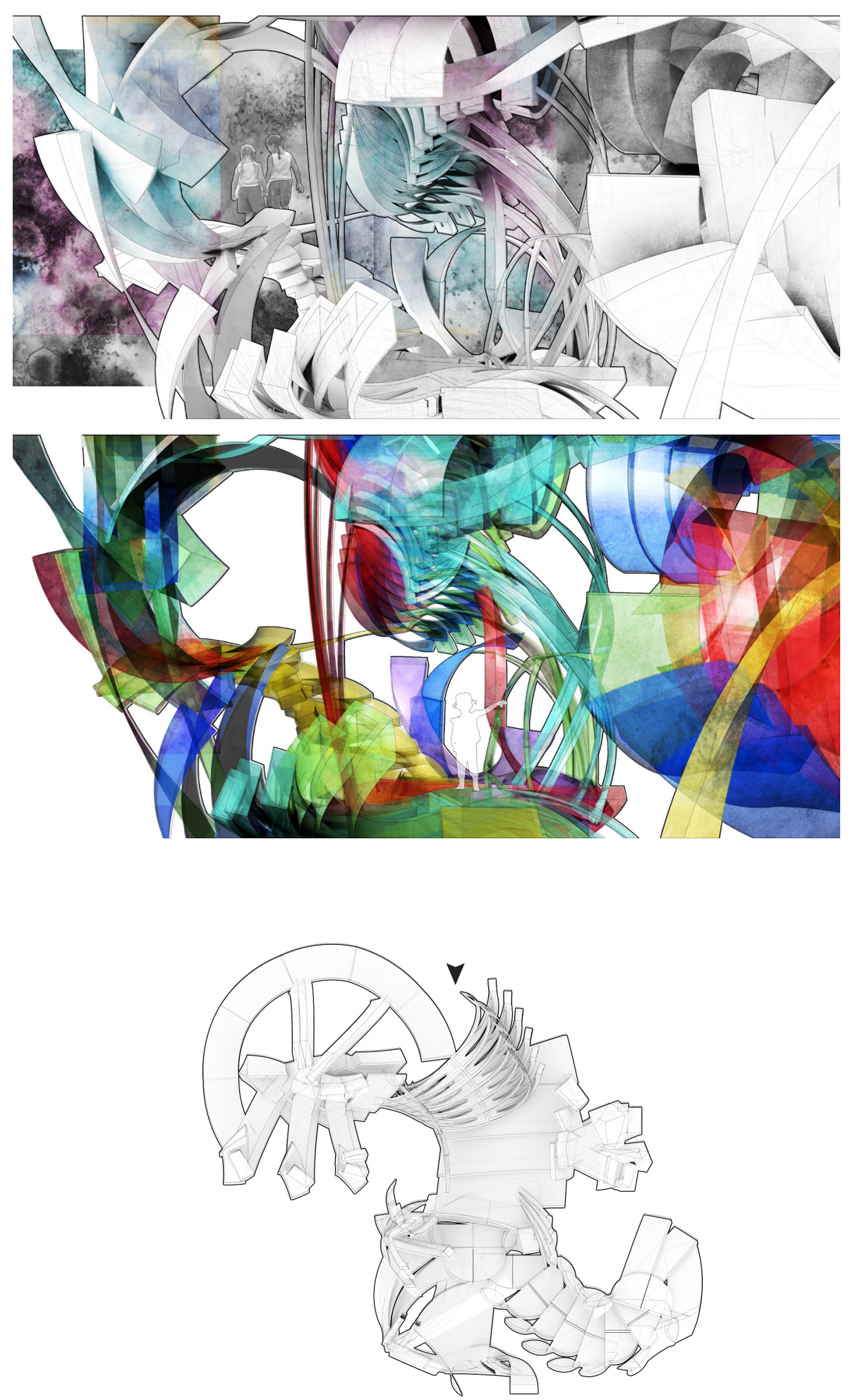

ground level 
Design Experiment \#2 (Prior to the Final Design)
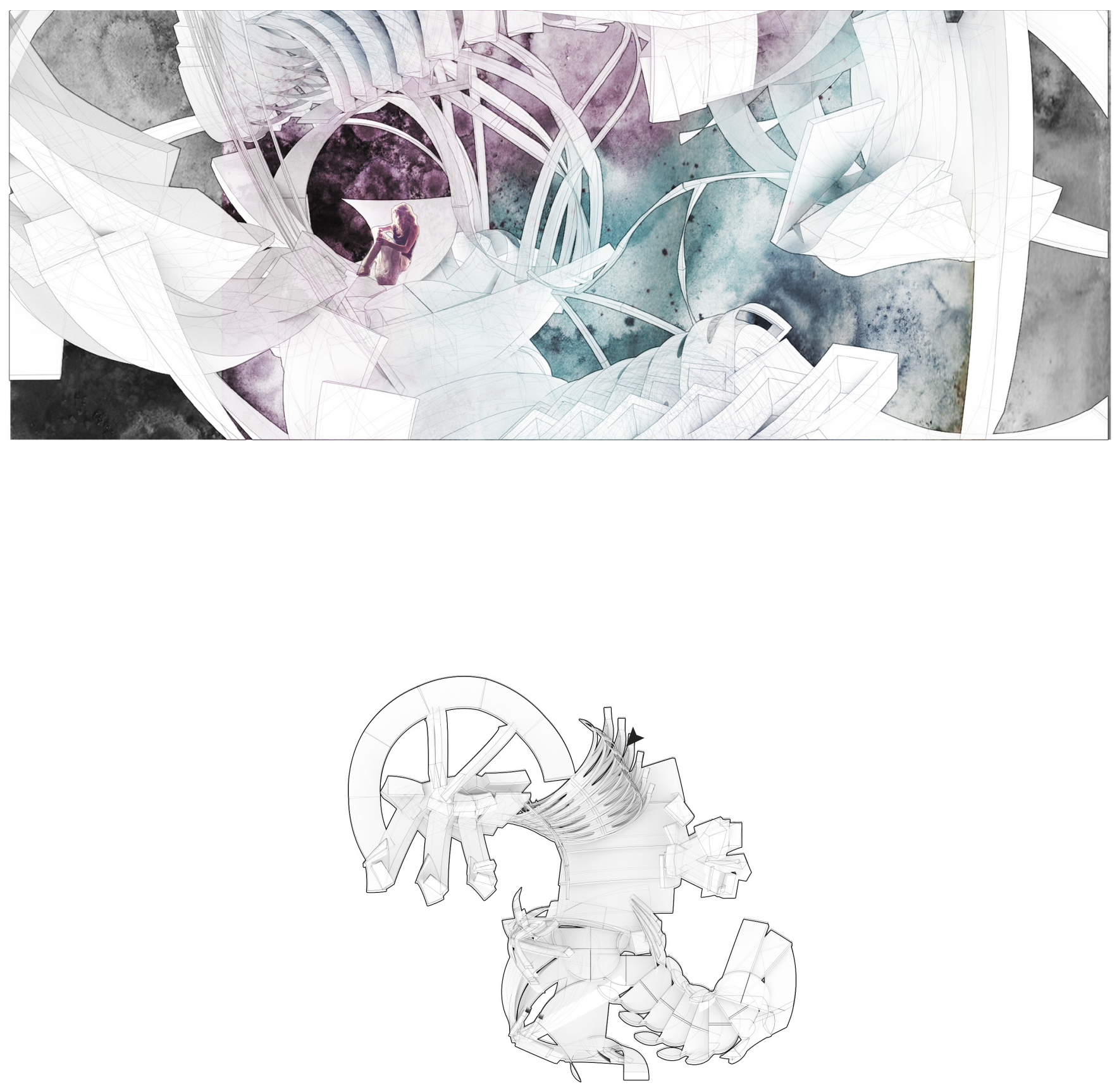

ground level 

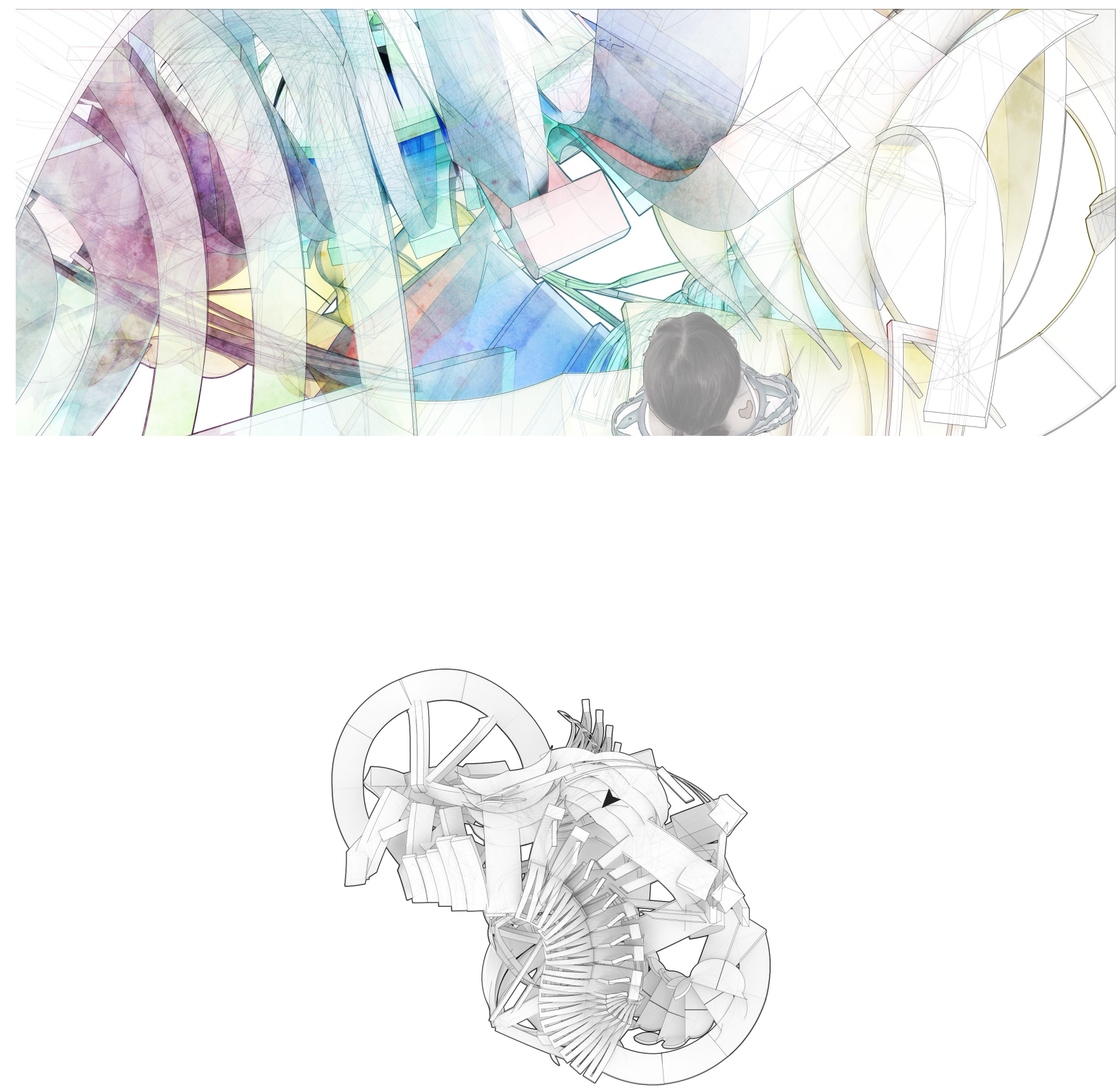

second level 


\section{Appendix E}

Physical Models

Source: Ashley Brooke Biren

a. Choreographing Negative Space

b. Visionary Proposition

c. Final Design 
a

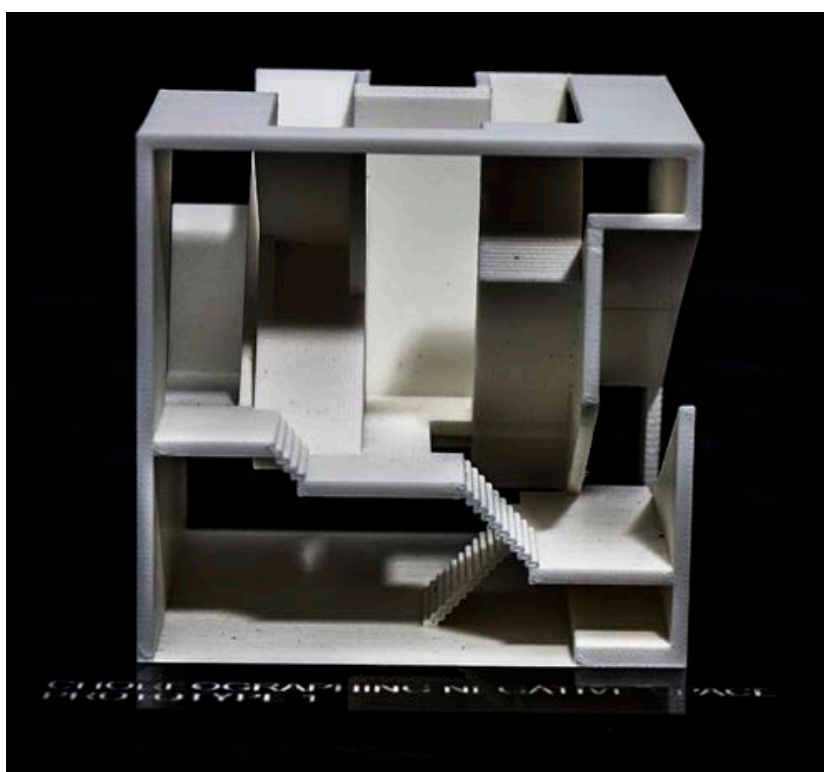

b

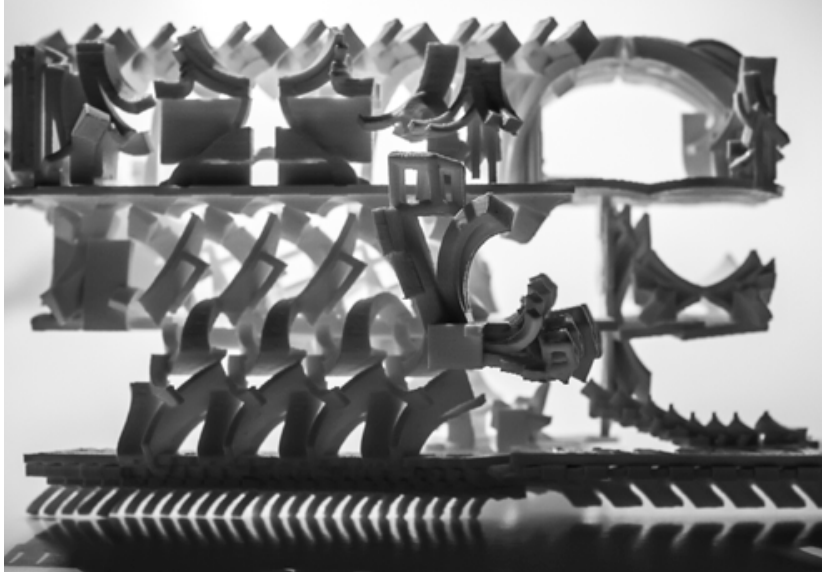

C

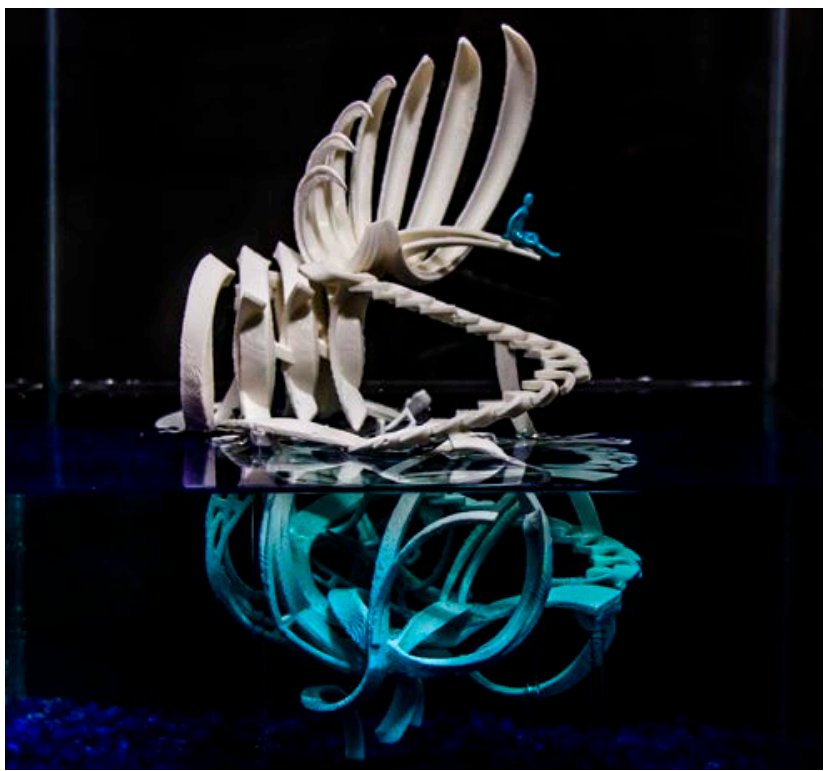


Choreographing Negative Space - Prototype 1

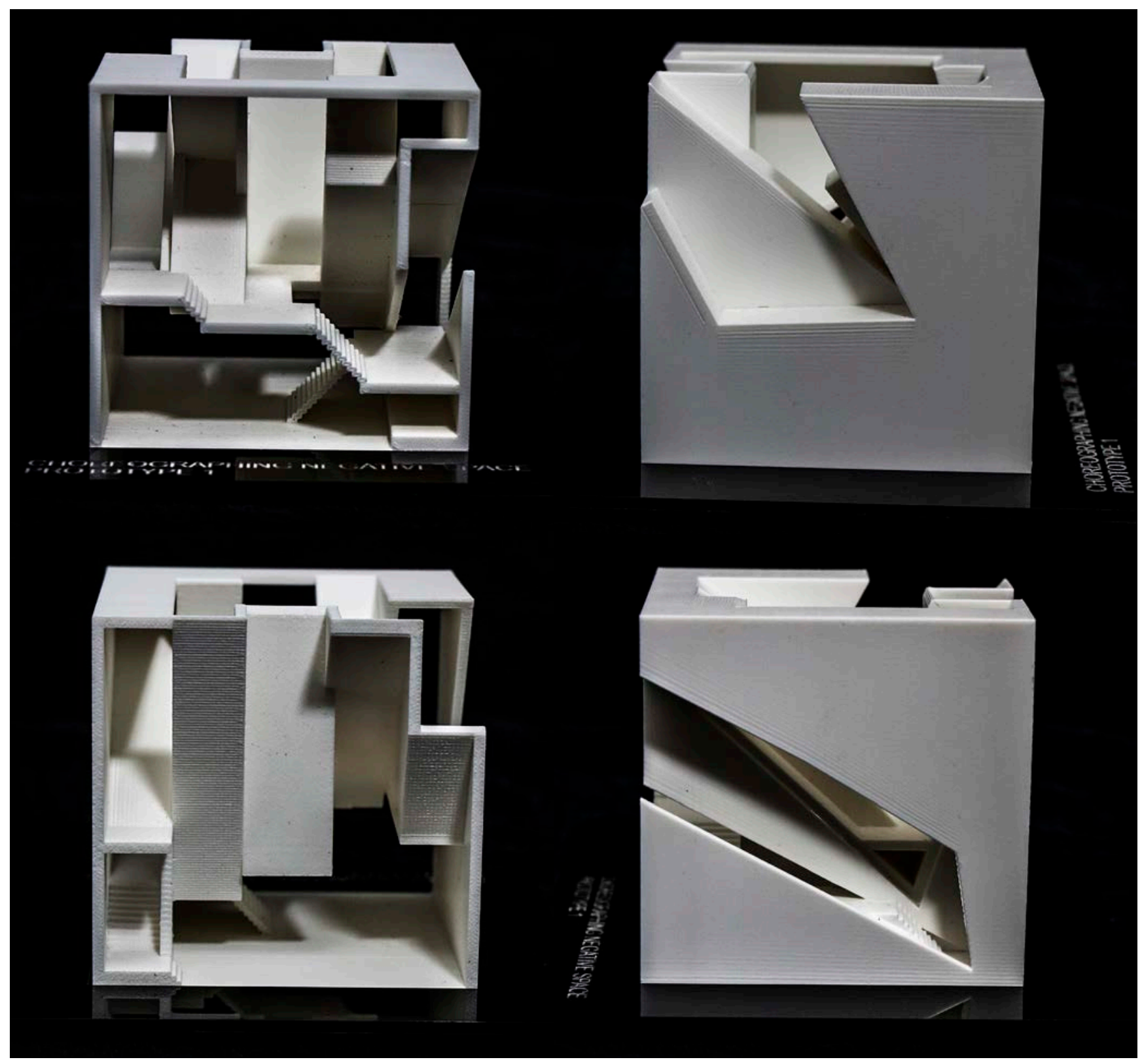


Choreographing Negative Space - Prototype 2

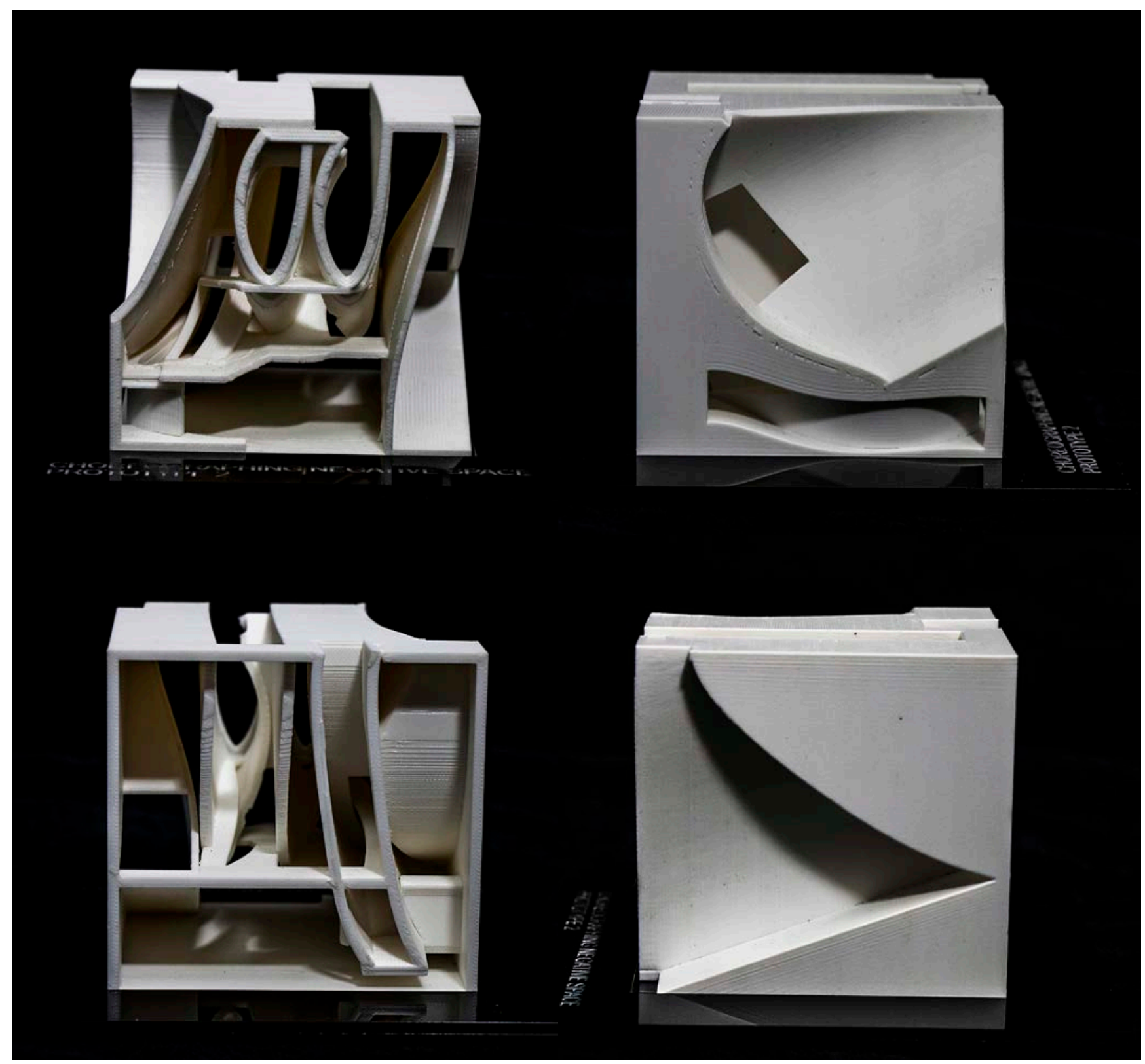




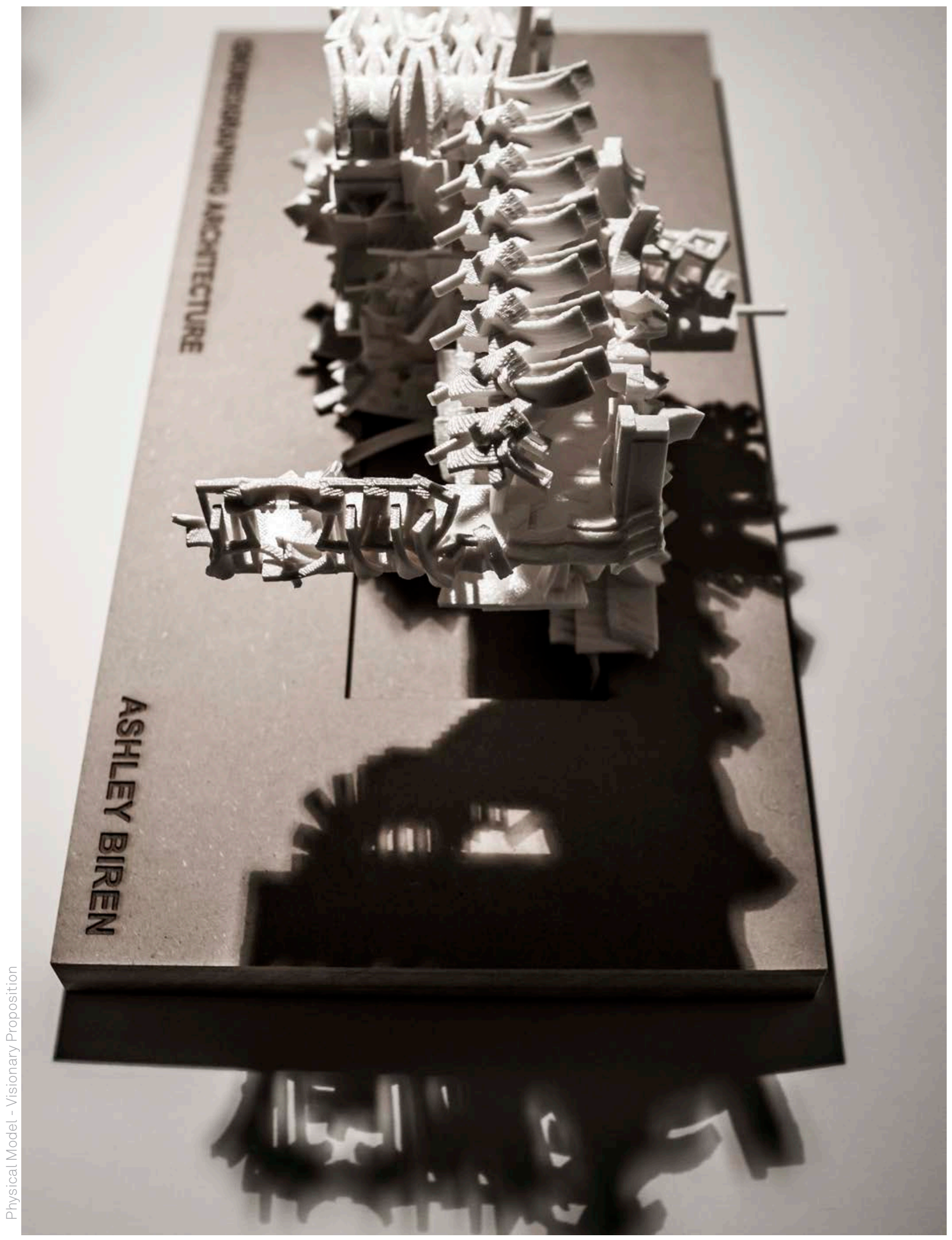



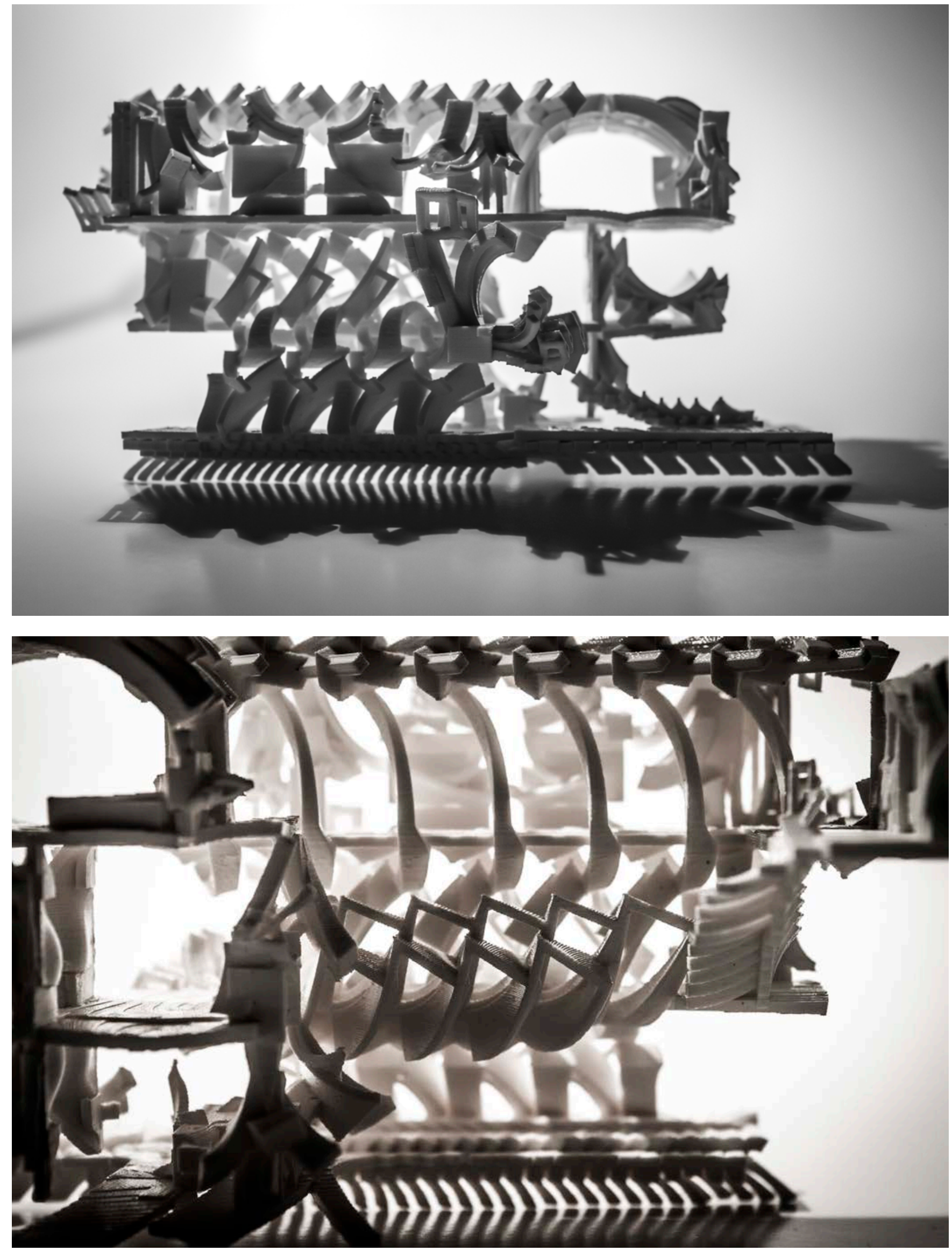
Kinesthetic Components - Physical Model
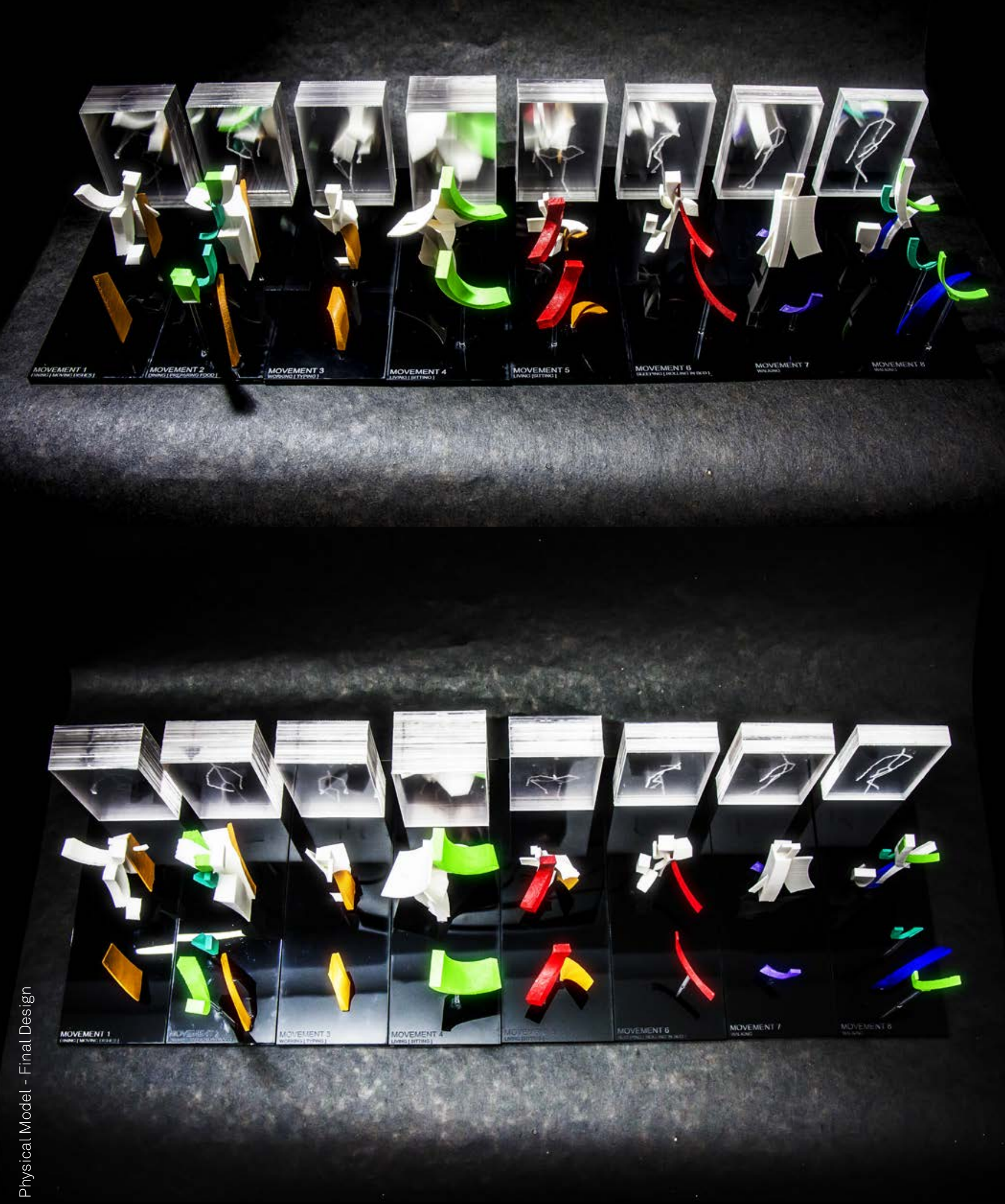

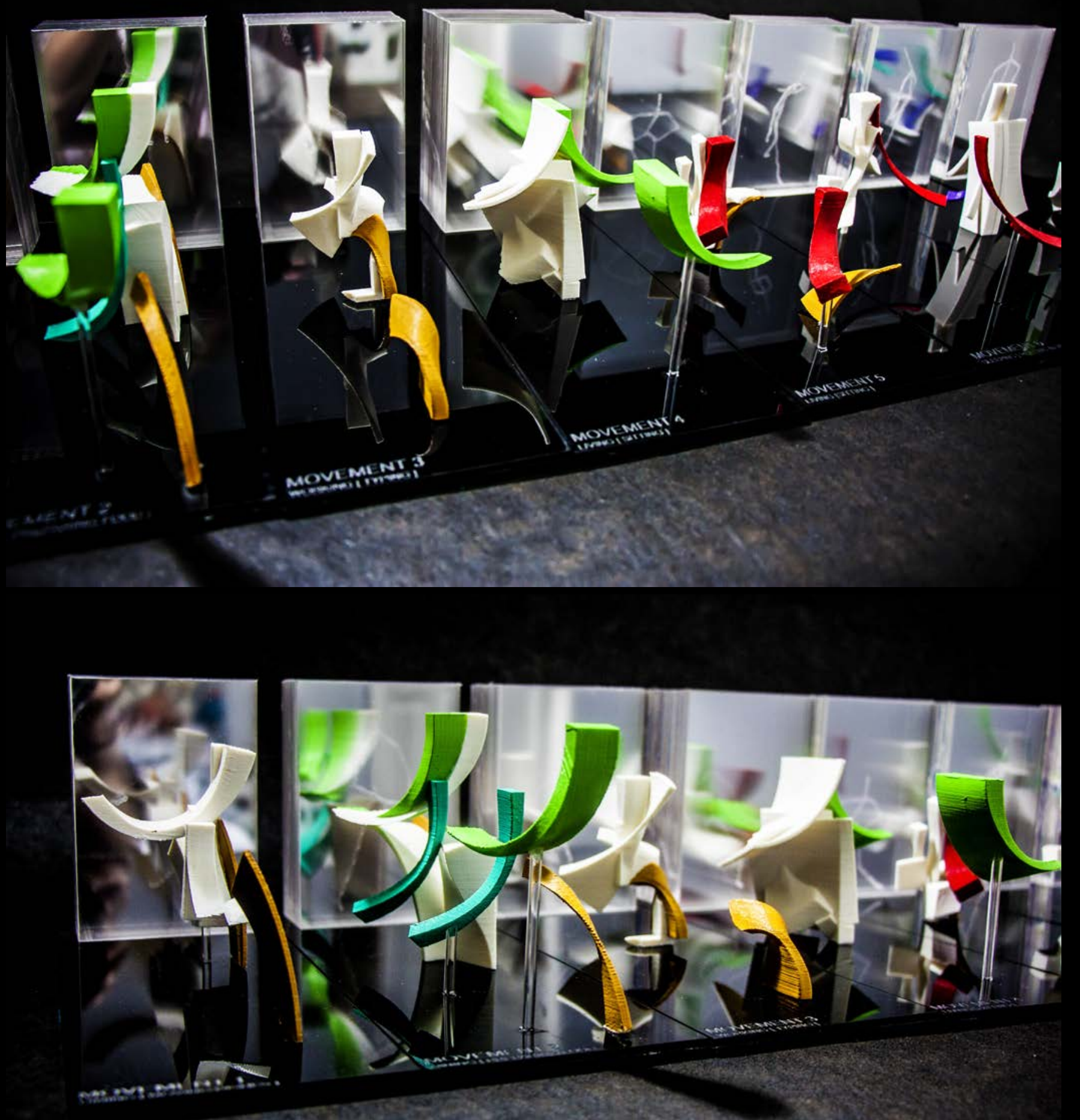
Kinesthetic Components - Physical Model
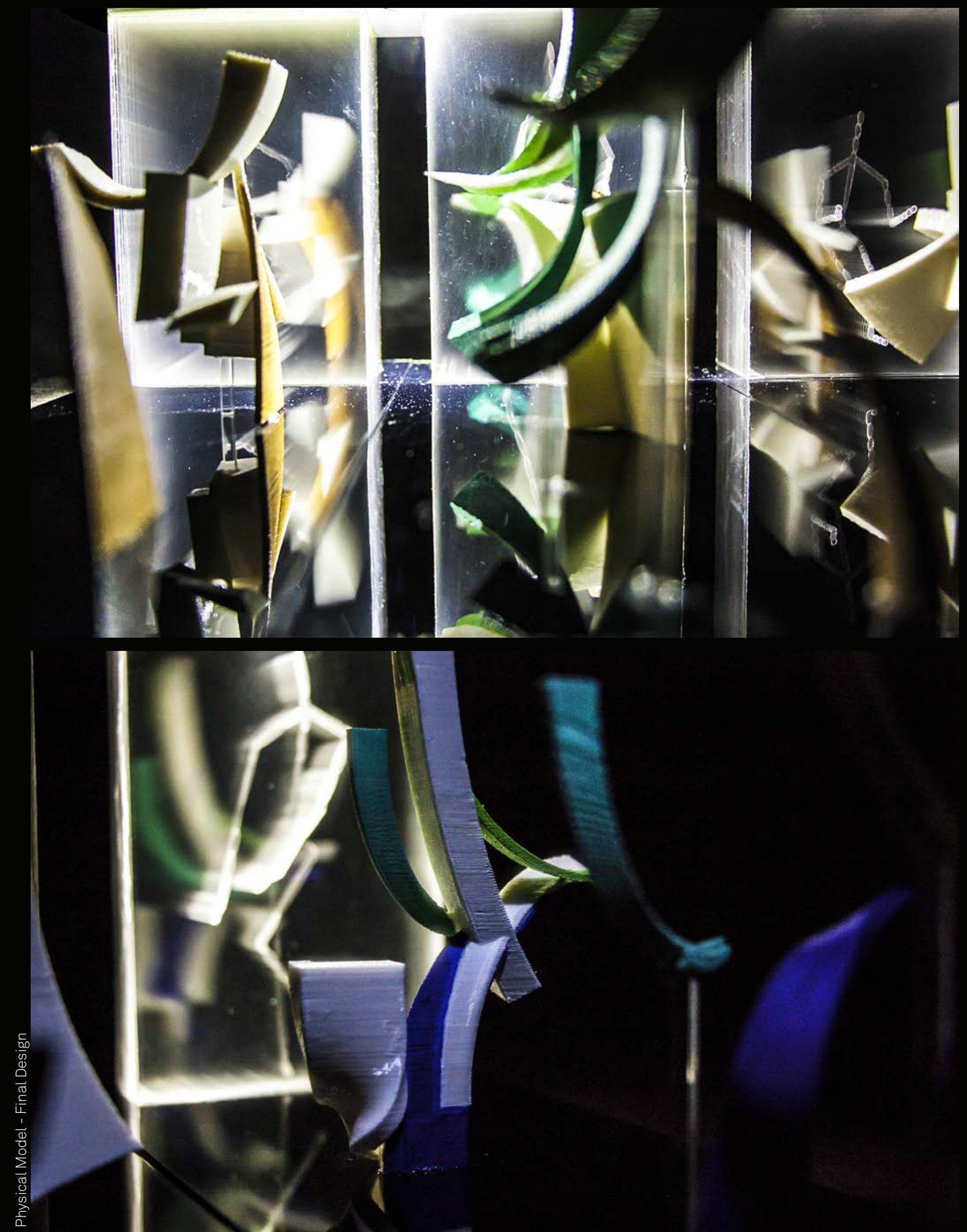


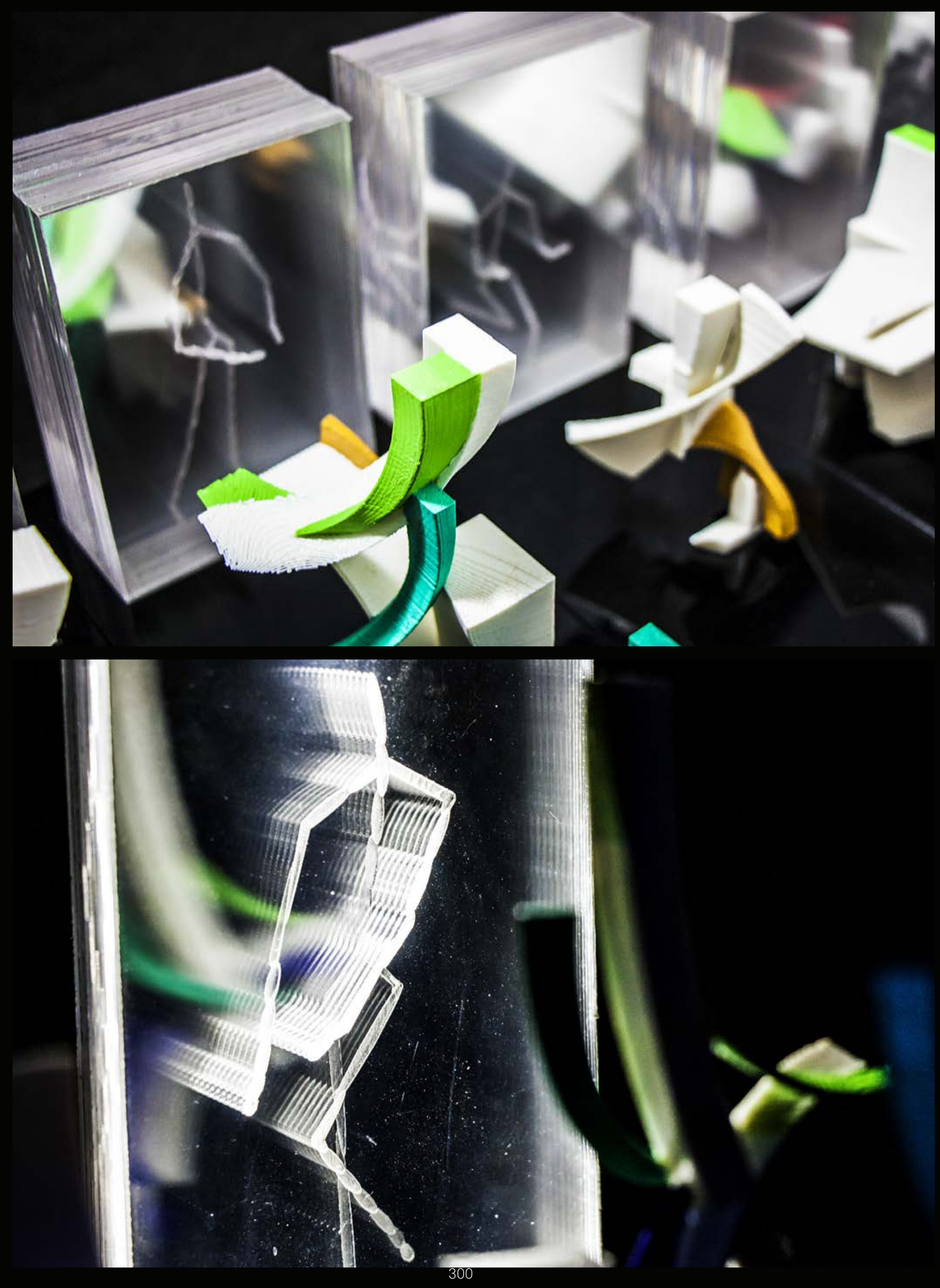


Movement \#1

"Dining [Moving Dishes]"

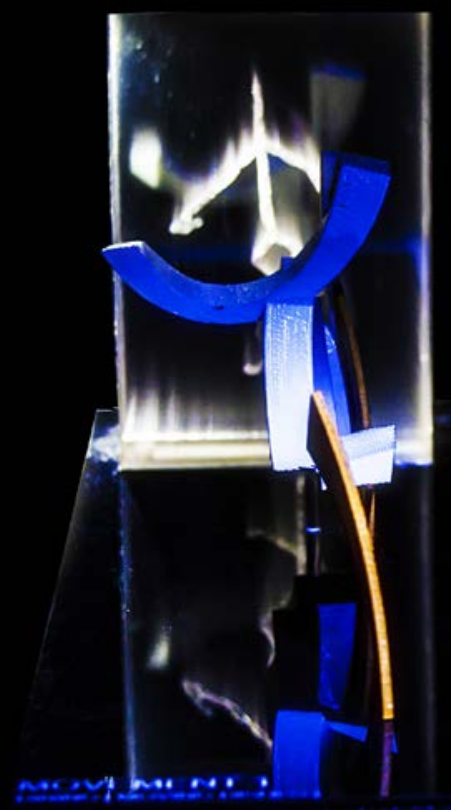

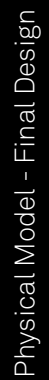



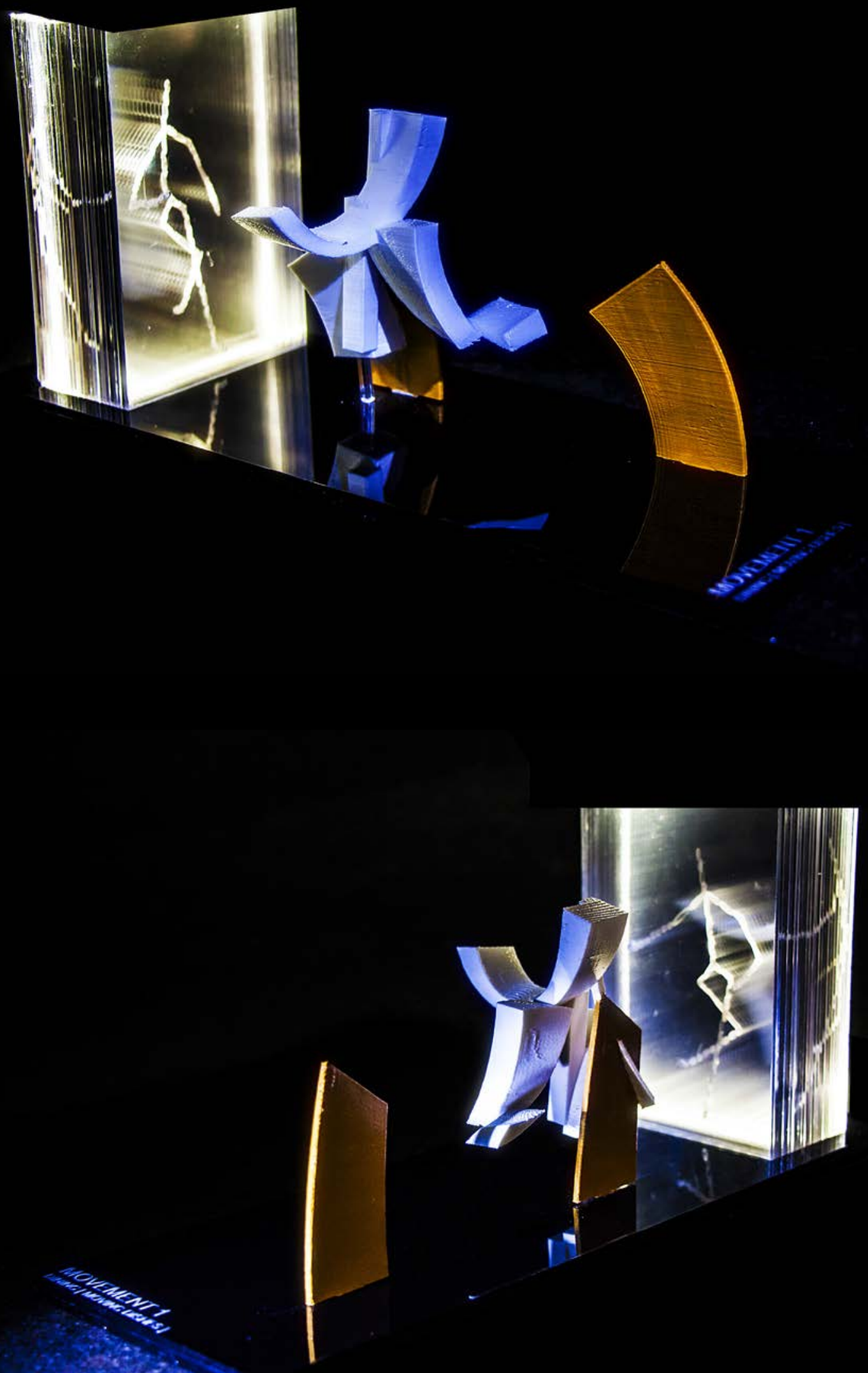
Movement \#2

"Dining [Preparing Food]"

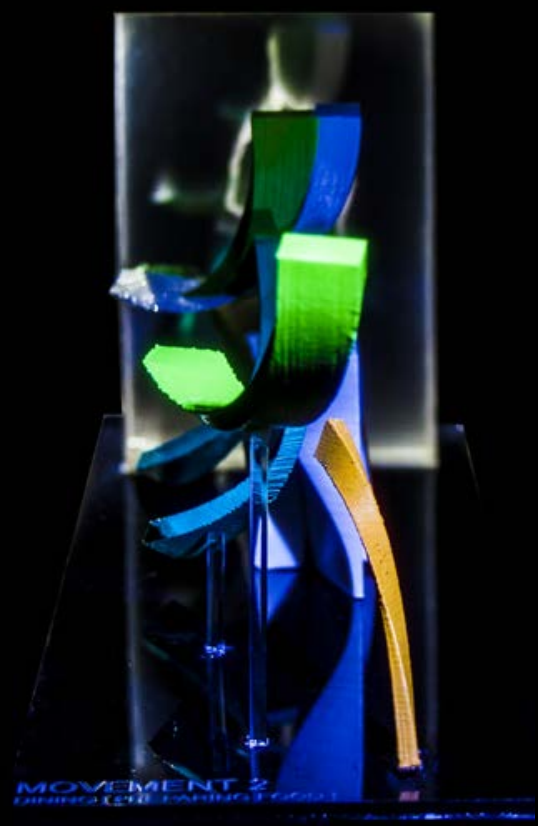

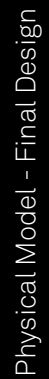



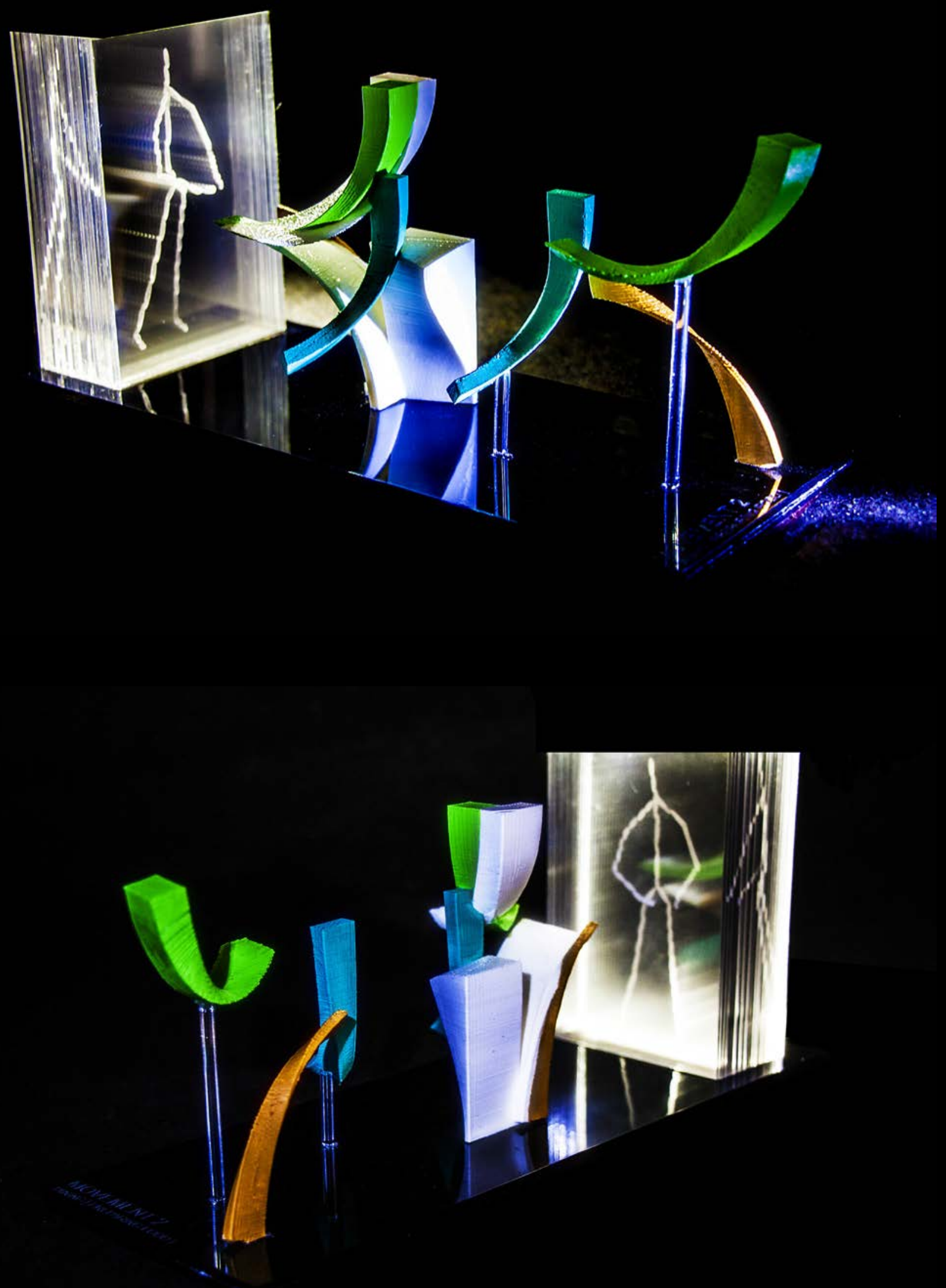


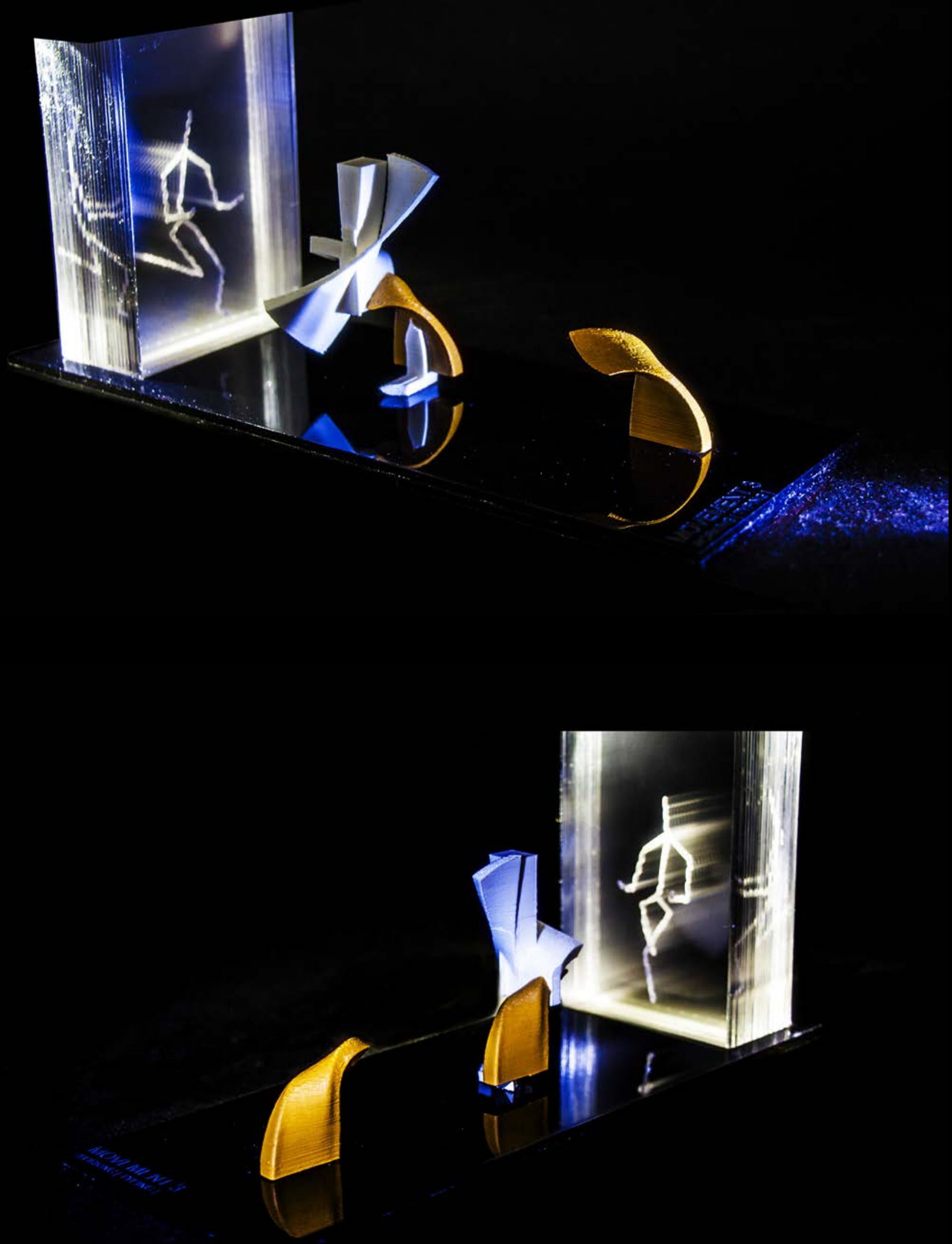
Movement \#4

"Living [Sitting]"

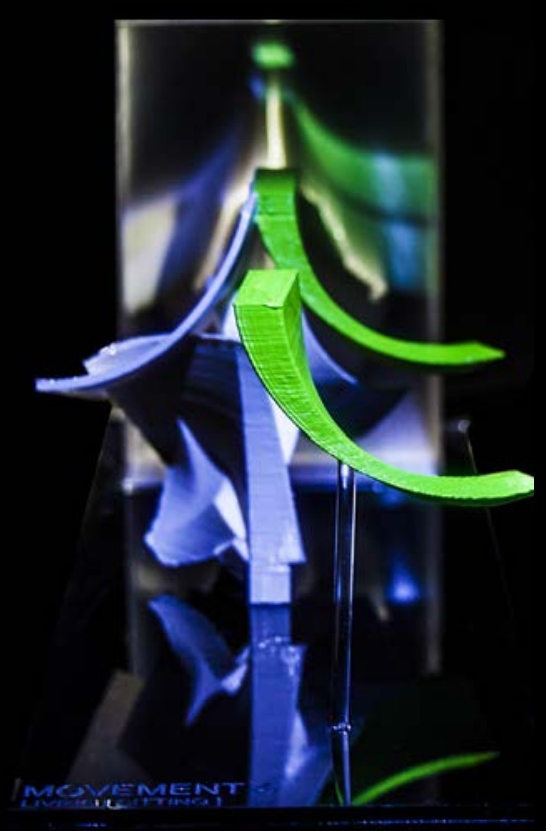

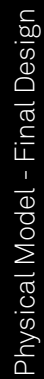



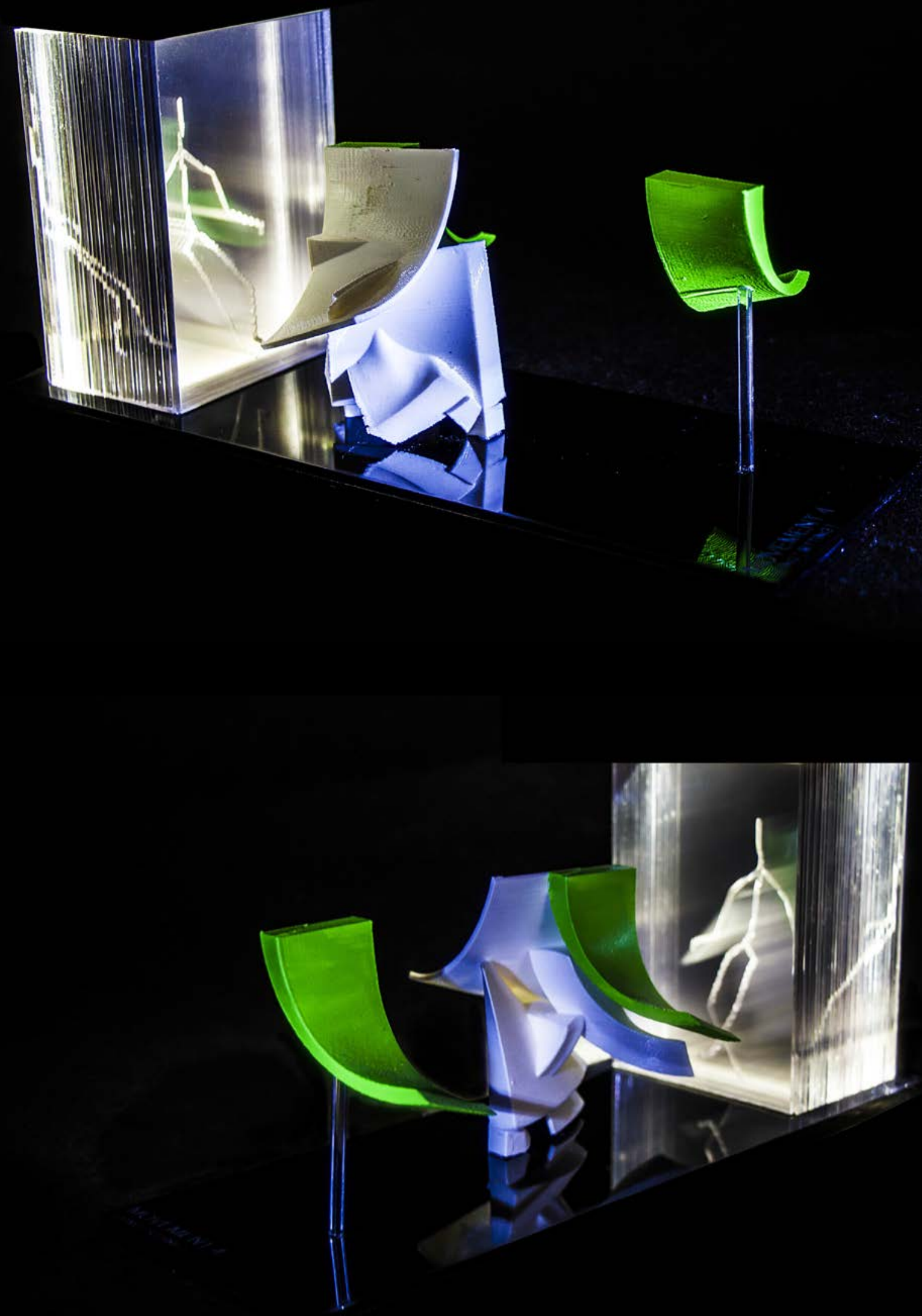
Movement \#5

"Living [Sitting]"

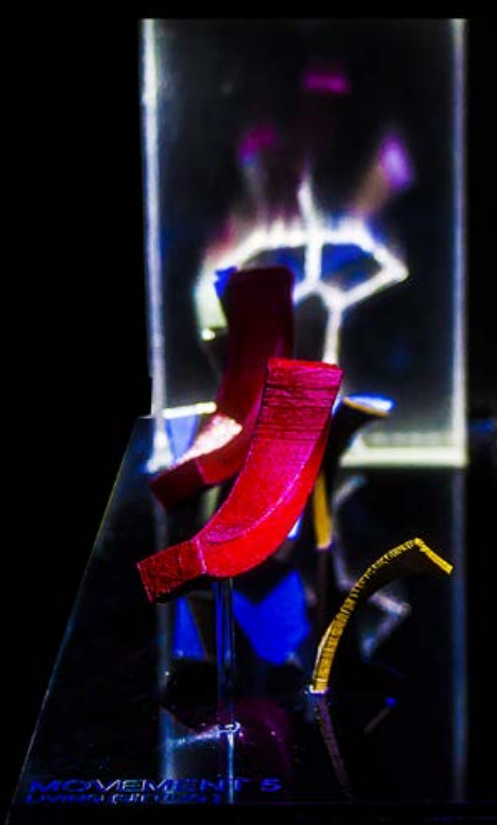

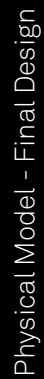



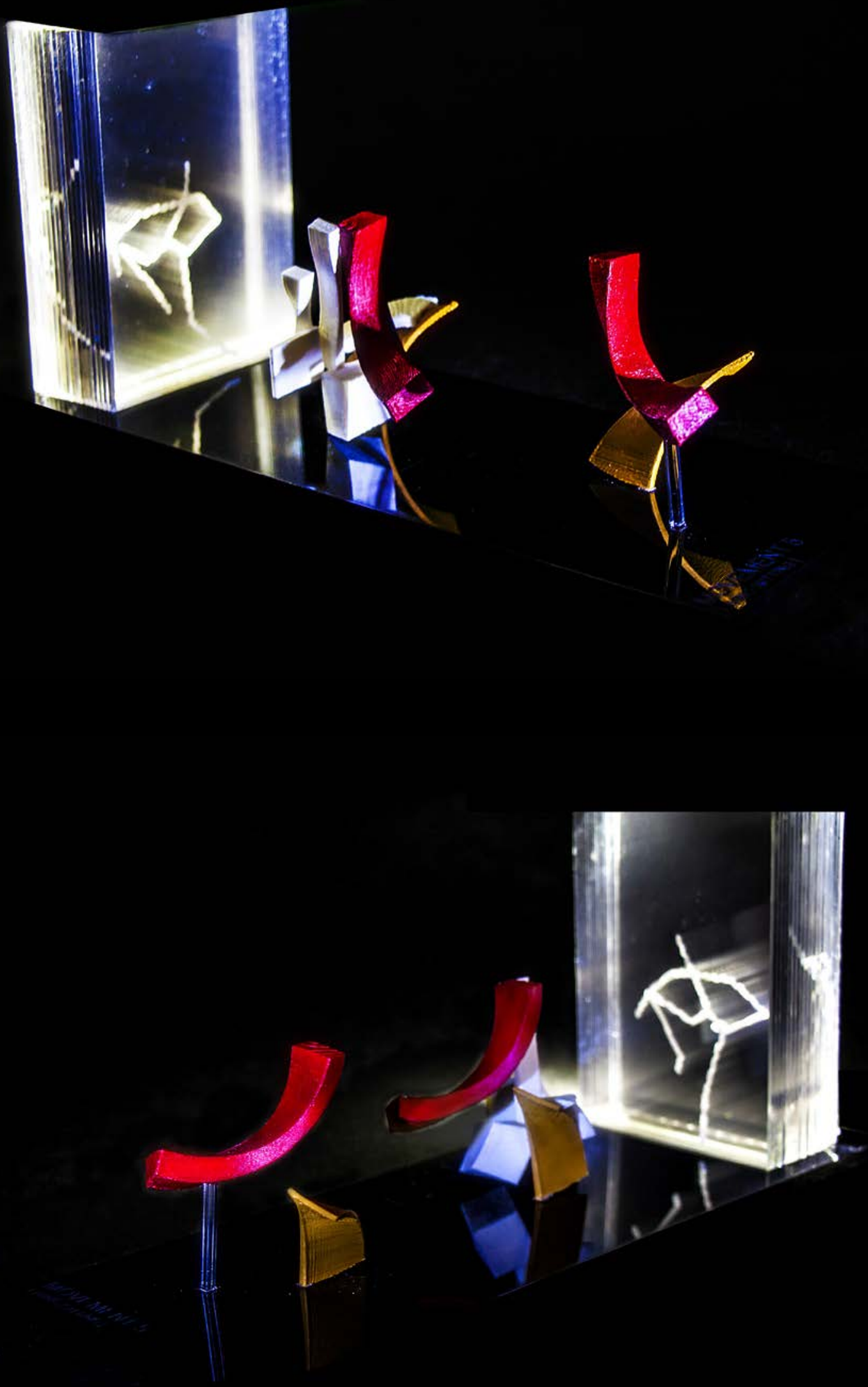
Movement \#6

"Sleeping [Rolling in Bed]"

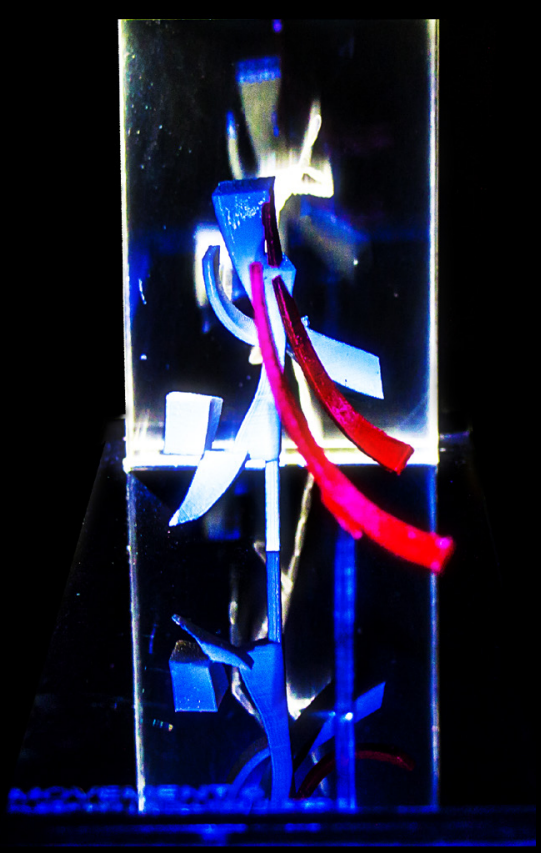

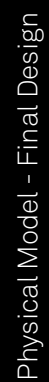



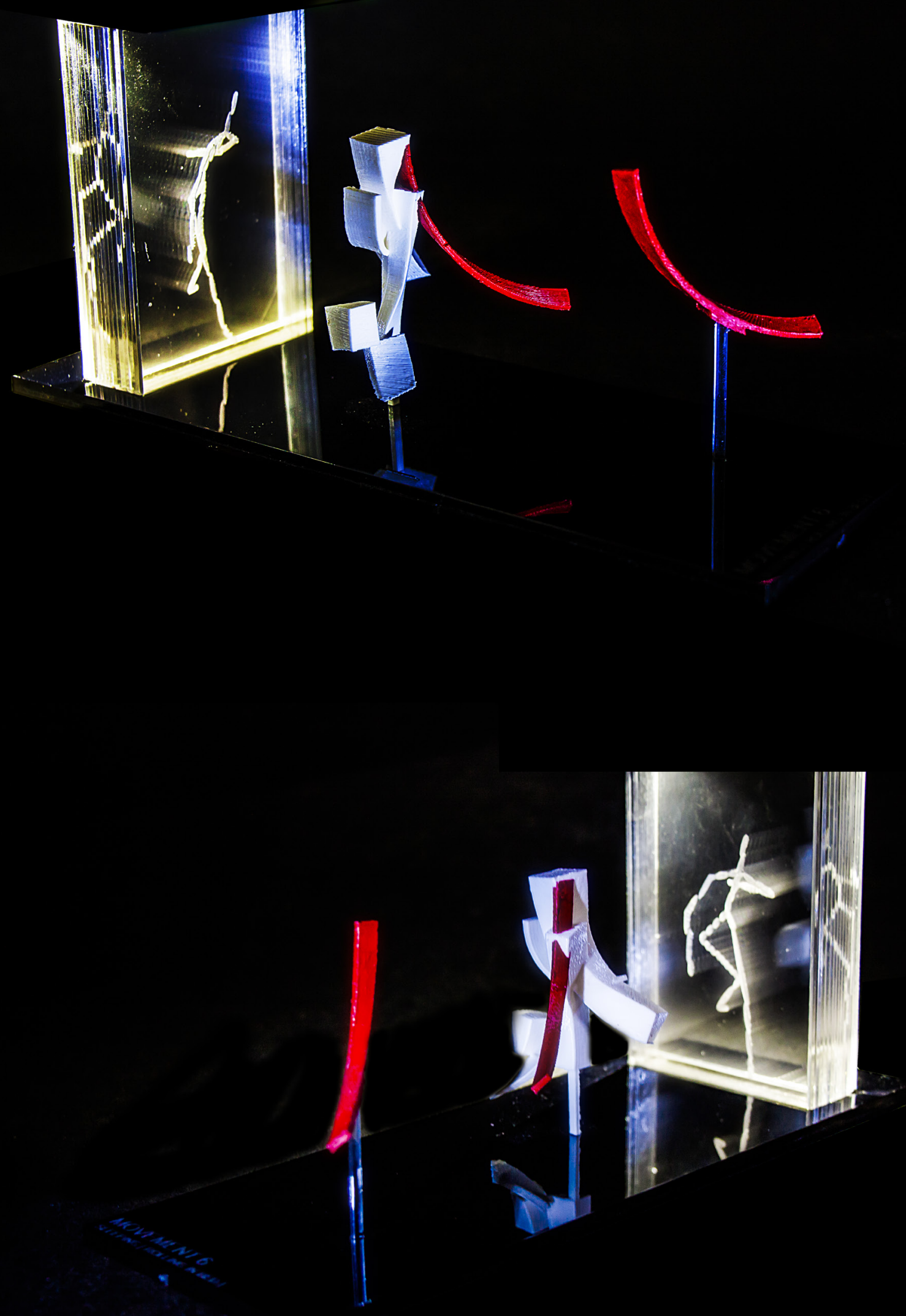
Movement \#7

"Walking"

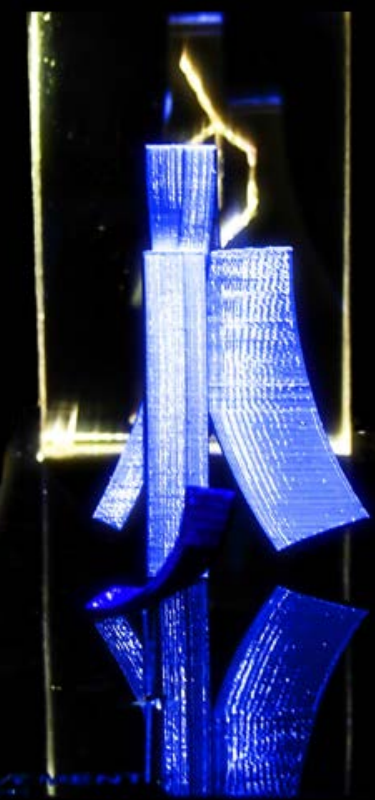

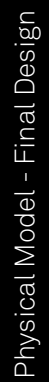



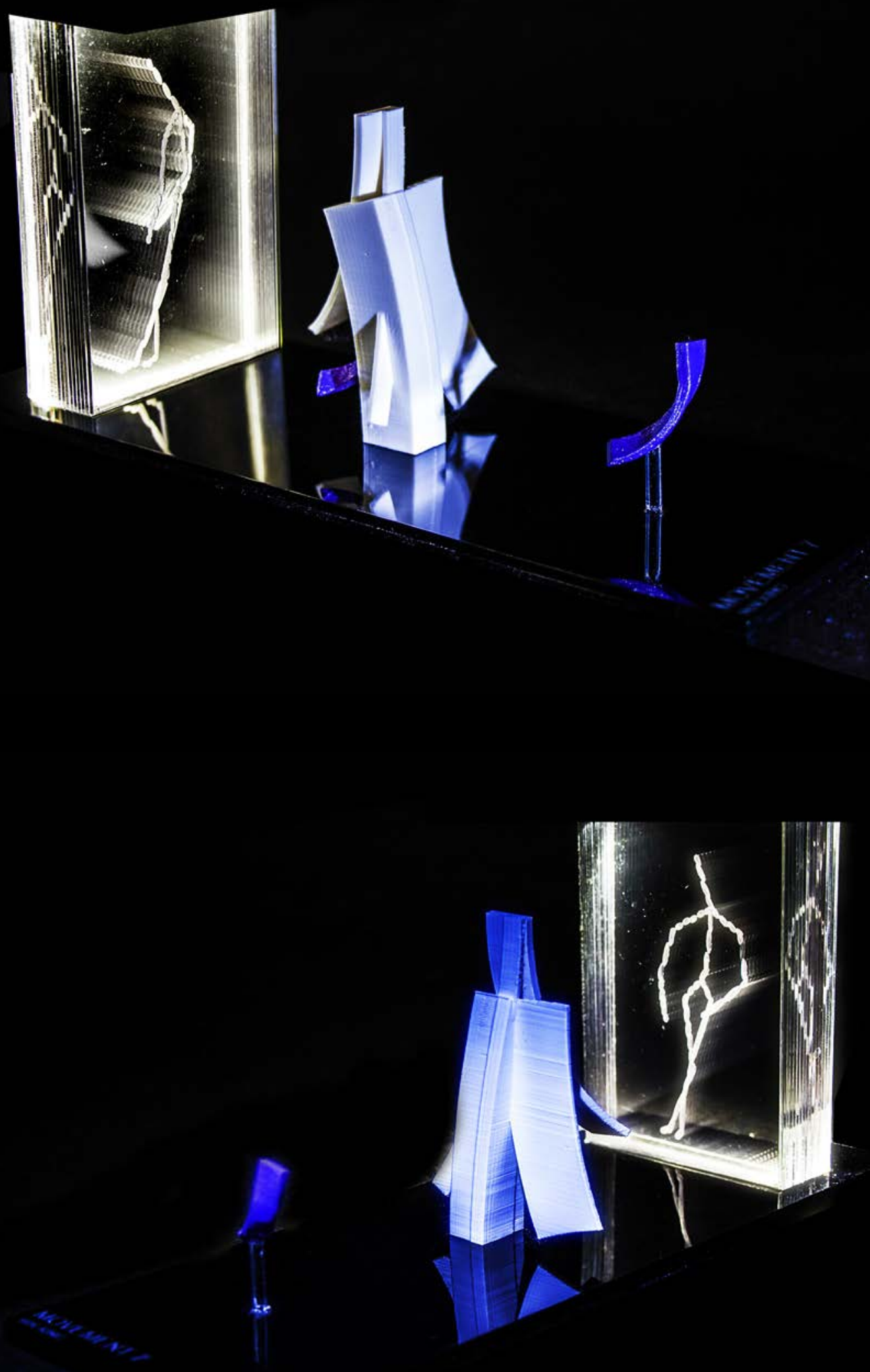
Movement \#8

"Walking"

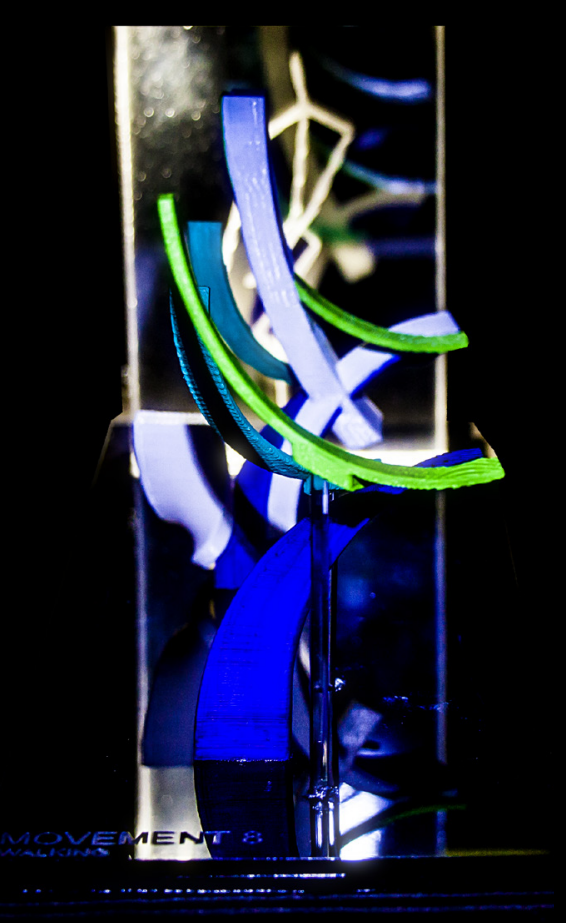

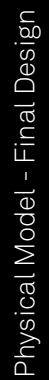




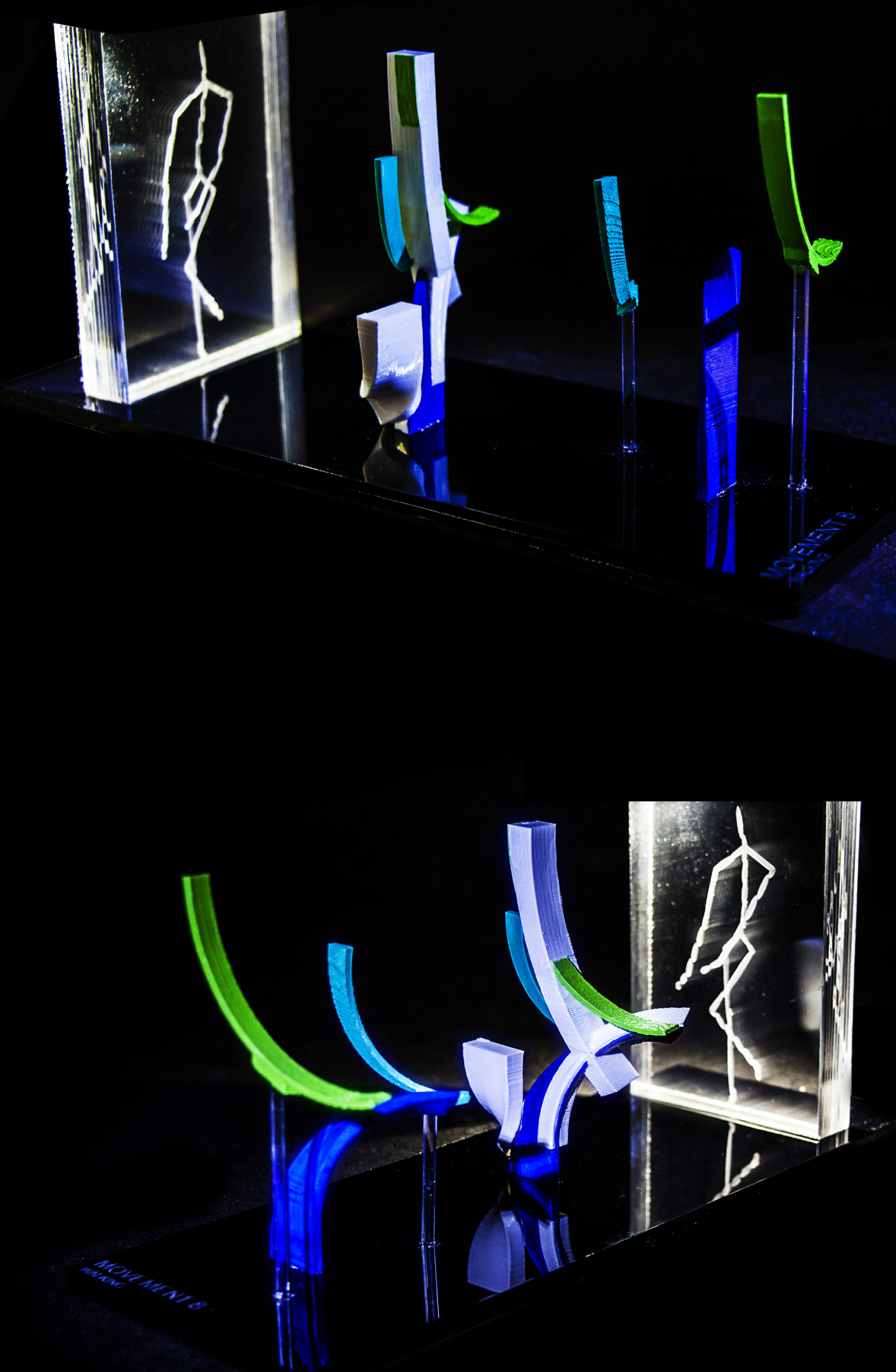




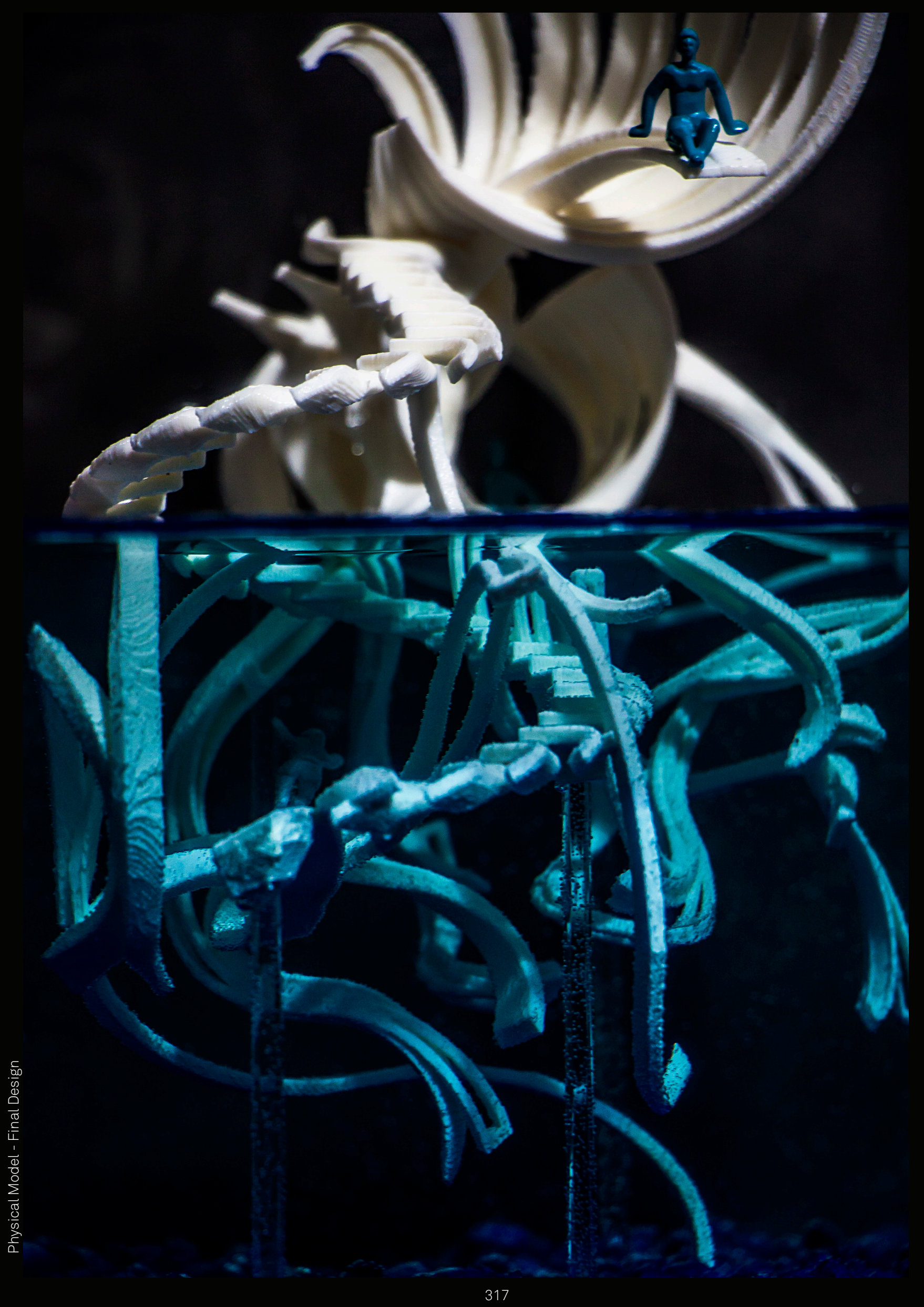




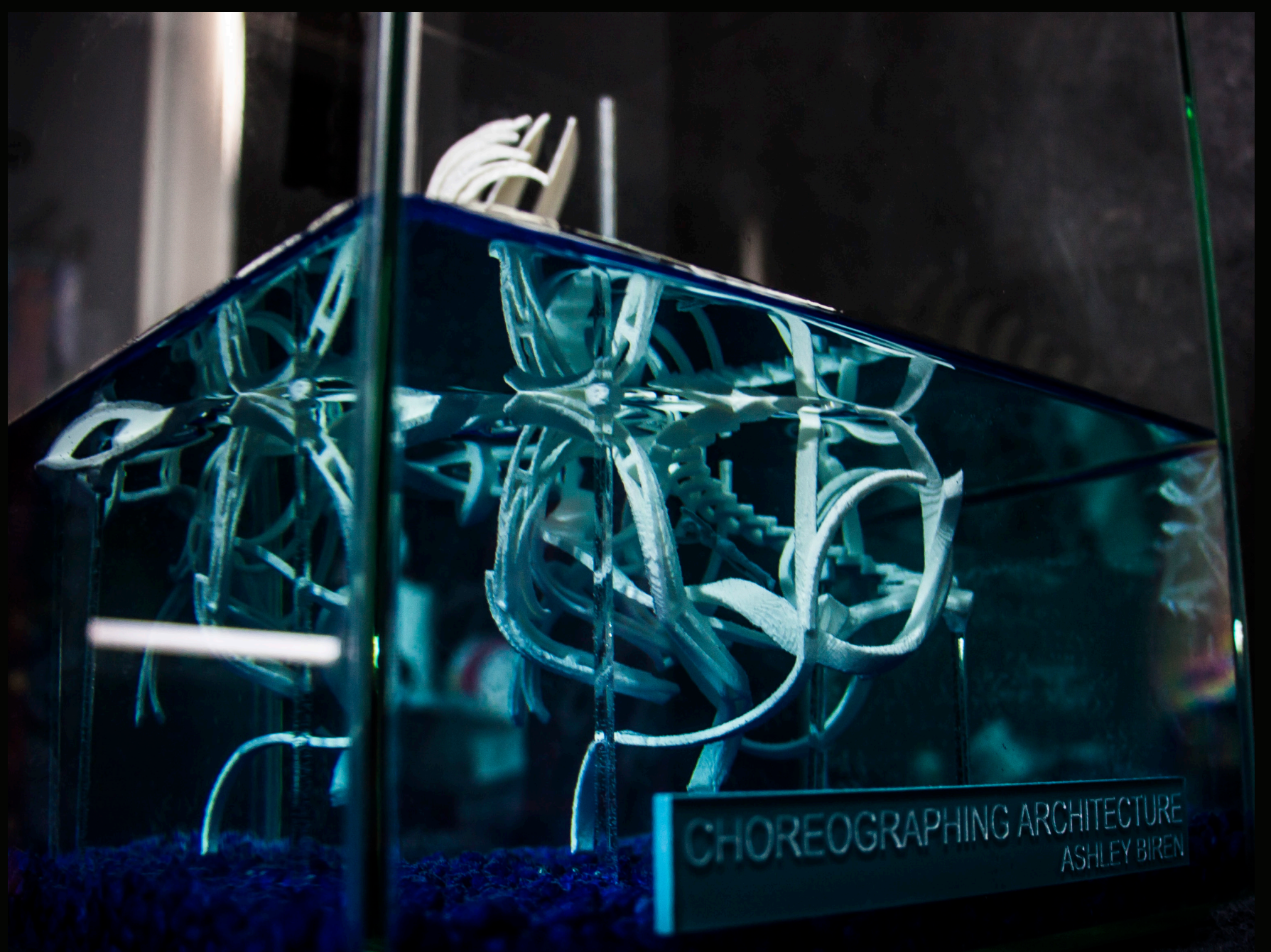




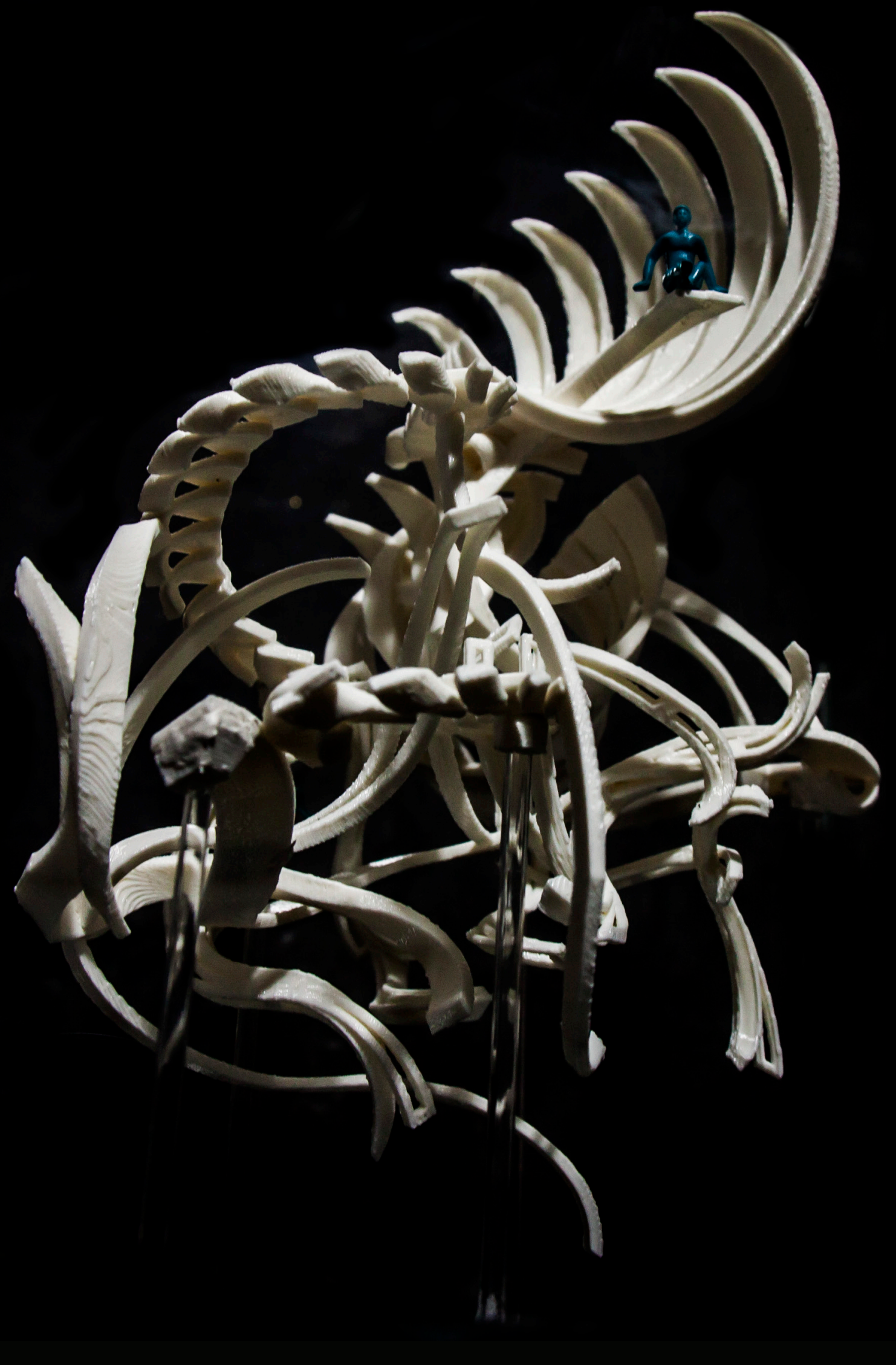




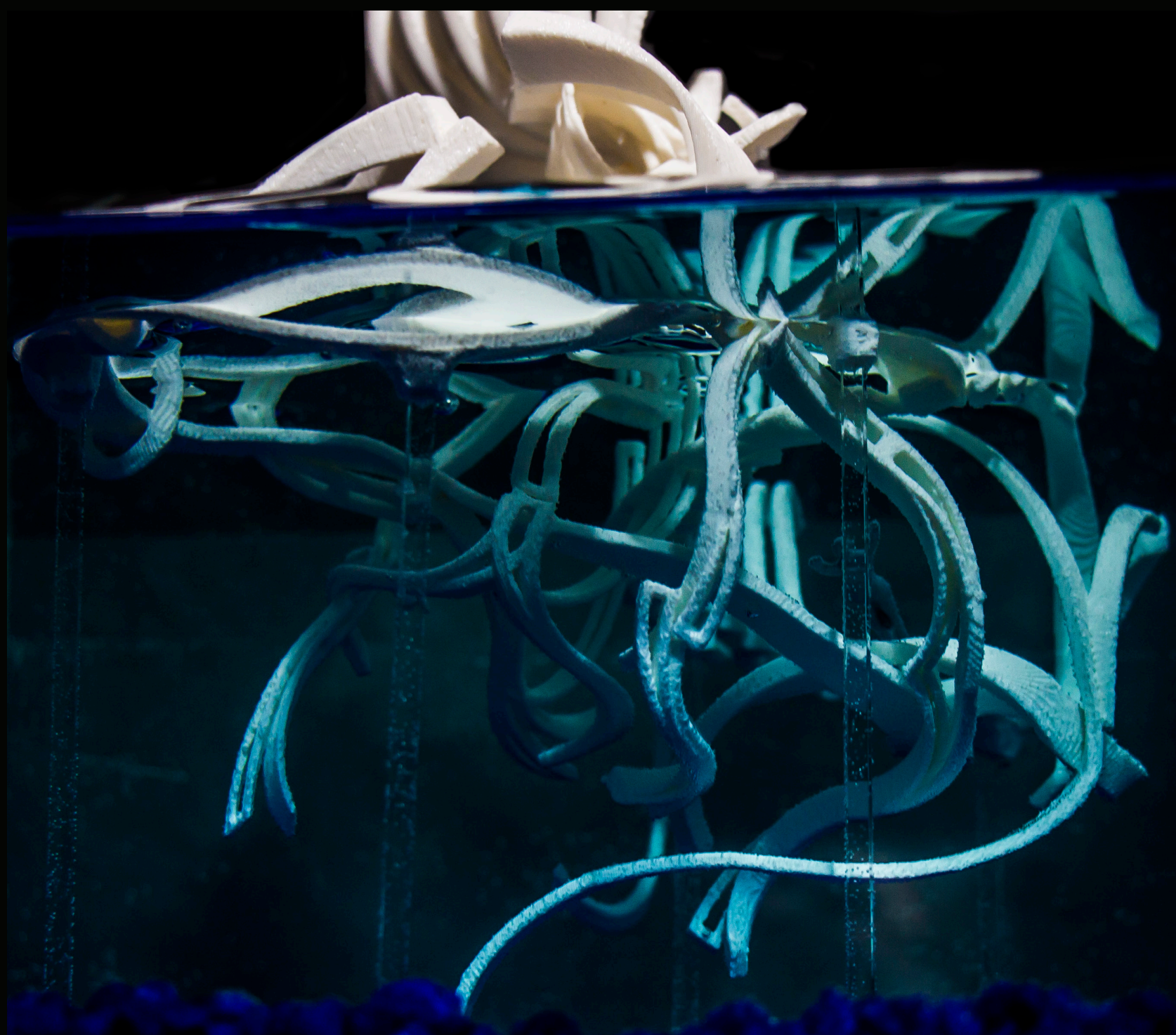




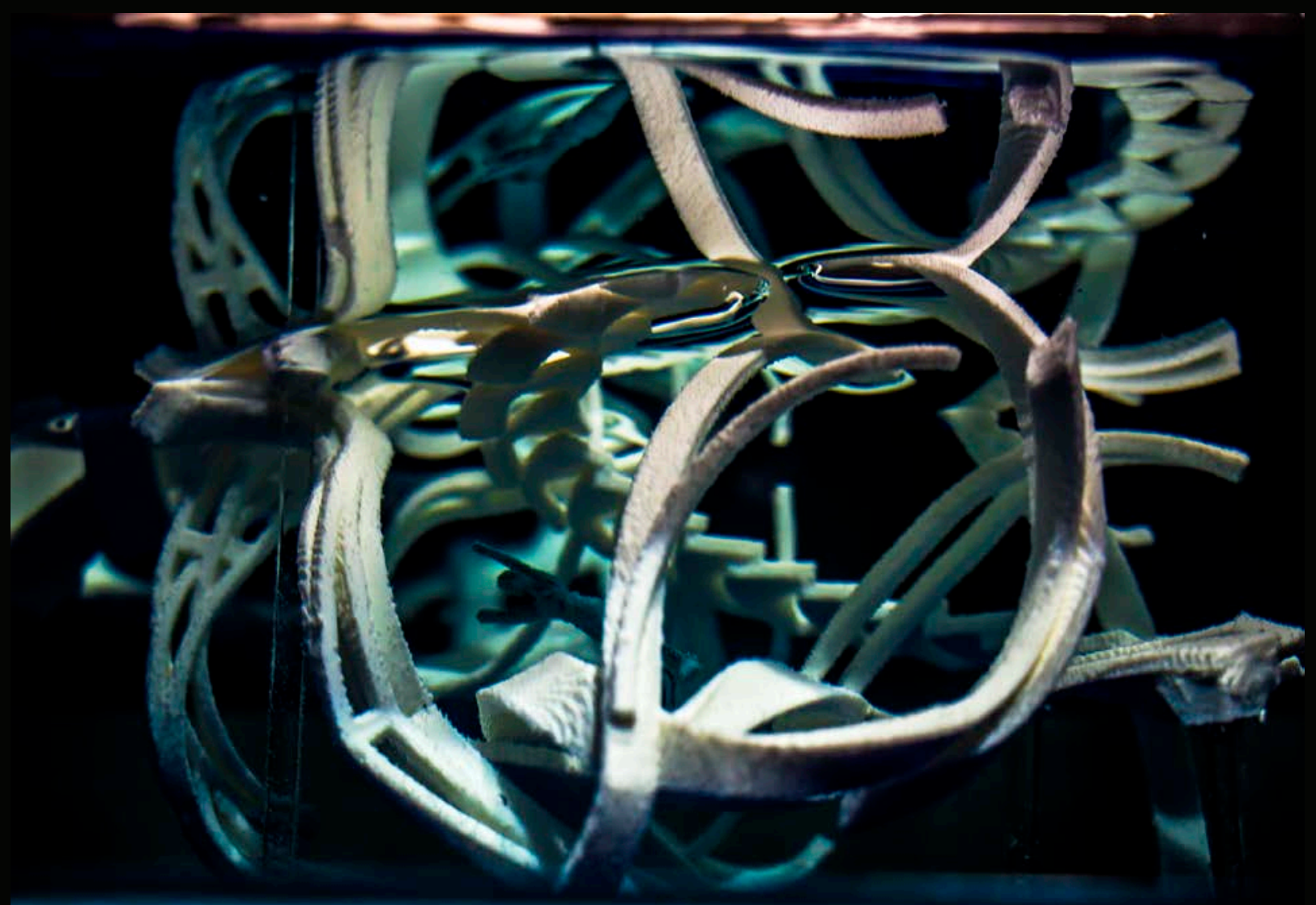

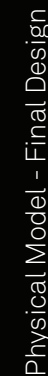

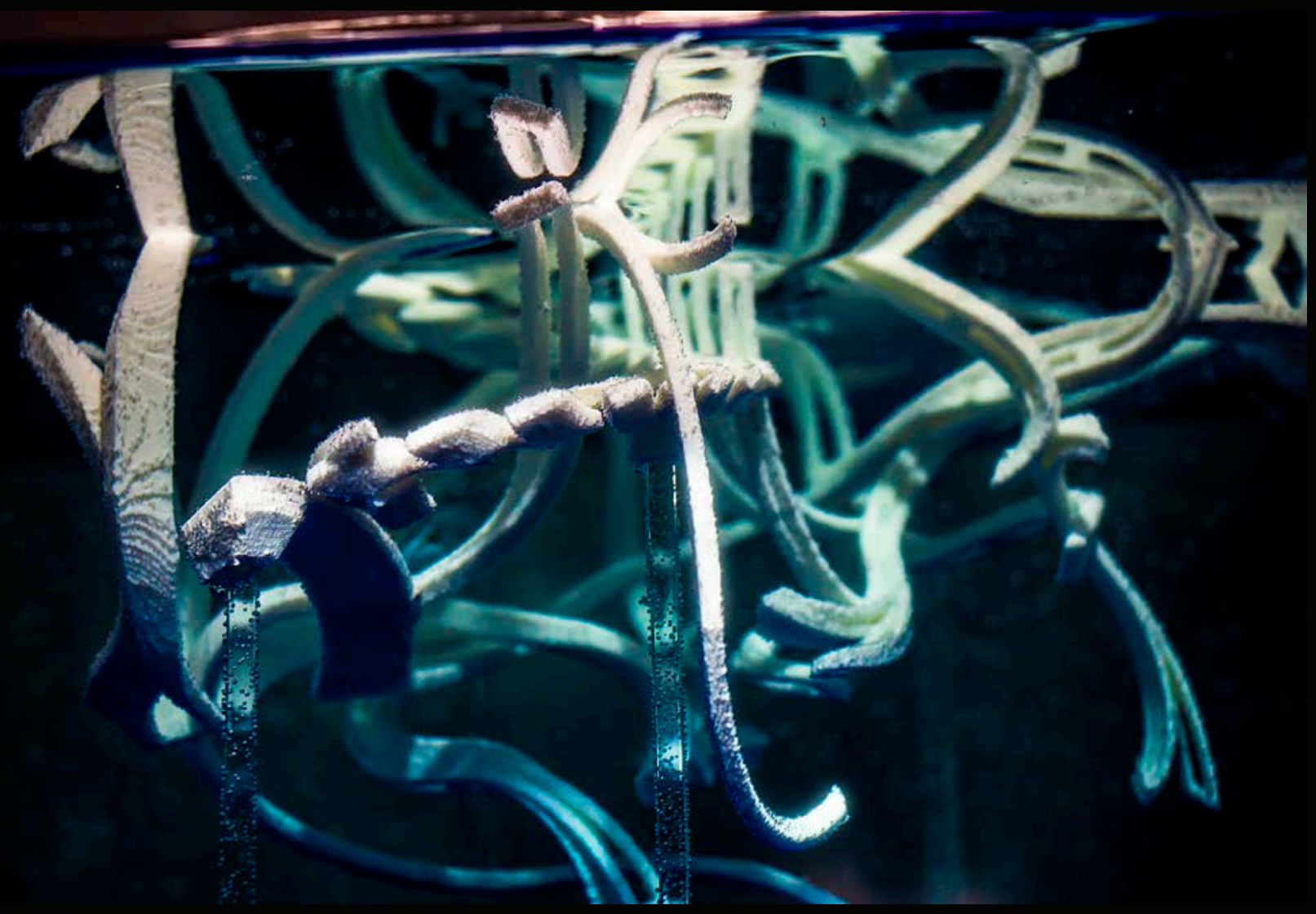



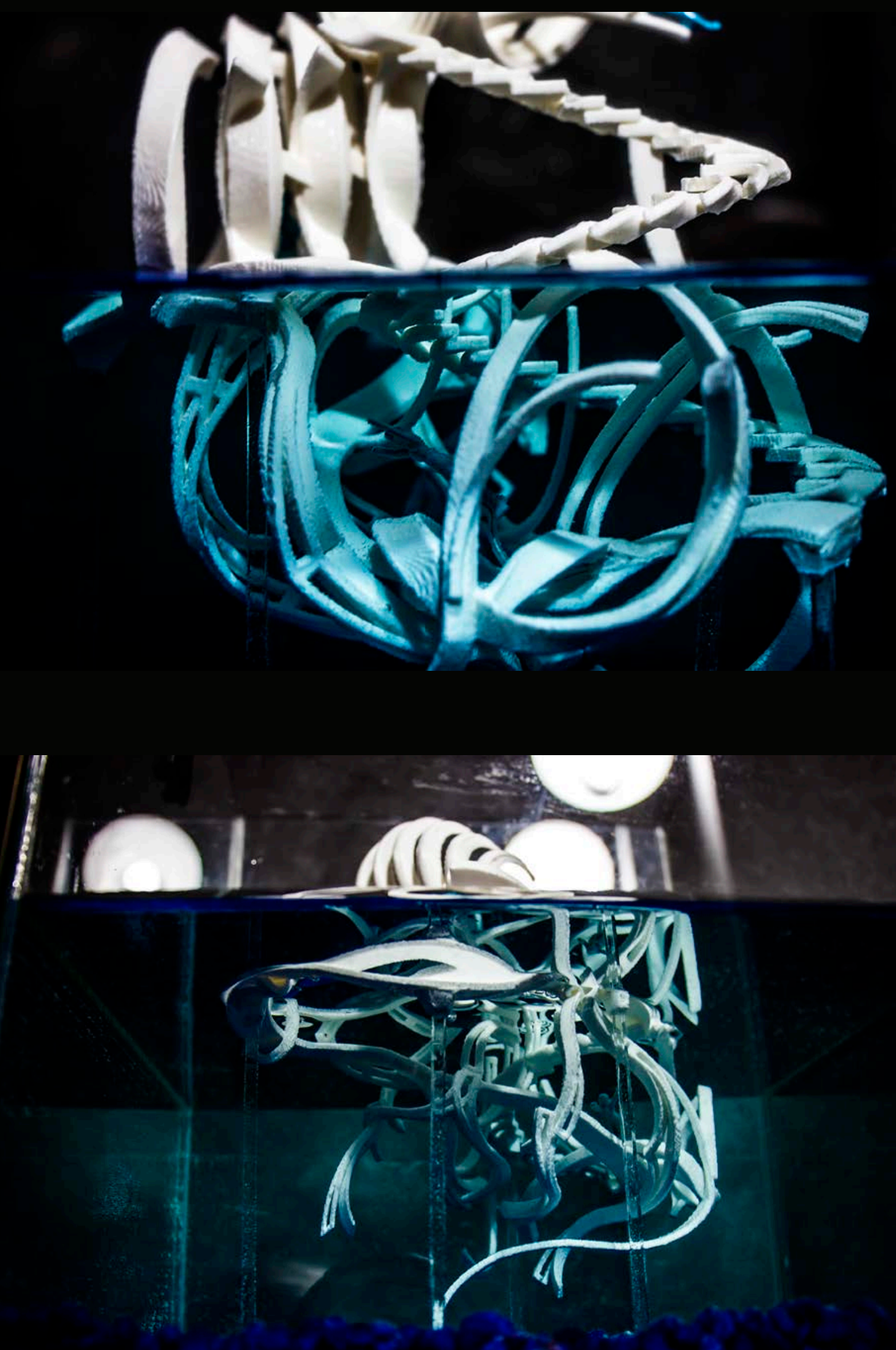


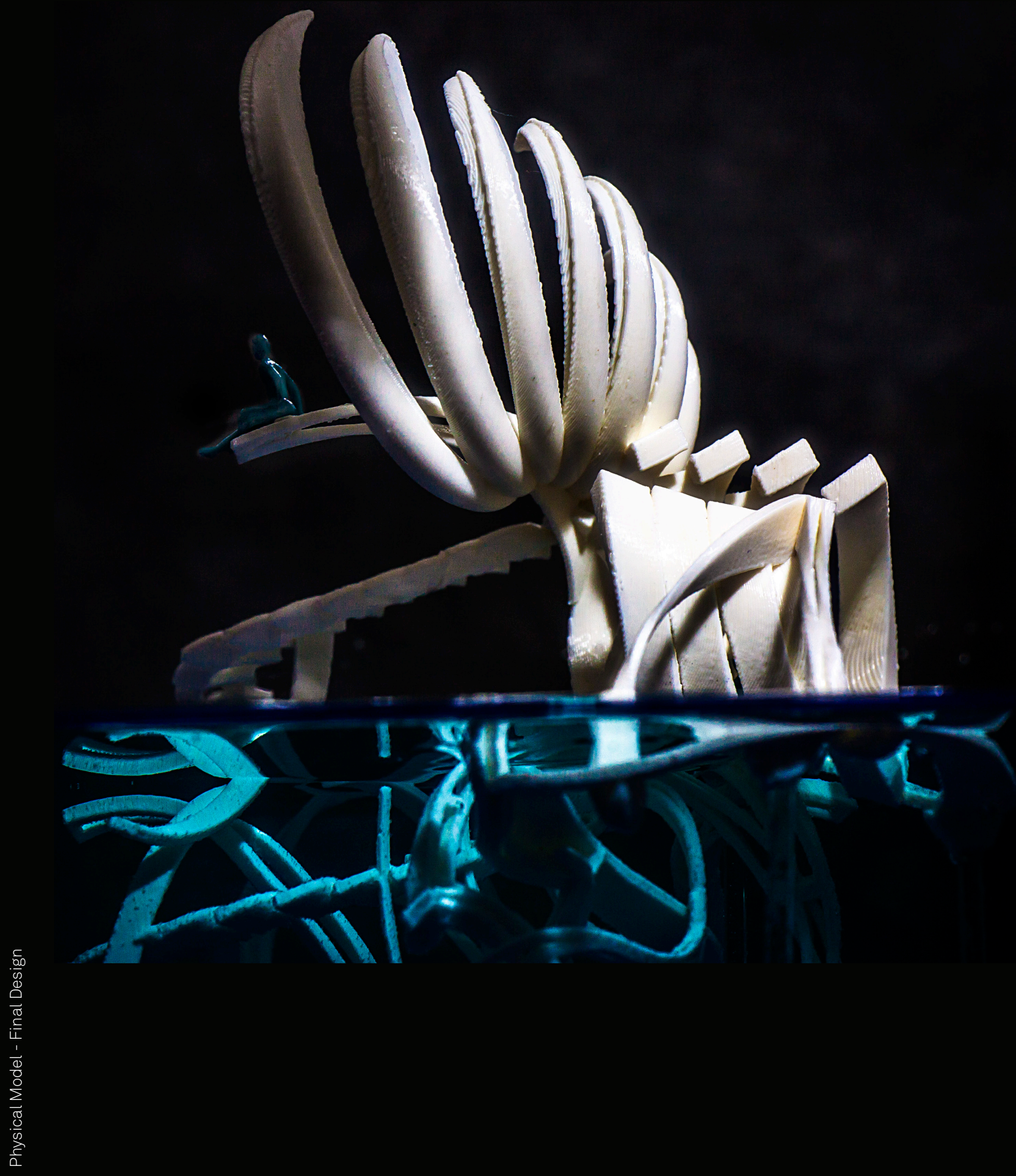



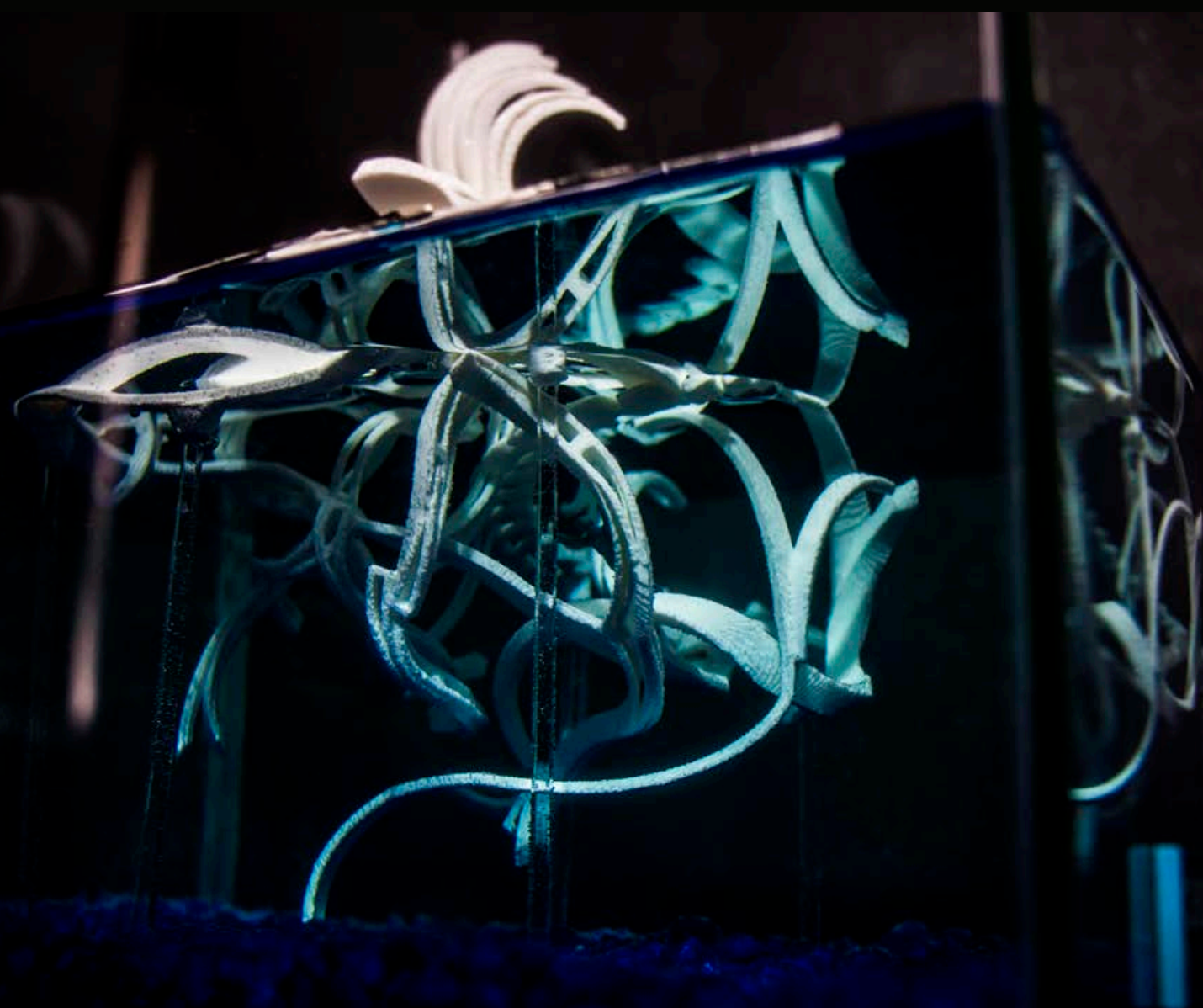

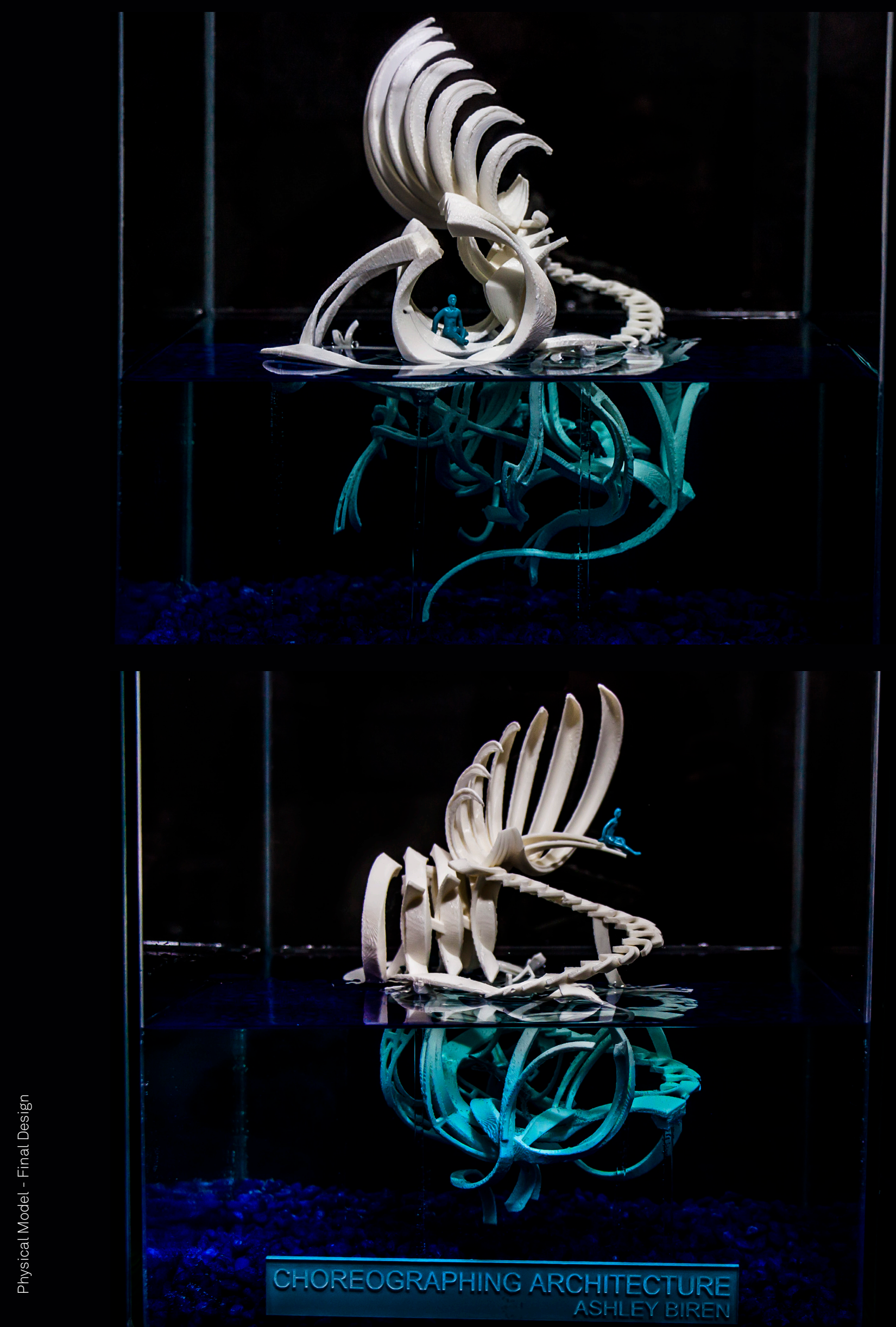

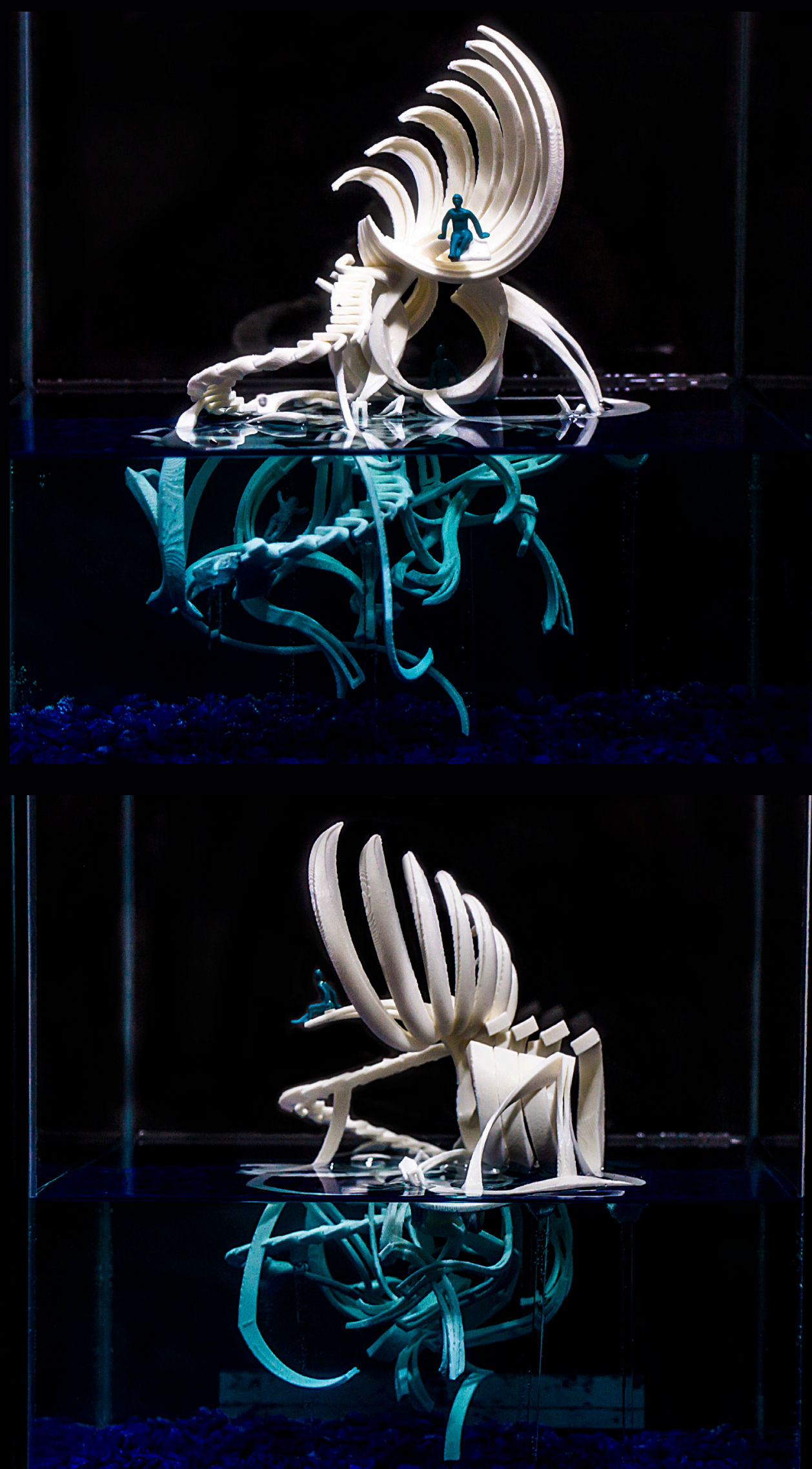


\section{Works Cited}

Adam, R., \& Adam, J. (1774). The Works in Architecture of Robert \& James Adam: Emsly, P

Ansari, I. (2013). Interview: Peter Eisenman. Retrieved, 2015, from http://www.architecturalreview.com/comment-and-opinion/interview-peter-eisenman/8646893.article

Baker, G. (1984). Le Corbusier, an analysis of form (1st ed.). Wokingham, Berkshire, England: Van Nostrand Reinhold.

Bausch, P. (2009). "I'm not interested in how people move but in what moves them.. Retrieved from http://www.co-lingua.com/content/im-not-interested-in-how-people-move-in-whatmoves-them

Berghaus, G. (1996). Futurism and politics: Between anarchist rebellion and fascist reaction, 1909-1944. Providence, R.I.: Berghahn Books.

Bergren, A. (2010). Plato's Timaeus and the Aesthetics of “Animate Form”. In R. D. Mohr \& B. M. Sattler (Eds.), One Book, the Whole Universe: Plato's Timaeus Today (pp. 343-372): Parmenides Pub.

Bloomer, K. C., \& Moore, C.W. (1977). Body, memory, and architecture (1st ed.). New Haven:Yale University Press.

Boccioni, U. (1912). Technical Manifesto of Futurist Sculpture. Unknown.nu. Retrieved 1 September 2015, from http://www.unknown.nu/futurism/techsculpt.html

Boccioni, U. (1913). The plastic foundations of futurist sculpture and painting Lacerba. Firenze: Tipografia di A. Vallecchi e C.

Bonnard, P., Ives, C. F., Giambruni, H. E., Newman, S. M., Art, M. M. o., \& Museum of Fine Arts, H. (1989). Pierre Bonnard, the Graphic Art: Metropolitan Museum of Art.

Bonnemaison, S., \& Macy, C. (2006). Some thoughts on Responsive Kinetic Architecture.

Retrieved from http://www.interactivearchitecture.org/some-thoughts-on-responsivekinetic-architecture.html

Broadbent, G. (1991). Deconstruction: A student guide. London: Academy editions. 
Brown, R. (2013). Futurist conceptions of space and time Retrieved from https://www.academia. edu/7056708/Futurist_conceptions_of_space_and_time

Chronopoulou, E. (2014). From the Sensous Spatiality of the Body to the Bodily Coordination of Space.

Consonni, E. (2014). Laban, good friend of us. Retrieved from https://ergonomicaproject. wordpress.com/2014/01/31/laban-good-friend-of-us/

de Vignemont, F., \& Singer, T. (2006). The empathic brain: how, when and why? Trends in cognitive sciences, 10(10), 435-441.

Deleuze, G. (1993). The fold: Leibniz and the baroque [Pli.]. Minneapolis: University of Minnesota Press.

di Pellegrino, G., Fadiga, L., Fogassi, L., Gallese, V., \& Rizzolatti, G. (1992). Understanding motor events: a neurophysiological study. Experimental brain research, 91(1), 176-180.

Diller, E., \& Scofidio, R. (1994). Flesh (1st ed.). New York: Princeton Architectural Press.

Diller, E., \& Scofidio, R. (2002). Blur: The making of nothing: Harry N Abrams Inc.

Eisenman, P. (1975). Cardboard architecture. In Museum of Modern Art (Ed.), Five architects:

Eisenman, Graves, Gwathmey, Hejduk, Meier (pp. 15-17). New York: Oxford University Press.

Eisenman, P. (2007). Written into the void: selected writings, 1990-2004. Yale University Press.

Eversion. (2003). Greg Lynn. Retrieved from http://everything2.com/user/eversion/writeups/ Greg+Lynn

Feuerstein, M. (2002). The bauhaus's darker side. In G. Dodds, R. Tavernor \& J. Rykwert (Eds.), Body and building (1st ed. ed., ). Cambridge, Mass.: MIT Press.

Fogtmann, M. H. (2007). Kinesthetic empathy interaction-exploring the possibilities of psychomotor abilities in interaction design. Paper presented at the Second International Workshop on Physicality.

Foster, S. L. (2010). Choreographing Empathy: Kinesthesia in Performance: Taylor \& Francis. 
Fox, M., \& Kemp, M. (2009). Interactive Architecture: Princeton Architectural Press.

Freyd, J.J. (1983). The mental representation of movement when static stimuli are viewed. Perception \& Psychophysics, 33(6), 575-581.

Frichot, H., \& Loo, S. (2013). Deleuze and Architecture: Edinburgh University Press.

Fuchs, T., \& Koch, S. C. (2014). Embodied affectivity: on moving and being moved. Frontiers in psychology, 5.

Gallagher, S. (2005). Dynamic models of body schematic processes. In H. de Preester, \& V. Knockaert (Eds.), Body image and body schema: Interdisciplinary perspectives on the body (pp. 233). Amsterdam ; Philadelphia: J. Benjamins.

Gallese, V. (2008). Empathy, Embodied Simulation, and the Brain: Commentary on Aragno and Zepf/Hartmann. Journal of American Psychoanalytic Association, 56(3), 769-781.

Gallese, V., Fadiga, L., Fogassi, L., \& Rizzolatti, G. (1996). Action recognition in the premotor cortex. Brain, 119(2), 593-610.

Garcia, M. (2010). The diagrams of architecture. Chichester, West Sussex, U.K.: Wiley.

Garofalo, L. (1999). Digital Eisenman: Birkhäuser-Publishers for Architecture.

Gazzola, V., Aziz-Zadeh, L., \& Keysers, C. (2006). Empathy and the somatotopic auditory mirror system in humans. Current biology, 16(18), 1824-1829.

Giedion, S. (1967). Space, time and architecture: The growth of a new tradition (5th ed.). Cambridge, MA: Harvard University Press.

Hagendoorn, I. (2003). The dancing brain. Paper presented at the Cerebrum: The Dana Forum on Brain Science.

Holden, S. (2007). Finding the architecture in Deleuze: Heinrich Wolfflin as a source of Deleuze's baroque. In Panorama to Paradise: Proceedings of the XXIVth Annual Conference of SAHANZ (Vol. 1, No. 1, pp. 1-12). Society of Architectural Historians, Australia \& New Zealand. 
Humphreys, R. (1999). Futurism: Tate Gallery.

Hunter, \& Victoria. (2009). Experiencing space: The implications for site-specific dance performance. In J. Butterworth, \& L. Wildschut (Eds.), Contemporary choreography: A critical reader (pp. 458). London; New York: Routledge.

Ishizu, T., \& Zeki, S. (2011). Toward a brain-based theory of beauty. PLoS One, 6(7), e21852.

Jaskiewicz, T. (2013). Towards a methodology for complex adaptive interactive architecture: TU Delft, Delft University of Technology.

Jencks, C. (2002). The New Paradigm in Architecture: The Language of Post-modernism:Yale University Press.

Kaminer, T. (2011). Architecture, crisis and resuscitation: The reproduction of post-fordism in latetwentieth-century architecture. Abingdon, Oxon ; New York, NY: Routledge.

Kearney, R. (1986). Modern movements in european philosophy. Manchester ; Dover, NH: Manchester University Press.

Keysers, C., Wicker, B., Gazzola, V., Anton, J. L., Fogassi, L., \& Gallese, V. (2004). A touching sight: SII/PV activation during the observation and experience of touch. Neuron, 42(2), 335-346.

Kiberd, R. (2015). Health tech's vitruvian man. Retrieved from http://motherboard.vice.com/read/ health-techs-vitruvian-man

King, D. B., Viney, W., \& Woody, W. D. (2009). A history of psychology: Ideas and context. Pearson/ Allyn and Bacon.

Klee, P. (1953). Pedagogical Sketchbook (S. Moholy-Nagy, Trans.). New York: Frederick A. Faber.

Kourtzi, Z., \& Kanwisher, N. (2000). Activation in human MT/MST by static images with implied motion. Journal of cognitive neuroscience, 12(1), 48-55.

Kuhlmann, D. (2014). Gender Studies in Architecture: Space, Power and Difference: Taylor \& Francis.

Laban, R., \& Lawrence, F. (1974). Effort; economy of human movement (1st ed.). London: Macdonald \& Evans. 
Langan, M. (2011). Choros. Retrieved from http://langanfilms.com/choros.html

Latour, B., \& Yaneva, A. (2008). Give me a gun and I will make all buildings move: An ANT's view of architecture. Explorations in architecture: Teaching, design, research, 80-89.

Le Corbusier. (1954). The modulor; a harmonious measure to the human scale universally applicable to architecture and mechanics, by le corbusier [pseud.] translated by peter de francia and anna bostock (2d ed.). London: Faber and Faber.

Leder, D. (1990). The Absent body (1st ed.). Chicago [Ill.][etc.]: The University of Chicago Press.

Lee, V. (1913). The beautiful: An introduction to psychological aesthetics. Cambridge: Univ. Press.

Leibniz, G. W. F. v., Remnant, P., \& Bennett, J. (1996). Leibniz: New Essays on Human Understanding: Cambridge University Press.

Liu, Y.-T. (2002). Defining Digital Architecture: 2001 Far East International Digital Architectural Design Award: Birkhäuser.

Loosma, B., \& Spuybroek, L. (1997). Aquatic pavilion and interactive installation, Neeltje Jans, Holland. DOMUS, 28-33.

Lynn, G. (1998). Folds, bodies \& blobs: Collected essays. Bruxelles: La Lettre volée.

Lynn, G. (1999). Animate form. New York: Princeton Architectural Press.

Macarthur, J. (2007). The picturesque: Architecture, disgust and other irregularities. London ; New York: Routledge.

Mallgrave, H. F. (2011). The architect's brain (Pbk ed.). Chichester, West Sussex, U.K. ; Malden, MA: Wiley-Blackwell.

Manning, E. (2009). Relationscapes: Movement, Art, Philosophy: MIT Press.

Merleau-Ponty, M. (1964). Sense and Non-sense: Northwestern University Press.

Merleau-Ponty, M., Lefort, C., \& Lingis, A. (1968). The Visible and the Invisible: Followed by Working Notes: Northwestern University Press.

Merleau-Ponty, M., \& Smith, C. (2002). Phenomenology of perception. New York: Routledge. 
Mitchell, W. J. (2003). Me++: The Cyborg Self and the Networked City: MIT Press.

MoMA. (2006). Umberto Boccioni States of Mind 1: The Farewells. Retrieved from http://www. moma.org/collection/works/78648

Morton, E. (2014). Reversible Destiny: The Apartments Designed With Immortality in Mind. Retrieved from http://www.slate.com/blogs/atlas_obscura/2014/10/24/the_reversible_ destiny_lofts_in_mitaka_tokyo.html

Ozel, G. (2012). Kinetic cerebral hut. Retrieved from http://www.designboom.com/readers/ cerebral-hut-by-guvenc-ozel/

Pallasmaa, J. (1996). The geometry of feeling: A look at the phenomenology of architecture. In K. Nesbitt (Ed.), Theorizing a new agenda for architecture: An anthology of architectural theory 1965-1995 (pp. 448-453). New York: Princeton Architectural Press.

Pallasmaa, J. (1994). An architecture of the seven senses. In S. Holl, \& A. Pérez Gómez (Eds.), Questions of perception: Phenomenology of architecture (pp. 34). Tōkyō: Ė ando Yū.

Pallasmaa, J. (1996). The eyes of the skin: Architecture and the senses. London; Lanham, MD: Academy Editions; Distributed to the trade in the USA by National Book Network.

Pallasmaa, J., \& MacKeith, P. B. (2005). Encounters: Architectural essays. Helsinki; Manchester: Rakennustieto; Cornerhouse distributor.

Peter D. Eisenman. (2004). Encyclopedia of World Biography.

Pipes, A. (2003). Foundations of Art and Design: Laurence King.

Preston, S. D., Bechara, A., Damasio, H., Grabowski, T. J., Stansfield, R. B., Mehta, S., \& Damasio, A. R. (2007). The neural substrates of cognitive empathy. Social Neuroscience, 2(3-4), 254275.

Reynolds, D. (2007). Rhythmic subjects. Alton: Dance Books.

Rizzolatti, G., \& Sinigaglia, C. (2010). The functional role of the parieto-frontal mirror circuit: interpretations and misinterpretations. Nature reviews neuroscience, 11(4), 264-274. 
Raleigh, A. S. (1993). Hermetic Science of Motion and Number. Health Research Books.

Reichardt, J. (2007). The Architectural Relevance of Gordon Pask. Retrieved from http:// whoWoSn.net/postit/wp-content/uploads/2011/09/architectural_relevance_of_gordon_ pask.pdf

Rasmussen, S. E. (1959). Experiencing architecture [Om et opleve arkitektur.]. London: Chapman \& Hall.

Robinson, S. (2011). Nesting: Body, Dwelling, Mind: William Stout Publishers.

Schlemmer, O., \& Gropius, W. (1961). The theater of the bauhaus (1st ed.). Middletown, Conn.: Wesleyan University Press.

Sciotto, M. F. (2009). Alternity in bodies in space. Retrieved from http://spacecollective.org/ soCinematic/6302/Alternity-in-Bodies-in-Space

Shane, G. (1976). Cologne in Context. Architectural Design, 11, 685-687.

Sobchack, V. C. (1992). The Address of the Eye: A Phenomenology of Film Experience: Princeton University Press.

Sommerfeld, J. (2012). Human brain gets a kick out of surprises. Health. Retrieved from http:// www.ccnl.emory.edu/Publicity/MSNBC.HTM

Straeten, B. V. d. (2003). The Uncanny and the Architecture of Deconstruction. Online Magazine of the Visual Narrative, 5.

Teyssot, G. (1994). The mutant body of architecture Flesh: architectural probes (pp. 8-35).

Tschumi, B. (1994). The manhattan transcripts (New ed.). London; New York, N.Y.: Academy Editions; St. Martin's Press.

Tuan, I. (1974). Topophilia: A study of environmental perception, attitudes, and values. Englewood Cliffs, N.J.: Prentice-Hall. 
Vischer, R., Mallgrave, H. F., \& Ikonomou, E. (1994). Empathy, form, and space: Problems in german aesthetics, 1873-1893. Santa Monica, CA; Chicago, Ill.: Getty Center for the History of Art and the Humanities; Distributed by the University of Chicago Press. de Certeau, M. (1984). The practice of everyday life [Arts de faire.]. Berkeley, Calif.: University of California Press.

Wasserman, J. (2012). A World in Motion: The Creative Synergy of Lawrence and Anna Halprin. Landscape Journal, 31(1-2), 33--52. 


\section{Works Considered}

Arbib, M. A. (2012). Brains, machines and buildings: towards a neuromorphic architecture. Intelligent Buildings International, 4(3), 147-168.

Armstrong, R. \& Ferracina, S. (2013). Unconventional computing. Cambridge: ACADIA And Riverside Architectural Press.

Artopoulos, G., \& Condorcet, E. (2006). House of Affects - time, immersion and play in digital design for spatially experienced interactive narrative. Digital Creativity, 17(4), 213 -220.

Berthoz, A. (2000). The brain's sense of movement [Sens du Mouvement.]. Cambridge, Mass.: Harvard University Press.

Bläsing, B., Puttke-Voss, M., \& Schack, T. (2010). The neurocognition of dance (1st ed.). Hove, East Sussex [England]: Psychology Press.

Beesley, P., Khan, O. \& Stacey, M. (2013). “ACADIA 2013 Adaptive Architecture”, paper presented at ACADIA 2013 Adaptive Architecture. Cambridge, Ontario, 24-26, October. Cambridge: ACADIA and Riverside Architectural Press, pp. 129-136.

Bier, H., \& Knight, T. (2010). Digitally-Driven Architecture. 6Th Footprint Issue, Stichting Footprint, Delft, $1--4$.

Brabrand, H. (2005). Architecture and embodyment. Nordisk Arkitekturforskning, 18(3), 54--67.

Bronet, F., \& Schumacher, J. (1999). Design in movement: The prospects of interdisciplinary design. Journal of Architectural Education, 53(2), 97-109.

Collins, P. (1998). Changing ideals in modern architecture, 1750-1950 (1st ed.). Montreal, Que.: McGill-Queen's University Press.

D’Angelo, G. (2008). Scale--body--architecture (1st ed.). Ann Arbor: ProQuest.

de Certeau, M. (1984). The practice of everyday life [Arts de faire.]. Berkeley, Calif.: University of California Press.

Deleuze, G. (1986). Cinema 1 (1st ed.). London: Athlone.

Deleuze, G. (1989). Cinema 2: the time image (1st ed.). London: Athlone. 
Dodds, G., Tavernor, R., \& Rykwert, J. (2002). Body and building (1st ed.). Cambridge, Mass.: MIT Press.

Ecija, A., \& Fernando, Q. (2009). Cairon. journal of dance studies. [Cairon nº 12. Revista de estudios de danza. Cuerpo y arquitectura] Cairon 12. Body and Architecture

Eng, K., Bäbler, A. \& Bernardet, U. (2003). “Ada - Intelligent Space: An artificial creature for the Swiss Expo.02", paper presented at 2003 IEEE/RSJ International Conference on Robotics and Automation. Taipei, Taiwan, 14 - 19, September.

Ferreira, M. P. (2010). Embodied (E)motions: A path to expand architectural consciousness. Third International Seminar Arquitectonics Network: Architecture and Research, Barcelona.

Ferreira, M. P., de Mello, D. C., \& Duarte, J. P. (2011). The grammar of movement: A step towards a corporeal architecture. Nexus Network Journal,13(1), 131-149.

Fortunati, L., Katz, J., \& Riccini, R. (2003). Mediating the human body (1st ed.). Mahwah, N.J.: Lawrence Erlbaum Associates, Publishers.

Foster, S. (2007). Movement's contagion: The kinesthetic impact of performance. In T. C. Davis (Ed.), The cambridge companion to performance studies (pp. 46-59). Cambridge: Cambridge University Press.

Forsythe, W. (2012). Improvisation technologies (1st ed.). Ostfildern, Germany: Hatje Cantz.

Hagendoorn, I.G. (2010). Dance, Choreography and the Brain. In: Melcher, D. and Bacci, F. [eds.]. Art and the Senses. Oxford: Oxford University Press, 499-514.

Hauptmann, D., \& Neidich, W. (2010). Cognitive architecture: From biopolitics to noopolitics; architecture \& mind in the age of communication and information. Rotterdam: 010 Publishers.

Gibson, J. J. (1966). The senses considered as perceptual systems. Boston: Houghton Mifflin.

Goldberg, R. (2001). Performance art: From futurism to the present (Revised and expanded ed.). London: Thames \& Hudson. 
Gorczyca, A. (2005). Motion as modern way of expressing architecture.Internet-Journal:

CG\&G, 7(3), 22-40.

Hagendoorn, I.G. (2010). Dance, Choreography and the Brain. In: Melcher, D. and Bacci, F. [eds.]. Art and the Senses. Oxford: Oxford University Press, 499-514.

Hansen, Mark B. N. (2002). Wearable Space. Configurations, 10.2, pp. 321-370.

Hardy, A. (2011). The expression of movement in architecture. The Journal of Architecture, 16(4), 471-497.

Harris, Y. (2002). Architecture and motion: ideas on fluidity in sound, image and space.

Hauptmann, D., \& Neidich, W. (2010). Cognitive architecture: From biopolitics to noopolitics; architecture \& mind in the age of communication and information. Rotterdam: 010 Publishers.

Hildebrand, G. (1999). Origins of architectural pleasure (1st ed.). Berkeley: University of California Press.

Hill, J. (2006). Immaterial architecture (1st ed.). London: Routledge.

Holl, S., Pallasmaa, J., \& Perez Gomez, A. (2006). Questions of perception (1st ed.). San Francisco, CA: William Stout.

Huang, E. (1991). Body in space: the sensual experience of architecture and dance (Master of Architecture). Massachusetts Institute of Technology.

Jormakka, K. (2002). Flying Dutchmen (1 st ed.). Basel: Birkhäuser.

Leach, N. (2006). Camouflage (1st ed.). Cambridge, Mass.: MIT Press.

Mallgrave, H. F. (2013). Architecture and embodiment: The implications of the new sciences and humanities for design: Taylor \& Francis.

Manning, E. (2006). Prosthetics making sense: dancing the technogenetic body. Fibreculture, 9. Massumi, B. (2002). Parables for the virtual: Movement, affect, sensation. Durham, NC: Duke University Press. 
Merriman, P. (2010). Architecture/dance: choreographing and inhabiting spaces with Anna and Lawrence Halprin. cultural geographies, 17(4), 427-449.

Meyer, E. d. C. (2009). The place of place in memory. In M. Treib (Ed.), Spatial recall: Memory in architecture and landscape. New York: Routledge.

Nayak, S. (2008). dance and architecture: body, form, space and transformation. ProQuest.

Noë, A. (2004). Action in perception. Cambridge, Mass.: MIT Press.

Norberg-Schulz, Christian. (1971). Existence, Space \& Architecture. New York: Praeger.

O’Neill, M. E. (2001). Corporeal experience: A haptic way of knowing. Journal of Architectural Education, 55(1), 3-12.

Oosterhuis, K. (2012). Hyperbody (1st ed.). Heijningen: Jap Sam Books.

Pallasmaa, J. (2009). Space, place, memory, and imagination: The temporal dimension of existential space. In M. Treib (Ed.), Spatial recall: Memory in architecture and landscape. New York: Routledge.

Palmer, H. (2014). Deleuze and futurism: A manifesto for nonsense. London: Bloomsbury Academic.

Pekol, B. (2011). BodyCAD: Creative Architectural Design Through Digital Re-Embodiment. ISEA.

Pine, A., \& Kuhlke, O. (2014). Geographies of dance: : body, movement, and corporeal negotiations (1st ed.). Lanham, Maryland : Lexington Books.

Portanova, S. (2013). Moving without a body (1st ed.). MIT Press.

Ramach, Ran, V. S. \& Hirstein, W. (1999). The science of art: a neurological theory of aesthetic experience. Journal Of Consciousness Studies, 6 (6-7), pp. 6--7.

Reisner-Cook, Y. (2009). The troubled relationship between architecture and aesthetic: Exploring the self and emotional beauty in design. (Doctor of Philosophy, RMIT University).

Reynolds, D. \& Reason, M. (2012). Kinesthetic empathy in creative and cultural practices. Bristol, UK:Intellect. 
Roald, T., \& Lang, J. (2013). Art and Identity (1st ed.). Amsterdam: Editions Rodopi.

Robinson, S., \& Pallasmaa, J. (2015). Mind in Architecture: Neuroscience, Embodiment, and the Future of Design: MIT Press.

Salter, C. (2010). Entangled: Technology and the Transformation of Performance (1st ed.). Cambridge, Mass.: MIT Press.

Schiller, G. (2003). The kinesfield: a study of movement-based interactive and choreographic art. University Of Plymouth.

Schumacher, M., Schaeffer, O., \& Vogt, M. M. (2010). MOVE:Architecture in motion - Dynamic components and elements: De Gruyter.

Schwartzman, M. (2011). See yourself sensing (1st ed.). London, UK: Black Dog Pub.

Sterk, T. (2003). Using actuated tensegrity structures to produce a responsive architecture. ACADIA 2003.

Sternberg, E. M. (2009). Healing spaces: The science of place and well-being: Harvard University Press.

Sternberg, E. M., \& Wilson, M. A. (2006). Neuroscience and architecture: seeking common ground. Cell,127(2), 239-242.

Steyn, G. (2012). Le Corbusier and the human body. South African Journal Of Art History, 27(2), $259--272$.

Tschumi, B. (1994). Architecture and disjunction (1st ed.). Cambridge, Mass.: MIT Press.

Teyssot, G. (2004). Prosthetic architecture: an environment for the techno-body; [ein Vortrag Für Die HfbK Hamburg, April 2002] (1 st ed.). Hamburg: Material-Verl.

Uysal, V. Ș. (2001). Bodies and Spaces "in Contact": A Study on the Dancing Body as means of Understanding Body-Space Relationship in an Architectural Context (Doctoral dissertation, BILKENT UNIVERSITY).

Uysal, V., \& Wilsing, M. (2014). Embodying architecture, studying dance: movement as means of studying bodyspace relationship (1st ed.). Ankara, Turkey. Retrieved from http://cumincad. architexturez.net/system/files/pdf/ddssar0028.content.pdf 
Weinstein, B. (2008). Flamand and His Architectural Entourage. Journal Of Architectural Education,61(4), 25--33.

Wohlwill, J. (2009). The physical environment: A problem for a psychology of stimulation. In R. Gutman (Ed.), People and buildings. New Jersey: Transaction Publishers.

Wölfflin, H. (1976). Prolegomena to a psychology of architecture (1st ed.). [Cambridge, Mass.]: [Dept. of Architecture, M.I.T.]. 